
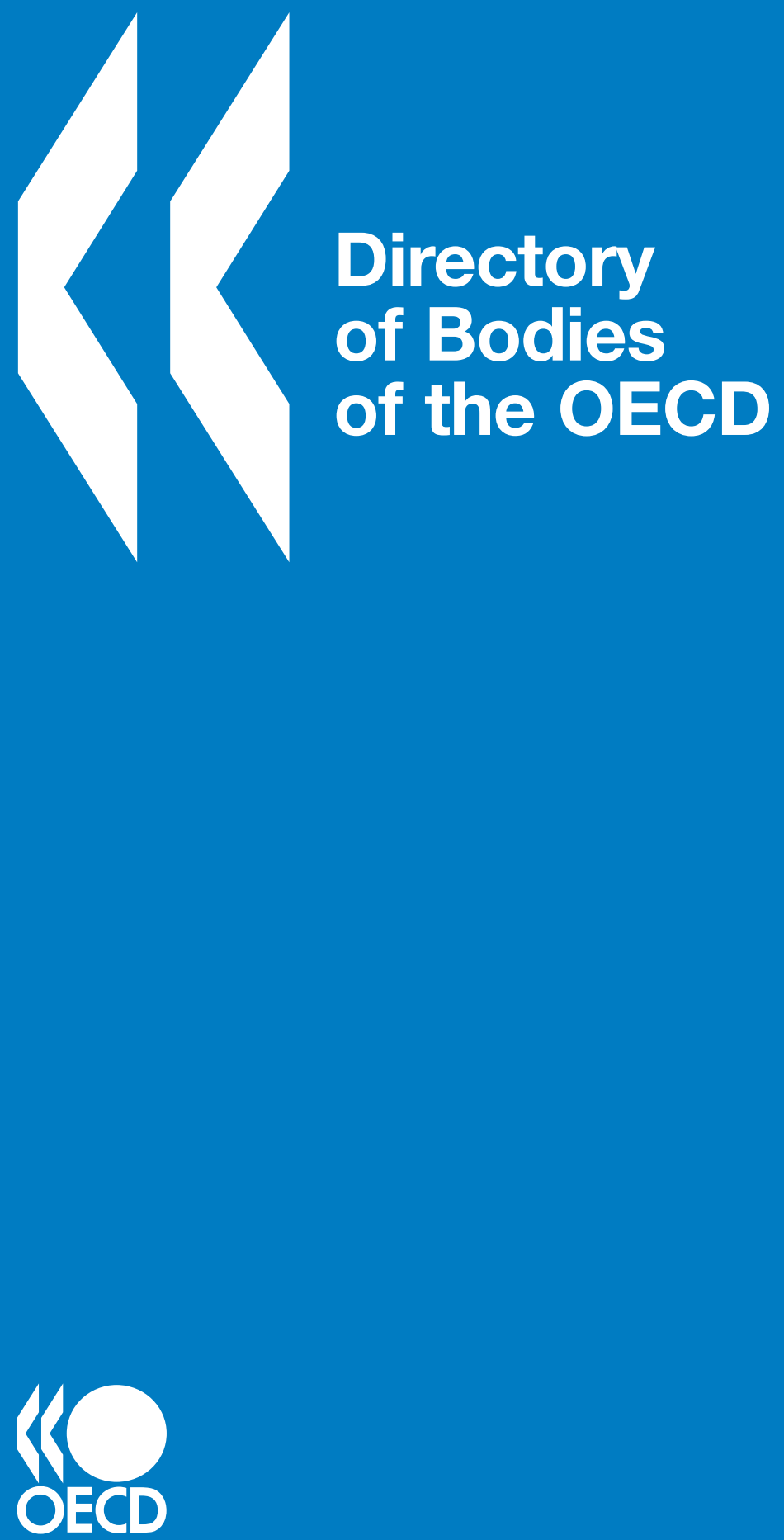

2009 



\section{ORGANISATION FOR ECONOMIC CO-OPERATION AND DEVELOPMENT}

\section{Directory of Bodies of the OECD}

MARCH 2009 


\section{ORGANISATION FOR ECONOMIC CO-OPERATION AND DEVELOPMENT}

The OECD Member countries are: Australia, Austria, Belgium, Canada, the Czech Republic, Denmark, Finland, France, Germany, Greece, Hungary, Iceland, Ireland, Italy, Japan, Korea, Luxembourg, Mexico, the Netherlands, New Zealand, Norway, Poland, Portugal, the Slovak Republic, Spain, Sweden, Switzerland, Turkey, the United Kingdom and the United States. The Commission of the European Communities takes part in the work of the OECD, as does the European Free Trade Association.

For several years, non-Members of the OECD have taken part in the work of various bodies of the Organisation, either as full participants or regular observers; ${ }^{1}$ a number of international organisations also participate in meetings of bodies.

\footnotetext{
${ }^{1}$ Resolution of the Council Concerning the Participation of non-Members in the Work of Subsidiary Bodies of the Organisation [C(2004)132/FINAL].
} 


\section{INTRODUCTION}

Article 9 of the Convention of 14th December 1960 on the OECD states that "the Council may establish an Executive Committee and such subsidiary bodies as may be required for the achievement of the aims of the Organisation".

This Directory includes all the bodies of the Organisation which are operative, namely the Council, the subsidiary bodies established by the Council, the sub-committees, as well as the groups created by the sub-committees. For ease of reference, the titles of the bodies created by the Council are framed; those of their working parties are underlined; and those of third-level subgroups are in italics.

For each body, information is given concerning the chairmanship and vicechairmanship(s), membership (in cases where the body does not include all OECD Member countries or where non-Members of the Organisation are full participants in its work), observers, date of creation, the mandate.

It should be noted that some bodies have been in continuous existence for a lengthy period and that their functions have evolved. Moreover, certain bodies have a precisely defined field of action and/or a sizeable sub-structure, while the definition of the competence of others has remained very broad. The present functions of some bodies, or the relative importance of their activities, may not, therefore, always be clearly and completely reflected by the texts of the mandates alone.

This Directory is updated annually. The information in this edition applies to the situation as of the beginning of March 2009. An electronic version of the base is also available on the OECD Internet Site (http://www.oecd.org). 



\section{TABLE OF CONTENTS}

COUNCIL

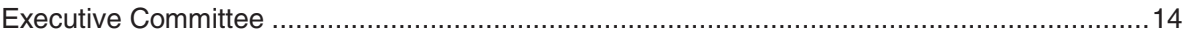

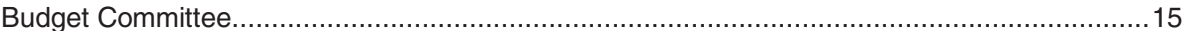

Budget Committee Monitoring Group on Implementation of the Budget and Financial

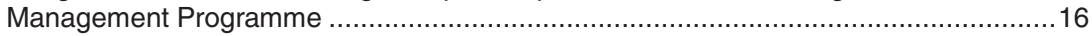
Informal Task Force on the Cost Recovery Charges applying to Voluntary

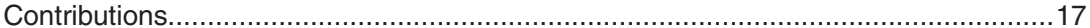

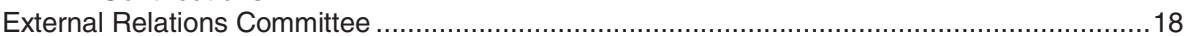

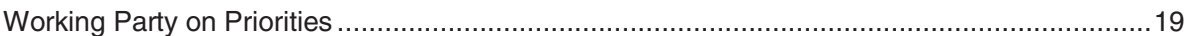

Committee on Public Affairs and Communications ................................................................

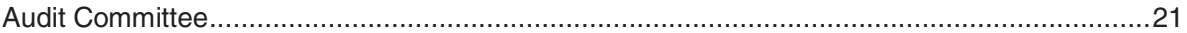

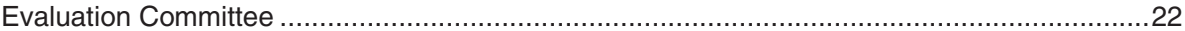

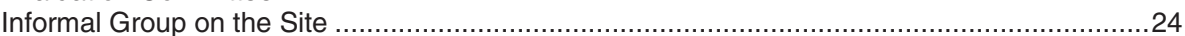

Pension Budget and Reserve Fund Management Board ..................................................25

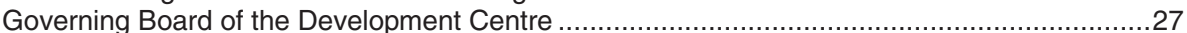

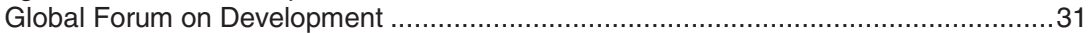

Annual Meeting of Sustainable Development Experts.......................................................... 33

Liaison Committee with International Non-Governmental Organisations ...............................35

Liaison Committee between the Russian Federation and the OECD …....................................37

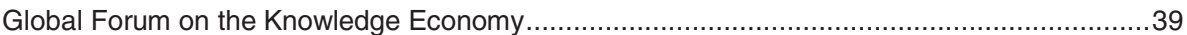

Global Forum on Sustainable Development...................................................................... 41

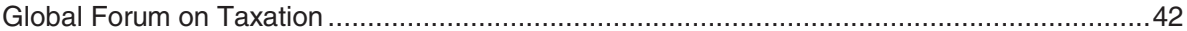

Coordination Group for the Global Project on "Measuring the Progress of Societies"................43

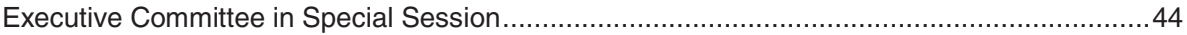

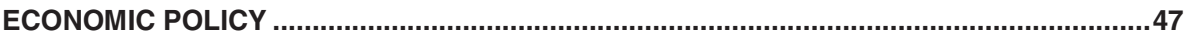

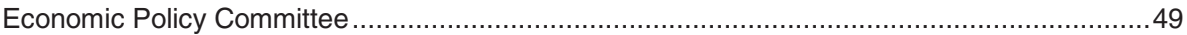

Working Party on Short-Term Economic Prospects.................................................50

Working Party No. 1 on Macro-Economic and Structural Policy Analysis ............................51

Working Party No. 3 on Policies for the Promotion of Better International Payments

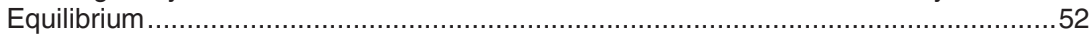

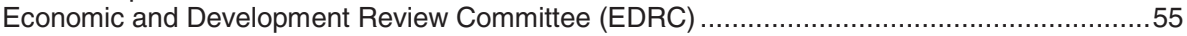

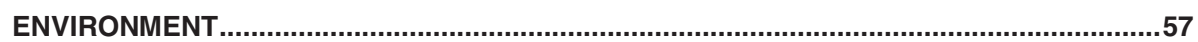

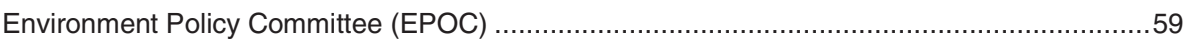

Joint Working Party on Agriculture and the Environment...........................................62

Joint Working Party on Trade and Environment ......................................................64

Joint Meetings of Tax and Environment Experts ..................................................6

Working Party on Global and Structural Policies ................................................66

Working Group on Economic Aspects of Biodiversity (WGEAB) ........................68

Working Party on National Environmental Policies ....................................................70

Working Group on Waste Prevention and Recycling................................... 72

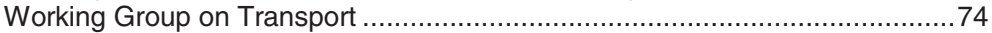

Working Party on Environmental Performance ..................................................... 76

Working Group on Environmental Information and Outlooks..........................78

Working Party on Chemicals, Pesticides and Biotechnology .....................................79

Working Group of National Co-ordinators of the Test Guidelines Programme

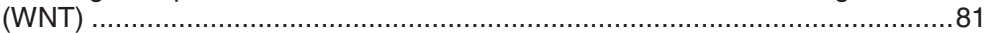

Working Group on Good Laboratory Practice ............................................ 83

Working Group on Pesticides ............................................................... 85 
Working Group on the Harmonisation of Regulatory Oversight in

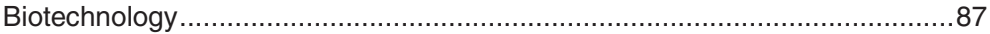

Task Force for the Safety of Novel Foods and Feeds ...................................89

Working Group on Chemical Accidents......................................................91

Task Force on Pollutant Release and Transfer Registers ..............................93

Chemicals Committee .......................................................................................................... 95

Working Party on Manufactured Nanomaterials .....................................................99

Task Force on Hazard Assessment ................................................................ 101

Task Force on Harmonisation of Classification and Labelling....................................103

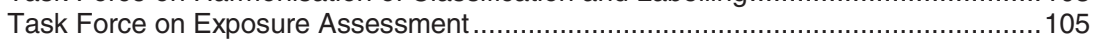

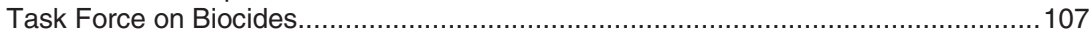

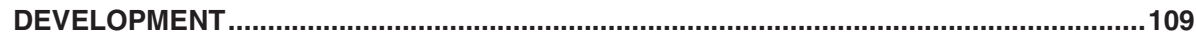

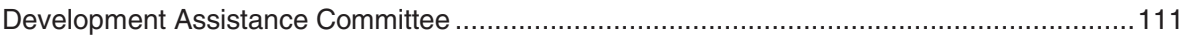

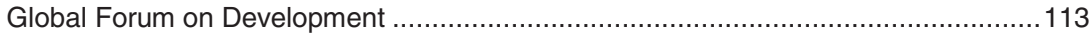

DAC Working Party on Statistics (WP-STAT) ….............................................114

Working Party on Aid Effectiveness (WP-EFF) ...................................................116

DAC Network on Development Evaluation ........................................................118

DAC Network on Gender Equality (GENDERNET)..........................................120

DAC Network on Environment and Development Co-operation (ENVIRONET) ..........123

DAC Network on Poverty Reduction (POVNET) ................................................. 125

DAC Network on Governance (GOVNET) ...................................................... 128

DAC Network on Conflict, Peace and Development Co-operation (CPDC)................. 131

PUBLIC GOVERNANCE AND TERRITORIAL DEVELOPMENT...........................................135

Public Governance Committee (PGC) …............................................................. 137

Global Forum on Public Governance ……..................................................... 140

Working Party on Regulatory Management and Reform (REG).............................141

Working Party of Senior Budget Officials (SBO) ................................................ 142

Network on Financial Management......................................................... 143

Network of Parliamentary Budget Committee Chairpersons...........................144

Network on Performance and Results ....................................................145

Network of Senior Officials from Centres of Government (COG) ..............................146

Public Employment and Management Working Party (PEMWP) .............................147

Expert Group on Conflict of Interest: Ensuring Accountability and Transparency in

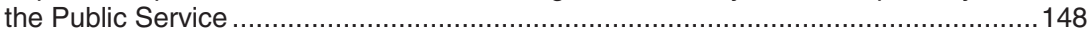

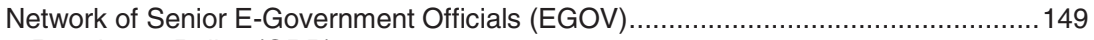

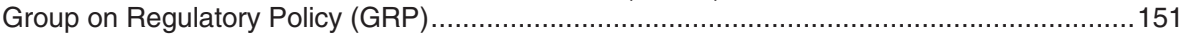

Territorial Development Policy Committee (TDPC) …........................................................ 153

Working Party on Territorial Policy in Urban Areas.................................................156

Working Party on Territorial Policy in Rural Areas .................................................158

Working Party on Territorial Indicators .............................................................. 160

TRADE AND AGRICULTURE ............................................................................... 163

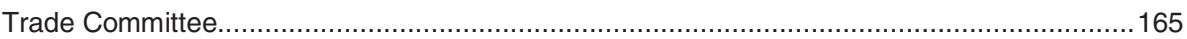

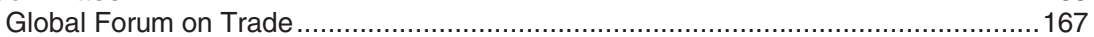

Working Party of the Trade Committee ........................................................... 168

Working Party on Export Credits and Credit Guarantees...........................................169

Joint Working Party on Agriculture and Trade ...................................................... 171

Joint Working Party on Trade and Environment ................................................. 172

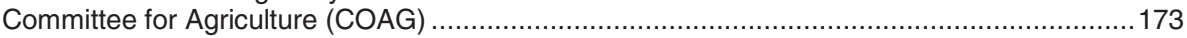

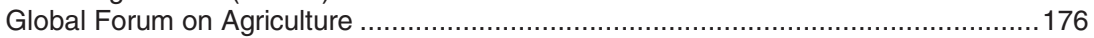

Working Party on Agricultural Policies and Markets (APM).................................... 177

Joint Working Party on Agriculture and Trade …....................................................179

Joint Working Party on Agriculture and the Environment........................................ 180 
Group on Commodity Markets

Plenary Meeting of the OECD Scheme for the Application of International Standards

for Fruit and Vegetables.

OECD Scheme for the Application of International Standards for Fruit and

Vegetables - Meeting of Heads of National Inspection Services ....................185

Annual Meeting of Representatives of the National Designated Authorities for the

Implementation of the OECD Schemes for the Varietal Certification of Seed Moving in

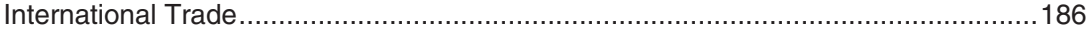

Scheme for Grass and Legume Seed .......................................................187

Scheme for Crucifer Seed and other Oil or Fiber Species............................... 189

Scheme for Cereals .............................................................................. 191

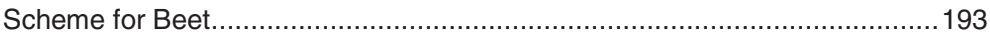

Scheme for Maize and Sorghum ............................................................ 194

Scheme for Subterranean Clover and Similar Species................................... 195

Scheme for Vegetables ....................................................................... 196

OECD Scheme for the Certification of Forest Reproductive Material Moving in

International Trade.

Annual Meeting of Representatives of the National Designated Authorities for the Implementation of the OECD Standard Codes for the Official Testing of Agricultural and Forestry Tractors.

Governing Body of the Co-operative Research Programme: Biological Resource Management

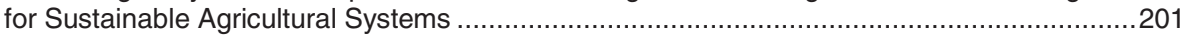

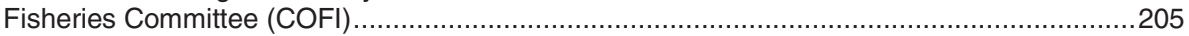

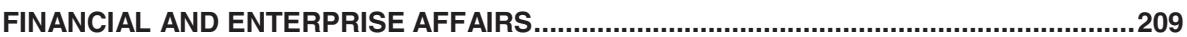

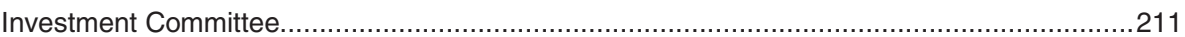

Global Forum on International Investment........................................................213

Working Group on Bribery in International Business Transactions ..........................215

Working Party of the Investment Committee .......................................................218

Advisory Group on Co-operation with Non-Members …….....................................219

Working Group on International Investment Statistics .........................................220

Annual Meeting of the National Contact Points for the OECD Guidelines for

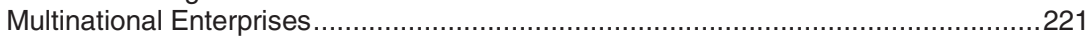

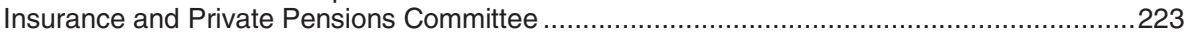

Task Force on Private Health Insurance ……....................................................225

Working Party of Governmental Experts on Insurance .........................................226

Working Party on Private Pensions ...........................................................................228

Task Force on Personal Pension Plans .......................................................229

Task Force on Pension Statistics............................................................230

Task Force on Terrorism Insurance ................................................................231

Joint Task Force on Financial Literacy and Financial Inclusion Statistics ..................232

Task Force on Insurance Statistics .......................................................................233

Joint Task Force on Financial Regulation..............................................................2. 234

Ad Hoc Task Force on the Governance of Insurers..............................................225

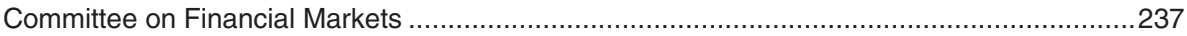

Working Party on Financial Statistics ...................................................................240

Working Party on Debt Management .................................................................. 241

Joint Task Force on Financial Literacy and Financial Inclusion Statistics ......................242

Joint Task Force on Financial Regulation...........................................................243

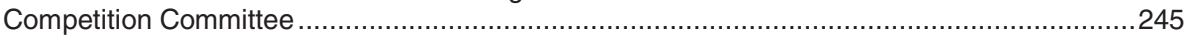

Global Forum on Competition .......................................................................248

Working Party No. 2 on Competition and Regulation.............................................250

Working Party No. 3 on Co-operation and Enforcement .........................................251

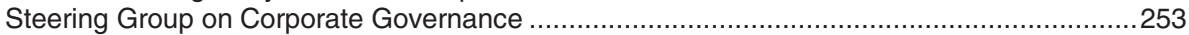

Working Group on Privatisation and Corporate Governance of State Owned Assets .254

Advisory Group on Non-Member Work ...................................................................25 


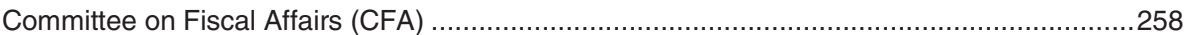

Board for Co-operation with Non-OECD Economies ............................................261

Advisory Group for Co-operation with Non-OECD Economies (AGCNOE) ....262

Joint Meetings of Tax and Environment Experts ...................................................263

Working Party No. 1 on Tax Conventions and Related Questions ..............................264

Steering Group on the Revision of the Model Tax Convention ........................265

Joint Drafting Group for Working Party No. 1 and Working Party No. 6 on

Attribution of Profits to Permanent Establishments ......................................266

Working Party No. 2 on Tax Policy Analysis and Tax Statistics ................................267

Working Party No. 6 on the Taxation of Multinational Enterprises .............................268

Joint Drafting Group for Working Party No. 1 and Working Party No. 6 on

Attribution of Profits to Permanent Establishments ......................................269

Working Party No. 8 on Tax Avoidance and Evasion ............................................270

Joint Working Parties No. 8 and No. 9 Tax Information Exchange System

Sub-Group (TIES).............................................................................271

Sub-Group on Tax Crimes and Money Laundering ...................................272

Working Party No. 9 on Consumption Taxes.........................................................273

Joint Working Parties No. 8 and No. 9 Tax Information Exchange System Sub-Group

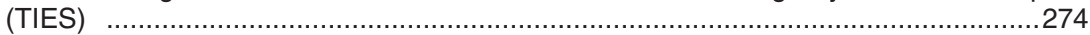

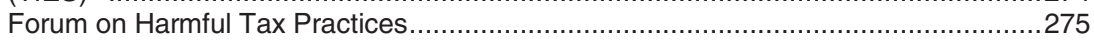

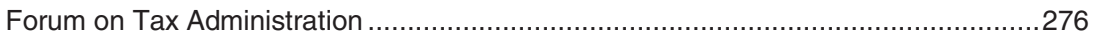

Forum on Tax Administration Compliance Sub-Group ...............................277

Forum on Tax Administration Taxpayer Services Sub-Group.......................278

OECD Network on Fiscal Relations Across Levels of Government .......................................279

SCIENCE, TECHNOLOGY AND INDUSTRY ..............................................................281

Committee on Industry, Innovation and Entrepreneurship (CIIE) ....................................28

Working Party on SMEs and Entrepreneurship (WPSMEE) ..................................28

Working Party on Industry Analysis (WPIA) ......................................................28

Working Party on Globalisation of Industry (WPGI) .............................................2. 290

Advisory Expert Group on Innovation in the Software Sector ..................................293

Advisory Expert Group on Sustainable Manufacturing..........................................294

Committee for Scientific and Technological Policy (CSTP) ..............................................295

Working Party of National Experts on Science and Technology Indicators (NESTI) ...297

Working Party on Biotechnology (WPB) ...........................................................29

Task Force on Industrial Biotechnology (TFIB) .........................................301

Task Force on Biomedicine and Health Innovation (TFBHI) ..........................303

OECD Global Science Forum (GSF) ...................................................................304

Working Party on Innovation and Technology Policy (TIP) ......................................306

Working Party on Research Institutions and Human Resources (RIHR) .....................308

Working Party on Nanotechnology (WPN) ……................................................. 310

Committee for Information, Computer and Communications Policy (ICCP) ............................313

Working Party on Communication Infrastructures and Services Policy (CISP) .........315

Working Party on the Information Economy (WPIE) ..............................................317

Working Party on Information Security and Privacy (WPISP) ..................................319

Working Party on Indicators for the Information Society (WPIIS) ..............................321

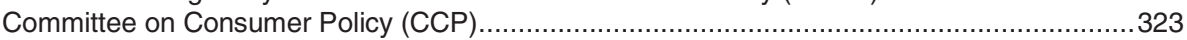

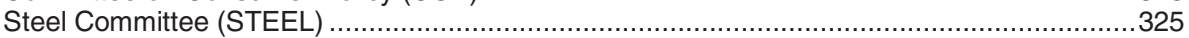

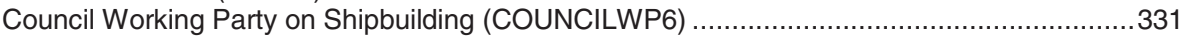

Informal Expert Group on the Sector Understanding on Export Credits for Ships ........333

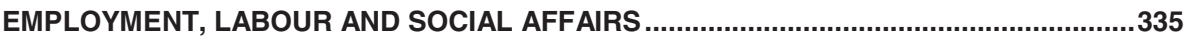

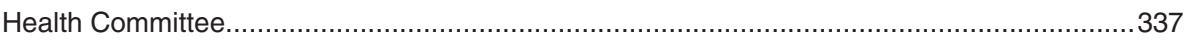

OECD Health Data National Correspondants .................................................... 340 


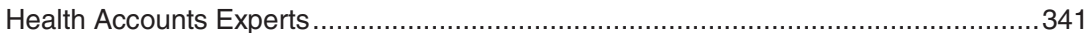

Task Force on Health-Specific Purchasing Power Parities............................342

Health Care Quality Indicators Expert Group (HCQI) ................................................343

HCQI Sub-group of Patient Safety Experts ............................................. 344

HCQI Sub-group of Mental Health Experts ...............................................345

National Experts on Information and Communication Technologies in Health

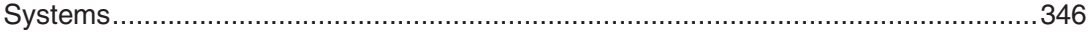

National Experts on Economics of Prevention ........................................................ 347

Employment, Labour and Social Affairs Committee (ELSAC) ........................................... 349

Working Party on Migration............................................................................. 351

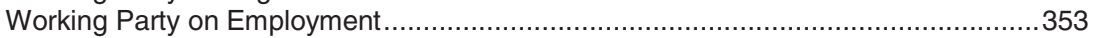

Working Party on Social Policy ……................................................................. 355

Board of Participating Countries for the Programme for the International Assessment

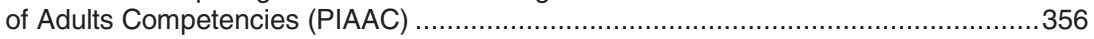

ENTREPRENEURSHIP, SMES AND LOCAL DEVELOPMENT ..........................................361

Co-operative Action Programme on Local Economic and Employment Development (LEED) 363

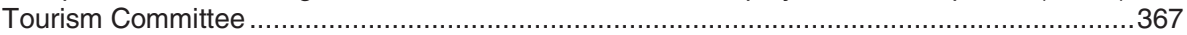

International Forum on Tourism Statistics .............................................................369

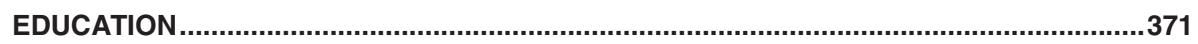

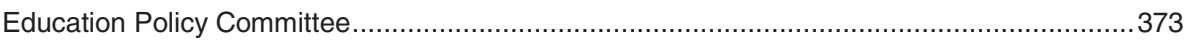

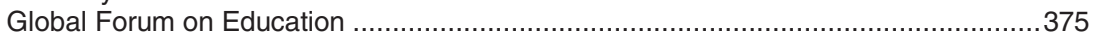

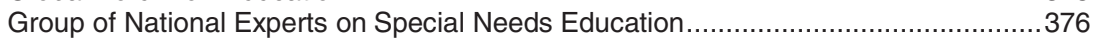

Network on Combatting School Bullying and Violence ...........................................378

Network on Early Childhood Education and Care.................................................380

Board of Participating Countries of the Teaching and Learning International Survey

(TALIS) 382

Group of National Experts on the Education of Migrants ........................................384

Group of National Experts on Vocational Education and Training..............................385

Working Party on Indicators of Educational Systems (INES) ...................................386

INES Network for the collection and the adjudication of system-level descriptive

information on educational structures, policies and practices ....................................388

INES Network for Data Development on labour market and social outcomes of

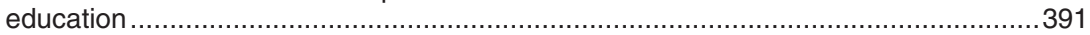

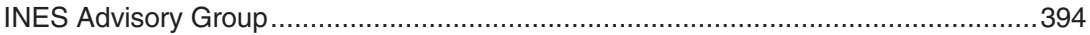

Board of Participating Countries for the Programme for the International Assessment

of Adults Competencies (PIAAC) .......................................................................... 396

Group of National Experts on the AHELO Feasibility Study (AHELO GNE) .................400

Centre for Effective Learning Environments Board of Participants.............................401

Group of National Experts on Education Facilities Evaluation ...................................403

Centre for Educational Research and Innovation Governing Board (CERI) ...........................405

Group of National Experts on Vocational Education and Training.............................408

Institutional Management in Higher Education Governing Board (IMHE) ...............................409

Group of National Experts on the AHELO Feasibility Study (AHELO GNE) ................412

Programme for International Student Assessment Governing Board (PISA) .......................... 413

PISA Strategic Development Group ……...................................................... 417

Group of PISA National Project Managers ..................................................... 418

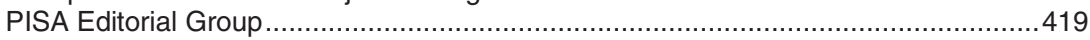

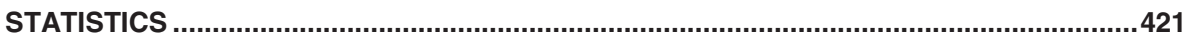

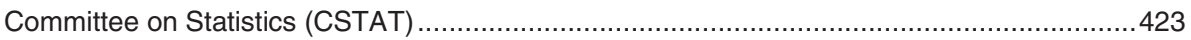

Working Party on National Accounts (WPNA) ................................................... 425

OECD Expert Group on Statistical Data and Metadata Exchange (SDMX) ................427 
Working Party on International Trade in Goods and Trade in Services Statistics (WPTGS).

TRANSPORT

INTERNATIONAL ENERGY AGENCY (IEA) .................................................................. 437

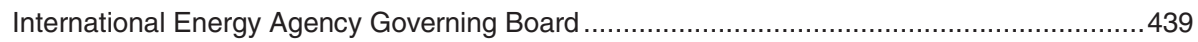

Standing Group on Emergency Questions .................................................... 444

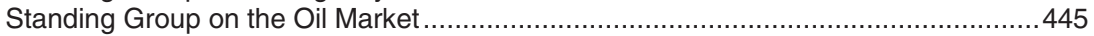

Standing Group on Long-Term Co-operation ...................................................446

Working Party on Energy Efficiency ..................................................... 447

Committee on Energy Research and Technology (CERT) ................................... 449

Working Party on Energy End-Use Technologies ....................................... 451

Working Party on Fossil Fuels ..................................................................453

Working Party on Renewable Energy Technologies ....................................455

Fusion Power Co-ordinating Committee (Fusion Working Party) ................... 457

Experts' Group on Science and Energy Research .........................................459

Committee on Budget and Expenditure ............................................................... 461

Standing Group for Global Energy Dialogue........................................................... 462

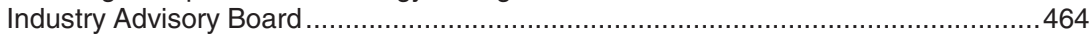

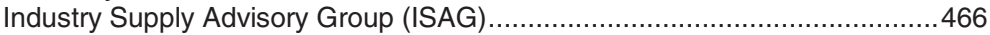

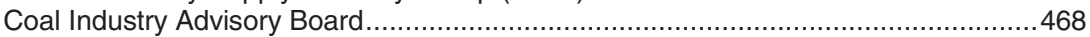

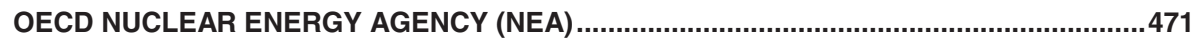

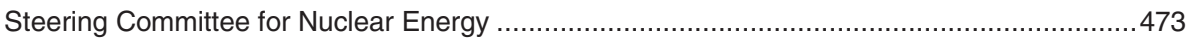

Committee on the Safety of Nuclear Installations (CSNI) ….................................479

CSNI Programme Review Group (CSNI PRG) .........................................481

Working Group on Risk Assessment (WGRISK) ......................................482

Working Group on Analysis and Management of Accidents (WGAMA) ..........484

Working Group on Integrity of Components and Structures (IAGE)...............486

Working Group on Human and Organisational Factors (WGHOF) .................488

Working Group on Fuel Safety (WGFS) ..................................................490

Working Group on Fuel Cycle Safety (WGFCS) ….................................... 492

Committee on Nuclear Regulatory Activities (CNRA) ............................................. 494

Working Group on Inspection Practices (WGIP) .......................................496

Working Group on Public Communication of Nuclear Regulatory Organisations

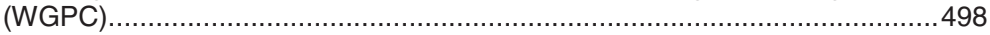

Working Group on Operating Experience (WGOE) ....................................499

Working Group on the Regulation of new Reactors (WGRNR) .....................501

Radioactive Waste Management Committee (RWMC) ...........................................503

RWMC Regulators' Forum (RWMC-RF) ….............................................505

Integration Group for the Safety Case of Radioactive Waste Repositories

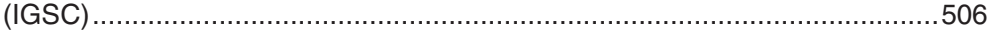

Forum on Stakeholder Confidence (FSC) ..................................................508

Working Party on Decommissioning and Dismantling (WPDD) ........................509

Committee on Radiation Protection and Public Health (CRPPH) ..............................511

Working Party on Nuclear Emergency Matters (WPNEM) ............................513

Nuclear Science Committee (NSC) …............................................................5 515

Working Party on International Nuclear Data Evaluation Co-operation

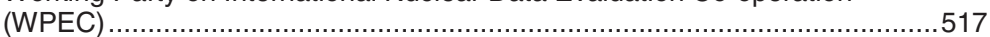

Working Party on Scientific Issues of Reactor Systems (WPRS) ..................520

Working Party on Nuclear Criticality Safety (WPNCS) ….............................522

Working Party on Scientific Issues of the Fuel Cycle (WPFC) .......................523 
Working Party on Multi-scale Modelling of Fuels and Structural Materials for

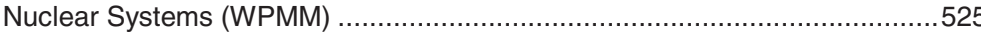

Executive Group of the NSC (Data Bank Management Committee) (DB) ...................527 The Scientific Co-ordination Group of the Joint Evaluated Fission and Fusion (JEFF) Data Project..........................................................................529

Committee for Technical and Economic Studies on Nuclear Energy Development

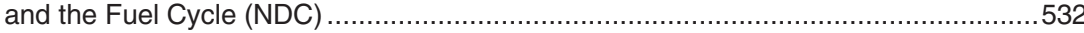
Joint NEA/IAEA Group on Uranium (UG) .............................................. 534

Working Party on Nuclear Energy Economics (WPNE) ...............................536

Nuclear Law Committee (NLC) ........................................................................ 537

JOINT SUBSIDIARY BODIES TO THE CO-ORDINATED ORGANISATIONS.......................539

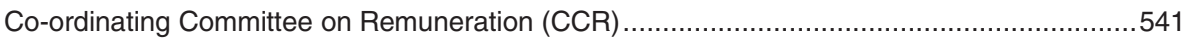





\section{COUNCIL}

Chairs:

Mr. Han Seung-soo

Prime Minister

(Ministerial session)

Mr. Angel Gurría

Secretary-General

(Sessions of Permanent Representatives)

$\begin{array}{ll}\text { Vice-Chairs: } & \begin{array}{l}\text { To be designated } \\ \text { (Ministerial session) }\end{array} \\ \text { Members: } & \text { All Member countries } \\ \text { Date of creation: } & \text { 30th September } 1961 \\ \text { Duration: } & \text { Unspecified }\end{array}$

(Korea)

Mandate: Articles 7, 8, 9 and 10.2 of the Convention on the Organisation for Economic Co-operation and Development

"Article 7

A Council composed of all the Members shall be the body from which all acts of the Organisation derive. The Council may meet in sessions of Ministers or of Permanent Representatives.

\section{Article 8}

The Council shall designate each year a Chairman, who shall preside at its ministerial sessions, and two Vice-Chairmen. The Chairman may be designated to serve one additional consecutive term.

\section{Article 9}

The Council may establish an Executive Committee and such subsidiary bodies as may be required for the achievement of the aims of the Organisation.

\section{Article 10}

2. The Secretary-General shall serve as Chairman of the Council meeting at sessions of Permanent Representatives. He shall assist the Council in all appropriate ways and may submit proposals to the Council or to any other body of the Organisation." 


\section{EXECUTIVE COMMITTEE}

Chair:

Mr. Harald Neple

(Norway)

Vice-Chairs:

Mr. Inigo Lambertini

(Italy)

Mr. Stefan Flückiger

(Switzerland)

Members:

Open to all Member countries

Date of creation:

30th September 1961

Duration:

Unspecified

Mandate: Resolution of the Council on a New Governance Structure for the Organisation adopted at the 1135th session held on 11 May 2006 [C(2006)78/FINAL and $\mathrm{C} / \mathrm{M}(2006) 9$, item 124]

\section{Extracts of Resolution C(2006)78/FINAL (para. 31 and 52)}

“31.

- The Executive Committee (ExCo)

- assists the Council by preparing for its decisions on reports and proposals - including draft Acts of the Organisation and agreements elaborated by the substantive committees or other such specialist bodies;

- advises the Council on preparations and follow-up to Ministerial meetings of OECD bodies; and on committee structures, mandates and evaluation;

- advises the Council on strategic issues and priorities, including those regarding the management and operations of the Organisation, where these fall within the competence of Council and which are not otherwise covered by other standing committees;

- advises the Council on policy issues not covered by the mandates of the other bodies directly subordinate to the Council;

- carries out any functions delegated to it by Council, and reports to it as appropriate.

52. Any problem of interpretation on the classification of a specific issue into one of the categories [see Section V of Chapter 3 of the Resolution of the Council on a New Governance Structure for the Organisation] will be referred to the Executive Committee as a normal case [as defined in para. 37 to 42 of the Resolution]." 


\section{BUDGET COMMITTEE}

Chair:

Mr. Philippe Marland

(France)

Vice-Chairs:

Ms. Lene Hyldig

(Denmark)

Mr. Curtis Stone

(United States)

Members:

Open to all Member countries

Date of creation:

30th September 1961

Duration:

Unspecified

Mandate: Resolution of the Council on a New Governance Structure for the Organisation adopted at the 1135th session held on 11 May 2006 [C(2006)78/FINAL and $\mathrm{C} / \mathrm{M}(2006) 9$, item 124]

\section{Extract of Resolution [C(2006)78/FINAL, para. 31]}

"31.

- The Budget Committee (BuCo)

- assists and advises the Council in preparing for its discussions and decisions on the budget priorities and envelope and on the biennial Programme of Work and Budget including amendments to the PWB,

- monitors the implementation of the agreed budget, the allocation/reallocation of financial resources and reports to and advises Council on these, as appropriate;

- assists the Council in preparing for discussions and decisions on elements of the integrated management cycle, such as the MTO and the PIR;

- advises the Council on the management of funds and voluntary contributions, the closing of accounts of each financial year and on the Financial Regulations;

- carries out any functions delegated to it by the Council, and reports to it as appropriate." 

FINANCIAL MANAGEMENT PROGRAMME
Chair:
Mr. Roman Holý
(Czech Republic)
Members:
Open to all Member countries
Date of creation:
17th January 2007
Duration:
31st December 2010

Mandate: - Creation of the group approved by Council at its 1147th session held on 20 December 2006 [C/M(2006)21, item 289 and document C(2006)199/REV1]

- Summary record of the Budget Committee meeting held on 17 January 2007 [BC/M(2007)1, item 8 a) and BC(2007)2]

\section{Extract of Terms of Reference as amended by BC(2007)2}

\section{Mandate for the Budget Committee Monitoring Group on the Implementation of the Budget and Financial Management Programme - BCMG-BFMP}

"1. The Council decision on the PWB 2007-08 included agreement to establish a group to assist the Budget Committee in its monitoring of the implementation of the BFMP over the next four years. On 17 January 2007, the Budget Committee agreed that a Budget Committee Monitoring Group on Implementation of the Budget and Financial Management Programme (BCMG-BFMP) should be convened for this purpose. This group would be open to all interested members of the Budget Committee, and be tasked with the following:

$>$ to monitor the timely and cost-effective implementation of a Budget and Financial Management Programme for the OECD in consultation with the OECD Secretariat's BFMP Steering Group and Secretariat staff as required;

$>$ to monitor BFMP expenditure relative to the approved budget and the agreed significant project milestones, to inform the Budget Committee of emerging problems, and to seek to ensure that the BFMP meets the needs of its stakeholders, both within the Secretariat and outside (Delegations, Auditors, etc);

$>$ to report to the Budget Committee on a quarterly basis and, if necessary, to make recommendations for the Budget Committee's consideration.

2. The Monitoring Group will be assisted in its work by the BFMP project coordinators within EXD/FIN and EXD/ITN.

3. The BCMG-BFMP shall meet at regular intervals consistent with the requirements of its terms of reference, commencing within one month of the establishment of the group. The Chair of the Monitoring Group will be appointed by the Budget Committee on an annual basis.

4. The BCMG-BFMP shall continue until the end of the implementation of the BFMP project, unless the Budget Committee decides otherwise." 


\section{INFORMAL TASK FORCE ON THE COST RECOVERY CHARGES}

APPLYING TO VOLUNTARY CONTRIBUTIONS

Chair:

Members:

Date of creation:

Duration:
Mr. Sergio Lozoya

(Mexico)

Mandate: Decision approved by Council at its 1186th session held 18 December 2008 [C/M(2008)22, item 334 and C(2008)217/REV1]

\section{Extract of document [C(2008)217/REV1]}

"13. In the light of the report by the Chair of the Budget Committee [C(2008)212], Council $\cdots$

b) invites the Budget Committee to undertake a thorough review of cost recovery charges applying to voluntary contributions, with a view to making recommendations to Council in 2009, with implementation of the revised policies and procedures to take effect from 1 January 2010;" 


\section{EXTERNAL RELATIONS COMMITTEE}

Chair:

Mr. Christopher Langman

(Australia)

Vice-Chairs:

Mr. Jacques Sturm

(France)

Mr. Takashi Ariyoshi

(Japan)

Members:

Open to all Member countries

Date of creation:

1st June 2006

Duration:

Unspecified

Mandate: Resolution of the Council on a New Governance Structure for the Organisation adopted at the 1135th session held on 11 May 2006 [C(2006)78/FINAL and $\mathrm{C} / \mathrm{M}(2006) 9$, item 124]

\section{Extract of Resolution [C(2006)78/FINAL, para. 31]}

"31.

- The External Relations Committee

- $\quad$ assists the Council in preparing for its discussions and decisions on strategies, policies and guidelines on external relations and relations with non-Members and international organisations, including conditions of their participation in the work of the Organisation;

- monitors the implementation of these decisions and advises the Council;

- advises the Council on the co-ordination of activities and programmes with nonMembers;

- assists the Council in ensuring that the global relations of the Organisation are taken into account in the preparation of the PWB;

- carries out any functions delegated to it by Council, and reports to it as appropriate." 


\section{WORKING PARTY ON PRIORITIES}

$\begin{array}{lll}\text { Chair: } & \text { Mr. Ulrik Vestergaard Knudsen } & \text { (Denmark) } \\ \text { Vice-Chairs: } & \begin{array}{l}\text { Mr. Norio Hattori } \\ \text { Mr. Chris Hoornaert } \\ \text { Mr. Dominic Martin }\end{array} & \begin{array}{l}\text { (Japan) } \\ \text { (Belgium) } \\ \text { (United Kingdom) }\end{array} \\ \text { Members: } & \text { Open to all Member countries } & \\ \text { Date of creation: } & \text { 18th December 2008 } & \\ \text { Duration: } & \text { 30th June 2009 }\end{array}$

Mandate: Decision approved by Council at its 1186th session held 18 December 2008 [C/M(2008)22, item 334 and C(2008)217/REV1]

"THE COUNCIL

\section{Extract of document [C/M(2008)22, item 334]}

"agrees to establish an open-ended working party, chaired by an Ambassador, to review the current procedures relating to priority-setting, resource reallocation and performance evaluation, with a view to making recommendations to Council before the end of June 2009" 


\section{COMMITTEE ON PUBLIC AFFAIRS AND COMMUNICATIONS}

Chair:

Members:

Date of creation:

Duration:
Mr. Eric Martin

(Switzerland)

Open to all Member countries

26th October 2000

31st December 2009

Mandate: - Resolution concerning the modification and renewal of the mandate of the Committee on Public Affairs and Communication approved by the Council at its 1101st session on 16 December 2004 [C(2004)199 and C/M(2004)27, item 357]

- Resolution on a New Governance Structure for the Organisation approved by the Council at its 1135th session held on 11 May 2006 [C(2006)78/FINAL, para. 32 and 33 and $\mathrm{C} / \mathrm{M}(2006) 9$, item 124]

\section{Resolution of the Council [C(2004)199]}

"THE COUNCIL,

Having regard to the Convention on the Organisation for Economic Co-operation and Development of 14 December 1960;

Having regard to the Rules of Procedure of the Organisation;

Having regard to the Resolution of the Council establishing a Committee on Public Affairs and Communications [C/M(2000)24, item 304 c) and document C(2000)199];

Recognising the necessity of ensuring widespread knowledge and understanding of the purpose, activities and work of the Organisation in order to best promote its aims;

Recognising the fact that communications technologies are rapidly modifying and expanding the traditional channels of information dissemination;

Recognising that evolving political, economic and social challenges require informed and actively participating citizens and that governments have a heightened responsibility to ensure transparency and clarity in policy-making;

Recognising that the Organisation can play an important role in assisting governments to improve communication and consultation with civil society on matters dealt with in its work programme;

\section{DECIDES:}

1. The Committee on Public Affairs and Communications shall serve as an advisory body to the Council on the Organisation's public affairs and communications policy and programmes, with a view to enhancing the coherence and efficiency of the Organisation in this area. In particular, the Committee shall exercise its responsibilities of monitoring and evaluation of the implementation of the OECD Publishing Policy as set out in the Appendix to document C(2002)80 and OECD Communications Strategy as set out in the Appendices to the documents $C(2004) 74$ and C(2004)198 and to report to the Council on its findings.

2. The Committee shall be composed of representatives of all Member countries and its Chair shall be designated by the Council. It shall meet and report to the Council as often as necessary.

3. The mandate of the Committee shall expire on 31 December 2009 unless the Council decides otherwise." 


\section{AUDIT COMMITTEE}

Chair:

Members:

Date of creation:

Duration:
Mr. Paul-Henri Lapointe

Mr. Philippe Marland

Mr. Norio Hattori

Mr. Dominic Martin

Mr. Jan Woroniecki

Mr. Curtis Stone

Ms. Leslie Aronovitz

Supreme Audit Institution

Mr. Jacek Jezierski

Supreme Audit Institution

Mrs. Danièle Lajoumard

Supreme Audit Institution

1st November 2008

Unspecified
(Canada)

(France)

(Japan)

(United Kingdom)

(Poland)

(United States)

(United States)

(Poland)

(France)

Mandate : $\quad$ Financial Regulations, Regulation 31 [C(2008)92/REV1], approved by Council at its 1179th session held 17 July 2008 [C/M(2008)15, item 180].

\section{Extract of the Financial Regulations [C(2008)92/REV1] (Regulation 31)}

"§1. There shall be an Audit Committee of Council which shall monitor the independence and effectiveness of the internal and external audit functions and review the financial situation of the Organisation. It shall report to Council on a regular basis.

§4. The Audit Committee shall adopt recommendations on a consensual basis. In the case of any dissent among Committee members, the conclusions of the Chair, together with the dissenting opinion, shall be presented in the subsequent Committee report.

§7. The Audit Committee's functions shall be as follows:

- review and comment on the annual work programme of the internal and external audit functions, including updates thereto;

- review the management responses to, and implementation of, the recommendations by the internal and the external audit function; and

- review the financial situation of the Organisation as well as its internal control system and its risk management system;

- provide an opinion to Council regarding the Secretary-General's appointment, and termination of appointment, of the Director of Internal Audit;

- recommend to Council the terms of reference for the External Auditor, including the performance audits to be carried out by the External Auditor, and, following a process of call for tender, recommend to Council the appointment of the External Auditor;

- in coordination with the Budget Committee, transmit its recommendations to Council on the discharge of the Secretary-General from all liability in respect of his or her administration during the financial period.

§8. The Audit Committee shall meet with the external and internal audit functions, and, as appropriate, other officials of the Organisation." 


\section{EVALUATION COMMITTEE ${ }^{1}$}

Chair:

Members:

Date of creation:

Duration:
Mr. Agustín García-López

Mr. Eduardo Ferro Rodrigues

Ms. Jana Kotová

Mr. Paul-Henri Lapointe

Mr. Chris Hoornaert

Mr. Péter Gottfried
(Mexico)

(Portugal)

(Slovak Republic)

(Canada)

(Belgium)

(Hungary)

10th February 2005

Unspecified

Mandate: - Decisions of the Council approved at its 1105th session held on 10 February 2005 $[\mathrm{C} / \mathrm{M}(2005) 4$, item 38] and its 1106th session held on 24 February 2005 [C/M(2005)5, item 46]

- Decision of the Council approved at its 1142nd session held on 12 and 13 October 2006 [C/M(2006)16, item 210]

- Resolution on a New Governance Structure for the Organisation approved by the Council at its 1135th session held on 11 May 2006 [C(2006)78/FINAL, para. 32 and 33 and $\mathrm{C} / \mathrm{M}(2006) 9$, item 124]

- Summary record of the 1164th session of the Council [C/M(2007)17, item 237 b)] transforming the sub-group into a committee

- Decision of the Council approved at its 1168th session held on 7 March 2008 $[\mathrm{C} / \mathrm{M}(2008) 4$, item 50]

\section{Extract of Summary Record [C/M(2005)4]}

"38. PROPOSAL FOR IN-DEPTH EVALUATION AT THE OECD

THE COUNCIL

b) noted document $\mathrm{C}(2004) 190$ and its CORR1;

d) recalled the ten principles agreed in April 2004 to guide the development of in-depth evaluations [C(2004)91];

e) agreed:

i) that the overarching goal of in-depth evaluation at the OECD is to provide a mechanism through which Council can assess whether Committees are conducting processes, delivering outputs and achieving impacts that are in line with Members policy expectations and priorities and with the comparative advantage of the OECD.

viii) that a sub-group of the Council, comprising five of its members proposed by the Chair of the Executive Committee and designated by Council for one year, would be established before the end of February to agree the terms of reference and

\footnotetext{
${ }^{1}$ The Evaluation Committee has succeded the sub-group created in 2005 [see C/M(2007)17, item 237b)]
} 
methodology for evaluation; review the evaluations themselves and present the Evaluation Report to Council; and monitor the follow-up of eventual recommendations arising from the evaluations;

ix) that in-depth evaluations conducted by the Evaluation Sub-group would follow the steps described in "Section VI, How In-depth Evaluations would be conducted" of document C(2004)190 as amended by this decision

\section{Extract of Summary Record [C/M(2006)16]}

“210. EXPERIENCE

IN DEPTH EVALUATION: FOLLOW-UP REPORT TO THE REVIEW OF THE INITIAL

THE COUNCIL

b) welcomed the measures proposed for broadening and deepening the evaluation work, and for refining its presentation and review as set out in Section I of document C(2006)124/REV1;

d) approved the recommendations for associating evaluations of Part II programmes with the in-depth evaluation mechanism as proposed in Section III of document C(2006)124/REV1, and requested the Secretariat to take the appropriate actions for their implementation;"

\section{Extract of Summary Record [C/M(2008)4]}

“50.

IN-DEPTH EVALUATION: THE WAY FORWARD

\section{THE COUNCIL}

d) agreed to use evaluation results with the aim of identifying and promoting the dissemination of good practices across the Organisation, and noted that future in-depth evaluations will further take into account salient issues pertaining to the functioning of committees, including the implementation of the Rules of Procedure;" 
Chair:

Mr. Harald Neple

(Norway)

Members:

Up to six Council Members

Date of creation:

4th February 2002

Duration:

Unspecified

Mandate: - Informal proposal of 13 December 2001

- Council Summary Record of the 1048th session held on 13 February 2003 [C/M(2003)3, item 40]

- Council Summary Record of the 1082nd session held on 8 April 2004 [C/M(2004)8, item 123]

- Resolution on a New Governance Structure for the Organisation approved by the Council at its 1135th session held on 11 May 2006 [C(2006)78/FINAL, para. 32 and 33 and $C / M(2006) 9$, item 124]

\section{Extract of the informal proposal of 13 December 2001}

"3. In order to ensure a better and permanent information of the Council, a Site Project Advisory Board consisting of up to six Ambassadors should monitor the Site Project and report regularly to Council (i.e., monthly, under "other business") on time and cost targets and project status. The Project Board would meet at least once a month with representatives of the Secretariat, consultants and architects to be informed about the status of the Site Project regarding time and cost aspects. It should be an informal group along the lines of the Development Group, with Ambassadors acting in a personal capacity to ask questions and pass information to Council. To be manageable in size, it should have up to six members from among interested Ambassadors; transparency would be assured through information of Council, which would, in any case, take all necessary decisions and issue statements. This informal group would have no mandate and would not issue recommendations. The Executive Committee would retain its responsibilities."

\section{Extract of the Summary Record [C/M(2004)8]}

(123)

"THE COUNCIL,

c) requested the Secretariat, in accordance with $\mathrm{C} / \mathrm{M}(2003) 22$, Item $337 \mathrm{~h}$ ) to continue to report regularly to the Executive Committee and the Informal Group on the Site in order to keep Council fully informed of progress on the project." 


\section{PENSION BUDGET AND RESERVE FUND MANAGEMENT BOARD}

Chair:

Vice-Chair:

Members:

Date of creation:

Duration:
Mr. Ahmet Erozan

Mr. Nikolaos Tatsos

Mr. Philippe Marland

Mr. Peter Krekel

Mr. Ivan Divoy

Mr. Adrian Blundell-Wignall

12th May 2005

Unspecified
(Turkey)

(Greece)

(France)

(Netherlands)

Mandate: - Approved by Council at its 1113th session held on 12 May 2005 [C/M(2005)12, item 143 and document C(2005)49]

- Resolution on a New Governance Structure for the Organisation approved by the Council at its 1135th session held on 11 May 2006 [C(2006)78/FINAL, para. 32 and 33 and $\mathrm{C} / \mathrm{M}(2006) 9$, item 124]

Extract of document [C(2005)49]

"STATUTE OF THE PENSION BUDGET AND RESERVE FUND

Part II - Fund Management and Governance

Article 3

\section{General Principles}

1. The Fund shall be managed by a Management Board composed of members named by Council on the proposal of the Member countries, the Secretary-General and the Staff Association.

2. The basic mission of the Management Board, which operates subject to control of the Council, is to propose to the Council for approval the general policies, goals and guidelines for investment of the assets of the Fund, to give external service providers the mandates necessary for the management of the Fund, and to assure that the Council approved policies are respected.

3. The operating budget of the Fund will be approved by Council.

4. The Fund will be administered and audited in accordance with the Financial Rules and Regulations of the Organisation.

5. The Management Board has no responsibility for the operation of the Pension Scheme and the payment of benefits to individuals other than the release of funds as required under Article 2, paragraph 4.

6. The Management Board is assisted by a Fund Secretariat designated by the SecretaryGeneral on recommendation of the Management Board.

7. The Management Board will report at least twice annually to Council on the status of the Fund. 
Article 5

\section{Functions of the Management Board}

1. Subject to any decisions of the Council, the Management Board shall:

a) submit to Council, for approval, a code of conduct;

b) submit to Council, for approval, proposals for the general policies, goals and guidelines for investment of the assets of the Fund;

c) select, in accordance with the Financial Regulations, Rules and Instructions of the Organisation, the external service providers necessary for the management of the Fund (e.g., investment advisers, investment managers, actuaries and custodian banks.);

d) review the operations of the Fund and verify their conformity with the policies, goals, and guidelines approved by the Council;

e) as necessary, bring to Council's attention any issue concerning the operation of the Fund;

f) approve, on the proposal of the Fund Secretariat, the Fund's operating budget and annual financial statements and submit them to Council for final approval; and

g) carry out other tasks as assigned by Council.

2. The Management Board shall report at least twice annually to Council on the status of the Fund. Every five years, the Management Board will carry out a thorough review of the Fund's investment policies, goals, guidelines and performance, its actuarial assumptions, rate of contribution and its capitalisation target and report its findings, decisions and recommendations to Council.

\section{Article 6}

\section{Meetings and Decisions of the Management Board}

1. The Management Board will establish its governing rules of procedure.

2. The Management Board shall meet as needed to carry out its functions but no less than quarterly, or at the request of its Chair or the majority of its members.

3. Decisions are taken by a majority of the Management Board members, with the Chair or, in his or her absence, the Vice-Chair having the casting vote." 
Chair:

Vice-Chairs:

Members: ${ }^{1}$

Observers:

Date of creation:

Duration:
Mr. Eric Martin

Mr. Ricardo Guerra de Araújo

Mr. Patricio Utreras

Mrs. Renate Van Boddien

Mr. Gerardo Bracho

Ms. Kristin H. Langsholt

Ms. Mihaela Popescu

Ms. Lale Agusman

Mrs. Huong Tra Nguyen

Austria
Belgium
Brazil
Chile
Colombia
Czech Republic
Egypt
Finland
France
Germany
Greece
Iceland
India
Ireland
Israel

Austria

Belgium

Colombia

Czech Republic

Egypt

Finland

France

Germany

Greece

Iceland

Ireland

Israel
(Switzerland)

(Brazil)

(Chile)

(Germany)

(Mexico)

(Norway)

(Romania)

(Turkey)

(Viet Nam)

Italy

Korea

Luxembourg

Mexico

Netherlands

Norway

Poland

Portugal

Romania

Slovak Republic

South Africa

Spain

Sweden

Switzerland

Thailand

Turkey

Mandate: - Resolution of the Council on the Establishment of the Development Centre Governing Board $[\mathrm{C}(2002) 228]$ as modified in the Council conclusions [C/M(2002)23, Item $337 \mathrm{i})]$

- Decision of the Council reforming the Development structure of the OECD [C/M(2002)18, item 258 b) c) d) e)] and document [C(2002)181/REV2]

Annex - Decision of the Council establishing a Development Centre of the Organisation [C(62)144(Final)] as amended by the Decision of the Council [C(63)54]. Also amended by the Council Decisions on: the Participation of the Republic of Korea [C/M(91)18, item 181 and $\mathrm{C}(91) 137]$, the Participation of Argentina and Brazil [C/M(94)2, item 28 and C(94)13(FINAL)] the Participation of Chile [C/M(98)16, item 187], the Participation of India $[\mathrm{C} / \mathrm{M}(2001) 3$, item 30] and the participation of Romania $[\mathrm{C} / \mathrm{M}(2004) 7$, item 100]; by the Decision of the Council of the 22

\footnotetext{
1 Poland re-joined on 1 January 2008. Egypt, Israel and Vietnam joined on 18 March 2008. Colombia joined on 24 July 2008.
} 
September 2002 deleting Article 6 [C/M(2002)18, item 258 c)]; by Council's endorsement of the proposals for the future mode of co-operation of the Development Centre's Governing Board, as set out in the Annex to document C(2003)139 and by the Decision of the Council of 22 April 2004 amending Article 11 [(2004)71/REV1; C/M(2004)10, item 138 d)].

\author{
Resolution of the Council on the Establishment of \\ the Development Centre Governing Board [C(2002)228] \\ as modified by the Council conclusions [C/M(2002)23, Item $337 \mathrm{i})]$
}

\title{
"THE COUNCIL
}

Having regard to Article 5 of the Convention establishing the OECD and Rule 18 a) iii) of the Rules of Procedure of the Organisation,

Having regard to the Decision of the Council of 23 October 1962 establishing a Development Centre of the Organisation [C(62)144/Final as amended];

Having regard to the Resolution of the Council [C(71)191] establishing an Advisory Board on the Development Centre;

Having regard to the conclusions of the Council of 12 September $2002[\mathrm{C} / \mathrm{M}(2002) 18]$ on Reforming the Development Structure of the OECD [C(2002)181/REV2];

On the proposal of the Secretary-General;

\section{DECIDES:}

- There is hereby established the Development Centre Governing Board, composed of representatives of the countries Members of the Centre ${ }^{1}$.

- The Governing Board shall work on all issues within the framework of the Development Centre's mandate, [C(62)144/Final as amended] and under the general guidance of the Council;

- The provisions of the Rules of Procedure of the Organisation shall apply to the Governing Board;

- The Governing Board shall ensure that the Development Centre engage in close co-ordination and co-operation with other parts of the OECD in forming and implementing a common strategy and co-ordinated work programme of the "development cluster," of which the Development Centre is a part.

- The Resolution of the Council [C(71)191] referred to above is hereby repealed.

\author{
ANNEX \\ Decision of the Council establishing \\ a Development Centre of the Organisation [C(62)144(Final)] \\ as amended by the Decision of the Council [C(63)54], by \\ the Decision of the Council of the 22 September 2002 [C/M(2002)18, Item $258 \mathrm{c})]$, and by the \\ Decision of the Council of 22 April 2004 [C(2004)71/REV1; C/M(2004)10, Item 138 d)]
}

\footnotetext{
1 In accordance with the provisions of Article 13 of the Convention and Supplementary Protocol No.1 to the Convention, the European Commission takes part in the work of the Governing Board.
} 


\section{THE COUNCIL,}

Having regard to the Convention on the Organisation for Economic Co-operation and Development of 14th December 1960, (hereinafter called the "Convention"), and, in particular, Articles $1 \mathrm{~b}), 2 \mathrm{e}), 3,5 \mathrm{a}), 12$ and 20 of the Convention;

Having regard to the Resolution of the Council adopted at the Meeting of Ministers on 17th November 1961, on Terms of Reference for a Development Centre of the Organisation [Documents OECD/C(61)54, paragraph 11; OECD/C/M(61)7, Item 52];

Having regard to the Financial Regulations of the Organisation and, in particular, to Articles 5 and $15 \mathrm{~b}$ ) thereof;

Having regard to the Staff Rules and Regulations and to the Rules and Regulations on Experts and Consultants of the Organisation and, in particular, to Regulation 2 b) thereof;

Recognising that there exists in participating countries a great amount of knowledge and experience on the problems of economic development and on the formulation of general economic policies which could be adapted to countries or regions in the process of economic development, and that this would contribute to achieving the objectives of the Organisation set out in the Convention by the placing of such knowledge and experience at the disposal of the countries concerned;

DECIDES:

\section{Article 1}

There is hereby established, within the framework of the Organisation, a Development Centre (hereinafter referred to as the "Centre").

\section{Article 2}

The purpose of the Centre shall be to bring together the knowledge and experience available in participating countries of both economic development and of the formulation and execution of general economic policies; to adapt such knowledge and experience to the actual needs of countries or regions in the process of economic development and to place the results by appropriate means at the disposal of the countries concerned. In accomplishing this purpose, the Centre shall in particular take into account the interdependence of the political, economic, and cultural conditions existing in the countries in the process of economic development.

\section{Article 3}

The Centre shall undertake the activities appropriate to achieve its purpose as defined in Article 2 in the context of any directives issued by the Council. It may, in particular, engage in training and research, and organise conferences, symposia and other meetings. It may also help meet the needs for advisory services for institutions engaged in teaching, training, or research, or for less-developed countries at their request, subject to Council approval when such services are rendered to Governments of non-participating countries.

\section{Article 4}

The Centre should establish with other international organisations and with national institutions concerned with economic development such working relations as may be appropriate to facilitate the accomplishment of its tasks. Such working relations should in particular allow the Centre to take full advantage of the work of these organisations and institutions. In order to accomplish its purposes the Centre may also encourage, promote and assist the activities of other institutions or organisations.

\section{Article 5}

The Centre shall report each year to the Council on its activities. It shall submit, either on request by the Council or on its own initiative, other communications to the Council. 


\section{Article 6}

Article 6 deleted by Decision of the Council of 22 September 2002 [C/M(2002)18, Item 258 c)].

\section{Article 7}

The Secretary-General, on the proposal of the President ${ }^{1}$ and with the approval of the Council, may name advisers who shall be consulted by the President as appropriate in the exercise of his duties. The Advisers shall be selected on the basis of their expert knowledge of problems of economic development or on the basis of the functions they may hold with other institutions or in countries in the process of economic development.

\section{Article 8}

a) The staff of the Centre shall form part of the Secretariat of the Organisation.

b) Notwithstanding the provisions of Regulation 2(b) of the Rules and Regulations on the Experts and Consultants of the Organisation, the appointment of individuals as consultants to the Centre may be made for periods of up to three years.

\section{Article 9}

The expenditure of the Centre shall be defrayed from assets earmarked for it in Part II of the Budget of the Organisation.

\section{Article 10}

Notwithstanding the provisions of the Financial Regulations, the Council may authorise the Secretary-General to seek and accept voluntary contributions, other resources, and payment for services rendered by the Centre. The Council may also authorise the Secretary-General to commit and expend such funds for periods of more than one year.

\section{Article 11}

Participating countries shall be the Member countries which have accepted this Decision and any other country which has been invited by the Organisation to participate and which has addressed a written acceptance to the Secretary-General, including acceptance to contribute to the expenditure of the Centre. Any participating country may withdraw by giving twelve months' written notice to the Secretary-General. The Organisation may suspend or terminate participation of a non-Member country by giving one month's written notice of suspension or twelve months' written notice of termination."

\footnotetext{
1 As of the Decision of the Council of 22 September 2002, the Development Centre is headed by an A7-level official [C/M(2002)18, item 258].
} 


\section{GLOBAL FORUM ON DEVELOPMENT ${ }^{1}$}

Chair:

Date of creation:

Duration:

Approved by:
No formally-appointed Chair

1st January 2009

31st December 2010

- Development Assistance Committee (DAC); 23 October 2008 [DCD/DAC/M(2008)9]

- Development Centre Governing Board (DEV GB); 31 October $2008[\mathrm{DEV} / \mathrm{GB} / \mathrm{M}(2008) 7]$.

\section{Mission Statement:}

"The OECD Global Forum on Development, which is jointly led by the OECD Development Centre and OECD Development Co-operation Directorate, addresses priority issues in the field of development policy through multi-year thematic cycles [C(2005)196]. It is structured around an annual meeting and a limited number of informal preparatory or follow-up events [COM/DCD/DEV/RD(2007)1; COM/DEV/DCD(2008)2].

The Forum operates around multi-annual themes, proposed by an Informal Steering Group and approved by the DAC and Development Centre Governing Board. Themes are designed to align closely with the Development Centre and DAC programmes of work and may be adjusted if and as necessary following the DAC's reflection exercise [DCD/DAC(2008)28/REV1].

The Global Forum on Development will help:

- advance understanding of global development issues and improve the quality and development impact of OECD products. The Forum will encourage dialogue with a wide range stakeholders outside the OECD, supporting the organisation's strong and visible role on key global development issues;

- enable a core network of participants to follow key policy issues of current and emerging global relevance on a multi-annual basis, and contribute to policy progress and consensus with nonmembers through OECD methods of work;

- enhance OECD-wide coherence on development related work, promoting horizontal and multidisciplinary approaches within the organisation and in partnership with other international organisations."

Members:

\section{Designated Participants:}

Open to all Member countries
A. DAC and DEV GB Observers: IMF, UNDP, World Bank
B. Members of DEV GB:
Chile, Israel,
Brazil, India, Indonesia, South Africa,
Colombia, Egypt, Romania, Thailand, Vietnam
C: Other non-Members:
DEFINE (Development Finance Network): Ghana, Philippines, Bangladesh

Accession Countries: Estonia, Russia, Slovenia

\footnotetext{
1 Information on this Global Forum is provided for the sake of completeness, but Global Forums are not, in accordance with C(2008)208/FINAL, official OECD bodies.
} 
Enhanced Engagement Country: China

Regional Organisations: African Development Bank, Asian

Development Bank, Inter-American Development Bank, Arab

Fund for Economic and Social Development (as secretariat of the Arab Co-ordination Group) 


\section{ANNUAL MEETING OF SUSTAINABLE DEVELOPMENT EXPERTS}

Chair:

Members:

Date of creation:

Duration:
Mr. Bernard Mazijn

(Belgium)

Open to all Member countries

13th May 2004

31st December 2010

Mandate: - 1086th Session of the Council held at Ministerial Level on 13 and 14 May 2004 [C/M(2004)12/PART1, item 164 d)]

- Council Resolution approved at its 1144th session held on 15 and 16 November 2006 [C(2006)147 and C/M(2006)18, item 241]

- Council resolution approved at its 1185th session held on 04 December 2008 [C(2008)181 and C/M(2008)21]

\section{Document [C(2008)181]}

\section{"MANDATE FOR THE ANNUAL MEETING OF SUSTAINABLE DEVELOPMENT EXPERTS (AMSDE)}

1. The Annual Meeting of Sustainable Development Experts (AMSDE) shall:

1. Advise the Organisation on how to mainstream sustainable development across the work programme of the OECD, focusing on policy coherence, the integration of economic, social and environmental concerns, and the adoption of long-term orientations. Specifically, the AMSDE will:

- $\quad$ Review an annual survey of ongoing, OECD-wide work on sustainable development and identify major gaps from the sustainable development perspective;

- Identify obstacles to policy reform and recommend topical sustainable development issues for discussion at a higher level;

- Maintain close contacts among OECD Committees and Directorates, including through joint sessions with Committee Chairs/Bureaus, on specific sustainable development topics; and

- Encourage the inclusion of sustainable development perspectives in the development of analytical approaches, statistics and methodologies in the work of OECD Committees for use by Member countries.

2. Share best practices for sustainable development strategies in OECD Member countries, and engage also with non-Member countries, particularly the Accession countries and the Enhanced Engagement countries.

3. Co-operate with other international and regional organisations, including contributions to the United Nations Commission on Sustainable Development (UNCSD), to promote synergies and avoid duplication in promoting sustainable development.

2. The Annual Meeting of Sustainable Development Experts will be composed of representatives of all Member Countries and will designate its Chair. 
3. The Annual Meeting of Sustainable Development Experts will report annually to the Council, including recommendations on priority cross-cutting areas for future work from the sustainable development perspective.

4. The mandate of the Annual Meeting of Sustainable Development Experts will remain in force until 31 December 2010, when the Council will decide in what form, if any, the work on sustainable development should continue." 


$\begin{array}{ll}\text { Chair: } & \begin{array}{l}\text { Mr. Angel Gurría } \\ \text { Secretary-General }\end{array} \\ \text { Members: } & \text { Open to all Member countries } \\ \text { Date of creation: } & \text { 13th March } 1962 \\ \text { Duration: } & \text { Unspecified }\end{array}$

Mandate: Decision of the Council [C(62)45] on Relations with International non-Governmental Organisations, as amended by [C(64)181, C(66)144(Final) and C(89)15(Final)]

\section{Decision of the Council [C(62)45], as amended}

"THE COUNCIL,

Having regard to Article 12 of the Convention on the Organisation for Economic Co-operation and Development of 14th December 1960;

Having regard to the Rules of Procedure of the Organisation and in particular Rule 10 thereof $[\mathrm{OECD} / \mathrm{C}(61) 21]$;

Considering it desirable to specify the fundamental rules governing the procedure for liaison and consultation between the Organisation and international non-Governmental organisations interested in its activities;

Recognising in particular the importance emphasized in paragraph 132 of the Preparatory Committee's Report of maintaining and developing consultations between the Organisation and representatives of labour and management of Member countries;

\section{DECIDES:}

1. The Secretary-General shall be generally responsible for maintaining liaison with international non-Governmental organisations and for preparing and arranging consultations with those most representative of the different sectors of economic life.

2. Any international non-Governmental organisation may be consulted by the Organisation provided that it satisfies the following three conditions:

a) It has wide responsibilities in general economic matters or in a specific economic sector.

b) It has affiliated bodies belonging to all or most of the Member countries in the organisation.

c) It substantially represents the non-Governmental interests in the field or sector in question.

3. The Secretary-General shall prepare a list of the organisations specified in paragraph 2 above and shall submit it for the approval of the Council. 
a) Hold exchanges of views with the Organisation at meetings convened either at its own request or on the initiative of the Secretary-General dealing with subjects of common interest or subjects determined beforehand which have a bearing on the work of the Organisation;

b) Receive general information on the work of the Organisation and certain of the Organisation's documents or summaries thereof, whenever the Secretary-General considers such documents or summaries useful for the study of a particular subject.

5. At the meetings specified in paragraph 4 a) above, the organisation in question may be invited either to express its views orally on questions on the Agenda or to submit a memorandum stating its position.

6. Such meetings shall be convened and organised by a Liaison Committee of which the Chairman shall be the Secretary-General and which shall be open to all members of the Council.

7. All Member countries may designate to attend these meetings representatives of their Governments and/or if they so desire, representatives of national organisations in the field concerned.

8. Where appropriate and in order to make allowance in arranging such consultations, for any difference which may exist between the interests of such organisations, the Secretary-General may make with any of the organisations specified in paragraph 2 above or, if necessary, with any other international non-Governmental organisation, such arrangements as may be appropriate and as shall be previously approved by the Council.

9. a) International non-Governmental organisations, whether or not specified in the list in paragraph 3 above and which are active in a sector covered by the aims or falling within the province of the Organisation, may be kept informed of such part of the Organisation's work as is likely to be of interest to them and may, in certain cases, be consulted for the study of a given question.

b) Such consultations shall be held either in application of Rule $10 \mathrm{~b}$ ) of the Rules of Procedure of the Organisation or at special meetings arranged between the representatives of such organisations and the officers of such subsidiary bodies of the Organisation as are interested, the Secretary-General, in each case, first ascertaining the opinion of the Chairman of the subsidiary body in question.

c) The provisions of paragraph 7 shall also apply to the cases provided for in sub-paragraph b) above.

d) The Secretary-General shall periodically inform the Council of the names of the Organisations not specified in the list referred to in paragraph 3 above, to which this paragraph applies." 


\title{
LIAISON COMMITTEE BETWEEN THE RUSSIAN FEDERATION AND THE OECD
}

\author{
Chair: \\ Mr. Angel Gurría \\ Secretary-General \\ Members: \\ Open to all Member countries \\ Russian Federation \\ Date of creation: \\ 27th May 1997 \\ Duration: \\ Unspecified
}

Mandate: Protocol on the Establishment of the Liaison Committee between the Russian Federation and the OECD approved by Council at its 901st session held on 22 and 23 May 1997 [C/M(97)12, item 165 and C(97)116/Final] and signed on 27 May 1997

PROTOCOL BETWEEN THE RUSSIAN FEDERATION AND THE ORGANISATION FOR ECONOMIC CO-OPERATION AND DEVELOPMENT (OECD) ON THE ESTABLISHMENT OF THE LIAISON COMMITTEE BETWEEN THE RUSSIAN FEDERATION AND THE OECD [C(97)116/FINAL]

\section{"THE RUSSIAN FEDERATION AND THE ORGANISATION FOR ECONOMIC CO- OPERATION AND DEVELOPMENT, HEREAFTER 'THE PARTIES',}

Having regard to the Declaration on Co-operation between the Russian Federation and the OECD (hereafter 'the Declaration'), signed in Paris on June 8, 1994, and in particular paragraph 5 thereof,

Having regard to the letter from the Prime Minister of the Russian Federation to the Secretary-General of the OECD, dated 20 May 1996, and to the reply by the Secretary-General, dated 6th February 1997,

Determined to intensify the co-operation between them in accordance with the Declaration in order to assist the Russian Federation in its progress towards establishing a fullyfledged market economy within a framework of democratic institutions,

Mindful that this co-operation should help the Russian Federation to meet and sustain all the conditions for its membership in the OECD, an ultimate goal shared by both Parties, and that it should therefore focus on the areas that are relevant to this end,

Have agreed on the following:

\section{Article 1}

The Parties establish a Liaison Committee (hereafter 'the Liaison Committee') in order to monitor and review the implementation of the annual work programmes provided for in paragraph 3 of the Declaration and assess their results as well as to discuss progress in the economic reform process in the Russian Federation, the co-operation between the Parties and other issues of mutual interest.

\section{Article 2}

The Liaison Committee consists, on the one hand, of Delegations from all OECD Member countries and of members of the OECD Secretariat and, on the other hand, of representatives of the Governmental bodies of the Russian Federation, supported by appropriate experts. 


\section{Article 3}

The Liaison Committee will meet periodically, as necessary and agreed, both at the level of Permanent Representatives to the OECD and senior officials representing the Russian Governmental bodies, and at the level of Ministers from both Parties, including on the occasion of OECD Council Ministerial sessions.

The Liaison Committee will adopt its agenda and any rules of procedure that might be necessary for the efficient conduct of its work." 


\section{GLOBAL FORUM ON THE KNOWLEDGE ECONOMY ${ }^{1}$}

Chair:

\section{Members:}

Non-Member Participants:

Date of creation:

Duration:
No formally-appointed Chair

Open to all Member countries

Open to invited non-Members

2001

Unspecified

\section{Mandate:}

The OECD Global Forums were created at the beginning of the Organisation's 2001-02 Programme of Work [C/PWB(2000)01/02/FINAL]. They constitute one of the two main pillars of the OECD's outreach programme, the other being that of the country and regional programmes. The Forums cover a set of thematic areas and provide a basis for building networks with global (though not universal) participation. The Forums address trans-boundary issues of concern to OECD Members and non-Members from multiple world regions for which OECD analytical work based on the use and development of comparable data can enhance the policy dialogue with relevant nonMembers world-wide. Global Forum meetings often involve high-level policy makers, policy analysts and various other stakeholders and help build consensus on how to make policies more effective at achieving stated government objectives.

The Global Forum on Knowledge Economy has two main branches: i) the digital economy, and ii) biotechnology, bridged by a set of common elements of a policy nature.

The Digital Economy and Electronic Commerce branch promotes an internationally coherent approach to the formulation of government policies and regulatory frameworks for the digital economy and e-commerce. This contributes to growth of commerce and trade and the economic growth of Members and non-Members of the OECD more broadly. The dialogue aims at removing obstacles to fulfilling the potential offered by new technologies. To achieve this objective, the Global Forum deals with such issues emerging from the use of these technologies that require international co-ordination, engaging stakeholders in a wide-ranging policy debate and ultimately promoting a rules-based environment.

The OECD, through the Global Forum mechanism, contributes to the definition of a truly global policy framework for the development of ICTs and the digital economy. One of its main elements will be the Security of Information Systems and Networks, including coherent policy strategies. In the fiscal area, non-Members are associated with the implementation of the Ottawa Ministerial Taxation Framework Conditions for Electronic Commerce, which requires a global strategy to ensure effective taxation of electronic commerce and to avoid double taxation.

Contributions to the World Summit on the Information Society (WSIS) and the G8 DOT force respond to the high pressure on the OECD to provide needed substantive input. Leveraging ODA for the best use of ICT links development co-operation with ICT and involves considerable involvement from the development co-operation community and reaches both emerging economies and poorer countries.

The Biotechnology branch of the Global Forum on the Knowledge Economy deals with two areas pertinent for economic and social progress worldwide: i) human health and environmental safety assessment methods, and ii) biological resource centres.

\footnotetext{
1 Information on this Global Forum is provided for the sake of completeness, but Global Forums are not, in accordance with C(2008)208/FINAL, official OECD bodies.
} 
Based on consensus in the biotechnology field on the importance of biotechnology activity on human health and environmental safety assessment methods, the Forum unites OECD Members and non-Members in discussing and setting international standards in the globally important area of biosafety.

Access to well-developed biological resource centres (BRCs) will increasingly be at the core of successful life science research and ex situ biodiversity conservation. The activity of the Global Forum in this area brings together OECD Members and non-Members in making a reality of the OECD blueprint for a global network of BRCs. The aim is to increase the coherence of international efforts, to improve capacity in Members and non-Members, and to encourage the transfer of technology and know-how. Additional focus will be put on ensuring appropriate and safe access to health-related biotechnology research, processes and materials for use in combating infectious diseases.

Common elements of the activities covered by the Global Forum on the Knowledge Economy include: Science and Technology Indicators - international standards and benchmarking in strategic science and technology areas; International Mobility - measurement and analysis of highly-skilled labour force's mobility ("brain drain/circulation") and its impact on economic development; World Education Indicators; and the Programme for International Student Assessment (PISA). 


\section{GLOBAL FORUM ON SUSTAINABLE DEVELOPMENT ${ }^{1}$}

\section{Chair:}

Members:

Non-Member Participants:

Date of creation:

Duration:
No formally-appointed Chair

Open to all Member countries

Open to invited non-Members

2001

Unspecified

\section{Mandate:}

The OECD Global Forums were created at the beginning of the Organisation's 2001-2002 Programme of Work [C/PWB(2000)01/02/FINAL]. They constitute one of the two main pillars of the OECD's outreach programme, the other being that of the country and regional programmes. The Forums cover a set of thematic areas and provide a basis for building networks with global (though not universal) participation. The Forums address trans-boundary issues of concern to OECD Members and non-Members from multiple world regions for which OECD analytical work based on the use and development of comparable data can enhance the policy dialogue with relevant non-Members world-wide. Global Forum meetings often involve high-level policy makers, policy analysts and various other stakeholders and help build consensus on how to make policies more effective at achieving stated government objectives.

The OECD Council at Ministerial level (MCM), recognised sustainable development as an overarching goal of OECD governments and the OECD and expressed its commitment to work energetically with countries outside the OECD's membership to achieve the joint sustainable development goals. Issues to be addressed in the Global Forum have also been shaped by the outcomes of the World Summit on Sustainable Development (WSSD), held in Johannesburg, in August-September 2002.

The Global Forum on Sustainable Development focuses principally on the environmental dimension of sustainable development and its linkages with economic and social policies. It builds on twelve years of co-operation with non-Members in this field, and on the 2002 inaugural meeting of this Global Forum on the financing the environmental dimension of sustainable development at which participants emphasised the importance of continuing work on this topic within the Forum. While financing issues are important within the framework of international efforts to promote sustainable development, implementation is crucial as well. There are also important linkages to the Millennium Development Goals and to the post-Doha and Monterrey agendas, which commit to advancing economies, trade and human welfare in the 21 st century.

Environmental finance, especially for water - a priority at the WSSD - receives particular attention. The creation of markets to address issues previously dealt with in the public domain (e.g. biodiversity, greenhouse gas emissions) and environmental compliance and enforcement are also addressed. Further focus are the environmental dimensions of the Guidelines on Multinational Enterprises and of the Doha Development Agenda in collaboration with other Global Forums, such as that on International Investment.

This Global Forum engages OECD Members and Non-Members in debate on evolving policies and approaches for tackling climate change issues. The result aims at a better understanding of mitigation commitments post-Kyoto to come into effect after 2012 and provides a solid analytical basis for a new round of negotiations (as of 2005) under the UN Framework Convention on Climate Change.

\footnotetext{
1 Information on this Global Forum is provided for the sake of completeness, but Global Forums are not, in accordance with C(2008)208/FINAL, official OECD bodies.
} 


\section{GLOBAL FORUM ON TAXATION ${ }^{1}$}

Chair:

\section{Members:}

Non-Member Participants:

Date of creation:

Duration:
No formally-appointed Chair

Open to all Member countries

Open to invited non-Members

2001

Unspecified

\section{Mandate:}

The OECD Global Forums were created at the beginning of the Organisation's 2001-02 Programme of Work [C/PWB(2000)01/02/FINAL]. They constitute one of the two main pillars of the OECD's outreach programme, the other being that of the country and regional programmes. The Forums cover a set of thematic areas and provide a basis for building networks with global (though not universal) participation. The Forums address trans-boundary issues of concern to OECD Members and non-Members from multiple world regions for which OECD analytical work based on the use and development of comparable data can enhance the policy dialogue with relevant nonMembers world-wide. Global Forum meetings often involve high-level policy makers, policy analysts and various other stakeholders and help build consensus on how to make policies more effective at achieving stated government objectives.

The objective of Global Forum on Taxation is to encourage and develop the on-going dialogue among tax officials in Members and non-Members of the OECD, allowing for the discussion of best practices in policy and administration and the development of models, standards and guidelines on international tax issues in the mutual interest of all parties.

The main topics for the Global Forum on Taxation coincide with the core work of the OECD's Committee on Fiscal Affairs, namely tax treaties and transfer pricing. Additionally, there have been growing demands for dialogue in other key areas, such as electronic commerce, harmful tax practices and exchange of information. In order to carry out the work, the Forum organises approximately twenty five policy dialogue events per year, held in Paris, and at the OECD multilateral tax centres.

A major new element of the Global Forum is the development of partnerships with other Organisations working in the tax area. In 2003, the recently launched International Tax Dialogue, which is a joint initiative between the OECD, the World Bank and the International Monetary Fund (and possibly the United Nations), became operational. The Committee of International Organisations on Tax Administration (CIOTA) became fully operational in 2003 and it is also a key partner in this Partnership. This new initiative will permit the development of tax programmes which explicitly take into account activities being carried out by the OECD's international partners. Such co-operation will improve programme co-ordination and result in more effective delivery of policy dialogue and advice.

Taxation poses challenges not only for non-Members but also for Members. By producing, issuing and discussing with non-Members the results of its analysis on relevant issues, OECD plays a useful bridge-building role. As such, it contributes to advancing the process of co-operation on taxation and promotes adherence to the OECD led international standards and guidelines.

\footnotetext{
1 Information on this Global Forum is provided for the sake of completeness, but Global Forums are not, in accordance with C(2008)208/FINAL, official OECD bodies.
} 
Chair:

Vice-Chair:

Members:

Date of creation:

Duration:
To be designated

To be designated

To be designated

Participation in the Co-ordination Group shall be open to experts from statistical offices, governments and other sectors of society from all OECD members. Those countries or economies who have the status of observers to the Committee on Statistics shall be observers to the Co-ordination Group. They shall be represented by experts from statistical offices, governments and other sectors of society.

17th July 2008

31st December 2012

Mandate: - Establishment of the Global Project on Measuring the Progress of Societies [C(2008)100, C(2008)100/CORR1] approved at its 1179th session on 17 July 2008 [C/M(2008)15, Item 174]

- Mandate of the Co-ordination Group for the Global Project on Measuring the Progress of Societies [C(2008)157] approved at its 1182nd session on 16 October 2008 [C/M(2008)18, Item 246]

\section{Document [C(2008)157]}

“1) The Co-ordination Group shall provide advice and guidance to the Secretariat of the Global Project on the engagement of the OECD in the Global Project. In particular, the Coordination Group shall:

- Provide recommendations and guidelines to the Global Project Board for the development and improvement of the Global Project.

- Participate actively via its networks in the development of activities included in the work programme.

- Act as a forum in which OECD member countries shall be able to exchange information and experience on best practices and initiatives to measure the progress of societies.

- Identify ways to increase the relevance of the Global Project for OECD member countries.

2) The Co-ordination Group shall prepare an annual report to the OECD Council about the Global Project's activities and achievements.

3) The Co- ordination Group shall designate its Chair and two Vice-Chairs.

4) Participation in the Co-ordination Group shall be open to experts from statistical offices, governments and other sectors of society from all OECD Members." 


\section{EXECUTIVE COMMITTEE IN SPECIAL SESSION}

Chair:

Members:

Date of creation:

Duration:
Mr. Bernd Pfaffenbach

Open to all Member countries

10th October 1972

Unspecified
(Germany)

Mandate: $\quad$ Minutes of the 293rd and 305th sessions of the Council [C/M(72)15(Final) Annex and $\mathrm{C} / \mathrm{M}(72) 27$ (Final) Part I]

\section{Extract from document $[$ C/M(72)15(Final) Annex $]$}

\section{"THE COUNCIL}

noting the intentions of Member Governments to work for reform of the international monetary system and, at the same time, to achieve further progress towards trade liberalisation;

considering that negotiations in these fields will take place in world-wide organisations;

considering that the present situation required more information, active co-operation and consultation among Member Governments;

1. agreed that the OECD has an important role to play in analysing and consulting on international monetary, trade, investment and related economic issues, including particularly their interrelationships;

2. instructed the competent bodies of the OECD to continue their work on international monetary and trade questions, recognising that negotiations are due to take place in other organisations;

3. agreed that, to this end, meetings of the Council at Ministerial level may be desirable, and that the competent bodies of the Organisation, particularly the Executive Committee, the Economic Policy Committee and its appropriate Working Parties, and the Trade Committee, should discuss these questions;

4. agreed that Member countries will be represented at an appropriately high level in the meetings referred to above;

5. instructed the Secretary-General to propose to the Council such adaptation and improvement of existing structures and procedures of the Organisation as may appear appropriate to discharge adequately and in the most effective manner the role agreed above.

The Council, in adopting the foregoing text, noted that, in making proposals pursuant to paragraph 5 of the text, the Secretary-General would take into account the statements made during the discussion of this agenda item." 
"THE COUNCIL

a) recalled the guidance given at Ministerial level at its 293rd Meeting, following the examination of international monetary and trade issues, on the way in which the Organisation should contribute to discussion in these fields;

b) recalled that Ministers agreed, to this end, that meetings of the Council at Ministerial level may be desirable, and that the competent bodies of the Organisation, particularly the Executive Committee, the Economic Policy Committee and its appropriate Working Parties, and the Trade Committee, should discuss these questions;

c) regarded the report by the High-level Group on Trade and Related Problems [C(72)175], which contains a series of considerations corresponding to the preoccupations of Ministers on the interrelationships between the various issues discussed, as a useful contribution to the discussions on international monetary, trade, investment and related economic issues in the above-mentioned Committees;

d) invited the Executive Committee to carry forward, on the basis of the Ministerial guidance referred to above, and in the light of the considerations contained in the Report by the High-level Group, the discussions on international monetary and trade issues initiated by Ministers;

e) agreed that for the discussions foreseen in d) above, the Executive Committee will meet at the high level appropriate and that the provisions for taking part in such discussions by Member countries not members of that Committee are satisfied;

f) invited the Executive Committee to meet as soon as possible, at the high level appropriate, to organise its work under the present instruction;

g) requested the Secretary-General to keep the Council informed on the progress of the work under the present instruction and agreed to discuss on the basis of such reports questions concerned with holding a meeting at Ministerial level." 

ECONOMIC POLICY

47 



\section{ECONOMIC POLICY COMMITTEE}

$\begin{array}{lll}\text { Chair: } & \text { Mr. Edward P. Lazear } & \begin{array}{l}\text { (United States) } \\ \text { Vice-Chairs: }\end{array} \\ \text { Mr. Henri Bogaert } & \begin{array}{l}\text { (Belgium) } \\ \text { (Japan) }\end{array} \\ \text { Members: } & \text { Open to all Member countries } & \\ \text { Observers: } & \begin{array}{l}\text { Bank for International Settlements (BIS) } \\ \text { European Free Trade Association (EFTA) } \\ \end{array} & \begin{array}{l}\text { International Monetary Fund (IMF) } \\ \text { World Bank }\end{array}\end{array}$

Date of creation:

30th September 1961

Duration:

31st December 2013

Mandate: - Paragraph 12 of the Report by the Preparatory Committee

- Council Decision regarding a Sunset Clause for all Committees [C/M(2004)5, item 75] entered into force on 22 April 2004 [C/M(2004)10, item 143, IV, c)]

- Resolution of the Council concerning the Renewal of the Mandate of the Economic Policy Committee [C(2008)21] approved at its 1171st session held on 17th April 2008 [C/M(2008)7].

\section{Extract of Council Summary Record [C/M(2008)7]}

“89.

THE COUNCIL

c) agreed to renew the mandate of the Economic Policy Committee as set out in Annex II to document C(2008)21 for a period of 5 years until 2013;"

\section{Extract of Annex II to document C(2008)21}

"12. It is further recommended that the mandate of the Economic Policy Committee should be as follows:

a) The Economic Policy Committee will keep under review the economic and financial situation and policies of Member countries with a view to attaining the objectives of the Convention.

b) In reviewing the economic policy of Member countries, the Committee will pay special attention to the international effects of national policies in the light of the increasing interdependence of their economies and of the recognition that efforts of individual countries will be influenced by the actions of others, with a view to establishing a climate of mutual understanding conducive to the harmonious adjustment of policies." 


\section{WORKING PARTY ON SHORT-TERM ECONOMIC PROSPECTS}

Chair:

Members:

Observers:

Date of creation:

Duration:

\section{Secretariat}

Open to all Member countries

Bank for International Settlements (BIS)

European Free Trade Association (EFTA)

International Monetary Fund (IMF)

World Bank

17th July 1963

31st December 2013

Mandate: - Meeting of the Economic Policy Committee on 27th-28th February 1963

- Report by the Chairman to the Council [C(63)39]

- Meeting of the Economic Policy Committee on 10th-11th July 1963

- Report by the Chairman to the Council [C(63)101]

\section{Extract from document [C(63)39, paragraph 6]}

"e) The Committee considered a suggestion for more systematic exchange of short-term forecasts of economic developments and invited the Secretary-General to make arrangements for this."

\section{Extract from document [C(63)101]}

"11. The Committee agreed upon arrangements to enable the Secretariat to prepare, for its next meeting, forecasts of the broad movements of the supply and use of resources in 1964. The Secretariat will be communicating with Delegations to this end.

The Economic Policy Committee has subsequently confirmed that its Working Group on Short-term Economic Prospects should meet shortly before meetings of the Committee." 


\begin{tabular}{|c|c|}
\hline Chair: & (United Kingdom) \\
\hline Vice-Chair: & Mr. Lorenzo Codogno \\
\hline Members: & Open to all Member countries \\
\hline Observers: & $\begin{array}{l}\text { Bank for International Settlements (BIS) } \\
\text { European Free Trade Association (EFTA) } \\
\text { International Monetary Fund (IMF) } \\
\text { World Bank }\end{array}$ \\
\hline Date of creation: & 20th May 1980 \\
\hline Duration: & 31st December 2013 \\
\hline
\end{tabular}

Mandate: New Working Party on Macro-Economic and Structural Policy Analysis [CPE(80)7]

\section{Annex to document [CPE(80)7]}

"1. This Working Party is charged with the policy analytic aspects of macro-economic and structural problems. With a view to highlighting the analytic aspects of policy issues and proposals and with special emphasis on the medium term, it will report regularly to the Economic Policy Committee its findings with respect to the means of achieving the main objectives of economic policy, notably growth, high employment, welfare and price stability, using, where appropriate, quantitative assessment. The Working Party will in particular consider:

i) Control of demand and inflation, including the role of fiscal policy, monetary policy and prices and incomes policy;

ii) Supply side policies, including policies affecting labour supply, investment, factor mobility and energy;

iii) Allocation and distribution of resources, including public expenditure and revenue decisions, financing and analysis of major expenditure programmes.

2. The Working Party will call as necessary on subgroups to prepare the technical aspects of its work. Subgroups will, in general, be ad hoc, temporary, and tailored to a specific technical question.

3. In executing its mandate, the Working Party will bear in mind the special problems of the less-industrialised Member countries as well as relations with non-Member countries. In its activities it will take into account related work being done in other Working Parties and Committees of the OECD and in other international fora." 

PAYMENTS EQUILIBRIUM $^{1}$

Chair:

Members:

Observers:

Date of creation:

Duration:

$$
\text { Philipp Hildebrand }
$$

Canada

France

Germany

Italy

Japan
(Switzerland)

Netherlands

Sweden

Switzerland

United Kingdom

United States

EC

Bank for International Settlements (BIS)

International Monetary Fund (IMF)

30th September 1961

31st December 2013

Mandate: - Sixth Meeting of the Economic Policy Committee Report to the Council by the Chairman [C(61)66]

- Agreed Minutes by the Economic Policy Committee 19th April 1961 [CPE(61)4]

\section{Extract from the Report to the Council by the Chairman [C(61)66]}

"1. The Economic Policy Committee held its Sixth Meeting on 18th and 19th April. This was the first meeting since the ratification of the OECD Convention by the United States and Canada and, in anticipation of their full membership of the OECD, both countries were strongly represented.

At the beginning of the meeting, the Head of the United States Delegation, Mr. Heller, said that he could give every assurance that the United States would be an active, interested and flexible member of the new Organisation. His Government attached particular importance to this meeting of the Committee and they looked forward to close and continuous working partnership within the Committee to deal with economic problems as they unfolded.

3. In pursuit of this aim, the United States Delegation made proposals for extending and intensifying the Committee's work. These were warmly welcomed by the other members of the Committee. Following discussion of these proposals, it was decided to establish two working groups to study and consult upon problems of policy in two areas where such action seemed likely to produce the most valuable results. The first group would deal with the problem of economic growth. The second group would deal with the balance of payments and with monetary, fiscal and other related policies. The Committee hoped to consider reports from these two groups with a view to making further proposals for action to the Ministerial Council of OECD."

\section{Extract from Document $[\mathrm{CPE}(61) 4]$}

"The Economic Policy Committee has considered the proposals made by the United States Delegation at its meeting on 18th-19th April 1961, for a programme of closer co-ordination of

\footnotetext{
1 To help prepare the technical background for its meetings and assist the Secretariat in its assessment of monetary policy issues, the Working Party asked the Secretariat to convene a small informal group of monetary experts, drawn from Member countries of the Working Party on a personal basis. The Secretariat has taken the initiative to seek consultation from such a group about once a year, starting in the late 1960s.
} 
economic policy [CPE(61)2]. The Committee agrees to set up two Working Parties to deal with the problems outlined below, and to submit their findings and recommendations to the full Committee as soon as possible:

i) Policies for the promotion of economic growth .....

ii) Policies for the promotion of better international payments equilibrium

The Working Party will analyse the effect on international payments of monetary, fiscal and other policy measures and will consult together on policy measures, both national and international, as they relate to international payments equilibrium." 

Chair:

Vice-Chairs:

Members:

Observer:

Date of creation:

Duration:
Mr. Bill White

Mr. Gerry Antioch

Mr. Noel O'Gorman

(Australia)

(Ireland)

Open to all Member countries

Russian Federation

(Country Reviews only, subject in each case to invitation by the country under examination)

Bank for International Settlements (BIS)

European Free Trade Association (EFTA)

International Monetary Fund (IMF)

World Bank

World Trade Organization (WTO)

30th September 1961

31st December 2013

Mandate: - Council Decision regarding the Revision of the mandate of the Economic and Development Review Committee [C/M(2006)2, item 15] approved at its 1128th session held on 26 January 2006

- Proposed Renewal of the Mandate of the Economic and Development Review Committee [C(2008)20] approved at the Council's 1171st session held on 17th April 2008 [C/M(2008)7].

\section{Extract of the Annex of document [C(2008)20]}

“15. PROPOSED REVISION OF THE MANDATE OF THE ECONOMIC AND DEVELOPMENT REVIEW COMMITTEE

THE COUNCIL

a) noted document $\mathrm{C}(2006) 5$;

b) decided, mindful of the vision of the founders of the Organisation as laid out in Article 1 of the Convention on the OECD, notably to achieve the highest sustainable economic growth and employment and a rising standard of living in Member countries' and 'to contribute to sound economic expansion in Member as well as non-member countries', that the Economic and Development Review Committee (EDRC) will examine on a regular basis and make comments and country-specific recommendations on the macroeconomic and structural policies of the Member countries and selected non-Member economies and on the interaction of these policies in raising economic performance;

c) noted that the modus operandi of the EDRC is laid out in its Agreed Principles and Practices [Annex to $C(2006) 5$ ], which will be updated by the Committee from time to time as appropriate;" 


\section{Extract of Council Summary Record [C/M(2008)7]}

“89.

THE COUNCIL

b) agreed to renew the Mandate of the Economic and Development Review Committee as set out in the Annex to document C(2008)20 until 31 December 2013." 
ENVIRONMENT 

Chair:

Vice-Chairs:

Members:

Observers:

Date of creation:

Duration:
Mr. Kevin Keeffe

Mr. François André

Mr. István Pomázi

Mr. Masaru Moriya

Mr. Enrique Lendo Fuentes

Mr. Mats Olsson
(Australia)

(Belgium)

(Hungary)

(Japan)

(Mexico)

(Sweden)

Open to all Member countries

Council of Europe

UN Commission for Sustainable Development (CSD)

UN Economic Commission for Europe (UNECE)

UN Environment Programme (UNEP)

World Bank

World Health Organization (WHO)

World Trade Organization (WTO)

22nd July 1970

30th June 2009

Mandate: Resolution of the Council concerning the Renewal of the Mandate of the Environment Policy Committee [C(2004)99/REV1] approved by the Council on 9 June 2004 at its 1088th session [C/M(2004)14, Item 191]

\section{Resolution of the Council [C(2004)99/REV1 and C/M(2004)14, Item 191]}

\section{"THE COUNCIL,}

Having regard to Articles 1, 2, 5(a) and 12 of the Convention on the Organisation for Economic Co-operation and Development of 14 December 1960;

Having regard to the Terms of Reference of the Environment Committee [C(85)47/FINAL], as extended by the Resolution of the Council of 23 February 1990 [C/M(90)4/FINAL, Item 48], and as amended and extended by the Resolution of the Council of 12 March 1992 [C(92)25/FINAL], and extended by the Resolution of the Council [C(97)9/FINAL], and extended by the Resolution of the Council [C(99)76/FINAL];

Having regard to the Rules of Procedure of the Organisation;

Recognising that the quest of societies for economic well being and improved living standards often places undesirable and sometimes unanticipated pressures on the natural environment and on finite natural resources;

Mindful also of the potential risk to human health and well-being from certain socio-economic activities;

Aware that sustainable development requires that economic, environmental and social policies be pursued by governments in an integrated and reinforcing manner; 
Believing that the effective and efficient implementation of environmental policies is dependent on sound economic analysis, technological innovation and diffusion, and strong legal, institutional and administrative arrangements;

Aware also that close co-operation among governments, industry, labour and non-governmental environmental organisations, as well as public participation and access to environmental information, are critical to building and maintaining public support for environmental investments and policies;

Conscious that OECD Member countries have a responsibility to safeguard their own environments, and have expressed a commitment to assist other nations in addressing their environmental challenges at the national level as well as to engage them in co-operative efforts to confront regional and global-scale environmental threats;

Recalling that OECD Environment Ministers, adopted in May 2001, the 'OECD Environmental Strategy for the First Decade of the 21st Century', to provide clear directions for environmentally sustainable policies in OECD Member countries, and to guide the future work of the OECD in the field of environment. The Strategy identifies five inter-linked objectives for enhancing cost-effective and operational environmental policies in the context of sustainable development:

- Maintaining the integrity of ecosystems through the efficient management of natural resources.

- De-coupling environmental pressures from economic growth.

- Improving information for decision making: Measuring progress through indicators.

- The social and environmental interface: Enhancing the quality of life.

- Global environmental interdependence: Improving governance and co-operation.

Recalling that OECD Environment Ministers reviewed the implementation of the OECD Environmental Strategy in April 2004 and agreed that OECD countries are currently 'not on track' for implementing the Strategy by 2010 , and more ambitious policies are needed;

\section{DECIDES:}

1.

The Environment Policy Committee will have the following responsibilities:

a) Provide a senior-level forum for Member countries to share views on, and consider policy responses to, major environmental issues and threats.

b) Encourage co-operation among Member countries in the pursuit of shared environmental objectives, including, inter alia, co-ordinated consultation on policies, approaches and major actions taken or proposed; work to identify the costs of inaction; data sharing; and joint research and analysis.

c) Promote, in support of sustainable development, the integration of environmental, economic and social policies, technological innovation and diffusion, and protection of unique environmental values and natural ecosystems.

d) Assess on a systematic basis the environmental performances of Member countries in relation to their national and international policies and commitments.

e) Assess and report on the implementation of the "OECD Environmental Strategy for the First Decade of the 21st Century".

f) Develop and promulgate environmental and decoupling indicators, and standardised, comparable sets of data and statistics, as a basis for identifying environmental trends, progress and deficiencies in individual Member countries and the OECD as a whole.

g) Promote the sharing with non-member countries of the environmental management expertise, information and experience which reside in Member countries and the OECD. 
h) Ensure that the views and expertise of non-government institutions are drawn upon in the conduct of OECD's environmental work, utilising, inter alia, the Business and Industry Advisory Committee to the OECD (BIAC), the Trade Union Advisory Committee to the OECD (TUAC) and relevant non-governmental organisations.

2. In the pursuit of these objectives, the Environment Policy Committee shall maintain close working relationships with other relevant bodies of the Organisation, seeking to ensure that environmental considerations are fully addressed in the overall work of the OECD, in particular the project on sustainable development, in a well co-ordinated and horizontal manner.

3. The Environment Policy Committee shall also maintain, as appropriate, and in conformity with the OECD Convention and Rules of Procedures, relations with other international organisations, seeking to achieve co-ordinated and complementary work programmes in areas of shared interest and mutual benefit, and ensuring that the experience and expertise of other bodies is appropriately incorporated into OECD environmental work.

4. These terms of reference are valid until 30 June 2009, unless the Council decides otherwise.

5. The Resolution of the Council of 24 June 1999 concerning the renewal of the mandate of the Environment Policy Committee [C(99)76/FINAL], is hereby repealed.

6. Paragraph 15 of the Annex of the Rules of Procedure shall be amended to read as follows:

'Environment Policy Committee: its terms of reference are defined in the Resolution of the Council [C(2004)99/REV1]."' 


\section{JOINT WORKING PARTY ON AGRICULTURE AND THE ENVIRONMENT}

Chair:

Vice-Chairs:

Members:

Observer:

Date of creation:

Duration:
Mr. Frode Lyssandtrae

Mr. Jeremy Eppel

Mr. Grant King

Ms. Maiko Murayama

Ms. Marca Weinberg

Ms. Annalisa Zezza
(Norway)

(United Kingdom)

(New Zealand)

(Japan)

(United States)

(Italy)

Open to all Member countries

UN Food and Agricultural Organization (FAO)

January 1993

31st January 2014

Mandate: - Summary Record of the 150th Session of the Committee for Agriculture held on 1315 May 2008 [TAD/TC/M(2008)1] and by written procedure by the EPOC on 12 January 2009 [ENV/EPOC(2008)20]

\section{Extract from documents [TAD/CA(2008)8] and [ENV/EPOC(2008)20]}

\section{"Objectives}

The Joint Working Party on Agriculture and the Environment will provide a forum to exchange information, identify and analyse the implications for achieving environmentally sustainable agriculture of policies and market approaches in the context of technological change, agricultural policy reform and multilateral trade and environmental agreements, and communicate the results to the wider public."

\section{Terms of reference}

The Joint Working Party will:

Identify and analyse policy relevant domestic and trans-boundary issues at the interface between agriculture and the environment in both OECD and, where relevant, nonOECD countries; quantify the relationships between agriculture and the environment, including in a forward-looking perspective; monitor and evaluate policy measures and actions addressing environmental issues in agriculture; and provide guidance on an integrated and coherent approach for agricultural and environmental policies to help achieve sustainable agriculture.

Undertake the analysis of agricultural and environmental issues of relevance to policy makers; in particular to: co ordinate, undertake and review relevant work mandated by the two parent Committees; co-ordinate, receive reports and review relevant on going and proposed work carried out elsewhere in the OECD; advise and report to the parent Committees on new and emerging problems and major issues with respect to agrienvironment relationships; identify successful policies and courses of action at national and international levels; and identify new initiatives for consideration by the appropriate bodies of the Organisation.

Co operate and liaise with other competent bodies in the OECD, and ensure appropriate co ordination with other relevant international organisations, in particular the Food and Agricultural Organisation of the United Nations, the United Nations Environment Programme and the Commission on Sustainable Development and the 
Convention on Biological Diversity, and with relevant non-governmental organisations, representing the farming, agro-food industry, and environmental interests; strengthen efforts to present and communicate the work to relevant organisations, the media and wider public." 


\section{JOINT WORKING PARTY ON TRADE AND ENVIRONMENT}

\begin{tabular}{|c|c|c|}
\hline Co-Chairs: & $\begin{array}{l}\text { Mr. Julius Langendorff } \\
\text { Mr. Vangelis Vitalis }\end{array}$ & $\begin{array}{l}\text { (European Commission) } \\
\text { (New Zealand) }\end{array}$ \\
\hline Vice-Chairs: & $\begin{array}{l}\text { Mrs. Nicole Dispa } \\
\text { Mr. Joseph Ferrante } \\
\text { Mr. Thomas Gillmore } \\
\text { Mr. Mitsutsune Yamaguchi }\end{array}$ & $\begin{array}{l}\text { (France) } \\
\text { (United States) } \\
\text { (Canada) } \\
\text { (Japan) }\end{array}$ \\
\hline Members: & \multicolumn{2}{|l|}{ Open to all Member countries } \\
\hline Observers: & \multicolumn{2}{|l|}{$\begin{array}{l}\text { Brazil } \\
\text { Hong Kong, China }\end{array}$} \\
\hline & \multicolumn{2}{|c|}{$\begin{array}{l}\text { European Free Trade Association (EFTA) } \\
\text { International Monetary Fund (IMF) } \\
\text { North American Commission for Environment Co-operation } \\
\text { (NACEC) } \\
\text { UN Conference on Trade and Development (UNCTAD) } \\
\text { UN Environment Programme (UNEP) } \\
\text { World Trade Organization (WTO) }\end{array}$} \\
\hline Date of creation: & \multicolumn{2}{|l|}{ 1st April 1991} \\
\hline Duration: & \multicolumn{2}{|l|}{ 31st December 2013} \\
\hline
\end{tabular}

Mandate: Written procedures by the Trade Committee[TAD/TC(2008)16] and by EPOC [ENV/EPOC(2008)30] on 10 October 2008

\section{Extract of documents [TAD/TC(2008)16] and [ENV/EPOC(2008)30]}

"The Joint Working Party should:

focus on analytical work, including empirical studies of selected policy areas and economic sectors, aimed at promoting the mutual compatibility of trade and environment policies in practice, in order to contribute to sustainable development, while building on its work to date;

focus on those areas where it has the greatest value added while supporting the activities of other OECD bodies and international organisations, and avoiding duplication;

co-operate and liaise with other relevant OECD bodies, and with relevant international organisations including the WTO, UNEP, UNCTAD, ISO, and the UN Commission on Sustainable Development;

consult with emerging economies and developing countries, and provide them with expertise as appropriate;

consult regularly as appropriate with both industry and environmental NGOs on environment and trade related matters;

advise and report to the parent Committees on new and emerging problems and major issues with respect to trade environment relationships;

assist the parent Committees in ensuring the coherence and consistency of the trade and environment related work being carried out in the various bodies of the OECD." 


\title{
JOINT MEETINGS OF TAX AND ENVIRONMENT EXPERTS
}

\author{
Co-Chairs: \\ Mr. Christian Valenduc \\ Mr. Robin Miege \\ (Belgium) \\ (European Commission) \\ Members: \\ Open to all Member countries \\ Date of creation: \\ 1st January 2001 \\ Duration: \\ 31st December 2010
}

Mandate: Text of the mandate in document [COM/ENV/EPOC/DAFFE/CFA(2000)105] renewed by EPOC under written procedure on 14 November 2008 [ENV/EPOC(2008)32] and by the CFA at its 24-25 June 2008 meeting(identical text in both documents)

\section{Extract from document [DAFFE/CFA(2001)72, Annex II]}

\section{ANNUAL JOINT MEETINGS ON TAXATION AND ENVIRONMENT TERMS OF REFERENCE}

"1. The Committee on Fiscal Affairs (CFA) and the Environment Policy Committee (EPOC) agree to continue the joint meetings of tax and environment experts, from the Working Party No2 on Tax Policy Analysis and Tax Statistics of the CFA, and the Working Party on National Environmental Policy of EPOC.

2. These experts will take part in annual back-to-back meetings with the following terms of reference, taking into account ongoing work following the OECD programme on sustainable development, and the specific economic, fiscal and environmental conditions of OECD countries ${ }^{1}$ :

a) To monitor and analyse existing environmentally related taxes, including collecting and analysing data within a common statistical framework.

b) To assess the environmental effectiveness of relevant taxes (and where appropriate related economic support measures, fees and charges) and to review practical implementation issues, drawing on experiences in Member countries.

c) To examine further issues arising from the integration of environmental concerns into the design of tax systems.

3. The Group of experts will provide input into the OECD Sustainable Development work and to follow-up work to this project involving consideration of tax and environment issues.

4. The Group of experts will also monitor developments and contribute, where appropriate, to tax aspects of the follow-up to the Kyoto Protocol to the United Nations Framework Convention on Climate Change.

5. The Group of experts will report, on an annual basis, the findings of the Joint Meetings, including discussions of policy options and transmit these to the CFA and the EPOC.

6. The terms of reference are established for an indefinite period from 1 January 2001, but subject to review and endorsement every second year by both the CFA and the EPOC."

\footnotetext{
1 Should the need arise for two meetings per year, this need will be brought to the attention of the Committee on Fiscal Affairs and the Environment Policy Committee in a formal request for an adjustment.
} 


\section{WORKING PARTY ON GLOBAL AND STRUCTURAL POLICIES}

Chair:

Vice-Chairs:

Members:

Date of creation:

Duration:
Ms. Veronique Deli

Mr. Harald Neitzel

Mrs. Vasiliki Manavi

Mr. Kotaro Kawamata

Open to all Member countries

June 2001

31st December 2009
(Mexico)

(Germany)

(Greece)

(Japan)

Mandate : - Approved, renewed and revised by the Environment Policy Committee at its session on 13-15 April 2005 [ENV/EPOC/M(2005)1], [ENV/EPOC(2004)32/ADD1] and [ENV/EPOC/RD(2005)9]

\section{Extract from document [ENV/EPOC(2004)32/ADD1]}

"1. To define, oversee and co-ordinate the Environment Policy Committee (EPOC) work programme on global and international environmental policy issues, including the environmental implications of structural economic policies and institutional change, recognising that effective policies in these areas are essential for the promotion of sustainable development.

2. To identify, analyse and propose strategies, policies and instruments to promote the effective integration of environmental concerns into international structural and sectoral economic policies, including those addressed towards the sustainable management of natural resources and ecosystems. Special emphasis should be given to improved understanding of issues related to the effective and efficient management of the global commons (e.g. biodiversity and climate), focusing mainly on experience with, and opportunities to foster, partnerships and institutional capacitybuilding.

3. To analyse the environmental and economic implications of climate change, focusing on strategies and policies, and to provide information and analysis to policy-makers and main stakeholders to enable them to better understand mitigation and adaptation options, including approaches which would benefit from international co-operation.

4. To complement the work of the Annex 1 Expert Group on the UNFCCC, by undertaking policy analysis in support of EPOC interests related to climate change, and by supporting AIXG work related to ongoing international climate change negotiations and, more generally, to communicate and co-ordinate with other OECD entities to facilitate the effectiveness and transparency of OECD work on climate change.

5. To support the efforts of other Bodies of the Organisation (e.g. Committee on Investment (Cl); Working Party on Export Credits and Credit Guarantees (ECG); and (DAC) ENVIRONET) in identifying, analysing and proposing strategies, policies and instruments to manage the environmental implications of economic globalisation,, notably increased trade, investment, international competition, export credits, the influence of national environmental requirements on location and investment decisions, and the changing structure and role of multinational enterprises.

6. To analyse ways in which environmental and economic globalisation policies can be made more mutually supportive, thereby encouraging stronger economic growth, reduced poverty, and improved environmental quality (e.g. through improved management of environmental infrastructure and/or improved regulatory capacity in both OECD and non-Member countries). 
7. To develop and apply quantitative analytical tools to facilitate analysis of the environmental and economic implications of structural policy changes over time. Special emphasis in these analyses should be placed on improving understanding of these implications for both OECD and non-Member countries.

8. To ensure the appropriate application of economic analysis in its work and that of any supporting task forces, panels, or expert groups.

9. To establish ${ }^{1}$ and oversee the work of any ad hoc task forces, panels, or expert groups required to help carry out the work programme (in particular, the Working Group on the Economic Aspects of Biodiversity).

10. To ensure that policy conclusions and recommendations arising out of the work of the Working Party are transmitted to the Environment Policy Committee, and communicated effectively to interested outside parties, including appropriate mass media.

11. The Terms of Reference are established until 31st December 2009." require prior endorsement of the Environment Policy Committee. 


\title{
WORKING GROUP ON ECONOMIC ASPECTS OF BIODIVERSITY (WGEAB)
}

\author{
Chair: \\ Mr. Carlos Muñoz \\ (Mexico) \\ Vice-Chairs: \\ Mr. Arthur Eijs \\ Ms. Eszter Kovács \\ (Netherlands) \\ (Hungary) \\ Members: \\ Open to all Member countries \\ Date of creation: \\ 23rd June 1993 \\ Duration: \\ 30th June 2009
}

Mandate: - Approved by the Working Party on Global and Structural Policies at its meeting on 15-16 November 2004 [ENV/EPOC/GSP/BIO(2004)2/REV2]

\section{Annex I to document [ENV/EPOC/GSP/BIO(2004)2/REV2]}

“...

To help define and to implement the Programme of Work (PWB) of the Working Party on Global and Structural Policies (WPGSP) concerning the economic aspects of biodiversity, as part of the latter's work on natural resource management and climate change, inter alia by:

- developing a PWB related to the economic aspects of biodiversity every two years, as part of the regular programme planning cycle of the OECD;

- analysing the economic efficiency, environmental effectiveness, and social consequences of biodiversity policies associated with incentive measures, market creation, and the valuation of biodiversity resources;

- analysing linkages between biodiversity and the economic value of ecosystem services, as well as linkages between biodiversity and other "cross-cutting" natural resource management problems (e.g. agriculture, wetlands, habitat equivalency policies, invasive alien species, and water);

- analysing recent experiences with the management of "protected areas", including their links to non-protected areas;

- analysing domestic (sectoral, national, regional) and international distributive issues related to biodiversity conservation, with the aim of promoting a distribution of benefits and costs that supports sustainable use and conservation policies;

- monitoring, and periodically reporting on implementation of, OECD Council Recommendation C(2004)81;

- investigating the potential role of the private sector in supporting government objectives toward more sustainable biodiversity use and conservation (e.g. private sector participation; corporate social responsibility; public-private partnerships);

- contributing additional biodiversity-related outputs as may be requested by the WPGSP from time to time (e.g. Environmental Outlook; implementation of the OECD Environmental Strategy; sustainable development; costs of inaction); and

- developing empirically-based, proactive, and pragmatic guidance to OECD Member countries on the economic aspects of biodiversity policies examined by the Working Group.

To provide support for others working on issues relevant to the WGEAB, inter alia by: 
- supporting implementation of the Convention on Biological Diversity (CBD), insofar as CBD interests interact with those of the WGEAB, the WPGSP, and EPOC.

- maintaining active participation in the UNCBD process, and co-ordinating with relevant international organisations, such as the Secretariat of the CBD, IUCN, UNCTAD, UNEP, the World Bank, FAO, UNCSD, UNESCO, and the Club du Sahel;

- engaging in appropriate forms of dialogue about the economic aspects of biodiversity management with non-OECD countries;

- keeping abreast of the economic aspects of biodiversity issues (e.g. internationally-agreed development goals, including those contained in the Millennium Declaration) under discussion in related international fora (e.g. WSSD; CSD); and

- proactively disseminating information concerning WGEAB outputs through publications, workshops, training seminars, conferences and other events." 


\section{WORKING PARTY ON NATIONAL ENVIRONMENTAL POLICIES}

Chair:

Vice-Chairs:

Members:

Observer:

Date of creation:

Duration:
Mr. Robin Miege

Mr. Antonio Díaz de León

Ms. Silvia Ruprecht

Ms. Catherine Connolly

Mr. Alexander Cristofaro
(European Commission)

(Mexico)

(Switzerland)

(United Kingdom)

(United States)

Open to all Member countries

Israel

UN Economic Commission for Latin America and the Caribbean (ECLAC)

April 2001

31st December 2009

\section{Document [ENV/EPOC(2004)32]}

"The Environment Policy Committee agrees that the Working Party on National Environmental Policies shall have the following terms of reference:

1. To define, oversee and co-ordinate the Environment Policy Committee's (EPOC) work programme on the development and implementation of environmental policies at national and subnational levels, with particular emphasis on the decoupling of environmental pressures from economic growth, the efficient use of environmental resources and the integration and co-ordination of economic, environmental and social policies, which are essential components of sustainable development.

2. To identify, analyse, and propose strategies, policies and instruments that promote the aforementioned policy objectives and encourage the effective integration of environmental concerns into national economic and sectoral policies, to encourage the efficient use of environmental resources, and the decoupling of environmental pressures from economic growth, including the analysis of the economic aspects and implications of such strategies, policies and instruments, with particular reference to:

a) existing and new policy instruments which can promote sound economic and environmental policy integration, and enhance the effectiveness and economic efficiency of environmental policies, with a particular focus on policy mixes;

b) failures of markets, government intervention, information and institutions which constitute impediments to effective policy integration and co-ordination.

c) the implementation of environmental policies, including effective and efficient compliance, monitoring and enforcement;

d) the social and distributive implications of environmental policies, including environmental justice and the links between health and the environment, and, 
e) the integration and co-ordination of environmental policies with other public policies with which there are likely to be significant interactions (e.g. public finance, labour markets industrial policy, and innovation policies).

3. To identify, analyse and propose strategies, policies and instruments to encourage more sustainable patterns of production and consumption.

4. To develop tools and methodologies for the economic valuation of environmental benefits and costs, including the cost of inaction, as well as the ex ante and ex post evaluation of specific environmental policies and instruments.

5. To ensure the appropriate application of economic analysis in its work and that of any other supporting task forces, panels or expert groups, in particular Working Group on Waste Prevention and Recycling (WGWPR) and Working Group on Transport (WGT).

6. To establish1 and oversee the work of any task forces, panels or expert groups required to help carry out the work programme.

7. To maintain effective working relationships, as appropriate, with other relevant OECD Committees, Working Parties, Groups and programmes within the OECD -- including the Committee on Fiscal Affairs, Working Parties of the Economic Policy Committee (EPC), the Working Party on Innovation and Technology Policies, the Employment, Labour and Social Affairs Committee, and EPOC's Working Party on Global and Structural Policy and Working Party on Environmental Performance, Working Group on Environmental information and Outlooks and OECD's horizontal activity on sustainable development -- and with other relevant international organisations and bodies, and to carry out joint work as appropriate.

8. To ensure that policy conclusions and recommendations arising out of the work of the Working Party are transmitted to the Environment Policy Committee, and communicated effectively to interested outside parties, including relevant mass media."

1 The establishment of new level 3 bodies (other than project-oriented, short-term task groups) will require prior endorsement of the Environment Policy Committee. 


\section{WORKING GROUP ON WASTE PREVENTION AND RECYCLING}

Co-Chairs:

Vice-Chairs:

Members:

Observer:

Date of creation:

Duration:
Ms. Carolyne Blain

Mr. Andreas Jaron

Mr. Francisco Aleza Enciso
Mr. Marco Buletti
Mr. John Wante

Open to all Member countries

Israel

UN Economic Commission for Europe (UNECE)

UN Environment Programme (UNEP)

November 2000

30th June 2009
(Canada)

(Germany)

(...)

(Spain)

(Switzerland)

(Belgium)

Mandate: - Adopted by the Working Party on National Environmental Policies at its 11th Meeting on 3-4 October 2006 [ENV/EPOC/WPNEP/M(2006)2]

\section{Extract from document [ENV/EPOC/WPNEP(2006)14]}

"The Working Party on National Environmental Policy agrees to the following Terms of Reference for the Working Group on Waste Prevention and Recycling:

1) To carry out and oversee the implementation of projects and tasks assigned by the Council, the Environment Policy Committee or the Working Party on National Environmental Policy;.

2) To identify, develop and recommend ways to integrate actions targeted at reducing environmental impacts, taking into account economic and social implications, from the use of materials throughout their life-cycle, focusing in particular on:

- measures to remove barriers to "sustainable materials management"; and

- incentives to improve material use efficiency and product design for environment.

3) To identify, develop and evaluate policies and instruments for reducing the environmental impacts of waste generation and management. This includes waste prevention, minimisation and the management of remaining waste amounts, focusing inter alia on decoupling of environmental impacts of waste generation from economic growth.

4) To advise Member countries on the most environmentally effective and economically efficient policy options to use and manage materials and prevent and reduce waste generation, based on an analysis of the full benefits and costs of these policies;

5) To strengthen environmentally sound management (ESM) of wastes, through the implementation of the Council Recommendation on ESM, including the possible development of waste-stream specific ESM guidance;

6) To ensure environmentally sound and economically efficient recovery and trade of recoverable waste by facilitating the efficient implementation of the Council Decision 
C(2001)107/FINAL and consolidating and updating the other Council Acts on transboundary movements of waste, as appropriate;

7) To advise the Working Party on National Environmental Policy and the Environment Policy Committee on major emerging waste and materials management related problems and issues, as well as on appropriate and cost-efficient policies and tools to address these emerging challenges;

8) To ensure that the projects of the Working Group on Waste Prevention and Recycling are developed in a manner which responds to relevant priority objectives of the Environment Programme, and are carried out in close co-operation with other relevant OECD bodies and international organizations, such as the Secretariat of the Basel Convention .

These Terms of Reference are established until 30 June 2009." 


\title{
WORKING GROUP ON TRANSPORT
}

\author{
Chair: \\ Mr. Sven Hunhammar \\ (Sweden) \\ Vice-Chairs: \\ Mr. César Rafael Chávez Ortiz \\ (Mexico) \\ Ms. Mimi Ishida-Nameki \\ (Japan) \\ Members: \\ Open to all Member countries \\ Observers: \\ UN Economic Commission for Europe (UNECE) \\ UN Environment Programme (UNEP) \\ World Health Organization (WHO) \\ Date of creation: \\ 4th November 1994 \\ Duration: \\ 30th June 2014
}

Mandate: approved by the working party on national environmental policies on 20 November 2008 [ENV/EPOC/WPNEP/T(2008)14]

Extract from Document [Env/Epoc/Wpnep/T(2008)14]

\section{"PROPOSED NEW MANDATE AND TERMS OF REFERENCE FOR THE WORKING GROUP ON TRANSPORT}

Under the supervision of the Working Party on National Environmental Policies (WPNEP):

1. To help define and oversee the Programme of Work on Transport and the Environment, in the context of (i) the (2004) OECD Council Recommendation on Assessment and Decisionmaking for Integrated Transport and Environment Policy; and (ii) the (2008) OECD Framework for Effective and Efficient Environmental Policies - both of which emphasise integrating environmental and economic concerns as a key route toward efficient and effective sectoral policy.

2. To undertake transport/environment integration work inter alia in the following specific areas:

- The impacts of economic globalisation on transport volumes and structures, and the environmental consequences of these impacts, with a particular emphasis on international freight transport.

- The environmental externalities of various transport modes and transport-related infrastructure (e.g. seaports, marinas, airports), including the economic valuation of these externalities.

- The incentives for behavioural change and emission reductions in the short and longer term provided by various transport/environment policy instruments (e.g. taxes on motor vehicle purchases or usage, toll-road systems addressing urban transport problems).

- Effective and efficient instruments to address urban transport/environment problems. 
3. To provide a forum for information exchange on emerging environmental issues, trends and challenges in the transport sector, and for review of appropriate transport/environment policies.

4. To disseminate the outcome of its work in non-OECD countries, as appropriate, and to support outreach activities, in co-operation with other relevant international organisations.

5. To report to the WPNEP on major new and emerging environmental problems and issues related to transport, and on appropriate policy options to address them.

6. To promote and enhance co-ordination and co-operation with other relevant OECD related bodies, in particular the International Transport Forum (ITF), the International Energy Agency, and other organisations such as the European Commission, the UN Economic Commission for Europe and the World Health Organisation.

7. The Terms of Reference are established until 30 June 2014." 


\section{WORKING PARTY ON ENVIRONMENTAL PERFORMANCE}

Chair:

Vice-Chairs:

Members:

Date of creation:

Duration:
Mr. Øyvind Lone

Mr. Marc Aviam

Mr. István Pomázi

Mr. Akinori Ogawa

Ms. Veronique Deli
(Norway)

(France)

(Hungary)

(Japan)

(Mexico)

Open to all Member countries

December 1991

31st December 2009

Mandate: - Mandate approved by the Environment Policy Committee at its 14th Session in November 1998, this group was formerly known as "Group on the Environmental Performance" [ENV/EPOC(98)22/FINAL and ENV/EPOC/M(98)4].

- Mandate renewed and modified by the Environment Policy Committee at its meeting on 9-10 November 2004 [ENV/EPOC(2004)32 and ENV/EPOC/M(2004)2].

\section{Document [ENV/EPOC(2004)32]}

"The Environment Policy Committee agrees that the Working Party on Environmental Performance shall have the following terms of reference:

- $\quad$ To oversee and co-ordinate the OECD programme of Member country environmental performance reviews as carried out by the Environment Directorate, as well as any extension to non-Member countries as may be agreed by the Environment Policy Committee and the Council.

To examine with a peer review mechanism the reports and recommendations emerging from the individual country studies.

To report annually to the Environment Policy Committee on the results of the country studies conducted each year, identifying in particular major policy issues which the Environment Policy Committee may wish to examine.

To advise the Environment Policy Committee on measures that member countries might take to improve their individual or collective environmental performances, and to monitor progress with implementing the OECD Environmental Strategy.

To identify opportunities and requirements for improving the conduct of the performance reviews (including data needs, indicators and methodologies) and recommending necessary modifications of the review content and process, drawing on task groups and other relevant Environment Policy Committee subsidiary groups as required.

To keep under review, and direct, the Environment Directorate's work on the analysis of trends, and the development of indicators, statistics and reporting concerning the environment and sustainable development, drawing on task forces and other subsidiary groups as required.

To ensure that the work programme on environmental reviews, data and indicators is developed in a manner which responds to relevant priorities and policy objectives of the Environment Policy Committee. 
To maintain close working relationships with other relevant international organisations to avoid duplication of effort and to achieve efficient divisions of responsibilities in areas of mutual interests (e.g. data collection).

To carry out or supervise other projects and tasks assigned by the Environment Policy Committee or the Council." 


\section{WORKING GROUP ON ENVIRONMENTAL INFORMATION AND OUTLOOKS}

Chair:

Vice-Chairs:

Members:

Date of creation:

Duration:
Mr. Eric De Brabanter

Ms. Ingeborg Fiala

Ms. Paula Brand

Mr. Jarmo Muurman

Ms. Jacqueline Burkhardt

Mr. Yuichi Moriguchi

Mr. Stephen Hall
(Luxembourg)

(Austria)

(Canada)

(Finland)

(Germany)

(Japan)

(United Kingdom)

Open to all Member countries

October 1979

30th June 2009

Mandate: $\quad$ Approved by the Working Party on Environmental Performance at its meeting on 2 July 2004 [ENV/EPOC/GEP(2004)7/FINAL]

\section{Extract from [ENV/EPOC/GEP(2004)7/FINAL]}

To carry out or supervise the implementation of projects and tasks assigned by the Working Party on Environmental Performance, the Environment Policy Committee or the Council.

- To advise the Environment Policy Committee and its Working Parties on major new and emerging problems and issues, and on appropriate policy options concerning information and reporting relating to environment and to sustainable development, and to recommend ways and means for national and international action.

- $\quad$ To give special attention:

1.to further development of internationally comparable data on environmental conditions and trends;

2.to report on the state of the environment in OECD member countries at appropriate intervals decided by the Environment Policy Committee;

3.to further development of indicators relating to environment and to sustainable development, including indicators of environmental performance, key indicators, sectoral indicators and indicators derived from environmental accounting;

4.to contribute to the improvement of environmental outlooks and projections, environmental accounts, environmental information systems and environmental reporting.

- To maintain close working relationships with other relevant groups within OECD.

- To maintain close working relationships with other relevant international organisations to avoid duplication of effort and to achieve efficient division of responsibilities in areas of mutual interests (e.g. data collection).

- To ensure that its projects are developed in a manner which responds to relevant priority objectives of the OECD Environment Programme. 


\section{WORKING PARTY ON CHEMICALS, PESTICIDES AND BIOTECHNOLOGY}

Chair:

Vice-Chairs:

Members:

Full Participants: ${ }^{1}$

Observers:

Date of creation:

Duration:
Mrs. Susan Hazen

Ms. Jee-Yoon Lee

Dr. Dick Sijm

Mr. Jerzy Majka

Open to all Member countries

Israel

Slovenia

South Africa

Israel

Slovenia

South Africa

March 1971

31st December 2012
(United States)

(Korea)

(Netherlands)

(Poland)

$\begin{array}{ll}\text { Mandate: } & \text { - Terms of reference for the Working party on Chemicals, Pesticides and } \\ & \text { Biotechnology [ENV/EPOC(2004)32] } \\ \text { - The Working Party meets together with the Chemicals Committee in a Joint Meeting }\end{array}$

\section{Extract from document [ENV/EPOC(2004)32]}

1. In conjunction with the Chemicals Committee ${ }^{2}$ to carry out, or to supervise, the implementation of projects and tasks assigned by the Environment Policy Committee or the Council;

2. To identify and examine existing, emerging and new problems and policy issues of common interest and priority concern relating to the control of chemicals, pesticides and products of modern biotechnology;

3. To advise the Environment Policy Committee on major existing, emerging and new problems and issues and on appropriate policy options to secure improved control of chemicals, pesticides and products of modern biotechnology and to recommend ways and means for national and international approaches;

4. In conjunction with the Chemicals Committee, to identify and elaborate the principles for and elements of overall chemicals, pesticides and biotechnology management policies which meet both the needs of environmental and human health protection and take economic objectives into account;

5. In conjunction with the Chemicals Committee, to work on issues related to the practical implementation of the Council Acts related to the Mutual Acceptance of Data, including Test Guidelines and Good Laboratory Practice, and furthermore to give special attention to:

a) improving the means of developing, acquiring and disseminating the data necessary for assessing chemicals, pesticides and applications of biotechnology;

\footnotetext{
1 Full participant for issues related to Mutual Acceptance of Data.

2 The Chemicals Committee is the body mentioned as the "Management Committee" in Council Decision [C(78)127(Final)] establishing the Special Programme on the Control of Chemicals.
} 
b) improving the efficiency of existing procedures for the assessment of the potential hazards of chemicals;

c) assisting member countries in developing policies and practices for the management of risks posed by them;

d) assisting member countries in their co-operative efforts to share the burdens of the systematic investigation of existing chemicals; and

e) facilitate co-operation between OECD countries and specific non-members in order to promote effective and efficient chemical safety policies throughout the world.

6. To hold from time to time special meetings at high level, as required, in order to give general orientation to the work on chemicals, pesticides and biotechnology;

7. To maintain close working relationships with other relevant groups within OECD;

8. To maintain close working relationships with other relevant international organisations;

9. To ensure that its projects are developed in a manner which responds to relevant priority objectives of the Environment Programme.

10. The above terms of reference are established until 31 December 2009. 


\section{WORKING GROUP OF NATIONAL CO-ORDINATORS OF THE TEST GUIDELINES PROGRAMME (WNT)}

$\begin{array}{lll}\text { Chair: } & \text { Ms. Betty Hakkert } & \text { (Netherlands) } \\ \text { Vice-Chair: } & \text { Mr. Eisaku Toda } & \text { (Japan) } \\ \text { Members: } & \text { Open to all Member countries } & \\ \text { Full Participants: } & \begin{array}{l}\text { Israel } \\ \text { Slovenia } \\ \text { South Africa }\end{array} \\ & \begin{array}{l}\text { Brazil } \\ \text { Observers: }\end{array} & \begin{array}{l}{ }^{1} \\ \text { Argentina } \\ \text { Malaysia }\end{array} \\ & \text { Singapore } \\ \text { Date of creation: } & \text { June 1999 } \\ \text { Duration: } & \text { 31st December } 2012\end{array}$

Mandate: $\quad$ Renewed by the 43rd Joint Meeting of the Chemicals Committee and the Working Party on Chemicals, Pesticides and Biotechnology [ENV/JM/M(2008)2, Annex IV]

\section{[Extract of document [ENV/JM/M(2008)2, Annex IV]}

\section{“I. Objective}

1. The objective of the Working Group of National Co-ordinators of the Test Guidelines Programme is to direct and oversee the work on: (i) OECD Guidelines for the Testing of Chemicals, including, as appropriate, Test Guideline development and the facilitation and harmonisation of test method validation; (ii) Guidance Documents on testing issues; and (iii) Detailed Review Papers on the state-of science of defined hazard areas. This work is undertaken to meet the regulatory needs, animal welfare and cost considerations regarding test methods in member countries and interested non-member economies.

\section{Tasks}

2. The Working Group of National Co-ordinators of the Test Guidelines Programme, under the supervision of the Joint Meeting of the Chemicals Committee and the Working Party on Chemicals, Pesticides and Biotechnology, shall

i. oversee the work of the Test Guidelines Programme which consists of:

- the development of new and the updating of existing Test Guidelines to cover regulatory data requirements for the assessment of chemicals relating to the protection of man and the environment in member countries. Chemicals include but are not limited to pesticides and industrial chemicals,

- the involvement in the validation of new and updated test methods, as appropriate;

\footnotetext{
${ }^{1}$ Provisional adherent to the Council Decisions Related to Mutual Acceptance of Data.
} 
- the development of Guidance Documents providing: (i) further guidance on the use of Test Guidelines, (ii) testing strategies, or (iii) information on specific issues associated with the Test Guidelines Programme;

- the development of Detailed Review Papers, providing the current state-of-science in a particular test or hazard area; and

- facilitating the active involvement of member countries and non-member economies and other stakeholders in projects in the development of Test Guidelines, Guidance Documents and Detailed Review Papers; and

- the engagement in international co-operation, as appropriate, for the harmonisation of hazard and risk assessment of chemical substances to benefit both member countries and non-members.

ii. direct and oversee the work of its subsidiary expert bodies, including:

- those for Endocrine Disrupters Testing and Assessment (EDTA) and Validation Management;

- all ad hoc Expert Groups, established to assist in the development of specific Test Guidelines, Guidance Documents, Detailed Review Papers, and/or other Test Guideline-related documents;

iii. review the progress made in the conduct of this work, identify new projects and update annually the workplan of the Test Guidelines Programme, taking into account other work under the Joint Meeting and work undertaken elsewhere, as appropriate;

iv. maintain close working relations with other international organisations active in the area of method development for chemical hazard and risk assessment; and

v. report on its activities to the Joint Meeting of the Chemicals Committee and the Working Party on Chemicals, Pesticides and Biotechnology.

3. Further details of tasks and responsibilities are provided in Guidance Document No.1 in the Series on Testing and Assessment, as amended in 2006 [ENV/JM/MONO(2006)20].

4. The Working Group of National Co-ordinators of the Test Guidelines Programme should meet when required by the needs of the Programme, but normally once per year.

\section{Participation}

5. The Working Group of National Co-ordinators of the Test Guidelines Programme is comprised of National Co-ordinators (from member countries and non-member economies that adhere to the Council Decision on the Mutual Acceptance of Data) appointed by member countries or non-member governments, representatives of the European Commission, invited experts and, as appropriate, observers from other international organisations and other non-member economies. National Co-ordinators should be able to provide a co-ordinated national view with respect to all areas of the Test Guidelines Programme.

6. The Chair and Vice-Chair(s) should be National Co-ordinators and are elected by the Working Group of National Co-ordinators of the Test Guidelines Programme. The Chair and ViceChair(s) together should provide expertise on both human health and the environment, and will function as the main consultative body (the Bureau) for the Secretariat between meetings of the Working Group." 


\section{WORKING GROUP ON GOOD LABORATORY PRACTICE}

Chair:

Vice-Chair:

Members:

Full Participants:

Observers: ${ }^{1}$

Date of creation:

Duration:
Ms. Katariina Rautalahti

Ms. Francisca Liem

Australia

Austria

Belgium

Canada

Czech Republic

Denmark

Finland

France

Germany

Greece

Hungary

Ireland

Italy

Japan

Korea

Israel

Slovenia

South Africa

Brazil

India

Argentina

Malaysia

Singapore

November 1990

31st December 2012
(Finland)

(United States)

Luxembourg

Netherlands

New Zealand

Norway

Poland

Portugal

Slovak Republic

Spain

Sweden

Switzerland

Turkey

United Kingdom

United States

European Commission

Mandate: $\quad$ Renewed by the 43rd Joint Meeting of the Chemicals Committee and the Working Party on Chemicals, Pesticides and Biotechnology [ENV/JM/M(2008)2, Annex IV]

\section{Extract of document [ENV/JM/M(2008)2, Annex IV]}

“I. Objectives

1.

The objectives of the Working Group on Good Laboratory Practice (GLP) are to facilitate and support the implementation by Member countries and interested non-members of the Council Acts (i) concerning Mutual Acceptance of Data in the Assessment of Chemicals [C(81)30(Final)], (ii) on Compliance with Principles of Good Laboratory Practice [C(89)87(Final)], and (iii) concerning the Adherence by Non-Member Countries to the OECD Council Acts related to the Mutual Acceptance of Date $[C(97) 114 /$ Final]. This should be done by promoting a common understanding of, and harmonised approaches to, technical and administrative matters related to Good Laboratory Practice and monitoring of compliance with the GLP Principles.

II.

Tasks

\footnotetext{
${ }^{1}$ Provisional adherent to the Council Decisions Related to Mutual Acceptance of Data.
} 
2. The Working Group on GLP, under the supervision of the Joint Meeting of the Chemicals Committee and the Working Party on Chemicals, Pesticides and Biotechnology shall: a) foster direct exchange of information and sharing of experiences, in particular among GLP compliance inspectors; b) discuss and, to the extent possible, resolve issues of common concern, particularly those issues relevant to international recognition of GLP compliance monitoring using on-site evaluation visits as appropriate; c) foster the harmonisation and development of specific guidance on technical and administrative matters pertaining to GLP Principles and monitoring of compliance therewith, including training of GLP inspectors; d) assist non-members in establishing and implementing procedures consistent with those of OECD; and e) advise the Joint Meeting regarding major policy issues related to GLP and compliance monitoring.

3

The Working Group on GLP shall take into account relevant activities related to international standard setting and assessment of compliance as well as other international activities in the areas of interest to its work. It shall meet regularly, at least once a year, and report thereafter to the Joint Meeting.

III.

\section{Participation}

4. The Working Group on GLP should include persons nominated by governments who are responsible for GLP compliance monitoring in member countries and in those non-members which are members of that part of the Chemicals Programme related to the mutual acceptance of data, as well as from the European Commission. Participation should be limited to one person per authority. Observers from other non-members may take part in the framework of the 1997 Council Decision. A Chairman and a Vice-Chairman shall be elected by the Members of the Working Group for two-year periods.

IV. Term

5. The Joint Meeting will assess the need for the continuation of the Working Group on GLP at the end of the next four-year phase of the Special Programme on the Control of Chemicals (31st December 2012)." 


\section{WORKING GROUP ON PESTICIDES}

$\begin{array}{lll}\text { Chair: } & \text { Mr. Richard Paul Davis } & \text { (United Kingdom) } \\ \text { Vice-Chair: } & \text { Mr. John Reeve } & \text { (New Zealand) } \\ \text { Members: } & \text { Open to all Member countries } & \\ \text { Observers: } & \begin{array}{l}\text { Israel } \\ \text { Slovenia }\end{array} \\ \text { Date of creation: } & \text { January } 1994 \\ \text { Duration: } & \text { 31st December } 2012\end{array}$

Mandate: Renewed at the 43rd Joint Meeting of the Chemicals Committee and the Working Party on Chemicals Pesticides and Biotechnology [ENV/JM/M(2008)2, Annex IV]

\section{Extract of document [ENV/JM/M(2008)2, Annex IV]}

“I. Objective

4. The objective of the Working Group on Pesticides (WGP) is to direct and oversee the work of the Pesticide Programme. The Working Group on Pesticides is a subsidiary body to the Joint Meeting of the Chemicals Committee and Working Party on Chemicals, Pesticides and Biotechnology. The term "pesticides" includes both chemical and biological pesticides.

II. Tasks

2. The Working Group on Pesticides shall:

(i) oversee the work on pesticides which aims to (a) help member countries harmonise and improve the efficiency of pesticide assessment and control procedures, (b) minimise non-tariff trade barriers, and (c) reduce risks to human health and the environment from the use of pesticides. These goals will be pursued through activities including, but not limited to:

- Work sharing ${ }^{1}$ and harmonisation: to facilitate and promote work sharing among OECD countries for pesticide evaluation (to support registration, re-registration and risk management) such that work sharing ultimately will become the routine way of working;

- Risk Reduction: to exchange ideas and to facilitate and promote the development and implementation of risk reduction policies and practices in OECD countries;

- Communication and Co-operation: to promote communication, collaboration and co-operation on work sharing and risk management among member countries and also with other stakeholders including industry, other interest groups and international organisations;

(ii) review the progress made in the conduct of this work, identify new projects and update the work plan, taking into account other work under the Environment Policy Committee, the Joint Meeting of the Chemicals Committee and Working Party on Chemicals, Pesticides and Biotechnology, the Agriculture Committee and other

Work sharing is meant to include all types of sharing of work in pesticide review, from the ad-hoc exchange of information, to well structured divisions of work such as parallel reviews and joint reviews. 
relevant OECD Committees and Groups, and work undertaken elsewhere, as appropriate;

(iii) maintain close working relations and co-ordinate activities related to agricultural pesticides and biocides with other international organisations and selected nonmembers;

(iv) report on its activities to the Joint Meeting of the Chemicals Committee and Working Party on Chemicals, Pesticides and Biotechnology, and shall liaise with the Joint Working Party of the Committee for Agriculture and the Environment Policy Committee.

III. Participation

3. The Working Group on Pesticides shall be comprised of the OECD member countries, the European Commission and observers (e.g. from IPCS, UNEP Chemicals, FAO). As appropriate, experts from non-member economies, environmental citizen organisations, PAN, EPPO, industry and grower associations can be invited. The Chair of the Working Group on Pesticides and a ViceChair shall be elected by the members for a term of three years. The Chair, Vice-Chair and chairs of the WGP steering groups, will function as the main consultative body for the Secretariat between meetings of the Working Group.

4. The Working Group shall meet when required by programme need, but no less than once per year." 


\title{
WORKING GROUP ON THE HARMONISATION OF REGULATORY OVERSIGHT IN BIOTECHNOLOGY
}

\author{
Chair: \\ Ms. Sally McCammon \\ (United States) \\ Vice-Chairs: \\ Mr. Stephen Yarrow \\ (Canada) \\ Ms. Marja Ruohonen-Lehto \\ (Finland) \\ Mr. Kenichi Hayashi \\ (Japan) \\ Mr. Hans Bergmans \\ (Netherlands) \\ Members: \\ Open to all Member countries \\ Observers: \\ Russian Federation \\ Slovenia \\ Argentina \\ Date of creation: \\ 1st February 1995 \\ Duration: \\ 31st December 2012
}

Mandate: $\quad$ Renewed at the 43rd Joint Meeting of the Chemicals Committee and the Working Party on Chemicals, Pesticides and Biotechnology [ENV/JM/M(2008)2, Annex IV]

\section{Extract of document [ENV/JM/M(2008)2, Annex IV]}

"As a subsidiary body to the Joint Meeting of the Chemicals Committee and Working Party on Chemicals, Pesticides and Biotechnology, the Working Group on Harmonisation of Regulatory Oversight in Biotechnology has the following terms of reference:

1. To oversee the implementation of the projects which are included in the Programme of Work on Harmonisation of Regulatory Oversight in Biotechnology for 2006 - 2008 as approved by the Joint Meeting, which have been established with the aims of promoting international harmonisation of regulatory oversight of biotechnology and biosafety among member countries; these projects include:

- identifying and addressing emerging issues that facilitate biotechnology and biosafety regulatory harmonisation.

- publishing science based consensus documents; and,

- participating in information dissemination and co-operating with non-member economies.

2. To advise the Joint Meeting on matters related to environmental aspects of products of modern biotechnology and to recommend appropriate policies and actions aimed at the harmonisation of biotechnology regulatory oversight, and thereby promoting the safety of products derived through modern biotechnology.

3. To ensure co-ordination with the work of the Task Force for the Safety of Novel Foods and Feeds, in particular, with respect to the development of Consensus Documents.

4. To recommend the most appropriate means of undertaking the various activities, for example, through the lead country approach, small steering groups or workshops.

5. To develop proposals for future work taking into account the priorities established by the Joint Meeting. 
6. To maintain close working relationships with other relevant groups within the OECD through OECD's Internal Co-ordination Group on Biotechnology (ICGB), and with subsidiary bodies to the Joint Meeting of the Chemicals Committee and Working Party on Chemicals, Pesticides and Biotechnology on issues of mutual interest.

7. To maintain close working relationships with other relevant international organisations, especially, UNEP, CBD Secretariat, UNIDO, WHO, FAO and WTO.

8. To report to the Environment Policy Committee through the Joint Meeting. At the same time, the Working Group will co-ordinate its efforts, through the ICGB, with the relevant work of other Committees such as the Committee for Scientific and Technological Policy and the Committee for Agriculture, and will inform them on the progress of work relevant to their interests, and will refer issues to them as appropriate; and

9.

The Group will elect a Chair and vice-Chairs for a period of one year."

Duration: The Terms of Reference are established until 31st December 2012. 


\section{TASK FORCE FOR THE SAFETY OF NOVEL FOODS AND FEEDS}

Chair:

Vice-Chairs:

Members:

Observers:

Date of creation:

Duration:
Ms. Lisa Kelly

Ms. Lynne Underhill

Mr. Hans-Joerg Buhk

Ms. Diána Bánáti

Dr. Kazutaka Yamamoto

Ms. Kathleen Jones

Open to all Member countries

Israel
Russian Federation
Slovenia
Brazil

5th November 1998

31st December 2012
(Australia)

(Canada)

(Germany)

(Hungary)

(Japan)

(United States)

\author{
South Africa \\ Argentina \\ Thailand
}

Mandate: Renewed at the 43rd Joint Meeting of the Chemicals Committee and Working Party on Chemicals, Pesticides and Biotechnology [ENV/JM/M(2008)2, Annex IV]

\section{Extract of document [ENV/JM/M(2008)2, Annex IV]}

\section{"I. Objectives}

1. The objective of the Task Force is to promote international harmonisation in the safety assessment and regulation of novel foods and feeds especially products of modern biotechnology. Its programme of work is organised into three areas: a) publishing science based consensus documents which contain information for use in risk/ safety assessment; b) assessing emerging issues that will facilitate future harmonisation; and c) disseminating information especially in respect of co-operation with non-member economies.

II. Tasks

2. The Task Force I, under the supervision of the Joint Meeting of the Chemicals Committee and the Working Party on Chemicals, Pesticides and Biotechnology, shall:

- recommend the most appropriate means of undertaking its projects, for example, through a lead country approach, and/ or small steering groups or workshops;

- develop proposals for future work taking into account the priorities established by the Joint Meeting;

- co-ordinate its activities with those of the Working Group for the Harmonisation of Regulatory Oversight in Biotechnology, especially in the drafting of consensus documents and the development of BioTrack Online;

- advise the Joint Meeting on matters related to the safety and regulation of novel foods and feeds; and

- recommend appropriate policies and actions aimed at harmonisation, while promoting the safe use of novel foods and feeds.

3. The Task Force will maintain close working relationships with other subsidiary bodies of the Joint Meeting on issues of mutual interest. At the same time, the Task Force will co-ordinate its 
efforts with the relevant work of other OECD Committees such as the Committee for Scientific and Technological Policy and the Committee for Agriculture. It will inform them on the progress of work relevant to their interests and refer issues to them as appropriate. This co-ordination will be facilitated by the secretariat through OECD's Internal Co-ordination Group for Biotechnology (ICGB).

4. The Task Force will also maintain close working relationships with other relevant organisations, especially, FAO, WHO and the Codex Alimentarius Commission, so avoiding duplication and ensuring complementarity with other intergovernmental activities.

III. Participation

5. The Task Force will include persons nominated by governments (and the European Commission) who are responsible for the risk/ safety assessment of novel foods and feeds including products of modern biotechnology. Where appropriate, it will seek input from non-member countries especially those which have been involved previously in its activities under the auspices of the biotechnology component of the Global Forum of the Knowledge-based Economy. In addition, it will include (as necessary) observers from FAO, WHO and the Codex Alimentarius Commission. Finally, it will include invited experts from BIAC, TUAC and consumer groups when they are able to make input into specific projects. A Chair and vice-Chairs will be elected by the members of the Task Force.

IV. Term

6. The Terms of Reference are established until 31 December 2012." 


\section{WORKING GROUP ON CHEMICAL ACCIDENTS}

\begin{tabular}{|c|c|c|}
\hline Chair: & Mr. Mark Hailwood & (Germany) \\
\hline Vice-Chairs: & $\begin{array}{l}\text { Mr. Asit Hazra } \\
\text { Mr. Pavel Forint } \\
\text { Mr. Tobias Biermann } \\
\text { Mr. Roland Fendler } \\
\text { Mr. Byeong-Ho Ham } \\
\text { Mr. Hyuck-Myun Kwon } \\
\text { Mr. Ralph Brieskorn } \\
\text { Mr. Akke Persson } \\
\text { Ms. Elizabeth Schofield } \\
\text { Ms. Kim Jennings }\end{array}$ & $\begin{array}{l}\text { (Canada) } \\
\text { (Czech Republic) } \\
\text { (European Commission) } \\
\text { (Germany) } \\
\text { (Korea) } \\
\text { (Korea) } \\
\text { (Netherlands) } \\
\text { (Sweden) } \\
\text { (United Kingdom) } \\
\text { (United States) }\end{array}$ \\
\hline Members: & Open to all Member countries & \\
\hline Observers: & $\begin{array}{l}\text { Israel } \\
\text { Slovenia } \\
\text { South Africa }\end{array}$ & \\
\hline Date of creation: & 1st February 1995 & \\
\hline Duration: & 31st December 2012 & \\
\hline
\end{tabular}

Mandate: $\quad$ Renewed at the 43 rd Joint Meeting of the Chemicals Committee and the Working Party on Chemicals, Pesticides and Biotechnology [ENV/JM/M(2008)2, Annex IV]

\section{Extract of document [ENV/JM/M(2008)2, Annex IV]}

\section{"I. Objectives}

1. The objective of the Working Group on Chemical Accidents (WGCA) is to recommend appropriate policy options, including ways and means for national and international action, for enhancing the prevention of, preparedness for, and response to, chemical accidents. This involves development of common principles, procedures and policy guidance; analysis of issues of concern and recommendations for best practices; and information/experience sharing and communication.

\section{Tasks}

2. The Working Group on Chemical Accidents under the supervision of the Joint Meeting of the Chemicals Committee and the Working Party on Chemicals, Pesticides and Biotechnology, shall:

i. oversee the work and foster the implementation of the projects and activities which are included in the Programme of Work on Chemical Accidents for $2009-2012$ as approved by the 43rd Joint Meeting in November 2008 using, in particular, the lead country approach;

ii. recommend appropriate policy options, including ways and means for national and international action, for enhancing the prevention of, preparedness for, and response to, chemical accidents;

iii. improve, primarily through the efforts of member country experts, the awareness, knowledge, and capabilities in member and non-member countries, with respect to relevant technology, practices and policies for chemical accident prevention, emergency preparedness and response, and in particular by: 
- furthering the implementation of the OECD Guiding Principles for Chemical Accident Prevention, Preparedness and Response in and beyond OECD and ensuring that the Guiding Principles remain up-to-date and incorporates experience in member countries and international organisations;

- furthering the implementation of the Guidance on Developing Safety Performance Indicators in and beyond OECD and ensuring that Guidance on $\mathrm{SPI}$ remains up-to-date and incorporates experience in member countries and international organisations;

- analysing issues in selected areas of mutual interest, including those aimed at facilitating the use of the Guiding Principles and the Guidance on SPI;

- promoting efforts to ensure that appropriate safety measures are in place at potentially hazardous installations, including measures to prevent accidents and mitigate effects of accidents which might occur;

- continuing to promote the exchange of information and experience among stakeholders (e.g., public authorities, industry, workers and their representatives and the public);

- facilitating the collection and analysis of data on chemical accidents, including economic data, in order to enhance the integration of economic considerations into selected policies and procedures for chemical accident prevention, preparedness and response;

- promoting OECD work in this area in order to benefit both member and nonmember countries and, to this end, engage in international co-operation as appropriate; and

- maintaining close working relationships with other relevant OECD groups and with UNEP, UNECE, EEB, IMO, WHO, IPCS, ILO, OCHA and other appropriate international organisations in order to co-ordinate the planned and ongoing work and to ensure close liaison with other stakeholders including industry and trade unions.

3. The WGCA shall meet normally once a year.

\section{Participation}

4. The WGCA shall be comprised of representatives nominated by member countries and representatives of the European Commission, observers from non-member countries and international organisations that carry out work in the field of chemical accidents. Experts from BIAC, TUAC and relevant environmental organisations can be invited to participate. Members of the WGCA should be able to represent various issues related to chemical accidents, including prevention, preparedness, response and clean-up.

5. The Chair and Vice-Chairs (i.e. the Bureau) of the Working Group shall be elected by the members at the annual meeting. The Bureau will function as the main consultative body for the Secretariat between meetings of the Working Group.

\section{Term}

6.

The Terms of Reference are established until 31 December 2012." 


\section{TASK FORCE ON POLLUTANT RELEASE AND TRANSFER REGISTERS}

$\begin{array}{lll}\text { Chair: } & \text { Mr. Michel Amand } & \text { (Belgium) } \\ \text { Vice-Chairs: } & \begin{array}{l}\text { Mr. Alain Chung } \\ \text { Mr. Noriyuki Suzuki }\end{array} & \begin{array}{l}\text { (Canada) } \\ \text { (Japan) }\end{array} \\ \text { Members: } & \text { Open to all Member countries } & \\ \text { Observers: } & \begin{array}{l}\text { Israel } \\ \text { Slovenia } \\ \end{array} & \text { South Africa }\end{array}$

Date of creation:

10th June 2005

Duration:

31st December 2012

Mandate: - Summary Record of the 43 rd Joint Meeting of the Chemicals Committee and Working Party on Chemicals, Pesticides and Biotechnology [ENV/JM/M(2008)2, Annex IV]

\section{Extract of Document [ENV/JM/M(2008)2, Annex IV]}

\section{"I. Objectives}

1. The objectives of the Task Force on Pollutant Release and Transfer Registers (PRTRs) are to assist OECD member countries to establish PRTRs for the implementation of the public's "right to know" by developing tools and providing guidance on areas that would promote the establishment of PRTRs, advancing and improving the uses of PRTR data, facilitating the sharing of PRTR data between countries and continuing to improve and make widely available release estimation techniques.

II. Tasks

2. The Task Force on Pollutant Release and Transfer Registers, under the supervision of the Joint Meeting of the Chemicals Committee and the Working Party on Chemicals, Pesticides and Biotechnology, shall:

- advise the Joint Meeting of the Chemicals Committee and the Working Party on Chemicals, Pesticides and Biotechnology on specific opportunities and challenges for the implementation of PRTRs, and propose appropriate measures to meet the challenges, including ways and means for national and international actions;

- promote communication and close working relationship between the Task Force on PRTRs and relevant organisations on the various aspects of the PRTR work; and

- analyse developments in the field of PRTRs and bring to the attention of the member countries the implications of such developments.

\section{Participation}

3. The Task Force on Pollutant Release and Transfer Registers (PRTRs) is comprised of policy and technical experts nominated by member governments who are responsible for PRTRs and related issues in their country, observers from relevant intergovernmental organisations, including CEC, EC, UNEP, UNECE and UNITAR, invited experts, such as the Business and Industry Advisory Committee to the OECD (BIAC), Trade Union Advisory Committee to the OECD (TUAC) and European Environment Bureau (EEB) and, as appropriate, observers from nonmember economies. A Chair and three Vice-Chairs shall be elected by the members of the Task Force.

IV. Term

4. The Terms of Reference are established until 31 December 2012." 

Chair:

Vice-Chairs:

Members: ${ }^{1}$

Full Participants: ${ }^{2}$

Observers:

Date of creation:

Duration:
Mrs. Susan Hazen

Mr. Bjorn Hansen

Mr. Hiroshi Fukushima

Mr. Georg Karlaganis

Australia
Austria
Belgium
Canada
Czech Republic
Denmark
Finland
France
Germany
Greece
Hungary
Ireland
Italy
Japan

Israel

Slovenia

South Africa

Israel

Slovenia

South Africa

1st October 1978

31st December 2012
(United States)

(European Commission)

(Japan)

(Switzerland)

Korea

Mexico

Netherlands

New Zealand

Norway

Poland

Slovak Republic

Spain

Sweden

Switzerland

Turkey

United Kingdom

United States

European Commission

Mandate: - Decision of the Council concerning a Special Programme on the Control of Chemicals [C(78)127(Final)]

- This mandate was extended by the Council at its 535th, 598th, 606th, 665th, 736th, 799th, 872nd, 948th,1027th, 1107th and 1172nd meetings [C/M(2008)8, item 102 and C(2008)48 \& CORR1]

- Name changed from "Management Committee of the Special Programme on the Control of Chemicals" 23 July 1998 [C/M(98)17, item $208 \mathrm{f}$ ) and C(98)145/ANN]

- The Chemicals Committee meets together with the Working Party on Chemicals, Pesticides and Biotechnology

\footnotetext{
1 The following countries became Participants to the Programme subsequent to the adoption by the Council of decision [C(78)127(Final)]: Czech Republic, Finland, Greece, Hungary, Ireland, Italy, Japan, Korea, Mexico, New Zealand, Poland, Slovak Republic, Spain, Turkey.

2 Full participant for issues related to Mutual Acceptance of Data.
} 


\section{Extract from the Decision of the Council [C(78)127(Final)]}

\section{"THE COUNCIL,}

Having regard to the Convention on the Organisation for Economic Co-operation and Development of 14th December 1960, and, in particular, Articles 2 a) and b), 3, 5 a) and 20 thereof;

Having regard to the Rules of Procedure of the Organisation;

Having regard to the Financial Regulations of the Organisation and, in particular,

Articles 5 and 10 thereof;

Having regard to the Resolution of the Council of 25th March 1975, amending the Mandate of the Environment Committee [C(75)17(Final)];

Having regard to the Recommendation of the Council of 7th July 1977, establishing guidelines in respect of procedure and requirements for anticipating the effects of chemicals on man and in the environment [C(77)97(Final)];

Considering that at its meeting on 24th-26th April 1978 the Environment Committee agreed to certain working arrangements for its Programme on Chemicals in the Environment and endorsed the suggestion that within the framework of the Chemicals Group's programme, Member countries wishing jointly to carry out supplementary work which is urgently needed by them should agree to form a Special Programme on the Control of Chemicals financed within the framework of Part II of the Budget;

Considering that Australia, Austria, Belgium, Canada, Denmark, France, Germany, the Netherlands, Norway, Sweden, Switzerland, the United Kingdom, the United States and the Commission of the European Communities (hereinafter referred to as 'the Participants') have stated their intention to participate in a Special Programme on the Control of Chemicals (hereinafter called the 'Programme').

\section{DECIDES:}

\section{Part I}

\section{RESPONSIBILITIES OF THE ENVIRONMENT COMMITTEE CONCERNING THE CONTROL OF CHEMICAL SUBSTANCES}

a) The Chemicals Group of the Environment Committee shall be responsible for the work in the field of control of chemical substance to protect the environment and man's health while avoiding negative effects for the economy and trade.

b) The Chemicals Group should from time to time hold special meetings, as required, in order to give general orientation to the work on chemicals. On such occasions, it should be composed of high-level representatives responsible for the administration of national chemical regulation. Conclusions then reached as well as specific directives indicated in respect of priority tasks will be reported to the Environment Committee.

\section{Part II PROGRAMME \\ Article 1 \\ PURPOSE}

Within the framework of the chemicals' activities of the Organisation, a Programme with a view to providing a forum for co-operation between those Member countries wishing jointly to carry out supplementary work which is urgently needed by them to develop and harmonize practices in order to improve the control of chemicals, is hereby established. The results of the work are intended to contribute to the protection of man and his environment from chemicals' hazards, and to prevent the creation of non-tariff barriers to trade. The Definition of the Programme is set out 
in the Appendix to this Decision of which it is an integral part. It may be adapted as necessary on subsequent proposals of the Management Committee referred to in Article 2 below.

\section{Article 2}

\section{MANAGEMENT COMMITTEE OF THE PROGRAMME}

a) A Management Committee of the Programme (hereinafter referred to as the 'Management Committee') shall be established and shall be composed of one representative appointed by each Participant.

b) Each Participant may appoint an alternate to its representative on the Management Committee.

c) The Management Committee shall designate each year among its Members, a bureau composed of a Chairman and an appropriate number of Vice-Chairmen.

d) Taking due account of the overall activities of the Organisation in the field of chemicals, the Management Committee shall submit each year to the Council proposals with respect to the annual programme of work and budget.

Article 3

\section{FUNCTIONS OF THE MANAGEMENT COMMITTEE}

a) The Management Committee shall be responsible for ensuring the carrying out of the Programme and may consider all questions related thereto. It shall exercise the functions defined in this Decision in accordance with the Decisions and Resolutions of the Council.

b) The Management Committee may set up working groups as required to carry out specific tasks.

c) The Management Committee shall submit each year to the Council a report on the work under the Programme which might include proposals for appropriate action resulting from this work. Such reports and proposals shall be reported to the Environment Committee in order to ensure coordination between activities financed under Part I and those financed under Part II of the Budget.

d) The Management Committee shall receive regular reports on the implementation of the Programme.

Article 4

\section{EXPENDITURE}

a) The expenditure arising from the implementation of the Programme shall be defrayed from the appropriations authorised for it under Part II of the Budget of the Organisation.

b) The Programme may include activities to be financed in whole or in part from grants by public or private institutions.

c) Notwithstanding the provisions of Article 14 b) of the Financial Regulations, the Secretary-General may accept grants not exceeding FF 200000 each in respect of activities which have been included in the annual programme as adopted by the Council.

d) Notwithstanding the provisions of Article 16 b) of the Financial Regulations, appropriations in respect of the Programme for which no commitment has been entered into before 31st December 1978, shall be automatically carried forward to the Financial year 1979.

Article 5

\section{PARTICIPANTS}

a) The Participants shall be the Member countries as listed in the Preamble and the Commission of the European Communities. 
b) Any other Member country of the Organisation may participate at a later stage in the Programme.

Article 6

\section{DURATION}

a) The Programme is established for the period 1st October 1978, to 31st December 1981.

b) The Council shall review the provisions of this Decision before the end of this period, taking into account the experience acquired in carrying out the Programme."

\section{Extract from Summary Record [C/M(2008)8, item 102]}

(70)

"THE COUNCIL,

a) Noted document C(2008)48 and its CORR1;

b) Agreed to extend the duration of the Special Programme on the Control of Chemicals to 31st December 2012, unless Council decides otherwise;

c) Agreed to review the provisions of the Decision concerning a Special Programme on the Control of Chemicals $[C(78) 127$ (Final)], including the need for the continuation of a Special Programme, prior to 31st December 2012." 


\section{WORKING PARTY ON MANUFACTURED NANOMATERIALS}

\begin{tabular}{|c|c|c|}
\hline Chair: & Mr. Jim Willis & (United States) \\
\hline Vice-Chairs: & $\begin{array}{l}\text { Mr. Takashi Fukushima } \\
\text { Mrs. Eva Hellsten } \\
\text { Ms. Roshini Jayewardene } \\
\text { Mr. Bernard Madé } \\
\text { Ms. Jane Stratford }\end{array}$ & $\begin{array}{l}\text { (Japan) } \\
\text { (European Commission) } \\
\text { (Australia) } \\
\text { (Canada) } \\
\text { (United Kingdom) }\end{array}$ \\
\hline Members: & Open to all Member countries & \\
\hline Date of creation: & 14th September 2006 & \\
\hline Duration: & 31st December 2012 & \\
\hline
\end{tabular}

Mandate : $\quad$ Renewed at the 43rd Joint Meeting of the Chemicals Committee and the Working Party on Chemicals, Pesticides and Biotechnology [ENV/JM/M(2008)2, Annex IV]

\section{Extract of document [ENV/JM/M(2008)2, Annex IV]}

"I. Objective

1. The objective of the Working Party on Manufactured Nanomaterials is to promote international co-operation in human health and environmental safety aspects of manufactured nanomaterials among member countries and certain non-member economies (in accordance with the outreach policy of the Chemicals Committee).

\section{Tasks}

2. The Working Party on Manufactured Nanomaterials, under the supervision of the Chemicals Committee, shall:

i. implement a programme of work for 2009-2012, which will involve the exchange of information on regulatory and risk management frameworks (limited mainly to the industrial chemicals sector). It will also exchange information on environmental benefits. The main projects included in the programme of work include:

- development of a Database on Human Health and Environmental Safety Research;

- research Strategies on Manufactured Nanomaterials;

- safety Testing of a Representative Set of Manufactured Nanomaterials;

- manufactured Nanomaterials and Test Guidelines;

- co-operation on Voluntary Schemes and Regulatory Programmes;

- co-operation on Risk Assessment;

- the role of Alternative Methods in Nanotoxicology; and

- exposure Measurement and Exposure Mitigation.

ii. advise the Chemicals Committee on priorities amongst the above projects which need to be addressed in the short, medium and longer-term within the context of the Chemicals Programme; 
iii. take a proactive approach in regard to co-operation on the health and environmental safety related aspects of manufactured nanomaterials by advising the Chemicals Committee on issues related to human health (e.g., from both public and occupational exposures) and environmental impacts resulting from manufactured nanomaterials;

iv. recommend the best means of undertaking the various projects, for example, through a lead country approach, small task groups or workshops;

v. promote an understanding of the health, environmental and exposure implications of manufactured nanomaterials by:

- tracking relevant scientific research efforts;

- identifying relevant research needs; and

- developing and promoting a strategy to meet identified needs.

vi. co-ordinate with other subsidiary bodies of the Chemicals Committee and refer issues to them as appropriate, through the Chemicals Committee;vii.. co-ordinate with other relevant groups within the OECD, especially the Working Party on Nanotechnology, a subsidiary body of the Committee for Scientific and technological Policy; and

viii. co-ordinate with other relevant intergovernmental organisations, especially those of the Inter-Organisation Programme for the Sound Management of Chemicals (i.e., UNEP, ILO, OECD, FAO, WHO, UNIDO and UNITAR); the Intergovernmental Forum on Chemical Safety (IFCS) and possibly NATO and UNESCO; standardisation organisations (e.g., ISO and IUPAC); and nomenclature organisations (e.g., CAS), so avoiding duplication and ensuring complementarity with other international activities;

III. Participation

3. The Working Party will be open and transparent in its activities. Accordingly the participation of stakeholders will be agreed by the Working Party, in line with the outreach policy of the Chemicals Committee;

4. The Working Party will elect a Chair and Vice-Chairs for a period of one year.

IV. Term

5. The Terms of Reference are established until 31 December 2012." 


\section{TASK FORCE ON HAZARD ASSESSMENT $^{1}$}

Chair: ${ }^{2}$

Vice-Chair: ${ }^{3}$

Members:

Observers:

Date of creation:

Duration:
Open to all Member countries

Israel

Slovenia

South Africa

7th November 2008

31st December 2012

Mandate: Summary Record of the 43rd Joint Meeting of the Chemicals Committee and Working Party on Chemicals, Pesticides and Biotechnology [ENV/JM/M(2008)2, Annex IV]

\section{Extract of Document [ENV/JM/M(2008)2, Annex IV]}

\section{"MANDATE FOR THE TASK FORCE ON HAZARD ASSESSMENT}

\section{Objectives}

2. The objectives of the Task Force on Hazard Assessment are to facilitate and support the work of OECD on the hazard assessment of new and existing industrial chemicals, with special emphasis on increasing the output of the HPV Chemicals Programme while maintaining the quality of the assessments produced and improving the visibility and accessibility of the assessments and the data behind them.

\section{Tasks}

3. The Task Force on Hazard Assessment, under the supervision of the Joint Meeting of the Chemicals Committee and the Working Party on Chemicals, Pesticides and Biotechnology, shall:

- oversee the evolution of the HPV Chemicals Programme;

- oversee the development and implementation of improved methodologies, procedures and guidance for the SIDS Initial Assessment Meetings;

- oversee the further development and implementation of the Global Portal to Information on Chemical Substances (eChemPortal);

- oversee the work on (Quantitative) Structure Activity Relationships [(Q)SARs] and facilitate the regulatory acceptance of (Q)SARs, in particular, the further development of the (Q)SAR Application Toolbox;

- oversee the continuous improvement and harmonisation of hazard assessment methodologies, in collaboration with other bodies under the Joint Meeting (such as

\footnotetext{
1 Replaces the Task Force on Existing Chemicals created in 2005 and broadens scope of its mandate.

2 To be nominated at the next meeting.

${ }^{3}$ To be nominated.
} 
the Advisory Group on Toxicogenomics) and relevant IOMC organisations as appropriate;

- promote and oversee activities on integrated approaches to testing and assessment in cooperation with other bodies under the Joint Meeting, as appropriate; and

- advise the Joint Meeting regarding policy issues related to the work on hazard assessment of industrial chemicals, including those related to outreach to nonmembers.

4. The Task Force on Hazard Assessment shall take into account relevant work related to industrial chemicals at the national, regional and international level. It shall meet when required by the needs of the Programme, and report thereafter to the Joint Meeting.

III. Participation

5. The Task Force on Hazard Assessment is comprised of members nominated by governments who are responsible for the assessment of industrial chemicals in member countries, representatives of the European Commission, invited experts and, as appropriate, observers from other international organisations and non-member economies. A Chairperson and two ViceChairpersons shall be elected by the members of the Task Force.

IV. Term

5. $\quad$ The Terms of Reference are established until 31 December 2012." 


\section{TASK FORCE ON HARMONISATION OF CLASSIFICATION AND LABELLING}

Chair:

Vice-Chairs:

Members:

Observers:

Date of creation:

Duration:
Professor Thomas Gebel

Ms. Elisabet Berggren

Ms. Kim Headrick

Ms. Amy Rispin

Open to all Member countries

Israel

Slovenia

10th June 2005

31st December 2012
(Germany)

(European Commission)

(Canada)

(United States)

Mandate: Summary Record of the 43rd Joint Meeting of the Chemicals Committee and Working Party on Chemicals, Pesticides and Biotechnology [ENV/JM/M(2008)2, Annex IV]

\section{Extract of Document [ENV/JM/M(2008)2, Annex IV]}

\section{"MANDATE FOR THE TASK FORCE ON HARMONISATION OF CLASSIFICATION AND LABELLING}

\section{Objectives}

1 The main objective of the Task Force on Harmonisation of Classification and Labelling $(\mathrm{HCL})$ is to contribute to the development and update of the Globally Harmonised System of Classification and Labelling of Chemicals (GHS). The OECD was invited to be the focal point of the UN Sub-Committee of experts on the GHS regarding health and the environmental hazards. A detailed work programme for OECD work on HCL is requested every two years by the SubCommittee. The Task Force may also contribute to the facilitation of GHS implementation.

II. Tasks

2 The Task Force on Harmonisation of Classification and Labelling, under the supervision of the Joint Meeting of the Chemicals Committee and the Working Party on Chemicals, Pesticides and Biotechnology, shall:

- oversee the development of proposals for new or updated GHS classification criteria or guidance;

- oversee the development of reports related to specific hazards, application of GHS criteria or implementation of the GHS; and

- advise the Joint Meeting regarding policy issues related to the work on harmonisation of classification and labelling.

3. The Task Force on Harmonisation of Classification and Labelling shall meet once a year, or as required by the needs of the Programme, and report thereafter to the Joint Meeting.

III. Participation

4. The Task Force on Harmonisation of Classification and Labelling should comprise members nominated by governments who are responsible for the classification and labelling of chemicals in member countries, representatives of the European Commission, observers from other 
international organisations, invited experts and participants in the Sub-Committees of Experts on the GHS and on the Transport of Dangerous Goods, including from non-member economies. A Chairperson and three Vice-Chairpersons shall be elected by the members of the Task Force.

\section{Term}

5. The Terms of Reference are established until 31 December 2012." 


\section{$\underline{\text { TASK FORCE ON EXPOSURE ASSESSMENT }^{1}}$}

Chair: $^{2}$

Members:

Date of creation:

Duration:
Open to all Member countries

7th November 2008

31st December 2012

Mandate: Summary Record of the 43rd Joint Meeting of the Chemicals Committee and Working Party on Chemicals, Pesticides and Biotechnology [ENV/JM/M(2008)2, Annex IV]

\section{Extract of Document [ENV/JM/M(2008)2, Annex IV]}

\section{"MANDATE FOR THE TASK FORCE ON EXPOSURE ASSESSMENT}

\section{Objective}

1. The objective of the Task Force on Exposure Assessment is to facilitate and support the work of OECD on the exposure assessment of chemicals and chemical products with special emphasis on release estimation, exposure models and use of monitoring data.

\section{Tasks}

2. The Task Force on Exposure Assessment, under the supervision of the Joint Meeting of the Chemicals Committee and the Working Party on Chemicals, Pesticides and Biotechnology, shall:

- develop and update OECD Emission Scenario Documents (ESDs) for estimating the release of chemicals from production and use of chemicals, and to elaborate guidance for developing ESDs;

- develop guidance for using monitoring data for exposure assessment;

- develop exposure models and facilitate further improvement of models by compiling relevant information regarding existing models;

- advise the Joint Meeting regarding policy issues related to the work on exposure assessment, including those related to outreach to non-members;

- collaborate with other bodies under the Joint Meeting (such as the Task Force on Biocides, the Working Group on Pesticides and the Working Party on Manufactured Nanomaterials) in the elaboration of ESDs for biocides, pesticides and manufactured nanomaterials, and with, relevant IOMC organisations, as appropriate; and

- exchange information with the Task Force on Pollutant Release and Transfer Registers (PRTRs) regarding tools for estimating the release of chemicals.

\footnotetext{
1 Replaces the Task Force on Environmental Exposure Assessment created in 2005 and broadens scope of its mandate.

${ }^{2}$ To be nominated.
} 


\section{Participation}

3. The Task Force on Exposure Assessment is comprised of members nominated by governments who are responsible for the exposure assessment of chemicals and chemical products in member countries, representatives of the European Commission, invited experts and, as appropriate, observers from other international organisations and non-member economies. A Chairperson shall be elected by the members of the Task Force.

4. The Task Force shall ensure that appropriate expertise on environmental exposure and on human exposure is available when work on the latter is undertaken, by establishing sub-groups on consumer exposure, occupational exposure or human exposure via the environment, as appropriate).

\section{Term}

6. The Terms of Reference are established until 31 December 2012." 


\title{
TASK FORCE ON BIOCIDES
}
Chair:
Mr. Edmund Plattner
(Austria)
Members:
Open to all Member countries
Date of creation:
10th June 2005
Duration:
31st December 2012

\begin{abstract}
Mandate: Summary Record of the 43rd Joint Meeting of the Chemicals Committee and Working Party on Chemicals, Pesticides and Biotechnology [ENV/JM/M(2008)2, Annex IV]
\end{abstract}

\section{Extract of Document [ENV/JM/M(2008)2, Annex IV] \\ "MANDATE FOR THE TASK FORCE ON BIOCIDES}

\section{Objectives}

1. The objectives of the Task Force on Biocides are to facilitate and support the work of the OECD Programme on biocides. The term "biocides" essentially means non-agricultural pesticides.

II. Tasks

2. The Task Force on Biocides, under the supervision of the Joint Meeting of the Chemicals Committee and the Working Party on Chemicals, Pesticides and Biotechnology, shall:

i. foster the harmonisation and development of test guidelines and guidance on environmental and human exposure assessment and efficacy;

ii. facilitate information exchange and work sharing ${ }^{1}$ of government reviews of biocidal active substances through harmonisation of data requirements, dossiers and monograph formats;

iii. exchange ideas as well as facilitate and promote the development and implementation of risk reduction policies and practices in OECD countries;

iv. monitor emerging scientific and policy areas; and

v. advise the Joint Meeting regarding policy issues related to the work on biocides.

3. The Task Force on Biocides shall take into account relevant work related to biocides at the national, regional and international level. It shall meet when required by the needs of the Programme, but no less than once per year, and report thereafter to the Joint Meeting.

III. Participation

4. The Task Force on Biocides should comprise members nominated by governments who are responsible for the assessment of biocides in member countries, representatives of the European Commission, invited experts and, as appropriate, observers from other international organisations and non-member economies, as appropriate. A Chairperson shall be elected by the members of the Task Force.

\section{Term}

5. The Terms of Reference are established until 31 December 2012."

\footnotetext{
${ }^{1}$ Work sharing is meant to include all types of sharing of work in biocide review, from the ad-hoc exchange of information, to well structured divisions of work such as parallel reviews and joint reviews.
} 

DEVELOPMENT 

Chair:

Vice-Chairs:

Members: ${ }^{2}$

Observers:

Date of creation:

Duration:
Mr. Eckhard Deutscher

Ms. Nicole Gesnot

Mr. Franco Conzato

Mr. Bert van Geel

Australia

Austria

Belgium

Canada

Denmark

Finland

France

Germany

Greece

Ireland

Italy

Japan
(Germany)

(Canada)

(European Commission)

(Netherlands)

Luxembourg

Netherlands

New Zealand

Norway

Portugal

Spain

Sweden

Switzerland

United Kingdom

United States

European Commission

International Monetary Fund (IMF)

UN Development Programme (UNDP)

World Bank

14th January 1960

31st December 2010

Mandate: - Paragraph 14 of the Report by the Preparatory Committee

- Council Decision regarding a Sunset Clause for all Committees [C/M(2004)5, item 75] entered into force on 22 April 2004 [C/M(2004)10, item 143, IV, c)]

- Council Decision to extend the mandate up to 31 December 2010 [C(2008)42 and $\mathrm{C} / \mathrm{M}(2008) 6$, item $77 \mathrm{c}]$

\section{Paragraph 14 of the Report by the Preparatory Committee}

"14. As decided by the Ministerial Resolution of 23rd July 1960 [OECD(60)13], the Development Assistance Group shall, upon the inception of the OECD, be constituted as the Development Assistance Committee, and given the following mandate:

a) The Committee will continue to consult on the methods for making national resources available for assisting countries and areas in the process of economic development and for expanding and improving the flow of long-term funds and other development assistance to them.

\footnotetext{
1 The predecessor to the Development Assistance Committee, the Development Assistance Group (DAG) was set up on 13 January 1960 by the Special Economic Committee and approved by Council on 14 January 1960 [CM(60)2(Final) Item 14C]

OECD countries that are not members of the DAC are entitled to participate in all meetings of the DAC and its Subsidiary Bodies in areas of mutual interest.
} 
b) The Development Assistance Committee will acquire the functions, characteristics and membership possessed by the Development Assistance Group at the inception of the Organisation. (See below, "Resolution of the Common Aid Effort")

c) The Committee will select its Chairman, make periodic reports to the Council and its own Members, receive assistance from the Secretariat as agreed with the Secretary-General, have power to make recommendations on matters within its competence to countries on the Committee and to the Council, and invite representatives of other countries and international organisations to take part in particular discussions as necessary.

d) The Development Assistance Committee may act on behalf of the Organisation only with the approval of the Council.

e) In case the responsibilities of the Development Assistance Committee were to be extended beyond those set forth under a), any Member country not represented in the Development Assistance Committee could bring the matter before the Council." 


\section{GLOBAL FORUM ON DEVELOPMENT}

Joint body of the the Governing Board of the Development Centre - See page 31. 


\section{DAC WORKING PARTY ON STATISTICS (WP-STAT)}

Chair:

Vice-Chairs:

Members:

Observers:

Date of creation:

Duration:
Mr. Geert Deserranno

Ms. Hedwig Riegler

Mr. Hitoshi Shoji

Australia
Austria
Belgium
Canada
Denmark
Finland
France
Germany
Greece
Ireland
Italy
Japan

Australia

Austria

Belgium

Canada

Denmark

Finland

Germany

Greece

Italy

International Monetary Fund (IMF)

UN Development Programme (UNDP)

World Bank

19th July 1968

31st December 2010
(Belgium)

(Austria)

(Japan)

Luxembourg

Netherlands

New Zealand

Norway

Portugal

Spain

Sweden

Switzerland

United Kingdom

United States

European Commission

Mandate: - Terms of reference for the DAC Working Parties approved on 13th-14th March 1975 [DAC(75)18]

- Change of name, 5 February 1998 [DCD/DAC/M(98)3]

- New mandate approved by the DAC on 17 September 2003 [DCD/DAC/M(2003)6/FINAL]

- Renewal of the mandate approved by the DAC on 10 May 2007 [DCD/DAC/M(2007)6/FINAL, item IX, para. 22 and DCD/DAC(2007)25/REV2]

- Revision of the DAC subsidiary body mandates approved by the DAC on 23 October 2008 [DCD/DAC/M(2008)9, para. 7]

1. The Development Assistance Committee (DAC) is the principal forum through which bilateral donors deal with issues related to the volume and effectiveness of development cooperation. It aims to impact donor policies and practices in ways that promote aid effectiveness, capacity development, and inclusive globalisation, in order to support poverty reduction and sustainable development in developing countries.

2. Subsidiary Bodies of the DAC will function as communities of practice and sources of expertise that promote collective learning and produce deliverables in accordance with the DAC mandate. The deliverables of Subsidiary Bodies are to be based on the Programme of Work and Budget (PWB) and on additional guidance from the DAC, as communicated by its Chair. They could include leading edge thinking, policy recommendations, good practices, and tools, which are to be relevant, practical, timely, and user-friendly. These deliverables should be accompanied by communication and dissemination strategies designed to ensure impact on behaviour change. Subsidiary Bodies will also promote synergies among other Subsidiary Bodies in contributing to the DAC's PWB. 
3. The operations of Subsidiary Bodies, as part of the Organisation for Economic Cooperation and Development (OECD), will be in line with the rules, regulations, and guidance of the Organisation. Together with the Secretariat, they will carry out horizontal work with other parts of the OECD where appropriate to particularly contribute to policy coherence for development. Furthermore, Subsidiary Bodies will develop substantive interactions with international organisations and non-DAC donors -including in support of the Organisation's efforts toward enlargement and enhanced engagement- as well as reach out on a case by case basis to partner countries and other relevant actors.

\section{Extract from document [DCD/DAC(2008)39/REV1]}

"VII. Working Party on Statistics (WP-STAT)

\section{A. Individualised Mandate}

1.

The Working Party on Statistics keeps under review and proposes improvements in the statistical system and in the reporting of resource flows to developing countries and multilateral agencies by DAC and non-DAC donors, as well as flows from multilateral agencies and private sources of aid. It makes recommendations to the DAC about: ODA eligibility; guidelines and definitions for reporting; data comparability; and the use of DAC statistics. It proposes, for decision by the DAC, significant amendments to the statistical reporting directives, making minor adjustments on its own authority; deals with related subjects referred to it by the DAC; continuously improves the quality, comparability, accessibility and user-friendliness of aid data; and reports to the DAC as appropriate." 


\section{WORKING PARTY ON AID EFFECTIVENESS (WP-EFF)}

Chair:

Vice-Chairs:

OECD Members: ${ }^{1}$

Non-OECD Members:

Invited Organisations:

Date of creation:

Duration:
Mr. Jan Cedergren

Mr. Christopher Hall

Mr. J.B. Siriboe

Australia
Austria
Belgium
Canada
Denmark
Finland
France
Germany
Greece
Ireland
Italy
Japan

Indonesia

South Africa

Bangladesh

Bolivia

Cambodia

Ethiopia

Fiji

Ghana

Honduras

Kyrgyzstan

Madagascar

Mali
(Sweden)

(World Bank)

(Ghana)

Luxembourg

Netherlands

New Zealand

Norway

Portugal

Spain

Sweden

Switzerland

United Kingdom

United States

European Commission

\section{Morocco \\ Mozambique \\ Nicaragua \\ Niger \\ Philippines \\ Rwanda \\ Senegal \\ Tanzania \\ Uganda \\ Viet Nam \\ Zambia}

African Development Bank (ADB)

Asian Development Bank (ADB)

Education for All - Fast Track Initiative (EFA-FTI)

European Bank for Reconstruction and Development (EBRD)

Global Fund to Fight AIDS, Tuberculosis and Malaria

Inter-American Development Bank (IDB)

International Monetary Fund (IMF)

Stategic Partnership with Africa (SPA)

UN Development Group (UNDG)

UN Development Programme (UNDP)

World Bank

24th April 2003

30th June 2009

Mandate: - Approved by the DAC on 17 September 2003 [DCD/DAC/M(2003)6/FINAL]

- Renewed mandate and change of name approved by the DAC on 10 May 2007 [DCD/DAC/M(2007)6/FINAL, item IX, para. 22; DCD/DAC(2007)25/REV2 and DCD/DAC/EFF(2007)33 (amendments included)]

\footnotetext{
${ }^{1}$ OECD countries that are not members of the DAC are entitled to participate in all meetings of the DAC and its Subsidiary Bodies in areas of mutual interest.
} 
- Extension of the mandate up to 30 June 2009 approved by the DAC on 26 June 2008 [DCD/DAC/M(2008)6/FINAL, para. 17]

\section{Extract from document [DCD/DAC/EFF(2007)33]}

"1. The Working Party on Aid Effectiveness (WP-EFF) is an international partnership of donors and partner countries hosted by the DAC. It is the major forum for dialogue between bilateral donors, multilateral organisations and partner countries which aims at improving the effectiveness of aid for greater impact on development and poverty reduction. Its current mandate is to promote, facilitate and monitor the implementation of the Paris Declaration on Aid Effectiveness endorsed at a High Level Forum in March 2005. This includes the following responsibilities:

- $\quad$ Encourage dissemination efforts to spread the messages of the Paris Declaration (PD).

- Support implementation of the PD Partnership Commitments on ownership, alignment, harmonisation, managing for development results and mutual accountability by developing policy and good practice guidance as well as joint tools in areas critical for implementing the Paris Declaration.

Respond to the mandate entrusted by the Paris Declaration on monitoring the indicators of progress and proposing arrangements for medium term monitoring.

Act as a focal point where parties engaged in implementing PD commitments can report back on progress for experience-sharing.

Prepare for the 3rd High Level Forum (HLF) on Aid Effectiveness to take place in Accra in September 2008.

2. To carry out its mandate, the Working Party relies on the expertise of its four specialised Joint Ventures:

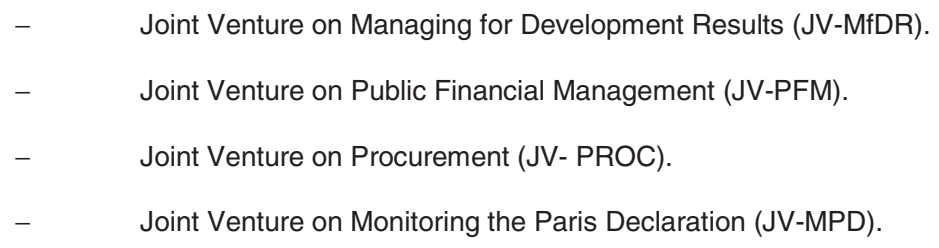

3. In addition, an Advisory Group on Civil Society and Aid Effectiveness (AG-CS), which will function at least until the $3 r d$ HLF, has been set up.

4. The WP-EFF has established for itself the principle of a 'tripartite' chairing arrangement with representation from a bilateral donor, a multilateral organisation, and a partner country, reflecting the partnership commitment of mutual responsibility and accountability in implementing the Paris agenda."

\footnotetext{
${ }^{1}$ OECD countries that are not members of the DAC are entitled to participate in all meetings of the DAC and its Subsidiary Bodies in areas of mutual interest.
} 


\section{DAC NETWORK ON DEVELOPMENT EVALUATION}

\begin{tabular}{|c|c|c|}
\hline Chair: & Mr. Nick York & (United Kingdom) \\
\hline Vice-Chairs: & $\begin{array}{l}\text { Mr. Dominique de Crombrugghe } \\
\text { de Looringhe } \\
\text { Mr. Benoît Chervalier } \\
\text { Ms. Penny Hawkins }\end{array}$ & $\begin{array}{l}\text { (Belgium) } \\
\text { (France) } \\
\text { (New Zealand) }\end{array}$ \\
\hline Members: & $\begin{array}{l}\text { Australia } \\
\text { Austria } \\
\text { Belgium } \\
\text { Canada } \\
\text { Denmark } \\
\text { Finland } \\
\text { France } \\
\text { Germany } \\
\text { Greece } \\
\text { Ireland } \\
\text { Italy } \\
\text { Japan }\end{array}$ & $\begin{array}{l}\text { Luxembourg } \\
\text { Netherlands } \\
\text { New Zealand } \\
\text { Norway } \\
\text { Portugal } \\
\text { Spain } \\
\text { Sweden } \\
\text { Switzerland } \\
\text { United Kingdom } \\
\text { United States } \\
\text { European Commission }\end{array}$ \\
\hline Observers: & \multicolumn{2}{|c|}{$\begin{array}{l}\text { International Monetary Fund (IMF) } \\
\text { UN Development Programme (UNDP) } \\
\text { World Bank }\end{array}$} \\
\hline Invited Organisations: & \multicolumn{2}{|c|}{$\begin{array}{l}\text { African Development Bank (ADB) } \\
\text { Asian Development Bank (ADB) } \\
\text { European Bank for Reconstruction and Development (EBRD) } \\
\text { Inter-American Development Bank (IDB) }\end{array}$} \\
\hline
\end{tabular}

Date of creation:

28th March 2003

Duration:

31st December 2010
Mandate: - Approved by the DAC on 17 September 2003 [DCD/DAC/M(2003)6/FINAL]
- Renewal of the mandate approved by the DAC on 10 May 2007 [DCD/DAC/M(2007)6/FINAL, item IX, para. 22 and DCD/DAC(2007)25/REV2]
- Revision of the DAC subsidiary body mandates approved by the DAC on 23 October 2008 [DCD/DAC/M(2008)9, para. 7]

1. The Development Assistance Committee (DAC) is the principal forum through which bilateral donors deal with issues related to the volume and effectiveness of development cooperation. It aims to impact donor policies and practices in ways that promote aid effectiveness, capacity development, and inclusive globalisation, in order to support poverty reduction and sustainable development in developing countries.

2. Subsidiary Bodies of the DAC will function as communities of practice and sources of expertise that promote collective learning and produce deliverables in accordance with the DAC mandate. The deliverables of Subsidiary Bodies are to be based on the Programme of Work and Budget (PWB) and on additional guidance from the DAC, as communicated by its Chair. They could include leading edge thinking, policy recommendations, good practices, and tools, which are to be relevant, practical, timely, and user-friendly. These deliverables should be accompanied by communication and dissemination strategies designed to ensure impact on behaviour change. 
Subsidiary Bodies will also promote synergies among other Subsidiary Bodies in contributing to the DAC's PWB.

3. The operations of Subsidiary Bodies, as part of the Organisation for Economic Cooperation and Development (OECD), will be in line with the rules, regulations, and guidance of the Organisation. Together with the Secretariat, they will carry out horizontal work with other parts of the OECD where appropriate to particularly contribute to policy coherence for development. Furthermore, Subsidiary Bodies will develop substantive interactions with international organisations and non-DAC donors -including in support of the Organisation's efforts toward enlargement and enhanced engagement- as well as reach out on a case by case basis to partner countries and other relevant actors.

\section{Extract from document [DCD/DAC(2008)39/REV1]}

\section{"II. Network on Development Evaluation}

\section{A. Individualised Mandate}

a) Overall Objective and Comparative Advantage

1. The DAC Evaluation Network is a unique body in the international evaluation architecture bringing together evaluation managers and specialists from development agencies and ministries of member countries, with representation also from multilateral development institutions. Its overall purpose is to increase the development effectiveness of aid policies and programmes through high quality, independent evaluation. Evaluation supports evidence-based decision-making and is a means to influence donor and partner behaviour through lesson learning and by providing accountability for results of development programmes. The usefulness to a range of development partners is also an important dimension for the Evaluation Network.

\section{b) Areas of Focus and Types of Deliverables}

2. The main areas of focus are: strengthen individual members' evaluation systems, improve the quality of evaluations, harmonise evaluation processes, facilitate joint evaluations, support partner country evaluation capacities, and improve knowledge sharing in evaluation. It serves as a platform for mutual learning and co-ordination among members. The Network produces evaluation guidance for practical application and joint evaluation studies, as well as providing a web-based evaluation resource centre as a service to its members and the broader public.

c) Modalities, including Members, Observers, Outreach and Stakeholders

3. Participants are evaluation heads from DAC member countries, OECD countries not yet DAC members, the independent evaluation offices of the World Bank, IMF, UNDP, ADB, AfDB, IDB, and the EBRD. Other development agencies are invited on an ad hoc basis based on the requirements of the work programme. Workshops, in particular, provide an opportunity for outreach to non-OECD members and to developing countries and professional evaluation associations.

d) Synergies with other Subsidiary Bodies and OECD Bodies

4. The Evaluation Network works with other subsidiary bodies of the DAC in the areas of their specific competence. The Network has a long record of active collaboration with different subsidiary bodies whenever an evaluation has addressed a specific topical area and will continue to seek such collaboration. It also collaborates informally with other parts of OECD involved in evaluation activities." 


\title{
DAC NETWORK ON GENDER EQUALITY (GENDERNET)
}

Chair:

Members:

Observers:

Invited Organisations:

Date of creation:

Duration:
Ms. Dorthea Damkjaer

Australia

Austria

Belgium

Canada

Denmark

Finland

France

Germany

Greece

Ireland

Italy

Japan
(Denmark)

Luxembourg

Netherlands

New Zealand

Norway

Portugal

Spain

Sweden

Switzerland

United Kingdom

United States

European Commission

International Monetary Fund (IMF)

UN Development Programme (UNDP)

World Bank

\author{
African Development Bank (ADB) \\ Asian Development Bank (ADB) \\ Commonwealth Secretariat \\ Inter-American Development Bank (IDB) \\ UN Development Fund for Women (UNIFEM) \\ United Nations
}

28th March 2003

31st December 2010
Mandate: - Approved by the DAC on 17 September 2003 [DCD/DAC/M(2003)6/FINAL]
- Renewal of the mandate approved by the DAC on 10 May 2007
[DCD/DAC/M(2007)6/FINAL, item IX, para. 22 and DCD/DAC(2007)25/REV2]
- Revision of the DAC subsidiary body mandates approved by the DAC on 23 October 2008 [DCD/DAC/M(2008)9, para. 7]

1. The Development Assistance Committee (DAC) is the principal forum through which bilateral donors deal with issues related to the volume and effectiveness of development cooperation. It aims to impact donor policies and practices in ways that promote aid effectiveness, capacity development, and inclusive globalisation, in order to support poverty reduction and sustainable development in developing countries.

2. Subsidiary Bodies of the DAC will function as communities of practice and sources of expertise that promote collective learning and produce deliverables in accordance with the DAC mandate. The deliverables of Subsidiary Bodies are to be based on the Programme of Work and Budget (PWB) and on additional guidance from the DAC, as communicated by its Chair. They could include leading edge thinking, policy recommendations, good practices, and tools, which are to be relevant, practical, timely, and user-friendly. These deliverables should be accompanied by communication and dissemination strategies designed to ensure impact on behaviour change. Subsidiary Bodies will also promote synergies among other Subsidiary Bodies in contributing to the DAC's PWB. 
3. The operations of Subsidiary Bodies, as part of the Organisation for Economic Cooperation and Development (OECD), will be in line with the rules, regulations, and guidance of the Organisation. Together with the Secretariat, they will carry out horizontal work with other parts of the OECD where appropriate to particularly contribute to policy coherence for development. Furthermore, Subsidiary Bodies will develop substantive interactions with international organisations and non-DAC donors -including in support of the Organisation's efforts toward enlargement and enhanced engagement- as well as reach out on a case by case basis to partner countries and other relevant actors.

\section{Extract from document [DCD/DAC(2008)39/REV1]}

"IV. Network on Gender Equality (GENDERNET)

A. Individualised Mandate

a) Overall Objectives and Comparative Advantage

19. The DAC Network on Gender Equality:

Contributes to improving the quality and effectiveness of development co-operation. The GENDERNET works to ensure that practice and implementation match global and national commitments to gender equality and women's empowerment in advancing economic, social and political development in partner countries. It is responsive to changing contexts and development priorities.

Provides strategic support to the policy priorities of the DAC. The GENDERNET plays a catalytic role, provides professional expertise for integrating gender equality perspectives into the DAC's work, reinforces this priority in members' programmes, and supports partner countries' development efforts. It collaborates with the other DAC subsidiary bodies.

Provides members with a unique forum for sharing experiences and disseminating good practice and innovative approaches for integrating gender perspectives and women's empowerment into key aspects of development co-operation in support of partners' own efforts.

\section{b) Areas of Focus and Types of Deliverables}

20. Building on lessons learned during the 2005-06 biennium, the Network's priorities are sharply focussed on the "core" work of the DAC, namely aid effectiveness, statistics and peer reviews. The Network aims to improve donor policy and practice by stimulating fresh thinking designed to:

- $\quad$ Close the policy to implementation gap in donor agencies

- Improve donor performance and change behaviour both within individual agencies and collectively through increased collaborative work in partner countries, and

- Intensify investments in achieving gender equality and women's empowerment (MDG3).

21. The Network's deliverables have included the development of Issues briefs and guiding principles; case study based workshops; contributions to DAC policy guidance; and policy and practice consultations with other development actors.

c) Modalities, including Members, Observers, Outreach and Stakeholders

22. The core membership of the GENDERNET is drawn from the DAC and its permanent observers (the World Bank and UNDP). Several other relevant UN agencies, notably UNIFEM, the 
UN's Division for the Advancement of Women and UNESCO participate on a regular basis, along with the Commonwealth Secretariat, the regional development banks and TUAC. Research and civil society organisations are also invited to contribute to specific workshops and agenda topics. The case study approach to meetings has been a valuable way of actively engaging with both partner country governments and CSOs.

23. Every two years the Network holds a joint workshop with the UN's Inter-Agency Network on Women and Gender Equality (IANWGE) to exchange ideas and share information on issues of mutual relevance and interest.

d) Synergies with other DAC Bodies

24. The GENDERNET works collaboratively with other DAC subsidiary bodies. This can be through partnerships such as the joint work with the Working Party on Statistics to improve the DAC gender equality policy marker or with the GOVNET, WP-EFF and ENVIRONET on the Dublin workshop in April 2007. More often, it is through contributions to and review of draft DAC guidance. GENDERNET is an ex officio member of the POVNET." 


\begin{tabular}{|c|c|c|}
\hline Chairs: & $\begin{array}{l}\text { Mr. Paul Hassing } \\
\text { Mr. Paul Samson }\end{array}$ & $\begin{array}{l}\text { (Netherlands) } \\
\text { (Canada) }\end{array}$ \\
\hline Members: & $\begin{array}{l}\text { Australia } \\
\text { Austria } \\
\text { Belgium } \\
\text { Canada } \\
\text { Denmark } \\
\text { Finland } \\
\text { France } \\
\text { Germany } \\
\text { Greece } \\
\text { Ireland } \\
\text { Italy } \\
\text { Japan }\end{array}$ & $\begin{array}{l}\text { Luxembourg } \\
\text { Netherlands } \\
\text { New Zealand } \\
\text { Norway } \\
\text { Portugal } \\
\text { Spain } \\
\text { Sweden } \\
\text { Switzerland } \\
\text { United Kingdom } \\
\text { United States } \\
\text { European Commission }\end{array}$ \\
\hline Observers: & \multicolumn{2}{|c|}{$\begin{array}{l}\text { International Monetary Fund (IMF) } \\
\text { UN Development Programme (UNDP) } \\
\text { World Bank }\end{array}$} \\
\hline Invited Organisations: & \multicolumn{2}{|c|}{$\begin{array}{l}\text { International Institute for Environment and Development (IIED) } \\
\text { International Institute for Sustainable Development (IISD) } \\
\text { International Union for Conservation of Nature (IUCN) } \\
\text { UN Environment Programme (UNEP) } \\
\text { World Resources Institute }\end{array}$} \\
\hline
\end{tabular}

Date of creation:

28th March 2003

Duration:

31st December 2010
Mandate: - Approved by the DAC on 17 September 2003 [DCD/DAC/M(2003)6/FINAL]
- Renewal of mandate approved by the DAC on 10 May 2007 [DCD/DAC/M(2007)6/FINAL , item IX, para. 22 and DCD/DAC(2007)25/REV2]
- Revision of the DAC subsidiary body mandates approved by the DAC on 23 October 2008 [DCD/DAC/M(2008)9, para. 7]

1. The Development Assistance Committee (DAC) is the principal forum through which bilateral donors deal with issues related to the volume and effectiveness of development cooperation. It aims to impact donor policies and practices in ways that promote aid effectiveness, capacity development, and inclusive globalisation, in order to support poverty reduction and sustainable development in developing countries.

2. Subsidiary Bodies of the DAC will function as communities of practice and sources of expertise that promote collective learning and produce deliverables in accordance with the DAC mandate. The deliverables of Subsidiary Bodies are to be based on the Programme of Work and Budget (PWB) and on additional guidance from the DAC, as communicated by its Chair. They could include leading edge thinking, policy recommendations, good practices, and tools, which are to be relevant, practical, timely, and user-friendly. These deliverables should be accompanied by communication and dissemination strategies designed to ensure impact on behaviour change. Subsidiary Bodies will also promote synergies among other Subsidiary Bodies in contributing to the DAC's PWB. 
3. The operations of Subsidiary Bodies, as part of the Organisation for Economic Cooperation and Development (OECD), will be in line with the rules, regulations, and guidance of the Organisation. Together with the Secretariat, they will carry out horizontal work with other parts of the OECD where appropriate to particularly contribute to policy coherence for development. Furthermore, Subsidiary Bodies will develop substantive interactions with international organisations and non-DAC donors -including in support of the Organisation's efforts toward enlargement and enhanced engagement- as well as reach out on a case by case basis to partner countries and other relevant actors.

\section{Extract from document [DCD/DAC(2008)39/REV1]}

"III. Network on Environment and Development Co-operation (ENVIRONET)

\section{A. Individualised Mandate}

a) Overall Objectives and Comparative Advantage

10. The DAC Network on Environment and Development Co-operation contributes to the formulation of coherent approaches to sustainable development in the context of the OECD cross-sectoral approach to sustainable development. It formulates specific guidance for development co-operation efforts in support of environment and sustainable development. It also provides its members with a policy forum for sharing experience and disseminating good practice with regard to the integration of environmental concerns in development co-operation.

\section{b) Areas of Focus and Types of Deliverables}

11. ENVIRONET aims to influence donor policy and approaches to sustainable development and to make these more coherent across donors by producing consensus-based policy guidance. During 2009-10 ENVIRONET will pursue this agenda by: (i) disseminating its policy guidance for donors on integrating climate change adaptation into development co-operation; and (ii) preparing sector specific climate change guidance; and (iii) updating the 1995 Guidelines on Capacity Development for Environment. Deliverables include policy guidance publications, policy briefs, seminars for headquarters staff, workshops in developing countries, and policy consultations. c) Modalities, including Members, Observers, Outreach and Stakeholders

12. ENVIRONET's core membership is drawn from the DAC and its permanent observers (World Bank, UNDP). Representatives of non-DAC OECD countries, other United Nations agencies, researchers and civil society organizations contribute to ENVIRONETs work as appropriate, particularly through participation in its task teams. ENVIRONET consults with other stakeholders (including developing country officials as well as with civil society and the private sector in developed and developing countries) when formulating and testing its policy guidance.

d) Synergies with other DAC Subsidiary Bodies

13. ENVIRONET has collaborative working relationships with a number of DAC subsidiary bodies. It is working with GENDERNET in ensuring the Guidance on Integrating Climate Change Adaptation into Development Co-operation is gender sensitive. In addition, ENVIRONET is an ex officio member of POVNET and is increasingly working with CPDC on issues related to environment and conflict." 


\section{DAC NETWORK ON POVERTY REDUCTION (POVNET)}

Chair:

Vice-Chairs:

Members:

Observers:

Date of creation:

Duration:
Mr. Pierre Jacquet

Mr. Earnan O'Cleirigh

Mr. Hitoshi Shoji

Australia
Austria
Belgium
Canada
Denmark
Finland
France
Germany
Greece
Ireland
Italy
Japan

Australia

Austria

Belgium

Canada

Denmark

Finland

Germany

Greece

Italy
(France)

(Ireland)

(Japan)

Luxembourg

Netherlands

New Zealand

Norway

Portugal

Spain

Sweden

Switzerland

United Kingdom

United States

European Commission

International Monetary Fund (IMF)

UN Development Programme (UNDP)

World Bank

8th June 1998

31st December 2010

1. The Development Assistance Committee (DAC) is the principal forum through which bilateral donors deal with issues related to the volume and effectiveness of development cooperation. It aims to impact donor policies and practices in ways that promote aid effectiveness, capacity development, and inclusive globalisation, in order to support poverty reduction and sustainable development in developing countries.

2. Subsidiary Bodies of the DAC will function as communities of practice and sources of expertise that promote collective learning and produce deliverables in accordance with the DAC mandate. The deliverables of Subsidiary Bodies are to be based on the Programme of Work and Budget (PWB) and on additional guidance from the DAC, as communicated by its Chair. They could include leading edge thinking, policy recommendations, good practices, and tools, which are to be relevant, practical, timely, and user-friendly. These deliverables should be accompanied by communication and dissemination strategies designed to ensure impact on behaviour change. Subsidiary Bodies will also promote synergies among other Subsidiary Bodies in contributing to the DAC's PWB.

3. The operations of Subsidiary Bodies, as part of the Organisation for Economic Cooperation and Development (OECD), will be in line with the rules, regulations, and guidance of the Organisation. Together with the Secretariat, they will carry out horizontal work with other parts of the 
OECD where appropriate to particularly contribute to policy coherence for development. Furthermore, Subsidiary Bodies will develop substantive interactions with international organisations and non-DAC donors -including in support of the Organisation's efforts toward enlargement and enhanced engagement- as well as reach out on a case by case basis to partner countries and other relevant actors.

\section{Extract from document [DCD/DAC(2008)39/REV1]}

"VI. Network on Poverty Reduction (POVNET)

\section{A. Individualised Mandate}

\section{a) Overall Objectives and Comparative Advantage}

1. The DAC Network on Poverty Reduction is a community of practice and a source of expertise on understanding and tackling poverty. It takes a holistic approach, sees poverty as multidimensional and recognises that progress in one dimension of poverty both depends on and supports progress in other dimensions. POVNET builds on the diversity and experience of its members to serve as a forum for dissemination, mutual learning and seeking common understandings on how donors can best contribute to poverty reduction. POVNET takes the poverty reduction targets in the MDGs as its point of reference and supports the implementation of the Paris Declaration on Aid Effectiveness in matters related to poverty reduction through its work on the design and delivery of poverty reduction initiatives.

\section{b) Areas of Focus and Types of Deliverables}

2. It presently focuses on the relationships between poverty, inequality and growth, seeking to increase the poverty reduction impact of economic growth. Working mostly on the basis of existing analysis, POVNET seeks to draw out and test policy advice on how to promote pro-poor growth, which it sees as rapid and sustained economic growth in which the poor participate as both agents and beneficiaries. POVNET identifies, harmonises and disseminates good practices among aid agencies in implementing effective pro-poor growth policies. Empowering poor people so that they can participate more effectively in the economic, social and political processes that influence their livelihoods is a central component of this agenda, as are gender equity and environmental sustainability.

\section{c) Modalities, Including Members, Observers, Outreach and Stakeholders}

3. POVNET influences donor policy and approaches through the design, delivery, harmonisation and co-ordination of donors' pro-poor growth and poverty reduction activities at the field level. It does this by informing choices and policies on poverty reduction and by preparing products (e.g. policy papers, good practices notes, workshops in developing countries, seminars and operational staff training for donors) that take account of and are based on country specific analysis and by supporting donor engagement in country level policy and development processes. In these ways, POVNET promotes the alignment of donor initiatives with locally owned development plans and poverty reduction strategies and by supporting country based approaches.

4. POVNET's core membership is drawn from the DAC and its permanent observers (World Bank, IMF, UNDP). Representatives of non-DAC OECD countries as well as BIAC and TUAC often participate in POVNET meetings. Various other United Nations agencies, as well as researchers and civil society organisations contribute to POVNET work as appropriate, particularly through involvement in its Task Teams. POVNET consults widely with these other stakeholders when formulating and testing its policy guidance and other products for donors. POVNET has recently established a working relationship with China and will support and contribute to the work of the DAC-China Study Group.

d) Synergies with other DAC Subsidiary Bodies 
5. As issues related to gender and environmental sustainability cut across all dimensions of poverty, the Chairs of the DAC Networks on Gender Equality and on Environment and Development Co-operation have been ex officio members of POVNET from its inception, and they participate in its meetings as appropriate. POVNET's multidimensional approach to poverty requires its activities to be undertaken in collaboration with other DAC subsidiary bodies as well as to provide its perspectives on the work of other subsidiary bodies. Present discussion partners beyond ENVIRONET and GENDERNET include GOVNET, CPDC and the WP-EFF's JV-MfDR." 


\section{DAC NETWORK ON GOVERNANCE (GOVNET)}

Chair:

Vice-Chairs:

Members:

Observers:

Invited Organisations:

Date of creation:

Duration:
Mr. René Holenstein

Mrs. Amy Baker

Mr. Kevin Carroll

Dr. Dennis de Jong

Dr. Mark Robinson

Australia
Austria
Belgium
Canada
Denmark
Finland
France
Germany
Greece
Ireland
Italy
Japan

Australia

Canada

Denmark

Finland

Germany

Greece

Japan
(Switzerland)

(Canada)

(Ireland)

(Netherlands)

(United Kingdom)

Luxembourg

Netherlands

New Zealand

Norway

Portugal

Spain

Sweden

Switzerland

United Kingdom

United States

European Commission

International Monetary Fund (IMF)

UN Development Programme (UNDP)

World Bank

African Development Bank (ADB)

Asian Development Bank (ADB)

Inter-American Development Bank (IDB)

International Institute for Democracy and Electoral Assistance

(IDEA)

UN Children's Fund (UNICEF)

UN Development Fund for Women (UNIFEM)

UN Economic Commission for Africa (UNECA)

UN Global Compact

UN Office of the High Commissioner for Human Rights (OHCHR)

United Nations

World Health Organization (WHO)

4th December 2000[DCD/DAC/GOVNET(2001)1]

31st December 2010

Mandate: - The Network was created by merging the DAC informal Network on Participatory Development and Good Governance (PD/GG) and the DAC informal Network on Institutional and Capacity Development (I/CD) during the 754th meeting of the DAC [DCD/DAC/M(2000)5]

- New mandate approved by the DAC on 17 September 2003 [DCD/DAC/M(2003)6/FINAL]

- Mandate extended until 31 December 2006 by the DAC at its 816th Meeting on 17 June 2004 [DCD/DAC/M(2004)8/FINAL]

- Renewal of the mandate approved by the DAC under the written procedure on 19 June 2007 [DCD/DAC/M(2007)7/FINAL and DCD/DAC/GOVNET(2007)2/FINAL]

\footnotetext{
${ }^{1}$ A number of developing country experts are invited at each meeting in relation to items for discussion.
} 
1. The Development Assistance Committee (DAC) is the principal forum through which bilateral donors deal with issues related to the volume and effectiveness of development cooperation. It aims to impact donor policies and practices in ways that promote aid effectiveness, capacity development, and inclusive globalisation, in order to support poverty reduction and sustainable development in developing countries.

2. Subsidiary Bodies of the DAC will function as communities of practice and sources of expertise that promote collective learning and produce deliverables in accordance with the DAC mandate. The deliverables of Subsidiary Bodies are to be based on the Programme of Work and Budget (PWB) and on additional guidance from the DAC, as communicated by its Chair. They could include leading edge thinking, policy recommendations, good practices, and tools, which are to be relevant, practical, timely, and user-friendly. These deliverables should be accompanied by communication and dissemination strategies designed to ensure impact on behaviour change. Subsidiary Bodies will also promote synergies among other Subsidiary Bodies in contributing to the DAC's PWB.

3. The operations of Subsidiary Bodies, as part of the Organisation for Economic Cooperation and Development (OECD), will be in line with the rules, regulations, and guidance of the Organisation. Together with the Secretariat, they will carry out horizontal work with other parts of the OECD where appropriate to particularly contribute to policy coherence for development. Furthermore, Subsidiary Bodies will develop substantive interactions with international organisations and non-DAC donors -including in support of the Organisation's efforts toward enlargement and enhanced engagement- as well as reach out on a case by case basis to partner countries and other relevant actors.

\section{Extract from document [DCD/DAC(2008)39/REV1]}

\section{"V. Network on Governance (GOVNET)}

\section{A. Individualised Mandate}

\section{a) Overall Objective and Comparative Advantage}

1. The DAC Network on Governance aims to improve the effectiveness of donor assistance in support of democratic governance ${ }^{1}$ in developing countries. It provides members with a forum to exchange experiences and lessons, identify and disseminate good practice, and develop policy and analytical tools relating to the reform of institutions, the dynamics of change and the interplay of checks and balances, and issues surrounding domestic accountability and respect for human rights. Consistent with the Paris Declaration on Aid Effectiveness (2005), the GOVNET promotes partner country ownership, aligned and co-ordinated donor approaches, results and mutual accountability.

\section{b) Areas of Focus and Types of Deliverables}

2. The GOVNET's work on governance spans a range of issues, including human rights, transparency, accountability, participation and equality, anti-corruption and capacity development in support of these elements of democratic governance. The GOVNET is a resource for DAC member states, and the DAC and its subsidiary bodies, providing a perspective on the interface between states and societies and the challenges of state-building in developing countries. Deliverables

\footnotetext{
1 Democratic governance is taken to encompass the broad principles of supporting human rights, transparency, accountability, legitimacy, participation and equality, without being narrowly prescriptive about formal or procedural forms of democratic government.
} 
include policy guidance publications, policy briefs, seminars for headquarters staff, workshops, and policy consultations.

c) Modalities, Membership and Outreach

3. The membership of the GOVNET is composed of representatives from responsible Ministries of DAC members and observers ${ }^{1}$. Engagement and dialogue with partner countries are essential in undertaking the GOVNET's work on governance and are encouraged at both GOVNET and task team level. The GOVNET may invite experts from developing countries, international organisations, academia and international non-governmental organisations (NGOs) to participate to enhance the implementation of the work programme.

4. The work of the GOVNET is steered by a Chair and a Bureau consisting of 2-4 interested members. Plenary meetings are usually held every nine months in Paris. Groups of interested members may be formed to ensure the implementation of individual work programme components, meeting as necessary either in Paris or other locations, or via other communication means. Linkages between these groups are encouraged, so as to promote intra-network learning.

d) Synergies with Other Subsidiary Bodies and OECD Bodies

5. To enhance policy coherence and synergies across the DAC and the wider OECD, the GOVNET seeks to interact and establish effective links with other DAC subsidiary bodies and OECD groups more widely regarding governance issues. Members are encouraged to liaise with other parts of their governments where this will enhance collaboration and coherence."

\footnotetext{
1 In its work on governance and anti-corruption, including interactions with other partners, the World Bank, an Observer to the Network, must act within the framework of its Articles of Agreement which include a limitation on interference in its members' political affairs and prohibit decisions being influenced by its members' political character (see the IBRD Articles of Agreement, Article IV, Section 10).
} 


\section{DAC NETWORK ON CONFLICT, PEACE AND DEVELOPMENT CO-OPERATION (CPDC)}

Chairs:

Vice-Chair:

Members:

Observers:

Invited Organisations:

Date of creation:

Duration:
Ms. Kathleen Cravero

Mr. Koen Davidse

Ms. Cristina Hoyos

Australia

Austria

Belgium

Canada

Denmark

Finland

France

Germany

Greece

Ireland

Italy

Japan
(UN Development Programme

(UNDP))

(Netherlands)

(Switzerland)

Luxembourg

Netherlands

New Zealand

Norway

Portugal

Spain

Sweden

Switzerland

United Kingdom

United States

European Commission

International Monetary Fund (IMF)

UN Development Programme (UNDP)

World Bank

International Committee of the Red Cross (ICRC)

UN High Commissioner for Refugees (UNHCR)

UN Office for the Coordination of Humanitarian Affairs (UNOCHA)

1995

31st December 2010

Mandate: - Transformed into a Network in June 2000 [DCD/DAC/M(2000)5]

- New mandate approved by the DAC on 17 September 2003 [DCD/DAC/M(2003)6/FINAL]

- Mandate extended until 31 December 2006 by the DAC at its 816th Meeting on 17 June 2004 [DCD/DAC/M(2004)8/FINAL]

- Renewal of the mandate approved by the DAC on 10 May 2007 [DCD/DAC/M(2007)6/FINAL, item IX, para. 22 and DCD/DAC(2007)25/REV2]

- Revision of the DAC subsidiary body mandates approved by the DAC on 23 October 2008 [DCD/DAC/M(2008)9, para. 7]

1. The Development Assistance Committee (DAC) is the principal forum through which bilateral donors deal with issues related to the volume and effectiveness of development cooperation. It aims to impact donor policies and practices in ways that promote aid effectiveness, capacity development, and inclusive globalisation, in order to support poverty reduction and sustainable development in developing countries.

2. Subsidiary Bodies of the DAC will function as communities of practice and sources of expertise that promote collective learning and produce deliverables in accordance with the DAC mandate. The deliverables of Subsidiary Bodies are to be based on the Programme of Work and Budget (PWB) and on additional guidance from the DAC, as communicated by its Chair. They could include leading edge thinking, policy recommendations, good practices, and tools, which are to be relevant, practical, timely, and user-friendly. These deliverables should be accompanied by communication and dissemination strategies designed to ensure impact on behaviour change. 
Subsidiary Bodies will also promote synergies among other Subsidiary Bodies in contributing to the DAC's PWB.

3. The operations of Subsidiary Bodies, as part of the Organisation for Economic Cooperation and Development (OECD), will be in line with the rules, regulations, and guidance of the Organisation. Together with the Secretariat, they will carry out horizontal work with other parts of the OECD where appropriate to particularly contribute to policy coherence for development. Furthermore, Subsidiary Bodies will develop substantive interactions with international organisations and non-DAC donors -including in support of the Organisation's efforts toward enlargement and enhanced engagement- as well as reach out on a case by case basis to partner countries and other relevant actors.

\section{Extract from document [DCD/DAC(2008)39/REV1]}

\section{"I. Network on Conflict and Fragility}

\section{A. Individualised Mandate}

\section{a) Overall Objectives and Comparative Advantage}

1. The objective of the DAC Network on Conflict and Fragility is to facilitate the improvement of development co-operation and coherent international action in situations where the Millennium Development Goals are undermined, or may in future be undermined, by the threats of violent conflict, human insecurity, fragility, weak governance and instability. The Network's comparative advantage is as a unique donor forum to address collective action problems arising from conflict and fragility. Through lesson learning and promoting best practice among its members, the Network will work to achieve policy commitments and behaviour change among international actors in headquarters and at the field level to address these threats in order to provide the foundations for growth and poverty reduction. Tracking progress and measuring results will be an important ongoing area of work.

\section{b) Areas of Focus and Types of Deliverables}

2. The Network will be organised around three complementary pillars: (i) state building, conflict prevention and peace building; (ii) security and development, including supporting the DAC in considering security related aspects of ODA eligibility; and (iii) aid and development effectiveness in situations of conflict and fragility, including improved methodologies for monitoring and measuring results. The deliverables of the Network will build on existing principles and guidelines developed by the FSG and CPDC including the Principles for Good International Engagement in Fragile States and Situations and the Preventing Violent Conflict guidelines. The Network will aim to build wholeof-government ownership for deliverables by involving actors from a range of agencies in discussions. The Network will ensure that the DAC's overarching priority concern with capacity development is addressed, for example institutional development work as part of state building and peace building.

c) Modalities, including Members, Observers, Outreach and Stakeholders

3. Ways of working will be characterised by a comprehensive approach to examine and improve international practice, including organisational issues such as staffing and the speed with which international actors respond to situations of fragility and conflict, policy frameworks, resource allocations and the development of international instruments and tools.

4. The core of the Network's membership will be staff working on conflict and fragility in donor agencies. To maximise coherent international action in situations of conflict and fragility, a whole-of-government approach will be built into delivering the work of the Network, with engagement and outreach with other policy communities, for example security and diplomatic communities, where appropriate. Reflecting growing collaboration with partner countries, the Network will engage with partner countries in the development of its outputs on a case by case 
basis. The Network will reach out to non-DAC and non-OECD donors in order to bring together the full international effort aimed at addressing situations of conflict and fragility.

d) Synergies with other DAC Subsidiary Bodies

5. The Network will maintain strong links with all other DAC Networks and selectively with other OECD bodies." 

PUBLIC GOVERNANCE AND TERRITORIAL DEVELOPMENT 



\section{PUBLIC GOVERNANCE COMMITTEE (PGC)}

Chair:

Vice-Chairs:

Members:

Observers:

Date of creation:

Duration:
Ms. Roberta Santi

Ms. Katju Holkeri

Mr. Bernard Blanc

Mr. Andreas Wegend

Ms. Vassiliki Moustakatou

Mr. Koos Roest

Mrs. Ilgin Atalay

Open to all Member countries

Chile

Slovenia

Brazil

Egypt

Ukraine
(Canada)

(Finland)

(France)

(Germany)

(Greece)

(Netherlands)

(Turkey)

30th September 1961

31st December 2009

Mandate: - Resolution of the Council concerning the Mandate of the Public Management Committee [C(99)175/FINAL] approved at its 964th session held on 9 December 1999

- Change of name from "Public Management Committee" to "Public Governance Committee" approved by Council at its 1075th session held on 15th January 2004 [C/M(2004)1, item 13 and C(2003)206]

- Resolution of the Council renewing the terms of reference of the Public Governance Committee approved at its 1092nd session held on 26 July 2004 [C(2004)116 \& CORR1 and C/M(2004)18, item 235]

\section{Resolution of the Council [C(2004)116 and CORR1 and C/M(2004)18, Item 235]}

"THE COUNCIL,

Having regard to Articles 1 and 2 of the Convention on the Organisation for Economic Co-operation and Development of 14th December 1960;

Having regard to the Resolution of the Council amending the name and the Mandate of the Technical Co-operation Committee of 23rd June 1989 [C(89)92(Final)], the mandate renewal resolutions of 23rd June 1994 [C(94)125/Final] and 9th December 1999 [C(99)175/Final], and the Resolution of the Council amending the name of the Public Management Committee of 15 January 2004 [C/M(2004)1];

Having regard to the Rules of Procedure of the Organisation and in particular to paragraph 4 of the Annex thereto;

Recognizing that globalisation and societal change are strengthening the need for improved governance at supranational, national and sub-national level;

Recognizing the importance of good public governance as an essential element in strengthening pluralistic democracy, promoting sustainable development and in maintaining confidence in public administration; 
Recognizing the importance of good public management in ensuring policy effectiveness, economic efficiency and sound fiscal balances, and in maximizing the quality of and programme results achieved with regard to government expenditure;

Recognizing that public governance reforms are and must be specific to the public sector as well as context-dependent and country-specific, dealing with different situations but aiming at the same long-term goals;

Recognizing the interest of non-member countries in sharing OECD values and experience in enhancing public governance;

Considering the central role of public governance as both an agent for achieving structural adjustment and international competitiveness, as well as a subject for reform itself;

Considering the statement of the Public Governance Committee on the PGC Mandate which sets out how PGC will contribute to the economic and social policy objectives of Member countries;

\section{DECIDES:}

1. The Public Governance Committee is responsible for designing and implementing a concentrated programme:

i) to identify and help address the strategic challenges that governments face in modernising public governance in a changing world, particularly by strengthening trust in public institutions and the capacity to adapt to the new challenges;

ii) to assist members and non-members in achieving more coherent and effective policies, and in raising the integrity, quality and performance of their public institutions and services;

iii) to promote key elements of a good governance framework, and thus contribute to the improvement of the effectiveness, efficiency, transparency, responsiveness and accountability of public institutions.

2. In carrying out its responsibilities, the Committee shall:

i) provide a forum for exchanges of experience among civil servants engaged in designing and implementing policies for modernising public governance and management;

ii) follow, assess and report on key developments and results in modernising public governance and public management in member and, as appropriate, non-member countries;

iii) develop a range of tools and frameworks to enable comparative evidence-based analysis of public management issues from a governance perspective.

iv) share results of its work with interested non-member countries and other relevant international organizations and institutions;

v) contribute to the Organisation's activities for technical assistance and other forms of support to the improvement of public governance and management in nonmember countries.

vi) contribute a public governance and public management perspective on major policy concerns addressed by the Organisation, including its horizontal activities;

vii) maintain close working relationships with other relevant bodies of the Organisation and other international institutions.

3. These terms of reference shall remain in force until 31st December 2009, unless the Council decides otherwise. The Committee will review progress in achieving the goals of the mandate at the mid-point of the mandate. 
4. The Resolution of 14 January 2000 concerning the renewal of the mandate of the Public Management Committee [C(99)175/FINAL] is hereby repealed.

5. Paragraph 4 of the Annex of the Rules of Procedure shall be amended to read as follows:

4. 'Public Governance Committee: its terms of reference are defined in the Resolution of the Council C(2004)116 and C(2004)116/CORR1."' 


\section{GLOBAL FORUM ON PUBLIC GOVERNANCE $^{1}$}

Chair:

Date of creation:

Duration:

Approved by:
No formally-appointed Chair

1st January 2009

31st December 2009

Public Governance Committee, 23 October 2008

[GOV/PGC/M(2008)2]

\section{Mission Statement:}

The OECD Global Forum on Public Governance aims to contribute to the PGC's Programme of Work outputs by fostering dialogue and network development within the thematic framework of its mandate, through a venue where member and non-member economies, and other stakeholders can:

- Identify and address the strategic challenges faced in modernising public governance, particularly when aiming to strengthen trust in public institutions and their capacity to adapt to new challenges;

- Generate dialogue and enhanced learning in order to achieve more coherent and effective policies, and to raise the integrity, quality and performance of public institutions and services;

- Discuss and promote key elements of a good governance framework, thereby contributing to the effectiveness, efficiency, transparency, responsiveness and accountability of public institutions.

The Global Forum on Public Governance would contribute to build consensus on such proposed cross-cutting public governance themes such as innovative policies for designing and delivering public services, citizen engagement and participation in the policy process and the governance of reforms, cutting red tape, integrity/anti-corruption, budget transparency, human resource management, etc.

Members:

Designated Participants:
Open to all Member countries

Regular PGC observers: Brazil, Chile, Egypt, Slovenia, Ukraine; Accession countries other than observers: Estonia, Israel, Russia

Enhanced Engagement partners other than observers : China, India, Indonesia, South Africa

South East Asian countries: Malaysia, Thailand, Singapore, Vietnam

Participants in the OECD MENA Initiative: Algeria, Bahrain, Dubai UAE, Egypt, Iraq, Jordan, Lebanon, Libya, Morocco, Palestinian National Authority, Syria, Tunisia, United Arab Emirates, Yemen

\footnotetext{
1 Information on this Global Forum is provided for the sake of completeness, but Global Forums are not, in accordance with C(2008)208/FINAL, official OECD bodies.
} 


\section{WORKING PARTY ON REGULATORY MANAGEMENT AND REFORM (REG)}

Chair:

Bureau Members:

Observers:

Date of creation:

Duration:
Mr. Jeroen Nijland

Mr. George Redling

Mr. Luigi Carbone

Mr. Hong-Keun Gil

Mr. Alexander Hunt
(Netherlands)

(Canada)

(Italy)

(Korea)

(United States)

Open to all Member countries
Brazil
Chile
Egypt
Slovenia
Ukraine

March 1991

31st December 2009

Mandate: "The Working Party, unique in the OECD in bringing together policy officials responsible for cross-cutting and horizontal regulatory reform policies, works to build policy support and skills for good regulations in Member countries, emphasizing regulatory quality - combining both good regulation where needed to protect health, safety, and the environment and to enhance the functioning of markets, and deregulation where free markets work better." 


\section{WORKING PARTY OF SENIOR BUDGET OFFICIALS (SBO)}

Chair:

Members:

Observers:

Ad hoc Observers:

Date of creation:

Duration:
Mr. Ian Watt

Open to all Member countries

\author{
Brazil \\ Chile \\ Israel \\ Slovenia \\ Ukraine
}

(Australia)

International Monetary Fund (IMF)

World Bank

1980

31st December 2009

\section{Mandate:}

\section{WORKING PARTY OF SENIOR BUDGET OFFICIALS}

"1. The Working Party of Senior Budget Officials (SBO) aims to improve the effectiveness and efficiency of resource allocation and management in the public sector.

2. The Working Party addresses the entire budget cycle, including budget formulation, budget approval (role of the legislature), budget implementation (management, organisational structure), and audit.

3. The SBO provides a collaborative forum for policy makers and senior officials to address major budgeting concerns, including information exchange on emerging issues, trends and challenges; as well as identifying and disseminating good practice and developing policy and analytical tools. The SBO establishes separate networks for specific components of the budget cycle ${ }^{1}$.

4. In support of its mission, the SBO carries out analysis and research on the full range of budgeting issues. It conducts "peer review" examinations of the budgeting systems of individual Member countries and analyses individual aspects of the budgeting system across Member countries. The SBO also maintains a comprehensive database of national budgeting practices in Member countries.

5. The Working Party recognises that the institutions for allocating, managing and accounting for public resources are fundamental to good governance, and it therefore co-operates with non-Members in order to share the results of its work, including through the maintenance of regional networks.

6. The duration of the Working Party's mandate is concurrent with that of the Public Governance Committee."

\footnotetext{
${ }^{1}$ At present, there are 4 satellite networks: the Network of Parliamentary Budget Committee Chairpersons, the Network on Financial Management, the Network on Performance and Results, and the Network on Organisational Structures.
} 


\section{NETWORK ON FINANCIAL MANAGEMENT ${ }^{1}$}

Chair: $^{2}$

Members:

Observers:

Ad hoc Observers:

Date of creation:

Duration:
Mr. Ian Mackintosh

Open to all Member countries

Brazil
Chile
Egypt

International Monetary Fund (IMF)

World Bank

2001

31st December 2009
(United Kingdom)

Israel

Slovenia

Ukraine

\section{Mandate:}

\section{NETWORK ON FINANCIAL MANAGEMENT}

\section{TERMS OF REFERENCE}

"1. The Network supports the mandate of the Working Party of Senior Budget Officials "to improve the effectiveness and efficiency of resource allocation and management in the public sector" by assisting Member countries to design and implement financial management and accountability reforms.

2. More specifically, the Network will assist Member countries and Outreach partners in:

- $\quad$ The implementation of accrual-based financial reporting and budgeting systems;

- $\quad$ Fostering convergence in the accrual treatment of specific transactions, and liaison with the appropriate standard-setting bodies in this regard;

- $\quad$ Enhancing the structure and format of government financial statements;

- $\quad$ Establishing incentive-based cash and asset management practices;

- $\quad$ Adopting effective internal and external control and audit practices; and

- Other related activities.

3. The Network provides a forum for senior officials, and conducts research and analysis addressing the above issues in line with the operating methods specified in the Mandate of the Working Party of Senior Budget Officials. The Network shall provide an annual report on its activities to the Working Party.

4. The duration of the Network's mandate is concurrent with that of the Working Party of Senior Budget Officials."

\footnotetext{
1 Previously "Network of Financial Management and Accountability Officials". Chair selected on an ad hoc basis.
} 


\section{NETWORK OF PARLIAMENTARY BUDGET COMMITTEE CHAIRPERSONS}

Chair:

Members:

Observers:

Ad hoc Observers:

Date of creation:

Duration:
The host country acts as the chair of the meeting (revolving annually)

Open to all Member countries

Brazil

Chile

Israel

Slovenia

Ukraine

International Monetary Fund (IMF)

World Bank

2001

31st December 2009

\section{Mandate:}

\section{NETWORK OF PARLIAMENTARY BUDGET COMMITTEE CHAIRPERSONS TERMS OF REFERENCE}

"1. The Network supports the mandate of the Working Party of Senior Budget Officials "to improve the effectiveness and efficiency of resource allocation and management in the public sector" by assisting the legislatures of Member countries to effectively play their role in the budget process.

2. More specifically, the Network will assist the legislatures of Members and Outreach partners in:

- Improving the working methods for scrutinising the government's budget proposals;

- $\quad$ Designing the appropriate rules and restrictions, if any, for amending the government's budget proposal;

- $\quad$ Building capacity in the design of budgeting and management reforms in Member countries;

- Improving the working methods for holding the government to account for budget implementation; and

- $\quad$ Other related activities.

3. The Network provides a forum for parliamentarians and their staff, and conducts research and analysis addressing the above issues in line with the operating methods specified in the Mandate of the Working Party of Senior Budget Officials. The Network shall provide an annual report on its activities to the Working Party.

4. The duration of the Network's mandate is concurrent with that of the Working Party of Senior Budget Officials." 


\section{NETWORK ON PERFORMANCE AND RESULTS}

Chairs:

Members:

Observers:

Date of creation:

Duration:

\section{Mandate}

Revolving chair

Open to all Member countries

$\begin{array}{ll}\text { Chile } & \text { Brazil } \\ \text { Israel } & \text { Egypt } \\ \text { Slovenia } & \text { Ukraine }\end{array}$

1st January 2004

31st December 2009

\section{NETWORK ON PERFORMANCE AND RESULTS}

TERMS OF REFERENCE

"1. The Network supports the mandate of the Working Party of Senior Budget Officials "to improve the effectiveness and efficiency of resource allocation and management in the public sector" by assisting Member countries to design and implement performance- and results-based budgeting and management reforms.

2. More specifically, the Network will assist Member countries and Outreach partners in:

- Establishing mechanisms to ensure the reliability and consistency of performance and results information;

- $\quad$ Developing evaluation policies and processes

- Designing systems for linking performance and results information and the resource allocation process;

- Establishing accountability regimes based on performance and results information; and

- The definition of appropriate performance and results outcomes and/or outputs for the range of government activities;

- The measurement of defined outcomes and/or outputs;

- Other related activities.

3. The Network provides a forum for senior officials and conducts research and analysis addressing the above issues in line with the operating methods specified in the Mandate of the Working Party of Senior Budget Officials. The Network shall provide an annual report on its activities to the Working Party.

4. The duration of the Network's mandate is concurrent with that of the Working Party of Senior Budget Officials." 
Chair:

Head of the Centre of Government of the host country (revolving annually)

Members:

Open to all Member countries

Observers:

Brazil

Chile

Egypt

Slovenia

Ukraine

Date of creation:

1980

Duration:

31st December 2009

\section{Mandate:}

"NETWORK OF SENIOR OFFICIALS FROM CENTRES OF GOVERNMENT

The Network of Senior Officials from Centres of Government aims:

to review issues of making the centre of national government work effectively;

- $\quad$ to understand decision- and policy-making systems;

- to strengthen the relations among peers in order to encourage them to exchange experiences and priorities;

- $\quad$ to work on broad governance issues; and

- $\quad$ to provide the Public Governance Committee with insight and guidance on ongoing activities and future work."

\footnotetext{
${ }^{1}$ Meetings of the network began in the early 1980s and were consolidated into an annual event in the 1990s.
} 


\section{PUBLIC EMPLOYMENT AND MANAGEMENT WORKING PARTY (PEMWP) ${ }^{1}$}

Chair:

Members:

Observers:

Date of creation:

Duration:

Mandate:

\section{"PUBLIC EMPLOYMENT AND MANAGEMENT WORKING PARTY}

1. The Public Employment and Management Working Party aims to improve public sector governance in Member countries by addressing human resources-related public management.

2. The Working Party addresses the entire field of human resources in Government focusing specifically on issues such as leadership and the management of senior civil servants, civil service ethics, employment policies retention, performance management and knowledge management.

3. The Working Party provides a collaborative forum for senior officials of central government bodies in charge of general government management or more human resourcesfocused bodies to address major HRM-related concerns, such as future shortage skills, the competitiveness of the public employer, the improvement of performance, the need for more citizenfocused public services, or finding a well balanced system of pay and employment.

4. It includes information exchange on emerging issues, trends and challenges, identifies and disseminates best practices, as well as develops policy and analytical tools. The Working Party establishes separate networks for specific components of human resources. Active networks include networks on performance-related pay, the management of senior civil servants, and knowledge management.

5. In support of its mission, the Working Party carries out analysis and research on the full range of HRM issues and maintains a comprehensive database on public sector pay and employment and on human resources management."

\footnotetext{
1 Formerly know as Human Resources Management Working Party. Change of name approved by the Public Governance Committee on 7 April 2006.
} 


\title{
EXPERT GROUP ON CONFLICT OF INTEREST: ENSURING ACCOUNTABILITY AND TRANSPARENCY IN THE PUBLIC SERVICE
}

Chair:

Members:

Observers:

Ad hoc Observers:

Date of creation:

Duration:
Ms. Catherine MacQuarrie

(Canada)

\section{Brazil \\ Chile \\ Egypt \\ Slovenia \\ Ukraine}

\author{
Asian Development Bank (ADB) \\ Inter-American Development Bank (IDB) \\ Organization of American States (OAS) \\ World Bank
}

2002

31st December 2009

\section{Mandate:}

\author{
EXPERT GROUP ON CONFLICT OF INTEREST: \\ ENSURING ACCOUNTABILITY AND TRANSPARENCY \\ IN THE PUBLIC SERVICE \\ TERMS OF REFERENCE
}

"1. The Expert Group aims to improve governance arrangements for promoting integrity in the public service. This ad hoc Expert Group provides input and guidance to the Secretariat in implementing the output on promoting integrity and preventing corruption in the Public Governance Committee's bi-annual programme of work on Governance and Management of Public Institutions and Resources. In addition, the Expert Group provides a unique forum for:

- $\quad$ exchanging first-hand experiences on emerging issues and best practices;

- $\quad$ reviewing trends and developing best practice guidelines;

- $\quad$ disseminating lessons and supporting the dialogue with non-member countries.

2. The Expert Group reviews issues related to conflicts of interest in the public service and identified vulnerable areas in the public-private sector interface, including public procurement, postemployment, lobbying.

3. The Expert Group prepares a report on the implementation of the 2003 OECD Recommendation on Managing Conflict of Interest in the Public Service to be presented to the Council." 


\section{NETWORK OF SENIOR E-GOVERNMENT OFFICIALS (EGOV)}

Chair:

Members:

Observers:

Date of creation:

Duration:

Mandate:

\section{NETWORK OF E-GOVERNMENT OFFICIALS \\ TERMS OF REFERENCE}

"1. The Network of Senior E-Government Officials aims to improve the effectiveness and efficiency of e-government initiatives in the public sector.

2. The Network also seeks to ensure that e-government is better integrated into the broader public management agenda.

3.

The OECD provides a collaborative forum for policy-makers and senior officials to address major e-government concerns, including identification of and information exchange on emerging issues, trends and challenges, as well as identifying and disseminating good practices and developing policy and analytical tools.

4. In support of its mission, the Network of Senior E-Government Officials carries out analysis and research on the full range of e-government issues. It conducts "peer review" examinations of national e-government initiatives and analyses individual aspects of e-government across member countries. The network also maintains a database of national e-government practices in member countries.

5. The Network recognizes ICT use as a contributing element to good governance and cooperates with non-member countries in order to share the results of its work." 



\section{GROUP ON REGULATORY POLICY (GRP)}

Chairs:

Members:

Date of creation:

Duration:
Chairs from participating committees

Open to all Member countries

1996

31st December 2010

Mandate : $\quad$ Resolution of the Council adopted at its 1121st session held on 14 October 2005 [C(2005)122 and C/M(2005)20]

\section{Resolution of the Council [C(2005)122 and C/M(2005)20]}

\section{"THE COUNCIL,}

Having regard to the Convention on the Organisation for Economic Co-operation and Development of 14th December 1960, and in particular articles 1 and 2;

Having regard to the Rules of Procedure of the Organisation;

Having regard to the Resolution of Council establishing an OECD Special Group on Regulatory Policy of 8th November 2002 [C(2002)189/REV2];

Recognising the need for regulatory reform in a global environment with increased international competition, market openness and greater attention to the rule of law;

Acknowledging the importance of regulatory reform as a dynamic, long-term multidisciplinary process for sustainable economic growth;

Recognising the importance of a whole-of-government approach to create a regulatory environment favourable to the creation and growth of firms, productivity gains, competition, investment and international trade, and promoting good governance principles;

Recognising that the 2005 OECD Guiding Principles for Regulatory Quality and Performance provide a sound basis for further assessment of Member countries' regulatory frameworks from a multi-disciplinary perspective, including capacities for high quality regulation, competition policy, market openness and specific sectoral approaches;

Taking account of the high value that non-Member countries attach to OECD work on regulatory reform, enhancing the mutual sharing of values, experiences and best practice, including the collaborative work undertaken under the APEC-OECD Co-operative Initiative on Regulatory Reform;

\section{DECIDES:}

1. The Group on Regulatory Policy is to function as a platform for high level, multidisciplinary policy dialogue on regulatory reform at the OECD, drawing on the expertise of the Public Governance, Trade and Competition Committees and of their subsidiary bodies. Its role will be:

i) to identify and help address the strategic challenges that governments face in designing and implementing regulatory reform;

ii) to provide a framework for concluding country peer reviews on regulatory reform and of the monitoring exercises conducted in expert committees; 
iii) to facilitate a thematic exchange of experience regarding regulatory policies among Member countries;

iv) to facilitate a policy dialogue with non-Member countries on regulatory policy and reform.

2. In carrying out its responsibilities, the Group on Regulatory Policy shall:

i) be open to all Member countries. Its Chair will be assured on a rotating basis by representatives of the bureaux of the Trade, Competition and Public Governance Committees or their respective subsidiary bodies.

ii) ensure close working relationships with the participating Committees and with other relevant bodies of the Organisation;

iii) share results, when appropriate, with interested non-Members and other relevant international organizations and institutions, including APEC.

3. These terms of reference shall remain in force until 31 December 2010, unless the Council decides otherwise." 
Chair:

Vice-Chairs ${ }^{1}$ :
Mr. Mark Drabenstott

Mr. Wolf-Dietrich Huber

Mr. Paul Leblanc

Mrs. Odile Bovar

Mr. Prodromos-Ioannis (John)

Prodromidis

Mrs. Flavia Terribile

Mr. Takeshi Abe

Mrs. Sara Topelson

Open to all Member countries

Observers:

Date of creation:

Duration:

Members:
(United States)

(Austria)

(Canada)

(France)

(Greece)

(Italy)

(Japan)

(Mexico)

Mandate: - The TDPC was created by the Resolution [C(98)198/FINAL] adopted by the Council on 20th January 1999 under the written procedure [C/M(99)1]

- Resolution of the Council concerning the Renewal of the Mandate of the Territorial Development Policy Committee set out in annex I to document [C(2004)114] adopted by the Council on 8th July 2004 at its 1091st session [C(2004)114/CORR1 and $\mathrm{C} / \mathrm{M}(2004) 17$, item 216]

\section{Resolution of the Council [C(2004)114 \& CORR1 and C/M(2004)17, item 216]}

\section{"THE COUNCIL,}

Having regard to Articles 5 a) and 9 of the Convention on the Organisation for Economic Co-operation and Development;

Having regard to the Resolution of the Council concerning the Creation of a Territorial Development Policy Committee [C(98)198/FINAL];

Having regard to the report "The OECD Committee Structure - A review" [CE(98)3];

Having regard to the Resolution of the Council concerning the Renewal of the Mandate of the Territorial Development Policy Committee [C/M(2001)26, item 426 and C(2001)257/REV1];

Having regard to the emerging synergies with the work in the newly created directorate on Public Governance and Territorial Development;

Having regard to the Rules of Procedure;

Having regard to the mission statement agreed on by the Territorial Development Policy Committee for its future work:

\footnotetext{
${ }^{1}$ One seat currently vacant until the election of the Bureau Members in December 2009.
} 
- The mission of the TDPC is to improve policy performance in enhancing well-being and living standards across all OECD regions by influencing the main factors that generate and sustain regional competitive advantage and by promoting effective and innovative governance. TDPC should serve as a premier international forum for senior-level government policy makers to identify, discuss, and disseminate a vision of development policy that is place-based, multi-level, innovative and geared to different types of regions. This policy approach focuses on economic growth while integrating environmental and social concerns, which are necessary to enhancing regional competitive advantage.

- To accomplish its mission, and to permit an evaluation of the overall policy impact of this approach, the Committee will develop high-quality and relevant statistical indicators, will compare economic development issues and policies across countries, and will assess multi-level governance mechanisms.

Having regard to the conclusions of the High Level Meeting on Territorial Policy held in Switzerland in June 2003;

Considering that the conclusions of the High-Level Meeting underlined the role of regional policies in OECD countries in promoting long-term, sustained economic growth, regional competitiveness through private and public investment, entrepreneurship and greater reliance on local assets;

Considering that, as a consequence of the above trends, central governments are increasingly called upon to stimulate and foster regional strategies that are more likely to be effective, and to enhance the capacities of local communities to participate in their own development;

Considering that in responding to these challenges, OECD countries can obtain great benefits from international co-operation both to develop new policy frameworks and share the results of experiments and innovations; and

Recognising the consensus of the TDPC to transform the Committee into the premier international forum for discussion of these issues;

Recognising and linking the important contribution of the Working Parties on Policies in Rural and Urban Areas, and on Statistics and Indicators; and

Recognising the importance the Committee attaches to contributing to the evaluation process in the OECD.

On the proposal of the Secretary-General after consultation with the Committee on Territorial Development Policy, the Council:

\section{DECIDES:}

1. The terms of reference of the Territorial Development Policy Committee are to:

a) implement the general principles contained in the agreed mission statement, specifically to enhance regional competitive advantage, based on a progressive policy shift from subsidy-based sectoral policies that thwart business innovation to integrated place-based policies which address the specific causes that prevent each region from realising its full potential;

b) provide a forum for member countries to share views on regional development policy implementation in the OECD area and to improve the understanding of economic, social, environmental and institutional trends;

c) contribute a regional perspective on major policy concerns and priorities of the Organisation, including its horizontal activities;

d) undertake policy analysis of competitiveness strategies, with a view to promoting regional advantages and unused potentials for growth, as well as enhancing 
cohesion and integrating economic, social and environmental concerns, as captured by the concept of sustainable development;

e) analyse and promote innovative policies at the territorial level that will enable member countries, through shared efforts and an exchange of experience, to further improve their governance, with particular reference to horizontal and vertical institutional partnerships;

f) develop a range of comparable data, indicators and other statistical tools to support policy analysis;

g) strengthen the contribution of the three Working Parties to the Territorial Development Policy Committee by further developing their work on specific priority aspects of regional development;

h) make available the outcome of its work to interested non-member countries.

2. In pursuit of these objectives, the Territorial Development Policy Committee, and its Working Parties, shall maintain close working relationships with other relevant bodies of the Organisation, in particular the Public Governance Committee and its subsidiary bodies, seeking to ensure complementarity and co-operation between levels of government.

3. The Territorial Development Policy Committee shall maintain, as appropriate, and in conformity with the OECD Convention and Rules of Procedure, relations with other international organisations.

4. The terms of reference of the Territorial Development Policy Committee shall enter into force on 1 January 2005 and shall expire on 31 December 2009, unless the Council decides otherwise.

5. Paragraph 29 of the Annex to the Rules of Procedure of the Organisation shall be amended as follows: Territorial Development Policy Committee: its terms of reference are defined in the Resolution of the Council C(2004)114 and C(2004)114/CORR1." 


\section{WORKING PARTY ON TERRITORIAL POLICY IN URBAN AREAS}

Chair:

Vice-Chairs:

Members:

Observers:

Date of creation:

Duration:
Mr. Adam Ostry

(Canada)

Mr. Dennis Alvord

Mr. Marco Magrassi

Mr. Vincent Fouchier

Ms. Brigitte Helff

Mr. Takeshi Abe

Mrs. Sara Topelson

Mrs. Willy Bruinsma

Open to all Member countries

Chile

Morocco

South Africa

20th January 1999

31st December 2009
(France)

(Germany)

(Japan)

(Mexico)

(Netherlands)

Mandate: - Decision of the Territorial Development Policy Committee [DT/TDPC(99)23]

Renewal of the Working Party's Mandate by the Territorial Development Policy

- Committee during its 6th Session on 22, 23 January 2002 [DT/TDPC/M(2002)1]

\section{Working Party on Territorial Policy in Urban Areas [DT/TDPC(99)23]}

"The Territorial Development Policy Committee,

Having regard to Articles 1, 2, 5a) and 12 of the Convention on the Organisation for Economic Co-operation and Development of 14th December 1960;

Having regard to the resolution of the Council creating the Territorial Development Policy Committee and granting it the responsibility to "make ... special arrangements, including the establishment of Working Parties, as may be necessary to capitalise on and further develop work on specific, priority aspects of territorial development, such as urban affairs, ..." [C(98)198/FIN];

Having regard to the Rules of Procedure of the Organisation;

Taking account of the importance of urban issues in territorial development policies;

Noting that since 1979, the OECD programme of work on urban affairs has provided analysis and policy guidance on issues of pressing concern to Member countries such as distressed urban areas, urban governance, urban environmental policy and urban economic development;

Recognising that policies to improve the quality of life, social cohesion, and economic opportunities in cities are an important element in national strategies for territorial development, that the benefits and costs associated with urban growth often have regional and even national consequences, and that urban policy is an effective means of achieving the integration of economic, social and environmental issues;

Taking account that better urban policies are a response to the medium-term objective of the Secretary-General, to advise "Member governments on ways to maximise the benefits of economic development, whether local, national or global, and at the same time, to ensure that economic growth is consistent with sustainability as a global objective; 
Noting that new challenges for cities are emerging in relation to economic activity and investment, social change, public finance and services, environmental conditions and technological innovation for which existing policies may be inadequate, and that institutional changes are often needed to enhance the capacity of urban governments, in partnership with civil society and the private sector, to respond more effectively to urban problems;

Observing that there is a growing trend for countries to consult with each other on urban trends and on policies at the national, regional and local level to guide urban development; that Member countries are working toward similar objectives for urban policy; and that successful urban policies in Member countries may be an example elsewhere in the world, where urbanisation remains a potent force for change and development;

And in light of the priorities of the TDPC for national and regional reviews, which may focus on urban policy and urban regions, and for horizontal studies of territorial policy and prospects, which can benefit from analyses with an urban dimension;

\section{DECIDES:}

1.

The Working Party on Territorial Policy in Urban Areas shall report to the TDPC concerning:

a) The nature, scale and complexity of economic, social and environmental challenges which urban regions in OECD countries are facing, and potential sources of longterm development;

b) Ways to improve the monitoring of changes and trends in urban areas, and to achieve the sustainable development of urban regions in OECD countries through a cross-sectoral, integrating approach;

c) The interaction between urban municipalities and other levels of government, and between cities and other sub-national, territorial units, stressing in particular urban/rural links.

d) The results of national and regional territorial reviews with a focus on urban regions, in particular by using internationally comparable indicators, identifying best practices among Member countries and suggesting the means to co-ordinate sectoral and territorial approaches in these regions.

2. The Working Party shall initially concentrate on a study of better management of urban growth, including follow-up on earlier work on regeneration of urban brownfields and on urban housing, and new work on urban sprawl and infrastructure, with a focus on coherent policies and effective policy instruments for landuse and spatial planning. The Working Party shall also contribute to prospective studies with a focus on the policy implications of trends that could affect the competitiveness and sustainability of cities in the medium term. Issues of governance are to be integrated to these topics.

3.

In the pursuit of these objectives, the Working Party on Territorial Policy in Urban Areas shall work with the Territorial Development Policy Committee (TDPC), the other TDPC working parties and other competent bodies in the Organisation. This will permit OECD to harness all its capabilities for the comprehensive study of priority urban development issues and to ensure that the Organisation's overall work programme on territorial development proceeds in a coordinated manner.

4. The Working Party shall maintain, as appropriate, and in conformity with the OECD Convention and Rules of Procedure, relations with other international organisations and shall carry out its tasks taking fully into account the work of these organisations.

5. The duration of the Working Party's mandate is concurrent with that of the Territorial Development Policy Committee." 


\section{WORKING PARTY ON TERRITORIAL POLICY IN RURAL AREAS}

Chair:

Vice-Chairs:

Members:

Observers:

Date of creation:

Duration:
Mr. Richard Wakeford

Mr. Theo Augustin

Ms. Sabrina Lucatelli

Mr. Yukiya Saika

Mr. Germán Palafox

Mrs. Jolinda van der Endt

Mr. Allan Johnson
(United Kingdom)

(Germany)

(Italy)

(Japan)

(Mexico)

(Netherlands)

(United States)

Open to all Member countries

Chile

Morocco

South Africa

20th January 1999

31st December 2009

Mandate: Decision of the Territorial Development Policy Committee [DT/TDPC(99)22]

Renewal of the Working Party's Mandate by the Territorial Development Policy

Committee during its 6th Session on 22, 23 January 2002 [DT/TDPC/M(2002)1]

\section{The Working Party on Territorial Policy in Rural Areas [DT/TDPC(99)22]}

"The Territorial Development Policy Committee,

Having regard to Articles 1, 2, 5a) and 12 of the Convention on the Organisation for Economic Co-operation and Development of 14 December 1960;

Having regard to the resolution of the Council creating the Territorial Development Policy Committee and granting it the responsibility to "Make such special arrangements, including the establishment of Working Parties, as may be necessary to capitalise on and further develop work on specific, priority aspects of territorial development, such as ... rural development, ..." [C(98)198/FINAL];

Having regard to the Rules of Procedure of the Organisation;

Taking account of the importance of rural issues in territorial development policies;

Noting that since 1991, the OECD Rural Development Programme has provided analysis and policy guidance on important issues such as rural amenities, partnerships for rural development, employment creation and services in rural areas, rural governance and the generation of appropriate data and internationally comparable statistics;

Recognising that dynamic rural development policies improve national and rural well-being by facilitating structural reform in the various sectors and by diversifying the economic base of rural areas and that rural policies are an effective means of achieving integrated solutions to economic, social and environmental problems, e.g., through appropriate valorisation of resources in rural areas and promotion of their recreational, ecological and cultural heritage;

Noting that new challenges for rural areas are emerging in relation to agriculture restructuring, development of services and new activities, social change, environmental conditions and technological innovations for which existing policies may be inadequate and that institutional 
changes are often needed to facilitate co-ordination between several ministries at the national level, as well as the participation of both local and regional authorities and the private sector;

Observing that there is a growing trend for countries to consult with each other on rural trends and on policies at national, regional and local level to guide rural development and that the OECD Member countries will greatly benefit from analysis of rural conditions and changes in the economic and social structure of rural areas, carried out in a multinational framework and based on comparable information, both quantitative and qualitative;

Recognising that the activities carried out within this framework are horizontal in nature and involve close co-operation with different committees within the Organisation;

And in light of the priorities of the TDPC for national and regional reviews, which may focus on rural policy and rural regions, and for horizontal studies of territorial policies and prospects, which can benefit from analyses with a rural dimension;

\section{DECIDES:}

1.

The Working Party on Territorial Policy in Rural Areas shall report to the TDPC concerning:

a) The nature, scale and complexity of economic, social and environmental challenges which rural regions in OECD countries are facing, and potential sources of long term development;

b) Ways to improve the monitoring of changes and trends in rural regions and to achieve the sustainable development of rural regions through a cross-sectoral, integrated approach;

c) Selected aspects of rural developments such as rural amenities, multisectoral initiatives, new forms of partnerships and governance and the interrelation of urban and rural development;

d) The results of national and regional territorial reviews with a focus on rural regions, in particular by using internationally comparable indicators, identifying best practices among Member countries and suggesting the means to co-ordinate sectoral and territorial approaches in these areas;

2. The Working Party on Territorial Policy in Rural Areas shall concentrate on growth factors in rural regions, how rural areas contribute to the growth of the economy as a whole and on policy recommendations on the basis of reviews of several rural regions. The impact of information technologies on rural development will also be reviewed. Follow-up of the work on rural amenities will include the preparation of a conference on valuation/evaluation of methods for pricing such amenities. The Working Party shall also contribute to prospective studies with a focus on the policy implications of trends that could affect the competitiveness and sustainability of rural regions in the medium term.

3.

In the pursuit of these objectives, the Working Party on Territorial Policy in Rural Areas shall work with the Territorial Development Policy Committee (TDPC), the other TDPC working parties and other competent bodies in the Organisation. This will permit OECD to harness all its capabilities for the comprehensive study of priority rural development issues and to ensure that the Organisation's overall work programme on territorial development proceeds in a co-ordinated manner.

4.

The Working Party on Territorial Policy in Rural Areas shall maintain, as appropriate and in conformity with the OECD Conventions and Rules of Procedure, relations with other international organisations and shall carry out its task with all due regard to the work of these organisations.

5. The duration of the Working Party's mandate is concurrent with that of the Territorial Development Policy Committee." 


\section{WORKING PARTY ON TERRITORIAL INDICATORS}

Chair:

Vice-Chairs:

Members:

Observers:

Date of creation:

Duration:
Mr. Dev Virdee

Mr. Giovanni Barbieri

Mr. Ray Bollman

Mr. William Kittredge

Ms. Antonia Milbert

Mr. Bernard Morel

Mr. Prodromos-Ioannis (John)

Prodromidis

Open to all Member countries

Chile

Morocco

South Africa

20th January 1999

31st December 2009
(United Kingdom)

(Italy)

(Canada)

(Germany)

(France)

(Greece)

Mandate: - Decision of the Territorial Development Policy Committee [DT/TDPC(99)24]

- Renewal of the Working Party's Mandate by the Territorial Development Policy Committee during its 6th Session on 22, 23 January 2002 [DT/TDPC/M(2002)1]

The Working Party on Territorial Indicators [DT/TDPC(99)24]

"The Territorial Development Policy Committee,

Having regard to Articles 1, 2, 5a) and 12 of the Convention on the Organisation for Economic Co-operation and Development of 14 December 1960;

Having regard to the resolution of the Council creating the Territorial Development Policy Committee and granting it the responsibility to "make ... special arrangements, including the establishment of Working Parties, as may be necessary to capitalise on and further develop work on specific, priority aspects of territorial development, such as ...territorial indicators and data bases;" [C(98)198/FINAL];

Having regard to the Rules of Procedure of the Organisation;

Considering that quantitative information on territorial differences across OECD Member countries is indispensable for facilitating international communication, comparison and co-operation with respect to sustainable development conditions and trends;

Emphasising that territorial statistics and indicators can help to better understand national and sub-national patterns and dynamics of structural change and adjustment in economic competitiveness and innovation, in social cohesion and convergence, in environmental quality and amenity;

Emphasising the contribution of territorial statistics and indicators to integrative, cross-sectoral policies that balance economic, social and environmental concerns and have the potential to reduce disparities; 
Recognising that sub-national territorial statistics and indicators can improve OECD's analytical capacities in general, facilitate analyses on territorial development problems, perspectives and policies in particular and aid in the development and application of indicators to target and evaluate policies;

\section{DECIDES:}

1. The Working Party on Territorial Indicators shall report to the TDPC on the following

tasks:

a) Establishing a statistical information base using existing information where possible and providing quantitative information on sub-national development conditions and trends that can be interpreted in a multi-national context, supporting, in particular, the analytical work of the Territorial Development Policy Committee (TDPC) and its working parties;

b) Developing a suitable territorial data base covering relevant demographic economic, social, institutional and environmental topics, as well as developing and refining methods of territorial data collection, processing and presentation;

c) Selecting and interpreting sets of territorial indicators, both basic, multi-purpose, revealing the diversity and disparities of territorial development in general as well as specific policy related indicators, for different types of territory, such as rural and urban areas, leading or lagging regions, etc.;

d) Contributing to the indicator work of other OECD directorates, task forces and international organisations as well as national, regional and local initiatives in OECD Member countries and abroad by offering conceptual frameworks, or by providing territorial data and indicators for spatially dis-aggregated quantitative analyses.

2. In the pursuit of these objectives, the Working Party on Territorial Indicators shall work with the Territorial Development Policy Committee (TDPC), the other TDPC working parties and other competent bodies in the Organisation. This will permit OECD to harness all its capabilities for the comprehensive study of key territorial development issues and to ensure that the Organisation's overall work programme on territorial development proceeds in a co-ordinated manner.

3.

The Working Party on Territorial Indicators shall maintain, as needed and in accordance with the OECD Conventions and Rules of Procedure, relations with other international organisations and perform its task with all due regard to the work of these organisations.

4

The duration of the Working Party's mandate is concurrent with that of the Territorial Development Policy Committee." 

TRADE AND AGRICULTURE 

Chair:

Vice-Chairs:

Members:

Observers:

Date of creation:

Duration:
Mr. Fernando de Mateo

Mr. Knut Brünjes

Mr. Kenji Hiramatsu

Ms. Marie-Gabrielle Ineichen

Fleisch

Mr. Matthew Rohde

Open to all Member countries

Chile

Brazil

Argentina

Hong Kong, China

European Free Trade Association (EFTA)

International Monetary Fund (IMF)

World Bank

World Trade Organization (WTO)

30th September 1961

31st December 2013
(Mexico)

(Germany)

(Japan)

(Switzerland)

(United States)

Mandate: Resolution of the Council [C(2008)177] approved at its 1184th session on 13 November 2008 [C/M(2008)20, Item 287]

\section{Resolution of the Council [C(2008)177 and C/M(2008)20, Item 287]}

\section{"THE COUNCIL,}

Having regard to Articles 1 and 2 of the Convention on the Organisation for Economic Co-operation and Development of 14 December 1960;

Having regard to the Ministerial Resolution of 23 July 1960 [OECD(60)9(Final)] and to paragraph 16 of the Report of the Preparatory Committee concerning the creation of a Trade Committee;

Having regard to the Rules of Procedure of the Organisation; Resolution C(2006)6;

Having regard to the mandate of the Trade Committee as set out in Council

Having regard to the Trade Committee Draft Medium-Term Strategy [TAD/TC(2007)2];

Having regard to the recommendations of the In-depth Evaluation of the Trade Committee [C(2008)77 and C(2008)77/CORR1];

[C(2008)177];

Having regard to the proposal to revise the mandate of the Trade Committee 
Considering that international trade is essential for growth and sustainable economic development;

Considering that the mission of the Trade Committee is to provide a forum for international co operation, dialogue and policy analysis in order to help countries benefit fully from trading opportunities and adjust to changing trade patterns, as encompassed in Article 1 of the OECD Convention;

\section{DECIDES:}

1. The Trade Committee shall have the following mandate:

a) Encourage frank and open dialogue among OECD Members and undertake and disseminate rigorous, objective trade policy analysis, in order to:

- increase understanding of evolving trade policy issues, including on controversial subjects;

- $\quad$ build support for liberalised trade within a strengthened multilateral, rulesbased trading system;

- contribute objective information and analysis to advance the on-going and future agenda of the World Trade Organisation (WTO);

- support, as appropriate, multilateral trade negotiations;

- facilitate the promotion of coherence between trade policy and other related domestic and international policies.

b) Support the work on establishing common guiding principles and exchange of information in respect of Members' official export credit systems.

c) Collaborate closely with other relevant bodies of the OECD on cross-cutting issues related to trade.

d) Engage invited non-Members in the analytical work and policy dialogue of the Committee as appropriate.

e) As appropriate, consult and share information with the advisory bodies to the OECD, BIAC and TUAC, as well as civil society organisations and academia.

f) Co-operate with other international organisations, such as the World Bank, the IMF and others as appropriate, on issues of mutual interest.

2. The mandate of the Trade Committee shall remain in force until 31 December 2013, unless the Council decides otherwise." 


\section{GLOBAL FORUM ON TRADE ${ }^{1}$}

Chair:

Date of creation:

Duration:

\section{Approved by:}

\section{Mission Statement:}

The OECD Global Forum on Trade plays an important role in forwarding the Trade Committee's strategic objective to "improve understanding of the benefits and the costs of further trade liberalisation, so as to increase support for an open, rules-based multilateral trading system" ${ }^{\text {2 }}$. The Global Forum on Trade is the only regular venue sponsored by the Trade Committee to engage non-Member economies in support of this strategic objective. It is also an important venue for disseminating analytical work in support of free trade to policy makers in non-Member economies.

Where relevant, the Trade Committee will use the Global Forum on Trade as an opportunity to partner with other OECD Committees to promote trade-related policy dialogue across policy disciplines at the highest levels of government.

The Global Forum on Trade discusses issues that are critical to both Members and non-Members. The topics chosen for each Global Forum on Trade are precisely those global trade-related issues that cannot be solved by OECD Members alone. These topics are closely linked to the Trade Committee's Programme of Work and Budget, and the discussions that take place directly enhance the analytical work of the Trade Committee.

The Global Forum on Trade provides an important venue for forging ties with trade policy makers and other stakeholders in non-Member economies. The systematic nature of these high level interactions allows the OECD to build consensus around core trade issues. This meets an important need, as trade-related meetings held under the auspices of other organisations, such as the WTO, often focus on negotiations, implementation of multilateral agreements and dispute settlement.

The Global Forum on Trade also affords the Secretariat the opportunity to listen and learn, and thus helps the Trade Committee to identify important "next generation" trade issues that may require new analytical work. This allows the Trade Committee to stay "upstream" of emerging trade policy issues.

\section{Members:}

Open to all Member countries International Monetary Fund (IMF)

\section{World Bank \\ World Trade Organization (WTO)}

Designated Participants: Regular observers to the Trade Committee (Argentina, Brazil, Chile, and Hong Kong, China) Accession countries (Estonia, Israel, Russian Federation and Slovenia) and Enhanced Engagement countries(China, India, Indonesia and South Africa).

Other key countries in the multilateral trading system, in particular those from South-East Asia: Thailand, Malaysia and Vietnam.

\footnotetext{
1 Information on this Global Forum is provided for the sake of completeness, but Global Forums are not, in accordance with C(2008)208/FINAL, official OECD bodies.

2 See the Trade Committee's Medium-term Strategy (TAD/TC(2007)2).
} 


\section{WORKING PARTY OF THE TRADE COMMITTEE}

Chair:

Vice-Chairs:

Members:

Observers:

Date of creation:

Duration:
Mr. Robert McDougall

Mr. Graham Andrews

Ms. Meg Hawley-Young

Mr. Philip-Xenophon Pierros

Mr. Wieger Wiersema

Open to all Member countries

Chile

Brazil

Argentina

Hong Kong, China

International Monetary Fund (IMF)

World Bank

February 1962

31st December 2013
(Canada)

(Australia)

(United States)

(European Commission)

(Netherlands)

Mandate: Summary Record of the 150th Session of the Trade Committee held on 5-7 May 2008 [TAD/TC/M(2008)3/PROV]

\section{Extract of document TAD/TC(2008)6/REV1}

"THE TRADE COMMITTEE,

AGREED that its Working Party, shall have the following terms of reference:

a) The Working Party should carry forward the work of the Trade Committee taking as guidance the discussions and conclusions of the Trade Committee;

b) The Working Party should participate in developing and implementing the Committee's Strategy.

c) The Working Party should engage invited non-Members in the analytical work and policy dialogue of the Committee as appropriate;

d) The Working Party may, as appropriate, appoint special groups to deal with particular questions;

e) Should the Working Party consider that there is urgent need to submit a report to the Council and should it not be possible to convene the Trade Committee at short notice, the report shall be issued as a report of the Trade Committee, once the individual members of the Working Party have obtained its approval by the representative of their respective countries in the Trade Committee." 


\section{WORKING PARTY ON EXPORT CREDITS AND CREDIT GUARANTEES}

Chair:

Vice-Chairs:

Bureau Members:

Members:

Observer:

Date of creation:

Duration:
Mrs. Nicole Bollen

Mr. Pekka Karkovirta

Mr. Kohei Okada

Mr. Dirk Terweduwe

Mr. David Drysdale

Australia

Austria

Belgium

Canada

Czech Republic

Denmark

Finland

France

Germany

Greece

Hungary

Ireland

Italy

Japan

Korea
(Netherlands)

(Finland)

(Japan)

(Belgium)

(United States)

Luxembourg

Mexico

Netherlands

New Zealand

Norway

Poland

Portugal

Slovak Republic

Spain

Sweden

Switzerland

Turkey

United Kingdom

United States

Mandate: - Report by the Special Meeting of the Trade Committee on Export Credits and Credit Guarantees [C(63)141, Annex]

- Minutes of the 56th Meeting of the Council on 10th December 1963 [C/M(63)22(Final), Annex, Item 225]

\section{Annex to document [C(63)141]}

\section{ESTABLISHMENT OF A GROUP ON EXPORT CREDITS AND CREDIT GUARANTEES}

\section{Draft terms of reference}

"1. At its meeting on 5th and 6th November 1963, the Trade Committee considered the report of the special meeting on export credits and credit guarantees held on 23rd and 24th October 1963 [TC(63)42] and decided to set up a Group on Export Credits and Credit Guarantees, made up of senior government officials with a major responsibility in the formulation of policies in this field, accompanied by senior officials of the export credit and credit insurance institutions. ${ }^{1}$ The Working Party on Export Credits and Credit Guarantees should be open to Members and invited nonmembers which have in existence facilities for financing or guaranteeing export credits which are controlled or assisted, directly or indirectly, by government or para-governmental bodies;

\footnotetext{
${ }^{1}$ The original composition was set out in paragraph 10 of TC(63)42; it was adjusted at the 150th Trade Committee held inMay 2008 in the light of expanded membership since 1963 and the change of name in 1999 from "Group" to "Working Party".
} 
representatives of the Commission of the European Economic Community may attend the meetings of the Working Party.

2. The Working Party on Export Credits and Credit Guarantees is charged with carrying forward the work of the OECD in this field. In particular, it is responsible for holding regular confrontations on the policies pursued by the Governments of Member countries, in the field of export credits and credit guarantees, with the general objectives of:

- Evaluating these policies;

- $\quad$ Determining the problems which arise;

- Resolving or mitigating these problems by multilateral discussion. confrontations, at:

Further objectives should be to aim, on the basis of experience acquired from the

- Working out common guiding principles;

- Considering all possibilities of improving co-operation between Member countries in this field by such means as prior consultation, prior notification and/or a question-and-answer procedure or by other suitable means.

Account should be taken of the competence of the Development Assistance Committee in the field of development aid, including the undertakings reached in that Committee, and appropriate liaison should be established between the work arising from confrontations envisaged and the work of the DAC.

3. As recommended in paragraph 4 of the report of the special meeting [TC(63)42], these confrontations should be concentrated, at least at the outset, on transactions exceeding five years' duration. The Working Party is requested to make all necessary arrangements for the provision of the information required, as outlined in paragraphs 5-7 of the report. It shall review this information system and make whatever improvements may be necessary, as recommended by the special meeting.

4. The Working Party shall have full latitude and discretion to pursue its work, to elect its officers, to establish the form of liaison it considers necessary with the DAC or other bodies of the Organisation, and to determine the frequency and manner of its reporting. In particular, it shall take whatever measures it considers desirable, in consultation with the Chairman of the DAC and the Secretariat, to ensure adequate co-ordination of its work with that of the Development Assistance Committee. When the reports of the Working Party call for action by the Organisation as such, they shall be forwarded in toto to the Council, with any comments the Trade Committee may wish to make." 


\section{JOINT WORKING PARTY ON AGRICULTURE AND TRADE}

Chair:

Mr. Jorge Rueda Sousa

(Mexico)

Vice-Chairs:

Ms. Cornelia Berns

(Germany)

Mr. Darryl Brehm

(United States)

Members:

Open to all Member countries

Observers:

Chile

Brazil

Argentina

World Trade Organization (WTO)

Date of creation:

6th June 1962

Duration:

31st December 2013

Mandate: Summary Record of the 149th Session of the Committee for Agriculture held on 28-30 November 2007 [TAD/CA/M(2007)3] and of the 150th Session of the Trade Committee held on 5-7 May 2008 [TAD/TC/M(2008)3/PROV]

\section{Extract from documents [TAD/CA(2007)27] and [TAD/TC(2008)7]}

"The Joint Working Party on Agriculture and Trade is to provide analytical support to the process of agricultural and food trade liberalisation by:

(i) Analysing actual and projected effects of agricultural trade liberalisation and the globalising food economy.

(ii) Examining on-going and new agricultural trade and trans-boundary policy issues and their impacts.

(iii) Examining the trade effects of agricultural support policies, regulatory frameworks and other instruments of agricultural policy.

(iv) Analysing the characteristics of efficient and effective policies that are also no more trade distorting than necessary." 


\section{JOINT WORKING PARTY ON TRADE AND ENVIRONMENT}

\section{Co-Chairs:}

Vice-Chairs:

Members:

Observers:

Date of creation:

Duration:
Mr. Julius Langendorff

Mr. Vangelis Vitalis

Mrs. Nicole Dispa

Mr. Joseph Ferrante

Mr. Thomas Gillmore

Mr. Mitsutsune Yamaguchi

Open to all Member countries

Brazil

Hong Kong, China

European Free Trade Association (EFTA)

International Monetary Fund (IMF)

North American Commission for Environment Co-operation

(NACEC)

UN Conference on Trade and Development (UNCTAD)

UN Environment Programme (UNEP)

World Trade Organization (WTO)

1st April 1991

31st December 2013
(European Commission)

(New Zealand)

(France)

(United States)

(Canada)

(Japan)

Mandate: Written procedures by the Trade Committee[TAD/TC(2008)16] and by EPOC [ENV/EPOC(2008)30] on 10 October 2008

\section{Extract of documents $[\mathrm{TAD} / \mathrm{TC}(2008) 16]$ and [ENV/EPOC(2008)30]}

"The Joint Working Party should:

focus on analytical work, including empirical studies of selected policy areas and economic sectors, aimed at promoting the mutual compatibility of trade and environment policies in practice, in order to contribute to sustainable development, while building on its work to date;

focus on those areas where it has the greatest value added while supporting the activities of other OECD bodies and international organisations, and avoiding duplication;

co-operate and liaise with other relevant OECD bodies, and with relevant international organisations including the WTO, UNEP, UNCTAD, ISO, and the UN Commission on Sustainable Development;

consult with emerging economies and developing countries, and provide them with expertise as appropriate;

consult regularly as appropriate with both industry and environmental NGOs on environment and trade related matters;

advise and report to the parent Committees on new and emerging problems and major issues with respect to trade environment relationships;

assist the parent Committees in ensuring the coherence and consistency of the trade and environment related work being carried out in the various bodies of the OECD." 
Chair:

Vice-Chairs:

Members:

Observers:

Date of creation:

Duration:
Mr. Gerrit Meester

Mr. Neil Fraser

Mr. François Pythoud

Ms. Hedwig Wögerbauer

Mr. Gregg Young

Open to all Member countries
(Netherlands)

(New Zealand)

(Switzerland)

(Austria)

(United States)

\author{
Argentina \\ Brazil \\ Chile \\ South Africa \\ Council of Europe \\ UN Food and Agricultural Organization (FAO) \\ World Trade Organization (WTO)
}

30th September 1961

31st December 2013

Mandate : Resolution of the Council concerning the revision of the mandate of the Committee for Agriculture [C(2008)182 and CORR1] adopted at its 1186th session on 18 December 2008 [C/M(2008)22, item 326]

\section{Resolution of the Council [C(2008)182 \& CORR1 and C/M(2008)22, Item 236]}

THE COUNCIL,

Having regard to the Articles 1 and 2 of the Convention on the Organisation for Economic Co-operation and Development of 14 December 1960;

Having regard to the Rules of Procedure of the Organisation;

Having regard to paragraphs 21, 22, 23, 26 and 89 of the Report of the Preparatory Committee concerning the creation of a Committee for Agriculture; 1982 and 1987;

Having regard to the Communiqués of the meetings of the Council at Ministerial level in

Having regard to the Communiqués of the meetings of the Committee for Agriculture at Ministerial level in 1992 and 1998 and the Chair's summary of the 2005 High level meeting of the Committee for Agriculture; C(2008)182;

Having regard to the proposed revision of the mandate of the Committee for Agriculture

Considering the need for further domestic agricultural policy reform and integration of the agriculture and food sector into the multilateral trading system; and 
Considering the need for maintaining the productive capacity and effective use of natural resources to satisfy future demand for food and non-food products;

\section{DECIDES:}

A. The Committee for Agriculture has the following mandate:

1. To provide a forum for the discussion of issues related to all aspects of agricultural, agro-food and agricultural trade developments and policies with a view to promoting mutual understanding of these developments and to improving the effectiveness of policies, at both the domestic and the international levels, as they affect agriculture and the agri-food sector, in ways consistent with the overall mission of the OECD.

Specifically,

- To define guidelines and promote best practices for a positive policy reform agenda with the purpose of helping governments to achieve their objectives for their agriculture and agri-food sectors in ways that are efficient, effective and no more trade distorting than necessary.

- To define and promote policy and market approaches that improve agriculture's contribution to sustainability in all its aspects, and improve its overall environmental performance against a background of global issues that will be important for the sector concerning resource use (particularly water) and climate change, in Member and non-Member countries.

- To provide forward looking policy information, analysis and advice, that considers the perspectives of both Member and non-Member countries, so as to facilitate growth and development and the integration of the agriculture and agri-food sectors into the international trading system.

- To monitor and analyse structural, economic and policy developments throughout the supply chain from farm to consumer, their implications for the farm sector and for farm sector policies.

2. Agricultural and agricultural trade developments and policies should be regularly monitored, using the best available qualitative and quantitative tools, and the impacts of structural change and policies on a range of sectoral performance criteria should be continuously evaluated.

In fulfilling this mandate the Committee for Agriculture will:

- Define the work to be undertaken during each programming period. Following the processes and schedules set for the Organisation as a whole, participate in all required reporting and evaluation mechanisms in place at OECD level, and manage the substantive and analytical work delegated to its subsidiary bodies.

- Work in close co-operation with other relevant committees, notably with the Trade Committee, the Environment Policy Committee, the Development Assistance Committee and the Territorial Development Policy Committee, striving for a full sharing of knowledge and expertise in pursuit of improved policy coherence.

- Engage with selected non-Member countries with a view to sharing experiences and expertise in policy development and evaluation and encouraging them to apply relevant OECD guidelines and recommendations. In this respect, Observers to the Committee will play a key role.

- Work in close co-operation with other international organisations notably the FAO, the World Bank and the WTO to share expertise, to provide mutual support, while avoiding overlap or duplication in the respective tasks undertaken. 
- Develop close working relationships with international commodity organisations (ISO, IGC, IDF, IMS) ${ }^{1 *}$ in monitoring international commodity markets and developments to ensure that we benefit from their expertise and that our work programmes are mutually reinforcing.

- Involve non-governmental organisations in its work through consultation/advisory mechanisms such as BIAC, IFAP ${ }^{2}$ and TUAC and by engaging with relevant civil society organisations representing a broad crosssection of relevant interests.

- Undertake communication activities in Member countries, in light of the needs and interests in capitals and the availability of substantive policy relevant outputs from its work programme.

B. The mandate of the Committee for Agriculture shall remain in force until 31 December 2013, unless the Council decides otherwise.

\footnotetext{
1 ISO: International Sugar Organisation, IGC : International Grains Council; IDF: International Diary Federation; IMS: International Meat Secretariat 2

IFAP: International Federation of Agricultural Producers
} 


\section{GLOBAL FORUM ON AGRICULTURE $^{1}$}

Chair:

Date of creation:

Duration:

Approved by:
No formally appointed Chair

1st January 2009

31st December 2013

The Committee for Agriculture, 28 May 2008 [TAD/CA/M(2008)1]

\section{Mission Statement:}

The purpose of the OECD Global Forum on Agriculture (GFA) is to support the Committee for Agriculture (COAG) in fulfilling its mandate of providing forward looking information, analysis and advice that considers the perspectives of member and non-member economies, as well as other stakeholders. ${ }^{2}$

The GFA is the main instrument for broad-based dialogue between OECD members and non-members, including Accession and Enhanced Engagement countries, and responds to the COAG's mandate to enhance its engagement with non-members in both groups. ${ }^{3}$

The GFA fosters an informed dialogue on agricultural policies, including trade and market policies, and particularly on agricultural policy and trade reform and the fight against poverty. The aim of that dialogue is to promote a global consensus on agricultural trade and policy issues.

In order to achieve such a consensus, it is necessary to involve a wide range of stakeholders, and to examine the issues of most pressing importance to developing countries. These issues include both developing country-specific matters and policy concerns that arise as a result of non-members' economic linkages with OECD countries.

The focus of the GFA will accordingly be on global agricultural policy issues, and topics of mutual interest to OECD countries and non-member economies. The GFA will provide the mechanism for discussion of the Monitoring and Evaluation of agricultural policies undertaken for non-member economies.

Where relevant, the COAG will use the GFA as an opportunity to work with other OECD committees to promote policy dialogue on important cross-cutting issues.

The GFA will also contribute to the Committee for Agriculture's work by providing it with a broader perspective on its output results and facilitating the dissemination of completed work

\begin{abstract}
Members:
\end{abstract}
Designated Participants:
Open to all Member countries

Inter-American Development Bank (IDB)

International Fund for Agricultural Development (IFAD)

UN Food and Agricultural Organization (FAO)

World Bank

COAG Observers: Argentina, Brazil, Chile, South Africa

Accession countries : Estonia, Chile, Israel, Russian Federation, Slovenia

Enhanced Engagement countries: Brazil, People's Republic of China, India, Indonesia

Other non-members for which the monitoring exercise is undertaken : Bulgaria, Latvia, Lithuania, Romania and Ukraine

\footnotetext{
1 Information on this Global Forum is provided for the sake of completeness, but Global Forums are not, in accordance with C(2008)208/FINAL, official OECD bodies.

See "Renewal of the mandate of the Committee for Agriculture (2009-13)", TAD/CA(2007)26/REV1.

See "Strategy for the Committee for Agriculture for enlargement and enhanced engagement", $\mathrm{TAD} / \mathrm{CA}(2007) 23$.
} 


\section{WORKING PARTY ON AGRICULTURAL POLICIES AND MARKETS (APM)}

Chair:

Vice-Chairs:

Members:

Observers:

Date of creation:

Duration:
Mr. Mogens Nagel Larsen

Ms. Anne Effland

Mr. Antonio Lizcano Palomares

Mr. Cameron Short

Open to all Member countries

Chile

Brazil

Argentina

Council of Europe

UN Food and Agricultural Organization (FAO)

World Trade Organization (WTO)

30th September 1987

31st December 2013
(Denmark)

(United States)

(Spain)

(Canada)

Mandate: Summary Record of the 149th Session of the Committee for Agriculture held on 28-30 November 2007 [TAD/CA/M(2007)3]

\section{Extract from document [TAD/CA(2007)28]}

"The Working Party on Agricultural Policies and Markets will undertake the preparatory studies required for the work of the Committee for Agriculture in accordance with the priorities as defined in the programme of work and report to the Committee for Agriculture. Its functions will cover in particular the following areas:

(i) Monitoring of agricultural policies, and of their effects on markets and trade including in the longer term, and of the implementation of the various principles and actions related to agriculture and to the agricultural policy reform process, as defined in the Ministerial communiqués.

(ii) Discussion of all aspects of the development of analytical tools, including particularly support measurement and related analysis and modelling exercises, with a view to deepening the analysis, updating and improving these tools and ensuring that they keep pace with economic and policy developments.

(iii) Prepare and review special studies related to the various means and instruments which could contribute to the achievement of the objectives of agricultural policy reform. Evaluate policy instruments in terms of their effectiveness, their efficiency, their distributional and social impacts, and their contribution to sustainability, in addition to their impacts on production and trade.

(iv) Provide guidelines or recommendations on policy design, implementation and monitoring, in order to assist governments in defining and implementing the policies that allow them to achieve their evolving objectives in a changing environment. The WP will draw on theoretical, applied and comparative methods as appropriate. 
(v) Extend policy analysis upstream and downstream to assist governments in understanding and monitoring structural, technological, supply and demand side changes affecting the entire agrofood sector and in designing policy responses that are appropriate, integrated and coherent across the entire sector.

(iv) Discussion and co-ordination of the work and reports of the commodity groups (Cereals, Feeds and Sugar, Meat and Dairy Products), the purpose of which is to prepare and review baseline projections and first drafts of texts for the annual Agricultural Outlook report, to provide guidance for Aglink maintenance and development, and review commodity related agri-food policy issues before the related reports are forwarded for further discussion to the Working Party.

Where this enhances the analytical approach, the Working Party will work closely with other committees and working parties and with other international organisations such as the Food and Agriculture Organisation of the UN (FAO). Specifically, it will work in co-operation with the Joint Working Party Agriculture/Trade to the extent that issues related to agricultural trade are included in its activities and with the Joint Working Party on Agriculture and the Environment with respect to issues that touch on the environment. It will also work in cooperation with The Working Party on Territorial Policy in Rural Areas and The Territorial Development Policy Committee, when engaged in issues related to linkages between the agro-food sector and rural development." 


\section{JOINT WORKING PARTY ON AGRICULTURE AND TRADE}

Chair:

Mr. Jorge Rueda Sousa

(Mexico)

Vice-Chairs:

Ms. Cornelia Berns

(Germany)

Mr. Darryl Brehm

(United States)

Members:

Open to all Member countries

Observers:

Chile

Brazil

Argentina

World Trade Organization (WTO)

Date of creation:

6th June 1962

Duration:

31st December 2013

Mandate: Summary Record of the 149th Session of the Committee for Agriculture held on 28-30 November 2007 [TAD/CA/M(2007)3] and of the 150th Session of the Trade Committee held on 5-7 May 2008 [TAD/TC/M(2008)3/PROV]

\section{Extract from documents [TAD/CA(2007)27] and [TAD/TC(2008)7]}

"The Joint Working Party on Agriculture and Trade is to provide analytical support to the process of agricultural and food trade liberalisation by:

(i) Analysing actual and projected effects of agricultural trade liberalisation and the globalising food economy.

(ii) Examining on-going and new agricultural trade and trans-boundary policy issues and their impacts.

(iii) Examining the trade effects of agricultural support policies, regulatory frameworks and other instruments of agricultural policy.

(iv) Analysing the characteristics of efficient and effective policies that are also no more trade distorting than necessary." 


\section{JOINT WORKING PARTY ON AGRICULTURE AND THE ENVIRONMENT}

Chair:

Vice-Chairs:

Members:

Observer:

Date of creation:

Duration:
Mr. Frode Lyssandtrae

Mr. Jeremy Eppel

Mr. Grant King

Ms. Maiko Murayama

Ms. Marca Weinberg

Ms. Annalisa Zezza
(Norway)

(United Kingdom)

(New Zealand)

(Japan)

(United States)

(Italy)

Open to all Member countries

UN Food and Agricultural Organization (FAO)

January 1993

31st January 2014

Mandate: - Summary Record of the 150th Session of the Committee for Agriculture held on 1315 May 2008 [TAD/TC/M(2008)1] and by written procedure by the EPOC on 12 January 2009 [ENV/EPOC(2008)20]

\section{Extract from documents [TAD/CA(2008)8] and [ENV/EPOC(2008)20]}

\section{"Objectives}

The Joint Working Party on Agriculture and the Environment will provide a forum to exchange information, identify and analyse the implications for achieving environmentally sustainable agriculture of policies and market approaches in the context of technological change, agricultural policy reform and multilateral trade and environmental agreements, and communicate the results to the wider public."

\section{Terms of reference}

The Joint Working Party will:

Identify and analyse policy relevant domestic and trans-boundary issues at the interface between agriculture and the environment in both OECD and, where relevant, nonOECD countries; quantify the relationships between agriculture and the environment, including in a forward-looking perspective; monitor and evaluate policy measures and actions addressing environmental issues in agriculture; and provide guidance on an integrated and coherent approach for agricultural and environmental policies to help achieve sustainable agriculture.

Undertake the analysis of agricultural and environmental issues of relevance to policy makers; in particular to: co ordinate, undertake and review relevant work mandated by the two parent Committees; co-ordinate, receive reports and review relevant on going and proposed work carried out elsewhere in the OECD; advise and report to the parent Committees on new and emerging problems and major issues with respect to agrienvironment relationships; identify successful policies and courses of action at national and international levels; and identify new initiatives for consideration by the appropriate bodies of the Organisation.

Co operate and liaise with other competent bodies in the OECD, and ensure appropriate co ordination with other relevant international organisations, in particular the Food and Agricultural Organisation of the United Nations, the United Nations Environment Programme and the Commission on Sustainable Development and the Convention on Biological Diversity, and with relevant non-governmental organisations, representing the farming, agro-food industry, and environmental interests; strengthen efforts to present and communicate the work to relevant organisations, the media and wider public." 


\section{GROUP ON COMMODITY MARKETS}

$\begin{array}{lll}\text { Chairs: } & \begin{array}{l}\text { Mr. Pierre Charlebois } \\ \text { Ms. Birgitta Vainio-Mattila }\end{array} & \begin{array}{c}\text { (Canada) } \\ \text { (Finland) }\end{array} \\ \text { Members: } & \text { Open to all Member countries } \\ \text { Observers: } & \begin{array}{l}\text { Chile } \\ \text { Russian Federation } \\ \text { Brazil } \\ \text { South Africa } \\ \text { Argentina }\end{array} \\ & \text { Council of Europe } \\ & \text { UN Food and Agricultural Organization (FAO) } \\ & \text { World Trade Organization (WTO) } \\ & \text { 1st January 2009 } \\ \text { Date of creation: } & \text { 31st December 2013 } \\ \text { Duration: } & \end{array}$

Mandate: Summary Record of the 151st Session of the Committee for Agriculture held on 18-19 November 2008 [TAD/CA/M(2008)2]

\section{Extract from document [TAD(2008)22]}

"(i) - To review the current situation for agricultural commodities and the joint OECDFAO medium-term agricultural outlook;

(ii) - To identify emerging trends and policy issues relevant to agricultural commodities and assess the impacts on markets and the general economy;

(iii) - To undertake studies as may be requested from time to time by the Committee for Agriculture;

(iv) - To report on all these matters to the Working Party on Agricultural Policies and Markets." 


\section{PLENARY MEETING OF THE OECD SCHEME FOR THE APPLICATION OF INTERNATIONAL STANDARDS FOR FRUIT AND VEGETABLES}

Chair:

Vice-Chairs:

OECD Members:

Non-OECD Members:

Observers:

Date of creation:

Duration:
Mr. Pierre Schauenberg

Mr. Ran Ben-David

Ms. Viera Baricicova

Austria

Belgium

Finland

France

Germany

Greece

Hungary

Ireland

Italy

Israel

South Africa

Bulgaria

Kenya
(Switzerland)

(Israel)

(Slovak Republic)

Luxembourg

Netherlands

New Zealand

Poland

Slovak Republic

Spain

Sweden

Switzerland

Turkey

Morocco

Romania

Serbia

European Union of the Fruit and Vegetable Wholesale, Import and Export Trade (EUCOFEL)

Freshfel Europe - European Fresh Produce Association

Liaison Committee for Mediterranean Citrus Fruit Culture (CLAM)

Liaison Committee for the Promotion of Tropical Fruit and Out-of-

season Vegetables Derived from ACP Countries (COLEACP)

UN Economic Commission for Europe (UNECE)

UN Food and Agricultural Organization (FAO)

20th February 1962

Unspecified

Mandate: Decision of the Council revising the OECD "Scheme" for the application of international standards for fruit and vegetables [C(99)10/FINAL]

\section{Extract from the Decision of the Council [C(99)10/FINAL]}

"...

On the proposal of the Committee for Agriculture;

THE COUNCIL,

I. DECIDES:

1. The OECD "Scheme" for the Application of International Standards for Fruit and vegetables (hereinafter called the "Scheme") is revised pursuant to the provisions of this Decision.

2. The "Scheme" has as its primary objectives:

- to promote the establishment of one single international grade standard setting body and,

- in the interim, to facilitate the implementation and harmonisation of international grade standards activities. Hence, the "Scheme" shall: 
a) facilitate the international harmonisation and adaptation of grade standards, standardisation of packaging and development of palletisation to present production, trade and marketing conditions;

b) review the operation and progress of its activities at Plenary Meetings of the national representatives appointed by their Governments to be responsible for its implementation (hereafter called the "Plenary Meeting");

c) promote uniform quality control procedures and the use of the model control certificate;

d) set up meetings of officers in charge of national control services;

e) propose new standards and revisions to those which are the subject of Annex I to this Decision;

f) develop the "Scheme's" operational guidelines;

g) study conditions and quality assurance operations, taking into account new methods of marketing, to ensure consumer interest in product quality is addressed.

3. The "Scheme" may establish Produce Working Groups, which are subsidiary bodies of the Plenary Meeting for the development and preparation of explanatory guidelines for the various standards.

4. The standards adopted by the United Nations Economic Commission for Europe, once approved by the Plenary Meeting, shall be applied under the "Scheme" to the products specified in Annex I to this Decision, at the export stage, when these products enter into international trade between countries participating in the "Scheme".

5. Each time a new standard is approved, each country participating in the "Scheme" willing to conform thereto shall inform the Secretary-General within a period of six months. Once a standard has been approved, participating countries willing to conform thereto may inform the Secretary-General at any time.

6. The Secretary-General shall bring to the attention of participating countries of the "Scheme" all notifications and information conveyed within the framework of the "Scheme".

7. Participating countries are obliged to establish within three years of joining the "Scheme", an export quality control of the produce in accordance with the guidelines set out in annex II of this Decision, by virtue of which they participate in the "Scheme".

8. Participation in the "Scheme" shall be open to any member of the United Nations or one of its specialised agencies or the World Trade Organization which desire to participate therein as regards all or some of the produce concerned and is willing, as an exporting country, to conform with the standards referred to in paragraph 5 and, as an importing country, to recognise them as standards which are to be applied to exported fruit and vegetables produced in the country of origin. Any country desiring to participate in the "Scheme" shall notify the Secretary-General indicating the institution responsible for quality control and a contact person.

9. Any participating country can withdraw from the "Scheme" by giving no less than twelve months' notice in writing to the Secretary-General.

10. The Secretariats of the:

- United Nations Economic Commission for Europe,

- Joint FAO/WHO Food Standards Programme of the United Nations,

- Confederation of Importers and Marketing Organisations in Europe of Fresh Fruit and Vegetables (CIMO),

- Liaison Committee for Mediterranean Citrus Fruit Culture (CLAM), 
- Liaison Committee for the Promotion of Tropical Fruits and Out-of-Season Vegetables derived from ACP Countries (COLEACP),

- European Union of the Fruit and Vegetable Wholesale, Import and Export Trade (EUCOFEL),

shall be invited to be represented as observers at the Plenary Meeting and its Produce Working Groups.

11. Other International Organisations or Non Governmental Organisations which have responsibilities in the sector covered by the "Scheme" may be invited to designate an ad-hoc observer or an expert to sessions of the Plenary Meetings of the "Scheme" or its Produce Working Groups.

\section{$(\ldots)$}

II. DECIDES that the countries which, at the adoption of the present Decision, already participated in the "Scheme" as revised by the Decision of the Council C(92)184/FINAL, shall participate in the "Scheme" established by this Decision subject to a notification to the contrary to the Secretary-General within three months following the adoption of the present Decision.

III. DECIDES that within a period of six months after the adoption of this Decision, the participating countries shall inform the Secretary-General of the standards currently in force with which they are willing to conform.

IV. INSTRUCTS the Committee for Agriculture to report to the Council, when appropriate, on the operation of the "Scheme", to submit to the Council, where necessary, proposals for its modification.

V. DECIDES that the Decision of the Council of 18 December 1992 referred to above is repealed and replaced by this Decision.

(...)

\section{ANNEX II}

\section{OPERATIONAL FRAMEWORK FOR THE CONTROL OF THE QUALITY OF PRODUCE EXPORTED UNDER THE "SCHEME"}

\section{OPERATIONAL FRAMEWORK CONCERNING QUALITY CONTROL}

1. The purpose of the control is to ascertain that the quality and classification of the produce exported are in conformity with the standards applied under the "Scheme".

2. Control operations are to be carried out according to the guidelines set out in Section II below by the control service authorised by each country participating in the "Scheme" to issue the control certificate comparable to the model set out in Appendix I to this Annex. Its use is described in the explanatory note appearing in Appendix II to this Annex.

3. The purpose of the control certificate is to attest that the appropriate control service has verified, according to the methods set out hereafter in section II of this Annex, that the consignment in question conforms with the standard applied under the "Scheme" at the time of inspection. That service is responsible to the corresponding services of importing countries participating in the "Scheme" for the statements attesting quality in the control certificate." 


\section{OECD SCHEME FOR THE APPLICATION OF INTERNATIONAL STANDARDS FOR FRUIT AND VEGETABLES - MEETING OF HEADS OF NATIONAL INSPECTION SERVICES}

Chairs:

Host Country

OECD Members:

Non-OECD Members:

Date of creation:

Duration:

Austria

Belgium

Finland

France

Germany

Greece

Hungary

Ireland

Italy

\author{
Israel \\ South Africa \\ Bulgaria \\ Kenya
}

May 1980

Unspecified
(..)

Luxembourg

Netherlands

New Zealand

Poland

Slovak Republic

Spain

Sweden

Switzerland

Turkey

Morocco

Romania

Serbia

\section{Mandate:}

The main goal of the Meeting of Heads of National Inspection Services is to enhance co-operation between experts in member countries regarding the quality inspection of fruit and vegetables moving in international trade. More specifically, to provide information on the latest developments regarding the organisation of quality inspection services in partner countries, quality inspection techniques, quality management by private companies, as well as the exchange of ideas on future developments in quality inspection, problems occurring during inspection and possible solutions and technical visits. 
Chair:

Ms. Merete Buus

(Denmark)

Vice-Chairs:

Mr. Peter Johnston

Mr. Chagema John Kedera

(New Zealand)

(Kenya)

Date of creation:

30th January 1962(OEEC 30th May 1958)

Duration:

Unspecified

Mandate:

There is no mandate setting up the Annual Meeting for the Seed Schemes as a whole. The seven Schemes, which make up the "Seed Schemes", each have specific country participation.

The latest Decision of the Council revising the OECD Schemes for the Varietal Certification or the Control of Seed Moving in International Trade is [C(2000)146/FINAL] and was approved during the Council meeting held on 28 September 2000 [C/M(2000)22, Item 280]. It has been subsequently amended by Council: [C(2003)18 and C/M(2003)4, Item 83]; [C(2003)23 and $\mathrm{C} / \mathrm{M}(2003) 8$, Item 129]; [C(2004)97 and C/M(2004)14, Item 199]; [C(2005)38 and C/M(2005)12, Item 148] and [C(2005)171 and C/M(2006)1, Item 10]. 


\section{OECD Members:}

Non-OECD Members:

\section{Observers: ${ }^{1}$}

\footnotetext{
1 Note: The Director-General of WIPO (World Intellectual Property Organization) is the Secretary General of UPOV.
}

\author{
Luxembourg \\ Mexico \\ Netherlands \\ New Zealand \\ Norway \\ Poland \\ Portugal \\ Slovak Republic \\ Spain \\ Sweden \\ Switzerland \\ Turkey \\ United Kingdom \\ United States
}

Kenya
Kyrgyzstan
Latvia
Lithuania
Moldova
Morocco
Romania
Serbia
Tunisia
Uganda
Uruguay
Zimbabwe

Kenya

Estonia
Israel
Slovenia
Brazil
India
South Africa
Argentina
Bolivia
Bulgaria
Croatia
Cyprus
Egypt

Zimbabwe

\author{
African Seed Trade Association (AFSTA) \\ Asia and Pacific Seed Association (ASPA) \\ Association of Official Seed Analysts (AOSA) \\ Association of Official Seed Certifying Agencies (AOSCA) \\ Bioversity International \\ Committee of Professional Agricultural Organisations in the \\ European Union (COPA) \\ Convention on Biological Diversity (CBD) \\ Eastern European Seed Network (EESNET) \\ European Association for Research on Plant Breeding (EUCARPIA) \\ European Seed Association (ESA) \\ Federation of Latin American Seed Associations \\ Inter-American Institute for Cooperation on Agriculture (IICA) \\ International Center for Agricultural Research in the Dry Areas \\ (WANA/ICARDA) \\ International Federation of Agricultural Producers (IFAP) \\ International Federation of Organic Agriculture Movements (IFOAM) \\ International Seed Testing Association (ISTA) \\ International Seed Trade Federation (FIS) \\ International Union for the Protection of New Varieties of Plants \\ (UPOV) \\ Latin American Integration Association (ALADI)
}


UN Economic Commission for Europe (UNECE)

UN Food and Agricultural Organization (FAO)

West Asia and North Africa Seed Network (W.A.N.A)

Date of creation:

30th January 1962(OEEC 30th May 1958)

Duration:

Unspecified 


\begin{tabular}{|c|c|c|}
\hline OECD Members: & $\begin{array}{l}\text { Australia } \\
\text { Austria } \\
\text { Belgium } \\
\text { Canada } \\
\text { Czech Republic } \\
\text { Denmark } \\
\text { Finland } \\
\text { France } \\
\text { Germany } \\
\text { Greece } \\
\text { Hungary } \\
\text { Iceland } \\
\text { Ireland } \\
\text { Italy } \\
\text { Japan }\end{array}$ & $\begin{array}{l}\text { Luxembourg } \\
\text { Mexico } \\
\text { Netherlands } \\
\text { New Zealand } \\
\text { Norway } \\
\text { Poland } \\
\text { Portugal } \\
\text { Slovak Republic } \\
\text { Spain } \\
\text { Sweden } \\
\text { Switzerland } \\
\text { Turkey } \\
\text { United Kingdom } \\
\text { United States }\end{array}$ \\
\hline Non-OECD Members: & $\begin{array}{l}\text { Chile } \\
\text { Estonia } \\
\text { Israel } \\
\text { Russian Federation } \\
\text { Slovenia } \\
\text { Brazil } \\
\text { India } \\
\text { South Africa } \\
\text { Argentina } \\
\text { Bolivia } \\
\text { Bulgaria } \\
\text { Croatia }\end{array}$ & $\begin{array}{l}\text { Cyprus } \\
\text { Egypt } \\
\text { Kenya } \\
\text { Lithuania } \\
\text { Moldova } \\
\text { Morocco } \\
\text { Romania } \\
\text { Serbia } \\
\text { Tunisia } \\
\text { Uganda } \\
\text { Uruguay } \\
\text { Zimbabwe }\end{array}$ \\
\hline Observers: ${ }^{1}$ & \multicolumn{2}{|c|}{$\begin{array}{l}\text { African Seed Trade Association (AFSTA) } \\
\text { Asia and Pacific Seed Association (ASPA) } \\
\text { Association of Official Seed Analysts (AOSA) } \\
\text { Association of Official Seed Certifying Agencies (AOSCA) } \\
\text { Bioversity International } \\
\text { Committee of Professional Agricultural Organisations in the } \\
\text { European Union (COPA) } \\
\text { Convention on Biological Diversity (CBD) } \\
\text { Eastern European Seed Network (EESNET) } \\
\text { European Association for Research on Plant Breeding (EUCARPIA) } \\
\text { European Seed Association (ESA) } \\
\text { Federation of Latin American Seed Associations } \\
\text { Inter-American Institute for Cooperation on Agriculture (IICA) } \\
\text { International Center for Agricultural Research in the Dry Areas } \\
\text { (WANA/ICARDA) } \\
\text { International Federation of Agricultural Producers (IFAP) } \\
\text { International Federation of Organic Agriculture Movements (IFOAM) } \\
\text { International Seed Testing Association (ISTA) } \\
\text { International Seed Trade Federation (FIS) } \\
\text { International Union for the Protection of New Varieties of Plants } \\
\text { (UPOV) } \\
\text { Latin American Integration Association (ALADI) } \\
\text { UN Economic Commission for Europe (UNECE) }\end{array}$} \\
\hline
\end{tabular}

\footnotetext{
${ }^{1}$ Note: The Director-General of WIPO (World Intellectual Property Organization) is the Secretary General of UPOV.
} 
UN Food and Agricultural Organization (FAO)

West Asia and North Africa Seed Network (W.A.N.A)

Date of creation:

30th January 1962(OEEC 30th May 1958)

Duration:

Unspecified 


\section{SCHEME FOR CEREALS}

OECD Members:

Non-OECD Members:

\section{Observers: ${ }^{1}$}

Australia
Austria
Belgium
Canada
Czech Republic
Denmark
Finland
France
Germany
Greece
Hungary
Iceland
Ireland
Italy

Chile

Estonia

Israel

Russian Federation

Slovenia

Brazil

India

Albania

Argentina

Bolivia

Bulgaria

Croatia

Egypt

\author{
Luxembourg \\ Mexico \\ Netherlands \\ New Zealand \\ Norway \\ Poland \\ Portugal \\ Slovak Republic \\ Spain \\ Sweden \\ Switzerland \\ Turkey \\ United Kingdom \\ United States
}

Kenya

Kyrgyzstan

Latvia

Lithuania

Moldova

Morocco

Romania

Serbia

Tunisia

Uganda

Uruguay

Zimbabwe

African Seed Trade Association (AFSTA)

Asia and Pacific Seed Association (ASPA)

Association of Official Seed Analysts (AOSA)

Association of Official Seed Certifying Agencies (AOSCA)

Bioversity International

Committee of Professional Agricultural Organisations in the

European Union (COPA)

Convention on Biological Diversity (CBD)

Eastern European Seed Network (EESNET)

European Association for Research on Plant Breeding (EUCARPIA)

European Seed Association (ESA)

Federation of Latin American Seed Associations

Inter-American Institute for Cooperation on Agriculture (IICA)

International Center for Agricultural Research in the Dry Areas

(WANA/ICARDA)

International Federation of Agricultural Producers (IFAP)

International Federation of Organic Agriculture Movements (IFOAM)

International Seed Testing Association (ISTA)

International Seed Trade Federation (FIS)

International Union for the Protection of New Varieties of Plants

(UPOV)

Latin American Integration Association (ALADI)

UN Economic Commission for Europe (UNECE)

\footnotetext{
1 Note: The Director-General of WIPO (World Intellectual Property Organization) is the Secretary General of UPOV.
} 
UN Food and Agricultural Organization (FAO)

West Asia and North Africa Seed Network (W.A.N.A)

Date of creation:

30th January 1962(OEEC 30th May 1958)

Duration:

Unspecified 


\section{SCHEME FOR BEET}

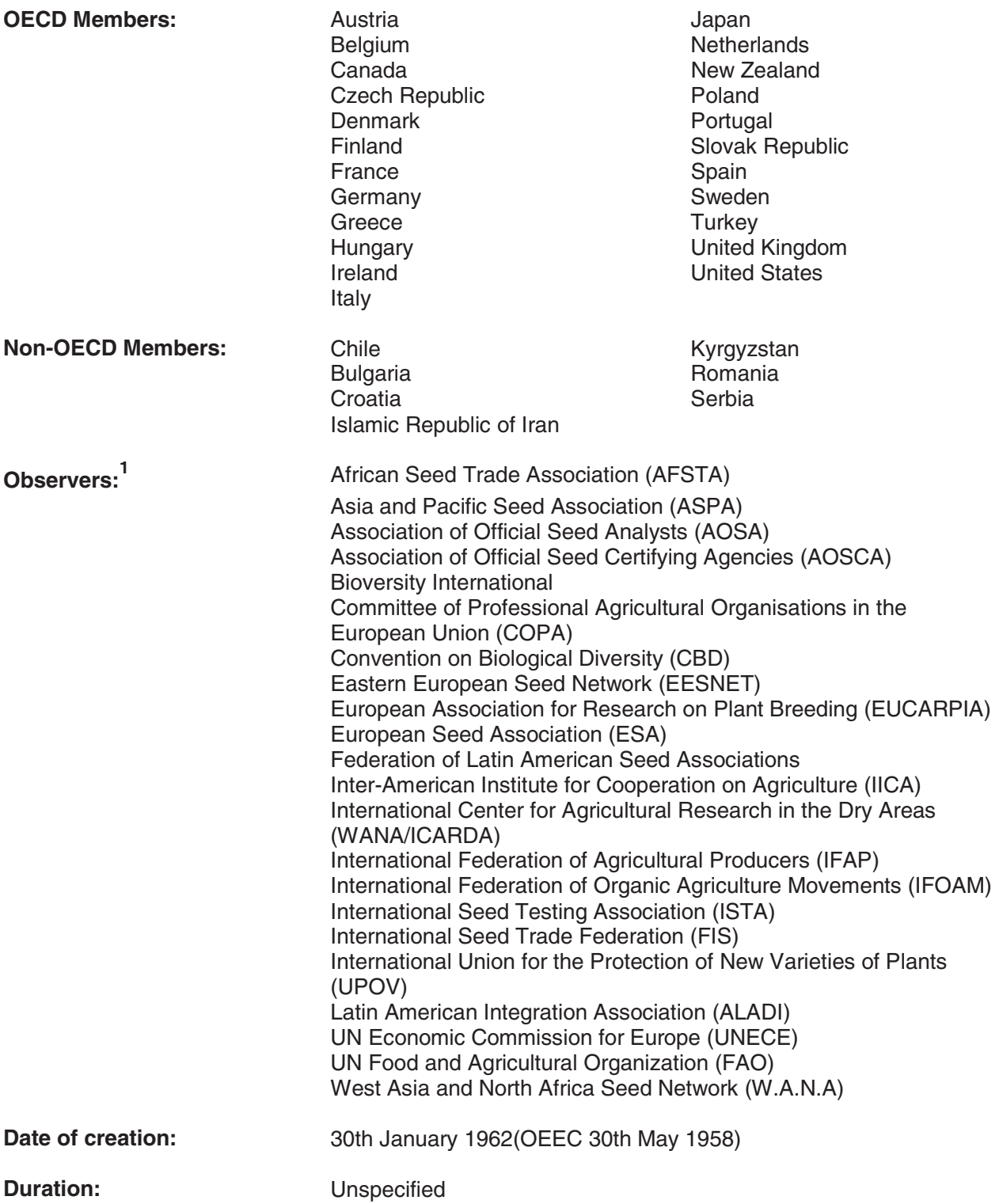

\footnotetext{
${ }^{1}$ Note: The Director-General of WIPO (World Intellectual Property Organization) is the Secretary General of UPOV.
} 
SCHEME FOR MAIZE AND SORGHUM

OECD Members:

Non-OECD Members:

Observers: ${ }^{1}$

Date of creation:

Duration:

Australia
Austria
Belgium
Canada
Czech Republic
Denmark
Finland
France
Germany
Greece
Hungary

Chile

Israel

Russian Federation

Slovenia

Brazil

India

South Africa

Albania

Argentina

Bolivia

Bulgaria
Italy

Mexico

Netherlands

New Zealand

Poland

Portugal

Slovak Republic

Spain

Switzerland

Turkey

United States

Croatia

Egypt

Kenya

Moldova

Morocco

Romania

Serbia

Uganda

Uruguay

Zimbabwe

African Seed Trade Association (AFSTA)

Asia and Pacific Seed Association (ASPA)

Association of Official Seed Analysts (AOSA)

Association of Official Seed Certifying Agencies (AOSCA)

Bioversity International

Committee of Professional Agricultural Organisations in the

European Union (COPA)

Convention on Biological Diversity (CBD)

Eastern European Seed Network (EESNET)

European Association for Research on Plant Breeding (EUCARPIA)

European Seed Association (ESA)

Federation of Latin American Seed Associations

Inter-American Institute for Cooperation on Agriculture (IICA)

International Center for Agricultural Research in the Dry Areas

(WANA/ICARDA)

International Federation of Agricultural Producers (IFAP)

International Federation of Organic Agriculture Movements (IFOAM)

International Seed Testing Association (ISTA)

International Seed Trade Federation (FIS)

International Union for the Protection of New Varieties of Plants

(UPOV)

Latin American Integration Association (ALADI)

UN Economic Commission for Europe (UNECE)

UN Food and Agricultural Organization (FAO)

West Asia and North Africa Seed Network (W.A.N.A)

30th January 1962(OEEC 30th May 1958)

Unspecified

\footnotetext{
${ }^{1}$ Note: The Director-General of WIPO (World Intellectual Property Orgorganisation) is the Secretary-General of UPOV.
} 


\section{SCHEME FOR SUBTERRANEAN CLOVER AND SIMILAR SPECIES}

OECD Members:

\section{Observers: ${ }^{1}$}

Date of creation:

Duration:
Australia
France
Portugal
Spain
New Zealand
Moldova

African Seed Trade Association (AFSTA)

Asia and Pacific Seed Association (ASPA)

Association of Official Seed Analysts (AOSA)

Association of Official Seed Certifying Agencies (AOSCA)

Bioversity International

Committee of Professional Agricultural Organisations in the

European Union (COPA)

Convention on Biological Diversity (CBD)

Eastern European Seed Network (EESNET)

European Association for Research on Plant Breeding (EUCARPIA)

European Seed Association (ESA)

Federation of Latin American Seed Associations

Inter-American Institute for Cooperation on Agriculture (IICA)

International Center for Agricultural Research in the Dry Areas

(WANA/ICARDA)

International Federation of Agricultural Producers (IFAP)

International Federation of Organic Agriculture Movements (IFOAM)

International Seed Testing Association (ISTA)

International Seed Trade Federation (FIS)

International Union for the Protection of New Varieties of Plants

(UPOV)

Latin American Integration Association (ALADI)

UN Economic Commission for Europe (UNECE)

UN Food and Agricultural Organization (FAO)

West Asia and North Africa Seed Network (W.A.N.A)

30th January 1962 (OEEC 30th May 1958)

Unspecified

\footnotetext{
Note: The Director-General of WIPO (World Intellectual Property Organization) is the Secretary General of UPOV.
} 


\section{SCHEME FOR VEGETABLES}

OECD Members:

Non-OECD Members:

\section{Observers: ${ }^{1}$}

Date of creation:

Duration:

\author{
Australia \\ Austria \\ Belgium \\ Czech Republic \\ Denmark \\ Finland \\ France \\ Germany \\ Iceland
}

Estonia
Israel
Russian Federation
Brazil
India
South Africa
Bolivia

\author{
Italy \\ Mexico \\ Netherlands \\ Portugal \\ Slovak Republic \\ Sweden \\ Switzerland \\ Turkey \\ United Kingdom
}

Cyprus
Egypt
Moldova
Morocco
Romania
Serbia
Uganda

African Seed Trade Association (AFSTA)

Asia and Pacific Seed Association (ASPA)

Association of Official Seed Analysts (AOSA)

Association of Official Seed Certifying Agencies (AOSCA)

Bioversity International

Committee of Professional Agricultural Organisations in the

European Union (COPA)

Convention on Biological Diversity (CBD)

Eastern European Seed Network (EESNET)

European Association for Research on Plant Breeding (EUCARPIA)

European Seed Association (ESA)

Federation of Latin American Seed Associations

Inter-American Institute for Cooperation on Agriculture (IICA)

International Center for Agricultural Research in the Dry Areas

(WANA/ICARDA)

International Federation of Agricultural Producers (IFAP)

International Federation of Organic Agriculture Movements (IFOAM)

International Seed Testing Association (ISTA)

International Seed Trade Federation (FIS)

International Union for the Protection of New Varieties of Plants

(UPOV)

Latin American Integration Association (ALADI)

UN Economic Commission for Europe (UNECE)

UN Food and Agricultural Organization (FAO)

West Asia and North Africa Seed Network (W.A.N.A)

30th January 1962(OEEC 30th May 1958)

Unspecified

\footnotetext{
${ }^{1}$ Note: The Director-General of WIPO (World Intellectual Property Organization) is the Secretary General of UPOV.
} 


\section{OECD SCHEME FOR THE CERTIFICATION OF FOREST REPRODUCTIVE MATERIAL}

\section{MOVING IN INTERNATIONAL TRADE}

Chair:

Vice-Chairs:

OECD Members:

Non-OECD Members:

Observers: ${ }^{1}$

Date of creation:

Duration:
Mr. Pierre Bouillon

(France)

Mrs. Lolona Ramamonjisoa

Mr. Dale Simpson

(Madagascar)

(Canada)

Austria

Belgium

Canada

Denmark

Finland

France

Germany

Hungary

Ireland

Italy

Burkina Faso
Croatia
Madagascar

Netherlands

Norway

Portugal

Slovak Republic

Spain

Sweden

Switzerland

Turkey

United States

Romania

Rwanda

Serbia

Bioversity International

Center for International Forestry Research (CIFOR)

Committee of Professional Agricultural Organisations in the

European Union (COPA)

European Forest Nursery Association (EFNA)

International Federation of Agricultural Producers (IFAP)

International Plant Genetic Resources Institute (IPGRI)

International Seed Testing Association (ISTA)

International Seed Trade Federation (FIS)

International Union for the Protection of New Varieties of Plants (UPOV)

International Union of Forestry Research Organisations (IUFRO)

UN Food and Agricultural Organization (FAO)

30th May 1967

Unspecified

Mandate: - Decision of the Council Establishing an OECD Scheme for the Control of Forest Reproductive Material Moving in International Trade [C(74)29(Final)] as amended by the Decisions of the Council [C(91)21/FINAL] and [C(2001)268 and $\mathrm{C} / \mathrm{M}(2001) 26$, Item 442].

- Council Summary record of the 1158th session held on 12 July 2007 [C/M(2007)11, Item 152 and C(2007)69]

\footnotetext{
${ }^{1}$ Note: The Director-General of WIPO (World Intellectual Property Organisation) is the Secretary-General of UPOV.
} 


\section{Extract from Annex I to the Decision of the Council [C(74)29(Final)]}

\section{"METHOD OF OPERATION OF THE SCHEME}

The OECD Scheme for Forest Reproductive Material is open, on a voluntary basis, to all Member countries of the Organisation, as well as to other States being Member countries of the United Nations Organisation or its Specialised Agencies. If a country participates in the OECD Scheme for Forest Reproductive Material, the Rules of this Scheme must be strictly observed for all reproductive material carrying the OECD label.

a) Designated Authorities

i) The government of each country participating in the OECD Scheme for Forest Reproductive Material will designate the Authority or Authorities to implement the Scheme in that country.

ii) The names and addresses of the National Designated Authorities and any changes in their designation will be circulated by the OECD to all countries participating in the Scheme and to all observers.

b) Review and Co-ordination

i) The operation and progress of the Scheme shall be reviewed as necessary (in practice every two years) at meetings of representatives of the national Designated Authorities. These meetings will report on the working of the Scheme and make such proposals as are deemed necessary to the Committee for Agriculture of the OECD.

ii) The necessary co-ordination of the operation of the Scheme at the international level shall be ensured by the OECD.

c)

\section{$\underline{\text { Responsibility }}$}

i) When forest reproductive material is labelled and sealed under one of the categories defined in these Rules and Directions it is understood that all controls have been made in strict accordance with the Rules and Directions." 


\section{TESTING OF AGRICULTURAL AND FORESTRY TRACTORS}

Chair:

Vice-Chairs:

OECD Members:

Non-OECD Members:

Observers:

Date of creation:

Duration:

Austria

Belgium

Czech Republic

Denmark

Finland

France

Germany

Greece

Iceland

Ireland

Italy

Japan

Korea

Unspecified
(United States)

(...)

(Austria)

Luxembourg

Netherlands

Norway

Poland

Portugal

Slovak Republic

Spain

Sweden

Switzerland

Turkey

United Kingdom

United States

\section{Russian Federation \\ India \\ People's Republic of China \\ Serbia}
Committee of Professional Agricultural Organisations in the European Union (COPA)
European Committee for Standardization (CEN)
European Committee of Association of Manufacturers of Agricultural Machinery (CEMA)
European Free Trade Association (EFTA)
International Commission of Agricultural Engineering (CIGR)
International Federation of Agricultural Producers (IFAP)
International Organisation for Standardisation (ISO)
UN Economic Commission for Europe (UNECE)
UN Food and Agricultural Organization (FAO)

3rd May 1962(OEEC 21st April 1959)

Mandate: Decision revising the Decision of the Council establishing the OECD Standard Codes for the Official Testing of Agricultural and Forestry Tractors [C(2005)1 and $\mathrm{C} / \mathrm{M}(2005) 9$, Item 105].

Appendix 3 to the decision [C(2005)1 and C/M(2005)9, Item 105]

METHOD OF OPERATION

1. The names and addresses of the national Authorities designated for operating the Codes and any changes in their designation will be circulated by the OECD to all countries participating in the Codes and to all observers.

2. The operation and development of the Codes shall be reviewed at the Annual Meeting of representatives of the Designated Authorities where Participating Member and non member 
Countries hold office strictly in alphabetic order. This Annual Meeting shall report on its work and make such proposals as deemed necessary to the Council of the OECD, subject to prior endorsement by the Committee for Agriculture.

3. The Officers of the Annual Meeting will be a Chairman, two Vice-Chairmen, who will be nominated at the end of the previous session. They shall take up their duties upon official approval of the Summary Record from the previous Annual Meeting.

4. In order to ensure continuity and efficient co-operation with the Secretariat, except as otherwise provided in the Rules of Procedure of the Organisation, it is desirable that a ChairmanDesignate be appointed to fill one of the offices of Vice-Chairman together with the Past-Chairman. Their terms should not exceed two years. The chairmanship should reflect the participation of various regions of the world and alternate between representatives of European Union Member States and other countries.

5. The chairmanship shall be carried out in one of the two official languages of the Organisation, even if interpretation in a third language is available at the meetings.

6. The co-ordination of Codes implementation on an international level shall be ensured by the OECD. However, the verification of individual test reports submitted by the participating Members as well as the related tasks may be delegated, by contract, to a national institute of a Member Country which will act as Co-ordinating Centre for the OECD Tests. The costs incurred shall be recovered under the annual contract between the OECD Secretariat and this Institute.

7. An Advisory Group is made up of the Officers of the Annual Meeting, and the Coordinating Centre takes part in its work. The Advisory Group shall assist in the preparation of the next Annual Meeting and, where necessary, propose solutions to the Secretariat to deal with urgent problems which may arise out of Codes implementation. The Advisory Group is convoked by the Secretariat at the request of any one of its Members or any country participating in the Codes to provide counsel in writing and invite one or more participating countries to be represented.

8. The Advisory Group will deal with any questions raised by a National Designated Authority regarding denied approval of a test report. The Advisory Group will take the following steps;

8.1 On the basis of the evidence submitted by the National Designated Authority concerned and the Co-ordinating Centre, the Advisory Group will make an initial decision within a week on whether the issue raised merits further examination and respond to the party or parties raising it. Any member of the Advisory Group who is directly involved or connected with the matter will be exempt from taking part in the initial decision. The Advisory Group may seek assistance from one or two experts;

8.2 Where the issue raised merits further examination, the Advisory Group will offer good offices to help to resolve the issue. For this purpose, the Advisory Group will consult with these parties and, where appropriate, seek advice from relevant authorities, and/or manufacturers, other non-governmental organisations, and legal or technical experts as it sees fit;

8.3 If the parties involved do not reach an agreement on the issues raised within two weeks, the Advisory Group will issue a written statement, make recommendations as appropriate on the interpretation of the Codes and their implementation, and refer the matter to the next Annual Meeting;

8.4 While the procedures under paragraph 2 are underway, confidentiality of the proceedings will be maintained;

8.5 If issues arise in non-adhering countries, the Advisory Group will take steps to develop an understanding of the issues involved and follow these procedures where relevant and practicable.

9. When a test report is published, it is understood that all specifications of the tractor or protective structure have been inspected as well as possible and that all tests have been made in strict compliance with the Codes. 


$\begin{array}{lll}\text { Chair: } & \text { Mr. Michel Dodet } & \text { (France) } \\ \text { Vice-Chair: } & \text { Mr. Yvon Martel } & \text { (Canada) } \\ & \text { Australia } & \text { Japan } \\ \text { Members: } & \text { Austria } & \text { Korea } \\ & \text { Belgium } & \text { Netherlands } \\ \text { Canada } & \text { New Zealand } \\ & \text { Czech Republic } & \text { Norway } \\ & \text { Denmark } & \text { Poland } \\ & \text { Finland } & \text { Portugal } \\ & \text { France } & \text { Slovak Republic } \\ & \text { Germany } & \text { Spain } \\ & \text { Greece } & \text { Sweden } \\ & \text { Hungary } & \text { Switzerland } \\ \text { Ireland } & \text { United Kingdom } \\ \text { Italy } & \text { United States }\end{array}$

Date of creation: 1st January 2000

Duration: $\quad 31$ st December 2009

Mandate: Decision of the Council concerning a Part II Programme: Biological Resource Management for Sustainable Agricultural Systems [C(2004)108] approved by the Council at its 1092nd session on 26 July 2004 [C/M(2004)18, item 236]

\section{Extract of the Decision of the Council [C(2004)108]}

"THE COUNCIL,

Having regard to the Convention on the Organisation for Economic Co-operation and Development of 14th December 1960 and, in particular, Articles 2 a) and b) and 5 a);

Article 5 thereof;

Having regard to the Financial Regulations of the Organisation and, in particular,

Having regard to the Decision of the Council C(99)169/FINAL;

Having regard to the proposal of the Governing Body of the Co-operative Research Programme: Biological Resource Management for Sustainable Agricultural Systems;

Having regard to the favourable opinion of the Committee for Agriculture;

Having regard to the decision of the Council to fund the 'Co-operative Research Programme: Biological Resource Management for Sustainable Agricultural Systems' as a nonconsolidated programme within Part II of the Budget of the Organisation [C(2004)96]. 
DECIDES:

Article 1

\section{DEFINITION OF THE RESEARCH PROGRAMME AND WORK PROGRAMME}

a) The Co-operative Research Programme: Biological Resource Management for Sustainable Agricultural Systems (hereinafter 'the Research Programme') defined in the Appendix to this Decision is hereby established as part of the co-operative effort between research institutions of Member countries in order to develop agricultural research.

b) A work programme, drawn up within the framework of the Research Programme, shall be adopted by the Council and implemented by the Secretary-General.

\section{Article 2}

\section{COMPOSITION OF THE GOVERNING BODY}

a) The Governing Body of the Research Programme (hereinafter called the 'Governing Body') shall be composed of one representative appointed by the Government of each participating country. Representatives should be chosen by virtue of their responsibilities in matters relating to agriculture or food.

b) The Government of each participating country may appoint an alternate to its representative on the Governing Body.

c) The Governing Body shall designate each year from among its members a Chair and a Vice-Chair.

d) The Governing Body may invite Member countries not participating in the Research Programme to be represented by observers.

\section{Article 3}

\section{FUNCTIONS OF THE GOVERNING BODY}

a) The Governing Body shall be competent to consider all questions related to the carrying out of the Research Programme. It shall exercise its functions in accordance with the Decisions and Resolutions of the Council and shall, in particular, exercise the functions defined in this Decision as well as such other functions as may be assigned to it by the Council.

b) The Governing Body shall define the general orientation of the Research Programme and shall prepare the draft upcoming programme and budget.

c) The Governing Body shall submit a summary report of work each year to the Committee for Agriculture for information and advice.

\section{Article 4}

\section{COMPOSITION OF THE MANAGEMENT COMMITTEE}

a) The Management Committee of the Research Programme (hereinafter called the 'Management Committee') shall be composed of eight members designated by the Governing Body from a list of distinguished individuals proposed by Governments of participating countries. Four members of the Management Committee shall be chosen by virtue of their scientific responsibilities in the topics of the Research Programme; the four other members of the Management Committee shall have responsibilities at a high level in the administration of agricultural research. In designating these members, the Governing Body shall ensure that, over the Programme period, two Scientific Coordinators and two Research Administrators rotate, preferably on an alternative basis. 
b) The Management Committee shall designate each year from amongst its members a Chair and a Vice-Chair.

\section{Article 5}

\section{FUNCTIONS OF THE MANAGEMENT COMMITTEE}

a) The Management Committee shall be responsible for implementing the programme and ensuring its scientific direction.

b) The Management Committee shall submit to the Governing Body proposals for the upcoming programme and budget.

c) The Management Committee shall submit to the Governing Body regular reports on the implementation of the programme.

\section{Article 6}

\section{FINANCING OF EXPENDITURE}

a) The expenditure arising from the implementation of the programme shall be defrayed from the appropriations authorised for it under Part II of the Budget of the Organisation.

b) The programme may include activities to be financed in whole or in part from grants by public or private institutions.

\section{Article 7}

\section{PARTICIPATING COUNTRIES}

a) The countries participating in the Research Programme shall be: Australia, Austria, Belgium, Canada, Czech Republic, Denmark, Finland, France, Germany, Greece, Hungary, Ireland, Italy, Japan, Korea, Netherlands, New Zealand, Norway, Poland, Portugal, Spain, Slovak Republic, Sweden, Switzerland, United Kingdom and the United States.

b) Any Member country of the Organisation which does not participate in the present Programme or any country having observer status in the Committee for Agriculture may participate in it by addressing a notification to the Secretary-General to this effect.

c) On the basis of a justified opinion of the Governing Body, the Organisation may invite any other country to participate in the present Programme. Such participation will become effective on the date of reception of the acceptance of that invitation by the Secretary-General. The Organisation may suspend or terminate that participation by giving one month's written notice of suspension or twelve months' written notice of termination to that country.

\section{Article 8}

\section{DURATION AND REVIEW}

a) The Research Programme is established for a period of five years from 1 January 2005.

b) By the end of this period, taking into account the results obtained and the recommendations made by the Governing Body, the Committee for Agriculture shall present to the Council proposals concerning the future of the Research Programme." 

Chair:

Vice-Chairs:

Members:

Observers:

Date of creation:

Duration:
Mr. Greg Schneider

Ms. Lori Ridgeway

Mr. Philippe Ferlin

Mr. Sang-Go Lee

Mr. Leon Lomans
(United States)

(Canada)

(France)

(Korea)

(Netherlands)

Open to all Member countries

Russian Federation

Argentina

Chinese Taipei

Thailand

UN Food and Agricultural Organization (FAO)

World Bank

World Trade Organization (WTO)

30th September 1961

31st December 2013

Mandate: Resolution of the Council concerning the mandate of the Fisheries Committee [C(2008)193/REV1] adopted at its 1185th session on 4 December 2008 [C/M(2008)21, item 304]

\section{Resolution of the Council [C(2008)193/REV1 and C/M(2008)21, Item 304]}

\section{"THE COUNCIL,}

Having regard to the Convention on the Organisation for Economic Co-operation and Development of 14 December 1960;

Having regard to the Rules of Procedure of the Organisation;

Having regard to paragraphs 21, 24 and 89 of the Report of the Preparatory Committee creating the fisheries Committee as of 30 September 1961;

Having regard to Decision of Council regarding a Sunset Clause for all Committees [C/M(2004)5, item 75] which entered into force on 22 April 2004 [C/M(2004)10, Item 143, IV, c)];

Having regard to the recommendation of the In-depth Evaluation of the Fisheries Committee [C(2008)80 and CORR1], approved by the Council at its 1179th Session on 17 July 2008 [C/2008)15, item 172]; [C(2008)193/REV1];

Having regard to the proposal to revise the mandate of the Fisheries Committee 


\section{DECIDES:}

A. The mandate of the Fisheries is as follows:

I. Objectives

The overarching policy objective of the Fisheries Committee is to use the specific strengths of the OECD to help promote well-managed, efficient and resilient fisheries and aquaculture that contribute to healthy ecosystems, while supporting sustainable livelihoods and communities, as well as to contribute to responsible trade and consumption.

Specifically, the Committee is mandated to achieve this outcome through:

- Helping OECD countries to identify needs, options and implementation advice for improved domestic fisheries and aquaculture policy - through effective monitoring, analysis and discussion of policy gaps, options and tradeoffs, and lessons from best practice;

- Improving the analytical foundations of international fisheries and aquaculture policy debate and agenda-setting by providing policy analysis and advice, especially on emerging issues, especially with a view to help develop consensus on sound management practices; and;

- Enriching OECD priorities and debate on cross-cutting issues by adding perspectives of management challenges in a global, common-property and natural renewable resource to ensure that OECD wide policy advice is relevant to all economic sectors;

These objectives will be achieved through: collection, assessment and dissemination of key data; monitoring and analysis of structural, economic and policy developments throughout the supply chain (from fisher/producer to consumer), and of the implications for the fisheries and aquaculture sectors and policies; policy dialogue and the provision of advice and recommendations; and outreach activities to ensure that the Committee is both open to diverse points of view and to maximize the impact of its work (see Appendix).

\section{Co-ordination}

To fulfil its mandate the Committee will, as appropriate, coordinate its activities with other bodies within the Organisation, and with other international organisations (in particular the FAO, the WTO, the World Bank and regional organisations, as appropriate), and undertake dialogue with fisheries stakeholders, including industry and non-governmental organisations.

B. The mandate of the Fisheries Committee shall remain in force until 31 December 2013 unless the Council decides otherwise.

\section{APPENDIX}

The Committee will ensure high-quality economic analysis, policy advice and an understanding of best practice, to enable wise management, good governance and sound commercial arrangements of fisheries. The Committee will provide a forum for the discussion of issues related to all aspects of fisheries and aquaculture developments and policies, with a view to promoting mutual understanding of these developments - the expected outcome of which is to enable wise management, good governance and sound commercial arrangements of fisheries and aquaculture, at both the domestic and the international level. 


\section{Context}

The activities of the Committee are guided by the following context, which describes the environment in which the mandate of the Committee is anchored:

- The strength of the OECD in economic analysis, and its emphasis on economic efficiency as an important benchmark for analysis of domestic and international policy questions and options, including to ensure fisheries sustainability;

- The importance of fisheries sustainability and healthy marine ecosystems to economic and social wellbeing, and the need to both ensure recovery of stocks that are already depleted or over fished and address emerging threats to sustainability;

- The interconnectedness of the fisheries sector with other sectors and the international economy (i.e., through trade, investment, services, labour, technology and environmental policies), and the implications of these linkages for managing opportunities and risks for fisheries;

- The importance of efficient and effective conservation and management policies and international cooperation to sustain a common property resource such as fisheries, complemented by the role of market-based approaches and responsible trade in aligning incentives coherently;

- Due regard to the mandate of other OECD committees whose work has implications for fisheries, cross-cutting OECD issues, and other international bodies addressing fishery-related issues, and the specific strength of the Committee in economic and policy analysis in complementing this work;

- The special and diverse challenges to fisheries posed by emerging issues such as globalisation and responsible trade. This includes the need for policy coherence in helping address the sustainable development needs and aspirations of non-OECD Members, especially developing countries;

- The dynamic nature of both the fisheries and OECD-wide policy agenda, and the need for the Committee to be alert, and able to respond, to new developments and policy priorities affecting its work.

Activities

The Committee's mandate frames the development and delivery of a programme of work and budget consistent with OECD planning parameters which addresses current and emerging issues in the fisheries sector:

- Collection, integration, assessment and dissemination of key national and international fisheries statistics and policy analysis;

- Monitoring of current and emerging OECD and global trends, issues and policy developments relevant to the fisheries sector, with a view to identifying policy issues benefiting from in-depth analysis at the OECD;

- In-depth analysis of key current and emerging fisheries-related economic and policy issues, to better understand their nature and identify possible remedies at both the domestic and global level;

- Policy dialogue to explore benefits and costs of policy options, promote lessons learned from across OECD Members, seek agreement on policy principles and recommend ways forward to improve the sustainability and efficiency of the fisheries sector; 
- Development and dissemination of policy advice, recommendations and best practice to help inform OECD Members and non-Members regarding domestic and international fisheries issues;

- Outreach activities that will demonstrate openness to diverse views in informing the Committee's activities, transparency about Committee activities, broaden the knowledge base for OECD Members and non-Members, and maximize the policy impact of the Committee's work; and

- A proactive communications strategy to ensure the widespread dissemination and maximum and long-lasting influence of the Committee's work among OECD Members, non-Members, within the OECD Secretariat, and in other relevant international bodies.

Monitoring

The Committee will periodically review its work, working methods and outcomes using, as appropriate, generic performance measures. These will be assessed in relation to its mandate and specific work deliverables, as enumerated in the Organisation's Programme of Work and Budget. The Committee will report to the Organisation, as required. The Committee will review its mandate on a regular basis in light of emerging developments and issues." 
FINANCIAL AND ENTERPRISE AFFAIRS 



\section{INVESTMENT COMMITTEE}

Chair:

Mr. Manfred Schekulin

(Austria)

Vice-Chairs:

Mr. Wesley Scholz

(United States)

Mr. Kenko Sone

(Japan)

Bureau Members:

Mr. Gregorio Manuel Canales

(Mexico)

Ramírez

Mr. Patrick Colmer

(Australia)

Mr. Wolfgang Igler

Mr. Vernon MacKay

Mr. Roel Nieuwenkamp

(European Commission)

(Canada)

(Netherlands)

Members:

Open to all Member countries

Observers:

Argentina

Brazil

Chile

International Monetary Fund (IMF)

UN Conference on Trade and Development (UNCTAD)

World Bank

World Trade Organization (WTO)

Date of creation:

1st March 2004

Duration:

31st December 2013

Mandate: Resolution of the Council on the Terms of Reference of the Investment Committee [C(2008)169 and C/M(2008)20, item 286, ii)]

\section{Resolution of the Council [C(2008)169 and C/M(2008)20, Item 286 ii)]}

\section{"THE COUNCIL}

Having regard to the Convention on the Organisation for Economic Co-operation and Development of 14 December 1960 and, in particular, articles 1, 3, 5a) and 9 thereof;

iii);

Having regard to the Rules of Procedure of the Organisation and in particular Rule 18 a)

Having regard to the Resolution of the Council C(2004)3 and CORR1;

Having regard to the proposal to revise the mandate C(2008)169;

DECIDES:

A. The Investment Committee (hereinafter "the Committee") has the following mandate:

i) Objectives

a. The mission of the Committee is to promote investment for growth and sustainable development worldwide by advancing international co-operation and policy reform;

b. Its main objectives include: 
ii) Method

-maintaining and expanding open and transparent policy frameworks for investment, capital movements and services;

-promoting responsible business conduct in a globalising economy;

-supporting the development and enhancing the outcomes of international investment agreements;

-improving measurement and analysis of emerging investment trends.

In order to achieve these objectives, the Committee shall:

a. act as a forum for peer surveillance of policy developments and multilateral dialogue on best practices in the fields of international investment and multinational enterprises, capital movements, and international financial and other services covered by the OECD investment instruments;

b. actively engage with major emerging and other non-Member economies, in particular through non-Members' adherence to existing OECD investment instruments, close association in the design of new or revised instruments, policy dialogue and assistance from the Committee;

c. carry out the tasks assigned to it by the OECD Codes of Liberalisation of Capital Movements and of Current Invisible Operations and Council Decisions related to the OECD Declaration on International Investment and Multinational Enterprises; tasks resulting from the OECD Recommendation on the OECD Benchmark Definition of Foreign Direct Investment and the OECD Recommendation on the OECD Principles for Private Sector Participation in Infrastructure; such other tasks as the Council may assign to it;

d. be responsible for monitoring and promoting coherence of all work carried out within the Organisation, including contributions to horizontal projects, in the field of international investment and multinational enterprises, capital movements and international financial and other services as covered by the OECD Codes, and for presenting recommendations and proposals for this purpose to the Council or to other committees;

e. focus its work on delivering policy and analytical outputs of high quality and with high impact and regularly evaluate how well the Committee is meeting its objectives.

iii) Co-operation

The Committee shall:

a. co-operate with other OECD bodies, including those involved in the work on the Policy Framework for Investment, and in this context promote whole-ofgovernment approaches to policies relating to investment;

b. promote and develop strategic partnerships with the relevant international and regional organisations, in particular in the context of capacity building programmes with non-Members, to avoid duplication of work and maximise synergies;

c. promote dialogue with, and consider input to its work from the business community, labour representatives, other major civil society stakeholders and leading academics.

B. The mandate of the Investment Committee shall remain in force until 31 December 2013, unless the Council decides otherwise." 


\section{GLOBAL FORUM ON INTERNATIONAL INVESTMENT ${ }^{1}$}

Chair:

Date of creation:

Duration:

Approved by:
No formally-appointed Chair

1st January 2009

31st December 2013

The Advisory Group on Co-operation with Non-Members on behalf of the Investment Committee, 7 October 2008 [DAF/INV/AGC/M(2008)2]

\section{Mission Statement:}

The mission of the OECD Global Forum on International Investment is to support the international investment policy community in its efforts to promote open, transparent and rulesbased investment policy frameworks for growth and sustainable development worldwide through informed, evidence-based policy dialogue and peer learning on pressing current and emerging issues.

\section{Members:}

Designated Participants:

\section{Open to all Member countries}

Accession and Enhanced Engagement countries :Chile, Estonia, Israel, Russian Federation, Slovenia

The OECD Investment Committee has an on-going programme involving requests for adherence to the OECD Declaration on International Investment and Multinational Enterprises. All adherents and applicants (Argentina, Egypt, Jordan, Latvia, Lithuania, Morocco, Peru, Romania, Serbia) have Designated Participant status.

The OECD Investment Committee also oversees extensive regional initiatives and active participants in such initiatives have Designated Participant status. These include :

- Countries not previously listed that participate in the Investment Compact South Eastern Europe programme: Albania, Bosnia and Herzegovina, Bulgaria, Croatia, FYROM, Moldova, Montenegro;

- Countries not previously listed that participate in the MENAOECD Investment Initiative: Algeria, Bahrain, Djibouti, Iraq, Kuwait, Lebanon, Oman, Qatar, Saudi Arabia, Tunisia, United Arab Emirates, Yemen;

- Countries not previously listed that participate in the NEPADOECD Africa Investment Initiative: Angola, Benin, Botswana, Burkina Faso, Burundi, Cameroon, Congo, Democratic Republic of Congo, Ethiopia, Gabon, Ghana, Kenya, Lesotho, Madagascar, Malawi, Mali, Mauritius, Mozambique, Namibia, Niger, Nigeria, Rwanda, Senegal, Tanzania, Uganda, Zambia

In addition, the Investment Committee has maintained active relations with those countries not previously listed in the following regions, which have Designated Participant status:

\footnotetext{
1 Information on this Global Forum is provided for the sake of completeness, but Global Forums are not, in accordance with C(2008)208/FINAL, official OECD bodies.
} 
- Caucasus: Armenia, Azerbaijan, Georgia;

- Central Asia: Afghanistan, Kazakhstan, Kyrgyzstan, Mongolia, Tajikistan, Turkmenistan, Uzbekistan;

- Eastern Europe: Ukraine;

- Latin America, excluding Observers and other Declaration adherents: Costa Rica;

- South Asia: Bangladesh, Nepal;

- South East Asia, especially within the context of on-going cooperation with APEC and ASEAN: Cambodia, Philippines, Thailand, Vietnam. 


\section{WORKING GROUP ON BRIBERY IN INTERNATIONAL BUSINESS TRANSACTIONS}

Chair:

Vice-Chair:

Members:

Full Participants: ${ }^{1}$

Observers:

Date of creation:

Duration:
Mr. Mark Pieth

(Other)

Mrs. Maria Gavouneli

(Greece)

Open to all Member countries

Chile

Estonia

Israel

Slovenia
Brazil

South Africa

Argentina

Bulgaria

Mandate: - Minutes of the meeting held 5 October 1994 of the IME Committee [IME/M(94)2/ANN]

- Revised Recommendation on Combating Bribery in International Business Transaction [C(97)123/FINAL]

- Decision of the Council concerning further work on Combating Bribery in International Business Transactions [C(97)240/FINAL]

The Committee on International Investment and Multinational Enterprises, as a follow-up to the Recommendation on Bribery in International Business Transactions adopted by the Council in May 1994, established the Working Group on Bribery in International Business Transactions.

The mandate of the Working Group was amended by the 1997 Revised Recommendation.

\section{Extract from the Revised Recommendation [C(97)123/FINAL]}

"Follow-up and institutional arrangements

VIII. INSTRUCTS the Committee on International Investment and Multinational Enterprises, through its Working Group on Bribery in International Business Transactions, to carry out a programme of systematic follow-up to monitor and promote the full implementation of this Recommendation, in co-operation with the Committee for Fiscal Affairs, the Development Assistance Committee and other OECD bodies, as appropriate. This follow-up will include, in particular:

i) receipt of notifications and other information submitted to it by the Member countries;

\footnotetext{
${ }^{1}$ Full participants, on a basis of equality with Member countries.
} 
ii) regular reviews of steps taken by Member countries to implement the Recommendation and to make proposals, as appropriate, to assist Member countries in its implementation; these reviews will be based on the following complementary systems:

- a system of self-evaluation, where Member countries' responses on the basis of a questionnaire will provide a basis for assessing the implementation of the Recommendation;

- a system of mutual evaluation, where each Member country will be examined in turn by the Working Group on Bribery, on the basis of a report which will provide an objective assessment of the progress of the Member country in implementing the Recommendation.

iii) examination of specific issues relating to bribery in international business transactions;

iv) examination of the feasibility of broadening the scope of the work of the OECD to combat international bribery to include private sector bribery and bribery of foreign officials for reasons other than to obtain or retain business;

v) provision of regular information to the public on its work and activities and on implementation of the Recommendation.

$\mathrm{X}$.

INSTRUCTS the Committee on International Investment and Multinational Enterprises to review the implementation of Sections III and, in co-operation with the Committee on Fiscal Affairs, Section IV of this Recommendation and report to Ministers in Spring 1998, to report to the Council after the first regular review and as appropriate there after, and to review this Revised Recommendation within three years after its adoption.

Co-operation with non members

XII. INSTRUCTS the Committee on International Investment and Multinational Enterprises through its Working Group on Bribery, to provide a forum for consultations with countries which have not yet adhered, in order to promote wider participation in the Recommendation and its followup.

Relations with international governmental and non-governmental organisations

XIII. INVITES the Committee on International Investment and Multinational Enterprises through its Working Group on Bribery, to consult and co-operate with the international organisations and international financial institutions active in the combat against bribery in international business transactions and consult regularly with the non-governmental organisations and representatives of the business community active in this field."

\section{Decision of the Council Concerning Further Work on Combatting Bribery in International Business Transactions [C(97)240/FINAL]}

\section{"THE COUNCIL,}

Having regard to Article 5 a) of the Convention on the Organisation for Economic Cooperation and Development of 14 December 1960;

Considering the Revised Recommendation of the Council on Combating Bribery in International Business Transactions adopted on 23 May 1997 [C(97)123/FINAL]; 
Noting the existing mandate of the Committee on International Investment and Multinational Enterprises, through its Working Group on Bribery in International Business Transactions, pursuant to Section VIII of the Revised Recommendation, "to carry out a programme of systematic follow-up to monitor and promote the full implementation of the Revised Recommendation, in co-operation with the Committee for Fiscal Affairs, the Development Assistance Committee and other OECD bodies, as appropriate", including "examination of specific issues relating to bribery in international business transactions";

Noting in particular that there will be an examination of the feasibility of broadening the scope of the work of the OECD to include private sector corruption in international business transactions;

Noting the view of the Negotiating Conference on a Convention on Combating Bribery of Foreign Public Officials in International Business Transactions, that further work was needed on a number of related corruption issues;

DECIDES that the Committee on International Investment and Multinational Enterprises, through its Working Group on Bribery in International Business Transactions, in the context of its work pursuant to the 1997 Revised Recommendation as well as, where appropriate, the monitoring and follow-up which will be carried out under article 12 of the Convention, and in co-operation with other OECD bodies and international organisations, shall examine on a priority basis the following issues with a view to reporting conclusions to the 1999 OECD Council meeting at Ministerial level:

- $\quad$ bribery acts in relation with foreign political parties;

- advantages promised or given to any person in anticipation of that person becoming a foreign public official;

- bribery of foreign public officials as a predicate offence for money laundering legislation;

- $\quad$ the role of foreign subsidiaries and of offshore centres in bribery transactions." 


\section{WORKING PARTY OF THE INVESTMENT COMMITTEE}

\section{Chair:}

Vice-Chair:

Members:

Full Participants: ${ }^{1}$

Date of creation:

Duration:

$$
\text { Mr. Vernon MacKay }
$$

Mr. Roel Nieuwenkamp

Open to all Member countries

Chile

Estonia

Israel

Slovenia

Brazil

Argentina

20th September 2004

31st December 2013
(Canada)

(Netherlands)

Egypt

Latvia

Lithuania

Peru

Romania

Mandate: $\quad$ DAF/INV/WD(2008)11 and DAF/INV/M(2008)3

\section{Extract from document DAF/INV/WD(2008)11}

"1. The Working Party of the Investment Committee (hereafter Working Party) shall carry out the following tasks:

(i) To assist the Investment Committee in implementing the Declaration on International Investment and Multinational Enterprises and related Decisions, including with respect to its responsibilities in relation to the Guidelines on Multinational Enterprises; in considering all questions concerning the interpretation or implementation of the provisions of the OECD Codes of Liberalisation of Capital Movements and of Current Invisible Operations pursuant to their Articles 18 and 19; and in encouraging nonMembers to adhere to the Declaration.

(ii) To assist the Investment Committee in implementing the OECD Principles for Private Sector Participation in Infrastructure, other OECD Recommendations and conclusions of Investment Committee's reports adopted by the OECD Council in the field of international investment and multinational enterprises;

(iii) To prepare analytical studies, policy reports and new work proposals for consideration by the Committee;

(iv) To undertake other tasks as requested by the Investment Committee.

2. In fulfilling its tasks, the Working Party shall consult, as appropriate, other OECD bodies, international organisations or experts as well as BIAC, TUAC, other non-governmental organisations and non-Member economies.

3. Non-Members adhering to the Declaration participate in the work of the Working Party relating to the Declaration.

4. The Working Party shall make regular reports on its activities to the Investment Committee.

5. The mandate of the Working Party shall remain in force until 31 December 2013 unless the Investment Committee decides otherwise."

\footnotetext{
1 The "sui generis" participation of non-Members in Investment Committee work related to the Declaration on International Investment and Multinational Enterprises is, for practical reasons, included in this category.
} 


\section{ADVISORY GROUP ON CO-OPERATION WITH NON-MEMBERS}

$\begin{array}{lll}\text { Chair: } & \begin{array}{l}\text { Mr. Gregorio Manuel Canales } \\ \text { Ramírez }\end{array} & \text { (Mexico) } \\ \text { Vice-Chair: } & \text { Mr. Patrick Colmer } & \text { (Australia) } \\ \text { Members: } & \text { Open to all Member countries } & \\ \text { Observers: } & \begin{array}{l}\text { Chile } \\ \text { Brazil } \\ \text { Argentina }\end{array} \\ \text { Date of creation: } & \text { January 2001 } \\ \text { Duration: } & \text { 31st December } 2013\end{array}$

Mandate: $\quad$ DAF/INV/WD(2008)11 and DAF/INV/M(2008)3

\section{Extract from document DAF/INV/WD(2008)11}

"1. The Advisory Group on Co-operation with non-Members (hereafter Advisory Group) shall assist the Investment Committee in carrying out its work with non-Member economies and in providing input as appropriate to other OECD activities with non-Members; it shall advise the Committee on work priorities, ensuring the integration of non-Member and other Committee's work, costs and funding, and evaluation of work performance.

2. The Advisory Group shall be guided in its activities and recommendations to the Committee by the following principles: i) work with non-members should be in line with the priorities of the Organisation and guidance of the Council, including the 2007 Resolution on Enhanced Engagement; ii) projects should be designed so as to enhance opportunities for government-togovernment dialogue and be selected if the Organisation has a demonstrated comparative advantage relative to other organisations; iii) policy areas for dialogue should be based on on-going core work of the Committee and take maximum advantage of the Policy Framework for Investment as an organising principle for co-operation; iv) their selection should reflect country and region needs; v) projects based on sustained commitments for outreach should be preferred over one-off events; vi) projects should be designed to lead to measurable improvements by the target countries/regions in the policy areas they seek to address;

3. The Advisory Group shall be open to all interested delegations and nonMember observers in the Committee.

4. The Chair of the Advisory Group shall make regular reports on its activities to the Committee.

5. The mandate of the Advisory Group shall remain in force until 31 December 2013 unless the Investment Committee decides otherwise." 


\section{WORKING GROUP ON INTERNATIONAL INVESTMENT STATISTICS ${ }^{1}$}

Chair:

Vice-Chairs:

Members:

Observer:

Date of creation:

Duration:
Mr. Roger De Boeck

Mr. John Fitzpatrick

Mr. S. Hagino

Mr. Alejandro Tagle

Mr. Bruno Terrien

Open to all Member countries

International Monetary Fund (IMF)

8th March 1999

31st December 2013
(Belgium)

(Ireland)

(Japan)

(Mexico)

(France)

Mandate: DAF/INV/WD(2008)11 and DAF/INV/M(2008)3

\section{Extract from document DAF/INV/WD(2008)11}

“1. The Working Group on International Investment Statistics (hereafter Working Group) shall assist the Investment Committee in pursuing its mandate conferred by Council to monitor implementation of and develop recommendations on the OECD Benchmark Definition of Foreign Direct Investment, and in keeping abreast of new developments in multinational enterprises' activities and propose adjustments to related statistics and analyses as appropriate.

2. The Working Group shall act as a forum of senior statisticians of Member countries to share experience and promote best practices with implementation of international standards, to facilitate the availability of timely, reliable and comparable statistics, to analyse these statistics, to develop relevant indicators to respond to the needs for the analysis of the global economy, and to undertake other tasks as required by the Committee, in the field of international investment and multinational enterprises.

3. The Working Group shall be responsible for monitoring and promoting co-ordination of statistical work within the Organisation and statistical co-operation with other international organisations in the field of international investment and multinational enterprises.

4. The Working Group shall review the positions of countries candidate for OECD accession under the OECD Benchmark Definition of Foreign Direct Investment in accordance with OECD accession roadmaps.

5. The Working Group shall provide a network of experts to exchange views and experiences between OECD Member and non-OECD economies on statistics of international investment and multinational enterprises, and assistance to national authorities concerning the implementation and interpretation of the OECD Benchmark Definition of Foreign Direct Investment.

6. The Working Group shall make regular reports on its activities to the Investment Committee.

7. The mandate of the Working Group shall remain in force until 31 December 2013 unless the Investment Committee decides otherwise."

\footnotetext{
${ }^{1}$ Formerly "Workshop on International Investment Statistics". See document [DAF/INV(2007)7].
} 


\section{MULTINATIONAL ENTERPRISES}

Members:

Date of creation:

Duration:
Open to all Member countries

18th June 2001 (First meeting)

Unspecified

Mandate: - Decision of the Council adopted at its 982nd session on 26-27 June 2000 [C(2000)96/FINAL and C/M(2000)17/PROV]

\section{Extract of document [C(2000)96/FINAL]}

"THE COUNCIL,

Having regard to the Convention on the Organisation for Economic Co-operation and Development of 14th December 1960;

Having regard to the OECD Declaration on International Investment and Multinational Enterprises (the "Declaration"), in which the Governments of adhering countries ("adhering countries") jointly recommend to multinational enterprises operating in or from their territories the observance of Guidelines for Multinational Enterprises (the "Guidelines");

Recognising that, since operations of multinational enterprises extend throughout the world, international co-operation on issues relating to the Declaration should extend to all countries;

Having regard to the Terms of Reference of the Committee on International Investment and Multinational Enterprises, in particular with respect to its responsibilities for the Declaration [C(84)171(Final), renewed in C/M(95)21];

Considering the Report on the First Review of the 1976 Declaration [C(79)102(Final)], the Report on the Second Review of the Declaration [C/MIN(84)5(Final)], the Report on the 1991 Review of the Declaration [DAFFE/IME(91)23], and the Report on the 2000 Review of the Guidelines [C(2000)96];

Having regard to the Second Revised Decision of the Council of June 1984 [C(84)90], amended June 1991 [C/MIN(91)7/ANN1];

Considering it desirable to enhance procedures by which consultations may take place on matters covered by these Guidelines and to promote the effectiveness of the Guidelines; Enterprises:

On the proposal of the Committee on International Investment and Multinational

\section{DECIDES:}

To repeal the Second Revised Decision of the Council of June 1984 [C(84)90], amended June 1991 [C/MIN(91)7/ANN1], and replace it with the following:

\section{National Contact Points}

1. Adhering countries shall set up National Contact Points for undertaking promotional activities, handling inquiries and for discussions with the parties concerned on all matters covered by the Guidelines so that they can contribute to the solution of problems which may arise in this 
connection, taking due account of the attached Procedural Guidance. The business community, employee organisations, and other interested parties shall be informed of the availability of such facilities.

2. National Contact Points in different countries shall co-operate if such need arises, on any matter covered bythe Guidelines relevant to their activities. As a general procedure, discussions at the national level should be initiated before contacts with other National Contact Points are undertaken.

3. National Contact Points shall meet annually to share experiences and report to the Committee on International Investment and Multinational Enterprises." 
Chair:

Vice-Chairs:

Members:

Observers:

Date of creation:

Duration:
Mr. Manuel Aguilera Verduzco

(Mexico)

Mr. Michael Kehr

Mr. Ambrogio Rinaldi

Mr. Takashi Kamiya

Mr. Claude Wirion

Mr. Willem Dorst

Mr. Michael Mayer

Mr. Robert Donovan

Open to all Member countries

Israel

Russian Federation

International Actuarial Association (IAA)

International Association of Insurance Supervisors (IAIS)

International Monetary Fund (IMF)

World Federation of Insurance Intermediaries (WFII)

30th September 1961

31st July 2012
(Germany)

(Italy)

(Japan)

(Luxembourg)

(Netherlands)

(Switzerland)

(United States)

Mandate: Resolution concerning the mandate of the Insurance and Private Pensions Committee adopted by the Council at its 1159th session on 12 September 2007 [C(2007)86/REV1 and C/M(2007)12, item 160]

\section{Resolution of the Council [C(2007)86/REV1 and C/M(2007)12, item 160]}

"THE COUNCIL

Having regard to the Convention on the Organisation for Economic Co-operation and Development of 14 December 1960;

Having regard to the Rules of the Procedure of the Organisation;

Having regard to the Recommendations of the Council on the In-Depth Evaluation of the Insurance and Private Pensions Committee [C/M(2007)3, Item 27];

\section{DECIDES}

1. The mandate of the Insurance and Private Pensions Committee is as follows:

Objectives

- The overarching objective of the Insurance and Private Pensions Committee (hereinafter called 'The Committee') is to promote efficient, open and sound market-oriented insurance and private pensions systems, based on high levels of transparency, confidence, and integrity, and respecting recognised social objectives of these systems. The Committee shall assist policymakers in designing, adopting and implementing policies for achieving this objective. 
- The main objectives of the Committee shall include:

- improving insurance and private pensions awareness and education;

- strengthening private pensions systems to help them address the challenges of ageing;

- enhancing the efficiency and effectiveness of insurance and private pensions regulation;

- improving the financial management of large-scale risks.

Methods

- In order to achieve these objectives, the Committee shall:

- enhance surveillance of insurance and private pensions markets developments and of their impact on economic growth and development;

- focus its work on delivering outputs of high quality and with high policy impacts and shall regularly assess whether these targets are being met. It shall strive to achieve these targets through policy dialogue, the collection of information and statistics, the development of policy analysis, and the elaboration of policy options and of good practices, guidelines and principles for adequate policies and regulations, and mechanisms to foster their appropriate implementation,

- monitor and co-ordinate work undertaken by the Organisation in the insurance and private pensions fields and, as appropriate, submit opinions, recommendations and proposals to the Council or to other Committees.

- The Committee shall consider revisions to the mandate whenever appropriate, for instance following major policy developments in insurance and private pensions markets.

Co-operation

- The Committee shall co-operate with relevant OECD bodies, and especially the Committee on Financial Markets and the Working Party on Social Policy. It will also cooperate as necessary with the Investment Committee on work related to the insurance and pensions provisions of the OECD Codes of Liberalisation.

- The Committee shall keep itself informed of the activities carried out in other international bodies in respect of insurance and private pensions, coordinate work and avoid duplication with these bodies, especially the IOPS ${ }^{1}$ and the IAIS ${ }^{2}$, and shall provide a forum for consultations among Member countries to enable them to exchange views on issues raised in these bodies.

- The Committee shall co-operate closely with the major stakeholders in insurance and private pensions field, including in particular industry and -- whenever feasible -consumers.

- The Committee shall, to the extent permitted by its resources, promote policy dialogue and co-operation with non-Member economies, encourage the implementation of best principles and practices, and provide related assistance. The work related to non-Member economies will be fully integrated into the programme of work of the Committee.

2. The mandate of the Insurance and Private Pensions Committee shall remain in force until 31 July 2012 unless the Council decides otherwise."

\footnotetext{
${ }^{1}$ International Organisation of Pension Supervisors.

${ }^{2}$ International Association of Insurance Supervisors.
} 


\section{TASK FORCE ON PRIVATE HEALTH INSURANCE}

Chair:

Members: $\quad$ Open to all Member countries

Date of creation: 22nd June 2001

Duration: $\quad 31$ st July 2012

Mandate: Summary record of the 67th session of the Insurance Committee [DAFFE/AS/M(2001)2, Item 10] and document [DAFFE/AS/PHI/WD(2001)1, § 3]

\section{Extract from document [DAFFE/AS/M(2001)2, Item 10]}

"10. Private Health Insurance

The Committee:

$\cdots$

-- supported the creation of a task force on private health insurance which would be open to public and private health sector representatives; the think tank's first two tasks would be to finalise the comparative report on private health insurance in the OECD countries and to monitor the collection and analysis of statistical data on private health insurance;"

\section{Extract from document [DAFFE/AS/PHI/WD(2001)1, §3]}

"3. [...] The Insurance Committee (IC) established in June a Task Force on private health insurance, (...) whose short term main objective will be to assist in [the private health insurance] part of the [horizontal] project [on health] [...]. The Task Force may also discuss issues not directly covered by the project but of relevance for some of the topics discussed therein (for instance genetic testing, disability insurance and ageing)." 


\section{WORKING PARTY OF GOVERNMENTAL EXPERTS ON INSURANCE}

Chair:

Mr. Claude Wirion

(Luxembourg)

Members:

Open to all Member countries

Observers:

International Association of Insurance Supervisors (IAIS)

International Monetary Fund (IMF)

Date of creation:

November 1992

Duration:

31st July 2012

Mandate: -- Document [DAFFE/AS(92)23] approved by the Insurance Committee at its 50th session

-- Summary Record of the 69th Session of the Insurance Committee [DAFFE/AS/M(2002)2] and Document [DAFFE/AS(2002)3]

- Change of name of the "Working Party of governmental experts on insurance solvency" to "Working Party of insurance governmental experts" [DAFFE/AS/M(2002)2]

\section{Extract from document [DAFFE/AS(92)23]}

follows1:

"The mandate of the "Group of governmental experts on insurance solvency" is as

- this technical and ad hoc Group of governmental experts will survey and analyse regulatory and supervisory systems and techniques existing in Member countries concerning the solvency of insurance companies, the main issues currently raised in this field and measures and practices used or that could be used to address them;

- the Group will regularly report to the Insurance committee on the developments of its work;

- the Group will submit to the Insurance Committee a final report for comments and approval."

\section{Extract from the Summary Record of the 69th Session of the Insurance Committee}

\section{[DAFFE/AS/M(2002)2}

"9. The Committee:

-- endorsed the change of name of the "Working Party of governmental experts on insurance solvency" to "Working Party of insurance governmental experts."

\footnotetext{
1 The concept of "solvency" used in this mandate must be understood in the broad sense of the financial health of insurance companies (and groups of such companies), including reinsurance aspects.
} 


\section{Extract from document [DAFFE/AS(2002)3]}

"84. The Working Party will be expected to develop several further activities in 2003-2004. These activities will first include all the issues to be discussed by the Insurance Committee between governmental experts only. The Group is indeed the only forum where the Committee could hold such restricted discussion and creation of new OECD groups are currently strictly discouraged. In 2003-2004, it may be expected that such issues will be numerous; they will include the contribution to the CMIT discussion and examination of the Member countries reservations to the new obligations of the Invisible Code, the implementation of the Reinsurance Decision, the monitoring of solvency and selected other regulatory developments as well as all the issues covered by this programme of work where prior governmental discussion would be required (being on terrorism risk management, financial integrity or private heath insurance). This may especially concern issues to be developed in co-operation with the Committee on Financial Markets where delegates are governmental and central banks representatives only. All in all, the Group will thus basically deal with most of the activities of the Committee. Taking this increasing and larger role of the Group into consideration, it is also suggested to delete the word solvency in the name of the group, which would now read: the Working Party of insurance governmental experts." 


\section{WORKING PARTY ON PRIVATE PENSIONS}

Chair:

Vice-Chairs:

Members:

Observers:

Date of creation:

Duration:
Mr. Ambrogio Rinaldi

Mr. Ross Jones

Mr. Uluc Icoz

Mr. William Bortz

Open to all Member countries

Brazil
Chile
Estonia
India

Brazil

India
(Italy)

(Australia)

(Turkey)

(United States)

Israel

Russian Federation

South Africa

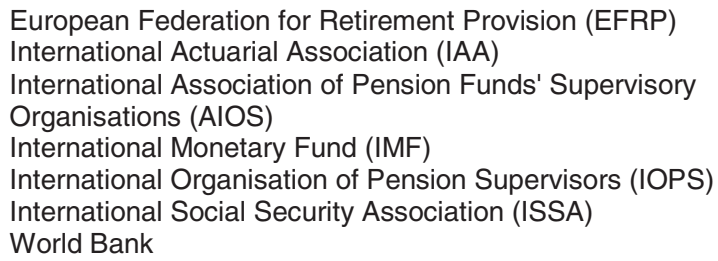

November 1998

31st July 2012

Mandate: Document [DAFFE/AS(99)3/REV1] approved by the Insurance Committee in March 1999 by written procedure.

\section{Extract from document [DAFFE/AS(99)3/REV1]}

\section{Terms of Reference}

"The Working Party on private pensions has the following tasks and objectives:

survey and monitoring of private pensions systems in OECD Member countries and analysis of related policy and technical issues;

formulation of appropriate policy conclusions and/or recommendations on the different approaches related to regulation and supervision of private pension systems;

keeping abreast of OECD activities related to private pensions; co-operation and coordination on these issues with other relevant OECD bodies as well as with other international bodies;

promotion of policy dialogue with Non Member countries on private pensions issues.

The programme of work of the Working Party will specify the orientations and details of implementation of the current terms of reference. The Working Party will regularly report to the Insurance Committee [---]. The Delegations may include representatives of the industry (insurance and pension funds in particular) except for closed governmental sessions, to be held upon decision by the Chair of the Working Party." 


\section{TASK FORCE ON PERSONAL PENSION PLANS}

Chair:

Members: $\quad$ Open to all Member countries

Date of creation: June 2001

Duration: $\quad 31$ st July 2012

Mandate: - Summary Record of the 66th session of the Insurance Committee [DAFFE/AS/M(2001)1, Item 8] and document [DAFFE/AS(2000)7/REV1, § 31]

- Summary Record of the 67th session of the Insurance Committee [DAFFE/AS/M(2001)2, Item 12.1] and document [DAFFE/AS(2001)3, § 14]

"The Insurance Committee will deal, in co-operation with its Working Party on Private Pensions, with issues involving the role of insurance companies in pension systems, and the development and regulation of retirement-related insurance products. Work on the latter will be initiated by a Task Force on Personal Pension Plans, which will be managed jointly by the Working Party and the Committee. This activity will be enlarged to comparison between insurance, pensions and savings instruments." 


\section{TASK FORCE ON PENSION STATISTICS}

Chair:

Members:

Non-Member Participant:

Date of creation:

Duration:
Mr. José Pavão Nunes

Open to all Member countries

Open to Observers to the Working Party on Private Pensions and to invited non-Member economies

June 2001

31st July 2012

Mandate: - Programme of Work of the Working Party on Private Pensions approved during the 5th session of the Working Party on Private Pensions [DAFFE/AS(2000)7/REV1, para. 8] and document [DAFFE/AS/PEN/WD(2002)8 para. 8 and 23]

\section{Extracts from document [DAFFE/AS/PEN/WD(2002)8]}

"8. In order to address the overall project objective, three main priorities are identified as follows:

- to review country data coverage of pension statistics and make recommendations for improving the methodology of pension statistics gathering;

- to improve the international comparability of pension statistics;

- to provide users with up-to-date statistics and indicators on salient aspects of retirement systems across OECD and INPRS countries.

23. The mandate of the Task Force on Pension Statistics is; i) to develop a thorough knowledge of the methodology used in the compilation of private pension data throughout OECD countries, ii) to review strengths and weaknesses of existing data, initially through a data collection pilot project for selected OECD countries, iii) to examine ways and means to improve the comparability of international pension statistics and provide recommendation, iv) to carry out the data collection monitoring and finally, v) to explore related issues and make recommendations as the task force finds appropriate" 


\section{TASK FORCE ON TERRORISM INSURANCE}

Chair:

Secretariat

Members:

Open to all Member countries

Date of creation:

December 2001

Duration:

31st July 2012

Mandate: - Summary Record of the 68th session of the Insurance Committee [DAFFE/AS/M(2002)1/REV1, Item 3]

- Summary Record of the 69th session of the Insurance Committee [DAFFE/AS/M(2002)2, Item 5]

\section{Extract from document [DAFFE/AS/M(2002)1/REV1, Item 3$]$}

"The Committee:

-- decided to create a Task force on the terrorism risk."

\section{Extracts from document [DAFFE/AS/M(2002)2, Item 5]}

“5.

\section{TERRORISM RISKS}

b) Definition of terrorism risks

The Committee:

-- discussed the document DAFFE/AS/WD(2002)7 which suggests a framework for future work on the definition of terrorism risk (definition criteria, introduction to the concept of insurable terrorism risks and mega terrorism) to be mainly undertaken through the Task Force created at the occasion of the December 2001 meeting, and underlined the need of a flexible approach in order to encompass as much as possible country specificity.

c) Policy options

The Committee:

-- noted the content of documents DAFFE/AS/WD(2002)9 - Communiqué of the Ministerial meeting requesting that the Secretariat should develop policy analysis and recommendations on how to define and cover terrorism risks and to assess the respective roles of the insurance industry, financial markets and governments, including for the coverage of "mega-terrorism" risks - discussed and endorsed the modalities for implementation of that mandate presented in document DAFFE/AS/WD(2002)8, taking into consideration that at this stage the Committee should adopt an open approach on options whose usefulness or feasibility will have to be carefully assessed (by the Task Force and the Committee)." 


\section{JOINT TASK FORCE ON FINANCIAL LITERACY AND FINANCIAL INCLUSION STATISTICS}

Members: $\quad$ Open to all Member countries

Date of creation: 3rd December 2008

Duration: $\quad 31$ st December 2010

Mandate: Committee on Financial Markets and Insurance and Private Pensions Committee

- Confirmation by the Executive Committee registered in the Summary Record of its 823rd Session [CE/M(2008)33, item 219 and CE(2008)19]

\section{Extract from document [CE(2008)19]}

"The joint task force will examine the potential and means to develop a survey methodology for generating a set of practical and internationally comparable data on the attitudes, awareness, knowledge and skills of financial consumers, and the degree to which they have access to financial services. Policymakers will use the findings of the Task Force to determine how they can best work together to generate data on financial literacy and inclusion. Data generated by the resulting methodology will be compiled and analysed by the OECD.

The methodology and resulting data would:

- $\quad$ Provide policy guidance and direction, allowing policy makers to identify priority areas for action on financial literacy, education, awareness and inclusion;

- Allow authorities to evaluate the impact of their public policy or national strategy on consumers' behaviour and inclusion, and compare that impact with that of similar policies or strategies implemented by other governments.

- $\quad$ Allow the OECD undertake solid quantitative comparative analyses, identify good practices, and elaborate further financial education guidelines (as recommended by the Council in its 2005 Recommendation on Principles and Good Practices for Financial Education and Awareness and by the G8 Finance Ministers in 2006).

- $\quad$ Allow the OECD to strengthen its international leadership and role as international standard setter on financial education and literacy." 


\section{TASK FORCE ON INSURANCE STATISTICS}

Chair:

Members:

Date of creation:

Duration:
Mr. José Pavão Nunes

Open to all Member countries

3rd December 2008

31st December 2012

Mandate: - Insurance and Private Pensions Committee

- Confirmation by the Executive Committee registered in the Summary Record of its 823rd Session $\quad$ [CE/M(2008)33, item 221 and $C E(2008) 22]$

\section{Extract from document [CE(2008)22]}

"The mandate of the Task Force on Insurance Statistics is to contribute to the elaboration, collection, and dissemination of sound and reliable comparable international insurance statistical information in order to contribute to more efficient and transparent insurance systems and promote the surveillance of insurance markets, and thereby promote economic growth and enhance the quality of government decision-making.

The main objectives are to:

- $\quad$ support the IPPC work on insurance statistics;

- $\quad$ assure the continuity of the insurance statistics exercise and further improve the overall quality of insurance statistical information according to OECD standards;

- examine ways and means to improve the relevance and comparability of international insurance statistics and provide recommendations as the exercise progresses;

- determine main priorities and contribute to development of appropriate statistics and indicators;

- achieve an enhanced analysis of trends in the insurance sector;

- provide inputs and directions for any global effort to improve insurance and any related financial statistics as the task force finds appropriate, and;

- enhance the global reach of the IPPC insurance statistics, notably by broadening its geographical scope.

In order to address the main objectives, its main priorities are to:

- improve the relevance of the exercise through the collection of more up-to-date insurance statistics and additional selected market variables;

- develop a thorough knowledge of the methodology used in the compilation of insurance data throughout OECD countries and selected non-OECD countries;

- review strengths and weaknesses of existing data, possibly through pilot exercises;

- examine ways and means to improve the comparability of international insurance statistics and provide recommendation where relevant;

- strengthen cooperation with other relevant bodies (e.g. EC, Eurostat, CEIOPS, IOPS); and,

- $\quad$ explore related issues and make recommendations as the Task Force finds appropriate." 


\section{JOINT TASK FORCE ON FINANCIAL REGULATION}

Members: $\quad$ Open to all Member countries

Date of creation: $\quad 3 r d$ December 2008

Duration: $\quad 31$ st December 2010

Mandate: Committee on Financial Markets and Insurance and Private Pensions Committee Confirmation by the Executive Committee registered in the Summary Record of its 823rd Session [CE/M(2008)33/PROV, item 219 and CE(2008)20]

\section{Extract from document [CE(2008)20]}

"The joint task force will support the CMF and IPPC in the development of any joint output results related to the effectiveness and efficiency of financial regulation, one of the main objectives of the CMF and IPPC. In light of the financial crisis, this joint task force is expected to play an active role in finding ways to develop a more effective regulatory system in the financial sector." 


\title{
AD HOC TASK FORCE ON THE GOVERNANCE OF INSURERS
}

\author{
Members: $\quad$ Open to all Member countries
}

Date of creation: 3rd December 2008

Duration: $\quad 31$ st December 2010

Mandate: Insurance and Private Pensions Committee

Confirmation by the Executive Committee registered in the Summary Record of its 823rd Session [CE/M(2008)33, item 219 and CE(2008)21]

\section{Extract from document [CE(2008)21]}

"The mandate of the ad hoc Task Force on Governance of Insurers is to assist the Insurance and Private Pensions Committee in its review of the OECD Guidelines on Insurers' Governance and to conduct joint work with the International Association of insurance Supervisors (IAIS) on the corporate governance of insurers.

Notes:

The planned work of the ad hoc Task Force is narrow in scope. A joint IAIS-OECD questionnaire has already been circulated and a joint issues paper will be developed in cooperation with the IAIS in 2008 and in the first half of 2009. This joint work will avoid overlap and duplication in the activities of the OECD and IAIS in this area and should lead to a higher quality product. Indeed, the IPPC and the OECD Council have emphasised the need for enhanced international coordination.

The modalities for cooperation between the IAIS and OECD were approved by the ad hoc Task Force on 9 June 2008 and by the IAIS Subcommittee on Governance and Compliance on 19-20 June 2008. With this recent approval of the modalities for cooperation, the ad hoc Task Force will take on a more formal and active role for the IPPC and will provide a formal and direct linkage with the IAIS. A joint IAIS-OECD roundtable on the governance of insurers is planned for the morning of 5 December 2008 at the OECD, to be followed in the afternoon by a joint session of the IPPC Task Force and IAIS Subcommittee.

The duration of the ad hoc Task Force is to be limited. If there is no joint work beyond the issues paper in 2009, then the ad hoc Task Force will work to assist the IPPC in reviewing the OECD Guidelines by the end of 2009. If there is further cooperation between the IAIS and OECD, then possible joint guidance would be developed in 2009 and in the first half of 2010 . This could lead to new international guidance on the corporate governance of insurers jointly developed between two international organisations." 

Chair:

Vice-Chairs:

Members:

Observers:
Mr. Thomas Wieser

Mr. John Veale

Mr. Erich Harbrecht

Mr. Gian Paolo Ruggiero

Mr. Takashi Kamiya

Mr. Gonzalo García Andrés

Mr. Wilbur Monroe
(Austria)

(Australia)

(Germany)

(Italy)

(Japan)

(Spain)

(United States)

Open to all Member countries

Hong Kong, China

Singapore

Bank for International Settlements (BIS)

European Investment Bank (EIB)

International Monetary Fund (IMF)

World Bank

Date of creation:

17th November 1969

Duration:

31st December 2013

Mandate: Resolution concerning the mandate of the Committee on Financial Markets adopted by the Council at its 1170th session on 28 March 2008 [C(2008)25 and C/M(2008)6, item 77]

\section{Resolution of the Council [C(2008)25 and C/M(2008)6, item 77]}

"THE COUNCIL

Having regard to the Convention on the Organisation for Economic Co-operation and Development of 14 December 1960;

Having regard to the Rules of the Procedure of the Organisation;

Having regard to the Resolution of the Council concerning the Establishment and Terms of Reference of a Group of Governmental Experts on Financial Markets [C(69)131(Final)];

Having regard to the Resolution of the Council amending the Resolution of the Council concerning the Establishment and Terms of Reference of a Group of Governmental Experts on Financial Markets [C(71)28(Final)];

Having regard to the Decision of the Council concerning the future of the Exchange Guarantee Agreement Between Certain Central Banks and of the Committee for Monetary and Foreign Exchange Matters [C(75)134(Final), Item IV];

Having regard to the Decision of the Council regarding a Sunset Clause for all Committees [C/M(2004)5, Item 75] which entered into force on 22 April 2004 [C/M(2004)10, Item 143, IV, c];

Having regard to the results of the In-depth Evaluation of the Committee on Financial Markets [C(2007)82 and C(2007)82/CORR1]; 
Having regard to the recommendations approved by Council on the In-Depth Evaluation of the Committee on Financial Markets [C/M(2007)12, Item 158];

\section{DECIDES}

1. The mandate of the Committee on Financial Markets is as follows:

i) Objectives

a) The overarching objective of the Committee on Financial Markets is to promote efficient, open, stable and sound market-oriented financial systems, based on high levels of transparency, confidence and integrity. To achieve this objective, the Committee shall improve awareness and understanding of major financial policy issues and shall assist policymakers in designing, adopting and implementing relevant policies.

b) The main objectives of the Committee include:

- improving efficiency and effectiveness of the regulatory approach in the financial sector;

- improving the capacity of financial markets and individuals to respond to financial challenges, in particular those associated with an ageing population and a riskier environment;

- improving financial education and awareness;

- promoting the contribution of financial markets and institutions to savings and investment, to the financing of business and individuals and to growth;

- promoting the liberalisation of international trade and market access in the financial services sector.

c) Additional objectives to be addressed by the Working Parties of the Committee are:

- improving public debt management;

- improving financial statistics.

d) With regard to non-Members, the Committee shall promote policy dialogue and cooperation, encourage the implementation of best principles and practices, and provide related assistance.

ii) Methods

a) In order to achieve these objectives, the Committee shall:

- develop in-depth and proactive surveillance of financial developments and of their impact on economic growth and stability;

- focus its work on delivering outputs of high quality and with high policy impacts and shall regularly assess whether these objectives are being met; it shall strive to achieve these objectives through policy dialogue, the collection of information and statistics, policy analysis, and the establishment of good practices and guidelines for adequate policies and regulations, and for mechanisms to facilitate their proper implementation;

- monitor and co-ordinate the work undertaken by the Organisation in the financial fields and, as appropriate, submit opinions, recommendations and proposals to the Council or to other Committees.

b) The Committee shall consider revisions to its mandate whenever appropriate, for instance following major policy developments in financial markets. 
iii) Co-operation

a) The Committee shall co-operate with relevant OECD bodies, particularly the Insurance and Private Pensions Committee;

b) The Committee shall keep itself informed of the activities carried out in other international bodies in respect of financial issues, coordinate work and avoid duplication with these bodies, and shall provide a forum for consultations among Member countries to enable them to exchange views on issues raised in these bodies;

c) The Committee shall consider the views and input of major stakeholders in the financial field.

2. The mandate of the Committee on Financial Markets shall remain in force until 31 December 2013 unless the Council decides otherwise." 


\section{WORKING PARTY ON FINANCIAL STATISTICS}

Chair:

Vice-Chairs:

Members:

Observers:
Mr. Patrick O'Hagan

Mrs. Dominique Durant

Ms. Paola de Rita

Ms. Beatriz Sanz Medrano

Mr. Stuart Brown

Ms. Susan Hume McIntosh
(Canada)

(France)

(Italy)

(Spain)

(United Kingdom)

(United States)

Open to all Member countries

Israel

Hong Kong, China

Singapore

Bank for International Settlements (BIS)

European Investment Bank (EIB)

International Monetary Fund (IMF)

World Bank

World Trade Organization (WTO)

Duration:

Mandate:

Date of creation: 7th March 1967

31st December 2013

Minutes of the 135th session of the Council [C/M(67)4(Final)]

\section{Extract from document [C/M(67)4(Final), Item 36]}

"THE COUNCIL

a) noted the Report on the Improvement of Capital Markets by the Committee for Invisible Transactions [C(66)122] and the Comments thereon by the Payments Committee [C(67)13];

b) approved the publication of the document [C(66)122] and of a Statistical Annex thereto after the Committee for Invisible Transactions had made any additions and corrections needed to perfect presentation and accuracy, and on the understanding that the document would indicate the constitution, composition and independent character of that Committee, and that it would be made clear that the report was the work of experts, which did not necessarily carry the endorsement of the Organisation in all respects and which did not bind the latter or individual Member States either generally or in any particular detail;

c) agreed that a group of official statisticians be convened to examine how financial statistics in this field could be improved;" 


\section{WORKING PARTY ON DEBT MANAGEMENT}

Chair:

Vice-Chairs:

Members:

Observers:

Date of creation:

Duration:
Mr. Ove Sten Jensen

Mr. Neil Hyden

Mr. Herwig Smissaert

Mr. Carl Heinz Daube

Mr. Zsolt Bango

Ms. Maria Cannata

Mr. Masaaki Kaizuka

Mr. Bo Lundgren

Mr. Coskun Cangöz

Mr. Robert Stheeman

Mr. Karthik Ramanathan

Open to all Member countries

Israel

Hong Kong, China

Singapore

Bank for International Settlements (BIS)

European Investment Bank (EIB)

International Monetary Fund (IMF)

World Bank
(Denmark)

(Australia)

(Belgium)

(Germany)

(Hungary)

(Italy)

(Japan)

(Sweden)

(Turkey)

(United Kingdom)

(United States)

Mandate: Summary Record of the 36th Meeting of the Committee on Financial Markets [CMF/M(81)3]

\section{Extract from document [CMF/M(81)3, Item 7 (iv)]}

"(iv) Future informal meetings of government debt management experts

\section{THE COMMITTEE}

a) endorsed the proposal made at the Expert Group's final meeting held in March 1981 that government debt management experts should meet from time to time, perhaps at 12 to 18 month intervals, to discuss debt management problems of common interest; this was all the more desirable as government debt managers had so far no other opportunities to meet at international level;

b) instructed the Secretariat to organise such meetings, it being understood, however, that any papers for discussion by the experts would have to be prepared by the experts themselves and that the Secretariat would only be responsible for the technical organisation of such meetings;

c) welcomed the suggestion that the Committee should receive reports on the outcome of such meetings." 


\section{JOINT TASK FORCE ON FINANCIAL LITERACY AND FINANCIAL INCLUSION STATISTICS}

Members: $\quad$ Open to all Member countries

Date of creation: $\quad 3 r d$ December 2008

Duration: $\quad$ 31st December 2010

Mandate: - Committee on Financial Markets and Insurance and Private Pensions Committee

- Confirmation by the Executive Committee registered in the Summary Record of its 823rd Session [CE/M(2008)33, item 219 and CE(2008)19]

\section{Extract from document [CE(2008)19]}

"The joint task force will examine the potential and means to develop a survey methodology for generating a set of practical and internationally comparable data on the attitudes, awareness, knowledge and skills of financial consumers, and the degree to which they have access to financial services. Policymakers will use the findings of the Task Force to determine how they can best work together to generate data on financial literacy and inclusion. Data generated by the resulting methodology will be compiled and analysed by the OECD.

The methodology and resulting data would:

- $\quad$ Provide policy guidance and direction, allowing policy makers to identify priority areas for action on financial literacy, education, awareness and inclusion;

- $\quad$ Allow authorities to evaluate the impact of their public policy or national strategy on consumers' behaviour and inclusion, and compare that impact with that of similar policies or strategies implemented by other governments.

- $\quad$ Allow the OECD undertake solid quantitative comparative analyses, identify good practices, and elaborate further financial education guidelines (as recommended by the Council in its 2005 Recommendation on Principles and Good Practices for Financial Education and Awareness and by the G8 Finance Ministers in 2006).

- $\quad$ Allow the OECD to strengthen its international leadership and role as international standard setter on financial education and literacy." 


\section{JOINT TASK FORCE ON FINANCIAL REGULATION}

Members:

Date of creation:

Duration:
Open to all Member countries

3rd December 2008

31st December 2010

Mandate: Committee on Financial Markets and Insurance and Private Pensions Committee Confirmation by the Executive Committee registered in the Summary Record of its 823rd Session [CE/M(2008)33, item 219 and CE(2008)20]

\section{Extract from document [CE(2008)20]}

"The joint task force will support the CMF and IPPC in the development of any joint output results related to the effectiveness and efficiency of financial regulation, one of the main objectives of the CMF and IPPC. In light of the financial crisis, this joint task force is expected to play an active role in finding ways to develop a more effective regulatory system in the financial sector." 



\section{COMPETITION COMMITTEE}

Chair:

Mr. Frédéric Jenny

(France)

Vice-Chairs:

Ms. Sheridan Scott

(Canada)

Mr. Bernard Heitzer

(Germany)

Mr. Hideo Nakajima

(Japan)

Mr. Byung Ju Lee

(Korea)

Mr. Walter Stoffel

(Switzerland)

Mr. Jonathan May

(United Kingdom)

Mr. Philip Lowe

(European Commission)

Mr. François Souty

Ex Officio as UNCTAD Co-ordinator

Mr. Alberto Heimler

(France)

Ex Officio as Chair of the Working Party N.2 on Competition and

Regulation

Mr. Eduardo Perez Motta (Mexico)

Ex Officio as Global Relations Co-ordinator

Mr. Thomas Barnett

(United States)

Ex Officio as Chair of the Working Party N.3 on Enforcement and

Co-operation

Members:

Observers:

Date of creation:

Duration:
Open to all Member countries

Brazil
Chile
Chinese Taipei
Indonesia
Israel

Lithuania

Romania

Russian Federation

Slovenia

South Africa

European Free Trade Association (EFTA)

UN Conference on Trade and Development (UNCTAD)

World Trade Organization (WTO)

5th December 1961

31st December 2013

Mandate: - Resolution of the Council concerning the Committee of Experts on Restrictive Business Practices and amending its name and terms of reference [C(87)138(Final)]

- Extract from the Communiqué [C(91)91] adopted by the Council at Ministerial level on 4-5 June 1991

- Change of name from 'Committee on Competition Law and Policy' to 'Competition Committee' agreed by Council at its 1017th session [C/M(2001)23, item 402] and document [C(2001)261]

- Council Decision regarding a Sunset Clause for all Committees [C/M(2004)5, item 75] entered into force on 22 April 2004 [C/M(2004)10, item 143, IV, c)]

- C(2008)134 and CORR1: proposed new mandate

- Resolution of the Council concerning the new mandate [C(2008)134 and CORR1 and $\mathrm{C} / \mathrm{M}(2008) 17$, item 219] 
Resolution of the Council [C(2008)134 \& CORR1 and C/M(2008)17, Item 219]

"THE COUNCIL,

Having regard to the Convention on the Organisation for Economic Co-operation and Development of 14 December 1960;

Having regard to the Rules of Procedure of the Organisation;

Having regard to Resolution of the Council C(87)138/FINAL

Having regard to the recommendations of the In-depth Evaluation of the Competition Committee [C(2007)121];

DECIDES:

A. The Competition Committee has the following mandate:

I. Objectives

a) The main objective of the Competition Committee is to protect and promote competition as an organising principle of modern economies, based on the knowledge that vigorous market competition boosts growth and employment and makes economies more flexible and innovative.

b) The intermediary objectives of the Committee include:

i. Reviewing developments in competition laws and policies both in individual countries and in international organisations;

ii. Examining and commenting upon particular competition law and policy issues taking into account the interaction between competition and other government policies;

iii. Enhancing the effectiveness of competition law enforcement, through measures that include the development of best practices and the promotion of cooperation among competition authorities of Member countries;

iv. Enhancing the effectiveness of pro-competitive economic reform, including by reviewing competition issues in jurisdictions and particular sectors, and identifying options for addressing these issues and developing best practices;

v. Proposing effective strategies and methods to help governments promote domestic pro-competitive reforms and overcome their transition costs;

vi. Strengthening synergies between competition policy and other framework policies in the work of the OECD;

vii. Supporting sound domestic competition policies and fostering policy convergence internationally to avoid inefficiencies and potential conflicts resulting from different competition standards;

viii. Promoting policy dialogue and cooperation with non-Members to encourage the implementation of competition best practices and principles, and providing related capacity building;

ix. Promoting understanding of the benefits of competition for business and consumers.

\section{Co-operation arrangements}

a) The Committee shall cooperate with other OECD committees on competition-related matters and seek to ensure that the Organisation as a whole promotes sound competition policy.

b) The Committee shall keep itself informed of the competition related activities carried out in other international organisations, notably the International Competition Network. It will promote and develop, as practicable, partnerships with these organisations and seek to ensure effective complementarities while avoiding undue duplication with other 
international organisations where appropriate. The Committee shall provide a forum for consultations to enable delegates to exchange views on issues raised in these bodies.

c) The Committee shall consider the views and input of BIAC and other major stakeholders in the competition field.

d) The Committee shall encourage participation by non-OECD economies in the Committee's work and their implementation of the Committee's recommendations and best practices.

B. The mandate of the Competition Committee shall remain in force until 31 December 2013 unless the Council decides otherwise." 


\section{GLOBAL FORUM ON COMPETITION ${ }^{1}$}

Chair:

Date of creation:

Duration:

\section{Approved by:}

\section{Mission Statement:}

"The OECD Global Forum on Competition (GFC) has been established as an efficient mechanism to (i) disseminate OECD Members' experience and best practices, (ii) to obtain information about nonMembers' conditions, experiences and views, (iii) to promote a greater understanding of why legitimate differences in approaches between developing and developed economies may continue to be warranted; (iv) to create larger networks of government officials that have the level of mutual understanding that comes from OECD-style dialogue; and (v) to promote policy dialogue, with an opportunity for contribution by the private sector and NGOs.

Other stated purposes have been described as "supporting effective law enforcement against worldwide cartels", and "increasing the efficiency of procedures to review transborder mergers". Worldwide cartels operate beyond the OECD area; hence, the anti-cartel programme which OECD Members endorsed in 2000 and actively pursued since then, cannot succeed without involvement of non-Members and their acquiring the tools and skills necessary to take effective remedial action. Similarly, ongoing work within the OECD aims at reducing the burden on global business of merger clearance rules by offering competition authorities the possibility to meet and develop options for reform will fall short of its full potential unless non-Members can be included in the dialogue.

The Forum also focuses on bringing competition principles to bear in regulatory reform. This underscores the fact that the scope of the GFC extends beyond competition law enforcement matters to include competition policy issues broadly defined. The GFC is also a forum in which nonMembers can benefit from the type of peer review process that Members have available to them in the Committee.

The GFC promotes widespread association with OECD standards in the field of competition, including the 2005 Recommendation of the Council concerning merger review, the 2001 Recommendation on Structural Separation in Regulated Industries, the 1998 Recommendation against Hard-Core cartels and the 1995 Recommendation on Co-operation. In addition, the GFC provides a venue to add a development dimension to the OECD's work on competition policy.

Meetings of the Global Forum on Competition are chaired by the Chairman of the Competition Committee."

Members:

Designated Participants:
Open to all Member countries

Observers to the Competition Committee: Brazil, Chile, Indonesia, Israel, Lithuania, Romania, Russian Federation, Slovenia, South Africa, Chinese Taipei

Non-Observer Accession country: Estonia

Non Observer Enhanced Engagement countries: China, India

Countries and organisations having attended (as of 19 November 2008) at least one GFC meeting, namely Albania, Algeria,

\footnotetext{
1 Information on this Global Forum is provided for the sake of completeness, but Global Forums are not, in accordance with C(2008)208/FINAL, official OECD bodies.
} 
Argentina, Azerbaijan, Bahrain, Bosnia and Herzegovina, Bulgaria, Cameroon, Colombia, Costa Rica, Croatia, Ecuador, Egypt, El Salvador, FYROM, Gabon, Georgia, Ivory Coast, Jamaica, Jordan, Kazakhstan, Kenya, Latvia, Lebanon, Malaysia, Malta, Mongolia, Morocco, Nigeria, Pakistan, Panama, Papua New Guinea, Peru, Philippines, Senegal, Serbia, Singapore, Tanzania, Thailand, Tunisia, Ukraine, Uzbekistan, Venezuela, Vietnam, Zambia and Andean Community, Asian Development Bank, Business and Industry Advisory Committee, CARICOM Commission, Common Market for Eastern and Southern Africa, Consumers International, Consumer Unity \& Trust Society(CUTS) International, International Bar Association, International Development Research Centre, Inter-American Development Bank, Trade Union Advisory Committee, United Nations Conference on Trade and Development, Commission of the West African Economic and Monetary Union, World Trade Organization, World Bank. 


\section{WORKING PARTY NO. 2 ON COMPETITION AND REGULATION}

Chair:

Members:

Observers:

Date of creation:

Duration:
Mr. Alberto Heimler

(Italy)

Open to all Member countries

\begin{tabular}{ll} 
Brazil & Lithuania \\
Chile & Romania \\
Chinese Taipei & Russian Federation \\
Indonesia & Slovenia \\
Israel & South Africa \\
& \\
\multicolumn{2}{l}{ UN Conference on Trade and Development (UNCTAD) } \\
World Trade Organization (WTO)
\end{tabular}

1st October 1994

31st December 2013

Mandate: Summary Record of the 66th meeting of the Committee on Competition Law and Policy [DAFFE/CLP/M(94)2] and document [DAFFE/CLP/M(94)2].

\section{Extract from document [DAFFE/CLP/M(94)2, § 17]}

"17. $\quad[\ldots]$ the Committee agreed to establish a new Working Party No. 2 (Working Party No. 2 on Competition and Regulation) and decided to give this Working Party the following tasks:

To review, analyse and make recommendations on competition issues related to the creation, operation, reforming or dismantling of sectoral or economy-wide regulatory regimes." 


\section{WORKING PARTY NO. 3 ON CO-OPERATION AND ENFORCEMENT}

Chair:

Members:

Observers:

Date of creation:

Duration:
Mr. Thomas O. Barnett

(United States)

Open to all Member countries

\begin{tabular}{ll} 
Brazil & Romania \\
Chile & Russian Federation \\
Indonesia & Slovenia \\
Israel & South Africa \\
Lithuania & Chinese Taipei \\
\multicolumn{2}{l}{} \\
UN Conference on Trade and Development (UNCTAD) \\
World Trade Organization (WTO)
\end{tabular}

October 1964

December 2013

Mandate: - Summary Records of the 7th, 13th, 20th, 40th and 60th meetings of the Committee of Experts on Restrictive Business Practices [RBP/M(64)2, RBP/M(67)2, $\mathrm{RBP} / \mathrm{M}(71) 1, \mathrm{RBP} / \mathrm{M}(81) 2$ and DAFFE/CLP/M(91)2]

- New name and mandate approved during the 89th session of the Competition Committee held on 15-17 October 2003 [DAFFE/COMP/M(2003)3 and Annex 1]. Former name: "Working Party No. 3 on International Co-operation".

\section{Extract of Summary Record [DAFFE/COMP/M(2003)3, Annex 1]}

"Working Party No. 3 on Co-operation and Enforcement

Working Party 3 promotes effective enforcement of competition laws and co-operation among competition law enforcement agencies.

Specifically, the Working Party shall, as directed by the Competition Committee, pursue the following tasks:

\section{Merger Control Procedures}

1. increase effective co-operation in reviews of transnational mergers;

2. identify areas of differences, convergence, and possible improvement; and

3. identify and seek to reduce unnecessary regulatory costs to firms and competition authorities.

\section{Hard Core Cartels}

1. increase co-operation and information exchanges among competition law enforcement agencies;

2. develop and promote effective enforcement practices and tools; and

3. raise public awareness of the harm of hard core cartels.

\section{Other Areas of Competition Law Enforcement}

1. provide a forum to review and discuss other areas of co-operation and competition law enforcement. 


\section{Council Recommendations}

1. periodically review existing OECD Council Recommendations in the area of its mandate and identify areas in which the Recommendations can be strengthened; and

2. consider new recommendations as needed.

$\underline{\text { Co-operation with Other Institutions }}$

1. co-operate with other international institutions addressing similar competition issues and contribute to their work." 
Chair:

Bureau Members:

Members:

Observers:

Date of creation:

Duration:
Mr. Marcello Bianchi

(Italy)

Mr. Takashi Kamiya

Mr. Marco Langendoen

Mr. Krzysztof Grabowski

Ms. Gabriela Figueiredo Dias

Mr. Juan Munguira Gonzalez

Mr. Rolf Skog

Mr. Ben Cushman

Open to all Member countries

Bank for International Settlements (BIS)

International Monetary Fund (IMF)

World Bank

15th June 2000

Unspecified
(Japan)

(Netherlands)

(Poland)

(Portugal)

(Spain)

(Sweden)

(United States)

Mandate: - Summary Record of June 2000 meeting of Steering Group on Corporate Governance [DAFFE/CA/CG/M(2000)1] and document [C/PWB(99)99/2000, page 169]

- Document [C(2001)147]

\section{Extract from document [DAFFE/CA/CG/M(2000)1, Item 1]}

"1. The Steering Group will:

- Provide co-ordinated guidance and active support by Member countries for the global corporate governance outreach activities on the basis of the OECD Principles, in co-operation with the World Bank;

- Support the development of a sustained policy discussion among Member countries on corporate governance trends and developments and thus prepare the process of reassessment of the Principles in due course;

- Provide high-quality inputs on a voluntary basis on specific corporate governance issues, in the context of projects fully funded by individual Member countries;

- Carry out other corporate governance work agreed by Member countries." 


\section{WORKING GROUP ON PRIVATISATION AND CORPORATE GOVERNANCE OF STATE}

\section{OWNED ASSETS}

Chair:

Bureau Members:

Members:

Observer:

Date of creation:

Duration:
Mr. Pekka Timonen

Mr. Petr Musil

Mrs. Lucie Muniesa

Mr. Aimilios Stasinakis

Mr. Kyungho Choo

Mr. Morten Kallevig

Mr. Juan Munguira Gonzalez

Mr. Lars Erik Fredriksson

Open to all Member countries

World Bank

March 2001

Unspecified
(Finland)

(Czech Republic)

(France)

(Greece)

(Korea)

(Norway)

(Spain)

(Sweden)

Mandate: Constitution of the Working Group [DAFFE/CA/CG(2001)6] and [DAFFE/CA/PRIV(2001)1/REV1]

\section{Extract from document [DAFFE/CA/PRIV(2001)1/REV1, paragraph 1]}

"1. $\quad[\ldots]$ the mandate of the "Working Group" is to:

i. Develop policy dialogue and information exchange among Member countries on issues dealing with privatisation and governance of state-owned assets and their effectiveness;

ii. Develop best practices principles on the basis of this dialogue;

iii. Serve as a pool of expertise from which member and non-member countries can draw, in the process of designing, adjusting or implementing their programmes;

iv. Guide the process of dialogue on these issues with non-member economies." 


\section{ADVISORY GROUP ON NON-MEMBER WORK}

Chair:

Members:

Observer:

Date of creation:

Duration:
(..)

Open to all Member countries

World Bank

October 2004

Unspecified

Mandate: Summary Record of the meeting of Steering Group on Corporate Governance held on 19-20 October 2004 [DAFFE/CA/CG/M(2004)2], Item 5 b]

\section{Extract from document [DAFFE/CA/CG/M(2004)2], Item 5 b]}

"...agreed to establish an informal advisory group on non-member work 'to enhance interaction between members and non-members and to support oversight of the outreach programme.' The group's primary objectives are to 'help define priorities for outreach work and ensure their future effectiveness and sustainability, including by facilitating fund-raising and enhancing interchange between members and non-members."

See also:

"Report to the OECD Council on the Steering Group's Pro-active strategy for Corporate Governance Work with Non-Members" [DAF/CA/CG(2005)11], which sets out advisory group's responsibility to monitor and advise on the non-member work programme (Regional Roundtables, MENA Working Group, China policy dialogue, etc.). 

TAX POLICY AND ADMINISTRATION 
Chair:

Deputy-Chair:

Vice-Chairs:

Bureau Members:

Members:

Observers:

Date of creation:

Duration:
Mr. Paolo Ciocca

Mr. Robin Oliver

Ms. Marie-Christine Lepetit

Mr. Paul Vlaanderen

Mr. Thorbjørn Gjølstad

Mr. Miguel Ferre

Mr. John Harrington

Mr. Michael Rawstron

Mr. Florian Scheurle

Mr. Takuji Tanaka

Mr. Mike Williams

Open to all Member countries

Chile

Russian Federation

India

International Monetary Fund (IMF)

World Bank

1st May 1971

31st December 2013
(International Fund for Agricultural Development (IFAD))

(New Zealand)

(France)

(Netherlands)

(Norway)

(Spain)

(United States)

(Australia)

(Germany)

(Japan)

(United Kingdom)

People's Republic of China South Africa

Argentina

Mandate: Resolution of the Council on the Mandate of the Committee on Fiscal Affairs [C(2008)147 and C/M(2008)20, item 285)]

\section{Resolution of the Council [C(2008)147 and C/M(2008)20, item 285]}

"THE COUNCIL,

Having regard to the Convention on the Organisation for Economic Co-operation and Development of 14 December 1960;

Having regard to the Rules of the Procedure of the Organisation;

Having regard to the following Council Recommendations concerning the Organisation's work on taxation:

- Resolution of the Council concerning the Activities of the Organisation in the Field of Taxation [C(71)41]

- Recommendation of the Council on Tax Avoidance and Evasion [C(77)149(Final)]

- Recommendation of the Council on the Determination of Transfer Prices between Associated Enterprises [C(79)83(Final)]

- $\quad$ Minutes of the 669th session of the Council [C/M(87)16(Final)]

- Recommendation of the Council on Tax Treaty Override [C(89)146(Final)] 
- Recommendation of the Council concerning the model tax convention on income and capital [C(94)11/FINAL]

- Recommendation of the Council on the Transfer Pricing Guidelines for Multinational Enterprises and Tax Administrations [C(95)126/FINAL]

- Recommendation of the Council on Counteracting Harmful Tax Competition [C(98)17/FINAL];

Having regard to Council Decision regarding a Sunset Clause for all Committees [C/M(2004)5, item 75] entered into force on 22 April 2004 [C/M(2004)10, item 143, IV, c)] Council $\mathrm{C}(2004) 37$;

\section{DECIDES}

1. The mandate of the Committee on Fiscal Affairs as follows:

Objectives

a) The overarching objective of the Committee on Fiscal Affairs (hereinafter called "The Committee") is to contribute to the shaping of globalisation for the benefit of all through the promotion and development of effective and sound tax policies and guidance that will foster growth and allow governments to provide better services to their citizens. Its work is intended to enable OECD and non-OECD governments to improve the design and operation of their national tax systems, to promote co-operation and co-ordination among them in the area of taxation and to reduce tax barriers to international trade and investment.

b) In light of this objective, the Committee shall:

i) facilitate the negotiation of bilateral tax treaties and the design and administration of related domestic legislation,

ii) promote communication between countries and the adoption of appropriate policies to prevent international double taxation and to counteract tax avoidance and evasion,

iii) encourage the elimination of tax measures which distort international trade and investment flows;

iv) promote a climate that encourages mutual assistance between countries and establish procedures whereby potentially conflicting tax policies and administrative practices can be discussed and resolved;

v) support domestic tax policy design through the development of high quality economic analysis of tax policy issues, comparative statistics and comparisons of country experiences in the design of tax systems;

vi) improve the efficiency and effectiveness of tax administrations, both in terms of taxpayer services and enforcement.

vii) support the integration of non-OECD economies into the international economy by strengthening policy dialogue with them to increase their awareness of and contribution to the Committee's standards, guidelines and best practices.

Methods

In order to achieve these objectives, the Committee will focus its work on delivering outputs of high quality and with high policy impacts and shall regularly assess whether these targets are being met. In particular, the Committee shall:

a) develop standards, guidelines and best practices in areas where international coordination is desirable and monitor the practical implementation of them and other recommendations; 
b) provide a forum for discussions by senior policymakers and tax administrators, and where appropriate the business community and other parts of civil society, of international and domestic tax policy and administration issues and emerging issues in a global economy which require a response from senior tax policy makers;

c) supply OECD countries with internationally comparable tax statistics and comparisons of the major taxes used throughout the OECD area, and provide strategic analysis of important tax policy and administration issues for use in publications, briefs, and the like;

Co-operation

a) The Committee shall strengthen policy dialogue with non-OECD economies in order to increase their awareness and use of the Committee's standards, guidelines and to explore together the identification of good practices.

b) The Committee shall monitor and contribute to relevant activities carried out in other international bodies. In particular, it will continue to participate in the UN Committee of Experts on International Cooperation in Tax Matters and will continue its co-operation with the Financial Action Task Force on issues of mutual interest.

c) It will promote and develop strategic partnerships with regional tax and other international organisations and will continue to develop the International Tax Dialogue. The Committee will monitor and co-ordinate work undertaken by the Organisation in related fields and shall co-operate with relevant OECD bodies. In particular, it will continue to work jointly with other committees carrying out projects having tax policy aspects, in particular with the Economic and Development Review Committee, Economics; in the Environment Policy Committee; in the Employment, Labour and Social Affairs Committee; in the Development Assistance Committee; and in the Working Group on Bribery.

d) The Committee shall continue to co-operate closely with BIAC and other major stakeholders.

2. The mandate of the Committee shall remain in force until 31 December 2013 unless the Council decides otherwise." 


\section{BOARD FOR CO-OPERATION WITH NON-OECD ECONOMIES}

Co-Chairs:

Members:

Date of creation:

Duration:

Mr. Takuji Tanaka

Mr. Paul Vlaanderen

(Japan)

(Netherlands)

Mexico

Australia

Austria

Belgium

Canada

Czech Republic

Germany

Hungary

Ireland

Japan

Korea

30th January 2001

31st December 2013
Netherlands

New Zealand

Norway

Portugal

Spain

Sweden

Turkey

United Kingdom

United States

Mandate: Summary Record of the 60th Session of the Committee on Fiscal Affairs [DAFFE/CFA/M(2001)1, Item VIII]

\section{Extract from document [DAFFE/CFA/M(2001)1, Item VIII]}

\section{"Creation of a Board for Co-operation with NMEs}

35. The Committee accepted the recommendations of the CFA Bureau to create a new Board on Co-operation with Non-Member Economies on Fiscal Affairs. The Board will have responsibility for supervising the alignment of the co-operation programme and CFA core topics. Reporting directly to the CFA, the Board will consist of delegates from countries (1) that are actively involved in Committee activities and (2) contribute significantly to co-operation with non-member economies." 


\section{ADVISORY GROUP FOR CO-OPERATION WITH NON-OECD ECONOMIES (AGCNOE)}

Chair:

Members:

Date of creation:

Duration:
Mr. Robert Reade

Australia

Austria

Belgium

Canada

Czech Republic

Germany

Hungary

Ireland

Japan

Korea
(Canada)

Mexico

Netherlands

New Zealand

Norway

Portugal

Spain

Sweden

Turkey

United Kingdom

United States

Mandate: - The Advisory Group first appeared, albeit only briefly, as the Steering Group for the Multilateral Training Network, before it was converted into its current form. The Steering Group held its first meeting on 16 December 1991 [CCEET/DAFFE/CFA/M(92)18]

- It was converted and given a mandate in its current form on 22 January 1993, Summary Record of the 44th Session of the Committee on Fiscal Affairs [DAFFE/CFA/M(93)1, item X]

- Summary Record of the Second Meeting of the Steering Group for the Multilateral Training Network for Tax Officials from Central and Eastern Europe, the Baltic States and the NIS [CCEET/DAFFE/M(93)17]

\section{Extract from document [DAFFE/CFA/M(93)1, Item X]}

- The Committee noted the Secretariat statement that on the 22nd January, the Steering Group for the Multilateral Training network would be asked to agree to convert itself into a "Consultative Group on Taxation and Tax Training". The creation of this Group was agreed to by the Steering Group and its Mandate was to provide guidance on the training courses, to provide a forum for policy exchanges between the Economies in Transition and to facilitate the exchange of views on bilateral and multilateral assistance programmes."

\section{Extract from document [CCEET/DAFFE/M(93)17]}

"ITEM VII - Conversion of the Steering Group into a Consultative Group on Taxation and Tax Training $[\ldots]$

After an extended discussion, the Steering Group agreed to change its name to Consultative Group on Taxation and Tax Training (CGTTT), with the mandate as set out in Annex III.

It was agreed that the main function of the CGTTT would be to review the operation of the tax training network. Th CGTTT would also encourage the development of a policy dialogue between the economies in Transition, on the one hand, and between these countries and the OECD countries, on the other hand. It was also noted that the new Group could help strengthen the link between the training courses and the bilateral and multilateral assistance programmes and would also provide a useful forum for exchanging views on these programmes." 


\title{
JOINT MEETINGS OF TAX AND ENVIRONMENT EXPERTS
}

\author{
Co-Chairs: \\ Mr. Christian Valenduc \\ Mr. Robin Miege \\ (Belgium) \\ (European Commission) \\ Members: \\ Open to all Member countries \\ Date of creation: \\ 1st January 2001 \\ Duration: \\ 31st December 2010
}

Mandate: Text of the mandate in document [COM/ENV/EPOC/DAFFE/CFA(2000)105] renewed by EPOC under written procedure on 14 November 2008 [ENV/EPOC(2008)32] and by the CFA at its 24-25 June 2008 meeting(identical text in both documents)

\section{Extract from document [DAFFE/CFA(2001)72, Annex II] \\ ANNUAL JOINT MEETINGS ON TAXATION AND ENVIRONMENT TERMS OF REFERENCE}

"1. The Committee on Fiscal Affairs (CFA) and the Environment Policy Committee (EPOC) agree to continue the joint meetings of tax and environment experts, from the Working Party No2 on Tax Policy Analysis and Tax Statistics of the CFA, and the Working Party on National Environmental Policy of EPOC.

2. These experts will take part in annual back-to-back meetings with the following terms of reference, taking into account ongoing work following the OECD programme on sustainable development, and the specific economic, fiscal and environmental conditions of OECD countries ${ }^{1}$ :

a) To monitor and analyse existing environmentally related taxes, including collecting and analysing data within a common statistical framework.

b) To assess the environmental effectiveness of relevant taxes (and where appropriate related economic support measures, fees and charges) and to review practical implementation issues, drawing on experiences in Member countries.

c) To examine further issues arising from the integration of environmental concerns into the design of tax systems.

3. The Group of experts will provide input into the OECD Sustainable Development work and to follow-up work to this project involving consideration of tax and environment issues.

4. The Group of experts will also monitor developments and contribute, where appropriate, to tax aspects of the follow-up to the Kyoto Protocol to the United Nations Framework Convention on Climate Change.

5. The Group of experts will report, on an annual basis, the findings of the Joint Meetings, including discussions of policy options and transmit these to the CFA and the EPOC.

6. The terms of reference are established for an indefinite period from 1 January 2001, but subject to review and endorsement every second year by both the CFA and the EPOC."

\footnotetext{
1 Should the need arise for two meetings per year, this need will be brought to the attention of the Committee on Fiscal Affairs and the Environment Policy Committee in a formal request for an adjustment.
} 


\section{WORKING PARTY NO. 1 ON TAX CONVENTIONS AND RELATED QUESTIONS}

Chair:

Vice-Chair:

Members:

Observers:

Date of creation:

Duration:
Mr. Andrew Dawson

Mrs. Ariane Pickering

Open to all Member countries

Chile

Russian Federation India

\section{South Africa}

Argentina

International Monetary Fund (IMF)

World Bank

(United Kingdom)

(Australia)

1st May 1971

31st December 2013

Mandate: $\quad$ Minutes of the 1st and 56th sessions of the Committee on Fiscal Affairs [CFA/M(71)1 and DAFFE/CFA/M(99)1, Item VIII] and document [DAFFE/CFA(99)8, § 61]

\section{Extract from document [DAFFE/CFA(99)8, § 61]}

"61.

"The general mandate of Working Party No. 1 on Tax Conventions and related Questions is to act as a forum for the discussion of issues related to the negotiation, application and interpretation of tax conventions, to examine proposals for the modification of the OECD Model Tax Convention and to draft appropriate recommendations for dealing with the issues it has examined and for periodic updates to the Model Tax Convention." 
STEERING GROUP ON THE REVISION OF THE MODEL TAX CONVENTION

Members:
Australia
Austria
Belgium
Canada
France
Germany

Japan

Netherlands

Norway

United Kingdom

United States

Date of creation:

January 1991

Duration:

31st December 2013

Mandate: Summary Record of the 51st session of the Working Party No. 1 on Double Taxation of the Committee on Fiscal Affairs [DAFFE/CFA/WP1/M(91)1]

\section{Extract from document [DAFFE/CFA/WP1/M(91)1, Item VI, § 6$]$}

"6. A Steering Group would be constituted to screen these issues and present them to the Working Party with possible recommendations." 


\section{JOINT DRAFTING GROUP FOR WORKING PARTY NO. 1 AND WORKING PARTY NO. 6 ON ATTRIBUTION OF PROFITS TO PERMANENT ESTABLISHMENTS}

Chair:

Members:

Date of creation:

Duration:

Mr. Alain Castonguay

Austria

Belgium

Canada

France

Germany

Ireland

Italy

Japan

January 2005

31st December 2013
(Canada)

Netherlands

New Zealand

Norway

Spain

Sweden

Switzerland

United Kingdom

United States

\section{Mandate:}

The WP1-WP6 Joint Drafting Group on Attribution of Profits to Permanent Establishments (“JDG") was created at the January 2005 meeting of the Committee on Fiscal Affairs and was given the following mandate:

The mandate of the WP1 and WP6 Joint Drafting Group is to draft, for the approval of both Working Parties and the CFA, how the guidance that the OECD will provide to reflect the conclusions of WP6 on the attribution of profits to permanent establishments could be incorporated in the OECD Model Tax Convention and/or Guidelines.

The JDG will make a progress report to CFA in June 2005 on the form the guidance could take, including on whether it should be in the Commentary on Article 7, on which other parts of the Commentary will be affected, on other issues identified by the JDG, including whether changes might need to be made to Article 7 , and on the likely timetable for the completion of the work (no later than January 2007).

At its June 2006 meeting, however, the Committee on Fiscal Affairs revised the deadline for the completion of the work and reached the following decisions concerning the project on attribution of profits to permanent establishments.

\section{Extract of [CTPA/CFA/M(2006)2]}

"B. Implement Plan A through new text for Model Article 7, with new Commentary

C. Also prepare new Commentary for existing Model Article 7, importing as much as possible of AOA as does not conflict with existing Commentary

IV. Timetable

C. Proceed with preparation of draft implementation package by JDG, to be released in 2007 for public comment." 


\section{WORKING PARTY NO. 2 ON TAX POLICY ANALYSIS AND TAX STATISTICS}

Chair:

Mr. Christian Valenduc

(Belgium)

Vice-Chairs:

Mr. Marc Seguin

(Canada)

Mr. Martin Jares

(Czech Republic)

Members:

Open to all Member countries

Observers:

Chile

Russian Federation

People's Republic of China India South Africa

Argentina

International Monetary Fund (IMF)

World Bank

Date of creation:

May 1971

Duration:

31st December 2013

Mandate: Summary Records of the 1st, 56th, and 62nd Sessions of the Committee on Fiscal Affairs [CFA/M(71)1, DAFFE/CFA/M(99)1, DAFFE/CFA/M(2002)1/REV1] and documents [DAFFE/CFA(99)9 and DAFFE/CFA/WP2(2002)1]

\section{Extract from Document [DAFFE/CFA/WP2(2002)1]}

"1.[...] a new mandate for Working party No.2:

"To analyse and measure the social and economic implications of tax policy, as referred to it by the Committee on Fiscal Affairs. In particular:

- $\quad$ to be responsible for the annual publication of Revenue Statistics and Taxing Wages;

- $\quad$ to analyse current tax policy issues;

- $\quad$ to provide advice and experience in tax-related issues to other parts of the OECD;

- to be responsible for the maintenance and appropriate dissemination of the OECD Tax Database."..." 


\section{WORKING PARTY NO. 6 ON THE TAXATION OF MULTINATIONAL ENTERPRISES}

Chair:

Vice-Chairs:

Members:

Observers:

Date of creation:

Duration:
Ms. Marlies A. de Ruiter

Mr. Marc Simpson

Mr. David Ernick

Open to all Member countries

Chile

Russian Federation

India

January 1973

31st December 2013
(Netherlands)

(Australia)

(United States)

People's Republic of China South Africa

Argentina

Mandate: Recommendation of the Council C(95)126/FINAL as amended:

\section{Extract of the Recommendation of the Council C(95)126/FINAL}

"The Council,

III. INSTRUCTS the Committee on Fiscal Affairs:

III.1. to pursue its work on issues pertinent to transfer pricing and to issue the additions to the guidelines referred to in the 1995 Report;

III.2. to monitor the implementation of the 1995 Report in cooperation with the tax authorities of Member countries and with the participation of the business community and the recommend to the Council to amend and update, if necessary, the 1995 Report in the light of this monitoring;

III.3. to report periodically to the Council on the results of its work in these matters together with any relevant proposals for improved international cooperation;

III.4. to develop its dialogue with non-Member countries, consistently with the policy of the Organisation, with the aim of assisting them to become familiar with the 1995 Report and where appropriate encourage them to associate themselves with the 1995 Report." 


\section{JOINT DRAFTING GROUP FOR WORKING PARTY NO. 1 AND WORKING PARTY NO. 6 ON ATTRIBUTION OF PROFITS TO PERMANENT ESTABLISHMENTS}

Chair:

Members:

Date of creation:

Duration:

Mr. Alain Castonguay

Austria

Belgium

Canada

France

Germany

Ireland

Italy

Japan

January 2005

31st December 2013
(Canada)

Netherlands

New Zealand

Norway

Spain

Sweden

Switzerland

United Kingdom

United States

\section{Mandate:}

The WP1-WP6 Joint Drafting Group on Attribution of Profits to Permanent Establishments (“JDG") was created at the January 2005 meeting of the Committee on Fiscal Affairs and was given the following mandate:

The mandate of the WP1 and WP6 Joint Drafting Group is to draft, for the approval of both Working Parties and the CFA, how the guidance that the OECD will provide to reflect the conclusions of WP6 on the attribution of profits to permanent establishments could be incorporated in the OECD Model Tax Convention and/or Guidelines.

The JDG will make a progress report to CFA in June 2005 on the form the guidance could take, including on whether it should be in the Commentary on Article 7, on which other parts of the Commentary will be affected, on other issues identified by the JDG, including whether changes might need to be made to Article 7 , and on the likely timetable for the completion of the work (no later than January 2007).

At its June 2006 meeting, however, the Committee on Fiscal Affairs revised the deadline for the completion of the work and reached the following decisions concerning the project on attribution of profits to permanent establishments.

\section{Extract of [CTPA/CFA/M(2006)2]}

"B. Implement Plan A through new text for Model Article 7, with new Commentary

C. Also prepare new Commentary for existing Model Article 7, importing as much as possible of AOA as does not conflict with existing Commentary

IV. Timetable

C. Proceed with preparation of draft implementation package by JDG, to be released in 2007 for public comment." 


\section{WORKING PARTY NO. 8 ON TAX AVOIDANCE AND EVASION}

Chair:

Vice-Chairs:

Bureau Members:

Members:

Observers:

Ad hoc Observers:

Date of creation:

Duration:
Mr. Per Olav Gjesti

Mr. John Nash

Ms. A. Luisa Perrotti

Mr. James D. Carroll

Mr. Michael Nugent

Mrs. Torill Wettre

Open to all Member countries

Chile

Russian Federation

India

International Monetary Fund (IMF)

World Bank

Estonia

Israel

Slovenia

January 1977

31st December 2013
(Norway)

(New Zealand)

(Italy)

(United States)

(Australia)

(Norway)

People's Republic of China

South Africa

Argentina

Mandate: When approving the work programme of the Working Party No. 8 at its meeting of January 2002, the Committee on Fiscal Affairs approved the following mandate for WP8 [CTPA/CFA/WP8(2004)2/CONF].

\section{Extract of document [CTPA/CFA/WP8(2004)2/CONF]}

"1. $\quad$ To further develop and improve the legal, practical and administrative framework to facilitate exchange of information and mutual administrative assistance while ensuring that a proper balance is maintained with respect to the protection of taxpayers' rights;

2. To examine both from a domestic and international point of view the legal, policy, and administrative aspects of tax avoidance and evasion;

3. To contribute to the implementation and promotion of the tax dimension of the Convention on Bribery;

4. To organise meetings of Tax Inspectors on subjects and at such times as agreed by the Committee on Fiscal Affairs." 

GROUP (TIES)

\section{Co-Chairs:}

Members: ${ }^{1}$

Observers:

\section{Ad hoc Observers:}

Date of creation:

Duration:
Mr. James D. Carroll
Mr. Michael Nugent

Australia

Austria

Belgium

Canada

Czech Republic

Denmark

Finland

France

Germany

Hungary

Italy

Chile

Russian Federation

India

Estonia

Israel

Slovenia

1998

31st December 2013
(United States)

(Australia)

Japan

Luxembourg

Netherlands

New Zealand

Norway

Poland

Spain

Sweden

United Kingdom

United States

European Commission

People's Republic of China

South Africa

Argentina

Mandate: Document [DAFFE/CFA/WP8(98)16/REV1]

The Work Program for the TIES Sub-group is drawn from unfinished work from the merger of the WP8 Cybertax Sub-group and the ad-hoc group on EDI and work referred by other groups under the Committee on Fiscal Affairs (CFA).

The main items for the TIES group that flow from the above-mentioned areas are, and suggestions by delegates are:

(i) adapting the OECD Standard Magnetic Format (SMF) for use in the current technological environment;

(ii) creating a reference or user manual for automatic exchange of information (Eol) using the OECD SMF [both refer: DAFFE/CFA/WP8(96)6 and DAFFE/CFA/M(98)1];

(iii) developing an electronic format for a certificate of residence [refer: DAFFE/CFA/WP8/M(98)1 and DAFFE/CFA/WP8(98)9];

(iv) conducting a pilot exercise to electronically exchange Tax Identification Numbers (TINs) [refer: DAFFE/CFA/WP8/M(98)1];

(v) updating and expanding the 1995 survey on the implementation of the OECD standard Magnetic Format;

(vi) addressing data security and data quality issues for exchange of information; and

(vii) considering the benefits and appropriate processes for exchanging information on consumption taxes.

\footnotetext{
${ }^{1}$ Current members. Sub-Group open to all Member countries.
} 


\section{SUB-GROUP ON TAX CRIMES AND MONEY LAUNDERING}

Chair:

Mr. Denis Meunier

(Canada)

Members:

Open to all Member countries

Observers:

Chile

Russian Federation

India

People's Republic of China

South Africa

Argentina

Ad hoc Observers:

Estonia

Israel

Slovenia

Date of creation:

20th December 2005

Duration:

31st December 2013

Mandate: Summary record of the 65th meeting of the Committee on Fiscal Affairs [DAFFE/CFA/M(2003)2]

\section{Extract from [DAFFE/CFA/M(2003)2]}

"54. The Deputy Chair, Frank Mullen, presented the Bureau proposals [...]

55. The proposals were then approved and the Secretariat will initiate preparations for developing the informal group."

\section{Approved proposals}

"The CFA Bureau proposes several courses of action to further the goal of improving co-operation between tax and anti-money laundering authorities. The proposals are:

- $\quad$ Establishing small informal groups that would focus on specific sectors.

- $\quad$ Developing a document describing the existing institutional arrangements in member countries for cooperation between tax administrations and FIUs.

Identifying the constraints on tax administrators being able to share information with FIUs.

Exploring further the commonalities between money laundering and tax fraud indicators.

Developing additional typologies.

The CFA Bureau also proposes that Working Party No. 8 establish a sub-group consisting of criminal tax experts to take forward this work in the most efficient manner." 


\section{WORKING PARTY NO. 9 ON CONSUMPTION TAXES}

Chair:

Members:

Vice-Chairs:

Observers:

Date of creation:

Duration:
Mr. Richard Brown

Open to all Member countries

\author{
Mr. Rainer Nowak \\ Mr. Arthur Kerrigan \\ Mr. Yasushi Onishi \\ Ms. Dimitra Koulouri
}

Chile

Russian Federation

India

International Monetary Fund (IMF)

World Bank

January 1998

31st December 2013
(United Kingdom)

(Canada)

(European Commission)

(Japan)

(Greece)

People's Republic of China South Africa

Argentina

Mandate: $\quad$ Mandate approved by the Committee on Fiscal Affairs under the written procedure on 1st February 2006 [CTPA/CFA/WP9(2006)1]

\section{Extract of Document [CTPA/CFA/WP9(2006)1]]}

"Working Party No 9 on Consumption Taxes is a forum for the discussion of issues, both domestic and international, relating to consumption tax policy and administration. The Working Party will assist member countries to secure appropriate and effective taxation outcomes through the development of relevant outputs that address these issues, and through the publication of comparative data and information concerning the application of consumption taxes. The Working Party will develop a dialogue with non-OECD economies and work with them, as appropriate, to improve the design and operation of their consumption tax systems." 

GROUP (TIES)

\section{Co-Chairs:}

Members: ${ }^{1}$

Observers:

\section{Ad hoc Observers:}

Date of creation:

Duration:
Mr. James D. Carroll
Mr. Michael Nugent

Australia

Austria

Belgium

Canada

Czech Republic

Denmark

Finland

France

Germany

Hungary

Italy

Chile

Russian Federation

India

Estonia

Israel

Slovenia

1998

31st December 2013
(United States)

(Australia)

Japan

Luxembourg

Netherlands

New Zealand

Norway

Poland

Spain

Sweden

United Kingdom

United States

European Commission

People's Republic of China

South Africa

Argentina

Mandate: Document [DAFFE/CFA/WP8(98)16/REV1]

The Work Program for the TIES Sub-group is drawn from unfinished work from the merger of the WP8 Cybertax Sub-group and the ad-hoc group on EDI and work referred by other groups under the Committee on Fiscal Affairs (CFA).

The main items for the TIES group that flow from the above-mentioned areas are, and suggestions by delegates are:

(i) adapting the OECD Standard Magnetic Format (SMF) for use in the current technological environment;

(ii) creating a reference or user manual for automatic exchange of information (Eol) using the OECD SMF [both refer: DAFFE/CFA/WP8(96)6 and DAFFE/CFA/M(98)1];

(iii) developing an electronic format for a certificate of residence [refer: DAFFE/CFA/WP8/M(98)1 and DAFFE/CFA/WP8(98)9];

(iv) conducting a pilot exercise to electronically exchange Tax Identification Numbers (TINs) [refer: DAFFE/CFA/WP8/M(98)1];

(v) updating and expanding the 1995 survey on the implementation of the OECD standard Magnetic Format;

(vi) addressing data security and data quality issues for exchange of information; and

(vii) considering the benefits and appropriate processes for exchanging information on consumption taxes.

\footnotetext{
${ }^{1}$ Current members. Sub-Group open to all Member countries.
} 


\section{FORUM ON HARMFUL TAX PRACTICES}

Chair:

Bureau Members:

Members:

Observers:

Date of creation:

Duration:
Mr. Christian Comolet-Tirman

(France)

France

Ireland

Japan

United States

Open to all Member countries

Chile

Russian Federation

India

People's Republic of China

South Africa

Argentina

International Monetary Fund (IMF)

World Bank

July 1998

31st December 2013

Mandate: Recommendation of the Council on Counteracting Harmful Tax Competition [C(98)17/FINAL]

\section{Extract from document [C(98)17/FINAL]}

"1. to establish a Forum on Harmful Tax Practices;

2. to implement the relevant measures identified in the attached Appendix;

3. to report periodically to the Council on the results of its work in these matters together with any relevant proposals for further improvements in the co-operation to counter harmful tax practices;

4. to develop its dialogue with non-member countries, consistently with the policy of the Organisation, with the aim of assisting these countries to become familiar with the analysis and conclusions of the Report and, where appropriate, to encourage them to associate themselves with the recommendations set out in the Report." 


\section{FORUM ON TAX ADMINISTRATION}

Chair:

Members:

Observers:

Date of creation:

Duration:
Mr. Pravin Gordhan

(South Africa)

Open to all Member countries

Chile

Russian Federation

India

People's Republic of China

South Africa

Argentina

International Monetary Fund (IMF)

United Nations

World Bank

20th December 2005

31st December 2013

Mandate: - To provide an open forum for tax administrators to provide strategic analysis of, and propose responses to, important tax administration issues. The work methods will involve virtual and ad hoc meeting procedures [DAFFE/CFA(97)37] as approved by the Committee on Fiscal Affairs during its 53rd Session [DAFFE/CFA/M(97)2].

- Name changed and mandate modified by the CFA in June 2002 [DAFFE/CFA/M(2002)2/CONF, Item VIII] and document [DAFFE/CFA(2002)28/REV1, § 7]

"The 'Forum on Strategic Management' - now the Forum on Tax Administration - was created by the CFA in June 1997 to act as the focal point for CFA work on tax administration. The CFA recognised the need for a forum in which tax administrators could exchange experiences in addressing existing and future strategic challenges for tax administrations in a rapidly changing and globalising environment.

The aims of the FTA are:

To share information \& experiences on common tax administration issues, such as service and compliance approaches as well as non-tax specific administrative issues such as performance measurement \& management.

To share thoughts on emerging administrative challenges." 


\section{FORUM ON TAX ADMINISTRATION COMPLIANCE SUB-GROUP ${ }^{1}$}

Chair:

Members:

Observers:

Date of creation:

Duration:
Mr. Lennart Wittberg

(Sweden)

Open to all Member countries

Chile

Russian Federation

India

People's Republic of China South Africa

Argentina

Mandate: Document [DAFFE/CFA/FSM(2002)1] approved by the CFA at its 62nd session in January 2002 [DAFFE/CFA/M(2002)1].

The FSM ${ }^{2}$ Compliance Sub Group was created in 2002 by the Forum on Strategic Management. The following mandate has been agreed:

The mandate of the Compliance Sub-group of the Forum on Tax Administration is to provide a forum for members to share experiences and knowledge of compliance approaches to progress good practice in compliance activities and administration both domestically and internationally.

Specifically it will:

Periodically monitor and report on trends in compliance approaches, strategies and activities.

Consider and compare member compliance objectives, the strategies to achieve those objectives and the underlying behavioural compliance models and assumptions being used.

Consider and compare member compliance structures, systems (including case selection, actioning, and management) and staff skills and training.

Create and maintain best practice papers and discussion papers on emerging trends and innovative approaches.

\footnotetext{
1 Formerly "Sub-Group on Compliance", name changed on 27th june 2002.

2 Now called "Forum on Tax Administration" or "FTA" [DAFFE/CFA/M(2002)2/CONF]
} 


\section{FORUM ON TAX ADMINISTRATION TAXPAYER SERVICES SUB-GROUP'}

Chair:

Members:

Observers:

Date of creation:

Duration:
Mr. Terry Hawes

(United Kingdom)

Open to all Member countries

Chile

Russian Federation

India
People's Republic of China South Africa

Argentina

2001

31st December 2013

Mandate: Document [DAFFE/CFA/FTA/ESERV(2002)1/REV1] discussed at the 1st meeting of the FTA in October 2002

\section{Extract from document [DAFFE/CFA/FTA/ESERV(2002)1/REV1]}

"Mandate

The primary mandate of the Forum on Tax Administration (FTA) eServices Sub-group* is to provide a forum for members to share experiences and knowledge in Taxpayer Service provision and to progress good practice both in Taxpayer Service domestically and internationally.

Specifically it will:

- $\quad$ Periodically monitor and report on trends in Taxpayer Service delivery, with a particular focus on the development and deployment of e-Services by Tax administration.

Examine ways to promote the uptake and use of e-Services by Tax administrations.

Examine options for cross border administrative simplification and consistency, thus making it easier to comply."

\footnotetext{
${ }^{1}$ Formerly "Forum on Tax Administration E-Service Sub-Group".
} 
Chair:

Members:

Date of creation:

Duration:
Ms. Silvia López Ribas

Australia

Austria

Belgium

Canada

Denmark

Finland

France

Greece

Italy

18th December 2003

31st December 2010
(Spain)

Japan

Korea

Netherlands

Norway

Portugal

Spain

Switzerland

Turkey

Mandate: - Decision of the Council establishing an OECD Network on Fiscal Affairs Across Levels of Government approved at its 1074th session held on 18 December 2003 [C/M(2003)29, item 414 and C(2003)192]

- The mandate was extended by Council during its 1128 th session held on 26 January 2006 [C/M(2006)2, item 17]

\section{Extract of the Summary Record [C/M(2003)29, item 414]}

(414)

"THE COUNCIL

b) agreed to the creation of an OECD Network on Fiscal Relations Across Levels of Government for a period of three years until December 2006, with a review to be made at the end of 2005 to determine whether the Network's mandate should be extended, and agreed to the proposed mode of financing subject to Council decision on the 2005-2006 biennium;

c) agreed with its proposed activities, output, work programme, membership and funding as described in C(2003)192 and its CORR1/REV1 and the Annex hereto."

\section{Extract of Document C(2003)192}

"7. The main objectives of the Network would be to:

- Provide a place where officials and others can exchange experience and views on the policy issues involved in reforming fiscal relations across levels of government;

- Analyse aspects of the design of fiscal relations across levels of government and their impact on local, regional and national development;

- Establish and maintain a consolidated statistical database, covering both quantitative and qualitative aspects of fiscal relations across levels of government for Network members." 
(17)

"THE COUNCIL

b) Agreed to the extension of the mandate of the Network on Fiscal Relations Across Levels of Government for a period of four additional years, until December 2010, with a review to be made at the end of 2009 to determine whether the Network's mandate should be further extended." 
SCIENCE, TECHNOLOGY AND INDUSTRY 

Chair:

Vice-Chairs:

Members:

Observer:

Date of creation:

Duration:
Mr. Ken Warwick

Mr. Finn Lauritzen

Mr. Yasuhisa Nakao

Ms. Jane Corwin

Open to all Member countries

Israel

1st January 2007

31st December 2011
(United Kingdom)

(Denmark)

(Japan)

(United States)

Mandate: Resolution on the mandate of the Committee on Industry and Business Environment [C/M(2006)16, Item 209 and C(2006)132/REV1 and CORR1]

\section{Resolution of the Council [C(2006)132/REV1 and CORR1 and C/M(2006)16, item 209]}

1. The overarching objective of the Committee on Industry, Innovation and Entrepreneurship shall be to assist member countries, and as appropriate, non-member countries, in designing, adapting and implementing policies that can foster sustainable productivity growth and competitiveness in the changing context for industry, innovation and entrepreneurship. This changing context is characterised by the globalisation of markets and value chains, rising importance of entrepreneurship, innovation and intellectual assets, increasing reliance of manufacturing on services, and profound changes in the countries' industrial structures, driven by the activity of multinational firms as well as a vibrant population of SMEs.

In the context of the Committee's overall objective, it will:

a) Identify policies and regulatory frameworks, which help enterprises meet new challenges, encourage the progress of new industrial sectors and the modernisation of established ones, through:

i) The exploration of trends in the evolution of industry structures, including the changing nature of manufacturing and services in a global economy.

ii) The assessment of the impact of the globalisation of production across member countries, including the roles and interactions of SMEs and global value chains.

iii) The examination of the effects of microeconomic policies such as conditions for entrepreneurship and firm dynamics, human capital and regulatory reform on industrial economic performance.

b) Promote the prospects for enhanced competitiveness and productivity growth through the fostering of a better understanding of the roles for innovation in firm/industry business plans and strategies.

c) Foster value creation by accelerating the effective and efficient management of intellectual assets through analysis, exchange of ideas and dissemination of good practices. 
3. In particular, the Committee on Industry, Innovation, and Entrepreneurship shall be responsible for analysing and developing policy recommendations, which require co-operation and consultation among member countries, with a view to achieving the above objectives.

4. The scope of the Committee's work will include both macro- and micro-level research and analysis of industry, clusters, sectors and firms encompassing both manufacturing and services, large firms and SMEs at national and global levels and will have the following dimensions:

a) Economic and industry analysis, theme reviews and discussion forums.

b) Policy analysis and evaluation to identify good practices that meet adjustment challenges.

c) Active involvement in and links to the horizontal programmes of the Organisation.

d) Dissemination of results through publication of studies and special conferences.

5. The Committee shall devote particular efforts to understanding and articulating better the contribution of SMEs to innovation, growth and employment in the new and emerging context for industry and entrepreneurship, and develop recommendations for policy reforms that are needed to address the specific needs of SMEs.

6. In pursuit of the objectives outlined in paragraphs 1 and 2, the Committee on Industry, Innovation and Entrepreneurship shall:

a) Co-ordinate the work programmes of its subsidiary bodies ${ }^{1}$ and receive regular reports from them to ensure analysis and policy recommendations are fully integrated and evaluated.

b) Recognise the central role of innovation as a catalyst for economic development and growth, work closely with the Committee for Scientific and Technological Policy, including providing the CSTP with an industrial and business innovation perspective and receiving from it reports on related studies, in order to allow strategic coordination between CIIE and CSTP as they pursue their respective objectives.

c) Maintain close working relationships with other relevant bodies of the Organisation to complement and support analysis underway, discuss industrial aspects of questions raised and, where appropriate, undertake joint projects.

7. Subject to the Programme of Work and Budget of the Organisation, the Committee on Industry, Innovation and Entrepreneurship will organise ad hoc workshops and business and industry policy forums to explore timely issues with the private sector and to develop policy recommendations. When appropriate, the Committee will also consult with representatives of industry, business, trade unions and public interest groups.

8. Where possible, member countries shall appoint to the Committee on Industry, Innovation and Entrepreneurship high-ranking officials concerned with co-ordination of policies in the fields of industry in their own countries.

9. For the purpose of its activities in the fields of industry, the Organisation shall periodically collect all relevant statistics and other information; in principle, these data will be assembled by the Secretariat and published on the responsibility of the Secretary-General.

10. The terms of reference of the Committee on Industry, Innovation and Entrepreneurship will take effect on 1 January 2007 and remain in force until 31 December 2011, unless the Council decides otherwise." 


\section{WORKING PARTY ON SMES AND ENTREPRENEURSHIP (WPSMEE)}

Chair:

Vice-Chairs:

Members:

Observers:

Date of creation:

Duration:
Mr. Jacques Augustin

Mr. Nikolaos Tritaris

Mr. Hiromichi Moriyama

Mr. Iván Ornelas Diaz

Ms. Ewa Baranowska

Mr. Christian Weber

Mr. Dilip Shah
(France)

(Greece)

(Japan)

(Mexico)

(Poland)

(Switzerland)

(United Kingdom)

Open to all Member countries

The Russian Federation
Israel
Brazil
Romania
Thailand
Ukraine

Inter-American Development Bank (IDB)

31st March 1993

31st December 2011

Mandate: - Summary Record of the 101st Session of the Committee on Industry and Business Environment [DSTI/IND/M(2002)1]

- Summary Record of the 107th Session of the Committee on Industry and Business Environment [DSTI/IND/M(2005)1] and document DSTI/IND(2002)9]

- Summary Record of the 110th Session of the Committee on Industry, Innovation and Entrepreneurship [DSTI/IND/M(2007)1 and document DSTI/IND(2007)2]

\section{Extract from document [DSTI/IND(2007)2]}

\section{"Background}

SMEs are the dominant form of business organisation in all countries and create more than half of the jobs in most economies. The majority are foundation firms which provide the every day goods and services on which economies depend. A few SMEs are especially important because they drive innovations in knowledge-based and globalised economies: they play a key role in driving sustainable economic growth and in the creation of skilled jobs and training places for young workers.

In March 1993, the Committee on Industry and Business Environment (then Industry Committee) created the Working Party on SMEs to examine the nature and scale of issues and policies at the national and international levels pertaining to SMEs (including micro-enterprises) and entrepreneurship. In order to complement the work of the parent Committee, which is in charge, inter alia, of broader industry policy matters, the WPSMEE focuses on issues and challenges specific to SMEs and entrepreneurs.

At the first OECD Ministerial Conference on SMEs, Ministers, in the Bologna Charter on SME Policies, welcomed the work on SMEs by the OECD and encouraged continued multilateral exchange of policy experiences and best practices. In June 2004, at the Istanbul Ministerial Conference, Ministers recognised the important role played by the OECD in fostering the 
entrepreneurial agenda and SME competitiveness at the global level. They invited the Organisation to consider undertaking a number of activities in pursuit of these goals.

In recognition of the importance given to the OECD work on SMEs and entrepreneurship and of the growing need for an integrated policy approach, the OECD SecretaryGeneral created, in July 2004, the Centre for Entrepreneurship, SMEs and Local Development (CFE). The CFE aims to strengthen horizontal co-operation and synergies within the OECD and to build on the close links between entrepreneurship, SMEs and local development.

Objective

1. Under the general direction of the Committee on Industry, Innovation and Entrepreneurship (CIIE), the Working Party on SMEs and Entrepreneurship (WPSMEE) is responsible for promoting and taking forward OECD work on SMEs and entrepreneurship.

2. In this respect, the WPSMEE provides the information (including policy analysis, evaluation of policies and best practices, and recommendations) needed by member countries to develop policies that foster entrepreneurship, that facilitate sustainable growth, competitiveness, and the creation of skilled jobs, and that finally, help their SMEs to meet the challenge of globalisation.

Activities

3. To meet this objective, the Working Party's core activities include:

- Improving and developing SME and firm-level statistics, as well as entrepreneurship policy and entrepreneurship-related indicators, and making analysis based on those statistics and indicators, in co-operation with other OECD bodies and the appropriate national and international bodies (e.g. the European Commission and APEC).

- Undertaking policy analysis and examining the effects of microeconomic policies on SME growth and entrepreneurship and developing policy recommendations in cooperation and consultation with member countries.

- Acting as a clearing house through which member countries can exchange information and experience on SME and entrepreneurship issues, policies and programmes in order to make assessments of these policies and distil best practices. Consistent with the CIIE outreach strategy and where WPSMEE deems appropriate, non-member economies will be invited to participate in these exchanges, including through the OECD Bologna Process on SME and Entrepreneurship Policies.

- Facilitating the development of networks among, and convening fora of, public, private and non-profit organisations and institutions involved in the development of SMEs and entrepreneurship.

- Reporting regularly to WPSMEE members, the CIIE and other relevant bodies on the progress it is making in achieving its objective and on trends and best practices in SME policies.

4. In line with its objectives, the issues covered by the WPSMEE include:

- SMEs and Innovation:

- High-growth SMEs.

- Innovation in the service sector (including improving customer relations).

- Intellectual assets and value creation (IAVC).

- Access to Markets:

- Perceived barriers to access to markets. 
- SMEs in global value chains.

- SMEs and sustainable development.

- SMEs and Employment

- Creation of skilled jobs.

- Human resource and management skills.

- Financing of SMEs

- SME financing statistics and indicators.

- Understanding the Entrepreneurial and SME Business Environment:

- SME taxation.

- Enterprise policy analysis.

- Evaluation of SME \& entrepreneurship policies and programmes.

- Entrepreneurship policy indicators.

- Entrepreneurship education: youth and higher education.

- Promotion of entrepreneurship.

- SME-related statistics.

- Partnerships, networks and clusters.

- Women's entrepreneurship.

- Utilisation of information and communication technologies (ICT), including electronic commerce.

5. The issues being worked on by the WPSMEE at any point in time will have been selected on the basis of the ranking described in its current programme of work. The WPSMEE will continue to work horizontally, where relevant, with OECD committees other than the CIIE and their subsidiary bodies and will ensure that work on SMEs and entrepreneurship is well-integrated and consistent with the work carried out within the OECD. The WPSMEE develops, for member countries, and when appropriate non-member economies, information and advice on SMEs and entrepreneurship and best practice examples of measures and policies for dealing with them.

6. To ensure efficiency and effectiveness in carrying out its activities, the WPSMEE will hold, as appropriate, joint bureau meetings, back-to-back meetings and/or joint seminars and similar events aimed at taking forward issues of mutual interest with the CIIE and its Working Parties as well as with other concerned bodies.

7. The WPSMEE co-operates with international institutions, regional economic bodies, the business community and the financial community, as necessary in order to pursue issues of interest to the WPSMEE.

8. The WPSMEE meets twice a year and at least once at the OECD Headquarters. A second meeting is generally hosted by a member country (or a non-member economy participating actively in the OECD Bologna Process on SME and Entrepreneurship Policies), thereby providing delegates with the opportunity to take a closer look at the host country's SME policies and to meet with local entrepreneurs.

9. The mandate of the Working Party on SMEs and Entrepreneurship (WPSMEE) shall expire on 31 December 2011. The WPSMEE or its parent Committee will review, and may decide to propose a revision of these terms of reference after a two-year period." 


\section{WORKING PARTY ON INDUSTRY ANALYSIS (WPIA) ${ }^{1}$}

Chair:

Vice-Chairs:

Members:

Observer:

Date of creation:

Duration:
Mr. Kazuyuki Motohashi

Mr. Donald Brunker

Mr. François Delorme

Mr. Georg Licht

Mr. Hans-Olof Hagen

Mr. Shawn Klimek

Open to all Member countries

Israel
(Japan)

\author{
(Australia) \\ (Canada) \\ (Germany) \\ (Sweden) \\ (United States)
}

International Labour Organization (ILO)
UN Economic Commission for Europe (UNECE)
UN Industrial Development Organisation (UNIDO)

2nd March 1971

31st December 2011

Mandate: - Summary Record of the 107th Session of the Committee on Industry and Business Environment [DSTI/IND/M(2005)1] and document DSTI/IND(2003)24

- Summary Record of the 110th Session of the Committee on Industry, Innovation and Entrepreneurship [DSTI/IND/M(2007)1] and document DSTI/IND(2007)2

\section{Extract from document DSTI/IND(2007)2}

"1. Under the general direction of the CIIE (Committee on Industry, Innovation and Entrepreneurship), the Working Party on Industry Analysis (WPIA) is responsible for developing indicators and quantitative analyses in the area of industrial performance.

2. More specifically, the Working Party will:

a) Contribute to the work of the CIIE by developing policy-oriented, quantitative analyses addressing:

- The changing determinants of growth, productivity and industrial performance in knowledge-based firms and in industry at large; including the role of technological and non-technological innovation, intellectual property rights, the diffusion of new technology, sector specificities (notably in the services), human capital, and entrepreneurship.

- The changing character of production and capital formation in the business sector as value chains become progressively globalised.

b) Facilitate the development and improvement of internationally comparable methodologies and the timely availability of statistical series and indicators to monitor structural change and to assess economic performance and policy outcomes.

c) Act as a forum for co-operative policy-oriented research with micro (firm-level) data, focusing on a better understanding of the links between business performance and its drivers, including innovation, entrepreneurship, human capital and organisational change.

\footnotetext{
1 Formerly known as the "Working Party on Statistics (SWIC)".
} 
3. The Working Party will seek to ensure synergies between its work and the statistical and analytical work undertaken by other OECD bodies, and by other competent international and supranational organisations.

4. In order to develop a better understanding of the determinants of growth, productivity, innovation and industrial performance, and consistent with the ClIE's outreach strategy, the Working Party will seek to involve the business community and relevant non-member economies in its activities.

5. To promote consistency with the CIIE framework and to ensure efficiency and effectiveness in carrying out its activities, the Working Party will provide regular reports to the CIIE on the progress it is making in achieving its objectives, and will hold, as appropriate, joint bureau meetings, back-to-back meetings, and/or joint seminars and similar events aimed at taking forward issues of mutual interest with the CIIE and its other Working Parties, as well as with other concerned OECD bodies.

6. The terms of reference of the Working Party on Industry Analysis shall expire on 31 December 2011. The WPIA or its parent Committee will review, and may decide to propose a revision of these terms of reference after a two-year period." 


\section{WORKING PARTY ON GLOBALISATION OF INDUSTRY (WPGI) ${ }^{1}$}

Chair:

Vice-Chairs:

Members:

Observer:

Date of creation:

Duration:
(..)

\author{
Mr. Lionel Fontagné \\ Mr. Peter Bøegh Nielsen \\ Mr. Masataka Saburi \\ Mr. Obie Whichard
}

(France)

(Denmark)

(Japan)

(United States)

Open to all Member countries

Israel

International Monetary Fund (IMF)

UN Conference on Trade and Development (UNCTAD)

World Bank

World Trade Organization (WTO)

22nd March 2007

31st December 2011

Mandate : - Summary Record of the 110th Session of the Committee on Industry, Innovation and Entrepreneurship [DSTI/IND/M(2007)1] and document DSTI/IND(2007)2

- Summary Record of the 113th Session of the Committee on Industry, Innovation and Entrepreneurship [DSTI/IND/M(2008)2] and document

DSTI/IND/WPGI(2008)13

\section{Extract from document DSTI/IND/WPGI(2008)13}

"1. Globalisation has been the major economic and political theme of the past three decades. The liberalisation of capital movements, the further opening of markets to trade and investment and the pivotal role played by the diffusion of information and communication technologies, have changed the framework economic conditions, increased the economic and financial interdependence of countries and facilitated the emergence of new actors in the global economy.

2. The OECD has a central role to play in the present phase of globalisation, by analysing all aspects of this process and proposing structural adjustment policies. In many respects, globalisation could be seen mainly as a microeconomic phenomenon, the mission of the OECD Working Party on Globalisation of Industry is to analyse the new strategies and behavior of firms in order to help governments adopt the appropriate reforms and maximise the benefits for globalisation.

3. Under the general direction of the CIIE (Committee on Industry, Innovation and Entrepreneurship), the Working Party on Globalisation of Industry (WPGI) is responsible for analysing the impact of the globalisation of industry in the economy of member countries through policy-oriented economic analyses and using international statistical surveys. Its objective is to contribute to the CIIE's policy discussions and to help the Committee respond to the numerous demands involving globalisation from both within and outside the OECD.

4. The Working Party on Globalisation of Industry shall assist the CIIE by developing policy-

\footnotetext{
1 Created in 1992. Formerly known as the "Special Session on Globalisation" of the Working Party on Statistics (SWIC).
} 
oriented quantitative analysis concerning the projects inscribed in its programme of work. More specifically, the Working Party shall:

a) On an analytical level:

- Measure the various forms of the globalisation of industry and their implications for the competitiveness and performance of enterprises.

- Analyse trends for different forms of international diffusion of technology and measure the effects on the innovation potential of the countries involved.

- In the framework of the global value chain, evaluate the impact of business operations on growth, productivity, employment, trade performance and the need for structural reforms.

- In co-operation with the Working Party on SMEs and Entrepreneurship, measure and analyse the factors that influence smaller firms and suppliers to become part of global value chains, as well as identify the barriers they face in participating in these chains.

- Analyse the impact of emerging economies on the industrial activity and performance of the OECD member countries.

- In co-operation with relevant bodies, prepare the biennial publication of $O E C D$ Economic Globalisation Indicators.

- Contribute to the publication of the OECD Science, Technology and Industry Scoreboard.

b) On a methodological level, and in respect of database management:

- Collect and disseminate basic data and indicators from the member countries:

- On the activity of multinational firms (affiliates under foreign control in host countries, parent companies and affiliates abroad controlled by compiling countries) in manufacturing and in services.

- On technology receipts and payments (technology balance of payments), in order to measure technology transfers and assess the role of intellectual property in international transactions.

- The Working Party will co-operate with WGIIS (Working Group on International Investment Statistics) and contribute to the work on reconciliation of the statistics on the activities of multinational enterprises with FDI statistics, with a view to establish the basis for a sound analysis of the global economy, as defined by the research agenda of the OECD Benchmark Definition of Foreign Direct Investment.

- Enhance the quality of the data and indicators collected and invite the member countries to adhere to the guidelines proposed in the OECD Handbook on Economic Globalisation Indicators; in addition, consider revising the Handbook, exploring topics that could not be included in the first edition.

- Act as a forum to discuss conceptual and data collection issues related to global value chains.

5. The Working Party shall pursue co-operative efforts in its areas of expertise with other OECD bodies (particularly the CSTP and the Investment Committee) and with the main international organisations concerned (WTO, UNCTAD, World Bank, IMF).

6. Taking account of the CIIE's outreach strategy, and to do a better job of evaluating the roles in the world economy of the main OECD non-members, the Working Party shall forge contacts with non-member economies that play substantial roles in globalisation, inviting them, for example, to compile data in accordance with the definitions of the OECD Handbook on Economic Globalisation Indicators. Contacts will also be pursued with the business community. 
7. To promote consistency with the CIIE framework and to ensure efficiency and effectiveness in carrying out its activities, the Working Party will provide regular reports to the CIIE on the progress it is making in achieving its objectives, and will hold, as appropriate, joint bureau meetings, back-to-back meetings, and/or joint seminars and similar events aimed at taking forward issues of mutual interest with the CIIE and its other Working Parties, as well as with other concerned OECD bodies.

8. The terms of reference of the Working Party on Globalisation of Industry shall expire on 31 December 2011." 


\section{ADVISORY EXPERT GROUP ON INNOVATION IN THE SOFTWARE SECTOR}

Date of creation:

23rd March 2007

Duration:

30th June 2009

Mandate: - Summary Record of the 110th Session of the Committee on Industry, Innovation and Entrepreneurship [DSTI/IND/M(2007)1], documents [DSTI/IND(2007)3 and CE(2008)10]

- Confirmation by the Executive Committee registered in the Summary Record of its 802nd session [CE/M(2008)12, Item 73 and CE(2008)10]

\section{Extract from document CE(2008)10}

"The mandate of the Advisory Expert Group is to help the Secretariat in the detailed scoping of the project on, to advise the Secretariat on the different technical aspects of the plan and to comment on draft reports. Members are also expected to participate in the conferences organised as part of the project.

The terms of reference of the Advisory Expert Group will take effect on 23 March 2007 and will remain in force until 30 June 2009 unless the Committee on Industry, Innovation and Entrepreneurship decides otherwise." 


\section{ADVISORY EXPERT GROUP ON SUSTAINABLE MANUFACTURING}

Date of creation:

Duration: 16th November 2007

30th April 2010

Mandate: - Summary Record of the 111th Session of the Committee on Industry, Innovation and Entrepreneurship [DSTI/IND/M(2007)2/REV1], and document CE(2008)9]

- Confirmation by the Executive Committee registered in the Summary Record of its 812th session [CE/M(2008)22, Item 120 and CE(2008)9]

\section{Extract from document $\mathrm{CE}(2008) 9$}

"1. The eco-innovation and sustainable manufacturing project will include: i) a review of existing studies and indicators; ii) an analytical framework; and iii) data collection and analysis. A synthesis report produced from these components will serve as a building block for the development of an eco-innovation roadmap and a toolkit for policy makers and companies to help build their own sustainable production initiatives.

2. The role of the Advisory Expert Group on Sustainable Manufacturing will be to:

Advise on the detailed scoping of the project;

Advise the Secretariat on the different technical aspects of the project;

Comment on draft reports.

The terms of reference of the Advisory Expert Group on Sustainable Manufacturing will take effect on 16 November 2007 and will remain in force until 30 April 2010 unless the Committee on Industry, Innovation and Entrepreneurship decides otherwise." 
Chair:

Vice-Chairs:

Members:

Observers:

Date of creation:

Duration:
Mr. Luis Sanz-Menendez

Mr. Ward Ziarko

Ms. Annu Jylhä-Pyykönen

Ms. Frédérique Sachwald

Mr. Klaus Matthes

Ms. Alicia Mignone

Mr. Shinichiro Ohgaki

Mr. Tae-Young Shin

Mr. Patrick Vock

Mr. E. Bruce Howard

Open to all Member countries

Chile

Israel

Russian Federation

Council of Europe

UN Conference on Trade and Development (UNCTAD)

3rd February 1972

31st December 2009
(Spain)

(Belgium)

(Finland)

(France)

(Germany)

(Italy)

(Japan)

(Korea)

(Switzerland)

(United States)

Mandate: - Resolution of the Council Concerning the Renewal of the Committee for Scientific and Technological Policy [C(99)185/FINAL]

- Resolution of the Council Concerning the Renewal of the Committee for Scientific and Technological Policy [C(2004)120] approved by Council at its 1091st session on 8 July 2004 [C/M(2004)17, item 217]

\section{Resolution of the Council [C(2004)120 and C/M(2004)17, item 217]}

"THE COUNCIL,

Having regard to Articles 1 and 2 of the Convention on the Organisation for Economic Co-operation and Development of 14 December 1960;

Having regard to the Resolution of the Council of 17 November 1999 concerning the terms of reference of the Committee for Scientific and Technological Policy [C(99)185/FINAL], and to the conclusions of the 964th Session of the Council on 9 December 1999 concerning the extension of the mandate of the Committee for Scientific and Technological Policy [C/M(99)25/PROV, Item 338];

Having regard to the conclusions of the meeting of the Committee for Scientific and Technological Policy at Ministerial level on 29-30 January 2004 [PAC/COM/NEWS(2004)4];

Having regard to the continuing need for a consultative mechanism within the OECD whereby science, technology and innovation policy issues, problems, and challenges of a national and international nature can be examined by Member countries and reported to the Council;

Having regard to the Rules of Procedure of the Organisation; 


\section{DECIDES:}

1. The Committee for Scientific and Technological Policy shall be responsible for encouraging co-operation among Member countries and, as appropriate, with non-member economies, in the field of science, technology and innovation policy, with a view to contributing to the achievement of their economic, social and scientific aims, including growth and the creation of skilled jobs, sustainable development, improved well-being of their citizens and advancing the frontiers of knowledge. It shall pay particular attention to the integration of science, technology and innovation policy with other aspects of government policy, which is of increasing importance in the development of increasingly globalised knowledge economies.

2. The Committee for Scientific and Technological Policy shall, more particularly, be responsible for:

a) Improving, through analytical work and the development of relevant internationally comparable indicators, the understanding of the process through which science, technology and innovation contribute to increased knowledge, productivity growth, economic performance, skilled job creation, sustainable development and social well-being.

b) Promoting the exchange of information and discussion among Member countries on the objectives, instruments and financing of science, technology and innovation policy, in order to facilitate international comparison, to develop evaluation models and to identify relevant best policy practices, particularly as relates to the production and dissemination of knowledge and the strengthening of links between research, higher education and industry, including in the fields of human resource development, innovation policy and mobility.

c) Promoting the exchange of information and discussion among Member countries on policies designed to maintain a strong and creative base of scientific research endowed with adequate tangible and intangible infrastructure.

d) Improving the understanding of Member countries both of foreseeable developments of technology and impact of biotechnologies and their likely national as well as international economic, social and environmental consequences, and the impact of globalisation on their national and regional research and innovation systems.

e) Promoting the exchange of information and discussion among Member countries on measures to promote public understanding of science and technology, to make science and technology studies and training more attractive; and to strengthen, within each Member country, dialogue and interaction with science, industry, and civil society in formulating and implementing science, technology and innovation policies.

f) Facilitating international co-operation in science and technology, as well as, as appropriate, policy co-ordination among Member countries, and among Member and non-member economies on the development of research, access to scientific information and the international mobility of researchers.

g) Facilitating the efforts of the governments of Member countries to strengthen the scientific and technological capabilities of developing countries.

3. In the pursuit of these objectives, the Committee for Scientific and Technological Policy shall determine the strategic orientations of its subsidiary bodies, and receive regular reports from them to ensure their co-ordination, policy integration and evaluation. It shall maintain close working relationships with other relevant bodies of the Organisation working on issues that affect the design and implementation of science and technology policies. The Committee shall co-operate with other international and regional organisations active in this policy field. It may consult with nongovernmental bodies as and when necessary.

4. These terms of reference shall enter into force on 1 January 2005 and shall expire on 31 December 2009, unless the Council decides otherwise.

5. Paragraph 14 of the Annex to the Rules of Procedure shall be amended to read as follows:

'14. Committee for Scientific and Technological Policy: Its terms of reference are defined in the Resolution of the Council C(2004)120." 


\begin{tabular}{|c|c|c|}
\hline Chair: & Mr. Ward Ziarko & (Belgium) \\
\hline Vice-Chairs: & $\begin{array}{l}\text { Mr. Mikael Akerblom } \\
\text { Mr. Giorgio Sirilli } \\
\text { Mr. Tomohiro ljichi } \\
\text { Mr. Svein Olav Nås } \\
\text { Mr. Ray Lambert } \\
\text { Ms. Lynda Carlson }\end{array}$ & $\begin{array}{l}\text { (Finland) } \\
\text { (Italy) } \\
\text { (Japan) } \\
\text { (Norway) } \\
\text { (United Kingdom) } \\
\text { (United States) }\end{array}$ \\
\hline Members: & \multicolumn{2}{|c|}{ Open to all Member countries } \\
\hline Observers: & $\begin{array}{l}\text { Chile } \\
\text { Israel } \\
\text { Russian Federation }\end{array}$ & $\begin{array}{l}\text { Brazil } \\
\text { People's Republic of China } \\
\text { South Africa }\end{array}$ \\
\hline & \multicolumn{2}{|c|}{ UN Educational Scientific and Cultural Organization (UNESCO) } \\
\hline Date of creation: & \multicolumn{2}{|l|}{ 1st September 1962} \\
\hline Duration: & \multicolumn{2}{|l|}{ 31st December 2009} \\
\hline
\end{tabular}
Mandate - Summary record of the 84th Session of the Committee for Scientific and Technological Policy [DSTI/STP/M(2004)3, para. 34] and [ DSTI/STP(2004)14]
- Summary record of the 74th Session of the Committee for Scientific and Technological Policy [DSTI/STP/M(2000)1, para. 11 and Annex 2 B]

\section{Extract from document [DSTI/STP/M(2004)3, para. 34]}

"The Committee:

Agreed to provisionally approve the CSTP Working Parties' new mandates pending the Council's decision on the CIBE/CSTP merger."

\section{Extract from document [DSTI/STP(2004)14]}

"1. The Working Party will monitor, supervise, direct and co-ordinate statistical work and contribute to the development of indicators and quantitative analyses needed to meet the requirements and priorities of the Committee for Scientific and Technological Policy (CSTP). In particular, the Working Party will:

i) Ensure the continued improvement of the methodologies for the collection of internationally comparable data for measuring the input, output, diffusion and impact of science, technology and innovation (including linkages to economic growth) as laid down in the series of manuals produced by the Working Party; encourage the use of these methodologies in member countries and non-member economies. This includes developing and maintaining manuals and standards for measurement in the areas of research and development, human resources in S\&T, innovation, patents, globalisation and other S\&T related matters.

ii) Ensure the timely availability of internationally comparable S\&T data and their analysis, such as the R\&D data collected through biennial OECD surveys and OECD analytical 
reports, and the further development of data collection and dissemination systems for other S\&T and knowledge indicators.

iii) Assist in developing and interpreting statistical indicators which aid formulation and evaluation of science and technology policies. This work should be undertaken in the light of policy priorities expressed by the CSTP, its subsidiary bodies and by member countries.

iv) As required, pursue any other work, needed to assist the CSTP or its subsidiary bodies in the development of quantitative analyses of S\&T-related issues such as the international mobility of researchers, internationalisation of research efforts and more generally the contribution of science and technology to economic growth.

2. The Working Party will promote efficient use of resources by seeking opportunities to work in collaboration with other groups with similar interests, both within the OECD and other competent international fora. The Working Party will also provide technical expertise to other organisations (within and outside of the OECD) on S\&T indicators.

3. The Working Party will co-operate, in particular, with other OECD statistical subgroups and working parties in dealing with broader statistical issues connecting industrial, science and technology, information technology, and human resources activities, and will co-ordinate the development of a coherent set of S\&T indicators across the various areas.

4. Finally, the Working Party will act as a clearing house via which member countries and nonmember economies can exchange information and experience on methods of collection, compilation, analysis and presentation of data which they use as science and technology indicators.

5. The Terms of Reference of the Working Party of National Experts on Science and Technology Indicators shall remain in force until 31 December 2009, unless the CSTP decides otherwise." 


\title{
WORKING PARTY ON BIOTECHNOLOGY (WPB)
}

Chair:

Vice-Chairs:

Members:

Observers:

Date of creation:

Duration:
Mr. Gerardo Jimenez-Sanchez

Mr. Mikael Hirsch

Mr. Robert Main

Mr. Hiroshi Yoshikura

Mr. Mark Bale

Ms. Anita Eisenstadt

Open to all Member countries

Chile

Israel

Russian Federation

31st March 1994

31st December 2009
(Mexico)

(Australia)

(Canada)

(Japan)

(United Kingdom)

(United States)

\author{
Brazil \\ People's Republic of China \\ South Africa
}

\begin{abstract}
Mandate: - Summary record of the 84th Session of the Committee for Scientific and Technological Policy [DSTI/STP/M(2004)3, paragraph 34]

- Summary Record of the 78th Session of the Committee for Scientific and Technological Policy [DSTI/STP/M(2002)1]
\end{abstract}

\section{Extract from document [DSTI/STP/M(2004)3, paragraph 34]}

"The Committee:

Agreed to provisionally approve the CSTP Working Parties' new mandates pending the Council's decision on the CIBE/CSTP merger."

\section{Extract from document [DSTI/STP(2004)16]}

\section{"MANDATE OF THE WORKING PARTY ON BIOTECHNOLOGY}

\begin{abstract}
- $\quad$ The Group will advise upon emerging policy-relevant issues of science, technology and innovation related to biotechnology including, as appropriate, their social and economic implications, with a view to assisting the development, application and diffusion of products, processes, infrastructure and services which, through industrial production, environmental protection, health care and health promotion, will contribute to sustainable economic growth and development, and human welfare.
\end{abstract}

- This should be achieved by: encouraging the international harmonisation of science-based policies, principles and concepts; facilitating scientific and technological co-operation, capacity-building and exchange; taking an appropriate role in debate with society including by promoting education and the public understanding of the opportunities and risks associated with advances in biotechnology, and informing and assisting the work of policy makers in Member countries.

- $\quad$ The Group will report to the Committee for Scientific and Technological Policy (CSTP), and will keep other Committees or their subsidiary bodies informed on the progress of work relating to their interests. It will also seek to work co-operatively with such bodies, where deemed mutually beneficial. The Internal Co-ordination Group for Biotechnology will also be consulted and informed 
about the work of the Group, with a view to the avoidance of duplication and the promotion of synergy and joint activities, where appropriate. Communication and co-operation should also extend, where relevant, to other international organisations.

When and where appropriate, and having identified appropriate activities, the Group shall seek through various forms of outreach activities to make known and extend the influence and impact of OECD work on biotechnology beyond Member countries, and so far as practicable take this wider context into account in the preparation and execution of its work.

In pursuance of its aims, the Group will endeavour to set strategic future directions for successive Programmes of Work from which to set clear, defined and costed objectives for work in which OECD activity adds value.

The Mandate shall run from 1 January 2005 to 31 December 2009, subject to modification by decision of the CSTP; with a mid-term review to assess the value, impact and effectiveness of the work of the Group." 


\section{TASK FORCE ON INDUSTRIAL BIOTECHNOLOGY (TFIB)}

Chair:

Vice-Chairs:

Members:

Observers:

Date of creation:

Duration:
Mr. Mikael Hirsch

Mr. Dirk Carrez

Mr. Saeed Khan

Dr. Monika Sormann

Mr. Kenji Kurata

Mr. Marvin R. Duncan

Open to all Member countries

Chile

Israel

Russian Federation

25th February 1998

31st December 2009
(Australia)

(Business and Industry

Advisory Committee (BIAC))

(Canada)

(European Commission)

(Japan)

(United States)

Brazil

People's Republic of China South Africa

Mandate: - Summary Record of the 6th Session of the Working Party on Biotechnology [DSTI/STP/BIO/M(98)2]

- Summary Record of the 23rd Session of the Working Party on Biotechnology [DSTI/STP/BIO/M(2008)2] and document [DSTI/STP/BIO(2008)7]. Change of name and mandate.

\section{Extract from document [DSTI/STP/BIO/M(98)2]}

"18. Canada proposed to initiate and lead a follow up activity on "Biotechnology for Sustainable Industrial Development", perhaps by a procedure similar to that used in the Megascience Forum. The proposal received strong support."

\section{Extract from documents [DSTI/STP/BIO(2008)7] and [DSTI/STP/BIO/M(2008)2]}

\section{MANDATE OF THE TASK FORCE ON INDUSTRIAL BIOTECHNOLOGY}

The Task Force on Industrial Biotechnology (TFIB) will advise the Working Party on Biotechnology (WPB) on eco-innovation and on opportunities for sustainable economic growth within the context of a developing bioeconomy.

It will advise on policy issues related to industrial biotechnology, including: science and technology, including their adoption; provision of supportive environments for efficient delivery of innovation and access to such innovation; policy responses to novel developments in science and technology, including convergence with other technologies; and the impact of such developments on policy, as well as the sustainability and eco-efficiency of industry.

In so doing, the TFIB will:

i. Collect data and conduct analysis, addressing the above points.

ii. Develop recommendations for policy, including, as appropriate, common approaches, best practices, principles and other instruments.

iii. Determine priorities and contribute to development of statistics indicators and analysis of trends for the bioeconomy. 
iv. Involve (through Council-approved procedures) non-member countries and other international organisations in relevant aspects of their activities.

The group will report to the Working Party on Biotechnology (WPB) and will keep other Committees or their subsidiary bodies informed on the progress of work relating to their interests. It will seek to work co-operatively with such bodies, where deemed mutually beneficial. The Internal Co ordination Group for Biotechnology will be consulted and informed about the work of the group.

The mandate of the Task Force on Industrial Biotechnology will run from 14 February 2008 to 31 December 2009, subject to modification by the Working Party on Biotechnology (WPB). A mid term review of progress and the effectiveness of the Task Force's programme of work will be carried out by the WPB." 
TASK FORCE ON BIOMEDICINE AND HEALTH INNOVATION (TFBHI)

Chair:

Vice-Chairs:

Observers:

Date of creation:

Duration:

Mandate: Summary Record of the 22nd Session of the Working Party on Biotechnology [DSTI/STP/BIO/M(2007)7/REV1], documents [DSTI/STP/BIO(2007)24/REV1 and CE(2008)6]

\section{Extract from document [DSTI/STP/BIO/M(2007)7/REV1]}

"32. Countries agreed to proceed with the creation of a time-limited Task Force, whose terms of reference were articulated in DSTI/STP/BIO(2007)24/REV1, and which would be constituted of delegates with knowledge of both health biotechnologies and health innovation challenges." 


\section{OECD GLOBAL SCIENCE FORUM (GSF)}

Chair:

Vice-Chairs:

Members:

Observers:

Date of creation:

Duration:
Mr. Hermann-Friedrich Wagner

(Germany)

Mr. Jørgen Kjems

Mr. Dany Vandromme

Mr. Alessandro Bettini

Mr. Hiroshi Nagano

Mr. Leo Le Duc

Mr. Paul Williams

Ms. Sharon Hays

Australia
Austria
Belgium
Canada
Czech Republic
Denmark
Finland
France
Germany
Greece
Hungary
Ireland
Italy
Japan
Korea

Chile

Israel

Russian Federation
(Denmark)

(France)

(Italy)

(Japan)

(Netherlands)

(United Kingdom)

(United States)

Mexico

Netherlands

New Zealand

Norway

Poland

Portugal

Slovak Republic

Spain

Sweden

Switzerland

Turkey

United Kingdom

United States

European Commission

Brazil

People's Republic of China South Africa

Mandate : - Summary of the Special Session of the Committee for Scientific and Technological Policy held on 30 April 1999 [DSTI/STP/M(99)2]

- Summary Record of the 82nd Session of the Committee for Scientific and Technological Policy, held on 12 December 2003 [DSTI/STP/M(2003)3]

- Summary Record of the 93rd Session of the Committee for Scientific and Technological Policy, held on 21-22 October 2008 [DSTI/STP/M(2008)2]

- Mandate of the Global Science Forum [DSTI/STP/MS(2008)6]

\section{Extract from document [DSTI/STP/M(2008)2, paragraph 10]}

"The CSTP decided that the Mandate of the OECD Global Science Forum shall remain in force until 31 January 2014, subject to the renewal of the mandate of the Committee by the Council."

\section{Extract from document [DSTI/STP/MS(2008)6]}

\section{Mandate of the Global Science Forum}

"The OECD Global Science Forum is a venue for consultations among senior science policy officials of the OECD Member countries, leading to findings and recommendations for action on high-priority 
science policy issues that require international consultations and/or co-operation, and, whenever possible, identifying opportunities for collaboration on major scientific undertakings. The OECD Global Science Forum shall build on its accomplishments and procedures since 1999, and on those of the Megascience Forum from 1992 to 1998, with flexible working mechanisms and a scope that includes issues at the intersection of science and other public policy domains. Substantive work will be performed by representatives of governments and invited experts, with the OECD Secretariat playing a facilitating and co-ordinating role.

Through its deliberations and activities, the OECD Global Science Forum shall assist Members in the formulation and implementation of their science policies by:

scientific areas.

Exploring opportunities for new or enhanced international co-operation in selected

- Defining international frameworks for vital national or regional science policy decisions.

- $\quad$ Addressing the scientific dimensions of issues of global concern.

The Forum's principal customers will be the government science policy officials who will bring issues forward for consultation. The Forum shall regularly report to the Committee on the progress of its work, its findings, and new topics and activities that are being considered for incorporation into its work programme. At the request of the Committee, it may undertake work on specific issues, for example, reviews and analyses of current policies, practices and emerging challenges. It shall maintain close working relationships with relevant bodies of the OECD and other international organisations. The OECD Global Science Forum shall define its operating procedures as needed. To ensure that the Forum's work attracts the broad support of delegations, and complements that of the Committee, the following criteria should be met before any new activity is undertaken:

- $\quad$ Specificity -- A specific challenge, problem, opportunity or programme area must be identified -- one that concerns international scientific co-operation, and requires a structured international consultation with the involvement of governmental officials.

- $\quad$ Relevance -- There must exist significant near- or mid-term decisions and actions by governments that would be facilitated by the activity.

- Workload -- A fixed time interval, as well as the type of activity should be specified (workshop, working group, study, structured discussion by the Forum, etc.). The resources required from the OECD Secretariat and the Member delegations should be described.

- $\quad$ Commitment -- There must be a high level of interest among Member countries, including broad geographic representation among the OECD membership. One or more lead countries must be willing to provide the needed leadership and resources. There must be a prospect for participation by the appropriate governmental representatives, and scientific experts.

- Inclusiveness -- Potential involvement of non-OECD countries, international bodies, and other OECD committees must be considered to maximise opportunities for productive interactions, and to avoid unnecessary duplication of effort.

The Mandate of the OECD Global Science Forum shall remain in force until 31 January 2014, subject to the renewal of the mandate of the Committee by the Council, unless the Committee decides otherwise. An evaluation exercise will be conducted prior to the end of the mandate period." 


\section{WORKING PARTY ON INNOVATION AND TECHNOLOGY POLICY (TIP)}

Chair:

Vice-Chairs:

Members:

Observers:

Date of creation:

Duration:
Mr. Patrick Vock

Mr. Ward Ziarko

Mr. Eric Hauet

Mr. Carlo Corsi

Mr. Shinji Okakura

Mr. Arie van der Zwan

Mr. Krzysztof Gulda

Mr. Mark Boroush

Open to all Member countries

Chile

Israel

Russian Federation

1st March 1993

31st December 2009
(Switzerland)

(Belgium)

(France)

(Italy)

(Japan)

(Netherlands)

(Poland)

(United States)

Brazil

People's Republic of China

South Africa

Mandate - Summary record of the 84th Session of the Committee for Scientific and
Technological Policy [DSTI/STP/M(2004)3, item 34] and [DSTI/STP(2004)13]
- Summary record of the 74th Session of the Committee for Scientific and
Technological Policy [DSTI/STP/M(2000)1, item 9 and Annex 2C] and
[DSTI/STP(2000)4]

\section{Extract from document [DSTI/STP/M(2004)3 item 34]}

“...the Committee:

- Agreed to provisionally approve the CSTP Working Parties' new mandates pending the Council's decision on the CIBE/CSTP merger."

\section{Extract from document [DSTI/STP(2004)13]}

\section{"MANDATE OF THE WORKING PARTY ON INNOVATION AND TECHNOLOGY POLICY}

1. Taking into account the priorities established by the Committee for Scientific and Technological Policy (CSTP), the Working Party on Innovation and Technology Policy will advise upon innovation and technology policies that enhance productivity; facilitate the creation, diffusion and application of knowledge; and foster sustainable growth and the creation of highly skilled employment.

2. In particular, the Working Party will:

a) Promote the exchange of information on new developments in the design, implementation and evaluation of innovation and technology policies, the management of science-innovation interfaces and the functioning of formal and informal markets for knowledge exchange to inform development and implementation of innovation policy and promote effective governance of national innovation systems.

b) Review specific policies and the mixes of policies put in place to foster the effective, efficient and complementary use of public and private resources devoted to innovation, 
notably through the strengthening of industry-science linkages, and identify good practices in this area.

c) Assess the implications of increased globalisation of economic activities, in particular those related to R\&D, on innovation performance and policy, notably as regards the development of intellectual assets.

d) Consider ways of encouraging international co-operation in the analysis, formulation and implementation of innovation policy, including between member and non-member economies, such as by contributing to the reviews of science, technology and innovation policy that may be entrusted to the Secretariat by Member countries or Observers to the CSTP.

3. In developing its activities, the Working Party will:

a) Draw upon and extend the National Innovation Systems framework it has contributed to develop.

b) Ensure an adequate balance between sectoral and economy-wide approaches to innovation and consider the regional (infra- or supra-national) aspects of innovation policy.

c) Make use of a range of methodologies in its policy assessment work, including surveys, workshops, peer reviews and qualitative and quantitative analysis.

d) Identify new requirements for policy-relevant indicators.

e) Explore new approaches to innovation and technology policy and the need for improving multilateral instruments.

4. The Working Party will undertake its work in close co-operation with other relevant bodies of the Organisation and other international organisations in order to increase the benefits of their respective activities and to avoid duplication of effort.

5. The Working Party will regularly report to the Committee for Scientific and Technological Policy and keep close relationships with other subsidiary bodies of that Committee, as well as with other bodies of the Organisation whose activities may address innovation and technology policy issues." 


\section{WORKING PARTY ON RESEARCH INSTITUTIONS AND HUMAN RESOURCES (RIHR)}

Chair:

Vice-Chairs:

Members:

Observers:

Date of creation:

Duration:
Ms. Renate Fischer

Ms. Ulrike Albrecht

Ms. Sveva Avveduto

Mr. Shinichi Kobayashi

Mr. Asgeir Flotre

Ms. Laura Cruz-Castro

Open to all Member countries

Chile

Israel

Russian Federation
(Austria)

(Germany)

(Italy)

(Japan)

(Norway)

(Spain)

1st April 2008Formerly Ad Hoc Working Group on Steering and Funding of Research Institutions (SFRI)

\section{Brazil}

People's Republic of China South Africa

31st December 2009

Mandate: - Summary record of the 92nd Session of the Committee for Scientific and Technological Policy [DSTI/STP/M(2008)1, item 7] and [DSTI/STP/SFRI(2008)5

- Summary record of the 84th Session of the Committee for Scientific and Technological Policy [DSTI/STP/M(2004)3, item 34] and [DSTI/STP(2004)24]

- Summary record of the 74th Session of the Committee for Scientific and Technological Policy [DSTI/STP/M(2000)1, paragraph13]

\section{Extract from documents [DSTI/STP/M(2008)1 item 7 and DSTI/STP/SFRI(2008)5]}

\section{"THE COMMITTEE:}

Approved the new mandate for this group and approved a new name and acronym: Research Institutions and Human Resources (RIHR).

\section{MANDATE OF THE WORKING PARTY ON RESEARCH INSTITUTIONS AND HUMAN RESOURCES (RIhr)}

1. The main objectives of the Working Party will be to exchange information on and to review the main institutional, regulatory, and management issues facing governments as they strive to strengthen the knowledge base for innovation and the research capabilities of their public research institutions (i.e. public research laboratories, universities and other higher education institutions involved in research) to contribute to sustainable economic growth and social well-being, and to secure the public benefits that flow from research and human capital. Specific issues to be addressed include:

$\ldots$

the evolving transformation and patterns of governing and financing research institutions, and universities, including issues related to their strategies and priority selection, public or private ownership and the use of financial instruments to enhance desired outcomes of the science systems, institutions or grant schemes as well as the emergence of new types of "semi-public" research performing institutions; 
- $\quad$ policies and best practices for evaluation and the use of evaluations in steering and funding of public research institutions and universities to monitor and improve their performance in the context of the research and innovation system (including industry); enhancing the skills base for research and innovation (such as skills for service industries and non-technological innovation, re-training), and fostering linkages and knowledge exchange within the research and innovation system (including collaboration and the internationalisation of research); and

the analysis of specific issues related to human resources for science and technology (HRST), such as career paths, policies to support their development including financial support, mobility and recruitment strategies across sectors, institutions and borders especially international mobility - as well as to contribute to the improvement of HRST data.

2. The Working Party will implement its activities through the provision and exchange of information on member countries' and non-member economies' practices and policy initiatives with a view to identifying good practices and possible reforms.

3. The Working Group will undertake its work in close co-operation with other relevant Working Parties of CSTP (TIP, Global Science Forum, NESTI) and other OECD areas (e.g. Education and Migration) in order to increase the benefits to their respective activities and to avoid duplication of effort. It will also liaise with other relevant international organisations (e.g. UNESCO, European Commission) as appropriate.

4. The Working Party will report regularly to the CSTP so that the value, impact and effectiveness of its work can be reviewed and assessed. The terms of reference of the Working Party on Research Institutions and Human Resources shall remain in force until 31 December 2009, unless the CSTP decides otherwise." 


\section{WORKING PARTY ON NANOTECHNOLOGY (WPN)}

Chair:

Vice-Chair:

Bureau Members:

Members:

Observers:

Date of creation:

Duration:
Mr. Robert Rudnitsky

Mrs. Françoise Roure

Ms. Vanessa Clive

Mr. Nicolas Deliyanakis

Ms. Rachel Grange

Mr. Jung-il Lee

Mrs. Jacqueline Mout-Leurs

Mr. Marc Van Rossum

Open to all Member countries

Brazil

Chile

Israel
(United States)

(France)

(Canada)

(European Commission)

(Switzerland)

(Korea)

(Netherlands)

(Belgium)

People's Republic of China

Russian Federation

South Africa

26th March 2007

31st December 2009

Mandate: - Summary Record of the 89th Session of the Committee for Scientific and Technological Policy [DSTI/STP/M(2007)1], documents [DSTI/STP(2007)2 and CE(2007)5]

- Confirmation by the Executive Committee registered in the Summary Record of its 778th session [CE/M(2007)6, Item 52 and CE(2007)5]

- Summary Record of the 93rd Session of the Committee for Scientific and Technological Policy [DSTI/STP/M(2008)2], and document [DSTI/STP/NANO(2008)10]

\section{Extract from documents [DSTI/STP(2007)2 and CE(2007)5]}

"1. The Working Party on Nanotechnology is a subsidiary body of the Committee for Scientific and Technological Policy. For the purposes of this document, the term "nanotechnology" encompasses nanoscale science, engineering, and technology. Moreover, it refers to the use of nanotechnology in various applications and sectors. The Working Party has the following terms of reference

2. The Working Party will advise upon emerging policy issues of science, technology and innovation related to the responsible development of nanotechnology. It will elaborate and implement a programme of work, with the aim of promoting international co-operation that facilitates research, development, and responsible commercialisation of nanotechnology in member countries and certain non-member economies.

3. Its work will focus on the following areas:

- Identifying opportunities and impediments for realising the economic, environmental and social benefits of nanotechnology;

- Fostering science, research and capacity building in support of advanced nanoscience and nanotechnology research and development;

- Encouraging an appropriate environment for commercialisation, technology transfer and innovation related to nanotechnology;

- Fostering approaches to formal and informal education related to nanoscience and nanotechnology; 
- Facilitating the development of internationally comparable statistics and indicators that can track research, development and commercialisation of nanotechnology;

- Assessing and taking account of public perceptions related to advances in nanotechnology and its convergence with other technologies, taking account of legal, social and ethical issues;

- Assessing methods for communication with the public related to advances in nanotechnology and its convergence with other technologies;

- Fostering a collaborative exchange on policy developments related to nanotechnology among member countries and certain non-member economies.

4. The Working Party will advise the CSTP on priorities among the above issues which need to be addressed in the short, medium and long term within the context of the CSTP Programme of Work.

5. In carrying out the work, the Working Party will take a proactive approach in regard to cooperation and will recommend the best means of undertaking the various projects, for example, through a lead country approach or through small task groups or workshops. Where appropriate, the Working Party may also refer issues to other CSTP bodies for their views.

6. The Working Party will report to the Committee for Scientific and Technological Policy (CSTP), and will keep other Committees or their subsidiary bodies informed on the progress of work relating to their interests. It will also seek to work co-operatively with such bodies, notably the Working Party on Manufactured Nanomaterials of the Chemicals Committee, where such work is deemed mutually beneficial and complementary. Working Parties may seek inputs from one another and/or take forward work falling within their respective terms of reference that originate in the other body. The OECD's Internal Co-ordination Group for Biotechnology will be consulted and informed about the activities of the Working Party, with a view to avoiding duplication and in order to promote synergy and joint activities.

7. The Working Party will co-ordinate its work with that of other relevant intergovernmental organisations (e.g. UNESCO) and standardisation organisations (e.g. ISO), with the aim of avoiding duplication and ensuring complementarity with their activities. It will recognise and take cognisance of the important role and work of non-governmental organisations in this area.

8. When and where appropriate, and having identified appropriate activities, the Working Party shall seek through various forms of outreach activities to make known and extend the influence and impact of OECD work on nanotechnology beyond member countries, and in so far as practicable take this wider context into account in the preparation and execution of its work.

9. The Working Party values openness and transparency in its activities. Accordingly, the participation of stakeholders will be decided by the Working Party, in line with the policy of the CSTP.

10. The Working Party will elect a Chair and Vice-Chairs for a period of one year.

The terms of reference of the Working Party on Nanotechnology will take effect on 26 March 2007 and will remain in force until 31 December 2009 unless the CSTP decides otherwise." 

Chair:

Vice-Chairs:

Members:

Observers:

Date of creation:

Duration:
Mr. Richard Simpson

Ms. Kristiina Pietikainen

Mr. Peter Voss

Mr. Giovanni Tria

Mr. Hitoshi Aida

Mr. In-Uk Chung

Mr. Luis Magalhaes

Mr. R. C. Beaird

Open to all Member countries

Estonia

Israel

Russian Federation

India

Council of Europe

1st April 1982

31st December 2013
(Canada)

(Finland)

(Germany)

(Italy)

(Japan)

(Korea)

(Portugal)

(United States)

Mandate: - Resolution of the Council concerning the Terms of Reference of the Committee for Information, Computer and Communications Policy [C(99)13/FINAL]

- Mandate extended by Council during its 1078th session on 26 February 2004 [C/M(2004)4 and C(2004)7 and CORR1]

- Mandate modified by Council during its 1107th session on 10 March 2005 [C/M(2005)6, Item 68, and C(2005)26]

- Mandate extended by Council during its 1187 th session on 15 January 2009 [C(2008)209 and C /M(2009)1, Item 5]

\section{Resolution of the Council [C(2008)209 and C/M(2009)1, Item 5]}

\section{"THE COUNCIL,}

Having regard to Articles 1 and 2 of the Convention of the Organisation for Economic Co-operation and Development of 14th December 1960;

Having regard to the Rules of Procedure of the Organisation;

Having regard to the Resolution of the Council of 10 March 2005 concerning the Terms of Reference of the Committee for Information, Computer and Communications Policy [C(2005)26; $\mathrm{C} / \mathrm{M}(2005) 6]$;

Having regard to the proposed revision of the mandate of the Committee for Information, Computer and Communications Policy [C(2008)209];

Having regard to the role of the Internet Economy in stimulating global sustainable economic growth and prosperity and to the ever-increasing need for a consultative mechanism within the OECD whereby information, computer and communications policy problems of a national 
and international nature can be examined by Member countries, in co-operation with non-Members, international organisations and non-governmental stakeholders, as appropriate, and reported to the Council;

Having regard to the 2008 Seoul Ministerial Declaration for the Future of the Internet Economy [SG(2008)99/FINAL] and to the OECD Report on Shaping Policies for the Future of the Internet Economy which was welcomed by Ministers, and to the leading role to be played by the Committee for Information, Computer and Communications Policy in the follow up to the Seoul Ministerial meeting;

\section{DECIDES:}

The Committee for Information, Computer and Communications Policy has the following mandate:

1. The Committee for Information, Computer and Communications Policy shall be responsible for promoting the policy and regulatory environments needed for the expansion of the Internet and information and communications technologies (ICTs) as a driver of innovation, productivity, growth, sustainable development, and social well-being. It will also be responsible for strengthening co-operation in this field between the Member countries and, as appropriate, between Member countries and non-Members.

2. The Committee shall, in particular, examine policy issues arising from the development and increasing use of the Internet and ICTs, and develop policies to:

a) Support innovation, investment, and competition in ICTs and related areas across the economy and society, and encourage creativity in the development and use of the Internet and ICT goods and services as a leading area of innovation;

b) Facilitate convergence of digital networks, devices, applications and services, and promote ubiquitous access to ICT networks and services, calling the attention of Member governments to the major implications of such developments;

c) Contribute to strengthening the resilience and security of information systems and networks as well as the protection of privacy to enhance trust in the use of Internet and ICT goods and services;

d) Foster co-operation among Member countries and facilitate the development, and, as appropriate, the co-ordination of their policies at the national and international levels;

e) Promote exchange of experience among Member countries in the information, computer and communication policy areas, including the development of indicators to measure the information society.

3. The Committee shall determine the strategic orientations of its subsidiary bodies, and receive regular reports from them to ensure the co-ordination of their activities in furthering these orientations.

4. The Committee shall maintain close working relationships with other relevant bodies within the OECD to ensure complementarity of efforts and effective use of resources. In the conduct of its work, the Committee will also, as appropriate, draw on the views and expertise of nonMembers, international organisations and non-governmental stakeholders, and work with business, trade unions, civil society, and the Internet technical community within a framework of co-operation that promotes mutual understanding and participation.

5. The mandate of the Committee for Information, Computer and Communications Policy shall remain in force until 31 December 2013, unless the Council decides otherwise." 


\section{WORKING PARTY ON COMMUNICATION INFRASTRUCTURES AND SERVICES POLICY}

\section{(CISP)}

Chair:

Vice-Chairs:

Members:

Observers:

Date of creation:

Duration:
Mr. Vincent Affleck

Mr. Yoshihiro Katagiri

Mr. Nae-Chan Lee

Mr. Wim Rullens

Open to all Member countries
(United Kingdom)

(Japan)

(Korea)

(Netherlands)

Russian Federation

Singapore

South Africa

Israel

International Telecommunication Union (ITU)

24th March 1988

31st December 2013

Mandate: - Summary Record of the 35th Session of the ICCP Committee held on 4-5 March 1999 [DSTI/ICCP/M(99)1]

- Summary Record of the 40th Session of the ICCP Committee held on 11-12 October $2001[\mathrm{DSTI} / \mathrm{ICCP} / \mathrm{M}(2001) 2]$

- Summary Record of the 45th Session of the ICCP Committee held on 2-3 October 2003 [DSTI/ICCP/M(2003)2]

- Summary Record of the 47th Session of the ICCP Committee held on 20-21 October 2004 [DSTI/ICCP/M(2004)2]

- Summary Record of the 50th Session of the ICCP Committee held on 9-10 March 2006 [DSTI/ICCP/M(2006)1]

- Summary Record of the 56th Session of the ICCP Committee held on 11-12 December 2008 [DSTI/ICCP/M(2008)3]

\section{Extract from document [DSTI/ICCP/M(2008)3]}

"Item 7. The Committee agreed to [...] the renewal of its existing Working Parties for a period of five years, until 31 December 2013, and agreed to the mandates of the Working Parties."

\section{Extract from document [DSTI/ICCP/M(2008)3, Annex 2]}

Working Party on Communication Infrastructures and Services Policy (WPCISP)

Terms of Reference

"The mandate of the Working Party on Communication Infrastructures and Services Policy (WPCISP) shall be:

1. To explore the different goals and strategies of member countries in the area of communication infrastructures and services in order to promote a common understanding of policies and increase international co-operation. 
2. To promote exchanges of experience and best practice among member countries and review global developments in the field of communication infrastructures and services policy, taking into account the objectives of the ICCP Committee.

3. To analyse the economic and social implications of changing communication market structures, including the Internet and the convergence between the broadcasting and telecommunication sectors, the development of next-generation networks and increased broadband access.

4. To analyse international and trade issues in communications and information services, and promote co-operation in this field.

5. The Working Party shall maintain close working relationships with other relevant bodies within the OECD to ensure complementarity of efforts and effective use of resources. In the conduct of its work, the Working Party will also, as appropriate, draw on the views and expertise of non-members, international organisations and non-governmental stakeholders, and work with business, trade unions, civil society, and the Internet technical community within a framework of co-operation that promotes mutual understanding and participation.

6. The Working Party will undertake work as requested by the ICCP Committee, and submit on a regular basis the results of its work for review by this Committee.

The mandate of the Working Party on Communication Infrastructures and Services Policy shall remain in force until 31 December 2013, unless the ICCP Committee decides otherwise." 


\section{WORKING PARTY ON THE INFORMATION ECONOMY (WPIE)}

Chair:

Vice-Chairs:

Members:

Observers:

Date of creation:

Duration:
Ms. Daniela Battisti

ad interim

Mrs. Josie Brocca

Mr. Antti Eskola

Dr. Sang-yirl Nam

Ms. Doreen McGirr

Open to all Member countries

Egypt
Estonia
India
Israel

20th October 1993

31st December 2013
(Italy)

(Canada)

(Finland)

(Korea)

(United States)

\author{
Russian Federation \\ Singapore \\ South Africa
}

Mandate: - Summary Record of the 35th Session of the ICCP Committee held on 4-5 March 1999 [DSTI/ICCP/M(99)1]

- Summary Record of the 40th Session of the ICCP Committee held on 11-12 October 2001 [DSTI/ICCP/M(2001)2]

- Summary Record of the 45th Session of the ICCP Committee held on 2-3 October 2003 [DSTI/ICCP/M(2003)2]

- Summary Record of the 47th Session of the ICCP Committee held on 20-21 October 2004 [DSTI/ICCP/M(2004)2]

- Summary Record of the 50th Session of the ICCP Committee held on 9-10 March 2006 [DSTI/ICCP/M(2006)1]

- Summary Record of the 56th Session of the ICCP Committee held on 11-12 December 2008 [DSTI/ICCP/M(2008)3]

\section{Extract from document [DSTI/ICCP/M(2008)3]}

"Item 7. The Committee agreed to [...] the renewal of its existing Working Parties for a period of five years, until 31 December 2013, and agreed to the mandates of the Working Parties."

\section{Extract from document [DSTI/ICCP/M(2008)3, Annex 2] \\ Working Party on the Information Economy (WPIE) \\ Terms of Reference}

"The mandate of the Working Party on the Information Economy (WPIE) shall be:

The Working Party on the Information Economy (WPIE) shall be responsible for:

1. Analysing policy frameworks that: foster creativity and innovation; strengthen economic growth, productivity, sustainable development, employment and social benefits; contribute to tackling global challenges in areas such as the environment, health care, and ageing societies; and expand international economic development, in conjunction with high-speed information and communications networks and the growth of the information society.

2. Reviewing, analysing and evaluating economic and social impacts of the development, diffusion, application and use of information and communication 
technologies, products and services, in areas including electronic business and digital content, and undertaking related policy reviews.

3. Identifying factors that encourage the use of information and communications technologies, products and services, and their applications, in the economy and society; and developing tools for measurement and international comparison.

4. The Working Party shall maintain close working relationships with other relevant bodies within the OECD to ensure complementarity of efforts and effective use of resources. In the conduct of its work, the Working Party will also, as appropriate, draw on the views and expertise of non-members, international organisations and non-governmental stakeholders, and work with business, trade unions, civil society, and the Internet technical community within a framework of co-operation that promotes mutual understanding and participation.

5. Undertaking work as requested by the Committee and submitting the results for review on a regular basis, taking into account the objectives of the ICCP Committee.

6. Disseminating results and analysis produced by the Working Party; and where appropriate developing policy guidance and recommendations.

The mandate of the Working Party on the Information Economy shall remain in force until 31 December 2013, unless the ICCP Committee decides otherwise." 


\section{WORKING PARTY ON INFORMATION SECURITY AND PRIVACY (WPISP)}

Chair:

Vice-Chairs:

Members:

Observers:
Mr. Keith Besgrove

Ms. E. Jane Hamilton

Mr. Young-Bin Kwon

Mrs. Katarina De Brisis

Mr. Manuel Pedrosa de Barros

Mr. Geoffrey Smith

Mr. Hugh Stevenson

Open to all Member countries

Estonia
Israel
Russian Federation
India

Council of Europe

1st October 1995

31st December 2013
(Australia)

(Canada)

(Korea)

(Norway)

(Portugal)

(United Kingdom)

(United States)

South Africa

Egypt

Singapore

Date of creation:

Duration:

Mandate : - Summary Record of the 35th Session of the ICCP Committee held on 4-5 March 1999 [DSTI/ICCP/M(99)1]

- Summary Record of the 40th Session of the ICCP Committee held on 11-12 October $2001[\mathrm{DSTI} / \mathrm{ICCP} / \mathrm{M}(2001) 2]$

- Summary Record of the 45th Session of the ICCP Committee held on 2-3 October 2003 [DSTI/ICCP/M(2003)2]

- Summary Record of the 47th Session of the ICCP Committee held on 20-21 October 2004 [DSTI/ICCP/M(2004)2]

- Summary Record of the 50th Session of the ICCP Committee held on 9-10 March 2006 [DSTI/ICCP/M(2006)1]

- Summary Record of the 56th Session of the ICCP Committee held on 11-12 December 2008 [DSTI/ICCP/M(2008)3]

\section{Extract from document [DSTI/ICCP/M(2008)3]}

"Item 7. The Committee agreed to [...] the renewal of its existing Working Parties for a period of five years, until 31 December 2013, and agreed to the mandates of the Working Parties."

\section{Extract from document [DSTI/ICCP/M(2008)3, Annex 2]}

Working Party on Information Security and Privacy (WPISP)

Terms of Reference

"The mandate of the Working Party on Information Security and Privacy (WPISP) shall be:

1. To research and monitor developments in information and communication technologies, including convergence of networks, new application areas, market and user behaviour and to analyse the economic and social implications of emerging technologies, applications and services for policy development in relation to security of information systems and networks, and protection of personal data and privacy; 
2. To assess, amend and/or develop, as appropriate, policy principles, guidelines, best practices or any other instrument for security of information systems and networks, and protection of personal data and privacy, particularly in areas in which there is an increased need for co-operation across international borders;

3. To exchange information and share experiences on various policy approaches related to security of information systems and networks, and protection of personal data and privacy, and to analyse the role of various actors in meeting policy goals in these areas; and

4. To promote the objectives and assess the implementation of relevant OECD Recommendations and Declarations, policy frameworks, and strategies.

The Working Party will undertake work as requested by the Committee for Information, Computer and Communications Policy (ICCP) and will submit on a regular basis to the ICCP Committee the results of its work.

The Working Party shall maintain close working relationships with other relevant bodies within the OECD to ensure complementarity of efforts and effective use of resources. In the conduct of its work, the Working Party will also, as appropriate, draw on the views and expertise of non-members, international organisations and non-governmental stakeholders, and work with business, trade unions, civil society, and the Internet technical community within a framework of co-operation that promotes mutual understanding and participation.

The mandate of the Working Party on Information Security and Privacy shall remain in force until 31 December 2013, unless the ICCP Committee decides otherwise." 


\section{WORKING PARTY ON INDICATORS FOR THE INFORMATION SOCIETY (WPIIS)}

Chair:

Vice-Chairs:

Members:

Observer:

Date of creation:

Duration:
Mr. Tony Clayton

Mr. Daniel April

Mr. Martin Mana

Mr. Martin Lundo

Mr. Aarno Airaksinen

Ms. Patricia Buckley

Mr. Hugh Stevenson
(United Kingdom)

(Canada)

(Czech Republic)

(Denmark)

(Finland)

(United States)

(United States)

Open to all Member countries

UN Conference on Trade and Development (UNCTAD)

Estonia
Israel
Russian Federation
India

South Africa

Egypt

Singapore

1st March 1999

31st December 2013

Mandate : - Summary Record of the 35th Session of the ICCP Committee held on 4-5 March 1999 [DSTI/ICCP/M(99)1]

- Summary Record of the 40th Session of the ICCP Committee held on 11-12 October $2001[\mathrm{DSTI} / \mathrm{ICCP} / \mathrm{M}(2001) 2]$

- Summary Record of the 45th Session of the ICCP Committee held on 2-3 October 2003 [DSTI/ICCP/M(2003)2]

- Summary Record of the 47th Session of the ICCP Committee held on 20-21 October 2004 [DSTI/ICCP/M(2004)2]

- Summary Record of the 50th Session of the ICCP Committee held on 9-10 March 2006 [DSTI/ICCP/M(2006)1]

- Summary Record of the 56th Session of the ICCP Committee held on 11-12 December 2008 [DSTI/ICCP/M(2008)3]

\section{Extract from document [DSTI/ICCP/M(2008)3]}

"Item 7. The Committee agreed to [...] the renewal of its existing Working Parties for a period of five years, until 31 December 2013, and agreed to the mandates of the Working Parties."

\section{Extract from document [DSTI/ICCP/M(2008)3, Annex 2]}

Working Party on Indicators for the Information Society (WPIIS)

\section{Terms of Reference}

"The mandate of the Working Party on Indicators for the Information Society (WPIIS) shall be:

1. The Working Party will monitor, supervise, direct and co-ordinate the statistical work and contribute to the development of indicators and quantitative analyses needed to meet the requirements of the Committee for Information, Computer and Communications Policy and its subsidiary bodies. More specifically, the Working Party will:

i) Ensure the continued improvement of the methodology for the collection of internationally comparable data for measuring the supply and demand for, and 
impacts of, information and communication technologies (ICTs). This will include developing and maintaining standards for measurement of the ICT sector, ICT goods and services, electronic business including electronic commerce, IT security, digital content and Internet access and use by citizens, businesses and institutions.

ii) Compile ICT statistics according to the standards described in the preceding paragraph and assist in developing and interpreting statistical indicators which aid formulation of ICT and related policies, and monitoring progress. This work should be undertaken in the light of policy priorities expressed by the ICCP Committee and by member countries.

iii) Undertake the evaluation of the impact of ICTs on economic performance, notably on growth, productivity and innovation, and social well-being, particularly through improved access to education, health and government services.

2. The Working Party will, when required, assist the other subsidiary bodies of the ICCP Committee in the development of analytical and quantitative analyses on ICT-related issues such as the impact of ICTs on productivity and jobs, effectiveness of policy measures such as regulatory reform, obstacles to diffusion and use of ICTs, and IT security and privacy.

3. The Working Party will promote efficient use of resources by seeking opportunities to work in co-operation with other relevant bodies within and outside the OECD, including non-member economies, other international organisations and non-governmental stakeholders, thus effectively sharing the knowledge of the group with a wider audience.

4. The Working Party will co-operate, in particular, with other OECD statistical sub-groups and working parties in dealing with broader statistical issues connecting industrial, science and technology activities.

5. The Working Party will act as a clearing house through which member and nonmember economies can exchange information and experience on methods of collection, compilation, analysis and presentation of data which they use as indicators for the information society.

The mandate of the Working Party on Indicators for the Information Society shall remain in force until 31 December 2013, unless the ICCP Committee decides otherwise." 
Chair:

Vice-Chairs:

Members:

Observer:

Date of creation:

Duration:
Mr. Michael Jenkin

Ms. Anja Peltonen

Ms. Nicole Nespoulous

Mr. Yoshiaki Takahashi

Mr. Graham Branton

Mr. Hugh Stevenson
(Canada)

(Finland)

(France)

(Japan)

(United Kingdom)

(United States)

Open to all Member countries

India

12th November 1969

31st December 2009

Mandate: Resolution Concerning the Renewal and Modification of the Mandate of the Committee on Consumer Policy, adopted by Council at its 1098th session held on 10 November 2004 [C(2004)170 and C/M(2004)24, item 309]

\section{Resolution of the Council [C(2004)170 and C/M(2004)24, item 309]}

\section{"THE COUNCIL,}

Having regard to the Rules of Procedure of the Organisation;

Having regard to the Resolution of the Council of 12 November 1969 establishing a Committee on Consumer Policy [C(69)143];

Having regard to the Resolutions of the Council of 18 July 1972, 22 July 1977, 1 October 1982, 10 July 1987, 25 June 1992, 18-19 and 22-23 December 1997, 10 December 1998 and 26 November 2001 concerning the continuation of the Committee on Consumer Policy [C(72)132(Final), $\quad \mathrm{C}(77) 134$ (Final), $\quad \mathrm{C}(82) 121$ (Final), $\quad \mathrm{C}(87) 116$ (Final), $\quad \mathrm{C}(92) 116 / \mathrm{FINAL}$, C(97)197/FINAL, C(98)199/FINAL and C(2001)239/REV1];

Having regard to the conclusions of the October 1998 Ottawa Ministerial conference "A Borderless World: Realising the Potential of Global Electronic Commerce", and in particular to the Ministerial Declaration on Consumer Protection in the Context of Electronic Commerce adopted by Ministers at this Conference [Annex 2 to $\mathrm{C}(98) 177]$, and to the OECD Action Plan for Electronic Commerce which was endorsed by Ministers, SG/EC(98)10/REV5];

Having regard to the Recommendation of the Council Concerning Guidelines for Consumer Protection in the Context of Electronic Commerce [C(99)184/FINAL];

Having regard to the Recommendation of the Council Concerning Guidelines for Protecting Consumers from Fraudulent and Deceptive Commercial Practices Across Borders [C(2003)116];

Considering the economic and social importance of a broad-based consumer policy in Member countries and the latter's close relationship with general economic and trade policies;

Considering the need to minimise economic costs to consumers and to facilitate the integration of consumer policy considerations into economic and other policy areas; 
Considering the need to improve the functioning of markets, encourage the development of a global marketplace for consumers, including through the use of new electronic media, and to provide effective protection to consumers;

OECD;

Considering the importance of collaborating with other relevant subsidiary bodies of the

Considering that the implementation of such a policy would be encouraged by exchanges of information and experience, discussions, and law enforcement and policy co-operation between Member countries, as well as co-operation with other international organisations and non-Member economies;

Consumer Policy:

On the proposal of the Secretary-General after consultation with the Committee on

\section{DECIDES:}

I. Terms of Reference

The terms of reference of the Committee on Consumer Policy are:

1. To examine questions relating to consumer policy and law in Member countries and within international and regional organisations and to contribute to the further development and strengthening of co-operation between Member countries in policy development and law enforcement.

2. To examine and help develop, in particular, consumer trust in the global digital economy, to participate in and encourage the development of the principles which should govern an efficient, transparent and fair global marketplace for consumers, and to develop mechanisms for the implementation of these principles and for the effective enforcement of consumer laws on line and across borders.

3. To examine issues of consumer policy and safety, particularly those concerning international trade or the development of a global marketplace for consumers.

4. To collaborate closely with other relevant subsidiary bodies of the OECD.

5. To consult with the advisory bodies to OECD, BIAC and TUAC, consumer organisations such as Consumers International, the private sector, academia and other international organisations.

6. To encourage the development and use of relevant quantitative information in consumer policy deliberations, to facilitate overall policy coherence through the inclusion of consumer policy considerations in other policy areas, and to engage in outreach to nonmember economies.

II. $\quad$ Review of terms of reference

The terms of reference of the Committee on Consumer Policy shall expire on 31 December 2009, unless the Council decides otherwise.

\section{Amendment to the Annex to the Rules of Procedure of the Organisation}

Paragraph 23 of the Annex to the Rules of Procedure of the Organisation shall be amended as follows: Committee on Consumer Policy: its terms of reference are defined in the Resolution of the Council annexed to document C(2004)170." 
Chair:

Vice-Chairs:

Members:

Full Participants: ${ }^{1}$

Observers:

Date of creation:

Duration:
Mr. Risaburo Nezu

Mr. Alberto Canevali

Mr. Ronald Lorentzen

Austria

Belgium

Canada

Czech Republic

Denmark

Finland

France

Germany

Greece

Hungary

Italy

Japan

Korea

Luxembourg

Brazil

Romania

Russian Federation

Slovenia

Ukraine
(Japan)

(Belgium)

(United States)

Mexico

Netherlands

Norway

Poland

Portugal

Slovak Republic

Spain

Sweden

Switzerland

Turkey

United Kingdom

United States

European Commission
India

Malaysia

South Africa

Chinese Taipei

Egypt

26th October 1978

31st December 2013

Mandate: - Decision of the Council establishing a Steel Committee [C(78)171(Final)]

- Minutes of the 501st Meeting of the Council [C/M(79)22(Final)]

- Minutes of the 582nd Meeting of the Council [C/M(83)6(Final)]

- Council Decision regarding a Sunset Clause for all Committees [C/M(2004)5, item 75] entered into force on 22 April 2004 [C/M(2004)10, item 143, IV, c)]

- Mandate of the Steel Committee adopted by Council at its 1183rd Session, on 4 November 2008 [C(2008)163 and C/M(2008)19, item 260]

\section{Resolution of the Council [C2008)163 and C/M(2008)19, item 260]}

\section{"THE COUNCIL,}

Having regard to the Convention on the Organisation for Economic Co-operation and Development of 14th December 1960 (hereinafter referred to as the 'Convention') and, in particular, Articles 5 a), 6, 12, 13 and 20 thereof;

\footnotetext{
1 Ukraine: awaiting ratification.
} 
Having regard to the Rules of Procedure of the Organisation;

Having regard to the Financial Regulations of the Organisation;

Having regard to the Communiqué approved by the Council meeting at Ministerial Level on 15th June 1978 and, in particular, Annex II thereof [C(78)96(Final)];

Considering that the Ad Hoc Working Group on the Steel Industry has reached the conclusion that a Steel Committee should be established within the framework of the Organisation under Part II of the Budget and that a number of Member countries as well as the European Community have expressed their intention to participate therein;

Noting that the Member countries participating in the proposed Committee and the European Community agree as initial commitment to the guidelines set out in the Annex hereto;

Having regard to the Resolution of the Council establishing a Steel Committee [C(78)171(Final)], as amended by documents $\mathrm{C} / \mathrm{M}(79) 22$ (Final), Item 231 (b) and $\mathrm{C} / \mathrm{M}(83) 6$ (Final), Item 51 (b); [C(2008)163];

Having regard to the proposal to renew the mandate of the Steel Committee

\section{DECIDES:}

Article 1

In order to seek solutions to the problems experienced by the Steel Industry and achieve the objectives set out in the Annex to the present Resolution, the Steel Committee (hereinafter referred to as the 'Committee') shall have the functions set out in this Annex.

\section{Article 2}

Current participants include Austria, Belgium, Brazil, Canada, Czech Republic, Denmark, the European Community, Finland, France, Germany, Greece, Hungary, Italy, Japan, Korea, Luxembourg, Mexico, the Netherlands, Norway, Poland, Portugal, Romania, Russian Federation, Slovak Republic, Slovenia, Spain, Sweden, Switzerland, Turkey, the United Kingdom, and the United States. Committee.

Any other Member country of the Organisation can decide to participate in the

The Committee shall, if the OECD Member countries participating therein so decide, propose to the Council that a non-Member with substantial steel interests may be invited to become a participant in the Committee. In making such a proposal the Committee must be satisfied that the non-Member has agreed and is able to undertake the same commitments, as appropriate, with regard to the Committee's work as the OECD Member countries which participate therein and that its participation in the Committee would contribute to achieving the objectives of the Committee. Such proposal shall specify the relevant provisions in respect of the non-Members' participation in the Committee's work.

\section{Article 3}

Expenditure required for the functioning of the Committee shall be defrayed from the appropriations authorised for that purpose under Part II of the Budget of the Organisation. The Committee shall prepare every two years a Programme of Work and this with the corresponding budgetary proposals shall be submitted by the Secretary-General to the Council. 


\section{Article 4}

The Committee may make proposals to the Council on any matter within its mandate and, at the request of the Council or on its own initiative, the Committee may submit other communications to the Council.

\section{Article 5}

a) The provisions of the Rules of Procedure of the Organisation shall apply to the Committee to the extent that this Resolution does not derogate therefrom.

b) The Committee may make recommendations to participants within the scope of its mandate.

\section{Article 6}

The mandate of the Steel Committee shall remain in force until 31 December 2013 unless the Council decides otherwise.

\section{Annex}

\section{Policy Environment}

The world's steel industry started a period of vigorous expansion in 2002, driven by strong growth in demand, particularly in emerging economies. At the same time the process of restructuring the sector has become broader and some global players have emerged. Nevertheless, the sector remains vulnerable to cyclical forces, increasing raw materials prices and environmental challenges, in particular related $\mathrm{t}$ its inherent $\mathrm{CO}_{2}$-emission performance. This can affect trade patterns and lead to trade frictions.

In some countries, governments intervene in steel supply which may create excess capacity and distort conditions of competition at the global level.

Government intervention in the trade of steel and raw materials can aggravate problems for the steel industry and can have implications for related industries, including steel-consuming industries.

In virtually all major steel-producing nations, steel occupies a central place in the national economy. In some areas, the magnitude of structural problems confronting the steel sector and resultant social and economic implications of the necessary structural adjustments are substantial.

\section{Objectives} together in order to:

In view of these difficulties, participants of the Steel Committee need to work closely

- Ensure that trade in steel will remain as unrestricted and free of distortion as possible. Restrictive actions should be avoided and, where necessary, strictly limited in scope and time, and in conformity with WTO rules; ${ }^{1}$

- $\quad$ Reduce barriers to trade;

\footnotetext{
1 It is noted that references to WTO rules and provisions in this Annex do not alter the rights and obligations under the WTO of individual participants which are contracting parties to the WTO nor confer by implication equivalent rights or obligations on participants which are not contracting parties to the WTO.
} 
- Act promptly to cope with crisis situations in close consultation with interested trading partners and in conformity with agreed principles;

- $\quad$ Facilitate needed structural adaptations that will diminish pressures for trade actions and promote rational allocation of productive resources with the aim of achieving fully competitive enterprises;

- Ensure that measures affecting the steel industry are consistent to the extent possible with general economic policies and take into account implications for related industries, including steel-consuming industries;

- Avoid encouraging economically unjustified investments which recognising legitimate development needs;

- Facilitate multilateral co-operation consistent with the need to maintain competition, to anticipate and, to the extent possible, prevent problems.

\section{Committee Functions}

The Steel Committee will meet regularly and additionally as required to:

1. Continuously follow national, regional and world supply and demand conditions in steel and closely related industries, including steel-consuming industries and raw material industries, with a view to identifying potential problems and implications and making assessments and forecasts available to all interested parties;

2. Continuously follow the evolution of national, regional and world steel industries with regard to employment, profits, investments, capacity, input costs, environmental performance and compliance costs, productivity, and other aspects of viability and competitiveness;

3. Develop common perspectives regarding emerging problems or concerns in the steel sector and establish, where appropriate, multilateral objectives or guidelines for government policies;

4. Regularly review and assess government policies and actions in the steel sector in the light of the current situation, agreed multilateral objectives and guidelines and the WTO and other relevant international agreements;

5. Identify deficiencies and gaps in existing data needed by the Committee with a view to improving national inputs to the Committee and cross-national comparability of data.

\section{Commitments}

Participants in the Steel Committee agree to the following guidelines:

a)

To abstain from destructive competition in official support of export credit; they agree that their policies in the field of export credits for steel plant and equipment will be fully consistent with the Arrangement on Guidelines for Officially Supported Export Credits and contribute to the avoidance of competitive subsidisation of such exports.

b) Domestic policies to sustain steel firms during crisis periods should not shift the burden of adjustment to other countries and thus increase the likelihood of restrictive trade actions by other countries (e.g. by artificially stimulating exports or by artificially displacing imports). Further, as a general rule, domestic measures should not prevent marginal facilities from closing in those instances where the facilities cannot become commercially viable within a reasonable period of time. 
c) To make every effort to provide effective programmes for steel worker readaptation away from facilities affected by structural adjustments into alternative employment. To this end, they will periodically exchange information on the effectiveness of policies and programmes to assist steel workers and communities.

d) To report promptly any action to restrict trade in steel-making materials and allow for consultation with affected parties." 

Chair:

Vice-Chairs:

Members:
Mr. Harald Neple

Mr. Stephan Hesselmann

Mr. Sung Cheon Kang

Mr. Hideaki Saito

Australia
Canada
Denmark
Finland
France
Germany
Greece
Italy
Japan

Full Participants: ${ }^{1}$

Date of creation:

Duration:

Croatia

Romania

24th May 1966

31st December 2013
(Norway)

(Germany)

(Korea)

(Japan)

Korea

Netherlands

Norway

Poland

Portugal

Slovak Republic

Spain

Sweden

Turkey

Mandate: - Resolution of the Council concerning the terms of reference of an ad hoc Working Party on Shipbuilding as amended [C(66)57; C(67)104(Final); C(70)165(Final); C(73)214(Final) and C(89)122(Final)]

- Council Decision regarding a Sunset Clause for all Committees [C/M(2004)5, Item 75] entered into force on 22 April 2004 [C/M(2004)10, Item 143, IV, c)]

- Mandate renewed as a non-consolidated Part II Programme [C/M(2006)7, Item 89, b)]

- Mandate of the Working Party on shipbuilding adopted by the Council at its 1180th Session on 18 September 2008 [C/M(2008)16, item 194]

\section{Resolution of the Council [C(2008)121 and C/M(2008)16, Item 194]}

\section{"THE COUNCIL,}

Having regard to the Convention on the Organisation for Economic Co-operation and Development of 14 December 1960;

Having regard to the Rules of Procedures of the Organisation;

Having regard to the creation of the Council Working Party on Shipbuilding (WP6) by Council Resolution [C(66)57], as amended;

Noting that the shipbuilding industry may continue the pattern of the past of severe cyclical downturns, and that unfair practices (subsidies and other support measures provided by governments to their industries, and other market distorting practices) prevent the market from functioning normally;

\footnotetext{
1 Romania: pending acceptance letter.
} 
Recognising that the Council Working Party on Shipbuilding remains the sole international forum which can bring OECD and non-OECD economies, as well as business/industry and trade union stakeholders, together to exchange views on economic and policy developments in the shipbuilding sector and act on these as appropriate;

Noting the progress made in increasing transparency in the shipbuilding industry, the engagement in the work of the WP6 by non-OECD economies with significant shipbuilding industries and the paused negotiations on a multilateral agreement on shipbuilding;

Noting that the participants to the Sector Understanding on Export Credits for Ships (which has been incorporated as an Annex to the OECD's "Arrangement on Officially Supported Export Credits") retain responsibility, through the WP6, for that Understanding, in co-operation with the Participants to the Arrangement on Officially Supported Export Credits;

\section{DECIDES:}

A

The Council Working Party on Shipbuilding (WP6) has the following mandate:

I. Objectives

- $\quad$ To work towards the identification and progressive reduction of the factors that distort normal competitive conditions in the shipbuilding industry.

- The Working Party will seek to meet this objective by:

- keeping the shipbuilding industry under review in order to increase transparency and improve the understanding of the shipbuilding market, including supply and demand;

- taking into account the economic, social and other relevant conditions in shipbuilding economies that impact on the industry;

- increasing the engagement - in accordance with the rules of the Organisation - of non-OECD economies with significant shipbuilding sectors, the shipbuilding industry and trade union stakeholders.

II. Co-ordination arrangements

- As appropriate, the Council Working Party on Shipbuilding shall work in conjunction with:

- other OECD bodies as appropriate, BIAC and TUAC;

- in accordance with the rules of the Organisation, non-OECD economies with significant shipbuilding sectors;

- other relevant international organisations such as the World Trade Organization (WTO) and the International Maritime Organization (IMO);

- the shipbuilding industry, including national and regional shipbuilder associations; and

- appropriate trade union stakeholders.

B. The mandate of the Council Working Party on Shipbuilding shall remain in force until 31 December 2013, unless the Council decides otherwise." 

SHIPS

Date of creation:

10th December 2007

Duration:

31st December 2011

Mandate: - Summary Record of the 105th Session of the Council Working Party on Shipbuilding [C/WP6/M(2007)2], documents [C/WP6(2007)15 and CE(2008)11]

- Confirmation by the Executive Committee registered in the Summary Record of its 802nd session [CE/M(2008)12, Item 74 and CE(2008)11]

\section{Extract from document CE(2008)11]}

"The expert group's mandate is to consider in detail the technical issues associated with aspects of the Sector Understanding on Export Credits for Ships, and advise the WP6 on possible ways forward.

The terms of reference of the Informal Expert Group on the Sector Understanding on Export Credits for Ships will take effect on 10 December 2007 and will remain in force until 31 December 2008 unless the Council decides otherwise." 

EMPLOYMENT, LABOUR AND SOCIAL AFFAIRS 

Co-Chair:

Bureau Members:

Members:

Observers:

Ad hoc Observers:

Date of creation:

Duration:
Ms. Jane Halton

Ms. Kathryn McDade

Mr. Raimo Jämsén

Mr. Hidehiko Itaya

Ms. Jacqueline Arzoz Padres

Mr. Feite Hofman

Mr. Barry McCormick
(Australia)

(Canada)

(Finland)

(Japan)

(Mexico)

(Netherlands)

(United Kingdom)

Open to all Member countries

Council of Europe

International Social Security Association (ISSA)

World Health Organization (WHO)

Chile

Estonia

Israel

Russian Federation

Slovenia

1st January 2007

31st December 2011

Mandate: Resolution of the Council, renaming the Group on Health as the Health Committee and revising its mandate, approved at its 1146th session held on 14 December 2006 [C(2006)175 and C/M(2006)20, item 264]

\section{Resolution of the Council [C(2006)175 and C/M(2006)20, Item 264]}

\section{"THE COUNCIL,}

Having regard to Article 1 of the Convention of the OECD of 14th December 1960 under which the Organisation shall promote policies designed:

- $\quad$ To achieve sustainable economic growth and employment, and rising standards of living in Member countries while maintaining financial stability, so contributing to the development of the world economy; and

- $\quad$ To assist sound economic expansion in Member countries and other countries in the process of economic development;

Recognising that good health is necessary for people to flourish as citizens, family members, workers and consumers, that improvements in health contribute to higher economic growth and improved welfare and that high-performing health systems are key to achieving better population health;

Acknowledging that while the health sector represents a large and growing share of OECD economies, health systems will face important challenges in the future, in particular in view of ageing populations and technical change; 
Having regard to the Resolution of the Council renaming the Ad Hoc Group on Health as the Group on Health and revising its mandate [C(2004)172/REV2];

On the proposal of the Secretary-General;

\section{DECIDES:}

1.

A Health Committee is hereby established.

2. The overarching objective of the Health Committee shall be to foster improvements in the performance of Member countries' and, as appropriate, non-Member countries' health systems in the following key areas:

$>$ financial sustainability and efficiency of their health and long-term care systems;

$>$ the provision of high-quality health care to all.

3. This shall be accomplished by the provision of Output Results that assist policymakers in designing, adapting and implementing policies for achieving high-performing health systems.

4. In this context, the Health Committee will provide a forum for Member countries to share views and experiences on, and consider responses to, current and emerging health issues and challenges, by building a body of health data, by filling gaps in health data and analysis at the international level, and by undertaking international comparisons and economic analysis of health systems, bearing in mind the competences and mission of the OECD, and the fact there is no one, ideal health system. More specifically, its activities will consist of:

a) Encouraging co-operation among Member countries in developing health accounts on a consistent basis, and in other relevant health data and information sharing.

b) Developing and promulgating health care indicators, and standardised, comparable sets of data and statistics, as a basis for research and analysis assessing the performance of OECD health systems.

c) Assessing options for sustainable financing of efficient health systems.

d) Assessing the performances of Member countries' health systems.

e) Undertaking policy analysis and evaluation to identify effective, efficient and highquality practices.

f) Promoting the sharing with non-Members of the health data systems and the expertise, information and experience which reside in Member countries.

g) Actively disseminating results through publication of studies and participation in conferences and meetings with policy-makers and stakeholders.

5. In order to efficiently implement the aforementioned activities, the Committee shall:

a) Maintain close working relationships with other relevant bodies of the Organisation, seeking to (i) be actively engaged in, and where appropriate lead, joint work and ensure that it is undertaken in a co-ordinated manner; (ii) complement and support work that other bodies are leading; and (iii) ensure that other work of the OECD considers the impacts on health systems.

b) Maintain, as appropriate, and in conformity with the OECD Convention and Rules of Procedures, relations with other entities, particularly the WHO, seeking to achieve non-duplicative, co-ordinated and complementary work programmes in areas of shared interest and mutual benefit, conducting joint projects where appropriate and ensuring that the experience and expertise of other bodies is appropriately incorporated into the Committee's health mandate.

c) Ensure that the views and expertise of non-government institutions are drawn upon in the conduct of OECD's health work, utilising, inter alia, the Business and Industry Advisory Committee to the OECD (BIAC), the Trade Union Advisory Committee to 
the OECD (TUAC) and contacts with relevant non-governmental organisations, including organisations representing patients and health professionals and outside experts. Subject to its Programme of Work and Budget, the Health Committee will organise, as appropriate, ad hoc workshops and expert meetings that involve all relevant actors to explore issues within its mandate.

d) Steer and review the progress of work and its financial status, and co-ordinate the work programmes of its subsidiary bodies and receive regular reports from them to ensure analysis and policy recommendations are fully integrated and evaluated.

6. Where possible, Member countries shall appoint to the Health Committee high-ranking officials concerned with development, implementation or administration of health policies in their own countries.

7. For the purpose of its activities in the health sector, the Organisation shall periodically collect all relevant statistics and other information; in principle, these data will be assembled by the Secretariat and published on the responsibility of the Secretary-General.

8. The Health Committee will advise the Council on appropriate priorities for work on health and long-term care.

9. The terms of reference of the Health Committee will take effect on 1 January 2007 and remain in force until 31 December 2011, unless the Council decides otherwise." 


\section{OECD HEALTH DATA NATIONAL CORRESPONDANTS}

Chair:

Members:

Observers:

Date of creation:

Duration: $(\ldots)$

Open to all Member countries

Mandate: Confirmation by the Executive Committee registered in the Summary Record of its 770th session [Room Document No. 4 and CE/M(2006)15, item 106]

\section{Mission}

To review progress in the OECD collection of health statistics under OECD Health Data and to discuss priorities for future improvements in terms of the scope and specifications of the data collection, the data collection process itself, and the dissemination of the data.

\section{Working Methods}

The Health Committee will devise appropriate working methods.

The Experts' Group shall provide regular reports to the Health Committee for monitoring the progress, quality and timeliness of outputs.

\section{Relationship with other bodies}

The Experts' Group shall maintain close working relationships with other relevant bodies of the Organisation. The Experts' Group shall cooperate with other international and regional organisations active in the field. It may consult with non-governmental bodies as and when necessary. 


\section{HEALTH ACCOUNTS EXPERTS}

Chair:

Members:

Observers:

Date of creation:

Duration:
(..)

Open to all Member countries

Business and Industry Advisory Committee (BIAC)

Trade Union Advisory Committee (TUAC)

World Bank

World Health Organization (WHO)

1999

31st December 2011

Mandate: Confirmation by the Executive Committee registered in the Summary Record of its 770th session [Room Document No. 4 and CE/M(2006)15, item 106]

\section{Mission}

To make recommendations to the Health Committee on the implementation and revision of the System of Health Accounts

\section{Working Methods}

The Health Committee will devise appropriate working methods.

The Experts' Group shall provide regular reports to the Health Committee for monitoring the progress, quality and timeliness of outputs.

\section{Relationship with other bodies}

The Experts' Group shall maintain close working relationships with other relevant bodies of the Organisation. The Experts' Group shall cooperate with other international and regional organisations active in the field. It may consult with non-governmental bodies as and when necessary. 


\section{TASK FORCE ON HEALTH-SPECIFIC PURCHASING POWER PARITIES}

Chair:

(...)

Members: $\quad$ Open to all Member countries

Observer: $\quad$ World Health Organization (WHO)

Date of creation: June 2007

Duration: $\quad 31$ st December 2009

Mandate: Proposal for renaming the Group on Health and for Revision of its Mandate [C(2006)175] Executive Committee 29 November 2006 [Room Document No. 4 and $\mathrm{C} / \mathrm{M}(2006) 20$, item 264]

\section{Mission}

To make recommendations to the Health Committee and to the Committee on Statistics on the development of output-based purchasing power parities for health goods and services.

\section{Working Methods}

The Health Committee and the Committee on Statistics will devise appropriate working methods

The Task Force shall report to the Health Committee and to the Committee on Statistics for monitoring the progress, quality and timeliness of outputs.

\section{Relationship with other bodies}

The Task Force shall maintain close working relationships with other relevant bodies of the Organisation. The Task Force shall cooperate with other international and regional organisations active in the field. It may consult with non-governmental bodies as and when necessary. 


\section{HEALTH CARE QUALITY INDICATORS EXPERT GROUP (HCQI)}

Chair:

Members:

Observers:

Date of creation:

Duration:
(..)

Open to all Member countries

Business and Industry Advisory Committee (BIAC) World Health Organization (WHO)

13th January 2003

31st December 2011

Mandate: Confirmation by the Executive Committee registered in the Summary Record of its 770th session [Room Document No. 4 and CE/M(2006)15, item 106]

\section{Mission}

To develop a set of health care quality indicators that reflect a robust picture of health care quality that can be reliably reported across countries using comparable data.

\section{Working Methods}

The Health Committee will devise appropriate working methods.

The Experts' Group shall provide regular reports to the Health Committee for monitoring the progress, quality and timeliness of outputs.

\section{Relationship with other bodies}

The Experts' Group shall maintain close working relationships with other relevant bodies of the Organisation. The Experts' Group shall cooperate with other international and regional organisations active in the field. It may consult with non-governmental bodies as and when necessary. 


\section{HCQI SUB-GROUP OF PATIENT SAFETY EXPERTS}

Chair:

(..)

Members:

Open to all Member countries

Observers:

Business and Industry Advisory Committee (BIAC)

World Health Organization (WHO)

Date of creation:

17th October 2006

Duration:

31st December 2008

Mandate : - Proposal for renaming the Group on Health and for Revision of its Mandate [C(2006)175] Executive Committee 29 November 2006 [Room Document No. 4 and $\mathrm{C} / \mathrm{M}(2006) 20$, item 264]

\section{Mission}

To develop quality indicators fit for international comparison and improve data systems at national level in the priority area of patient safety.

\section{Working Methods}

The Health Committee will devise appropriate working methods.

The Experts' Group shall provide regular reports to the Health Committee for monitoring the progress, quality and timeliness of outputs.

\section{Relationship with other bodies}

The Experts' Group shall maintain close working relationships with other relevant bodies of the Organisation. The Experts' Group shall cooperate with other international and regional organisations active in the field. It may consult with non-governmental bodies as and when necessary. 


\section{HCQI SUB-GROUP OF MENTAL HEALTH EXPERTS}

Chair:

Members:

Observers:

Date of creation:

Duration:
(..)

Open to all Member countries

Business and Industry Advisory Committee (BIAC)

World Health Organization (WHO)

April 2006

31st December 2008

Mandate : $\quad$ Proposal for renaming the Group on Health and for Revision of its Mandate [C(2006)175] Executive Committee 29 November 2006 [Room Document No. 4 and $\mathrm{C} / \mathrm{M}(2006) 20$, item 264]

\section{Mission}

To develop quality indicators fit for international comparison and improve data systems at national level in the priority area of mental health care.

\section{Working Methods}

The Health Committee will devise appropriate working methods.

The Experts' Group shall provide regular reports to the Health Committee for monitoring the progress, quality and timeliness of outputs.

\section{Relationship with other bodies}

The Experts' Group shall maintain close working relationships with other relevant bodies of the Organisation. The Experts' Group shall cooperate with other international and regional organisations active in the field. It may consult with non-governmental bodies as and when necessary. 


\section{HEALTH SYSTEMS}

Chair:

Members:

Open to all Member countries

Observers:

Business and Industry Advisory Committee (BIAC)

Trade Union Advisory Committee (TUAC)

World Health Organization (WHO)

Date of creation:

March 2007

Duration:

31st December 2009

Mandate : - Draft Summary Record of the 2nd meeting of the Group on Health, 14-15 November, 2006 [DELSA/HEA/M(2006)2, paragraph 34]

- Confirmation by the Executive Committee registered in the Summary Record of its 770th session [Room Document No. 4 and CE/M(2006)15, item 106]

\section{Mission}

To support the Health Committee in implementing the OECD project on Information and Communication Technologies in Health.

\section{Working Methods}

The Health Committee will devise appropriate working methods.

The Experts' Group shall provide regular reports to the Health Committee for monitoring the progress, quality and timeliness of outputs.

\section{Relationship with other bodies}

The Experts' Group shall maintain close working relationships with other relevant bodies of the Organisation. The Experts' Group shall cooperate with other international and regional organisations active in the field. It may consult with non-governmental bodies as and when necessary. 


\section{NATIONAL EXPERTS ON ECONOMICS OF PREVENTION}

Chair:

(...)

Members:

Open to all Member countries

Observers:

Business and Industry Advisory Committee (BIAC)

Trade Union Advisory Committee (TUAC)

World Health Organization (WHO)

Date of creation:

April 2007

Duration:

31st December 2009

Mandate : - Draft Summary Record of the 2nd meeting of the Group on Health, 14-15 November, 2006 [DELSA/HEA/M(2006)2, paragraph 38]

- Confirmation by the Executive Committee registered in the Summary Record of its 770th session [Room Document No. 4 and CE/M(2006)15, item 106]

\section{Mission}

To support the Health Committee in implementing the OECD project on the economics of prevention.

\section{Working Methods}

The Health Committee will devise appropriate working methods.

The Experts' Group shall provide regular reports to the Health Committee for monitoring the progress, quality and timeliness of outputs.

\section{Relationship with other bodies}

The Experts' Group shall maintain close working relationships with other relevant bodies of the Organisation. The Experts' Group shall cooperate with other international and regional organisations active in the field. It may consult with non-governmental bodies as and when necessary. 

Chair:

Vice-Chairs:

Members:

Observer:

Ad hoc Observers:

Date of creation:

Duration:
Mr. Bo Smith

Mr. Tomoaki Katsudo

Mr. Werner Aeberhardt

Ms. Agnieszka Chlon-Dominczak

Ms. Elizabeth Ruddick

Mr. Kenneth Swinnerton

Open to all Member countries

Russian Federation

Council of Europe

International Labour Organization (ILO)

Chile

Estonia

Israel

Slovenia

30th September 1961

30th June 2010
(Denmark)

(Japan)

(Switzerland)

(Poland)

(Canada)

(United States)

Mandate: -- Paragraph 35 of the Report of the Preparatory Committee

- Minutes of the 543rd Meeting of the Council [C/M(81)15(Final)]

- Minutes of the 761 st meeting of the Council [C/M(91)14/FINAL]

- Council Decision regarding a Sunset Clause for all Committees [C/M(2004)5, item 75] entered into force on 22 April 2004 [C/M(2004)10, item 143, IV, c)]

- Extension of current mandate [C(2008)199 and C/M(2008)21, item 303]

\section{Paragraph 35 of the Report of the Preparatory Committee}

"35. The Preparatory Committee recommend the creation of a Manpower Committee to deal with manpower questions connected with the general objectives of the Organisation and those social questions which are closely linked with manpower problems. This Committee would also continue the work of the OEEC in connection with manpower movements in Europe. The Committee could, if the Council so instructed it, carry out certain operational tasks."

\section{Extract from the Minutes of the Council [C/M(81)15(Final) Item 154 i)]}

\section{"THE COUNCIL}

$\cdots$

i) noted that overall programme co-ordination of the work of the Organisation in the field of manpower, social affairs and education will be ensured, when appropriate, by joint meetings of the Bureaux of the bodies concerned as well as by the setting up on an ad hoc basis of Joint Working Parties." 


\section{Extract from the Minutes of the Council [C/M(91)14 FINAL Item $130 \mathrm{~b})]$}

"THE COUNCIL

(130)

b) agreed that the Manpower and Social Affairs Committee shall in future be called "The Employment, Labour and Social Affairs Committee" and instructed the Secretary-General to issue the necessary amendment to paragraph 19 of the Annex to the Rules of Procedure."

\section{Extract from document [C/M(2008)21, Item 303]}

\section{"THE COUNCIL}

(4)

b) agreed to renew the existing mandate of the Employment, Labour and Social Affairs Committee until 30 June 2010." 


\section{WORKING PARTY ON MIGRATION}

Chair:

Bureau Members:

Members:

Observers:

Date of creation:

Duration:
Ms. Elizabeth Ruddick

Mr. Jacques Ouziel

Mr. Heino Jespersen

Dr. Arjen Taselaar

Mr. Kees Terwan

Mr. Stephen Dunstan

Ms. Magdalena Sweklej

Ms. Marta Wrzosek
(Canada)

(Belgium)

(Denmark)

(Netherlands)

(Netherlands)

(New Zealand)

(Poland)

(Poland)

Open to all Member countries

Council of Europe

International Labour Organization (ILO)

International Organisation for Migration (OIM)

UN High Commissioner for Refugees (UNHCR)

9th February 1967

31st December 2010

Mandate: - Summary record of the 1125th Session of the Council [C/M(2005)24, item 315] and documents [C(2005)121 and ADD1].

\section{Annex to document [C(2005)121]}

Terms of reference of the Working Party on Migration

"1. The Working Party on Migration shall:

a) serve as a forum for OECD Member countries to exchange information on national policies and practices and discuss matters related to migration, with emphasis on labour market and other economic and social aspects;

b) systematically collect, review and disseminate information, using the Continuous Reporting System on Migration (SOPEMI), on migratory trends as well as statistical data and policies and practices of Member countries and, to the extent feasible, of relevant non-Member countries;

c) initiate work on the economic, demographic, and social causes and consequences of migration in sending and receiving countries and discuss the results of this work and its wide-ranging policy implications;

d) evaluate and develop, on the basis of analytical work, policy options which would facilitate decisions by OECD Member countries to respond to the challenges and opportunities of international migration, including the integration and insertion of migrants and their children in the economy and society at large;

e) encourage and facilitate co-operation among sending and receiving countries by providing information and policy analysis that will assist them in assessing and managing migration flows to their mutual benefit; 
f) promote co-operation among the bodies of the Organisation dealing with work related to migration, and maintain regular contacts and co-operation with other International Organisations, as appropriate.

2. The procedure adopted by the Council in 1979 and confirmed in 1988 [C(88)32] according to which the Working Party is instructed "to report to the Council... at regular intervals, as required, such reports to be transmitted through the [Manpower and Social Affairs Committee] Employment, Labour and Social Affairs Committee, which may formulate comments thereon as appropriate" $[\mathrm{C} / \mathrm{M}(79) 5$, Item 65] remains unchanged." 


\section{WORKING PARTY ON EMPLOYMENT}

Chair:

Vice-Chairs:

Members:

Date of creation:

Duration:

Mr. Kenneth Swinnerton

Mr. Panagiotis Katis

Mr. Joyup Ahn

Mr. Bernhard Weber

Open to all Member countries

6th July 1976

June 2010
(United States)

(Greece)

(Korea)

(Switzerland)

Mandate: -Record of the 44th Meeting of the Manpower and Social Affairs Committee [MAS/M(76)3]

-Extension of current mandate [C(2008)199]

\section{Extract from document [MAS/M(76)3, paragraph 29]}

\section{"THE COMMITTEE}

ii) as regards paragraph 1-7 of MAS(76)10, approved the draft terms of reference for the reconstitution of the Working Party on Employment circulated during the meeting, as amended in the discussion and attached at Annex A hereto."

\section{Annex A to document [MAS/M(76)3}

\section{"TERMS OF REFERENCE}

\section{WORKING PARTY ON EMPLOYMENT}

1. The Working Party will be responsible to the Employment, Labour and Social Affairs Committee for following up the implementation of the 1976 Recommendation on a General Employment and Manpower Policy, and other assignments enumerated below:

i) With respect to the Report on the 1976 Recommendation, due not later than 31st March 1977 , and subsequently at intervals to be determined by the Manpower and Social Affairs Committee:

a) The maintenance and up-dating of the "inventory" of employment and manpower measures, including the classification and format of presentation of the "inventory";

b) The preparation of reports on the quantification of the measures in financial and manpower terms, as an element in the evaluation of the implementation of policies on a Member country basis;

c) The format and content of the Report to be submitted by Member countries on the implementation of the 1976 Recommendation.

\footnotetext{
${ }^{1}$ Now called the Employment, Labour and Social Affairs Committee
} 
ii) The selection of specific manpower and employment measures for evaluation of experience in selected countries, and reporting the results of such evaluations;

iii) The periodic review and assessment of the changing employment situation facing Member countries and the employment and manpower policy responses appropriate to the current situation;

iv) Analysis and evaluation of the implications of the medium-term growth strategy approved by the Council of Ministers for the implementation of the 1976 Recommendation, including preparation of a Report to the Manpower and Social Affairs Committee in co-operation with other relevant bodies of the Organisation;

v) Investigations and analyses as required from time to time on specific issues which are of particular concern (these can include, inter alia, the concept of full employment, the extent and character of structural unemployment and its policy implications, the effects of particular policies on labour market behaviour, and the co-ordination of income support policies and selective employment and manpower policies).

2. The Working Party will report its analyses, evaluations and conclusions to the Manpower and Social Affairs Committee on a periodic basis as required. In particular, it will report to the next meeting of the Manpower and Social Affairs Committee on the implementation of Item i); on progress made on (tem ii), iv) and v), and will present a report on Item iii)." 


\section{WORKING PARTY ON SOCIAL POLICY}

Chair:

Vice-Chairs:

Members:

Ad hoc Observers:

Observers:

Date of creation:

Duration:
Ms. Agnieszka Chlon-Dominczak (Poland)

Ms. Glenys Beauchamp

(Australia)

(Greece)

(Belgium)
Russian Federation

Slovenia

South Africa

\section{Estonia}

Israel

Open to all Member countries

Council of Europe

International Labour Organization (ILO)

International Social Security Association (ISSA)

14th December 1983

30th June 2010

Mandate: - Extension of current mandate [C(2008)199]

- Renewal of the mandate [DELSA/ELSA(2004)10] approved by the Employment, Labour and Social Affairs Committee as of 1st January 2005 for a period of four years, document [DELSA/ELSA/M(2004)2] at its 105th Session on 22-23 November 2004.

- Record of the 60th Meeting of the Manpower and Social Affairs Committee [MAS/M(83)2]. This mandate was renewed by the Committee at its 69th and 75th Meetings [MAS/M(87)1, MAS/M(89)3] and by the Employment, Labour and Social Affairs Committee at its 81st, 87th, 93rd and 99th meetings [DEELSA/ELSA/M(2001)2].

\section{Annex to document [DELSA/ELSA(2004)10]}

"Terms of Reference of the Working Party on Social Policy

1. The Working Party will address those issues of social policy which arise in the context of demographic, social and economic changes in the Member countries, bearing in mind the effective functioning of labour markets. It will, on behalf of the Committee, develop a framework for the assessment of social policy and oversee the development of a comprehensive data base enabling comparative trends to be tracked.

2. To achieve these goals, the Working Party will supervise, on behalf of the Committee, the implementation of activities on social policy issues allocated to the Committee in the Programme of Work and Budget of the Organisation.

3. The Working Party will contribute to and comment on studies and analyses undertaken for the Employment, Labour and Social Affairs Committee on the above topics and, in view of the specialised expertise from Member countries, may authorise the Secretariat to convene ad hoc meetings of national experts from time to time on specialised topics for the consideration of the Working Party and the Committee.

4. The Working Party will collaborate with other Committees and Groups through horizontal projects and exchanges of views wherever such work appears likely to be fruitful." 


$\begin{array}{lll}\text { Co-Chairs: } & \begin{array}{l}\text { Ms. Satya Brink } \\ \text { Mr. Paolo Sestito }\end{array} & \begin{array}{l}\text { (Canada) } \\ \text { (Italy) }\end{array} \\ \text { Member: } & \begin{array}{l}\text { Participation in PIAAC is open to } \\ \text { and participation of non-Member countries. Invitations } \\ \text { considered by the Board of Participating Countries in accordanc } \\ \text { with Council Resolutions C(2004)132/FINAL and C(2006)78/FIN }\end{array} \\ & \text { Australia } & \text { Korea } \\ \text { Austria } & \text { Netherlands } \\ \text { Belgium } & \text { New Zealand } \\ \text { Canada } & \text { Norway } \\ \text { Czech Republic } & \text { Poland } \\ \text { Denmark } & \text { Portugal } \\ & \text { Finland } & \text { Slovak Republic } \\ \text { France } & \text { Spain } \\ \text { Germany } & \text { Sweden } \\ \text { Hungary } & \text { United Kingdom } \\ \text { Ireland } & \text { United States } \\ \text { Italy } & \text { European Commission } \\ \text { Japan } & \end{array}$

Full Participants: $\quad$ Estonia

Slovenia

Ad hoc Observer: ${ }^{1} \quad$ Chile

Date of creation: $\quad$ 1st January 2008

Duration: $\quad 31$ st December 2011

Mandate: - Draft summary record of the Joint Session of the Education Policy Committee and CERI Governing Board [EDU/EDPC/CERI/M(2007)1 and COM/DELSA/EDU(2007)1 ]

- Resolution of the Council concerning the creation of the Programme for the International Assessment of Adult Competencies (PIAAC) [C(2007)62/REV3] approved by the Council on 12 July 2007 at its 1158 th session [C/M(2007)11, Item 135]

\section{Extract from document [C(2007)62/REV3/ANN]}

"RESOLUTION OF THE COUNCIL CONCERNING THE CREATION OF THE PROGRAMME FOR THE INTERNATIONAL ASSESSMENT OF ADULT COMPETENCIES (PIAAC)

\section{THE COUNCIL,}

Having regard to the Convention on the Organisation for Economic Co-operation and Development of 14 December 1960, and, in particular, Articles 5 a), 9 and 12 thereof;

Having regard to the Rules of Procedure of the Organisation;

\footnotetext{
${ }^{1}$ Waiting approval on full partcipation.
} 
Having regard to the Financial Regulations and the Financial Rules of the Organisation;

Having regard to the Resolution of the Council concerning the participation of nonMembers in the work of subsidiary bodies of the Organisation [C(2004)/132/FINAL] and the Resolution of the Council Concerning Fees for Non-Member Participation in Subsidiary Bodies of the Organisation [C(1996)223/REV3/FINAL];

Having regard to the Resolution of the Council on a New Governance Structure for the Organisation [C(2006)78/FINAL];

Having regard to the Main Principles Guiding the Governance Structure of the OECD Education Bodies [EDU(2006)8/ANN3/REV1], in particular, relative to the global coherence of OECD work on education, and the mandates of the other education bodies;

Having regard to the mandate of the Employment, Labour and Social Affairs Committee and the Education Policy Committee;

Having regard to the proposals set out in the Note by the Secretary-General concerning the creation of a Part II Programme and a Board of Participating Counties for the Programme for the International Assessment of Adult Competencies (PIAAC) [C(2007)62/REV3];

\section{DECIDES:}

The Programme for the International Assessment of Adult Competencies (PIAAC) is hereby created with the following mandate:

Mission

The Council shall, for the period of 1 January 2008 to 31 December 2011, create a Programme for the International Assessment of Adult Competencies (PIAAC). The work of PIAAC reflects and complements the priorities of the OECD as a whole, in improving living standards and promoting sustainable development and social cohesion through good governance. It contributes to fulfilling the Directorate for Education and the Directorate for Employment, Labour and Social Affairs missions of facilitating high-quality lifelong learning for all that contributes to personal development and sustainable economic growth, as well as fostering the conditions leading to more and better jobs and a more socially inclusive society. It is carried out within the framework of the Main Principles Guiding the Governance Structure of the OECD Education Bodies [EDU(2006)8/ANN3/REV1], and with due regard to the mandates of the other education bodies and the mandate of the Employment, Labour and Social Affairs Committee.

A multi-cycle programme of assessment, PIAAC will survey a representative sample of the adult population in each participating country in the assessment in a household context, in order to assess key competencies and their utilisation in the work place. The assessment will focus on literacy, which previous national and international assessments have shown to be essential for participation in modern societies, as well as on other generic work skills. PIAAC will extend the traditional concept of literacy by adapting it to competency requirements in the information age and will also break new ground by assessing other key generic skills required in the workplace. PIAAC will also survey other important social and labour-market outcomes and collect contextual data with the aim of facilitating policy-relevant analyses. The objectives of PIAAC are four-fold:

Identify and measure differences between individuals and across countries in key competencies believed to both underlie personal success and respond to labour market requirements.

- $\quad$ Assess the impact of competencies on a range of economic and social outcomes.

Assess the performance of education and training systems, workplace practices as well as labour market policies, in generating competencies at the levels required by social and economic demands.

- Help identify policy levers to reduce "deficiencies" in key competencies. 
Participation in PIAAC is open to Member countries. Invitations to and participation of non-Members in the work of PIAAC will be considered by the Board of Participating Countries in accordance with Council Resolutions C(2004)132/FINAL and C(2006)78/FINAL.

\section{Board of Participating Countries}

In support of the mandates of the Education Policy Committee and the Employment, Labour and Social Affairs Committee, the Board of Participating Countries shall oversee PIAAC. The Board of Participating Countries shall, in particular:

Recommend the policy priorities for PIAAC to the Education Policy Committee and the Employment, Labour and Social Affairs Committee and oversee adherence to these priorities during implementation. This includes the setting of priorities and standards for data development, analysis and reporting as well as the determination of the scope of work that will then form the basis for the implementation of PIAAC.

- $\quad$ Develop a draft work programme and budget and cost elements of a scale of contributions.

- $\quad$ Prioritise its activities and outputs in consultation with the Employment, Labour and Social Affairs Committee and the Education Policy Committee.

- $\quad$ Monitor the quality and timeliness of output results, activities and projects.

- $\quad$ Disseminate policy advice, analysis, research and data to a wide range of stakeholders in Member and non-Member countries.

Evaluate the outcomes of the work.

The Board is open to countries participating in the assessment. The European Commission shall participate in accordance with the provisions of Article 13 of the Convention and Supplementary Protocol No. 1 to the Convention. The International Labour Office, the World Bank and UNESCO may attend meetings of the Board as observers. Representatives of the Business and Industry Advisory Committee (BIAC) and the Trade Union Advisory Committee (TUAC) may attend meetings of the Board as experts.

Governments should, whenever possible, appoint representatives to the Board of Participating Countries who are knowledgeable about large-scale survey assessments and their interface with educational and employment policy and practice.

The Board of Participating Countries may organise its meetings outside OECD Headquarters on the basis of a reasoned request from a Permanent Representative on behalf of a member of the Board. The host will accept responsibility for additional direct and indirect expenditures related to the meeting so that it is no more expensive for the Organisation that it would have been if held at OECD Headquarters.

Working methods and relationship with the Education Policy Committee and the Employment, Labour and Social Affairs Committee

The Board of Participating Countries will seek strategic guidance on policy priorities, the programme of work and budget from the Education Policy Committee and the Employment, Labour and Social Affairs Committee.

The Board shall provide regular reports to the Education Policy Committee and the Employment, Labour and Social Affairs Committee on the implementation of its programme of work.

All decisions relating to the modalities for the participation in the assessment exercise, the operations of the Board of Participating Countries, the elements to be included in calculating the floor contribution for the scale of contributions, changes to project design and structure as well as the frequency of successive PIAAC surveys will be adopted by consensus of the members of the Board of Participating Countries. For other decisions, not specifically provided for in this mandate, 
the Board will tailor its working methods to its own needs, as provided by Council Resolution C(2006)78/FINAL.

Budget of the Programme

The programme of work, scale of contributions and budget of the Programme shall be agreed by the Budget Committee before transmission to Council for final approval.

The expenditure of the Programme shall be charged against the appropriations authorised for it under a Part II Chapter of the Budget of the Organisation.

The scale of contributions will be composed of a floor contribution, to be determined by the Board of Participating Countries, which is the minimum contribution for participating countries and represents the operational international cost of country participation, and other costs that will be assigned to participating countries on the basis of the OECD Part I scale of contributions.

In order to allow participating countries to contribute stable amounts for PIAAC over successive years, appropriations, for which no commitment has been entered into before the end of the Financial Year for which they were appropriated shall be automatically carried forward to the budget for the ensuing year by decision of the Secretary-General, notwithstanding the provisions of Articles 14 and 15 of the Financial Regulations of the Organisation.

\section{Relationship with other bodies}

The Board of Participating Countries shall also maintain close working relationships with other relevant bodies of the Organisation working on issues related to assessment, educational, training and employment outcomes, as well productivity and economic growth, in particular the Governing Board of the Centre for Educational Research and Innovation and the Committee for Industry, Innovation and Entrepreneurship. The Board of Participating Countries shall co-operate with other international and regional organisations active in its field of competencies. It may consult with non-governmental bodies after receiving advice from the Education Policy Committee and the Employment, Labour and Social Affairs Committee.

\section{Evaluation}

As part of the OECD in-depth evaluation process, an evaluation exercise will be conducted prior to the end of the mandate period by the Education Policy Committee and the Employment, Labour and Social Affairs Committee.

Duration

This mandate shall enter into force on 1 January 2008 and shall expire on 31 December 2011, unless the Council decides otherwise." 

ENTREPRENEURSHIP, SMES AND LOCAL DEVELOPMENT 



\begin{tabular}{|c|c|c|}
\hline Chair: & Mr. Jan Hendeliowitz & (Denmark) \\
\hline \multirow[t]{4}{*}{ Vice-Chairs: } & Mr. John Atherton & (Canada) \\
\hline & Mr. Michele Dau & (Italy) \\
\hline & Mr. Paul Barker & (New Zealand) \\
\hline & Mr. Mike Smith & (New Zealand) \\
\hline \multirow[t]{5}{*}{ Bureau Members: } & Ms. Ann Van den Cruyce & (Belgium) \\
\hline & Mr. Robert Strauss & (European Commission) \\
\hline & Mr. Jean-François Rocchi & (France) \\
\hline & Ms. Joanna Hofman & (Poland) \\
\hline & Mr. Björn Jonzon & (Sweden) \\
\hline \multirow[t]{22}{*}{ Members: } & Australia & Mexico \\
\hline & Austria & Netherlands \\
\hline & Belgium & New Zealand \\
\hline & Canada & Norway \\
\hline & Czech Republic & Poland \\
\hline & Denmark & Portugal \\
\hline & Finland & Slovak Republic \\
\hline & France & Spain \\
\hline & Greece & Sweden \\
\hline & Hungary & Switzerland \\
\hline & Ireland & Turkey \\
\hline & Italy & United Kingdom \\
\hline & Japan & United States \\
\hline & Korea & European Commission \\
\hline & Luxembourg & \\
\hline & Chile & \\
\hline & Slovenia & \\
\hline & Latvia & \\
\hline & Lithuania & \\
\hline & Romania & \\
\hline & Corporación Andina de Fo & AF) \\
\hline & Inter-American Developme & IDB) \\
\hline
\end{tabular}

Date of creation: $\quad$ 22nd July 1982

Duration: $\quad 31$ st December 2010

Mandate: Decision of the Council concerning the Co-operative Action Programme on Local Economic and Employment Development (LEED) approved at its 1106th session on 24 February 2005 [C/M(2005)5, Item 50 and C(2004)151/REV1] 


\section{Extract of the summary record [C/M(2005)5, Item 50]}

"THE COUNCIL

b) adopted the draft Decision of the Council concerning the Co-operative Action Programme on Local Economic and Employment Development as set out in Annex 1 to the document C(2004)151/REV1."

\section{Decision of the Council [C(2004)151/REV1, Annex 1]}

\section{"THE COUNCIL,}

Having regard to the Convention on the Organisation for Economic Co-operation and Development of 14th December 1960 and, in particular, Articles 1 a), 5 a), 9 and 20 thereof;

Having regard to the Rules of Procedure of the Organisation;

Having regard to the Financial Regulations of the Organisation;

Having regard to the Decision of the Council of 24 February 2000 concerning the Cooperative Action Programme on Local Economic and Employment Development [C(2000)16(FINAL) as amended by C(2001)303 \& CORR1; C/M(2001)26];

Having regard to the document on the Renewal of the Mandate of the Co-operative Action Programme on Local Economic and Employment Development and the opinion of the Directing Committee of the Programme [C(2004)151/REV1, Annex 2];

Considering that the Governments of Australia, Austria, Belgium, Canada, the Czech Republic, Denmark, Finland, France, Greece, Hungary, Ireland, Italy, Latvia, Lithuania, Mexico, New Zealand, Norway, Poland, Portugal, the Slovak Republic, Slovenia, Spain, Sweden, Switzerland, Turkey, the United Kingdom, the United States, as well as the European Commission, the World Bank, the European Bank for Reconstruction and Development (EBRD) together with the Central European Initiative (CEI), and the Inter-American Development Bank (hereinafter referred to as the "Participants") have formally expressed their willingness to participate in a Co-operative Action Programme on Local Economic and Employment Development;

On the proposal of the Secretary-General;

DECIDES:

\section{Article 1}

\section{DEFINITION OF THE PROGRAMME}

a) The Co-operative Action Programme on Local Economic and Employment Development, established within the framework of the Organisation, is hereby maintained.

b) The main objectives of the Programme shall be:

i) To improve the quality of local labour market and social policies, through continuous monitoring and assessment of current practices;

ii) to promote the exchange of experience and information and the diffusion of innovation in local economic, employment and entrepreneurship development. 
iii) to provide assistance for Member countries, to support exchanges with nonmember economies and to serve as a critical link between the OECD and local authorities.

c) A programme of work shall be adopted by the Council and implemented by the Secretary-General. The programme of work may include activities to be financed in part from voluntary contributions from public institutions and grants from private foundations.

\section{Article 2}

\section{COMPOSITION OF THE DIRECTING COMMITTEE}

a) Each Participant shall appoint at least one representative to the Directing Committee. Representatives to the Directing Committee of the Programme (hereinafter referred to as the 'Directing Committee') should be chosen by virtue of their responsibilities in matters relating to Local Economic and Employment Development.

b) Participants may appoint experts to assist their representatives and the Directing Committee.

c) The Directing Committee shall appoint from among its members, a Bureau consisting of at least the Chairman and two Vice-Chairmen. Bureau members shall be appointed for a maximum of five years (two mandates of two years and a half).

\section{Article 3}

\section{FUNCTIONS OF THE DIRECTING COMMITTEE}

a) The Directing Committee shall be competent to consider all questions related to the carrying out of the Programme.

b) Each biennium the Directing Committee shall submit to the Council for adoption the draft programme of work.

c) The Directing Committee shall submit a summary activity report each year to the Council.

\section{Article 4}

\section{FINANCING OF EXPENDITURE}

a) The expenditure arising from the implementation of the Programme shall be charged against the appropriations authorised for it under Part II of the Budget of the Organisation.

b) The above-mentioned appropriations shall be financed by special contributions paid by the Participants, voluntary contributions and grants.

c) The Directing Committee shall submit to the Council for adoption the annual estimates of expenditure and of income for the Programme.

Article 5

\section{RELATIONS WITH OTHER INSTITUTIONS}

In order to further the objectives of the Programme the Secretary-General may establish appropriate working relations, in agreement with a Member government, with a national institution concerned with local economic development and employment creation. Such relations may include the encouragement, promotion or assistance of activities of such institutions. The same 
arrangements may be applicable to other international organisations with a view to strengthening international co-operation in relation to job creation and local development. Furthermore, collaboration will be pursued in areas of synergy between the LEED Programme and the many OECD Directorates and Committees.

Article 6

\section{PARTICIPANTS}

a) The Participants shall be the Member countries and non-OECD economies and invited international organisations listed in the Preamble.

b) Any Member country of the Organisation the Government of which does not participate in the present Decision may participate in it by addressing a notification to the Secretary-General to this effect.

c) Subject to approval by the OECD Council and the LEED Directing Committee, nonMember economies and international organisations may be invited to participate in the Programme as full participants.

Article 7

\section{DURATION}

This Decision repeals the Decision of 24 February 2000, referred to above, and shall terminate on 31 December 2010, unless the Council decides otherwise." 


$\begin{array}{lll}\text { Chair: } & \text { Ms. Isabel Hill } & \text { (United States) } \\ \text { Vice-Chairs: } & \text { Mrs. Helen Cox } & \text { (Australia) } \\ & \text { Ms. Monika Klinger } & \text { (Austria) } \\ & \text { Mr. Lars Erik Jønsson } & \text { (Denmark) } \\ & \text { Mr. Satoru Mizushima } & \text { (Japan) } \\ & \text { Mr. Gabriel Szekely } & \text { (Mexico) } \\ & \text { Ms. Rita Duarte } & \text { (Portugal) } \\ & \text { Mr. Miguel Orea Malo } & \text { (Spain) } \\ & \text { Mr. Peter Laimer } & \text { (Austria) } \\ & \text { Bureau Officer in charge of Statistics } \\ & \text { Open to all Member countries } & \\ \text { Members: } & \text { Romania } & \\ \text { Observer: } & \text { Council of Europe } & \\ & \text { World Bank } & \\ \text { Date of creation: } & \text { 30th September 1961 } & \\ \text { Duration: } & \text { 31st December 2011 }\end{array}$

Mandate: Resolution of the Council [C(2006)182] approved at its 1146th session held on 14 December 2006 [C/M(2006)20, item 266]

\section{Resolution of the Council [C(2006)182 and C/M(2006)20, item 266]}

\section{"THE COUNCIL,}

Having regard to the Convention on the Organisation for Economic Co-operation and Development of 14 December 1960;

Having regard to the Rules of Procedure of the Organisation;

Having regard to paragraph 33 of the Report of the Preparatory Committee;

Having regard to the recommendations of the In-depth Evaluation of the Tourism Committee [C/M(2006)11, Item 142];

Considering that tourism is a significant contributor of wealth and employment to economies;

On the proposal of the Secretary-General;

\section{DECIDES:}

1. The Tourism Committee will assist Member countries and, as appropriate, non-member economies to:

\footnotetext{
1 The Bureau and its Chair were elected by the Tourism Committee during its 81 st session held on 21-22 April 2008.
} 
a) maximise the economic, social and environmental benefits of tourism through medium and longterm strategic development, soundly-developed tourism policy and greater coherence between tourism and other policies (e.g. transport, environment, security, trade, taxation or migration);

b) promote, in a globalisation and decentralisation context, sustainable tourism development as a source of economic growth, job creation and poverty alleviation in both major centres and regional areas;

c) improve the infrastructure and image of destinations to make them more attractive to the local population and visitors and more competitive to investors for the benefit of the whole economy;

d) contribute to the advancement of international co-operation in the tourism sector.

2. To achieve these objectives, the Tourism Committee will be responsible for analysing and developing tourism-related policy recommendations.

3. In the context of this mission, the Tourism Committee will:

a) prepare tourism policy analysis and evaluation, identify good policy and business practices to meet major challenges, provide policy advice and be a clearing house for information on tourism policy;

b) share knowledge and experiences to identify best practices on tourism-related policies and strategies, particularly in the areas of competitiveness, taxation, entrepreneurship and innovation, labour, environment, safety and security, culture, and infrastructure development;

c) carry out in-depth tourism industry and market analysis to help Member countries, the travel and tourism industry and, as appropriate, non-Member economies, realise the overall economic benefit of tourism;

d) improve the measurement of tourism services in OECD economies by addressing government and industry information needs and promoting the tourism satellite account, contribute to the dissemination of data on tourism economics and to a more effective use of such data for business and policy analysis and decision-making processes, and work in complementarity with other international organisations;

e) provide a forum for dialogue and disseminate results through publications and thematic conferences.

4. The actions undertaken by the Tourism Committee should be guided by the following operating principles. The Tourism Committee will:

a) develop, as appropriate, active links to the Organisation's horizontal programmes, maintain close working relations with other relevant bodies in the Organisation to complement and support analysis and discuss tourism aspects of questions raised and, where appropriate, undertake joint projects;

b) develop partnerships with the private sector and other stakeholders to build a shared vision of strategic developments and, where appropriate, organise forums to explore timely issues and develop policy recommendations;

c) engage Non-Member Economies in accordance with its Global Relations Strategy, share the results of its work with Non-Member Economies and co-operate closely with other international organisations active in the tourism field.

5. The Mandate of the Tourism Committee will take effect on 1 January 2007 and remain in force until 31 December 2011, unless Council decides otherwise." 


\section{INTERNATIONAL FORUM ON TOURISM STATISTICS}

Members:

Date of creation:

Duration:
Open to all Member countries

1994

31st December 2011

\section{Mandate :}

\section{INTERNATIONAL FORUM ON TOURISM STATISTICS}

\section{Background and objectives}

1. The International Forum on Tourism Statistics, set up in 1994 by the OECD and Eurostat, provides a unique platform for the regular exchange of views and experiences on developments in tourism statistics and application for policy and business, both within the European Union (EU), in other OECD countries and in selected non-member countries.

2. The International Forum on Tourism Statistics meets once every two years at the invitation of a hosting country.

3. The aim of the forum is to discuss major issues concerning the establishment of harmonised tourism statistics in an environment that strengthens co-operation between governments, the private sector, researchers, academics, OECD/EU Member and non-member countries and international organisations.

4.

The objectives are:

- Broad-based participation by experts and researchers from EU/OECD Member countries, some non-member countries, all sectors of the tourism industries and universities;

- Presentation and discussion of selected case studies dealing with the implementation of statistical methodologies, definitions and classifications as well as with the development of new statistical tools;

- Sharing of ideas, experiences, concepts as a basis for developing harmonised tourism statistics and concrete proposals to improve the definition and the measurement of tourism in the economy;

- Identification of alternative sources of information and promotion of new information technologies as a way to diminish the burden on tourism enterprises and to improve the dissemination of statistics to all partners;

- Development of integrated systems of tourism statistics and socio-economic indicators to present a global picture of the tourism industries, particularly to governments and to establish links with the rest of the economy.

Reference documents: [DAFFE/TOU/M(94)1, Item 5; DAFFE/TOU/STAT(94)1, Item 11 and DAFFE/TOU/STAT(94)12, Item 4] 

EDUCATION 



\section{EDUCATION POLICY COMMITTEE}

Chair:

Bureau Members:

Members:

Observers:

Invited Organisations:

Date of creation:

Duration:
Mr. Keray Henke

Ms. Oon Ying Chin

Mr. Jorma Ahola

Mr. Yukitsugu Ono

Mr. Stefan C. Wolter
(Canada)

(Australia)

(Finland)

(Japan)

(Switzerland)

Open to all Member countries

Chile
Estonia
Israel
Russian Federation
Slovenia

Council of Europe

UN Educational Scientific and Cultural Organization (UNESCO)

1st January 2007

31st December 2011

Mandate: Resolution of the Council approved at its 1046th Session held on 14 December 2006 [C(2006)173 and C/M(2006)20, item 265]

\section{Resolution of the Council [C(2006)173, Annex II and C/M(2006)20, item 265]}

\section{"THE COUNCIL,}

Having regard to Articles 1 and 2 of the Convention on the Organisation for Economic Co-operation and Development of 14 December 1960; Annex thereto;

Having regard to the Rules of Procedure of the Organisation and, in particular, to the

Having regard to the Resolution of the Council of 22 July 1970 establishing an Education Committee [C(70)134], as last renewed by Council on 26 July 2001 [C/M(2001)16/FINAL];

Having regard to the proposals set out in the Note by the Secretary-General concerning the renewal of the mandates of the Education Policy Committee, the Centre for Educational Research and Innovation (CERI), the Programme on Institutional Management of Higher Education (IMHE), the Programme on Educational Building (PEB) and the Programme on International Student Assessment (PISA) [C(2006)173];

\section{DECIDES:}

The Education Committee, hereby renamed Education Policy Committee, is renewed with the following mandate:

Mission

The work of Education Policy Committee reflects and complements the priorities of the OECD as a whole, in providing employment opportunities for all, improving human capital and social 
cohesion. It contributes to fulfilling the Directorate for Education's mission of assisting OECD member countries and non-members to achieve high quality lifelong learning for all, which contributes to personal development, sustainable economic growth and social cohesion. It is carried out with the framework of the Main Principles Guiding the Governance Structure of the OECD Education Bodies [EDU(2006)8/ANN3/REV1] and with due regard to the mandates of the other education bodies.

The Education Policy Committee is responsible for:

1. Assisting governments to develop effective and efficient policies for education and learning to meet individual, social, cultural and economic objectives through the development of specific policy recommendations, policy reviews, analyses and data collection.

2. Overseeing the strategic direction, coherence, quality and communication of OECD work on education carried out by the education bodies.

3. Exchanging information and promoting international co-operation among OECD member countries and, where relevant, with non-members on the objectives identified under 1) above.

4. Disseminating its policy advice, data and policy analysis to a wide range of stakeholders in OECD member countries and non-member economies.

Participation

Governments should, whenever possible, appoint to the Education Policy Committee senior officials with direct responsibility for advising their governments on general education policy and the allocation of educational resources.

Non-members may attend meetings of the Committee as regular observers, in line with the global relations strategy of the Committee and as approved by Council. The Council of Europe attends meetings of the Committee as an observer.

The Chairs or a Vice-Chair of the Governing Boards of the Centre for Educational Research and Innovation, the Programme on Institutional Management in Higher Education, the Programme on Educational Building and the Programme for International Student Assessment may attend meetings of the Committee ex officio.

Relationship with other bodies

The Education Policy Committee shall maintain close working relationships with other relevant bodies of the Organisation working on issues that affect the development and implementation of education policy and have implications for other policy areas. The Committee shall co-operate with other international and regional organisations active in this policy field. It may consult with non-governmental bodies as and when necessary.

\section{Co-ordination of the OECD's Work on Education}

The Committee will develop a medium-term strategy for work in the field of education, review the global coherence of the overall programme of work of the Directorate for Education and evaluate this work at the strategic level.

For work delegated to its subsidiary bodies, it shall establish integrated mechanisms for the development of orientations, prioritisation and evaluation. It shall receive regular reports from them to ensure their co-ordination, policy integration, timeliness and evaluation.

\section{Duration}

This mandate shall enter into force on 1 January 2007 and shall expire on 31 December 2011, unless the Council decides otherwise." 


\section{GLOBAL FORUM ON EDUCATION ${ }^{1}$}

Chair:

Date of creation:

Duration:

Approved by:
No formally-appointed Chair

1st January 2009

31st December 2011

- Education Policy Committee, 27-28 November 2008 [EDU/EDPC/M(2008)3]

- Governing Board of the Centre for Educational Research and Innovation, 2425 November 2008 [EDU/CERI/CD/M(2008)5]

\section{Mission Statement:}

"The OECD Global Forum on Education aims to validate the relevance of OECD work in education from a global perspective through a regular co-operation with a community of designated participants and stakeholders, in particular by:

- Strengthening and expanding the existing expert and policy-level networks between OECD members and non-member economies;

- Discussing and sharing outcomes in areas dependant on interaction and peer learning with relevant non-members in order to satisfy the growing global demand for OECD expertise in education;

- Fostering a global policy dialogue in education to enhance the non-members's capacity to benefit from the OECD work, thus contributing to the reputation of the Organisation as a world leader in promoting education policies responsive to economic and social changes."

Members:

Designated Participants:
Open to all Member countries

Full Participants and regular observers (accession countries) to the EDPC and the CERI Governing Board, and enhanced engagement countries (Brazil, China, India, Indonesia and South Africa);

Albania, Argentina, Belarus, Bosnia and Herzegovina, Bulgaria, Cameroon, Croatia, Dominican Republic, Egypt, Georgia, Kazakhstan, Kyrgyzstan, Latvia, Lithuania, FYROM, Moldova, Montenegro, Oman, Pakistan, Romania, Serbia, Sri Lanka, Tajikistan, Trinidad and Tobago, Ukraine, Uzbekistan, the United Arab Emirates and Vietnam

International Organisations: UNESCO, UNICEF, the World Bank, Inter- American Development Bank, African Development Bank, Asian Development Bank, Regional Co-operation Council of South Eastern Europe, International Association of Universities, International Student Associations

\footnotetext{
${ }^{1}$ Information on this Global Forum is provided for the sake of completeness, but Global Forums are not, in accordance with C(2008)208/FINAL, official OECD bodies.
} 


\section{GROUP OF NATIONAL EXPERTS ON SPECIAL NEEDS EDUCATION}

Chair:

Members:

$\begin{array}{ll}\text { Observers: }^{1} & \text { Chile } \\ & \text { Estonia } \\ & \text { Israel }\end{array}$
(United Kingdom)

Mr. Nigel Gee

Open to all Member countries

Invited Organisations:

Date of creation:

Duration:
UN Children's Fund (UNICEF)

UN Educational Scientific and Cultural Organization (UNESCO) World Bank

World Health Organization (WHO)

1st January 2007

31st December 2011
People's Republic of China

Russian Federation

Slovenia

Mandate: - Summary Record of the 55th Session of the Governing Board of the Centre for Educational Research and Innovation [CERI/CD/M(97)1, Item 8, B)]

- Summary Record of the 74th Session of the Governing Board of the Centre for Education Research and Innovation [EDU/CERI/CD/M(2006)1] and Summary Record of the 77th Session of the Education Committee [EDU/EC/M(2006)1]

- Summary Record of the 78th Joint Session of Education Committee [EDU/EC/M(2006)2 and EDU/EC(2006)24/REV1]

- Renewal of the Mandates of Education Sub-Groups [C(2006)173/ANN2 and $\mathrm{C} / \mathrm{M}(2006) 20$, Item 265]

\section{Extract from document EDU/CERI/CD/M(2006)1}

"The Governing Board

Approved the proposal to transfer the activity on students with disabilities, learning difficulties and disadvantage to Part I under the auspices of the Education Committee"

\section{Extract from document EDU/EC/M(2006)1}

"The Education Committee

Agreed to complete the ranking exercise insofar as all countries should rank all activities under the aegis of the Education Committee including those for INES, special needs and the network on early childhood education and care"

\section{Extract of Document [C(2006)173/ANN2]}

\section{"MANDATE FOR THE GROUP OF NATIONAL EXPERTS ON SPECIAL NEEDS EDUCATION}

In support of the mandate of the Education Policy Committee, the Group of National Experts on Special Needs Education will undertake studies required for the development and implementation of policies related to the effective education of students with disabilities, learning difficulties and disadvantages in member and non-member economies. Its functions will cover, in particular, the following areas:

\footnotetext{
${ }^{1}$ China: pending acceptance letter.
} 
i) Discussion and advice concerning all policies relating to the effective education of these students and the development of necessary analytic instruments.

ii) Monitoring, inter alia, the numbers of these students, gender and age profiles, and developing significant policy relevant indicators across all ISCED levels, seeking to harmonise descriptions of students with disabilities, learning difficulties and disadvantages and improve data quality.

iii) Developing procedures to measure educationally related outcomes of these students, including working with the Programme for International Student Assessment (PISA) to develop comparative measures of academic performance with a view to understanding more fully the links between education and outcomes and determining costeffectiveness ratios.

iv) Developing standards for effective transition programmes for students with disabilities from school to work and tertiary education and from tertiary education to employment.

v) Working with non-members to develop data on students with disabilities leading to the development of policies and effective planning of services to achieve education for all.

vi) Working with governments and organisations and sectors to develop strategies and action plans for providing a range of services for students with disabilities to achieve education for all and monitoring their implementation.

\section{Membership}

The Group is open to OECD member countries, observers to the Education Policy Committee and other non-member economies, in line with the global relations strategy of the Committee and as approved by the OECD Council. The World Bank, World Health Organisation (WHO), UNESCO and UNICEF may also attend meetings of the Group.

The Group may recommend the participation of additional observers in its work to the Education Policy Committee which will submit these requests, if approved and as appropriate, to the competent OECD decision-making body.

\section{Working methods}

In pursuance of its aims, the Group will endeavour to identify strategic future directions for successive programmes of work from which to set clear, defined and costed output results for work in which OECD activity adds value.

The Group may recommend the creation of sub-groups, networks, expert groups or task forces to the Education Policy Committee, which will submit these requests, if approved and as appropriate, to the competent OECD decision-making body.

The Group shall provide regular reports to the Education Policy Committee for monitoring the progress, quality and timeliness of outputs.

\section{Relationship with other bodies}

The Group shall maintain close working relationships with other relevant bodies of the Organisation, in particular, the Employment, Labour and Social Affairs Committee and the Development Assistance Committee. The Group shall co-operate with other international and regional organisations active in this policy field. It may consult with non-governmental bodies as and when necessary.

\section{Evaluation}

An evaluation exercise will be conducted prior to the end of the mandate period by the Education Policy Committee. The extent and format of the evaluation will be decided by the Education Policy Committee. The evaluation will be conducted within the framework of the recommendations of the Council Evaluation Sub-Group.

\section{Duration}

This mandate shall enter into force on 1 January 2007 and shall expire on 31 December 2011, unless the Education Policy Committee decides to terminate it earlier. 


\section{NETWORK ON COMBATTING SCHOOL BULLYING AND VIOLENCE}

Chair:

Members:

$\begin{array}{ll}\text { Observers: }^{1} & \text { Chile } \\ & \text { Estonia } \\ & \text { Israel }\end{array}$

Date of creation:

Duration:
Slovak Republic

Open to all Member countries

\author{
People's Republic of China \\ Russian Federation \\ Slovenia
}

Mandate: - Summary Record of the 78th Joint Session of Education Committee [EDU/EC/M(2006)2 and EDU/EC(2006)24/REV1]

- Confirmation by the Executive Committee registered in the Summary Record of its 770th session [CE/M(2006)16, Item 107 and C(2006)173/ANN1]

- Summary Record of the 1st Session of the Education Policy Committee [EDU/EDPC/M(2007)1/FINAL]

\section{Extract of Document [EDU/EDPC/M(2007)1/FINAL]}

"The Education Policy Committee .... DECIDED that the 'Network on School Bullying and Violence' be renamed to the 'Network on Combatting School Bullying and Violence' ..."

\section{Extract of Document [C(2006)173/ANN1]}

\section{"MANDATE FOR THE NETWORK ON SCHOOL VIOLENCE AND BULLYING}

Mission

The Network supports the mandate of the Education Policy Committee to assist countries to develop effective and efficient policies for education and learning to meet individual, social, cultural and economic objectives. The Network aims to support countries seeking to combat school bullying and violence by:

- Sharing and disseminating information on experience, research and good practice in the field.

- Providing a platform for co-operation on particular issues, for example on the problems of implementation or evaluation.

- Facilitating contacts - for example, among practitioners in different countries, or between researchers, on the one hand, and policy-makers and practitioners on the other.

- Providing a point of linkage with other international networks working in related fields.

Membership

The Network is open to OECD member countries, observers to the Education Policy Committee and other non-member economies, in line with the global relations strategy of the Committee and as approved by the OECD Council.

\footnotetext{
${ }^{1}$ China: pending acceptance letter.
} 


\section{Working Methods}

The Network will be hosted by a member country who will appoint an international coordinator to actively engage, sustain and develop communication among a network of national coordinators.

The Network shall provide regular reports to the Education Policy Committee for monitoring the progress, quality and timeliness of outputs.

Evaluation

An evaluation exercise will be conducted prior to the end of the mandate period by the Education Policy Committee. The extent and format of the evaluation will be decided by the Education Policy Committee. The evaluation will be conducted within the framework of the recommendations of the Council Evaluation Sub-Group.

Duration

This mandate shall enter into force on 1 January 2007 and shall expire on 31 December 2011, unless the Education Policy Committee decides to terminate it earlier." 


\section{NETWORK ON EARLY CHILDHOOD EDUCATION AND CARE}

Chair:

Vice-Chairs:

Invited Organisations:

Members:

Observers:

Date of creation:

Duration:
Mr. Karl Le Quesne

Ms. Kari Jacobsen

Ms. Mugyeong Moon

Mr. Keisuke Otani

Ms. Luisa Ucha Silva

Mr. Frank Weldon
(New Zealand)

(Norway)

(Korea)

(Japan)

(Portugal)

(Canada)

Council of Europe

UN Educational Scientific and Cultural Organization (UNESCO)

Open to all Member countries

Chile

Estonia

Israel

\author{
Russian Federation \\ Slovenia \\ People's Republic of China
}

1st January 2007

31st December 2011

Mandate: - Summary Record of the 78th Joint Session of Education Committee [EDU/EC/M(2006)2 and EDU/EC(2006)24/REV1]

- Confirmation by the Executive Committee registered in the Summary Record of its 770th session [CE/M(2006)16, Item 107 and C(2006)173/ANN1]

\section{Extract of Document [C(2006)173/ANN1]}

"MANDATE FOR THE NETWORK ON EARLY CHILDHOOD EDUCATION AND CARE

Mission

The Network supports the mandate of the Education Policy Committee to assist countries to develop effective and efficient policies for education and learning to meet individual, social, cultural and economic objectives. The Network aims to support the development of effective and efficient approaches and good practice in the field of early childhood education and care (ECEC) policy in participating countries by:

Developing, sharing and disseminating information on experience, research and good practice of country experiences in the field.

Serving as a clearing house of new policy research in the field and identifying new areas for fruitful policy research and analysis.

Identifying data development needs and contributing to the development of methodology for developing such data.

Organising workshops on selected policy themes.

Facilitating contacts among researchers, policy-makers and practitioners and among other international networks in related fields. 
Membership

The Network is open to OECD member countries, observers to the Education Policy Committee and other non-member economies in line with the global relations strategy of the Committee as approved by the Council.

Working Methods

The Network will be hosted by a member country who will appoint an international coordinator to actively engage, sustain and develop communication among a network of national coordinators. The Network shall provide regular reports to the Education Policy Committee for monitoring the progress, quality and timeliness of outputs.

Evaluation

An evaluation exercise will be conducted prior to the end of the mandate period by the Education Policy Committee. The extent and format of the evaluation will be decided by the Education Policy Committee. The evaluation will be conducted within the framework of the recommendations of the Council Evaluation Sub-Group.

Duration

This mandate shall enter into force on 1 January 2007 and shall expire on 31 December 2011, unless the Education Policy Committee decides to terminate it earlier." 


\title{
BOARD OF PARTICIPATING COUNTRIES OF THE TEACHING AND LEARNING INTERNATIONAL SURVEY (TALIS)
}

\author{
Chair: \\ Ms. Anne-Berit Kavli \\ (Norway) \\ Members: \\ Open to all Member countries \\ Observers: \\ Estonia \\ Slovenia \\ Invited Organisation: \\ UN Educational Scientific and Cultural Organization (UNESCO) \\ Date of creation: \\ 1st January 2007 \\ Duration: \\ 31st December 2011
}

Mandate: - Summary Record of the 74th Session of the Governing Board of the Centre for Education Research and Innovation [EDU/CERI/CD/M(2006)1] and Summary Record of the 77th Session of the Education Committee [EDU/EC/M(2006)1]

- Summary Record of the 78th Session of the Education Committee [EDU/EC/M(2006)2 and EDU/EC(2006)24/REV1]

- Confirmation by the Executive Committee registered in the Summary Record of its 770th session [CE/M(2006)16, Item 107 and C(2006)173/ANN1]

- Summary Record of the Joint Session of the Education Policy Committee and the CERI Governing Board, Paris 25 April 2007 [EDU/EDPC/CERI(2007)1 and EDU/2007)5/REV1]

\section{Extract of Document [EDU/EDPC/CERI(2007)1]}

“... the Education Policy Committee ... DECIDED to rename the "Group of National Experts for the Teaching and Learning Survey" to the "Board of Participating Countries of the Teaching and Learning International Survey (TALIS)" and to amend the mandate as set out in $\operatorname{EDU}(2007) 5 / R E V 1 \ldots$.

\section{Extract of document [EDU/2007)5/REV1]}

\section{"MANDATE FOR THE BOARD OF PARTICIPATING COUNTRIES OF THE TEACHING AND LEARNING INTERNATIONAL SURVEY (TALIS)}

Mission

In support of the mandate of the Education Policy Committee, the Board of Participating Countries will manage the teaching and learning international survey.

Its functions will cover, in particular, the following areas:

- Work with the OECD Secretariat to ensure compliance with the policy objectives of the survey and establish the specific priorities for indicators, analysis and instrument development in each wave of the survey.

- Ensuring compliance with these design parameters at key milestones during the implementation of the project.

- Insofar as the survey implementation will be covered entirely by voluntary contributions and grants, drawing up the budget and recommending budgetary allocations for participants. 
- Operationalising the scope of the work to be covered by the main international contractor.

- Guiding the preparation of the reports and analysis of the survey results. Policy Committee.

The Board will bring policy advice, reports and analysis to the attention of the Education Membership

The Board is open to OECD member countries, observers to the Education Policy Committee and other non-member economies participating in the survey in line with the respective global relations strategies of the Education Policy Committee as approved by the OECD Council. UNESCO may also attend meetings of the Group as an observer.

The Group may recommend the participation of additional observers in its work to the Education Policy Committee, which will submit these requests, if approved and as appropriate, to the OECD Council.

Member governments and non-member economies should wherever possible appoint experts in teacher, teaching and learning policy and practice.

Working methods

The Board will devise appropriate working methods.

Decisions concerning the drawing up of the draft budget, the proposed budgetary allocation between the survey participants and the operationalisation of the scope of work will be made by survey participants within the framework of the overall programme of work and budget prepared by the Education Policy Committee.

With the agreement of the Education Policy Committee, the Group may organise meetings outside OECD Headquarters at the request of an OECD member country on the basis of a reasoned request from its Permanent Representative. The host country will accept responsibility for additional direct and indirect expenditures related to the meeting so that it is no more expensive for the Organisation than it would have been if held at OECD Headquarters.

The Group shall provide regular reports to the Education Policy Committee for monitoring the progress and quality of outputs.

Relationship with other bodies

The Group shall maintain close working relationships with other relevant bodies of the Organisation. The Group shall co-operate with other international and regional organisations active in this field. It may consult with non-governmental bodies as and when necessary.

Evaluation

An evaluation exercise will be conducted prior to the end of the mandate period by the Education Policy Committee to monitor the progress and quality of outputs. The extent and format of the evaluation will be decided by the Education Policy Committee. The evaluation will be conducted within the framework of the recommendations of the Council Evaluation Sub-Group.

Duration

This mandate shall enter into force immediately and shall expire on 31 December 2011, unless the Education Policy Committee decides otherwise." 


\section{GROUP OF NATIONAL EXPERTS ON THE EDUCATION OF MIGRANTS}

Chair:

Mr. Jan Levy

(Norway)

Vice-Chairs:

Ms. Breda Naughton

(Ireland)

Ms. Nadine Prost

(France)

Members:

Open to all Member countries

Observers: ${ }^{1}$

Chile

Estonia

Russian Federation

Israel

Slovenia

People's Republic of China

Date of creation:

27th April 2007

Duration:

31st December 2010

Mandate: - Summary record of the 1st session of the Education Policy Committee [EDU/EDPC/M(2007)1 and EDU/EDPC(2007)5 ]

- Confirmation by the Executive Committee registered in the Summary Record of its 788th session [CE/M(2007)16, Item 135 and CE(2007)12]

- Renewal of the mandate [EDU/EDPC/MI(2008)11]

\section{Extract of document [EDU/EDPC/M(2007)1]}

"The Education Policy Committee:

- AGREED to the establishment of a group of national experts..."

\section{Extract of document EDU/EDPC(2007)5}

“...the group of national experts on the education of migrants is a subsidiary body of the Education Policy Committee and is responsible for guiding work on the education of migrants. In particular it will:

- guide the methods, timing and principles of the thematic review on migrant education;

- allow OECD countries to share information and experience on this issue and to keep in touch with the emerging findings of the exercise."

\footnotetext{
${ }^{1}$ China: pending acceptance letter.
} 


\section{GROUP OF NATIONAL EXPERTS ON VOCATIONAL EDUCATION AND TRAINING}

Chair:

Members:

Observers: ${ }^{1}$

Date of creation:

Duration:
Mr. Philip Pedersen

Open to all Member countries

Chile

Estonia

Israel
(Denmark)

Russian Federation

Slovenia

People's Republic of China

26th April 2007

31st December 2010

Mandate: - Summary Record of the 76th Session of the Governing Board of the Centre for Educational Research and Innovation [EDU/CERI/CD/M(2007)1, Item 9 §40]

- Summary Record of the 1st Session of the Education Policy Committee [EDU/EDPC/M(2007)1, Item 10 §43]

- Confirmation by the Executive Committee registered in the Summary Record of its 792th session [CE/M(2008)2, Item 15 and CE(2008)1]

- Renewal of the mandate [EDU/EDPC/CERI(2008)16]

\section{Extract from document [EDU/EDPC/CERI(2007)2/ANN1]}

"The group of national experts on vocational education and training is a subsidiary body of CERI Governing Board and the Education Policy Committee, and is responsible for guiding the work on vocational education and training (VET) on behalf of the two parent committees, particularly the collaborative project on "Vocational Education and Training: Policy and Innovation".

In particular it will:

- guide the methods, timing and principles of the work;

- allow OECD countries to share information and experience on VET policy and policy innovations;

- keep OECD countries in touch with the emerging findings of the exercise."

\footnotetext{
${ }^{1}$ China: pending acceptance letter.
} 


\section{WORKING PARTY ON INDICATORS OF EDUCATIONAL SYSTEMS (INES) ${ }^{1}$}

Chair:

Vice-Chair:

Bureau Members:

Observers:

Invited Organisation:

Date of creation:

Duration:
Mr. Claude Sauvageot

Mr. Hiromi Sasai

Mr. Dan Andersson

Ms. Valena Plisko

Mr. Dick Takkenberg

Estonia

Israel

Russian Federation

Slovenia
(France)

(Japan)

(Sweden)

(United States)

(Netherlands)

UN Educational Scientific and Cultural Organization (UNESCO)

28th November 2007

31st December 2011

\section{Extract from document [EDU/EDPC(2007)35/ANN]}

"Mission

In support of the mandate of the Education Policy Committee, the INES Working Party will monitor, oversee and coordinate statistical work as well as the development of indicators and quantitative analyses needed to meet the requirements and priorities of the Education Policy Committee. The INES Working Party will be in charge of all statistical and indicators-related work except those areas that are managed by the Boards of Participating Countries listed below. More specifically, in developing its work programme the INES Working Party will:

- Work with the OECD Secretariat to ensure compliance with the policy objectives and design parameters of the respective data collection programmes as established by the Education Policy Committee.

- Manage the implementation of data collections necessary to support the consolidation and development of indicators, notably the UNESCO/OECD/EU data collection on education systems (in collaboration with UNESCO and Eurostat).

- Set priorities and standards for data development, analysis and reporting and, in particular, establish common data standards and methodologies and advice on all technical matters regarding indicator methodologies, and consolidate indicator methodologies and review proposals for new indicators in areas agreed by the Education Policy Committee.

- Assure the quality and timeliness of output results, activities and projects and assess data and indicator comparability and establish plans for achieving improvements through the expert groups where necessary.

\footnotetext{
${ }^{1}$ Replaces the INES National Co-ordinators and the INES Technical Group
} 
- Disseminate its policy advice, analysis, research and data to a wide range of stakeholders in member and non-member economies and, in particular, review indicator material in preparation for its publication in Education at a Glance and sign off on national data publications and the use of national data in Education at a Glance.

Membership

The Working Party is open to OECD member countries. Observers to the Education Policy Committee may be observers to the Working Party.

Other non-member economies may be invited as observers, in line with the global relations strategies of the Education Policy Committee as approved by the OECD Council. Invitations to and participation of non-Members in the work of the Working Party will be considered by the Education Policy Committee in accordance with Council Resolutions C(2004)132/FINAL and C(2006)78/FINAL.

UNESCO may also attend meetings of the Group as an observer.

Member governments and non-member economies should wherever possible appoint experts in the development and analysis of internationally comparable educational data and indicators.

Working methods

The Working Party will elect its chair and vice chairs, whose annual term of office may be renewed up to six times, and will devise appropriate working methods.

The Working Party may, within its agreed resource envelope as part of the PWB process, create sub-groups to assist it in its tasks.

The Working Party shall provide regular reports to the Education Policy Committee to allow the latter to monitor the progress, quality and timeliness of outputs.

Relationship with other bodies

The Working Party shall maintain close working relationships with other relevant bodies of the Organisation, in particular, the other education bodies, the Employment, Labour and Social Affairs Committee and the Group of National Experts on Science and Technology Indicators. The Working Party shall co-operate with other international and regional organisations active in this field. It may consult with non-governmental bodies as and when necessary.

Evaluation

An evaluation exercise will be conducted prior to the end of the mandate period by the Education Policy Committee. The extent and format of the evaluation will be decided by the Education Policy Committee. The evaluation will be conducted within the framework of the recommendations of the Council Evaluation Sub-Group.

Duration

This mandate shall remain in force until 31 December 2011, unless the Education Policy Committee decides otherwise." 


\section{INES NETWORK FOR THE COLLECTION AND THE ADJUDICATION OF SYSTEM-LEVEL DESCRIPTIVE INFORMATION ON EDUCATIONAL STRUCTURES, POLICIES AND PRACTICES}

Chair:

Participating Countries:

Date of creation:

Duration:
Mr. Stephen Leman

Australia

Austria

Belgium

Canada

Czech Republic

Denmark

Finland

Germany

Ireland

Japan

Korea
(United Kingdom)

Luxembourg

Netherlands

New Zealand

Norway

Spain

Sweden

Switzerland

United Kingdom

Russian Federation

Brazil

28th November 2008

31st December 2011

Mandate: Summary Record of the 4th Session of the Education Policy Committee

[EDU/EDPC/M(2008)3, Item 7 b), and EDU/EDPC(2008)23]

\section{Extract from documents [EDU/EDPC(2008)23]}

Mission:

In support of the mandate of the Education Policy Committee, and reporting to the INES Working Party, the INES Network on System Level Indicators should seek to deliver the systemlevel information on the functioning of education systems that are required by the Education Policy Committee (and other education bodies). More specifically, the INES Network on System Level Indicators will:

- In agreement with the INES Working Party, establish its Programme of Work to deliver the information requirements identified by the Education Policy Committee.

- Use the research and development capacity of the Network to explore relevant areas for indicator development in keeping with the wider education programme of work.

- Design data collection instruments and guidance that can deliver the information needs specified in agreement with the INES Working Party. These should be annual, cyclical or, on occasion, specific ad-hoc data collections that could become cyclical with further development. Data collections would be designed having regard to existing comparative information available from other sources and giving consideration to how variation in the data at the sub-national level should be handled in the data collection and presentation of the results.

- Operationalise the agreed data collections, putting in place quality assurance mechanisms and data cleaning procedures necessary to deliver internationally comparable data and indicators.

- Collate, review and summarise the results from the cross-country comparisons, identifying trends and patterns among countries.

The Network will operationalise a Programme of Work to develop internationally comparable indicators of system levels features, policies and practices which addresses the areas 
agreed with the INES Working Party. The Network will provide annual reports to the INES Working party to facilitate their managerial and technical oversight.

\section{Operationalising the Network's Programme of Work}

It is important to recognise the research and development function of the Network. The Programme of Work and the resourcing of the Network should therefore adequately reflect this.

Having regard to this research and development capacity, the Network will operationalise a Programme of Work to develop internationally comparable indicators of system levels features, policies and practices which addresses the areas agreed with the INES Working Party. The areas for which system level data and indicators should be developed may either be commissioned from other Education bodies (in particular the BPCs of TALIS and PIAAC and the PISA Governing Board but possibly also in support of other Education programme of work activities) or, equally they could be proposed by the Network itself in line with the overall programme of work and budget for education.

In either case, the INES Working Party would have the responsibility for agreeing that the proposed activities are in keeping with the agreed overall programme of work. In the case of commissions from other bodies, these should be channelled via the INES Working Party to ensure coherence with the other INES data collections and to prevent the Network's activities becoming overloaded.

The INES Working Party will have technical oversight of all of the Network's statistical and indicator-related work, from data specification, through data collection, data cleaning and analysis and reporting. The INES Working Party will therefore need to be satisfied that the methods and definitions are robust and coherent with other INES data. The Network will provide such reports to the INES Working Party that facilitate this technical oversight.

Coordination of the Network data collection

Depending on how the Network Secretariat work is organised, the Network data collection could either be managed and implemented by the Network Secretariat or by the OECD Secretariat. This would include preparing the annual questionnaires, distributing them to countries, data cleaning, and then preparing the data in presentable forms.

Organising this through the Network Secretariat would have the advantage of greater ownership among countries and has proved valuable in the past. On the other hand, if the OECD Secretariat took this role, this would assist in maintaining quality control and common standards across INES data collections. Given that the OECD Secretariat produces Education at a Glance, efficiency gains could also be realised with greater synergies between data collection, quality control procedures and the on-going development and production of Education at a Glance.

Under either scenario, the OECD Secretariat would also work with the Network Secretariat to ensure effective quality control procedures are implemented to continually improve the data collections of the Network.

The OECD Secretariat would also assist in the operations of the Network. This would include an active participation in Network meetings to assist the Network in the quality-control of existing and new data collections and in its liaisons with the INES Working Party.

Country participation

The success of INES has relied on active country participation and this will be true of the new Network also. Corresponding to the activities, scope and ways of working of the Network, it is envisaged that country participation in the Network would entail:

- completing the annual Network questionnaires in the required timeline;

- $\quad$ reviewing quality-control issues of the data collection for discussion within the Network;

- active participation at Network meetings that could include the contribution of occasional papers; 
- $\quad$ participation in specific sub-groups to help develop new system level indicators; and

- participation in pilot studies for new indicator development.

In return, participating countries will have their questionnaire data processed and indicators compiled for publication in Education at a Glance, subject to their review.

All OECD member countries may attend Network meetings but decisions concerning the operationalisation of the Network's activities and the expenditure of the budget will be made by those countries making voluntary contributions in support of the Network.

\section{Frequency of meetings}

The frequency of meetings would be decided by the Network. The INES Network $C$ has traditionally met on a biannual basis but the creation of the new Network provides an opportunity to review this, giving consideration to the cost-benefit of holding full meetings of the Network. A single two-and-a-half day meeting per year, probably in June would permit the Network to review the previous year's data collection and to prepare for the next data collection, giving sufficient time for the development of material for new indicators. A typical sequence might be:

- In keeping with the agreed programme of work, a proposal for a new indicator would be prepared for discussion at the meeting in June.

- Following these discussions, further work would be undertaken to prepare and undertake a pilot data collection.

- Drawing on the outcomes of the pilot, a revised proposal would be prepared for the next June meeting with intention of including it in the September data collection of that year.

In between the annual meetings, sub-groups of experts who are tasked to take forward the development work could either meet in person or communicate electronically, as necessary.

\section{Country representation}

Given the potential breadth of the issues that system-level indicators might cover, it will be difficult for countries to field a single expert capable of covering all of these. Instead, what could be envisaged is each country nominating a permanent representative of the Network who could act as coordinator for the Network for their country as well as bringing their own area of expertise to the group. It would be their responsibility to identify appropriate national experts to help in the data and indicator development at the national and international level, according to the Network's Programme of Work. Such experts could attend the Network meetings as required by the agendas of the meetings. 


\section{INES NETWORK FOR DATA DEVELOPMENT ON LABOUR MARKET AND SOCIAL OUTCOMES OF EDUCATION}

Chair:

Participating Countries:

Date of creation:

Duration:
Mr. Patrice de Broucker

Australia

Austria

Belgium

Canada

Czech Republic

Denmark

Finland

France

Germany

Greece

Ireland

Korea
(Canada)

Luxembourg

Netherlands

New Zealand

Norway

Spain

Sweden

Switzerland

United Kingdom

United States

Russian Federation

Brazil

28th November 2008

31st December 2011

Mandate: Summary Record of the 4th Session of the Education Policy Committee [EDU/EDPC/M(2008)3, Item 7 b), and EDU/EDPC(2008)23]

\section{Extract from documents [EDU/EDPC(2008)23]}

Mission:

In support of the mandate of the Education Policy Committee, and reporting to the INES Working Party, the INES Network on labour market and social outcomes of education should develop and deliver information on labour market and social outcomes of education that are required by the Education Policy Committee. More specifically, the INES Network on labour-market and social outcomes will:

- In agreement with the INES Working Party, establish its Programme of Work to deliver the information requirements identified by the Education Policy Committee.

- Monitoring existing data collections by ensuring reliability and integrity of the data collected. Develop new data collections and improve upon existing data collections to enhance the quality and policy relevance of the networks data gathering efforts. These should be annual, cyclical or, on occasion, specific ad-hoc data collections that could become annual collections with further development.

- Conduct research and feasibility studies for potential new data collections and perform pilot studies and design data collection instruments that can deliver the information needs specified in agreement with the INES Working Party. Operationalise agreed data collections, putting in place quality assurance mechanisms and data cleaning procedures necessary to deliver internationally comparable data and indicators.

- Collate, review, analyse, and summarise the results from the cross-country comparisons, identifying trends and patterns among countries. Based on this analytical work, suggest specific indicators for inclusion in Education at a Glance and occasionally write more substantive reports on certain policy relevant topics within the Network's domain. 
- Support developments related to the Programme for International Assessment of Adult Competencies (PIAAC), assist PIAAC through the Network's own data collections, and support PIAAC by providing input to the analytical work of the data collected in this survey.

\section{Operationalising the Network's Programme of Work}

It is important to recognise the research and development function of the Network and the large scale nature of the Network's data collections. The Programme of Work and the resourcing of the Network should therefore adequately reflect this.

Having regard to this research and development capacity, the Network will compose a Programme of Work to develop internationally comparable indicators on labour market and social outcomes which addresses the areas agreed with the INES Working Party. The areas for which research and indicators should be developed may either be proposed by INES Working Party, by other Education bodies (most notably the PIAAC Board of Participating Countries and CERI Governing Board) or, equally they could be proposed by the Network itself.

The INES Working Party will have technical oversight over all of the Network's statistical and indicator-related work. The INES Working Party will therefore need to be satisfied that the methods and definitions are robust and coherent with other INES data. The Network will provide such reports to the INES Working Party that facilitate this technical oversight.

\section{Coordination of the Network's data collections}

The current vehicles for supplying Education at a Glance with information are the NEAC (National Education Attainment Classification) data collection which provides data on attainment levels and labour market outcome indicators, the TRANS data collection which provides information to the youth transition indicator and the earnings data collections which supply data to the economic outcomes indicators. These data collections provide data to Education at a Glance on an annual basis. The NEAC and TRANS data collections are currently managed through the OECD secretariat and the earnings data collection is managed by Statistics Sweden and financed by Swedish funds through the Network B secretariat. Under the new proposal of the Working Party, these annual data collections will be funded through the core INES work programme.

Data collections on adult learning are generally conducted with longer time intervals. The Network frequently engages in policy relevant one-off data collections. The more ad hoc data collections are foreseen to continue to be an important component in the Network's future work as it provides a good testing ground for collections that could become annual collections with further development. The common denominator of the Network's data collections are the basic source of the information, the national labour or household surveys.

Depending on how the Network Secretariat work is organised, the Network's data collection could either be managed and implemented by the Network Secretariat, by an external contractor or by the OECD Secretariat. This would include preparing the annual questionnaires, distributing them to countries, data cleaning, and then preparing the data in presentable forms.

Organising this through the Network Secretariat would have the advantage of greater ownership among countries and has proved valuable in the past. On the other hand, if the OECD Secretariat took this role, this would assist in maintaining quality control and common standards across INES data collections. Given that the OECD Secretariat produces Education at a Glance, efficiency gains could also be realised with greater synergies between data collection, quality control procedures and the on-going development and production of Education at a Glance.

There might also be a middle way in which certain data collections are managed by the OECD Secretariat and other data collections by the Network Secretariat as is currently the case. A potential division of labour that could prove efficient would be to manage the more established annual data collections through the OECD Secretariat and less frequent, ad-hoc, and data collections on a more developmental stage through the Network Secretariat. Under either scenarios, the OECD Secretariat would also work with the Network Secretariat to ensure effective quality control procedures are implemented to continually improve the data collections of the Network. 
The OECD Secretariat would also assist in the operations of the Network. This would include an active participation in Network meetings, providing input to new developments and analyses, assisting the Network in the quality-control of existing and new data collections and in its liaisons with the INES Working Party.

\section{Country participation}

The success of INES has relied on active country participation and this is a key to the success in the future. It is thus important that individuals in the Network both have knowledge of national data sources and an interest and engagement in the Network's work. The INES Network B has traditionally met twice a year with discussions on developmental work in the spring and discussions on implementation of surveys and long-term strategies in the autumn. Corresponding to the activities, scope and ways of working of the Network, it is envisaged that country participation in the Network would entail:

- completing the annual Network questionnaires in the required timeline;

- reviewing quality-control issues of the data collection for discussion within the Network;

- active participation at Network meetings that could include the contribution of occasional papers;

- $\quad$ participation in specific working groups to help develop new indicators; and

- participation in cyclical and ad-hoc questionnaires, and pilot studies for new indicator development.

In return, participating countries will have their questionnaire data processed and indicators compiled for publication in Education at a Glance, subject to their review.

All OECD member countries may attend Network meetings but decisions concerning the operationalisation of the Network's activities and the expenditure of the budget will be made by those countries making voluntary contributions in support of the Network.

Membership

The Network is open to all OECD member countries.

Observers to the Education Policy Committee may be observers to the Network. UNESCO may also attend meetings of the Network as an observer. The Network may recommend the participation of additional observers in its work, in line with the respective global relations strategies of the Education Policy Committee as approved by the OECD Council, via the INES Working Party to the Education Policy Committee, which will submit these requests, if approved and as appropriate, to the OECD Council. 


\section{INES ADVISORY GROUP $^{1}$}

Chair:

Members:

Date of creation:

Duration:
Ms. Anne-Berit Kavli

TALIS Board of participating Countries

\begin{tabular}{|c|c|}
\hline Ms. Satya Brink & (Canada) \\
\hline PIAAC Board of Partici & ies \\
\hline Mr. Keray Henke & (Canada) \\
\hline Education Policy Comn & \\
\hline Ms. Frances Kelly & (New Zealand) \\
\hline Education Policy Comn & \\
\hline Mr. Reijo Laukkanen & (Finland) \\
\hline CERI Governing Board & \\
\hline Mr. Hans-Åke Öström & (Sweden) \\
\hline Education Policy Comn & \\
\hline Ms. Pavla Polechova & (Czech Republic) \\
\hline Mr. Claude Sauvageot & (France) \\
\hline INES Working Party & \\
\hline Mr. Paolo Sestito & (Italy) \\
\hline PIAAC Board of Partici & ries \\
\hline Mr. Marcel Smits Van & (Netherlands) \\
\hline Education Policy Comn & \\
\hline Mr. J.C.G. van Steen & (Netherlands) \\
\hline $\begin{array}{l}\text { Working Party of Natio } \\
\text { Indicators (NESTI) }\end{array}$ & n Science and Technology \\
\hline $\begin{array}{l}\text { Mr. Ryo Watanabe } \\
\text { PISA Governing Board }\end{array}$ & (Japan) \\
\hline
\end{tabular}

28th November 2007

31st December 2011
(Norway)

(Canada)

(Canada)

(New Zealand)

(Finland)

(Sweden)

(Czech Republic)

(France)

ries

Mandate: - Summary Record of the 2nd Session of the Education Policy Committee [EDU/EDPC/M(2007)2, Item 6, para. 20 and EDU/EDPC(2007)35/ANN]

- Confirmation by the Executive Committee registered in the Summary Record of its 794th session [CE/M(2008)4, Item 27 and CE(2008)2]

\section{Extract from document [EDU/EDPC(2007)35/ANN]}

“Task

Within the framework of the priorities set for the development of statistics by the OECD Council and the strategic priorities set by the Education Policy Committee, the INES Advisory Group will advise the Education Policy Committee on work on OECD data and indicators of education with a view to informing and assisting its decision-making processes in this field.

The Group will prepare the deliberations of the Education Policy Committee on INES. Specific responsibilities of the Group include: monitoring the outputs, structures and working arrangements of INES as a basis for the formulation of advice to ensure that the INES programme of work is well managed and effectively prioritised within the resources available; providing advice to the Education Policy Committee with respect to the acceptability of proposals advanced by the

\footnotetext{
${ }^{1}$ Replaces the INES Strategic Management Group
} 
INES Working Party and Boards of Participating Countries; and providing means of horizontal coordination of the INES-related work between the INES bodies and other education bodies.

Membership

The Advisory Board will be composed of:

- Four members designated by the Education Policy Committee from among its members, for a period of two years, renewable up to three terms,

- Two members designated by the CERI Governing Board from among its members, for a period of two years, renewable up to three terms

- One member designated by the Employment, Labour and Social Affairs Committee from among its members,

- One member designated by the PISA Governing Board from among its members and one by each of the Boards of Participating Countries for large education surveys from among their members,

- One member designated by the Working Party of National Experts on Science and Technology Indicators (NESTI), and

- One member designated by the INES Working Party.

Delegates to the Education Policy Committee may attend meetings of the Advisory Group.

The Group may invite experts to its meetings to give advice on technical matters.

Working methods

The Education Policy Committee will devise appropriate working methods for the Group, which shall provide regular reports to the Education Policy Committee, the CERI Governing Board and the PISA Governing Board.

Relationship with other bodies

The Group shall maintain close working relationships with other relevant bodies of the Organisation, in particular, the Employment, Labour and Social Affairs Committee and the Group of National Experts on Science and Technology Indicators. They will ensure that appropriate linkages are made between the indicators and data programme of work of the Education Policy Committee and the Programme for International Student Assessment (PISA).

Evaluation

An evaluation exercise will be conducted prior to the end of the mandate period by the Education Policy Committee. The extent and format of the evaluation will be decided by the Education Policy Committee. The evaluation will be conducted within the framework of the recommendations of the Council Evaluation Sub-Group.

Duration

This mandate shall remain in force until 31 December 2011, unless the Education Policy Committee decides otherwise." 

Co-Chairs:
Ms. Satya Brink
(Canada)
Mr. Paolo Sestito
(Italy)

Members:

Participation in PIAAC is open to Member countries. Invitations to and participation of non-Members in the work of PIAAC will be considered by the Board of Participating Countries in accordance with Council Resolutions C(2004)132/FINAL and C(2006)78/FINAL.

OECD Members:

Australia
Austria
Belgium
Canada
Czech Republic
Denmark
Finland
France
Germany
Hungary
Ireland
Italy
Japan

Korea

Netherlands

New Zealand

Norway

Poland

Portugal

Slovak Republic

Spain

Sweden

United Kingdom

United States

European Commission

Full Participants: Estonia

Slovenia

Ad hoc Observer: ${ }^{1}$

Chile

Date of creation:

1st January 2008

Duration:

31st December 2011

Mandate: - Draft summary record of the Joint Session of the Education Policy Committee and CERI Governing Board [EDU/EDPC/CERI/M(2007)1 and COM/DELSA/EDU(2007)1]

- Resolution of the Council concerning the creation of the Programme for the International Assessment of Adult Competencies (PIAAC) [C(2007)62/REV3] approved by the Council on 12 July 2007 at its 1158th session [C/M(2007)11, Item 135]

\section{Extract from document [C(2007)62/REV3]}

RESOLUTION OF THE COUNCIL CONCERNING THE CREATION OF THE PROGRAMME FOR THE INTERNATIONAL ASSESSMENT OF ADULT COMPETENCIES (PIAAC)

"THE COUNCIL,

Having regard to the Convention on the Organisation for Economic Co-operation and Development of 14 December 1960, and, in particular, Articles 5 a), 9 and 12 thereof;

Having regard to the Rules of Procedure of the Organisation;

Having regard to the Financial Regulations and the Financial Rules of the Organisation;

\footnotetext{
${ }^{1}$ Waiting approval on full partcipation.
} 
Having regard to the Resolution of the Council concerning the participation of nonMembers in the work of subsidiary bodies of the Organisation [C(2004)/132/FINAL] and the Resolution of the Council Concerning Fees for Non-Member Participation in Subsidiary Bodies of the Organisation [C(1996)223/REV3/FINAL];

Having regard to the Resolution of the Council on a New Governance Structure for the Organisation [C(2006)78/FINAL];

Having regard to the Main Principles Guiding the Governance Structure of the OECD Education Bodies [EDU(2006)8/ANN3/REV1], in particular, relative to the global coherence of OECD work on education, and the mandates of the other education bodies;

Having regard to the mandate of the Employment, Labour and Social Affairs Committee and the Education Policy Committee;

Having regard to the proposals set out in the Note by the Secretary-General concerning the creation of a Part II Programme and a Board of Participating Counties for the Programme for the International Assessment of Adult Competencies (PIAAC) [C(2007)62/REV3];

\section{DECIDES:}

The Programme for the International Assessment of Adult Competencies (PIAAC) is hereby created with the following mandate:

\section{Mission}

The Council shall, for the period of 1 January 2008 to 31 December 2011, create a Programme for the International Assessment of Adult Competencies (PIAAC). The work of PIAAC reflects and complements the priorities of the OECD as a whole, in improving living standards and promoting sustainable development and social cohesion through good governance. It contributes to fulfilling the Directorate for Education and the Directorate for Employment, Labour and Social Affairs missions of facilitating high-quality lifelong learning for all that contributes to personal development and sustainable economic growth, as well as fostering the conditions leading to more and better jobs and a more socially inclusive society. It is carried out within the framework of the Main Principles Guiding the Governance Structure of the OECD Education Bodies [EDU(2006)8/ANN3/REV1], and with due regard to the mandates of the other education bodies and the mandate of the Employment, Labour and Social Affairs Committee.

A multi-cycle programme of assessment, PIAAC will survey a representative sample of the adult population in each participating country in the assessment in a household context, in order to assess key competencies and their utilisation in the work place. The assessment will focus on literacy, which previous national and international assessments have shown to be essential for participation in modern societies, as well as on other generic work skills. PIAAC will extend the traditional concept of literacy by adapting it to competency requirements in the information age and will also break new ground by assessing other key generic skills required in the workplace. PIAAC will also survey other important social and labour-market outcomes and collect contextual data with the aim of facilitating policy-relevant analyses. The objectives of PIAAC are four-fold:

Identify and measure differences between individuals and across countries in key competencies believed to both underlie personal success and respond to labour market requirements.

- Assess the impact of competencies on a range of economic and social outcomes.

Assess the performance of education and training systems, workplace practices as well as labour market policies, in generating competencies at the levels required by social and economic demands.

- Help identify policy levers to reduce "deficiencies" in key competencies. 
Participation in PIAAC is open to Member countries. Invitations to and participation of non-Members in the work of PIAAC will be considered by the Board of Participating Countries in accordance with Council Resolutions C(2004)132/FINAL and C(2006)78/FINAL.

\section{Board of Participating Countries}

In support of the mandates of the Education Policy Committee and the Employment, Labour and Social Affairs Committee, the Board of Participating Countries shall oversee PIAAC. The Board of Participating Countries shall, in particular:

Recommend the policy priorities for PIAAC to the Education Policy Committee and the Employment, Labour and Social Affairs Committee and oversee adherence to these priorities during implementation. This includes the setting of priorities and standards for data development, analysis and reporting as well as the determination of the scope of work that will then form the basis for the implementation of PIAAC.

- $\quad$ Develop a draft work programme and budget and cost elements of a scale of contributions.

- $\quad$ Prioritise its activities and outputs in consultation with the Employment, Labour and Social Affairs Committee and the Education Policy Committee.

- $\quad$ Monitor the quality and timeliness of output results, activities and projects.

- $\quad$ Disseminate policy advice, analysis, research and data to a wide range of stakeholders in Member and non-Member countries.

Evaluate the outcomes of the work.

The Board is open to countries participating in the assessment. The European Commission shall participate in accordance with the provisions of Article 13 of the Convention and Supplementary Protocol No. 1 to the Convention. The International Labour Office, the World Bank and UNESCO may attend meetings of the Board as observers. Representatives of the Business and Industry Advisory Committee (BIAC) and the Trade Union Advisory Committee (TUAC) may attend meetings of the Board as experts.

Governments should, whenever possible, appoint representatives to the Board of Participating Countries who are knowledgeable about large-scale survey assessments and their interface with educational and employment policy and practice.

The Board of Participating Countries may organise its meetings outside OECD Headquarters on the basis of a reasoned request from a Permanent Representative on behalf of a member of the Board. The host will accept responsibility for additional direct and indirect expenditures related to the meeting so that it is no more expensive for the Organisation that it would have been if held at OECD Headquarters.

Working methods and relationship with the Education Policy Committee and the Employment, Labour and Social Affairs Committee

The Board of Participating Countries will seek strategic guidance on policy priorities, the programme of work and budget from the Education Policy Committee and the Employment, Labour and Social Affairs Committee.

The Board shall provide regular reports to the Education Policy Committee and the Employment, Labour and Social Affairs Committee on the implementation of its programme of work.

All decisions relating to the modalities for the participation in the assessment exercise, the operations of the Board of Participating Countries, the elements to be included in calculating the floor contribution for the scale of contributions, changes to project design and structure as well as the frequency of successive PIAAC surveys will be adopted by consensus of the members of the Board of Participating Countries. For other decisions, not specifically provided for in this mandate, 
the Board will tailor its working methods to its own needs, as provided by Council Resolution C(2006)78/FINAL.

Budget of the Programme

The programme of work, scale of contributions and budget of the Programme shall be agreed by the Budget Committee before transmission to Council for final approval.

The expenditure of the Programme shall be charged against the appropriations authorised for it under a Part II Chapter of the Budget of the Organisation.

The scale of contributions will be composed of a floor contribution, to be determined by the Board of Participating Countries, which is the minimum contribution for participating countries and represents the operational international cost of country participation, and other costs that will be assigned to participating countries on the basis of the OECD Part I scale of contributions.

In order to allow participating countries to contribute stable amounts for PIAAC over successive years, appropriations, for which no commitment has been entered into before the end of the Financial Year for which they were appropriated shall be automatically carried forward to the budget for the ensuing year by decision of the Secretary-General, notwithstanding the provisions of Articles 14 and 15 of the Financial Regulations of the Organisation.

\section{Relationship with other bodies}

The Board of Participating Countries shall also maintain close working relationships with other relevant bodies of the Organisation working on issues related to assessment, educational, training and employment outcomes, as well productivity and economic growth, in particular the Governing Board of the Centre for Educational Research and Innovation and the Committee for Industry, Innovation and Entrepreneurship. The Board of Participating Countries shall co-operate with other international and regional organisations active in its field of competencies. It may consult with non-governmental bodies after receiving advice from the Education Policy Committee and the Employment, Labour and Social Affairs Committee.

\section{Evaluation}

As part of the OECD in-depth evaluation process, an evaluation exercise will be conducted prior to the end of the mandate period by the Education Policy Committee and the Employment, Labour and Social Affairs Committee.

Duration

This mandate shall enter into force on 1 January 2008 and shall expire on 31 December 2011, unless the Council decides otherwise." 


\section{GROUP OF NATIONAL EXPERTS ON THE AHELO FEASIBILITY STUDY (AHELO GNE)}

Chair:

Mr. Jan Levy

(Norway)

Vice-Chair:

Professor Fiorella Kostoris

(Italy)

Date of creation:

18th July 2008

Duration:

31st December 2011

Mandate: - [EDU/IMHE/GB(2008)8] approved under written procedure

- [CE(2008)17]

\section{Extract from document [EDU/IMHE/GB(2008)8]}

“Objectives

The group of national experts on the AHELO (assessment of higher education learning outcomes) feasibility study is a subsidiary body of the IMHE Governing Board and is responsible for guiding work on the AHELO feasibility study. In particular it will:

- Guide the methods, timing and principles of the AHELO feasibility study; and

- Allow OECD countries to share information and experience on this issue and to keep in touch with the emerging findings of the exercise.

Scope

The group shall undertake its mission in the context of the OECD Directorate for Education's Output Area 2.1.3 "Higher Education" and Output Result "Feasibility Study for the Assessment of Higher Education Learning Outcomes (AHELO)". The Group shall be open to all member countries as well as regular observers to the IMHE Governing Board." 


\section{CENTRE FOR EFFECTIVE LEARNING ENVIRONMENTS BOARD OF PARTICIPANTS ${ }^{1}$}

Chair:

Vice-Chairs:

Members:

Date of creation:

Duration:
Mr. Eduardo Bravo Esqueda

Mr. Abdussamet Arslan

Mr. José M. R. Freire da Silva

Austria

Greece

Hungary

Iceland

Ireland

Korea

Mexico
(Mexico)

(Turkey)

(Portugal)

New Zealand

Portugal

Slovak Republic

Spain

Turkey

United Kingdom

1st January 2009

31st December 2011

Mandate: Resolution of the Council approved at its 1187th session held on 15 January 2009, [C(2008)204 and C/M(2009)1, item 6].

\section{Resolution of the Council [C(2008)204 and C/M(2009)1, item 6]}

"THE COUNCIL,

Having regard to the Convention on the Organisation for Economic Co-operation and Development of 14 December 1960, and, in particular, Articles 5 a), 9 and 12 thereof;

Having regard to the Rules of Procedure of the Organisation;

Having regard to the Financial Regulations of the Organisation;

Having regard to the Decision of the Council of 12 July 1984 on Management of Activities in the Field of Educational Building [C(84)61(Final)], now referred to as the Programme on Education Building (PEB), as last renewed by Council on 14 December 2006 [C(2006)173 and $\mathrm{C} / \mathrm{M}(2006) 20$, Item 265];

Having regard to the mandates of other governing bodies in the field of Education, in particular of the Education Policy Committee, and to the Main Principles Guiding the Governance Structure of the OECD Education Bodies [EDU(2006)8/ANN3/REV1];

Having regard to the Proposal to transform the Programme on Educational Building (PEB) into a Centre for Effective Learning Environments (CELE) [C(2008)204];

Considering that members and associate members participating in the Programme on Educational Building have agreed to pursue their co-operation;

DECIDES:

The Programme on Educational Building (PEB) is transformed into the Centre for Effective Learning Environments (hereinafter "the CELE") with the following mandate:

Mission

The CELE will assist its members to improve the educational and operational effectiveness of educational infrastructure, for all education levels and programmes. Specifically, it

\footnotetext{
${ }^{1}$ This body replaces the Programme for Educational Facilities Governing Board.
} 
seeks to inform and advise countries on how to maximise the benefit of their investment in educational facilities and equipment through effective planning, design, construction, management and evaluation.

Participation

Participation in CELE is open to Member countries and non-Member economies, as recommended by its Board of Participants. In addition, government agencies, sub-national authorities, research agencies, non-government organisations and professional associations with an interest in educational facility issues are eligible to join CELE as Associate Participants.

\section{Budget of CELE}

The expenditure of CELE shall be charged against the appropriations authorised for it under a Part II Chapter of the Budget of the Organisation.

Notwithstanding the provisions of Regulation 10 of the Financial Regulations of the Organisation, appropriations, for which no commitment has been entered into before the end of the Financial Year for which they were appropriated, and surplus income shall be automatically carried forward to the budget for the ensuing year by decision of the Secretary General.

Board of Participants

In support of the mandate of the Education Policy Committee (EDPC) and as a subsidiary body to that Committee, the Board of Participants (BP) shall be concerned with all matters in the field of competence of CELE.

Associate Participants may take part in the Board of Participants as observers in accordance with criteria established by the BP.

The BP:

- Develops and approves CELE's draft programme of work, scale of contributions and budget, taking into account the Directorate for Education's medium-term strategy;

- Prioritises its activities and outputs in consultation with other governing and subsidiary Education bodies;

- Monitors the quality and timeliness of output results, activities and projects;

- Disseminates its policy advice, analysis, research and data to a wide range of stakeholders in Member countries and non-Member economies;

- Evaluates the outcomes of the work;

- Seeks the guidance of relevant governing and subsidiary Education bodies, and the approval of the EDPC, for recommendations with major policy implications and for decisions to launch major new activities with significant financial implications for OECD Members.

Working methods budget from the EDPC.

The BP will seek strategic guidance on policy priorities, the programme of work and

The BP shall report to the EDPC.

Relationship with other bodies

In line with the OECD Horizontal Work Programme, the BP shall maintain close working relationships with other bodies in the Organisation working on issues relevant to its work. The BP shall co-operate with bodies outside the OECD, when necessary.

Duration

This Resolution shall enter into force on 1 January 2009 and shall expire on 31 December 2011." 


\section{GROUP OF NATIONAL EXPERTS ON EDUCATION FACILITIES EVALUATION}

Date of creation:

19th November 2007

Duration:

31st December 2011

Mandate: - CE(2008)7 and CE/M(2008)7, item 44

- Resolution of the Council approved at its 1187 th session held on 15 January 2009, [C/M(2009)1/PROV, item 6 and [C(2008)204].

\section{Extract from document [CE(2008)7]}

"Mission

The mission of the Group shall be to carry out activities aimed at maximising the responsiveness of the physical learning environment to the changing needs and demands of the knowledge economy, of which users of educational facilities play a central role. Its mission shall be guided by the PEB Organising Framework on Evaluating Quality in Educational Facilities, which explores the important role of quality facilities in increasing access and equity for all in education, improving educational effectiveness and promoting acquisition of key competencies, and optimising building performance and operation." 

Chair:

Bureau Members:

Members: ${ }^{1}$

Date of creation:

Duration:
Ms. Frances Kelly

Ms. Anneke Boot

Mr. Gabor Halász

Mr. Teiichi Sato

Mr. Joern Skovsgaard

Mr. Jerzy Wisniewski

...

$\ldots$

Ms. Oon Ying Chin

Ms. Elsa Hackl

Ms. Martine Herphelin

Ms. Micheline Scheys

Ms. Satya Brink

Ms. Pavla Polechova

Mr. Joern Skovsgaard

Mr. Gordon Clark

Mr. Reijo Laukkanen

Mr. Claude Sauvageot

Mr. Rupert Deppe

Mr. Panagiotis Kazantzis

Mr. Gabor Halász

Mr. Sigurjón Mýrdal

Ms. Luisa Ribolzi

Mr. Teiichi Sato

Mr. Dong-Seop Jin

Mr. Michel Lanners

Mr. Miguel Szekely Pardo

Ms. Anneke Boot

Ms. Frances Kelly

Mr. Petter Skarheim

Mr. Jerzy Wisniewski

Mr. Bártolo Paiva Campos

Mr. Peter Plavçan

Mr. Eduardo Coba Arango

Ms. Kerstin Mattsson

Mr. Stefan C. Wolter

Mr. Ibrahim Ozdemir

Mr. Richard Bartholomew

Ms. Lynn Okagaki
(New Zealand)

(Netherlands)

(Hungary)

(Japan)

(Denmark)

(Poland)

(Germany)

(Ireland)

(Canada)

(Australia)

(Austria)

(Belgium)

(Belgium)

(Canada)

(Czech Republic)

(Denmark)

(European Commission)

(Finland)

(France)

(Germany)

(Greece)

(Hungary)

(Iceland)

(Italy)

(Japan)

(Korea)

(Luxembourg)

(Mexico)

(Netherlands)

(New Zealand)

(Norway)

(Poland)

(Portugal)

(Slovak Republic)

(Spain)

(Sweden)

(Switzerland)

(Turkey)

(United Kingdom)

(United States)

28th July 1967

31st December 2011

Mandate: Resolution of the Council approved at its 1146th session held on 14 December 2006 [C/M(2006)20, item 265 and C(2006)173]

\footnotetext{
${ }^{1}$ The European Commission participates by virtue of the Supplementary Protocol No.1 to the Convention on the OECD
} 

EDUCATIONAL RESEARCH AND INNOVATION

\section{"THE COUNCIL,}

Having regard to the Convention on the Organisation for Economic Co-operation and Development of 14 December 1960, and, in particular, Articles 2b), 5a), 9 and 12 thereof;

Having regard to the Rules of Procedure of the Organisation;

Having regard to the Financial Regulations and the Financial Rules of the Organisation;

Having regard to the Decision of the Council of 24 July 1981 concerning a Programme on Educational Research and innovation [C(81)53(Final)] as last renewed by Council on 26 July 2001 [C/M(2001)16/FINAL];

Having regard to the proposals set out in the Note by the Secretary-General concerning the renewal of the mandates of the Education Policy Committee, the Centre for Educational Research and Innovation (CERI), the Programme on Institutional Management of Higher Education (IMHE), the Programme on Educational Building (PEB) and the Programme on International Student Assessment (PISA) [C(2006)173];

DECIDES: following mandate:

The Centre for Educational Research and Innovation is hereby renewed with the Mission

The Council shall, for a period of five years as from 1st January 2007, renew the mandate of the Centre for Educational Research and Innovation (hereinafter referred to as "the Centre") within the framework of the OECD programme of work and budget. The work of the Centre reflects and complements the priorities of OECD member countries as a whole in providing education and training opportunities for all. It contributes to fulfilling the Directorate for Education's mission of assisting members and partner countries to achieve high quality lifelong learning for all that contributes to personal development, sustainable economic growth and social cohesion. It is carried out within the framework of the Main Principles Guiding the Governance Structure of the OECD Education Bodies [EDU(2006)8/ANN3/REV1] and with due regard to the mandates of the other education bodies.

The main objectives of the Centre shall be to:

- Provide and promote international comparative research, innovation and key indicators on current and emerging education and learning issues, and their links to other sectors of policy.

- Explore forward-looking and coherent approaches to education and learning in the context of national and international cultural, social and economic change.

- Facilitate practical co-operation among member countries and, where relevant, with non-member economies, in order to seek solutions and exchange views on educational problems of common interest.

Membership

Participation in CERI will be open to all OECD member countries. Non-member economies may become full participants or regular observers if recommended by the Governing Board in the framework of its global relations strategy and approved by the OECD Council.

The Governing Board of the Centre

The Governing Board shall be concerned with all matters in the field of competence of the Centre including those of any subsidiary bodies. Having regard to the mandate of the Education 
Policy Committee and the Main Principles Guiding the Governance Structure of the OECD Education Bodies, the Governing Board:

- Develops its work programme and budget taking into account the medium-term strategy developed by the Education Policy Committee.

- Prioritises its activities and outputs in consultation with the Education Policy Committee.

- Monitors the quality and timeliness of output results, activities and projects.

- Disseminates its policy advice and analysis, research and data to a wide range of stakeholders in member and non-member economies.

- Evaluates the outcomes of the Centre's work.

- Seeks the guidance of the Education Policy Committee for recommendations with major policy implications and for decisions to launch major new activities with significant financial implications for OECD members.

The Governing Board shall be composed of one national expert in the field of competence of the Centre from each of the Centre's participants. Experts shall be proposed by the participants, and should have senior standing and expertise in the field of educational research or innovation, with appropriate policy links. The Secretary General shall forward proposals for membership of the Governing Board to the Council for approval. The Council shall appoint the members for the duration of the Governing Board mandate or until the participant proposes an alternative expert for nomination in accordance with the foregoing procedure.

Participants in which the competence on education matters are shared between different levels of authority, may propose one additional national expert. These nominations will be reviewed by the Chair and Vice-Chairs and, if approved, will be submitted to Council in accordance with the foregoing procedure.

Representatives of OECD member countries may attend meetings of the Governing Board. The Chair or a Vice-Chair of the Education Policy Committee and the Governing Boards of the Programme on Institutional Management in Higher Education, the Programme on Educational Building and the Programme for International Student Assessment may attend meetings of the Governing Board ex officio. The Governing Board may invite experts on an ad hoc basis to attend its meetings as appropriate.

\section{Budget of the Centre}

The expenditure of the Centre shall be charged against the appropriations authorised for it under Part II of the Budget of the Organisation.

Notwithstanding the provisions of Articles 14 and 15 of the Financial Regulations of the Organisation, appropriations, for which no commitment has been entered into before the end of the Financial Year for which they were appropriated and surplus publications income shall be automatically carried forward to the budget for the ensuing year by decision of the Secretary General.

Relationship with other bodies

The Governing Board shall maintain close working relationships with other relevant bodies of the Organisation working on issues that affect the development and implementation of educational research and innovation and have implications for other policy areas. The Governing Board shall co-operate with other international and regional organisations active in its field of competence. It may consult with non-governmental bodies as and when necessary.

Duration

This mandate shall enter into force on 1 January 2007 and shall expire on 31 December 2011, unless the Council decides otherwise." 


\section{GROUP OF NATIONAL EXPERTS ON VOCATIONAL EDUCATION AND TRAINING}

Chair:

Members:

Observers: ${ }^{1}$

Date of creation:

Duration:
Mr. Philip Pedersen

Open to all Member countries

Chile

Estonia

Israel
(Denmark)

Russian Federation

Slovenia

People's Republic of China

26th April 2007

31st December 2010

Mandate: - Summary Record of the 76th Session of the Governing Board of the Centre for Educational Research and Innovation [EDU/CERI/CD/M(2007)1, Item 9 §40]

- Summary Record of the 1st Session of the Education Policy Committee [EDU/EDPC/M(2007)1, Item 10 §43]

- Confirmation by the Executive Committee registered in the Summary Record of its 792th session [CE/M(2008)2, Item 15 and CE(2008)1]

- Renewal of the mandate [EDU/EDPC/CERI(2008)16]

\section{Extract from document [EDU/EDPC/CERI(2007)2/ANN1]}

"The group of national experts on vocational education and training is a subsidiary body of CERI Governing Board and the Education Policy Committee, and is responsible for guiding the work on vocational education and training (VET) on behalf of the two parent committees, particularly the collaborative project on "Vocational Education and Training: Policy and Innovation".

In particular it will:

- guide the methods, timing and principles of the work;

- allow OECD countries to share information and experience on VET policy and policy innovations;

- keep OECD countries in touch with the emerging findings of the exercise."

\footnotetext{
${ }^{1}$ China: pending acceptance letter.
} 
Chair:

Vice-Chairs:

Members:

Full Participants:

Observers:

Date of creation:

Duration:
Ms. Marijk van der Wende

Mr. Stephen Egan

Mr. José-Ginés Mora

Ms. Claire M. Morris

Ms. Janice Reid

Mr. Kari Suokko

Australia
Austria
Belgium
Canada
Czech Republic
Denmark
Finland
France
Germany
Greece
Hungary
Iceland
Ireland
Italy
Japan

Estonia

Israel

Russian Federation

Slovenia

Brazil
India
South Africa
Barbados
Chinese Taipei
Croatia
Ecuador

20th July 1976

31st December 2011
(Netherlands)

(United Kingdom)

(Spain)

(Canada)

(Australia)

(Finland)

\author{
Korea \\ Mexico \\ Netherlands \\ New Zealand \\ Norway \\ Poland \\ Portugal \\ Slovak Republic \\ Spain \\ Sweden \\ Switzerland \\ Turkey \\ United Kingdom \\ United States
}

Hong Kong, China

Kenya

Latvia

Lithuania

Malta

Trinidad and Tobago

Mandate: Resolution of the Council approved at its 1185th Session held on 4 December 2008 [C/M(2008)21, item 306 and C(2008)198/REV1]

\section{Resolution of the Council [C(2008)198/REV1]}

"THE COUNCIL,

Having regard to the Convention on the Organisation for Economic Co-operation and Development of 14 December 1960, and, in particular, Articles 5 a), 9 and 12 thereof;

Having regard to the Rules of Procedure of the Organisation; 
Having regard to the Financial Regulations and the Financial Rules of the Organisation;

Having regard to the Decision of the Council of 20 July 1976 concerning a Decentralised Project on Institutional Management in Higher Education [C(76)75(Final)], as last renewed by Council on 26 July 2001 [C/M(2001)16/FINAL];

Having regard to the Resolution of the Council of 9 April 2004 on Harmonisation of Names of Part II Subsidiary Bodies Supported by the Directorate for Education [C(2004)72; $\mathrm{C} / \mathrm{M}(2004) 13]$;

Having regard to the proposals set out in the Note by the Secretary-General concerning the renewal of the mandates of the Education Policy Committee, the Centre for Educational Research and Innovation (CERI), the Programme on Institutional Management of Higher Education (IMHE), the Programme on Educational Building (PEB) and the Programme on International Student Assessment (PISA) [C(2006)173];

Considering that members participating in the Institutional Management in Higher Education have agreed to pursue their co-operation

DECIDES:

The Programme on Institutional Management in Higher Education is hereby renewed with the following mandate:

Mission

The Council shall, for a period of three years as from 1st January 2009, renew the Programme on Institutional Management in Higher Education (IMHE). The work of IMHE reflects and complements the priorities of the OECD as a whole, in promoting sustainable development and social cohesion through good governance. It contributes to fulfilling the Directorate for Education's mission of assisting members and partners to achieve high quality lifelong learning for all that contributes to personal development, sustainable economic growth and social cohesion. It is carried out within the framework of the Main Principles Guiding the Governance Structure of the OECD Education Bodies [EDU(2006)8/ANN3/REV1] and with due regard to the mandates of the other education bodies.

The specific objectives of IMHE are:

- To contribute to the improvement of higher education through the strengthening of institutional governance and management. It does this by assisting its participants including higher education institutions, ministries and agencies - collectively and individually, to understand the social and political environment in which they operate and to meet more effectively their organisational objectives - including high quality research, effective teaching, and contributing to social and economic development.

- To analyse the governance and strategic management of higher education institutions and the development of their role in society. This includes the analysis of policy development and institutional practice and makes use of OECD data and indicators as well as case-studies and the experience of participants.

Participation in the Programme

Participation in the Programme is open to government departments, higher education institutions and other organisations involved in higher education in member countries and nonmember economies in line with the global relations strategy of the Programme. Requests for participation from non-member economies, higher education institutions and other organisations are approved by the Governing Board in accordance with criteria established by it.

\section{Governing Board}

Participants in each member country will, together, elect one or two representatives to the Governing Board subject to a procedure approved by the Governing Board. Participants from 
non-member economies may participate in the Governing Board, either as full participants or observers, as decided by the Governing Board. ${ }^{1}$

The Governing Board shall be concerned with all matters in the field of competence of the Programme, including those of any subsidiary bodies. Having regard to the mandate of the Education Policy Committee and the Main Principles Guiding the Governance Structure of the OECD Education Bodies, the Governing Board:

- Develops and approves its draft work programme, its draft budget, and the annual amount to be contributed by participants taking into account the medium-term strategy developed by the Education Policy Committee;

- Prioritises its activities and outputs in consultation with the Education Policy Committee;

- Monitors the quality and timeliness of output results, activities and projects;

- Disseminates its policy advice, policy analysis, and research and data to a wide range of stakeholders in member and non-member economies;

- Evaluates the outcomes of the work;

- Seeks the guidance of the Education Policy Committee for recommendations with major policy implications and for decisions to launch major new activities with significant financial implications for OECD members.

The Governing Board may organise its meetings outside OECD Headquarters on the basis of a reasoned request of a participant to the Programme. The host will accept responsibility for additional direct and indirect expenditures related to the meeting so that it is no more expensive for the Organisation than it would have been if held at OECD Headquarters.

Budget of the Programme

The programme of work and the budget of the Programme shall be examined by the Budget Committee, which shall address its comments to the Governing Board and shall refer to the Council any question that cannot be settled by agreement with the Governing Board. The budget shall be deemed to be adopted at the end of this procedure.

The expenditure of the Programme shall be charged against the appropriations authorised for it under a Part II Chapter of the Budget of the Organisation. participant.

The Governing Board sets the annual amount to be contributed by each Programme

Notwithstanding the provisions of the Financial Regulations of the Organisation, appropriations for which no commitment has been entered into before the end of the Financial Year for which they were appropriated and surplus income shall be automatically carried forward to the budget for the ensuing year by decision of the Secretary-General.

Relationship with other bodies

The Governing Board and other relevant bodies of the Organisation shall maintain close working relationships on issues related to the improvement of higher education through the strengthening of institutional governance and management. The Governing Board shall co-operate with other international and regional organisations active in its field of competence. It may consult with non-governmental bodies as and when necessary.

Duration

This mandate shall enter into force on 1 January 2009 and shall expire on 31 December 2011."

\footnotetext{
${ }^{1}$ The Chair or a Vice Chair of the Education Policy Committee and the Governing Boards of the Centre for Educational Research and Innovation, and the Programme on International Student Assessment may attend meetings of the Governing Board ex officio.
} 


\section{GROUP OF NATIONAL EXPERTS ON THE AHELO FEASIBILITY STUDY (AHELO GNE)}

Chair:

Mr. Jan Levy

(Norway)

Vice-Chair:

Professor Fiorella Kostoris

(Italy)

Date of creation:

18th July 2008

Duration:

31st December 2011

Mandate: - [EDU/IMHE/GB(2008)8] approved under written procedure

- [CE(2008)17]

\section{Extract from document [EDU/IMHE/GB(2008)8]}

"Objectives

The group of national experts on the AHELO (assessment of higher education learning outcomes) feasibility study is a subsidiary body of the IMHE Governing Board and is responsible for guiding work on the AHELO feasibility study. In particular it will:

- Guide the methods, timing and principles of the AHELO feasibility study; and

- Allow OECD countries to share information and experience on this issue and to keep in touch with the emerging findings of the exercise.

Scope

The group shall undertake its mission in the context of the OECD Directorate for Education's Output Area 2.1.3 "Higher Education" and Output Result "Feasibility Study for the Assessment of Higher Education Learning Outcomes (AHELO)". The Group shall be open to all member countries as well as regular observers to the IMHE Governing Board." 
Chair:

Vice-Chairs:

OECD Members:

Non-OECD Members:

Date of creation:

Duration:
Mr. Ryo Watanabe

Mr. Beno Csapo

Ms. Anita Wester

Mr. Daniel McGrath

Open to all Member countries

Chile
Estonia
Israel
Russian Federation
Slovenia
Brazil
Indonesia
People's Republic of China
(Shanghai only)
Albania
Argentina
Azerbaijan
Bulgaria
Chinese Taipei
Colombia
Costa Rica
Croatia
Dominican Republic
Georgia
Hong Kong, China
Jordan

(Japan)

(Hungary)

(Sweden)

(United States)
Kazakhstan

Kyrgyzstan

Latvia

Lithuania

Macau China

Malta

Mauritius

Moldova

Montenegro

Netherlands Antilles

Panama

Peru

Qatar

Romania

Serbia

Singapore

Thailand

Trinidad and Tobago

Tunisia

United Arab Emirates

Uruguay

26th September 1997

31st December 2011

Mandate: $\quad$ Resolution of the Council approved at its 1046th Session held on 14 December 2006 [C/M(2006)20 item 265 and C(2006)173]

\section{Resolution of the Council [C(2006)173, Annex VI]}

\section{RESOLUTION OF THE COUNCIL CONCERNING THE MANDATE OF THE PROGRAMME FOR INTERNATIONAL STUDENT ASSESSMENT}

"THE COUNCIL,

Having regard to the Convention on the Organisation for Economic Co-operation and Development of 14 December 1960, and, in particular, Articles 5 a), 9 and 12 thereof;

Having regard to the Rules of Procedure of the Organisation;

Having regard to the Financial Regulations and the Financial Rules of the Organisation;

Having regard to the Decision of the Council of 26 September 1997 to establish a Decentralised Programme for Producing Indicators on Student Achievement on a Regular Basis 
[C(97)176/FINAL], now referred to as the Programme for International Student Assessment (PISA), as last renewed by Council on 26 July 2001 [C/M(2001)16/FINAL];

Having regard to the Resolution of the Council of 9 April 2004 on Harmonisation of Names of Part II Subsidiary Bodies Supported by the Directorate for Education [C(2004)72; C/M(2004)13];

Having regard to the proposals set out in the Note by the Secretary-General concerning the renewal of the mandates of the Education Policy Committee, the Centre for Educational Research and Innovation (CERI), the Programme on Institutional Management of Higher Education (IMHE), the Programme on Educational Building (PEB) and the Programme on International Student Assessment (PISA) [C(2006)173];

Considering that Member countries and Non-Member Economies participating in the Programme for International Student Assessment wish to pursue their co-operation;

\section{DECIDES:}

The Programme for International Student Assessment is hereby renewed with the following mandate:

The Programme for International Student Assessment

The Council shall for a period of five years from 1 January 2007, renew the Programme for International Student Assessment (PISA). The work of PISA reflects and complements the priorities of the OECD as a whole, in promoting sustainable development and social cohesion through good governance. It contributes to fulfilling the Directorate for Education's mission of assisting members and partners to achieve high quality lifelong learning for all that contributes to personal development, sustainable economic growth and social cohesion. It is carried out with the framework of the Main Principles Guiding the Governance Structure of the OECD Education Bodies [EDU(2006)8/ANN3/REV1] and with due regard to the mandates of the other education bodies.

\section{Mission}

Every three years, until the end of the current mandate, PISA implements and analyses internationally standardised assessments of student learning outcomes up to the end of compulsory education that extend to educational content in curricular and cross-curricular areas, as well as to learning processes, behaviours and attitudes. Within the overall OECD education work programme, PISA seeks to progressively enhance comparative policy insights on how to improve: the quality of learning outcomes; equity in learning opportunities; the effectiveness and efficiency of educational processes; and the impact of learning outcomes. The three-yearly implementation of the surveys also provides trend indicators that allow participants to monitor improvements in educational outcomes.

\section{Membership}

Membership of PISA is open to member countries and non-member economies in line with the global relations strategy of the Programme.

\section{Governing Board}

The Governing Board shall be concerned with all matters in the field of competence of the Programme including those of any subsidiary bodies. Having regard to the mandate of the Education Policy Committee and the Main Principles Guiding the Governance Structure of the $O E C D$ Education Bodies, the Governing Board, in particular,

- Determines the policy priorities for PISA and oversees adherence to these priorities during implementation. This includes the setting of priorities and standards for data development, analysis and reporting as well as the determination of the scope of work that will then form the basis for the implementation of PISA.

- Works with the OECD Secretariat to ensure compliance with the policy objectives and design parameters at milestones during implementation. 
- Develops and approves its work programme and budget and cost elements of the scale of contributions, taking into account the medium-term strategy developed by the Education Policy Committee.

- $\quad$ Prioritises its activities and outputs in consultation with the Education Policy Committee.

- Monitors the quality and timeliness of output results, activities and projects.

- Disseminates its policy advice, analysis, research and data to a wide range of stakeholders in member and non-member countries.

- Evaluates the outcomes of the work.

- Seeks the guidance of the Education Policy Committee for recommendations with major policy implications and for decisions to launch major new activities with significant financial implications for OECD members.

Members of the Governing Board are deemed to speak on behalf of the government that they represent. Governments should, whenever possible, appoint representatives to the Governing Board who are knowledgeable about large-scale student assessments and their interface with educational policy and practice.

The Chair and Vice-Chairs of the Governing Board will be elected for a period of three years. meetings.

The Governing Board may invite non-members as full participants or observers to its

The Chair or a Vice-Chair of the Education Policy Committee and the Governing Boards of the Centre for Educational Research and Innovation, the Programme on Institutional Management of Higher Education and the Programme on Educational Building may attend meetings of the Governing Board, ex officio.

The Governing Board may organise its meetings or meeting of its subsidiary bodies outside OECD Headquarters on the basis of a reasoned request from a Permanent Representative on behalf of a member. The host will accept responsibility for additional direct and indirect expenditures related to the meeting so that it is no more expensive for the Organisation that it would have been if held at OECD Headquarters.

\section{Decision-Making}

The PISA Governing Board shall seek the consensus in its deliberations and decisions. If unable to reach consensus, the matter will be brought to a vote and will be decided by a two-thirds majority of the Governing Board members. Notwithstanding this provision, decisions relating to the operation of the Governing Board, the elements to be included in calculating the floor contribution for the scale of contributions, changes to project design and structure as well as the frequency of successive PISA surveys will be adopted by consensus.

\section{Budget of the Programme}

The programme of work, scale of contributions and budget of the Programme shall be examined by the Budget Committee which shall address its comments to the Governing Board and shall refer to the Council any question which cannot be settled by agreement with the Governing Board. The budget shall be deemed to be adopted at the end of this procedure.

The expenditure of the Programme shall be charged against the appropriations authorised for it under a Part II Chapter of the Budget of the Organisation. The Programme budget is not included in the OECD consolidated budget envelope.

The scale of contributions will be composed of a floor contribution, to be determined by the Governing Board, which is the minimum contribution for full participants and observers, and other costs that will be assigned to full participants on the basis of the OECD Part I scale of contributions.

Notwithstanding the provisions of Articles 14 and 15 of the Financial Regulations of the Organisation, appropriations, for which no commitment has been entered into before the end of the Financial Year for which they were appropriated and surplus publications income shall be 
automatically carried forward to the budget for the ensuing year by decision of the Secretary-General.

Relationship with other bodies

The Governing Board shall maintain close working relationships with other relevant bodies of the Organisation working on issues related to educational assessment and outcomes. The Governing Board shall co-operate with other international and regional organisations active in its field of competence. It may consult with non-governmental bodies as and when necessary.

Duration

This mandate shall enter into force on 1 January 2007 and shall expire on 31 December 2011, unless the Council decides otherwise." 


\section{PISA STRATEGIC DEVELOPMENT GROUP}

Chair:

Members:

Date of creation:

Duration:
Ms. Lorna Bertrand

Open to all Member countries

Ms. Lorna Bertrand
Mr. Julius Bjornsson
Ms. Satya Brink
Mr. Piero Cipollone
Ms. Anne-Berit Kavli
Ms. Elfriede Ohrnberger
Mr. Enrique Roca Cobo
Ms. Lynne Whitney

9th October 2002

31st December 2011
(United Kingdom)

(United Kingdom)

(Iceland)

(Canada)

(Italy)

(Norway)

(Germany)

(Spain)

(New Zealand)

Mandate: - Summary Record of the 78th Joint Session of Education Committee [EDU/EC/M(2006)2 and EDU/EC(2006)24/REV1]

- Renewal of the Mandates of Education Sub-Groups [C(2006)173/ANN2 and $\mathrm{C} / \mathrm{M}(2006) 20$, Item 265]

\section{Extract of Document [C(2006)173/ANN2]}

\section{"THE PISA STRATEGIC DEVELOPMENT GROUP}

Task

The Strategic Development Group (SDG) will advise the PISA Governing Board on the establishment of a broader analytic agenda for PISA that would extend across the various future survey cycles and the strategic design and development of PISA. Aspects requiring input from national authorities are dealt with through the Governing Board rather than through the Strategic Development Group.

Composition

The PISA Governing Board will determine the processes for the selection of the members of the Strategic Development Group in line with the OECD rules of Procedure.

Duration

This mandate shall enter into force on 1 January 2007 and shall expire on 31 December 2011, unless the PISA Governing Board decides to terminate it earlier." 


\section{GROUP OF PISA NATIONAL PROJECT MANAGERS}

Chair:

Members:

Date of creation:

Duration:
(..)

Open to all Member countries

9th October 2002

31st December 2011

Mandate: - Summary Record of the 78th Joint Session of Education Committee [EDU/EC/M(2006)2 and EDU/EC(2006)24/REV1]

- Renewal of the Mandates of Education Sub-Groups [C(2006)173/ANN2 and $\mathrm{C} / \mathrm{M}(2006) 20$, Item 265]

\section{Extract of Document [C(2006)173/ANN2]}

Task

“MANDATE OF THE GROUP OF PISA NATIONAL PROJECT MANAGERS

The Group of PISA National Project Managers manages and co-ordinates the implementation of PISA at the operational level.

Composition

All participants of the survey cycle are represented on the Group. The PISA Governing Board will determine the profile of the National Project Managers at the start of each survey cycle and participants will then nominate their representatives accordingly.

Duration

This mandate shall enter into force on 1 January 2007 and shall expire on 31 December 2011, unless the PISA Governing Board decides to terminate it earlier." 


\section{PISA EDITORIAL GROUP}

Chair:

(..)

Members:

Open to all Member countries

Date of creation:

9th October 2002

Duration:

31st December 2011

Mandate: - Summary Record of the 78th Joint Session of Education Committee [EDU/EC/M(2006)2 and EDU/EC(2006)24/REV1]

- Renewal of the Mandates of Education Sub-Groups [C(2006)173/ANN2 and $\mathrm{C} / \mathrm{M}(2006) 20$, Item 265]

\section{Extract of Document [C(2006)173/ANN2]}

"MANDATE OF THE PISA EDITORIAL GROUP

Task

including:

The PISA Editorial Group guides and monitors the preparation of the thematic reports,

- $\quad$ Assistance in the development of the specifications for the calls for tender, evaluation of the bidders, within the framework of the OECD financial rules and regulations and make recommendations on the choice of contractor to the PISA Governing Board.

- $\quad$ Assistance in monitoring the development of each report, including reviewing and revising draft material to ensure its correspondence with the broad directions given by the PISA Governing Board.

Assistance in the finalisation of draft reports and in identifying issues on which consultation with the PISA Governing Board is needed.

Composition

The Editorial Board is made up from members of the PISA Governing Board. The PISA Governing Board will determine the process of selection of the Group members in line with the OECD Rules of Procedure.

Duration

This mandate shall enter into force on 1 January 2007 and shall expire on 31 December 2011, unless the PISA Governing Board decides to terminate it earlier." 

STATISTICS 



\section{COMMITTEE ON STATISTICS (CSTAT)}

Chair:

Vice-Chairs:

Bureau Members:

Members:

Observers:

Date of creation:

Duration:
Mr. Brian Pink

Mr. Jean-Philippe Cotis

Ms. Katherine K. Wallman

Ms. Heli Jeskanen-Sundström

Mr. Dae-ki Kim

Mr. Gosse van der Veen

Mr. A. Omer Toprak

Ms. Karen Dunnell

Open to all Member countries

Chile
Estonia
Israel
Russian Federation

22nd April 2004

31st December 2013
(Australia)

(France)

(United States)

(Finland)

(Korea)

(Netherlands)

(Turkey)

(United Kingdom)

Mandate: Resolution of the Council establishing a committee on statistics [C(2003)217 and C(2003)217/CORR1] approved at its 1077th session on 12 February 2004 [C/M(2004)3, Item 40]

- Resolution of the Council on the Proposed Renewal of the Mandate of the Statistics Committee [C(2008)126/REV1] approved at its 1182nd session held on 16 October 2008 [C/M(2008)18, item 245].

\section{Resolution of the Council [C(2008)126/REV1 and C/M(2008)18, item 245]}

“THE COUNCIL

Having regard to the Convention on the Organisation for Economic Co-operation and Development of 14 December 1960 , and, in particular, articles 1, 3, 5a) and 9 thereof;

iii);

Having regard to the Rules of Procedure of the Organisation and in particular Rule 18 a)

Having regard to the Financial Rules of the Organisation;

Having regard to the Council's conclusions of 25 July 2002 on the Structures of Committees and Multidisciplinarity: Recommendations [C/M(2002)17];

Having regard to the recommendation contained in document $\mathrm{C}(2003) 176$, Implementation of the Nicholson Report Recommendations to convert the Meeting of Chief Statisticians into a Committee on Statistics;

Having regard to document $\mathrm{C}(2003) 217$ and its CORR1 on the Establishment of an OECD Committee on Statistics; 
Having regard to document $\mathrm{C}(2008) 126 / \mathrm{REV} 1$ on the renewal of the mandate of the Committee on Statistics;

Recognising that the creation of a Committee on Statistics would reinforce the overall coherence of OECD activities in this field;

Noting that, in this respect, a Committee on Statistics would be a key instrument to improve the overall quality of OECD statistics, reinforcing the co-operation both among countries, and between them and the Secretariat; to reinforce the role of the OECD in influencing the development of reliable and comparable statistics, both at national and international levels and to improve the dialogue between policy makers, analysts and data providers;

On the proposal of the Secretary-General;

DECIDES:

\section{Article 1}

The Committee shall oversee the broad range of statistics and statistical policy issues relevant to the Organisation.

In carrying out its responsibilities it shall:

1. be responsible to Council for the statistical policy of the OECD, both within the Organisation and vis-à-vis the rest of the world;

2. ensure that OECD statistics are produced according to high quality standards;

3. oversee the Programme of Work and Budget of the Statistics Directorate;

4. give advice to other OECD committees and to OECD Directorates about their plans, highlighting gaps and challenges, and contributing to the development of an effective and well co-ordinated OECD Statistical Work Programme;

5. officially approve methodological recommendations elaborated on specific subjects, cooperating with other committees in charge of policy issues related to the latter, and promote their implementation;

6. approve common standards for data and metadata exchange between the OECD and national data providers;

7. take appropriate action on any other topics submitted by the OECD Chief Statistician and relevant for conducting his/her tasks.

Article 2

The Committee shall maintain a close working relationship with other relevant bodies of the Organisation, seeking to ensure that statistics within the OECD are dealt with in a wellcoordinated and horizontal manner.

The Committee shall maintain, as appropriate, and in conformity with the OECD rules, relations with other international organisations, seeking to achieve co-ordinated and complementary work programmes in areas of shared interest and mutual benefit.

\section{Article 3}

The mandate shall expire on 31 December 2013, unless the Council decides otherwise." 


\section{WORKING PARTY ON NATIONAL ACCOUNTS (WPNA)}

Chair:

Vice-Chairs:

Members:

Observers:

Date of creation:

Duration:
Mr. Brent Moulton

Ms. Ann Lisbet Brathaug

Mr. Hiroki Owaki

Open to all Member countries

Chile

Estonia

Israel

Russian Federation

Slovenia

27th October 2005

31st December 2013
(United States)

(Norway)

(Japan)

Brazil

India

People's Republic of China

South Africa

Mandate: - Resolution of the Council establishing subsidiary bodies of the Committee on Statistics [C(2005)138 and C(2005)138/CORR1] approved at its 1122nd session on 27 October 2005 [C/M(2005)21, Item 276]

\section{$\underline{\text { Resolution of the Council C(2005) } 138 \text { and C(2005)138/CORR1 }}$}

\section{THE COMMITTEE ON STATISTICS,}

Having regard to Articles 1, 2, 5a) and 12 of the Convention on the Organisation for Economic Co-operation and Development of 14 December 1960;

Having regard to the resolution of the Council creating the Committee on Statistics and granting it the responsibility to "ensure that OECD statistics are produced according to high quality standards" and "officially approve methodological recommendations elaborated on specific subjects" [C(2003)217 and C(2003)217/CORR1];

Having regard to the Rules of Procedure of the Organisation;

Considering that comparable quantitative information on national accounts across OECD Member countries is indispensable for carrying out national and international economic analysis;

Emphasising the importance of the System of National Accounts as a guide for the development of all economic statistics;

Recognising the historical role played by the OECD in the development of standards to compile national accounts data worldwide;

DECIDES:

1. The Working Party on National Accounts is established.

2. The Working Party will undertake work to improve the quality of national accounts data in accordance with priorities established by the OECD Committee on Statistics.

3. In particular the Working Party will: 
- facilitate the development and improvement of internationally comparable methodologies in order to allow users to better compare the growth and the levels of national accounts variables between OECD countries, including satellite accounts;

- monitor, in coordination with the Inter-Secretariat Working Group on National Accounts (ISWGNA), the changes and clarification needed in the Manual of the System of National Accounts to increase the relevance and the international comparability of national accounts statistics;

- monitor by regular studies the comparability of the data in all domains of national accounts;

- pay particular attention to the relevance and comparability in the area of general government accounts, considering the increasing use of national accounts data in the domain of government finance statistics;

- encourage the implementation of international guidelines and recommendations by Member countries, including those regarding compilation methods and accurate measurement of key phenomena;

- encourage the timely availability of statistical series and monitor their prompt transmission to the OECD in order to better serve international users of national accounts data.

4. The Working Party will seek the maximum practicable conformity of its own work with relevant statistical work undertaken by other parts of the OECD, and in particular the Working Party on Financial Statistics (WPFS) which covers financial accounts; and also with related work on national accounts undertaken by other competent international and supranational organisations. To avoid duplication of efforts, a particular attention has to be paid to the co-ordination of the activity of the Working Party with that carried out by other working groups active at international level.

5. The Working Party will act as a forum in which Member countries will be able to exchange information and experience on new concepts, best practices of compilation of national accounts and on new experiences on the use of national accounts data.

6. The present mandate shall expire on 31 December 2008. The Committee on Statistics will review the results obtained every year before the end of the mandate. 


\section{OECD EXPERT GROUP ON STATISTICAL DATA AND METADATA EXCHANGE (SDMX)}

Chair:

Members:

Observers:

Date of creation:

Duration:
Mr. Lars Thygesen

Open to all Member countries

Chile
Estonia
Israel
Russian Federation
Slovenia

January 2004

31st December 2013
Brazil

India

People's Republic of China

South Africa

Mandate: Committee on Statistics meeting 15-16 June 2005 [STD/CSTAT/A(2005)1/REV, item 7 and document STD/SIMS(2004)1]

\section{Extract of Document [STD/SIMS(2004)1]}

\section{"OECD EXPERT GROUP ON STATISTICAL DATA AND METADATA EXCHANGE}

1. Purpose

OECD works closely with Member countries, non-Member countries, and other international organisations in sharing internationally comparable statistics, creating an information base for analysis and decision making. The processes of exchanging, processing and disseminating statistical information and metadata are undergoing profound change as a consequence of new technological opportunities and evolving standards.

Several international meetings are regularly organised to compare recent ICT developments and share experiences in the field of statistical data and metadata collection, management and dissemination. On the other hand, the implementation of new models and approaches is left to individual countries, according to their needs and plans. Therefore, nowadays there is no international forum available for discussing and agreeing on common strategies and concrete actions to minimise the duplication of work carried out by countries and international organisations, promoting a "multilateral vision" of the exchange of statistical data and metadata between countries and international organisations. The Group is being set up to form a network of involved ICT experts who will discuss strategic issues related to the development and the practical implementation of new procedures for statistical data exchange and sharing between the OECD, its Member countries, and other international organisations. Ultimately, this will contribute to a more efficient international statistical system. The Group will be closely co-ordinated with other international bodies dealing with similar topics (Eurostat IT Steering Group and the joint ECE/EurostatIOECD meetings on Management of Statistical Information Systems, MSIS). The Group will report to the OECD High Level Group on Statistics, providing recommendations for developing statistical information systems and improving the efficiency and the effectiveness of statistical data and metadata exchange.

2.

\section{Content of Work}

The primary focus of the Group's work will be on data exchange and data sharing within the OECD network, i.e. between OECD and its Member countries. In order to reduce or eliminate duplication of work, the Group will also promote technical cooperation between OECD and other international 
organisations involved in data and metadata exchange with OECD. The Group will, in particular, work towards developing and implementing new solutions regarding:

- $\quad$ Standards and procedures for exchange of statistical data and metadata;

- $\quad$ Standards and procedures for sharing statistical data and metadata.

The Group will have close links to the SDMX initiative (see www.sdmx.org) which is leading development activity in these domains, and will rely on the conclusions achieved by the ECE/Eurostat/OBCD meetings on Management of Statistical Information Systems and other international groups (e.g. METIS). The Group will provide a forum in which national statistical offices, other national data providers and the OBCD can discuss strategies and practical issues for implementing solutions, and move in a coordinated and mutually beneficial way towards their implementation. It is expected that the Group will prepare recommendations for future actions to be undertaken by the Secretariat and Member countries.

\section{3.}

\section{Organisation}

The Group will advise the OECD (both the Secretariat and Member countries) as to future practices and standards for the collection, exchange and sharing of statistical data and metadata. It will submit an annual report to the OECD High Level Group Meeting. Chair and secretariat will be provided by OECD in co-operation between the Statistics Directorate (STD) and the Information Technology and Networks Service (ITN).

4.

Members

The Group will consist of ICT experts from Member countries closely involved with statistical activities, especially concerning data and metadata exchange and sharing. Therefore, experts from national statistical offices (NSOs) and other institutions in charge of statistical activities (e.g. ministries) of Member countries and from international organisations interacting with OECD will be invited to join the Group. The participation of experts from certain non-Member countries could be envisaged, in the context of the OECD's "outreach" activities.

5. Meetings

It is foreseen that meetings will normally take place at OECD headquarter in Paris. As the Group's members are expected to be drawn from institutions around the globe, it would be beneficial to set up meetings in conjunction with other international meetings already gathering some members in one place." 


\section{WORKING PARTY ON INTERNATIONAL TRADE IN GOODS AND TRADE IN SERVICES STATISTICS (WPTGS)}

Chair:

Members:

Observers:

Date of creation:

Duration:
Mr. Craig Kuntz

(Canada)

Open to all Member countries

Chile

Estonia

Israel

Russian Federation

Slovenia

13th June 2007

31st December 2013
Brazil

India

People's Republic of China South Africa

Mandate: - Summary record of the 4th meeting of the Committee on Statistics [STD/CSTAT/M(2007)13, Item 4, §8, and STD/CSTAT(2007)4]

- Confirmation by the Executive Committee registered in the Summary Record of its 785th session [CE/M(2007)13, Item 109 and CE(2007)9]

\section{Extract from document [STD/CSTAT(2007)4]}

"The Committee on Statistics,

Having regard to Articles 1, 2, 5a) and 12 of the Convention on the Organisation for Economic Co-operation and Development of 14 December 1960;

Having regard to the resolution of the Council creating the Committee on Statistics and granting it the responsibility to "ensure that OECD statistics are produced according to high quality standards" and "officially approve methodological recommendations elaborated on specific subjects" [C(2003)217 and C(2003)217/CORR1];

Having regard to the Rules of Procedure of the Organisation;

Considering that comparable quantitative information on international trade flows in goods and in services across OECD Member countries is indispensable for carrying out national and international economic analysis and to inform trade negotiations;

Emphasising the importance of established methodological standards, and their continuous development, for a better appreciation of statistics in trade in goods and trade in services as important elements in the measurement of the economic and environmental impact of increasing globalisation;

Recognising the important role played by the OECD in cooperation with partner international organisations in the development of standards to compile and analyse international trade flows worldwide;

\section{DECIDES:}

1. The Working Party on International Trade in Goods and Trade in Services Statistics is established;

2. The Working Party will undertake work to improve the quality of international trade statistics and carry out related analysis in accordance with priorities established by the OECD Committee on Statistics; 
Recognising the different methodological frameworks and manuals applying to merchandise trade and trade in services, the Working Party will continue the successful modus operandi of past meetings with a session devoted to merchandise trade statistics, another session devoted to trade in services statistics and a combined session dealing with trade in goods and services and related analytical issues. In particular, the Working Party will:

- facilitate the development and improvement of internationally comparable methodologies in order to promote comparable, sound, consistent and coherent trade in goods statistics, trade in services statistics and trade and trade-related globalisation indicators;

- monitor and encourage implementation, in coordination with the two InterSecretariat Task Forces on International Merchandise Trade Statistics and on International Trade in Services Statistics, of sound conceptual frameworks, guidelines and manuals to increase the relevance and the international comparability of international trade statistics and trade and globalisation-related indicators;

- research and analyse new trends in trade to address the needs of economic and trade analysis and inform trade negotiations;

- discuss statistical issues of relevance and concern to trade statisticians and analysts and generally act as forum of exchange and springboard for methodological developments;

- oversee the collection and dissemination of relevant statistics on international trade in goods and international trade in services;

- oversee the Secretariat's work on balance of payments statistics (excluding the specialised work on detailed investment statistics);

- oversee the Secretariat's work on linking trade and business statistics as part of globalisation;

- ensure closest possible coordination and co-operation with national statistical authorities and with other International Organisations active in this field, taking on and continuing existing cooperation agreements as necessary. In particular, the Working Party will strive and continue its practice of organizing meetings jointly with Eurostat so as to avoid duplication of efforts.

The Working Party will seek synergies and practicable conformity of its own work with relevant analytical and statistical work undertaken by other parts of the OECD, in particular the Trade Committee, the Committee for Innovation, Industry and Entrepreneurship, the Working Party on Industry Analysis and its Expert Group on the Globalisation of Industry, and the Environment Committee. The same applies also to related work on Business Statistics, Foreign Direct Investment and international activities by Multinationals, as also to relevant work undertaken by other competent international and supranational organisations.

The Working Party will act as a forum in which Member countries will be able to exchange information and experience on new concepts, best compilation practices of trade statistics and indicators and new statistical challenges.

The present mandate shall expire on 31 December 2008. The Committee on Statistics will review the results obtained every year before the end of the mandate." 
TRANSPORT 

Chair:

Vice-Chair:

Bureau Members:

Members: ${ }^{1}$

Date of creation:

Duration:

Mr. Jean-Pierre Medevielle

Mr. Heinrich Nöthe

Mr. Yoshihiro Fujimori

Mr. Kazuyuki Nozawa

Mr. Angel Aparicio

Mr. Dennis Judycki

Australia
Austria
Belgium
Canada
Czech Republic
Denmark
Finland
France
Germany
Greece
Hungary
Iceland
Ireland
Italy
Japan
Korea
Estonia
Russian Federation
Slovenia
Albania
Armenia
Azerbaijan
Belarus
Bosnia and Herzegovina
Bulgaria
Croatia
Georgia

Australia

Czech Republic

Denmark

Germany

Greece

Italy

Japan

1st January 2004

31st December 2011
(Canada)

(Hungary)

(France)

(Germany)

(Japan)

(Japan)

(Spain)

(United States)

Luxembourg

Mexico

Netherlands

New Zealand

Norway

Poland

Portugal

Slovak Republic

Spain

Sweden

Switzerland

Turkey

United Kingdom

United States

European Commission

Latvia

Liechtenstein

Lithuania

Macedonia, Former Yugoslav

Republic of

Malta

Moldova

Montenegro

Romania

Serbia

Ukraine

Mandate : - Resolution of the Council [C(2003)128/FINAL] adopted at its 1059th session held on 26 June 2003 [C/M(2003)14]

- Resolution of the Council [C(2006)172 and CORR1] adopted at its 1147th session held on 20 December 2006 [C/M(2006)21, item 287]

\footnotetext{
1 Open to all OECD and ECMT Member countries.
} 


\section{RESOLUTION OF THE COUNCIL CONCERNING THE REVISION AND RENEWAL OF THE CENTRE'S MANDATE}

\section{"THE COUNCIL}

Having regard to the Convention on the Organisation for Economic Co-operation and Development of 14th December 1960 and, in particular, articles 2 b), 5a), 9 and 20 thereof;

Having regard to the Financial Rules of the Organisation;

Having regard to Rule 18 a) iii) of the Rules of Procedure of the Organisation;

Having regard to the Recommendation of the Council of the OEEC on the establishment of a European Conference of Ministers of Transport (ECMT) of 24th July 1953 [C/M (53)22(Final)] and to the Decision of the Council concerning relations between the Organisation and the ECMT of 30th September 1961 [C/M(61)1(Final)];

Mindful of the resolutions of the Council of 28 March and 25 July 2002 concerning the creation of new subsidiary bodies [C/M(2002)6 and C/M(2002)17];

Recalling that the Council of Ministers of the ECMT (ECMT Council of Ministers) agreed on 24-25 April 2003 'to create a joint ECMT-OECD Transport Research Centre, in which members of the two organisations will have full and equal rights' [CEMT/CM(2003)12/FINAL];

Recalling that the OECD Council adopted a Resolution [C(2003)128/FINAL] on 26 June 2003 establishing the Joint OECD/ECMT Transport Research Centre from 1 January 2004 for a period of three years;

Recalling that, following consideration of a report on 'Progress with the Joint OECD/ECMT Transport Research Centre' [CEMT/CM(2005)8] at the ECMT Ministerial meeting in Moscow, in May 2005, Transport Ministers of OECD and ECMT countries requested a further evaluation report be provided for consideration at the meeting in May 2006, in Dublin;

Noting that a further Evaluation / Report on progress with the Centre [CEMT/CM(2006)9/FINAL] was considered by Transport Ministers of OECD and ECMT countries in Dublin, in May 2006;

Being aware that a new three year Programme of Work (2007-2009) for the Centre [CEMT/CM(2006)8/FINAL] was adopted by Transport Ministers of OECD and ECMT countries in May 2006, at their meeting in Dublin;

Noting that the ECMT Council of Ministers decided in May 2006 to transform the ECMT into an International Transport Forum [CEMT/CM(2006)2/FINAL];

On the proposal of the Secretary-General;

\section{DECIDES:}

\section{Article 1}

The 'Joint OECD/ECMT Transport Research Centre' (hereafter the Centre or JTRC) is hereby continued for a further period of five years.

Article 2

The Centre shall promote economic development and contribute to structural improvements of its members, through co-operative transport research programmes addressing inland and other transport modes and their intermodal linkages in a wider economic, social, environmental and institutional context.

Article 3

The Centre shall be open to all OECD and ECMT Member countries and to any other country or economy whose participation has been agreed to by the governing bodies of the OECD and ECMT (together: JTRC Members). 
OECD Members shall automatically participate in the Centre, subject to a notification to the contrary to the Secretary-General of the OECD.

Article 4

The Centre will be governed by a 'Joint OECD/ECMT Transport Research Committee' (hereafter the Committee) whose members are nominated by the governments of JTRC Members.

Article 5

The Committee shall:

a) establish a programme of work that reflects the interests of JTRC Members, consistent with a budget dedicated to this transport research programme;

b) ensure that the programme of work is carried out through co-operative approaches, including research working groups, round tables, seminars and other working methods that the Committee considers appropriate;

c) invite international organisations, institutions dealing with matters related to inland and other transport modes as well as industry and representative associations as appropriate to participate in selected aspects of the work of the Centre;

d) monitor the execution of its programme of work;

e) report on its activities to the International Transport Forum's Transport Management Board and finally to the Transport Ministers of JTRC Members at the annual International Transport Forum session meetings;

f) report on its activities annually to the OECD Council;

g) perform any other function that the governing bodies of both Organisations may jointly decide.

Article 6

The expenditure arising from the implementation of the work of the Centre shall be financed on an equal basis by countries participating in the OECD and ECMT and shall be charged against the appropriations authorised under the non-consolidated Part II of the Budget of the Organisation.

The expenditure for special programmes could be financed through voluntary contributions by private and public institutions.

The budget of the Centre shall be used exclusively to implement the programme of work established by the Committee, including support as appropriate to the International Transport Forum.

Except as otherwise agreed by the governing bodies of both Organisations, all the Centre staff-related costs including costs linked to the end of appointments shall be borne by the Centre.

Article 7

The Centre is to be served by officials working exclusively on transport research issues. Officials, who are administratively integrated into the OECD, shall be appointed in accordance with the OECD's recruitment procedures. Notwithstanding the provisions of Staff Regulation $7 \mathrm{~b}$ ) and the related instruction 107/1, the Secretary-General of the OECD shall be authorised to recruit nationals from any non-OECD country member of the ECMT, as officials for the Centre.

The Head of the Centre, who will be in charge of the day-to-day management of the Centre, will be appointed on a joint decision of the Secretary-General of the OECD and the Secretary-General of the ECMT. 
The Secretary-General of the ECMT exercises operational guidance over the officials of the Centre with regard to the day to day implementation of the work programme and budget. In doing so he/she will ensure the necessary consultations with the OECD Secretariat.

Unless otherwise decided by the governing bodies of both Organisations, the SecretaryGeneral of the OECD and the Secretary-General of the ECMT shall be jointly responsible for the administration of the programme of work and the budget of the Centre.

\section{Article 8}

The Resolution comes into force on 1st January 2007. It will expire on 31 December 2011 unless the Council decides otherwise." 
INTERNATIONAL ENERGY AGENCY (IEA) 


Chair:
Mr. Willy Rickett
(United Kingdom)
Vice-Chairs:
Mrs. Marie-Pierre Fauconnier
(Belgium)
Mr. Norio Hattori
(Japan)
Members:
All IEA Member countries
Participation in the work:
European Commission
Pursuant to Supplementary Protocol No. 1 to the Convention on the $O E C D$
Date of creation:
15th November 1974
Duration:
Unspecified

Mandate: - Decision of the Council Establishing an International Energy Agency of the Organisation [C(74)203(Final)]

- Articles 49 to 52 of the Agreement on an International Energy Program signed in Paris on 18th November 1974. [C(74)203(Final) Annex II]

- Decision on an International Energy Program adopted by the Governing Board at its 1st meeting on 18th 19th November 1974 [IEA/GB(74)9(1st Revision); IEA/GB/DOC.74/5, Annex]

\section{Extract from document IEA/GB(74)9(1st Revision)}

\section{"THE GOVERNING BOARD}

a) Agreed that until further decision its meetings would be deemed to be joint meetings of the Governing Board and the Management Committee of the Agency."

\section{Extract from Decision of the Council [C(74)203(Final)]}

\section{"THE COUNCIL,}

Development of 14th December 1960 (hereinafter called the "Convention") and, in particular, Articles 5 a), 6, 9, 12, 13 and 20 of the Convention;

Having regard to the Financial Regulations of the Organisation and, in particular, to Articles 5, 10, $14 \mathrm{~b}$ ) and $16 \mathrm{~b}$ ) thereof;

Having regard to the Regulations, Rules and Instructions for Council Experts and Consultants of the Organisation;

Noting that the Governments of certain Member countries have declared their intention to enter into a separate Agreement on an International Energy Program which is attached to document [C(74)204] of 6th November 1974, and Corrigendum 1 thereto, which is circulated for reference and is hereinafter referred to as the 'Agreement';

Having regard to the Recommendation of the Council of 29th June 1971 on Oil Stockpiling [C(71)113(Final)]; 
Having regard to the Decision of the Council of 14th November 1972 on Emergency Plans and Measures and Apportionment of Oil Supplies in an Emergency in the OECD European Area [C(72)201(Final)];

Having regard to the Recommendation of the Council of 10th January 1974 on the Supply of Bunker Fuels for Shipping and Fishing [C(73)257(Final)];

Having regard to the Recommendation of the Council of 10th January 1974 on the Supply of Fuel for Civil Aircraft [C(73)258(Final)];

Having regard to the Note by the Secretary General of 6th November 1974 concerning the International Energy Program [C(74)203 and Corrigendum 1];

\section{DECIDES:}

\section{Article 1}

An International Energy Agency (hereinafter called the 'Agency') is hereby established as an autonomous body within the framework of the Organisation. ...

\section{Article 4}

A Governing Board composed of all the Participating Countries of the Agency shall be the body from which all acts of the Agency derive, and shall have the power to make recommendations and to take decisions which shall, except as otherwise provided, be binding upon Participating Countries, and to delegate its powers to other organs of the Agency. The Governing Board shall adopt its own rules of procedure and voting rules.

\section{Article 5}

The Governing Board shall establish such organs and procedures as may be required for the proper functioning of the Agency.

\section{Article 6}

a) The Governing Board shall decide upon and carry out an International Energy Program for co operation in the field of energy, the aims of which are:

i) Development of a common level of emergency self sufficiency in oil supplies;

ii) Establishment of common demand restraint measures in an emergency;

iii) Establishment and implementation of measures for the allocation of available oil in time of emergency;

iv) Development of a system of information on the international oil market and a framework for consultation with international oil companies;

v) Development and implementation of a long term co operation programme to reduce dependence on imported oil, including: conservation of energy, development of alternative sources of energy, energy research and development, and supply of natural and enriched uranium;

vi) Promotion of co operative relations with oil producing countries and with other oil consuming countries, particularly those of the developing world.

The Governing Board may adopt other measures of co operation in the energy field which it may deem necessary and otherwise amend the Program by unanimity, taking into account the constitutional procedures of the Participating Countries.

b) Upon the proposal of the Governing Board of the Agency, the Council may confer additional responsibilities upon the Agency. 


\section{Article 7}

a) The organs of the Agency shall be assisted by an Executive Director and such staff as is necessary who shall form part of the Secretariat of the Organisation and who shall, in performing their duties under the International Energy Program, be responsible to and report to the organs of the Agency.

b) The Executive Director shall be appointed by the Governing Board on the proposal or with concurrence of the Secretary General.

c) Consultants to the Agency may be appointed for a period exceeding that provided in Regulation 2 b) of the Regulations and Rules for Council Experts and Consultants of the Organisation.

\section{Article 8}

The Governing Board shall report annually to the Council on the activities of the Agency. The Governing Board shall submit, upon the request of the Council or upon its own initiative, other communications to the Council.

\section{Article 9}

The Agency shall co operate with other competent bodies of the Organisation in areas of common interest. These bodies and the Agency shall consult with one another regarding their respective activities.

\section{Article 10}

a) The budget of the Agency shall form part of the Budget of the Organisation and expenditure of the Agency shall be charged against the appropriations authorised for it under Part II of the Budget which shall include appropriate Budget estimates and provisions for all expenditure necessary for the operation of the Agency. Each Participating Country's share in financing such expenditure shall be fixed by the Governing Board. Special expenses incurred by the Agency in connection with activities referred to in Article 11 shall be shared by the Participating Countries in such proportions as shall be determined by unanimous agreement of those countries. The Governing Board shall designate an organ of the Agency to advise the Governing Board as required on the financial administration of the Agency and to give its opinion on the annual and other budget proposals submitted to the Governing Board.

b) The Governing Board shall submit the annual and other budget proposals of the Agency to the Council for adoption by agreement of those Participating Countries of the Agency which voted in the Governing Board to submit the proposals to the Council.

c) Notwithstanding the provisions of Article $14 \mathrm{~b}$ ) of the Financial Regulations, the Governing Board may accept voluntary contributions and grants as well as payments for services rendered by the Agency.

d) Notwithstanding the provisions of Article 16 b) of the Financial Regulations of the Organisation, appropriations in respect of the special activities referred to in Article 11 of this Decision, for which no commitment has been entered into before the end of the Financial Year for which they were appropriated, shall be automatically carried forward to the budget for the ensuing year.

\section{Article 11}

Any two or more Participating Countries may decide to carry out within the scope of the Program special activities, other than activities which are required to be carried out by all Participating Countries under the Agreement. Participating Countries who do not wish to take part in such activities shall abstain from taking part in such decisions and shall not be bound by them. Participating Countries carrying out such activities shall keep the Governing Board informed thereof. 
In order to achieve the objectives of the Program, the Agency may establish relationships with countries which are not Participating Countries, international organisations, whether Governmental or non Governmental, other entities and individuals.

\section{Article 13}

a) A Participating Country for which the Agreement shall have ceased to be in force or to apply provisionally shall be deemed to have withdrawn from the Agency.

b) Notwithstanding the provisions of paragraph a), a Country whose Government shall have signed the Agreement may, upon written notice to the Governing Board and to the Government of Belgium to the effect that the adoption of the Program by the Governing Board is binding on it pursuant to this Decision, remain a Participating Country of the Agency after the Agreement shall have ceased to apply for it, unless the Governing Board decides otherwise. Such a Country shall have the same obligations and the same rights as a Participating Country of the Agency for which the Agreement shall have entered definitively into force.

\section{Article 14}

The present Decision shall enter into force on 15th November 1974."

\section{Extract from the Agreement on an International Energy Program [C(74)203(Final), Annex II]}

"Article 49

1. The Agency shall have the following organs:

- A Governing Board

- A Management Committee

- Standing Groups on:

- Emergency Questions

- Oil Market

- Long term Co operation

- Relations with Producer and Other Consumer Countries.

2. The Governing Board or the Management Committee may, acting by majority, establish any other organ necessary for the implementation of the Program.

3. The Agency shall have a Secretariat to assist the organs mentioned in paragraphs 1 and 2.

\section{GOVERNING BOARD}

\section{Article 50}

1. The Governing Board shall be composed of one or more ministers or their delegates from each Participating Country.

2. The Governing Board, acting by majority, shall adopt its own rules of procedure. Unless otherwise decided in the rules of procedure, these rules shall also apply to the Management Committee and the Standing Groups.

3. The Governing Board, acting by majority, shall elect its Chairman and Vice Chairmen.

\section{Article 51}

1. The Governing Board shall adopt decisions and make recommendations which are necessary for the proper functioning of the Program. 
2. The Governing Board shall review periodically and take appropriate action concerning developments in the international energy situation, including problems relating to the oil supplies of any Participating Country or Countries, and the economic and monetary implications of these developments. In its activities concerning the economic and monetary implications of developments in the international energy situation, the Governing Board shall take into account the competence and activities of international institutions responsible for overall economic and monetary questions.

3. The Governing Board, acting by majority, may delegate any of its functions to any other organ of the Agency.

\section{Article 52}

1. Subject to Article 61, paragraph 2 and Article 65, decisions adopted pursuant to this Agreement by the Governing Board or by any other organ by delegation from the Board shall be binding on the Participating Countries.

2. Recommendations shall not be binding.

Explanatory Note:

The general mandate of the Governing Board is contained in the texts quoted above. In addition, more detailed provisions concerning the Governing Board's mandate are found throughout the I.E.P. Agreement."

\section{Extract from the Annex to document [IEA/GB/DOC.74/5]}

"1. The International Energy Program set out in the Agreement is hereby adopted and shall be carried out by the Agency and Participating Countries in accordance with its terms;

2. The organs provided for in the Program are hereby established as organs of the Agency; they shall carry out their responsibilities in accordance with the procedures set out in the Program and shall take decisions, recommendations and other actions as provided therein." 


\section{STANDING GROUP ON EMERGENCY QUESTIONS}

Chair:

Vice-Chairs:

Members:

Participation in the work:

Date of creation:

Duration:
Ms. Sophie Galey-Leruste

Mr. Frank Bonaldo

Mr. James Hart

Mr. Nario Kadono

All IEA Member countries

European Commission

Pursuant to Supplementary Protocol $n^{\circ}$. 1 to the Convention on the $O E C D$

18th November 1974

Unspecified
(France)

(Germany)

(United States)

(Japan)

Mandate: - Article 55 of the Agreement on an International Energy Program, signed in Paris on 18th November 1974, deposited with the Government of Belgium

- Decision on an International Energy Program, adopted by the Governing Board at its 1st meeting on 18th-19th November 1974 [IEA/GB(74)9(1st Revision); IEA/GB/DOC.74/5, Annex]

\section{Article 55 of the Agreement on an International Energy Program}

"Article 55

1. The Standing Group on Emergency Questions shall carry out the functions assigned to it in Chapters I to V and the Annex and any other function delegated to it by the Governing Board.

2. The Standing Group may review and report to the Management Committee on any matter within the scope of Chapters I to $V$ and the Annex.

3. The Standing Group may consult with oil companies on any matter within its competence."

\section{Extract from the Annex to document [IEA/GB/DOC.74/5]}

"2. The organs provided for in the Program are hereby established as organs of the Agency; they shall carry out their responsibilities in accordance with the procedures set out in the Program and shall take decisions, recommendations and other actions as provided therein;" 


\section{STANDING GROUP ON THE OIL MARKET}
Chair:
Mr. Graham White
(United Kingdom)
Vice-Chairs:
Mr. Tamaki Tsukada
(Japan)
Mr. Alan Hegburg
(United States)
Members:
All IEA Member countries
Participation in the work:
European Commission
Pursuant to Supplementary Protocol $n^{\circ} 1$ to the Convention on the $O E C D$
Date of creation:
18th November 1974
Duration:
Unspecified

Mandate: - Article 56 of the Agreement on an International Energy Program, signed in Paris on 18th November 1974, deposited with the Government of Belgium

- Decision on an International Energy Program adopted by the Governing Board at its 1st meeting on 18-19 November 1974 [IEA/GB(74)9(1st Revision);

[IEA/GB/DOC.74/5, Annex]

\section{Article 56 of the Agreement on an International Energy Program}

"1. The Standing Group on the Oil Market shall carry out the functions assigned to it in Chapters V and VI and any other function delegated to it by the Governing Board.

2. The Standing Group may review and report to the Management Committee on any matter within the scope of Chapters V and VI.

3. The Standing Group may consult with oil companies on any matter within its competence."

\section{Extract from the Annex to document [IEA/GB/DOC.74/5]}

"2. The organs provided for in the Program are hereby established as organs of the Agency; they shall carry out their responsibilities in accordance with the procedures set out in the Program and shall take decisions, recommendations and other actions as provided therein;" 


\section{STANDING GROUP ON LONG-TERM CO-OPERATION}
Chair:
Mr. Doug Hengel
(United States)
Vice-Chairs:
Mr. Richard Lavergne
(France)
Mr. Keisuke Sadamori
(Japan)
Members:
All IEA Member countries
Participation in the work:
European Commission
Pursuant to Supplementary Protocol $n^{\circ} .1$ to the Convention on the $O E C D$
Date of creation:
18th November 1974
Duration:
Unspecified

Mandate: - Article 57 of the Agreement on an International Energy Program, signed in Paris on 18th November 1974, deposited with the Government of Belgium

- Decision on an International Energy Program adopted by the Governing Board at its 1st meeting on 18th-19th November 1974 [IEA/GB(74)9(1st Revision);

IEA/GB/DOC.74/5, Annex]

\section{Article 57 of the Agreement on an International Energy Program}

"1. The Standing Group on Long-Term Co-operation shall carry out the functions assigned to it in Chapter VII and any other function delegated to it by the Governing Board.

2. The Standing Group may review and report to the Management Committee on any matter within the scope of Chapter VII."

\section{Extract from the Annex to document [IEA/GB/DOC.74/5]}

"2. The organs provided for in the Program are hereby established as organs of the Agency; they shall carry out their responsibilities in accordance with the procedures set out in the Program and shall take decisions, recommendations and other actions as provided therein;" 


\section{WORKING PARTY ON ENERGY EFFICIENCY ${ }^{1}$}

Chair:

Vice-Chairs:

Members:

Participation in the work:

Date of creation:

Duration:
Mr. Wolfgang Stinglwagner

Mr. Peter Bach

Mr. Tim McIntosh

All IEA Member countries

European Commission

Pursuant to Supplementary Protocol $n^{\circ} .1$ to the Convention on the OECD

3rd December 1974

Unspecified
(Germany)

(Denmark)

(Canada)

Mandate: - Summary record of the 1st meeting of the Standing Group on Long-Term Co-operation on 3rd-4th December 1974 [IEA/SLT/M(74)1]

- Provisional terms of reference [IEA/SLT(74)3 (2nd Revision)]

\section{Extract from document [IEA/SLT/M(74)1 - Item 3]}

"The Standing Group on Long-Term Co-operation

A. Established a sub-group on conservation to meet 13th-14th January 1975.

B. Agreed that the IEA Secretariat, drawing on comments from all delegations, would draft a set of guiding principles for the work of this sub-group and would circulate them to all delegations prior to the next SLT meeting.

C. Agreed that the SLT at its 18th December meeting plan to adopt these guiding principles and to elect a sub-group chairman."

\section{Document [IEA/SLT(74)3(2nd Revision)]}

"After noting their intention to reduce their dependence on imported oil, as expressed in Article 41 of the Agreement on an International Energy Programme, the members of the Standing Group on Long-Term Co-operation of the International Energy Agency agreed at their meeting on 3rd and 4th December 1974, to establish a sub-group on conservation. This sub-group would operate under the general provisions of Article 42 of the Agreement and should hold its first meeting on 13th and 14th January 1975. This sub-group should undertake the following tasks:

I. It should collate and review planned and existing conservation programmes in Member countries, in order to address the question of the feasibility or desirability of setting dynamic targets or objectives by the SLT for the group's reduction in energy consumption growth rates as related to a reduction in dependence on imported oil. In this regard the sub-group may find it helpful to divide its work into specific time frames of a medium and longer-term nature.

II. With regard to the set of dynamic, long-term targets or objectives, the sub-group should consider whether these objectives should be strictly the sum of individual members' measures or if

\footnotetext{
1 The Standing Group on Long-Term Co-operation, at its meeting on 21st-22nd October 1997 agreed to the change in name from the Sub Group on Energy Conservation to the Working Partty on Energy Efficiency.
} 
they should be set so as to take into account any additional conservation effect for the group as a whole which the IEA considers desirable and feasible.

III. The sub-group should define what is meant by conservation and consider the impact which various conservation measures might have on overall economic activities, keeping in mind that while it is important to minimise the adverse economic effects it should recognise that changes in patterns of energy consumption and economies in general are unavoidable. The sub-group might consider the desirability of convening a separate group of economic experts to address the question of economic impact of conservation measures and make recommendations to the SLT on this point.

IV. The sub-group should develop the criteria required to evaluate the relative effort of Member countries needed to realise the objectives established, keeping in mind that the effort should be distributed among members on an equitable basis. The criteria should be developed in the light of each country's pattern of energy supply, patterns of energy use (energy consumption per capita, energy consumption per unit of output, etc.) and economic structure.

V. The sub-group should propose ways and means to the SLT for development of a periodic systematic review programme to evaluate and compare individual countries' conservation measures and progress, noting that such a review on an international level might assist member governments i) in making difficult political decisions requiring changes in patterns of energy utilisation and ii) in avoiding any distorting consequences on other member economies.

VI. The sub-group should consider the desirability and feasibility of constituting binding commitments on member countries to implement a certain set of conservation measures taking into account their differing situations.

VII. The sub-group should also continue the work of the ad hoc Sub-Group on Immediate Energy Saving by:

a) Establishing a system to monitor the results and impact of the 1975 conservation efforts now under discussion;

b) Establishing a system to update continuously the information collected on the conservation measures of member countries;

c) Submitting to the SLT not later than 31st March 1975 an initial report on the results of the tasks in a) and b) above as well as any proposals whose application may result in reinforcement of national conservation efforts for 1975.

In carrying out these tasks the sub-group should bear in mind the principles and considerations as set out in paragraphs I to VI. The sub-group should also keep in mind that the measures to eliminate the waste of energy might have immediate effects while the measures to increase the efficiency of energy require investment use and will have, therefore (in most cases) a longer term effect." 


\section{COMMITTEE ON ENERGY RESEARCH AND TECHNOLOGY (CERT) ${ }^{1}$}

Chair:

Members:

Vice-Chairs:

Participation in the work:

Date of creation:

Duration:
Mr. Peter Cunz

(Switzerland)

All IEA Member countries

Ms. Alicia Mignone

Mr. Tomoya Ichimura

Mrs. Isabel Cabrita

Mr. Carmen Difiglio
(Italy)

(Japan)

(Portugal)

(United States)

European Commission

Pursuant to Supplementary Protocol $n^{\circ} .1$ to the Convention on the $O E C D$

21st November 1975

Unspecified

Mandate: Conclusions of the 16th meeting of the Governing Board on 20th-21st November 1975 [IEA/GB(75)94]

\section{Extracts from document [IEA/GB(75)94, Item 7 and Annex II]}

\section{"7. ORGANISATION OF ENERGY R\&D}

\section{THE GOVERNING BOARD}

a) Adopted the Decision on the Establishment of the Committee on Energy Research and Development as set forth in Annex II hereto.

b) Instructed the Committee on Energy Research and Development to discontinue working parties and subsidiary bodies set up to examine co-operative programme possibilities if, within a reasonable time, there appeared to be little possibility of co-operative programmes being achieved."

\section{"Annex II}

Decision of the Governing Board on the Establishment of the Committee on Energy Research and Development

\section{THE GOVERNING BOARD}

Desiring to establish a body of adequate status to be responsible for energy research and development;

\footnotetext{
${ }^{1}$ At the 123rd Meeting of the IEA Governing Board on 20th March 1992, the name of this Committee was changed from the Committee on Energy Research and Development to Committee on Energy Research and Technology (CERT).
} 
Mindful of Article 57 of the I.E.P. Agreement, providing that the Standing Group on Long-Term Co-operation may report on any matter within the scope of Chapter VII of the Agreement;

Decided to establish a Committee on Energy Research and Development with the following terms of reference:

a) To submit to the Governing Board a strategy for energy research and development and to oversee the implementation of this strategy;

b) to ensure, through regular consultation and collaboration with the Standing Group on Long-Term Co-operation, a close co-ordination between the energy research and development strategy and other aspects of the Programme for Long-Term Co-operation of the Agency.

c) In the light of the preparation and surveillance of such a strategy, to review periodically national programmes of energy research and development.

d) Within such a strategy, and utilising the reviews of national programmes, to identify opportunities for collaboration between participating Countries, and to promote such collaboration.

e) To continue the promotion and implementation of co-operation on energy research and development as decided by the Governing Board on 21st November 1975.

f) To report to the Governing Board as appropriate, but not less frequently than once a year, on the above subjects in conjunction with the Standing Group on Long-Term Co-operation.

g) To carry out such other functions as may from time to time be delegated to it by the Governing Board." 


\section{WORKING PARTY ON ENERGY END-USE TECHNOLOGIES}
Chair:
Mr. Hermann Halozan
(Austria)
Vice-Chairs:
Mr. Hamid Mohamed
(Canada)
Mr. Nils-Olof Nylund
(Finland)
Mr. Peter Versteegh
(Netherlands)
Members:
All IEA Member countries
Participation in the work:
European Commission
Pursuant to Supplementary Protocol $n^{\circ}$. 1 to the Convention on the $O E C D$
Date of creation:
1st April 1982
Duration:
Unspecified

Mandate: - Summary Record of the 23rd meeting of the Committee on Energy Research and Development, 12-13 October 1981 [IEA/CRD/M(81)11 and IEA/CRD(81)13]; re-endorsed at the 31st, 43rd and 52nd meetings 19-20 June 1984, 21-22 June 1988 and 1-2 July 1991 [IEA/CRD/M(84)10; -- IEA/CRD/M(88)5 --IEA/CRD/M(91)7]

- Summary Records of the 7th, 17th, 29th, 36th and 45th meetings of the Committee on Energy Research and Technology 21-22 June 1994, 4-5 November 1997, 26-27 June 2001, 5-6 November 2003 and 16-17 October 2006 [IEA/CERT/M(94)2 -IEA/CERT(97)31 -- IEA/CERT/M(97)3 -- IEA/CERT(2001)28/REV1 -IEA/CERT/M(2001)3 -- IEA/CERT(2003)35 -- IEA/CERT/M(2003)3 -IEA/CERT/M(2006)3]

- This Working Party continues under the Committee on Energy Research and Technology

\section{Extract from document [IEA/CRD/M(81)11]}

"3. The mandate of the Working Parties would be reviewed by CRD every three years."

\section{Extract from document [IEA/CERT(2003)35]}

"1. Objective

The Working Party on Energy End-Use Technologies (EUWP) shall provide advice to the IEA Committee on Energy Research and Technology (CERT) and other IEA bodies on trends and policies relating to energy end-use technologies; guided by the IEA's Shared Goals of energy security, environmental sustainability and economic growth, it shall also support and facilitate cooperation among Member countries in research, development, demonstration and deployment of energy end-use technologies and, as appropriate, shall seek to expand collaboration with nonMember countries.

\section{Functions}

The functions of the EUWP are to:

(1) Identify high-priority areas in which to develop or expand international collaboration in research, development, demonstration and deployment;

(2) Periodically review and assess the effectiveness of such collaboration with a view to identifying gaps and overlaps in existing coverage, renewing existing programmes 
and stimulating new collaborative activities, discontinuing or expanding activities, and encouraging closer collaboration with industry; and

(3) Identify those technologies, processes and systems in end-use sectors that can effectively help to achieve energy security, environmental and economic goals of Member countries and, where appropriate, contribute to international collaboration in the development and market deployment of such technologies. 


\section{WORKING PARTY ON FOSSIL FUELS}

Chair:

Vice-Chairs:

Members:

Participation in the work:

Date of creation:

Duration:
Mr. Jostein Dahl Karlsen

Mr. Hubert Hoewener

Mr. Tae-Jin Park

Ms. Barbara McKee

All IEA Member countries

European Commission

Pursuant to Supplementary Protocol $n^{\circ}$. 1 to the Convention on the $O E C D$

13th October 1981
(Norway)

(Germany)

(Korea)

(United States)

Unspecified

Mandate: - Summary Record of the 23rd meeting of the Committee on Energy Research and Development 12-13 October 1981 [IEA/CRD/M(81)11 and IEA/CRD(81)13]; re-endorsed at the 31st, 43rd and 52nd meetings 19-20 June 1984, 21-22 June 1988 and 1-2 July 1991 [IEA/CRD/M(84)10 -- IEA/CRD/M(88)5 -- IEA/CRD/M(91)7]

- Summary Records of the 7th, 17th, 29th, 36th and 45th meetings of the Committee on Energy Research and Technology 21-22 June 1994, 4-5 November 1997, 26-27 June 2001, 5-6 November 2003 and 16-17 October 2006 [IEA/CERT/M(94)2 -IEA/CERT(97)31 -- IEA/CERT/M(97)3 -- IEA/CERT(2001)28/REV1 -IEA/CERT/M(2001)3 -- IEA/CERT(2003)35 -- IEA/CERT/M(2003)3 -IEA/CERT/M(2006)3]

- This Working Party continues under the Committee on Energy Research and Technology

\section{Extract from document [IEA/CRD/M(81)11]}

"3. The mandate of the Working Parties would be reviewed by CRD every three years."

\section{Extract from document [IEA/CERT(2003)35]}

"1. Objective

The Working Party on Fossil Fuels (WPFF) shall, within the framework of the IEA Shared Goals, provide advice to the IEA on:

- $\quad$ fossil fuel technology-related policies, trends, projects, programmes;

- $\quad$ strategies which address priority environmental protection and energy security interests, including adequate, flexible, and reliable supply of power and electrical service of Member countries; and

carry out activities to meet those needs through international co-operation and collaboration facilitated by the IEA.

2. Functions

The functions of the WPFF are:

(1) Identification of the fossil fuel technology-related priority interests, including electric power production technologies, common to IEA Member countries, including their integration with non-fossil fuel technologies; 
(2) Promotion of collaborative RD\&D and technology deployment, as well as electric power production by arranging studies and technology information exchange on topics of common interest, conferences, workshops and other activities;

(3) Technology co-operation with non-Member countries;

(4) Initiation, evaluation and review on a periodic basis of Implementing Agreements and other international collaborative activities;

(5) Co-ordination with other sectoral bodies of the IEA which conduct fossil fuel-related studies, information exchanges and meetings relevant to the goals of the WPFF;

(6) Review and evaluation of, and participation in, fossil fuel-related activities conducted by IEA bodies. 


\section{WORKING PARTY ON RENEWABLE ENERGY TECHNOLOGIES}
Chair:
Mr. Roberto Vigotti
(Italy)
Vice-Chairs:
Mr. Andreas Indinger
(Austria)
Mr. Martin Schöpe
Mr. Willem van der Heul
Mr. Michael Rantil
(Germany)
(Netherlands)
(Sweden)

\section{Members: \\ Participation in the work:}
Date of creation:
Duration:
All IEA Member countries
European Commission
Pursuant to Supplementary Protocol $n^{\circ} .1$ to the Convention on the OECD
1st April 1982
Unspecified

Mandate: - Summary Record of the 23rd meeting of the Committee on Energy Research and Development 12-13 October 1981 [IEA/CRD/M(81)11 and IEA/CRD(81)13]; re endorsed at the 31st, 43rd and 53rd meetings 19-20 June 1984, 2122 June 1988 and 26-27 November 1991 [IEA/CRD/M(84)10 -- IEA/CRD/M(88)5 -IEA/CRD/M(91)9]

- Summary Records of the 7th, 17th, 29th, 36th and 45th meetings of the Committee on Energy Research and Technology 21-22 June 1994, 4-5 November 1997, 26-27 June 2001, 5-6 November 2003 and 16-17 October 2006 [IEA/CERT/M(94)2 -IEA/CERT(97)31 -- IEA/CERT/M(97)3 -- IEA/CERT(2001)28/REV1 -IEA/CERT/M(2001)3 -- IEA/CERT(2003)35 -- IEA/CERT/M(2003)3 IEA/CERT(2006)43 -- IEA/CERT/M(2006)3]

- This Working Party continues under the Committee on Energy Research and Technology

\section{Extract from document [IEA/CRD/M(1981)11]}

"3. The mandate of the Working Parties would be reviewed by CRD every three years."

\section{Extract from document [IEA/CERT(2006)43]}

"1. Objective

The Working Party on Renewable Energy Technologies also known as Renewable Energy Working Party (REWP) shall provide advice to the IEA Committee on Energy Research and Technology (CERT) and other IEA bodies on: renewable energy sources and technologies, related policies, trends, projects, programmes and strategies which address energy security, diversity and environmental interests of Member countries, and activities to meet those needs through international co-operation and collaboration facilitated by the IEA process.

\section{2.}

\section{Functions}

Having regard to the Shared Goals, adopted by IEA Ministers in 1993, and to the co-operation in long-term research, demonstration and deployment of renewable energy technologies, and to the encouragement to expand clean and clever energy markets, including renewables, adopted by IEA Ministers in 2005, and the Action Plan CERT defined as part of the response to the request from the G8 Summit in Gleneagles and St. Petersburg, the Working Party shall: 
- Provide advice and suggestions on the promotion of collaborative research, development and demonstration (RD\&D), removal of institutional barriers, policies and other means of accelerating market deployment, and identification and mitigation of environmental impacts.

- Continue strong oversight of and support for the REWP Implementing Agreements to help ensure the effectiveness of their programmes for developing and deploying renewable energy technologies.

- Continue and strengthen its role as a primary energy source of information and analysis on renewable energy technologies for IEA committees and offices, and non-IEA stakeholders.

- Liaison with selected non-Member countries, and other institutions and entities whose functions address the area of renewable energy technology, with a view to promote and structure international collaboration.

All IEA Member governments and the European Commission are members of the REWP. Members shall be represented by delegates whose responsibilities are related to all or most of the renewable sources of energy including solar, wind, hydropower, biomass, geothermal, ocean, and hydrogen, both for RD\&D and market deployment. Each national representative shall report regularly on ongoing activities in his/her country, shall act as a conduit of information from and to the IEA Secretariat, shall provide contacts within the national region in relation to specific requests for participation or support of activities by the Working Party or Secretariat, and shall review and assess studies and reports as requested by the Working Party. Other national or international entities may be consulted as appropriate.

- The Working Party is given a renewable mandate of three years by the CERT. The revision and renewal of the mandate will be undertaken at the CERT meeting prior to the expiration of each three-year term. The Working Party will elaborate a Strategic Plan to be updated every three years and to be presented for acknowledgement and approval by the CERT.

- The REWP elects a Chairman and one or more Vice-Chairmen for a three-year period to lead its efforts. The Chair and Vice-Chairs meet between full REWP meetings in REWP Cabinet meetings with the Head of Renewable Energy Unit to provide continuity and direction to the REWP's ongoing activities. They report regularly to CERT also attending periodically the CERT meetings and Working Party and CERT Chairs joint meetings.

- The REWP is supported by the Renewable Energy Unit of the IEA Secretariat. The REU proposes activities to support the REWP's Strategy. The REU works according to an Operational Plan that is reviewed and approved by the REWP. In its capacity, the Renewable Energy Unit collects data and provides analysis on renewable energy technologies, markets and policies, oversees the collaboration with the Renewable Energy Implementing Agreements, provides link to other IEA Offices and other international organisations and supports dissemination of information.

- The REWP shall carry out its functions without the disclosure of confidential or proprietary information of any entity." 


\section{FUSION POWER CO-ORDINATING COMMITTEE (FUSION WORKING PARTY)}
Chair:
Mr. Masahiro Seki
(Japan)
Vice-Chairs:
Mr. Francesco Gnesotto
(Italy)
Mr. Erol Oktay
(United States)
Members:
All IEA Member countries
Participation in the work:
European Commission
Pursuant to Supplementary Protocol $n^{\circ} .1$ to the Convention on the $O E C D$
Date of creation:
28th June 1975
Duration:
Unspecified

Mandate: - Conclusions of the 12th meeting of the Governing Board on 28 July 1975 [IEA/GB(75)54]

- Summary Record of the 23rd meeting of the Committee on Energy Research and Development 12-13 October 1981 [IEA/CRD/M(81)11 and IEA/CRD(81)13]; re-endorsed at 31st, 43rd and 52nd meetings 19-20 June 1984, 21-22 June 1988 and 1-2 July 1991 [IEA/CRD/M(84)10 -- IEA/CRD/M(88)5 -- IEA/CRD/M(91)7]

- Summary Records of the 9th, 19th, 29th, 42nd and 50th meetings of the Committee on Energy Research and Technology 14-15 March 1995, 22-23 June 1998, 26-27 June 2001, 18-19 October 2005 and 6-7 October 2008 [IEA/CERT(95)7 -IEA/CERT/M(95)1 -- IEA/CERT(98)37 -- IEA/CERT/M(98)2 -IEA/CERT(2001)28/REV1 -- IEA/CERT/M(2001)3 -- IEA/CERT(2005)42 -IEA/CERT/M(2005)3] - IEA/CERT(2008)22 - IEA/CERT/M(2008)3]

- This Working Party continues under the Committee on Energy Research and Technology

\section{Extract from document [IEA/CRD/M(81)11]}

"3. The mandate of the Working Parties would be reviewed by CRD every three years."

\section{Extract from document [IEA/CERT(2008)22]]}

"1. Objective

The overall objective of the IEA Fusion Power Co-ordinating Committee (FPCC) is to enhance fusion research, development and deployment (RD\&D) activities with a strategic approach to realising fusion energy in both IEA Member countries and in non-Member countries. The FPCC accomplishes this objective by promoting, initiating and coordinating international co-operation on fusion under the auspices of the IEA and within the IEA Framework for International Energy Technology Collaboration.

In pursuing this objective, the FPCC is guided by the IEA shared goals: enhancing energy security, environmental protection and economic growth. The FPCC reports and provides advice on fusion technology to the IEA Committee on Energy Research and Technology (CERT), the IEA Governing Board and other IEA bodies.

2. Functions

Identify high-priority $R \& D$ areas and technology applications of fusion power where international co-operation is particularly worthwhile and cost-effective; 
- Promote, initiate and support collaboration activities in such areas through the IEA Implementing Agreements and other mechanisms for international co-operation and information exchange;

- Co-ordinate, promote and review the activities carried out by the Implementing Agreements, provide guidance to their Executive Committees, encourage the establishment of new Implementing Agreements as appropriate, and encourage and promote the rationalisation and efficiency of the existing Implementing Agreements;

Provide the CERT with reviews of the activities of the Implementing Agreements, technical and policy advice, information on advances in international fusion RD\&D programmes and roadmaps towards fusion energy realisation;

- Exchange information and organise meetings with other IEA bodies with particular emphasis on topics concerning long-term energy scenarios and technology projection studies;

- Co-operate and exchange information with other international organisations which are active in fusion RD\&D, namely the International Atomic Energy Agency (IAEA), the International Tokamaks Physics Activity (ITPA), and the OECD Nuclear Energy Agency (NEA);

- Encourage, promote and provide guidance for more efficient contribution to ITER and the Broader Approach activities." 


\section{EXPERTS' GROUP ON SCIENCE AND ENERGY RESEARCH ${ }^{1}$}

Chair:

Mr. Jim Skea

(United Kingdom)

Date of creation:

28th October 2004

Duration:

Unspecified

Mandate: - Summary Record of the 23rd meeting of the Committee on Energy Research and Development 12-13 October 1981 [IEA/CRD/M(81)11 and IEA/CRD(81)13]; re endorsed at the 31st, 43rd and 53rd meetings 19-20 June 1984, 2122 June 1988 and 26-27 November 1991 [IEA/CRD/M(84)10 -- IEA/CRD/M(88)5 -IEA/CRD/M(91)9]

- Summary Records of the 7th, 17th, 29th, 36th and 45th meetings of the Committee on Energy Research and Technology 21-22 June 1994, 4-5 November 1997, 26-27 June 2001, 5-6 November 2003 and 16-17 October 2006 [IEA/CERT/M(94)2 -IEA/CERT(97)31 -- IEA/CERT/M(97)3 -- IEA/CERT(2001)28/REV1 -IEA/CERT/M(2001)3 -- IEA/CERT(2003)35 -- IEA/CERT/M(2003)3 IEA/CERT(2006)43 -- IEA/CERT/M(2006)3 - IEA/CERT(2008)23]

- This Expert Group continues under the Committee on Energy Research and Technology

\section{Extract from document [IEA/CRD/M(1981)11]}

"3. The mandate of the Working Parties would be reviewed by CRD every three years."

\section{Extract from document [IEA/CERT(2008)23]}

\section{Mandate of the Experts' Group on Science and Energy Research}

"Scope and Activities

The Experts' Group will serve as a forum for collaboration and the exchange of information that contribute to strengthening the role of science and the connections between basic science and applied energy programmes. The results of the efforts of this autonomous Experts' Group will feed directly into the CERT and the IEA Secretariat's work, providing a more global perspective on the international activities and successes in these areas.

Specifically, the Group will:

- advise decision makers and inform IEA analytical efforts on the opportunities for science to contribute to energy technologies;

- undertake and promote an ongoing dialogue among IEA Member countries to promote strategic international collaborations in science;

- $\quad$ offer support to Implementing Agreements for strategic discussions; and

- identify model programmes, and develop and share approaches and tools to link the science and energy technology communities.

Specific activities could include:

- $\quad$ conducting comprehensive surveys on key areas covered by the Group, which can cover a range of activities including "mining" science advances that can have energy applications, as well as policies and programmes that foster greater collaboration between basic science and applied energy R\&D ministries/stakeholders;

\footnotetext{
${ }^{1}$ The Committee on Energy Technology and Research, at its meeting on 6 and 7 October 2008, agreed to the change in name from the "Ad Hoc Group on Science and Energy Technologies" to the "Experts' Group on Science and Energy Research".
} 
- undertaking seminars and workshops, which can cover a range of activities, including advances in cross-cutting scientific fields and a more in-depth analysis and assessment of country approaches and activities; and

- serving as an advisory body to the CERT on key issues and concerns requiring expert Duration discussion and review.

These activities will provide information and advice to the CERT for a three-year period. One year prior to the end of this period, and any other renewal cycle, an assessment of the effectiveness of the group will be undertaken, and the results submitted to the CERT. This review and any renewal of the mandate will be addressed at the CERT meeting prior to the expiration of each term. The current Chairman of AHGSET will serve as the initial Chairman of the Experts' Group for a threeyear term, with a Chairman thereafter to be elected by the members no later than every three years. A Vice Chairman may also be elected by Group members on an as-needed basis.

\section{Membership}

The Experts' Group is an informal advisory and consultative body. Membership in the Group is open-ended with no fixed limit. IEA Member countries, or their designated expert representatives, are eligible for membership in the Group. Countries may nominate more than one representative but not more than three. CERT delegates are encouraged to solicit senior-level, expert participation by governments and research organisations involved in scientific research programmes, science assessment, and technology potential. Group members may propose new participation and modify the objectives for the Group with notification to the CERT for its approval.

\section{Working Practice}

The Experts' Group will hold regular meetings, with the Chairman being responsible for the timing of the meetings and their agendas. The meetings will be workshop in nature and focus on key themes and issues that merit open discussion and analysis. The Group shall carry out its functions without disclosure of confidential or proprietary information of any entity. The Group shall provide the CERT with advice and prepare for the CERT an annual report on current activities and proposed actions.

\section{Funding}

The Experts' Group would be funded through in-kind contributions of time and events, as well as possible voluntary contributions." 


\section{COMMITTEE ON BUDGET AND EXPENDITURE}

Chair:

Mr. Mirko Zambelli

(Switzerland)

Vice-Chairs:

Mr. Gaute Erichsen

(Norway)

Ms. Dewi van de Weerd

(The Netherlands)

Members:

All IEA Member countries

Participation in the work:

European Commission

Pursuant to Supplementary Protocol No.1 to the Convention on the OECD and IEA/GB(74)9 (1st Revision)

Date of creation:

18th November 1974

Duration:

Unspecified

Mandate: Conclusions of the first meeting of the Governing Board on 18th-19th November 1974 [IEA/GB(74)9(1st Revision)]

\section{Extract from document [IEA/GB(74)9(1st Revision), Item 12]}

"THE GOVERNING BOARD

a) Established a Committee on Budget and Expenditure to advise the Governing Board on financial administration of the Agency and to give its opinion on the Annual and other budget proposals submitted to the Governing Board.

b) Instructed the Committee on Budget and Expenditure to convene its first session no later than 9th and 10th December 1974." 


\section{STANDING GROUP FOR GLOBAL ENERGY DIALOGUE ${ }^{1}$}

Chair:

Vice-Chairs:

Members:

Participation in the work:

Date of creation:

Duration:
Mr. Hartmut Schneider

Mr. Douglas Victor Cooke

Mr. Knut Mansika

Mr. Stephen Gallogly

All IEA Member countries

European Commission

Pursuant to Supplementary Protocol No. 1 to the Convention on the $O E C D$

27th June 1977

Unspecified

Mandate: - Conclusions of the 30th Meeting of the Governing Board on 27-28 June 1977 [IEA/GB(77)33]

- Conclusions of the 124th Meeting of the Governing Board on 11 May 1992 [IEA/GB(92)25]

- Conclusions of the 203rd Meeting of the Governing Board on 18-19 October 2006 [IEA/GB/C(2006)3/REV1]

\section{Extract from document [IEA/GB(77)33, Item 8 a)]}

\section{"THE GOVERNING BOARD}

a) Established an informal Ad Hoc Group on International Energy Relations [...] to report to the Governing Board on international energy relations and to carry out such other functions as may be assigned to it by the Governing Board."

\section{Extract from document [IEA/GB(92)25, Item 5]}

"THE GOVERNING BOARD

a) Noted the Note by the Secretariat entitled "Participation by non-Member Countries in the Activities of the IEA" [IEA/GB(92)18] and the statement of the Executive Director, appended [to document IEA/GB(92)25].

b) Adopted the general policy guidance and the specific guidelines for areas of co-operation with non-Member countries as set forth in Parts II and III of IEA/GB(92)18/FINAL.

c) Noted, with respect to Part IV of IEA/GB(92)18/FINAL, that the role of the Committee on non-Member Countries needs to be further developed over time, bearing in mind that specific areas of co-operation with non-Member countries must be integrated into the work of other Standing Groups."

\footnotetext{
1 Formerly "Committee on Non-Member Countries". Name change decided by the Governing Board at its 203rd session, 18-19 October 2006 [IEA/GB/C(2006)3/REV1, item 6 vi)].
} 


\section{Extract from document [IEA/GB/C(2006)3/REV1, Item 6]}

\section{"THE GOVERNING BOARD}

i) noted the Note by the Secretariat entitled 'IEA Outreach Strategy for Approval';

vi) agreed that henceforth the Committee on Non-Member Countries (CNMC) shall be renamed the Standing Group for Global Energy Dialogue (SGD);

viii) agreed that the Guidelines for Areas of NMC Co-operation, adopted by the Governing Board in 1992 [IEA/GB(92)18FINAL, Parts II and III] as amended by the Governing Board in 1994 [IEA/GB(95)1, Paragraph 6 (a)(ii) and (iii) and IEA.GB(95)2/ANN], shall be replaced by Guidelines for Implementation of the IEA's Outreach Strategy, attached as Annex I." 


\section{INDUSTRY ADVISORY BOARD}

Chair:

Secretary:

Members:

Date of creation:

Duration:
Mr. Tom Eizember

Ms. Teresa Fariello

Australian Institute of Petroleum BP Oil International Ltd. Chevron Texaco Corporation Conoco Phillips Incorporated ENI ExxonMobil Corporation Japan Petroleum Development Association Mabanaft Deutschland BmbH Marathon-Ashland Petroleum Mineralölwirtschafts-verband MOLTRADE-Mineralimpex Neste Oil OMV A.G. Petro-Canada Products Ltd. Petroleum Association of Japan Shell International Petroleum Co. Ltd. Statoil Total

5th February 1975

Unspecified

Mandate: - Article 19, Paragraph 7 of the Agreement on an International Energy Program signed in Paris on 18th November 1974 deposited with the Government of Belgium

- Emergency Management Manual, adopted by the Governing Board at its 21st Meeting on 20th-21st May 1976, updated and adopted by the Governing Board at its 38th Meeting on 25th October 1994 [IEA/GB(94)40, Annex I]

\section{Article 19, Paragraph 7 of the Agreement on an International Energy Program}

"7. An international advisory board from the oil industry shall be convened, not later than the activation of emergency measures to assist the Agency in ensuring the effective operation of such measures."

\section{Extract from document [IEA/GB(94)40, Annex I]}

\section{"Section 4}

\subsubsection{Industry Advisory Board (IAB)}

The IAB has been established by the IEA to provide advice and consultation on emergency response issues and oil supply/demand questions related to them. In the event of the activation of the IEP emergency measures, the IAB will be responsible, primarily through its ad hoc group ISAG, for advising on the practical execution of the emergency measures under the direct supervision of the IEA.

The IAB membership is drawn from the group of Reporting Companies. The IAB meets periodically or when convened by the IEA.

The IAB has been established to:

- be available permanently for consultation on issues of emergency response;

- develop and staff ISAG which would be available to work within the IEA in an emergency or a test;

- be available for consultation with the IEA, if an emergency appears possible, on the evolving supply situation, and assist in determining the extent of any "shortfall" in supplies; 
- advise the IEA on general steps necessary to minimise the disruptive effects of an interruption in oil supplies;

- $\quad$ provide expertise in oil supply and logistics as required;

- advise the IEA on technical procedures to be followed in measuring individual countries' stocks;

- advise on information systems and sources of data;

- $\quad$ advise the IEA on timetables and procedures to test emergency response systems;

- be available for consultation with and to advise the IEA on any other issues related to the emergency procedures.

The IAB participates in or establishes working groups to study and make recommendations to the IEA on specific questions on which IAB advice would assist IEA emergency response procedures.

the IEA."

The IAB will keep the Reporting Companies generally informed on its discussions with 
Manager:

Members:

Date of creation:

Duration:
Mr. Giuseppe Gasparini

Mr. Tony Yates

Mr. Klaus Dahlmann

Mr. Pietro Rossi

Mr. Thondiyil Premkumar

Dr. Andràs Holló

Mr. Makoto Seto

Mr. Hans Kolar

Ms. Diana Hildebrant

Mr. Ikuo Hamabayashi

Mr. Takeshi Mikami

Mr. Masahiro Sato

Mr. John De Cuba

Mrs. Mariann Tonstad
(BP)

(BP Refining \& Petrochemicals)

(Eni)

(ExxonMobil)

(MOL)

(Nippon Oil Corporation)

(OMV)

(Petro-Canada)

(Petroleum Association of

Japan)

(Sekiren)

(Sekiren)

(Shell Int. Trading \& Shipping)

(Statoil)

20th May 1976

Unspecified

Mandate: Emergency Management Manual, adopted by the Governing Board at its 21st meeting on 20th-21st May 1976, updated and adopted by the Governing Board at its 38th Meeting on 25th October 1994 [IEA/GB(94)40, Annex I]

\section{Extract from document [IEA/GB(94)40, Annex I]}

"Section 4

4.5.5 Industry Supply Advisory Group (ISAG)

The ISAG is an ad hoc group of the IAB made up of representatives from the Reporting Companies and is the main instrument of industry participation in the operation of the IEP emergency measures. ISAG is activated in the event of an emergency or test to participate in a combined Secretariat/Industry Emergency Operations Team (EOT). When activated for test or emergency purposes, ISAG will:

- $\quad$ provide industry supply expertise to the IEA;

- $\quad$ assist in monitoring the evolving supply situation and evaluate implications of the regional and individual country imbalances calculated by the IEA;

- establish balancing requirements guided by the Allocation Co-ordinator;

- communicate the guidance of the IEA to RCs to ensure the efficient operation of allocation;

- assist the Allocation Co-ordinator in co-ordinating voluntary offer activities of $\mathrm{RCs} / \mathrm{RCAs}$ and NESOs (for NRCs) during balancing activities;

- assist the Allocation Co-ordinator in evaluating voluntary offers and the need for further action. 
In the performance of the responsibilities listed above, ISAG members will act solely under the supervision and guidance of the Allocation Co-ordinator and the ISAG Manager. ISAG members will adhere to all applicable anti-trust rules, regulations and clearances. They will also adhere to pertinent rules prohibiting dissemination of confidential information gathered for the IEA/ISAG activities and will only make such information available to others on a need-to-know basis and in accordance with IEA rules. ISAG members will not disclose confidential information to their own companies except as required in order to perform their functions as ISAG members.

Outside of tests and the activation of IEP emergency measures, the ISAG Manager and Deputy Manager will co-ordinate assistance to the IEA Secretariat for the improvement of emergency procedures and training directly related to the work of ISAG and the EOT." 


\section{COAL INDUSTRY ADVISORY BOARD}

Chair:

Deputy-Chair:

Vice-Chairs:

Bureau Members:

Members:

Date of creation:

Duration:
Mr. Roger Wicks

Mr. Don Elder

Mr. J. Brett Harvey

Mr. Yoshihiko Nakagaki

Mr. Greg Boyce

Mr. Preston Chiaro

Mr. Matthais Hartung

Mr. Steven Leer

Mr. Steve Lennon

Mr. David Murray

Mr. Jürgen Stadelhofer
(Anglo American Coal, South Africa)

(Solid Energy New Zealand Ltd., New Zealand)

(CONSOL Energy Inc., USA)

(J-Power, Japan)

(Peabody Energy, USA)

(Rio Tinto plc, United Kingdom)

(RWE Power AG, Germany)

(Arch Coal Inc., USA)

(Eskom, South Africa)

(BHP Billiton, Australia)

(Coal and Minerals $\mathrm{GmbH}$, Germany)

Those above, plus approximately 35 individuals of high standing from coal-related enterprises.

11th July 1979

Unspecified

Mandate: Conclusions of the 44th meeting of the Governing Board held on 11 July 1979 [IEA/GB(79)49] as amended on 3 April 2003 [IEA/GB/C(2003)3] and 7-8 March 2007 [IEA/GB/C(2007)1].

\section{"THE GOVERNING BOARD}

i) Noting the continuing importance of coal now and in the future as a secure and low-cost source of energy in IEA Member countries and throughout the world;

ii)

Noting its support for the IEA Coal Industry Advisory Board ("the CIAB") as a source of advice to IEA Member country governments, particularly in relation to the continued use of coal as a secure source of energy and on measures to mitigate the environmental impacts of its use; and

iii) Noting changed circumstances in energy markets reflected in energy policies of IEA Member countries since the establishment of the CIAB in July 1979;

DECIDES:

1. The $\mathrm{CIAB}$, composed of individuals of high standing and active in coal-related enterprises, shall be a source of advice and suggestions to the Governing Board and to the Secretariat on matters related to coal production, transport, trade and utilisation. With the agreement of the Executive Director, the CIAB shall report to the Governing Board on developments and trends in coal production, transport, trade, and utilisation, and on any other matters requested by the Governing Board or the Executive Director.

2. The CIAB may consult with any other bodies and individuals considered appropriate by the $\mathrm{CIAB}$ and the Executive Director. 
3. The CIAB shall carry out its functions on a broad, industry-wide basis without the disclosure of confidential or proprietary data of any company or other entity.

4. The CIAB shall consist of members from IEA Member and IEA Non-member countries approved by the Governing Board on the recommendation of the Executive Director. Members may be proposed by national governments for recommendation to the Governing Board if they notify the Executive Director of their intention within one month of being advised by the Secretariat of a new position or a vacancy. If the national government does not indicate its intention within one month, then the Executive Director may recommend a nomination to the Governing Board. Members shall be encouraged to appoint associates to assist them in their work but associates may not represent members at meetings of the CIAB except with the approval of the Executive Director.

5. The terms of membership shall be up to three years with a common expiry date and may be renewed by the Executive Director every third year thereafter. The first expiry date shall be 30 April 2010. In consultation with the appropriate national government, the Executive Director also may cancel a term of membership, taking into account the contribution of the member to the work of the CIAB.

6.

The CIAB may elect a Chairman and other officers as it sees fit.

7. The CIAB may organise its activities as it considers appropriate, subject to the approval of the Executive Director. The CIAB and the Executive Director may agree to publish and otherwise disseminate the views of the CIAB." 

OECD NUCLEAR ENERGY AGENCY (NEA) 

Chair:

Vice-Chairs:

Members:

Date of creation:

Duration:
Mr. Richard Stratford

Mr. Olivier Caron

Mr. József Rónaky

Mr. Takayuki Shirao

Mr. Kjell Bendiksen

Australia

Austria

Belgium

Canada

Czech Republic

Denmark

Finland

France

Germany

Greece

Hungary

Iceland

Ireland

Italy
(United States)

(France)

(Hungary)

(Japan)

(Norway)

Japan

Korea

Luxembourg

Mexico

Netherlands

Norway

Portugal

Slovak Republic

Spain

Sweden

Switzerland

Turkey

United Kingdom

United States

Participation in the work: European Commission Under the NEA Statute

International Atomic Energy Agency (IAEA)

By agreement

18th July 1956 (maintained on 30th September 1961)

Unspecified

Mandate: - Decision of the Council Establishing a European Nuclear Energy Agency, as amended [Statute of the Agency] [C(57)255, paragraph 95 of the Report by the Preparatory Committee, C(77)183(Final), C(92)220 and C(95)157/FINAL]

\section{Extract from the Decision of the Council [C(77)183(Final)]}

"THE COUNCIL,

Having regard to the Convention on the Organisation for Economic Co operation and Development of 14 December 1960 and in particular Articles 5(a), 9 and 20 thereof; Annex thereto;

Having regard to the Rules of Procedure of the Organisation and to paragraph 16 of the

Having regard to the Decision of the OEEC Council of 17 December 1957 establishing a European Nuclear Energy Agency, approved by the Council on 30 September 1961 [C(57)255, OECD/C(61)5]; 
Having regard to the Decision of the Council of 23 February 1965 relating to the Association of the Government of Japan with the Work of the European Nuclear Energy Agency [C(65)17(Final)];

Having regard to the Decision of the Council of 17 May 1972 relating to the Participation of the Government of Japan in the European Nuclear Energy Agency and Amending the Statute of the said Agency [C(72)106(Final)], which Decision altered the name of the said Agency to 'OECD Nuclear Energy Agency';

Having regard to the Decisions of the Council of 9 May 1975 and 12 October 1976 relating respectively to the participation of the Governments of Canada and the United States of America in the OECD Nuclear Energy Agency and amending the Statute of the said Agency [C(75)68(Final) and C(76)172(Final)];

Having regard to the draft proposals concerning the modernisation of the Statute of the said Agency which were approved by the Steering Committee for Nuclear Energy on 26 October 1977 [NE(77)17, NE/M(77)2].

\section{DECIDES:}

I. The following amendments shall be made to the Statute of the OECD Nuclear Energy Agency.

$\cdots$

III. Paragraph 16 of the Annex to the Rules of Procedure of the Organisation shall be amended to read as follows:

'OECD Nuclear Energy Agency: Its terms of reference are defined in the Decision of the Council C(57)255, with the amendment set out in paragraph 95 of the Report of the Preparatory Committee and in the Decision of the Council C(77)183(Final).'

\section{Annex I}

\section{Statute of the OECD Nuclear Energy Agency}

As amended by the Decisions of the Council [C(77)183(Final), C(92)220 and C(95)157/FINAL]

\section{“PART I}

\section{Article 1}

a) There is hereby established within the framework of the Organisation an OECD Nuclear Energy Agency (hereinafter referred to as the 'Agency').

b) Taking due account of the public interest and mindful of the need to prevent the proliferation of nuclear explosive devices, the purpose of the Agency shall be to further the development of the production and uses of nuclear energy, including applications of ionizing radiations, for peaceful purposes by the participating countries, through co operation between those countries and a harmonization of measures taken at the national level.

\section{Article 2}

The tasks assigned to the Agency shall be carried out, under the authority of the Council, by the Steering Committee for Nuclear Energy (hereinafter referred to as the 'Steering Committee'), by the bodies which the latter has established in conformity with the provisions set forth below to assist it in its work or perform tasks of common interest to a group of countries, and by the Secretariat of the Agency which shall form part of the Secretariat of the Organisation. 


\section{Article 3}

The Steering Committee shall be competent to deal with any question relevant to the purpose of the Agency under conditions resulting from the provisions set forth below and from other applicable decisions of the Council.

\section{Article 4}

a) The Agency shall promote technical and economic studies and undertake consultations on the programme and projects of participating countries relating to the development of research and industry in the field of the production and uses of nuclear energy for peaceful purposes, in collaboration with other bodies of the Organisation in matters falling within their competence.

b) To this end, the programmes and projects shall be examined by the Steering Committee according to a procedure to be laid down by it.

\section{Article 5}

a) The Agency shall, where appropriate, promote the formation of joint undertakings for the production and uses of nuclear energy for peaceful purposes, endeavouring to secure the participation of the greatest possible number of countries.

b) If a group of participating countries declares its intention to set up a joint undertaking, the countries concerned may agree to undertake the necessary work for this purpose among themselves within the Organisation at their own cost, whatever the position adopted by other participating countries. The Working Parties or Study Groups set up in accordance with this paragraph shall keep the Steering Committee informed of their progress and report to it on their conclusions.

c) When joint undertakings have been established on the initiative or with the assistance of the Agency.

i) The Steering Committee - or a Restricted Group of the Steering Committee composed of representatives of the countries which take part in the undertaking - shall exercise the functions assigned to it by the agreements concluded for the establishment of the undertakings concerned;

ii) The joint undertakings shall report each year to the Steering Committee and, where appropriate, to a Restricted Group of the Steering Committee on the state of their affairs and their development;

iii) The Steering Committee shall consider such problems of general interest as may be raised by the operation of joint undertakings, with a view to proposing any necessary measures to the Governments;

iv) The agreements concluded for the creation of joint undertakings should contain provisions under which participating countries or groups of participating countries not taking part in joint undertakings might subsequently accede to them or benefit from the results of their activities.

\section{Article 6}

a) Given the need to prevent the proliferation of nuclear explosive devices, a security control shall be established with a view to ensuring that the operation of joint undertakings and the materials, equipment and services made available by the Agency or under its supervision shall be used solely for peaceful purposes.

b) The security control may be applied, at the request of the parties, to any bilateral or multilateral agreement, or, at the request of a participating country, to any of that country's activities in the field of nuclear energy.

c) The organisation of this control and the functions of the Agency relating to its exercise shall be the subject of a special Convention on security control. 


\section{Article 7}

a) The Agency shall encourage the development of research into the production and uses of nuclear energy for peaceful purposes in participating countries.

b) To this end, it shall, where appropriate, promote the conclusion of agreements for the joint use of research installations built by participating countries and, in accordance with the conditions set forth in Article 5 above, the creation of joint research establishments.

c) Agency shall encourage the exchange of scientific and technical information related to its purposes between participating countries.

\section{Article 8}

a) The Agency shall:

i) Contribute to the promotion, by the responsible national authorities, of the protection of workers and the public against the hazards of ionizing radiations and of the preservation of the environment;

ii) Contribute to the promotion of the safety of nuclear installations and materials by the responsible national authorities;

iii) Contribute to the promotion of a system for third party liability and insurance with respect to nuclear damage;

iv) Encourage measures to ensure the most efficient use of patented inventions in the field of nuclear energy;

v) So far as may be consistent with Article $1 \mathrm{~b}$ ) above, contribute to the elimination of obstacles to international trade or to development of the nuclear industry;

vi) Contribute to the dissemination of information which may be freely distributed on the peaceful uses of nuclear energy, in particular on the safety and regulation of nuclear activities as well as on the physical protection of nuclear installations and materials.

b) For the purpose of the above mentioned objectives, the Steering Committee shall:

i) Submit to the participating countries recommendations or common rules to serve as a basis for harmonizing national laws and regulations;

ii) Encourage the establishment between participating countries of joint services necessary, in particular, for the protection of public health and the prevention of accidents in the nuclear industry.

c) The Agency shall undertake its activities referred to in paragraphs a) and b) above, as far as possible in collaboration with the International Atomic Energy Agency an the Commission of the European Communities.

\section{PART II}

\section{Article 9}

The Steering Committee shall be composed of representatives of all Governments which participate in the present Decision.

\section{Article 10}

a) The Steering Committee shall designate each year a Chairman and Vice Chairmen from among its members. It shall adopt its own Rules of Procedure.

b) The Steering Committee may give its advice, in particular, in the form of recommendations, to participating countries on any question within its competence. 
c) Whenever it is necessary to take decisions which are binding on Governments and which exceed the powers specially conferred on the Steering Committee, the latter shall submit proposals to the Council to this end.

d) The Steering Committee shall report each year to the Council on the execution of its duties and on the situation and prospects of the nuclear industry in participating countries.

\section{Article 11}

a) The reports and proposals prepared by the Steering Committee shall, when appropriate, call attention to the different attitudes adopted by the members.

b) The decisions, opinions or recommendations of the Steering Committee shall be adopted by mutual agreement of those of its members present and voting.

c) However, decisions of the Steering Committee which relate to the adoption of the agenda, the undertaking of studies, the establishment of Working Parties and the submission of questionnaires to participating countries, shall be adopted by a majority of the members of the Steering Committee present.

d) Decisions which are binding on Governments and which are taken by the Steering Committee within the powers conferred upon it shall commit only those countries which have accepted them.

\section{Article 12}

a) The Steering Committee may establish such Commissions and Working Parties as it may consider necessary to assist it in the performance of its duties and entrust them with the execution of any task relevant to the purpose of the Agency.

b) Restricted bodies may be established to study questions or execute functions of interest to a group of participating countries, in accordance with the conditions set forth in Article 5 above or in a decision of the Council. Special expenditure assignable to the work of these bodies, such as the cost of studies or the remuneration of experts, shall be chargeable to the countries concerned.

\section{Article 13}

a) The Steering Committee shall perform its duties in collaboration with the competent bodies of the Organisation.

b) The Steering Committee shall consult these bodies on questions which come within their competence. These bodies shall consult the Steering Committee on all questions relating to the production and uses of nuclear energy for peaceful purposes.

\section{Article 14} Secretariat of the Agency.

a) The Steering Committee and its subsidiary bodies shall be assisted by the

b) Expenditures relating to the working of the Agency shall be covered by the Budget of the Organisation. To this end, the Steering Committee shall prepare annual estimates of expenditure, which shall be submitted to the Council for approval.

c) Expenditure of the Agency which is subject to special financial rules shall be covered by separate budgetary provisions and countries which make no financial contributions to such expenses shall abstain when the relevant item in the Budget is approved. 


\section{Article 15}

a) In the performance of its duties, the Steering Committee shall take account of the work done by other international Organisations concerned and may, subject to paragraphs b) and c) below, co operate with them.

b) The Steering Committee shall, in agreement with the Council, establish relations with international governmental Organisations concerned with nuclear energy questions.

c) The Steering Committee may establish contact with international non governmental Organisations concerned, within the framework of decisions or arrangements approved by the Council.

\section{Article 16}

a) The provisions of the present Decision do not affect rights and obligations resulting from treaties previously entered into by Governments participating in the present Decision.

b) Since the present Decision does not affect the exercise of competences granted to the European Atomic Energy Community (EURATOM) by the Treaty entered into at Rome on 25th March 1957, the Agency shall establish with the said Community a close collaboration, details of which shall be determined by common agreement.

\section{Article 17}

a) Participating countries shall be countries the Governments of which participate in the present Decision.

b) Any Member country of the Organisation, the Government of which does not participate in the present Decision, may notify the Secretary General of its wish to do so and shall become a participant in the Decision upon approval of the Council on the recommendation of the Steering Committee.

c) Any other Government invited by the Organisation to participate in the present Decision may do so by addressing to the Secretary General an acceptance of that invitation. The Organisation may suspend or terminate that participation by giving one month's written notice of suspension or twelve months' written notice of termination to that Government.

d) Any Government participating in the present decision may terminate the application thereof to itself by giving twelve months' notice to that effect to the Secretary General.

\section{Article 18}

The provisions of Supplementary Protocol No. 1 to the Convention on the Organisation for Economic Co operation and Development shall apply to the representation of the European Atomic Energy Community (Euratom) in the Agency and in its Steering Committee as well as to the participation of the Commission of the European Communities in the work of the Agency and of its Steering Committee.

\section{Article 19}

The present Decision shall enter into force on 1st February 1958." 


\section{COMMITTEE ON THE SAFETY OF NUCLEAR INSTALLATIONS (CSNI)}

\begin{tabular}{|c|c|c|}
\hline Chair: & Mr. Jacques Repussard & (France) \\
\hline Vice-Chairs: & $\begin{array}{l}\text { Dr. Kunihisa Soda } \\
\text { Dr. Brian Sheron }\end{array}$ & $\begin{array}{l}\text { (Japan) } \\
\text { (United States) }\end{array}$ \\
\hline Bureau Members: & $\begin{array}{l}\text { Mr. Andrew White } \\
\text { Mr. Lothar Hahn } \\
\text { Mr. Jean-Marc Cavedon }\end{array}$ & $\begin{array}{l}\text { (Canada) } \\
\text { (Germany) } \\
\text { (Switzerland) }\end{array}$ \\
\hline Members: & \multicolumn{2}{|l|}{ All NEA Member countries } \\
\hline Participation in the work: & \multicolumn{2}{|l|}{$\begin{array}{l}\text { European Commission } \\
\text { Under the NEA Statute }\end{array}$} \\
\hline & \multicolumn{2}{|c|}{$\begin{array}{l}\text { International Atomic Energy Agency (IAEA) } \\
\text { By agreement }\end{array}$} \\
\hline Observers: & \multicolumn{2}{|l|}{$\begin{array}{l}\text { Russian Federation } \\
\text { Slovenia }\end{array}$} \\
\hline & \multicolumn{2}{|c|}{ Union of the Electricity Industry (EURELECTRIC) } \\
\hline Date of creation: & \multicolumn{2}{|l|}{ 1st February 1973} \\
\hline Duration: & \multicolumn{2}{|l|}{ 31st December 2010} \\
\hline
\end{tabular}

Mandate : - Final Report on the Strategy and Programme of Work in the Field of Nuclear Safety [NE(82)2]

- Revised Mandate [NE(89)12]

- Review of the NEA Committee Structure [NEA/NE(2000)11/REV1]

- Review of Mandates of the NEA Standing Technical Committees [NEA/NE(2005)2]

- Summary of decisions taken at the 117th session of the Steering Committee for Nuclear Energy [NEA/SUM/DEC(2008)2]

\section{Extract from document [NEA/SUM/DEC(2008)2]}

"The Steering Committee:

ii) extended all standing technical committee mandates [...] until 31 December 2010, as presented in Appendix 1 of document NEA/NE(2008)6."

\section{Extract from document [NEA/NE(2005)2]}

"The Committee on the Safety of Nuclear Installations (CSNI) shall be responsible for the activities of the Agency that support maintaining and advancing the scientific and technological knowledge base of the safety of nuclear installations. The Committee shall constitute a forum for the exchange of technical information and for collaboration between organisations, which can contribute, from their respective backgrounds in research, development and engineering, to its activities. It shall have regard to the exchange of information between Member countries and safety R\&D programmes of various sizes in order to keep all Member countries involved in and abreast of developments in safety technology. 
The Committee shall review operating experience and the state of knowledge on selected topics of nuclear safety technology and safety assessment. It shall initiate and conduct programmes identified by these reviews and assessments in order to overcome discrepancies, develop improvements and research consensus on technical issues of common interest. It shall promote the co-ordination of work in different Member countries that serve to maintain competence in nuclear safety matters, including the establishment of joint undertakings, and shall assist in the feedback of the results to participating organisations.

The Committee shall focus primarily on existing power reactors and other nuclear installations; it shall also consider the safety implications of scientific and technical developments of new reactor designs. Furthermore, it shall examine any other matters referred to it by the Steering Committee.

The Committee shall organise its own activities. It may sponsor specialist meetings and technical working groups to further its objectives. In implementing its programme, the Committee shall establish co-operative mechanisms with the Committee on Nuclear Regulatory Activities to work with that Committee on matters of common interest, avoiding unnecessary duplications. The Committee shall also co-operate with the Committee on Radiation Protection and Public Health, the Radioactive Waste Management Committee and the Nuclear Science Committee on matters of common interest." 


\section{CSNI PROGRAMME REVIEW GROUP (CSNI PRG)}

Chair:

Members:

Date of creation:

Duration:
Mr. Masashi Hirano

Dr. Joanne Ball

Mr. Jean-Claude Micaelli

Mr. Victor Teschendorff

Mr. Gustaf Lowenhielm

Dr. Jennifer Uhle
(Japan)

(Canada)

(France)

(Germany)

(Sweden)

(United States)

December 1999

December 2009

Mandate: - The Strategic Plan for the Committee on the Safety of Nuclear Installations [NEA/CSNI/R(2000)3]

- CSNI Operating Plan (2006-2009)

- Summary Record of the Fortieth Meeting of the Committee on the Safety of Nuclear Installations (CSNI) [NEA/SEN/SIN(2007)1]

\section{Extract from document [NEA/SEN/SIN(2007)1 - CSNI Operating Plan (2006-2009)]}

"The Programme Review Group is to perform a programme quality review function within $\mathrm{CSNI}$ and to provide scientific assistance to the decision-making process of CSNI. The PRG should also support the Bureau in preparing the CSNI meetings and in proposing actions concerning the achievement of CSNI objectives.

The main functions of the Programme Review Group are the following:

Assist the CSNI Bureau in updating the list of Safety Issues and Topics (SIT).

Review the Integrated Work Plan of each WG with respect to overall work-load and priorities. WG chairpersons are encouraged to attend the PRG meetings.

- $\quad$ Evaluate new activity proposals from the WGs: check consistency with the SIT and the Integrated Plan, assess the resource and time requirements, issue a recommendation to CSNI.

- Review new project proposals aiming to improve the technical content and complementarity with WG work scope.

- $\quad$ For cross-cutting issues, assist the CSNI Bureau in appointing a specific WG to take the lead.

- Monitor the progress of ongoing activities in context of the Integrated Plan and recommend corrective actions as needed.

- Review, and if necessary, draft Technical Opinion Papers and Collective Opinion Statements.

- $\quad$ Review major CSNI Reports (i.e., state-of-the-art reports and documents of similar significance) and provide guidance and advice on technical subjects to the CSNI.

- $\quad$ Report on its activities and recommendations at each Committee meeting." 


\title{
WORKING GROUP ON RISK ASSESSMENT (WGRISK)
}

\author{
Chair: \\ Mr. Nathan Siu \\ (United States) \\ Vice-Chairs: \\ Mr. Pieter de Gelder \\ Ms. Jeanne-Marie Lanore \\ (Belgium) \\ (France) \\ Members: \\ All NEA Member countries \\ Participation in the work: \\ European Commission \\ Under the NEA Statute \\ International Atomic Energy Agency (IAEA) \\ By agreement \\ Observer: \\ Russian Federation \\ Date of creation: \\ December 1999 \\ Duration: \\ December 2009
}

Mandate: - Meeting of the enlarged CSNI Bureau [SEN/SIN(81)31]

- Summary Record of the 15th Meeting of the Committee on the Safety of Nuclear Installations [SEN/SIN(87)68]

- Summary Record of the 26th Meeting of the Committee on the Safety of Nuclear Installations [NEA/SEN/SIN(99)1]

- Summary Record of the 28th Meeting of the Committee on the Safety of Nuclear Installations (CSNI) [NEA/SEN/SIN(2001)1]

- Summary Record of the 33rd Meeting of the Committee on the Safety of Nuclear Installations (CSNI) [NEA/SEN/SIN(2003)4]

- CSNI Operating Plan (2006-2009)

- Summary Record of the 40th Meeting of the Committee on the Safety of Nuclear Installations (CSNI) [NEA/SEN/SIN(2007)1]

\section{Extract from document [NEA/SEN/SIN(2007)1 - CSNI Operating Plan (2006-2009)]}

"Scope

The Working Group shall support improved uses of Probabilistic Safety Assessment (PSA) in risk-informed regulation and safety management through the analysis of results and the development of perspectives regarding potentially important risk contributors and associated riskreduction strategies. The Working Group shall address PSA methods, tools, and data needed to provide this information.

Objectives

The main objective of the Working Group on Risk Assessment (WGRisk) is to advance the PSA understanding and to enhance its utilisation for improving the safety of nuclear installations, for improving the operation and the design of nuclear installations and for increasing the regulatory effectiveness through risk-informed approaches. In order to achieve this objective, the group shall:

1. Report to the Committee on the Safety of Nuclear Installations (CSNI) and assist that Committee with its work. The Working Group shall prepare an integrated plan 
for its activities consistent with the mandate as well as proposed CSNI safety issues, updated at regular intervals and CSNI directives.

2. Constitute a forum for exchange of information and experience related to risk assessment in Member countries. This exchange is not only limited to technical discussions on questions regarding risk analysis approaches, results, insights, applications and interactions with other disciplines and analysis techniques, but it shall also include identifying and prioritising important issues requiring additional research.

3. Prepare technical reviews (such as state-of-the-art reports, technical opinion papers, compilations of ongoing efforts, comparison studies etc. as appropriate) of work in all phases of risk assessment to assist further developments and the application of PSA in risk-informed decision making. This work will be done in task groups, whose work will be organized in a project-like manner with outcomes and milestones.

4. Sponsor specialist meetings and workshops to further its objectives.

5. Collaborate with or assist other CSNI Working Groups, CNRA and other NEA committees on request. The group will also co-operate with other international organisations, aiming among others to avoid duplication of effort." 
WORKING GROUP ON ANALYSIS AND MANAGEMENT OF ACCIDENTS (WGAMA)
Chair:
Mr. Ivan Toth
(Hungary)
Vice-Chair:
Mr. Salih Guentay
(Switzerland)
Members:
All NEA Member countries
Participation in the work:
European Commission
Under the NEA Statute
International Atomic Energy Agency (IAEA)
By agreement
Observer:
Russian Federation
Union of the Electricity Industry (EURELECTRIC)
Date of creation:
December 1999
Duration:
December 2009
Mandate: - Summary Record of the 28th Meeting of the Committee on the Safety of Nuclear Installations (CSNI) [NEA/SEN/SIN(2001)1]
- CSNI Operating Plan (2006-2009)
- Summary Record of the 40th Meeting of the Committee on the Safety of Nuclear Installations (CSNI) [NEA/SEN/SIN(2007)1]

\section{Extract from document [NEA/SEN/SIN(2007)1 - CSNI Operating Plan (2006-2009)]}

"Scope

The Working Group on the Analysis and Management of Accidents (WGAMA) shall be responsible for activities related to potential accidental situations in nuclear power plants, including the following technical areas: reactor coolant system thermal-hydraulics; design-basis accident including ECCS strainer clogging; pre-core melt conditions and progression of accident and invessel phenomena; coolability of over-heated cores; ex-vessel corium interaction with concrete and coolant; in-containment combustible gas control; physical-chemical behavior of radioactive species in the containment; fire safety. The activities will mainly focus on existing reactors, but will have application also for some advanced reactor designs. Priority setting will be based on established CSNI criteria and in particular on safety significance and risk and uncertainty considerations.

Objective

The WGAMA objective is to assess and where necessary strengthen the technical basis needed for the prevention, mitigation and management of potential accidents in nuclear power plants, and to facilitate international convergence on safety issues and accident management analyses and strategies.

In order to fulfil this objective, the working group shall:

- Exchange technical experience and information relevant for resolving current or emerging safety issues. 
- Promote the development of phenomena-based models and codes used for the safety analysis, including the performance of benchmarking exercises.

- Assess the state of knowledge in areas relevant for the accident analysis and, where needed.

- Promote research activities aimed to improve such understanding, while supporting the maintenance of expertise and infrastructure in nuclear safety research.

The Working Group shall report to the Committee on the Safety of Nuclear Installations (CSNI) and assist that Committee with its work. The programme will be carried out by small task groups, each set up for performing a specific programme activity under the WGAMA supervision. The output of the working group will consist of state-of-the-art reports and other technical reports, workshops and related proceedings, benchmarking exercises and joint research proposals.

The working group will aim to provide answers as requested by CNRA, CSNI and member countries and will co-ordinate its work with other working groups, notably with WGRisk for priority setting, WGOE for emerging issues and WGIAGE for ageing and structure integrity evaluation. WGAMA will also work in co-ordination with the NEA NSC on scientific items such as advanced neutronic and thermal-hydraulic methods. Interaction with joint projects will be strengthened as recommended in the CSNI Operating Plan." 


\title{
WORKING GROUP ON INTEGRITY OF COMPONENTS AND STRUCTURES (IAGE)
}

Chair:

Vice-Chair:

Members:

Participation in the work:

Observer:

Date of creation:

Duration:
Mr. Andrei Blahoianu

Mr. Claude Faidy

All NEA Member countries

European Commission

Under the NEA Statute

The European Commission shares secretarial duties with the NEA.

International Atomic Energy Agency (IAEA)

By agreement

Russian Federation

December 1999

December 2009
(Canada)

(France)

\begin{abstract}
Mandate: - Summary Record of the 28th Meeting of the Committee on the Safety of Nuclear Installations (CSNI) [NEA/SEN/SIN(2001)1]

- Summary Record of the 40th Meeting of the Committee on the Safety of Nuclear Installations (CSNI) [NEA/SEN/SIN(2007)1, Item 5] and CSNI Operating Plan (20062009) [NEA/CSNI/R(2007)7]
\end{abstract}

\section{Extract from document [NEA/CSNI/R(2007)7 - CSNI Operating Plan (2006-2009)]}

"The main mission of the Working Group on Integrity and Ageing of Components and Structures is to advance the current understanding of those aspects relevant to ensuring the integrity of structures, systems and components, to provide for guidance in choosing the optimal ways of dealing with challenges to the integrity of operating as well as new nuclear power plants, and to make use of an integrated approach to design, safety and plant life management.

The Working Group shall report to the Committee on the Safety of Nuclear Installations (CSNI) and assist the Committee with its work. With prior approval of CSNI, the Working Group shall collaborate with or respond to requests from the CSNI Programme Review Group and Working Groups and other NEA committees or other international organizations.

The Working Group will have three subgroups dealing with a) integrity and ageing of metal structures and components, b) integrity and ageing of concrete structures and c) seismic behaviour of components and structures.

The specific mandate should be as follows:

1. The Working Group shall constitute a forum to exchange views, information and experience on generic technical aspects of integrity and ageing of components and structures, and review, as necessary, national and international programmes concentrating on research, operational aspects and regulation.

2. The Working Group shall stimulate, in relevant technical areas, new research and recommend possible international co-operative projects.

3. The Working Group shall develop common technical positions on specific integrity issues of operating and new nuclear power plants, and identify areas where further work is needed. 
4. The Working Group shall discuss the potential impact of ageing and other challenges to integrity on the safety, regulation, and operability of operating and new nuclear power plants." 


\section{WORKING GROUP ON HUMAN AND ORGANISATIONAL FACTORS (WGHOF) ${ }^{1}$}

\begin{tabular}{|c|c|c|}
\hline Chair: & Mr. Craig Reiersen & (United Kingdom) \\
\hline Vice-Chairs: & $\begin{array}{l}\text { Mr. Yves van den Berghe } \\
\text { Mr. Benito Gil-Montes }\end{array}$ & $\begin{array}{l}\text { (Belgium) } \\
\text { (Spain) }\end{array}$ \\
\hline Members: & \multicolumn{2}{|l|}{ All NEA Member countries } \\
\hline Participation in the work: & \multicolumn{2}{|l|}{$\begin{array}{l}\text { European Commission } \\
\text { Under the NEA statute }\end{array}$} \\
\hline & \multicolumn{2}{|c|}{$\begin{array}{l}\text { International Atomic Energy Agency (IAEA) } \\
\text { By agreement }\end{array}$} \\
\hline Observer: & \multicolumn{2}{|l|}{ Russian Federation } \\
\hline & \multicolumn{2}{|c|}{$\begin{array}{l}\text { Halden Reactor Project } \\
\text { World Association of Nuclear Operators (WANO) }\end{array}$} \\
\hline Date of creation: & \multicolumn{2}{|l|}{ June 1999} \\
\hline Duration: & \multicolumn{2}{|l|}{ December 2009} \\
\hline
\end{tabular}
Mandate: - Based on The Principles included in the Strategic Plan for the Committee on the Safety of Nuclear Installations [NEA/CSNI/R(2000)3]
- Summary Record of the 39th Meeting of the Committee on the Safety of Nuclear Installations (CSNI) [NEA/SEN/SIN(2006)3]
- CSNI Operating Plan (2006-2009)
- Summary Record of the 40th Meeting of the Committee on the Safety of Nuclear Installations (CSNI) [NEA/SEN/SIN(2007)1]

\section{Extract from document [NEA/SEN/SIN(2006)3]}

"The discussion addressed mainly the list of Safety Issues and Topics and in particular the way to present it as related to the CSNI/CNRA challenges. Aspects of the programme monitoring and closure were also discussed. A remark was made on the classification of the CSNI reports and criteria for such classification. The discussion is summarized as follows:

- The CSNI structure as presented in the draft Operating Plan, including the conversion of SEGHOF, SEGFSM and FCS in working groups, was approved."

\section{Extract from document [NEA/SEN/SIN(2007)1 - CSNI Operating Plan (2006-2009)]}

"The main mission of the Working Group on Human and Organisational Factors (WGHOF) is to improve the understanding and treatment of human and organisational factors within the nuclear industry in order to support the continued safety performance of nuclear installations, and improve the effectiveness of regulatory practices, in Member countries.

The Working Group shall report to the Committee on the Safety of Nuclear Installations (CSNI) and assist that Committee with its work. The Working Group shall prepare an integrated plan

\footnotetext{
1 Formerly Special Expert Group on Human and Organisational Factors (change of name approval, see document [NEA/SEN/SIN(2006)3]).
} 
for its activities consistent with the mandate as well as proposed CSNI safety issues, and shall update this at regular intervals. The Group will also collaborate with, and respond to requests from, the Committee for Nuclear Regulatory Activities (CNRA) and other Working Groups of the CSNI. The WGHOF programme of work will be approved by CSNI.

In delivering its mission, WGHOF will seek to address the challenges identified in the joint CSNI/CNRA Strategic Plan and to implement the CSNI Operating Plan. WGHOF will:

1. Constitute a forum for exchange of information and experience about safetyrelevant human and organisational issues in Member countries, thereby promoting co-operation and maintaining an effective and efficient network of experts.

2. Identify and prioritise current and emerging human and organisational safety issues.

3. Identify human and organizational factors methodologies and practices where further work and research are needed.

4. Identify those issues which appear most suitable to be addressed by WGHOF in a co-ordinated way across the international community.

5. Facilitate international convergence on safety issues related to human and organisational factors and, where practicable, seek to develop a shared understanding and common positions on important issues.

6. Compare, and where possible benchmark, practices and methodologies currently applied by Member countries in the assessment of safety-relevant human and organisational issues.

7. Prepare technical reviews of human and organisational factors work where such reports are needed for further development and to assist the application of human and organisational factors methods in member countries.

8. Collaborate with, and support cross-cutting initiatives proposed by, other CSNI/CNRA groups. Ensure that CSNI, CNRA and other organizations are consulted as appropriate when potential cross-cutting work on human and organisational factors is proposed by WGHOF.

9. Sponsor specialist meetings, workshops and other means of fostering international collaboration with nuclear and other industries, where appropriate, to further its objectives." 


\title{
WORKING GROUP ON FUEL SAFETY (WGFS) ${ }^{1}$
}

\author{
Chair: \\ Mr. Toyoshi Fuketa \\ (Japan) \\ Vice-Chair: \\ Mr. Wolfgang Wiesenack \\ (Norway) \\ Members: \\ All NEA Member countries \\ Participation in the work: \\ European Commission \\ Under the NEA statute \\ International Atomic Energy Agency (IAEA) \\ By Agreement
Observer:
Russian Federation
Date of creation:
December 1999

Duration:

December 2009
Mandate: - The Strategic Plan for the Committee on the Safety of Nuclear Installations [NEA/CSNI/R(2000)3]
- Summary Record of the 39th Meeting of the Committee on the Safety of Nuclear Installations (CSNI) [NEA/SEN/SIN(2006)3]
- CSNI Operating Plan (2006-2009)
- Summary Record of the 40th Meeting of the Committee on the Safety of Nuclear Installations (CSNI) [NEA/SEN/SIN(2007)1]

\section{Extract from document [NEA/SEN/SIN(2006)3]}

"The discussion addressed mainly the list of Safety Issues and Topics and in particular the way to present it as related to the CSNI/CNRA challenges. Aspects of the programme monitoring and closure were also discussed. A remark was made on the classification of the CSNI reports and criteria for such classification. The discussion is summarized as follows:

- The CSNI structure as presented in the draft Operating Plan, including the conversion of SEGHOF, SEGFSM and FCS in working groups, was approved."

\section{Extract from document [NEA/SEN/SIN(2007)1 - CSNI Operating Plan (2006-2009)]}

"The main mission of this Special Experts Group is to advance the current understanding and address safety issues related to fuel safety.

The specific mandate is as follows:

1. The Group will report to the Committee on the Safety of Nuclear Installations (CSNI), assist the Committee with its work and carry out the programme of work approved by the CSNI.

2. Assess the technical basis for current safety criteria and their applicability to high burn-up (above $50 \mathrm{MWd} / \mathrm{kg}$ ) and to new fuel designs and materials. The assessment will focus on anticipated transients and postulated accident conditions.

\footnotetext{
1 Formerly "Special Expert Group on Fuel Safety Margins". See document [NEA/NE(2006)8].
} 
Information relevant to fuel performance under normal operating conditions will be considered only to the extent necessary to assess the safety behaviour.

3. Determine needs and priorities for future research programmes in the area of fuel safety behaviour, with the aim of understanding and adequately modelling key phenomena and of quantifying safety margins.

4. Review from the safety point of view, the adequacy of fuel codes and methodologies used for different core assessments as related to high burn-up fuel. Cores with different fuel assembly designs and with MOX fuel are to be considered. Neutronic, thermal-hydraulic and materials aspects are considered as they relate to core safety assessment.

5. Provide a forum where safety relevant fuel issues emerging from operating experience and research work can be addressed and resolved in an effective manner.

The group will aim at facilitating international convergence in fuel safety issues, including experimental approaches, interpretation and use of the experimental data or of other relevant information.

The group will perform its activities mainly trough organizing topical meetings on specific subjects or through small task forces dedicated to covering specific programme items." 


\section{WORKING GROUP ON FUEL CYCLE SAFETY (WGFCS) ${ }^{1}$}

$\begin{array}{lll}\begin{array}{ll}\text { Chair: } \\ \text { Vice-Chair: }\end{array} & \begin{array}{l}\text { Mr. Pierre Nocture } \\ \text { Mr. Daniel Dorman }\end{array} \\ \text { Members: } & \text { All NEA Member countries } & \text { (United States) } \\ \text { Participation in the work: } & \begin{array}{l}\text { European Commission } \\ \text { Under the NEA statute } \\ \text { International Atomic Energy Agency (IAEA) } \\ \text { By agreement } \\ \text { Observer: }\end{array} & \text { Russian Federation } \\ \text { Date of creation: } & \text { October } 1976\end{array}$

Duration: October 2009

Mandate: - Summary Record of the 4th Meeting of the Committee on the Safety of Nuclear Installations [SEN/SIN(76)37]

- Summary Record of the 6th Meeting of the Working Group on Fuel Cycle Safety [SEN/SIN $(80) 62]$

- Summary Record of the 15th Meeting of the Committee on the Safety of Nuclear Installations [SEN/SIN(87)68]

- Summary Record of the 28th Meeting of the Committee on the Safety of Nuclear Installations (CSNI) [NEA/SEN/SIN(2001)1]

- Summary Record of the 39th Meeting of the Committee on the Safety of Nuclear Installations (CSNI) [NEA/SEN/SIN(2006)3]

- CSNI Operating Plan (2006-2009)

- Summary Record of the 40th Meeting of the Committee on the Safety of Nuclear Installations (CSNI) [NEA/SEN/SIN(2007)1]

\section{Extract from document [NEA/SEN/SIN(2006)3]}

"The discussion addressed mainly the list of Safety Issues and Topics and in particular the way to present it as related to the CSNI/CNRA challenges. Aspects of the programme monitoring and closure were also discussed. A remark was made on the classification of the CSNI reports and criteria for such classification. The discussion is summarized as follows:

- The CSNI structure as presented in the draft Operating Plan, including the conversion of SEGHOF, SEGFSM and FCS in working groups, was approved."

\section{Extract from document [NEA/SEN/SIN(2007)1 - CSNI Operating Plan (2006-2009)]}

"Scope

The nuclear fuel cycle comprises a number of interrelated activities including; uranium mining and milling; uranium refining and conversion to uranium hexafluoride; uranium enrichment; fuel fabrication and storage (including MOX fuel); spent fuel storage; spent fuel reprocessing; decommissioning of nuclear facilities; radioactive waste management and disposal options

\footnotetext{
${ }^{1}$ Formerly "CSNI Fuel Cycle Safety Subgroup". See document [NEA/NE(2006)8].
} 
(including for spent fuel) and the research and demonstration facilities that support these activities. Reactor operation is conventionally not included in the so-called nuclear fuel cycle. Similarly, the long-term management of radioactive waste is a very broad field, widely covered in several other NEA Committees, and is therefore not addressed, although the safety aspects associated with processing and storing waste in the short term on the site of fuel cycle facilities are treated by the group.

Objectives

The objective of the Working Group on Fuel Cycle Safety (WGFCS) is to advance the understanding for both regulators and operators of relevant aspects of nuclear fuel cycle safety in member countries.

In order to accomplish this objective the working group shall:

- Meet periodically to exchange information on relevant matters including licensing systems, safety philosophy and safety standards to improve mutual understanding, and to review the information from the Fuel Incident and Notification and Analyses System (FINAS) and other data bases.

- Indicate where further research is needed, review and prioritise safety issues, prepare state-of-the-art reports, hold workshops as appropriate and collaborate with other groups as necessary.

To achieve this mandate the FCS Working Group shall:

1. Report to the Committee on the Safety of Nuclear Installations (CSNI) and assist that Committee with its work. The programme of work of WGFCS will be approved by CSNI.

2. Constitute a forum for exchange of information and experience of activities related to nuclear fuel cycle safety in Member countries. Accumulation of operational experience should be used to improve safety technology. Mutual understanding of licensing systems, safety philosophy and safety standards should be common goal between members.

3. Maintain FINAS as a database which collects and disseminates safety related information concerning incidents at nuclear fuel cycle facilities. The main objective of FINAS is to serve as a tool for sharing lessons-learned from significant events that can be used to improve safety.

4. Indicate where further research and analysis is needed and denote priorities actions to be undertaken. It should prepare technical reviews of work in all phases of the nuclear fuel cycle where such reports are needed for further development. In doing so, care will be taken to avoid duplication of effort or scope with other CSNI Working Groups, or with other international bodies.

5. With prior approval of CSNI, collaborate with or assist the other WGs, NEA committees or other international organisations." 


\section{COMMITTEE ON NUCLEAR REGULATORY ACTIVITIES (CNRA)}

\begin{tabular}{|c|c|c|}
\hline Chair: & Mr. Mike Weightman & (United Kingdom) \\
\hline Vice-Chairs: & $\begin{array}{l}\text { Mr. Jean-Christophe Niel } \\
\text { Mr. Eric Leeds }\end{array}$ & $\begin{array}{l}\text { (France) } \\
\text { (United States) }\end{array}$ \\
\hline Bureau Members: & $\begin{array}{l}\text { Mr. Ian Grant } \\
\text { Mr. Peter-Michael Herttrich } \\
\text { Mrs. Marta Ziakova } \\
\text { Mr. Tetsuo Ohmura }\end{array}$ & $\begin{array}{l}\text { (Canada) } \\
\text { (Germany) } \\
\text { (Slovak Republic) } \\
\text { (Japan) }\end{array}$ \\
\hline Members: & \multicolumn{2}{|l|}{ All NEA Member countries } \\
\hline Participation in the work: & \multicolumn{2}{|l|}{$\begin{array}{l}\text { European Commission } \\
\text { Under the NEA Statute }\end{array}$} \\
\hline & \multicolumn{2}{|c|}{$\begin{array}{l}\text { International Atomic Energy Agency (IAEA) } \\
\text { By agreement }\end{array}$} \\
\hline Observers: & \multicolumn{2}{|l|}{$\begin{array}{l}\text { Russian Federation } \\
\text { Slovenia }\end{array}$} \\
\hline Date of creation: & \multicolumn{2}{|l|}{ October 1989} \\
\hline Duration: & \multicolumn{2}{|l|}{ 31st December 2010} \\
\hline
\end{tabular}

Mandate : - Mandate, membership and organisation of the Committee on Nuclear Regulatory Activities [NE(89)12]

- Summary Record of the 9th Meeting of the Committee on Nuclear Regulatory Activities [NEA/SEN/NRA(98)1]

- Review of the NEA Committee Structure [NEA/NE(2000)11/REV1]

- Review of Mandates of the NEA Standing Technical Committees [NEA/NE(2005)2]

- Summary of decisions taken at the 117th session of the Steering Committee for Nuclear Energy [NEA/SUM/DEC(2008)2]

\section{Extract from document [NEA/SUM/DEC(2008)2]}

"The Steering Committee:

ii) extended all standing technical committee mandates [...] until 31 December 2010, as presented in Appendix 1 of document NEA/NE(2008)6."

\section{Extract from document [NEA/NE(2005)2]}

"The Committee on Nuclear Regulatory Activities (CNRA) shall be responsible for the programme of the Agency concerning the regulation, licensing and inspection of nuclear installations with regard to safety. The Committee shall constitute a forum for the exchange of information and experience among regulatory organisations. To the extent appropriate, the Committee shall review developments which could affect regulatory requirements with the objective of providing members with an understanding of the motivation for new regulatory requirements under consideration and an opportunity to offer suggestions that might improve them or avoid 
unwarranted disparities among Member countries. In particular it shall review current management strategies and safety management practices and operating experiences at nuclear facilities with a view to disseminating lessons learnt. The Committee shall promote co-operation among Member countries to use the feedback from experience to develop measures to improve safety, to enhance efficiency and effectiveness in the regulatory process and to maintain adequate infrastructure and competence in the nuclear safety field.

The Committee shall promote transparency of nuclear safety work and open public communication. The Committee shall maintain an oversight of all NEA work that may impinge on the development of effective and efficient regulation.

The Committee shall focus primarily on existing power reactors and other nuclear installations; it may also consider the regulatory implications of new designs of power reactors and other types of nuclear installations. Furthermore it shall examine any other matters referred to it by the Steering Committee. The Committee shall collaborate with, and assist, as appropriate, other international organisations for co-operation among regulators and consider, upon request, issues raised by these organisations. The Committee shall organise its own activities. It may sponsor specialist meetings and working groups to further its objectives.

In implementing its programme the Committee shall establish co-operative mechanisms with the Committee on the Safety of Nuclear Installations to work with that Committee on matters of common interest, avoiding unnecessary duplications. The Committee shall also co-operate with the Committee on Radiation Protection and Public Health and the Radioactive Waste Management Committee on matters of common interest." 


\section{WORKING GROUP ON INSPECTION PRACTICES (WGIP)}
Chair:
Mr. Stephen Lewis
(United Kingdom)
Vice-Chair:
Mr. Julio Crespo Bravo
(Spain)
Members:
All NEA Member countries
Participation in the work:
European Commission
Under the NEA Statute
International Atomic Energy Agency (IAEA)
By agreement
Observer:
Russian Federation
Date of creation:
12th November 1990
Duration:
12th December 2009
Mandate: - Summary Record of the 2nd annual meeting of the Committee on Nuclear Regulatory Activities [NEA/SEN/NRA(90)7]
- Summary Record of the 3rd meeting of the Committee on Nuclear Regulatory Activities [NEA/SEN/NRA(92)1]
- Summary Record of the CNRA Special Issues Meeting on the Regulatory Aspects of Ageing Reactors [NEA/SEN/NRA(98)3]
- CNRA Operating Guidelines, June 2006 [NEA/CNRA/R(2006)3]
- Summary Record of the 17th Annual Meeting of the Committee on Nuclear Regulatory Activities (CNRA) [NEA/SEN/NRA(2006)1]

\section{Extract from document [NEA/SEN/NRA(2006)1]}

"Working Group on Inspection Practices (WGIP) - CNRA Members approved the revised mandate (based on final editing by WGIP Chair) and the proposal to begin a new task on Inspection of Fire Protection Systems."

\section{Extract from document [NEA/CNRA/R(2006)3}

"Scope

The scope of work of the WGIP is to examine regulatory inspection practices within the following context:

- Inspection is any examination, observation, measurement, or test to assess structures, systems, components, materials, operational activities, processes, procedures, and personnel and organisational competence. Regulatory inspection is inspection by or on behalf of a regulatory body.

- One important responsibility of a regulatory body is to verify by inspection that licensees operate safely, that their activities fully comply with all applicable regulations, and that safety is given the highest priority. Regulatory inspection must therefore be supplemented by reviews and by other regulatory controls to yield an integrated assessment of safety and provide a basis for enforcement, which is an essential part of the regulatory oversight process. 


\section{Main Objectives}

The working group shall constitute an international forum for exchanging information and experience and with the agreement of CNRA will plan its work to ensure improvements in nuclear safety through more effective and efficient regulation.

To this end, the working group shall:

- promote co-operation and learning to mutually enhance regulatory effectiveness and efficiency by reviewing the effectiveness of existing regulatory inspection practices, prepare reports and disseminate lessons learnt, and by sponsoring and holding international workshops on regulatory inspection practices;

- consider what inspection and practices are appropriate to address the future regulatory challenges as identified by CNRA;

- consider the lessons learnt from regulators and regulatory inspections and practices from operational experience.

Methods of Working

Annually the WGIP will prepare a revised plan of work for the next 2 years for agreement by the CNRA.

The working group will closely interact with the Working Group on Operating Experience (WGOE), as the analysis of operating and inspection experiences are both highly important to the oversight of operational safely.

With CNRA's agreement the working group will collaborate with, and assist other NEA committees and other international regulatory organizations." 


\section{WORKING GROUP ON PUBLIC COMMUNICATION OF NUCLEAR REGULATORY ORGANISATIONS (WGPC)}

$\begin{array}{lll}\begin{array}{ll}\text { Chair: } \\ \text { Vice-Chair: }\end{array} & \begin{array}{l}\text { Mr. Luc Chanial } \\ \text { Members: }\end{array} & \text { Mr. Anton Treier } \\ \text { Participation in the work: } & \text { All NEA Member countries } \\ & \begin{array}{l}\text { European Commission } \\ \text { Under the NEA Statute } \\ \text { International Atomic Energy Agency (IAEA) } \\ \text { By agreement }\end{array} \\ \text { Observers: } & \begin{array}{l}\text { Russian Federation } \\ \text { Slovenia }\end{array} \\ \text { Date of creation: } & \text { June 2001 } \\ \text { Duration: } & \text { December } 2009\end{array}$

Mandate: - Summary Record of the 12th meeting of the Committee on Nuclear Regulatory Activities (CNRA) [NEA/SEN/NRA(2001)1]

- Summary Record of the 1st meeting of the Working Group on Public Communication of Nuclear Regulatory Organisations (WGPC) [NEA/SEN/NRA/WGPC(2001)2]

- Summary Record of the 2005 CNRA Summer meeting [NEA/SEN/NRA(2005)3]

- CNRA Operating Guidelines, June 2006 [NEA/CNRA/R(2006)3]

- Summary Record of the 2006 CNRA Summer meeting [NEA/SEN/NRA(2006)3]

\section{Extract from document [NEA/SEN/NRA(2006)3]}

1. "The Working Group will share information, news, documents, data, views, ideas, and experiences in the field of public communication and stakeholder interaction. It will keep abreast of activities of a similar or related nature undertaken by other parts of the NEA.

2. The Working Group will review developments, progress, techniques, tools, procedures and achievements in the area of nuclear regulatory communication with the public and stakeholders. It will highlight lessons learned and good practices.

3. The Working Group will provide assistance to CNRA members, through technical notes and workshops, by addressing specific issues and practices.

4. The Working Group will co-operate, internally and externally, with other organisations in regulatory public communication and stakeholder interaction matters, in line with NEA policy." 


\title{
WORKING GROUP ON OPERATING EXPERIENCE (WGOE)
}

\author{
Chair: \\ Ms. Kulvinder McDonald \\ (United Kingdom) \\ Vice-Chairs: \\ Mrs. Seija Suksi \\ (Finland) \\ Mr. Frederik W. van Iddekinge \\ (Netherlands) \\ Mrs. Mary Jane Ross-Lee \\ (United States) \\ Members: \\ All NEA Member countries \\ Participation in the work: \\ European Commission \\ Under the NEA Statute \\ International Atomic Energy Agency (IAEA) \\ By agreement \\ Observer: \\ Russian Federation \\ Union of the Electricity Industry (EURELECTRIC) \\ World Association of Nuclear Operators (WANO) \\ Date of creation: \\ July 2005
}

Duration:

December 2009

Mandate: - Recommendations to CSNI for Future Activities [SEN/SIN(82)50]

- Recommendation to CSNI from Report of the Task Group Reviewing the Activities of the Principal Working Group 1 (PWG1) [NEA/SEN/SIN/WG1(94)5]

- Summary Record of the 28th Meeting of the Committee on the Safety of Nuclear Installations (CSNI) [NEA/SEN/SIN(2001)1]

- Summary Records from the 2005 Summer Meeting of the Committee on Nuclear Regulatory Activities (CNRA) [NEA/SEN/NRA(2005)3] and the 37th Meeting of the Committee on the Safety of Nuclear Installations (CSNI) [NEA/SEN/SIN(2005)3]

- CNRA Operating Guidelines, June 2006 [NEA/CNRA/R(2006)3]

- Summary Record of the 17th Annual Meeting of the Committee on Nuclear Regulatory Activities (CNRA) [NEA/SEN/NRA(2006)1]

\section{Extract from document [NEA/SEN/NRA(2006)1]}

"Working Group on Operating Experience (WGOE) - CNRA Members approved the revised mandate (based on final editing by WGOE Chair) and emphasized the need to analyse operating experience towards improved inspection practices and new research (through specific proposals to the Committee) and to assess operating experience through IRS and other data bases (international and national)..."

"Objectives

\section{Extract from document [NEA/CNRA/R(2006]3]}

The main objective of WGOE is to share experience and knowledge, analyse and provide expert insights from operating experience to reach timely conclusions on trends, lessons learnt and effective responses in the short to medium term, and to promote proposals for reassessment of safety, additional research, new or revised regulatory inspection practices, improvements in managing operations, and other actions to maintain and improve safety in the longer term. 
In order to accomplish this prime objective the working group shall:

- Meet periodically to share from their member states incident and event information covering trends, significant important events, responses and measures taken, and lessons learnt.

- Meet periodically to review the information from the IRS and other data bases. Have oversight of the Incident Reporting System (IRS) established for collection and dissemination of operating experience. The Working Group should also ensure the quality of the IRS reports and that the corrective actions are presented in such a manner that they allow others to consider whether similar measures should be implemented, thus facilitating CNRA to discuss and decide on respective actions.

- Promote the development and sharing of improved techniques and methods for the collection, assimilation, review and analysis of incidents.

- Provide expert insight and analysis capabilities to event and inspection experience, and effectiveness of actions taken.

\section{Methods of Working}

- Constitute a forum of experts for the analysis of operating experience from regulatory authorities, technical support organisations and industry representatives.

- Closely co-ordinate with and provide input to the Working Group on Inspection Practices (WGIP), as the analysis of operating experience and analysis of inspection experience are both of high importance for regulatory oversight of operational safety.

- Report to the Committee on Nuclear Regulatory Activities (CNRA) and assist that Committee with its work. The programme of work of WGOE will be approved by CNRA. It shall also sponsor specialist meetings and workshops to further its objectives.

- Provide and receive regular reports to and from the Committee on the Safety of Nuclear Installations (CSNI), from which the CSNI may consider initiating specific tasks in existing working groups, establish new research programmes or provide input on the current state-of-the-art. The Working Group shall collaborate with or assist the CSNI Working Groups and NEA Projects.

- Coordinate its work with other NEA committees and international organisations (e.g., IAEA, EC, WANO, etc.).

- Provide regular reports to the CNRA on trends, significant important events, responses and measures taken, lessons learnt nationally and internationally." 


\section{WORKING GROUP ON THE REGULATION OF NEW REACTORS (WGRNR)}

Chair:

Vice-Chair:

\section{Members:}

Participation in the work: ${ }^{1}$

Observers:

Date of creation:

Duration:
Ms. Laura Dudes

(United States)

$(\ldots)$

All NEA Member countries

International Atomic Energy Agency (IAEA)

By agreement

European Commission

Under the NEA Statute

Russian Federation

Slovenia

3rd December 2007

3rd December 2010

Mandate: $\quad$ Summary Record of the 19th Annual CNRA Meeting [NEA/SEN/NRA(2007)2]

\section{Extract from document NEA/SEN/NRA(2007)2]}

"Summary of CNRA Approvals and Actions to be taken

I. Working Group on the Regulation of New Reactors (WGRNR) - CNRA approved the setting up of this Working Group and its mandate.

Appendix C

MANDATE - WORKING GROUP ON THE REGULATION OF NEW REACTORS (WGRNR)

Scope

The Working Group on Regulation of New Reactors (WGRNR) shall be responsible for the programme of work in the CNRA dealing with regulatory activities in the primary program areas of siting, licensing and oversight for new commercial nuclear power reactors (Generation III+ and Generation IV reactors). The working group shall constitute an international forum for exchanging information and experience and with the agreement of CNRA and will plan its work to ensure improvements in nuclear safety through more effective and efficient regulation. In order to accomplish this prime objective the working group shall:

- WGRNR shall constitute a forum of experts for the licensing of new commercial nuclear power reactors and should facilitate a cooperative approach to identify key new regulatory issues and promote a common resolution.

\footnotetext{
1 By agreement
} 
- WGRNR should co-ordinate its work with the work performed by the Multinational Design Evaluation Programme (MDEP) such that: it utilises its outputs and does not duplicate its efforts; extends the results of MDEP to other CNRA members and in coordination with MDEP plans for the transition of MDEP into CNRA.

- WGRNR should ensure that construction inspection issues and construction experience is shared through existing CNRA working groups or new working groups as appropriate.

- WGRNR should plan for the transition of new reactors into the operational phase and established CNRA programs.

- WGRNR should identify support needed from CSNI.

Methods of working

- Report to the Committee on Nuclear Regulatory Activities (CNRA) and assist that Committee with its work. The programme of work of WGRNR will be approved by CNRA.

- Closely co-ordinate its work with the CNRA Working Group on Inspection Practices and the Working Group on Operating Experience and the CSNI Working Group on Risk Assessment such that each of the respective groups use the expertise of the individual groups and do not duplicate efforts.

- Provide and receive regular reports to and from the Committee on the Safety of Nuclear Installations (CSNI), from which the CSNI may consider initiating specific tasks in existing working groups, establish new research programmes or provide input on the current state-of-the-art. The Working Group shall collaborate with or assist the CSNI Working Groups and NEA Projects.

- Co-ordinate its work with other NEA committees and international organisations (e.g., IAEA, EC, WANO, etc.)." 


\section{RADIOACTIVE WASTE MANAGEMENT COMMITTEE (RWMC)}

\begin{tabular}{|c|c|c|}
\hline Chair: & Ms. Marie-Claude Dupuis & (France) \\
\hline Vice-Chairs: & $\begin{array}{l}\text { Ms. Kathryn Shaver } \\
\text { Mr. Masaaki Mishiro } \\
\text { Mrs. Carmen Ruiz Lopez } \\
\text { Mr. Piet Zuidema }\end{array}$ & $\begin{array}{l}\text { (Canada) } \\
\text { (Japan) } \\
\text { (Spain) } \\
\text { (Switzerland }\end{array}$ \\
\hline Members: & \multicolumn{2}{|l|}{ All NEA Member countries } \\
\hline Participation in the work: & \multicolumn{2}{|l|}{$\begin{array}{l}\text { European Commission } \\
\text { Under the NEA Statute }\end{array}$} \\
\hline & \multicolumn{2}{|c|}{$\begin{array}{l}\text { International Atomic Energy Agency (IAEA) } \\
\text { By agreement }\end{array}$} \\
\hline Observer: & \multicolumn{2}{|l|}{ Russian Federation } \\
\hline & \multicolumn{2}{|l|}{ Slovenia } \\
\hline Date of creation: & \multicolumn{2}{|l|}{ 23rd June 1975} \\
\hline Duration: & \multicolumn{2}{|l|}{ 31st December 2010} \\
\hline
\end{tabular}

Mandate : - Record of the 50th meeting of the Steering Committee for Nuclear Energy on 9th October 1975 [NE/M(75)3]

- Proposed Strategy and Programme of Work in the Field of Radioactive Waste Management [NE(81)14]

- Revision of the Mandate of the Radioactive Waste Management Committee (RWMC) [NEA/NE(92)5], approved by the Steering Committee on Nuclear Energy on 6th-7th October 1992

- Review of the NEA Committee Structure [NEA/NE(2000)11/REV1]

- Review of Mandates of the NEA Standing Technical Committees [NEA/NE(2005)2]

- Summary of decisions taken at the 117th session of the Steering Committee for Nuclear Energy [NEA/SUM/DEC(2008)2]

\section{Extract from document [NEA/SUM/DEC(2008)2]}

"The Steering Committee:

ii) extended all standing technical committee mandates [...] until 31 December 2010, as presented in Appendix 1 of document NEA/NE(2008)6."

\section{Extract from document [NEA/NE(2005)2]}

"The NEA has an acknowledged role in developing a global strategy for considering aspects of sustainability concerning the use of nuclear power and nuclear materials. The general objective of the NEA in the field of radioactive waste management is to assist Member countries in the area of management of radioactive waste and materials, focusing on the development of strategies for the safe, sustainable and broadly acceptable management of all types of radioactive waste, in particular long-lived waste, and spent fuel. In this context, the mandate of the Radioactive Waste Management Committee (RWMC) shall be: 
1. To provide a forum of senior representatives from national agencies, regulatory authorities, policy-making bodies, research and development institutions with responsibilities in the management of waste and materials, as well as other government-nominated specialists, for the exchange of information and experience on waste management policies and practices in NEA Member countries, and for advancing the state of the art on the technical and societal aspects in this area.

2. To contribute to the dissemination of information in this field through the organisation of specialist meetings and the publication of reports and consensus statements summarising the results of joint activities for the benefit of the international scientific community, competent authorities at national level and other audiences generally interested in the subject matter.

3. To develop a common understanding of the basic issues involved, and to promote the adoption of common philosophies of approach based on the discussion of the various possible strategies by keeping under review the state of the art in the field of management of radioactive waste and material at the technical, scientific, regulatory and societal levels, and in public acceptance matters.

4. To offer, upon request, a framework for the conduct of international peer reviews of national activities in the field, such as R\&D programmes, safety assessments, specific regulations, etc.

5. To promote co-operative efforts such as the setting-up of joint R\&D projects, or the development of databases, and to promote initiatives to maintain relevant competencies and knowledge.

For developing its work programme, and in its modus operandi, the RWMC will rely on discipline-oriented working parties in the areas of disposal, decommissioning and associated societal issues. RWMC members delegated from regulatory authorities meet also in the RWMC Regulators' Forum (RWMC-RF) to exchange specific information on issues of specific regulatory significance. The RWMC-RF maintains appropriate links with the CNRA.

In the fulfilment of its responsibilities, the RWMC will interact with relevant NEA Committees, OECD directorates, scientific bodies and international organisations." 


\author{
Chair: \\ Mr. Georg Arens \\ (Germany) \\ Vice-Chairs: \\ Mr. Walter Blommaert \\ (Belgium) \\ Mr. Esko Ruokola \\ (Finland) \\ Members: \\ All NEA Member countries \\ Participation in the work: \\ European Commission \\ Under the NEA statute \\ International Atomic Energy Agency (IAEA) \\ By agreement \\ Observer: \\ Slovenia \\ Date of creation: \\ 2001 \\ Duration: \\ 31st December 2010
}

Mandate : - Mandate of the RWMC Regulators' Forum [NEA/RWM/RF(2001)2]

- Mandate of the RWMC Regulator's Forum [NEA/RWM/RF(2001)2/REV1]

\title{
Extract from document [NEA/RWM/RF(2001)2/REV1]
}

- facilitates multilateral communication and information exchange among RWMC regulators and promotes a frank interchange in open dialogue among peers;

- defines and addresses future regulatory challenges and issues in the area of waste management and disposal; decommissioning and dismantling are also relevant issues;

- promotes discussion and exchange with other groups involved with regulations both within the NEA, i.e., the CNRA and the CRPPH committees, and outside the NEA, such as the IAEA, the EC, and the ICRP. Emphasis is on two-way exchange to benefit from related experience;

- takes initiative within the RWMC in the area of regulation and licensing. This includes promoting discussions within the RWMC, proposing specific products to be developed, recommending relevant initiatives by other RWMC groups, and preparing concerted initiatives by the RWMC and other NEA committees." 


\section{INTEGRATION GROUP FOR THE SAFETY CASE OF RADIOACTIVE WASTE REPOSITORIES (IGSC)}

Chair:

Vice-Chairs:

Members:

Participation in the work:

Date of creation:

Duration:
Mr. Hiroyuki Umeki

Dr. Paul Gierszewski

Mr. Bruno Cahen

Dr. Klaus-Juergen Röhlig

Mr. Bo Stromberg

Mr. Eric Smistad

All NEA Member countries

European Commission

Under the NEA Statute

International Atomic Energy Agency (IAEA)

By agreement

June 2000

31st December 2010
(Japan)

(Canada)

(France)

(Germany)

(Sweden)

(United States)

Mandate : - Mandate of the RWMC Working Party: "Integration Group for the Safety Case of Radioactive Waste Repositories" (IGSC) [NEA/RWM(2005)6]

- Mandate for the Integration Group for the Safety Case (IGSC) - Update and Extension (through 2010) [NEA/RWM/IGSC(2008)5]

\section{Extract from document [NEA/RWM/IGSC(2008)5]}

"Mission

The IGSC provides advice to the RWMC on major and emerging issues in the areas III and IV of the RWMC strategic document [NEA/RWM(2007)2], namely: "facilitate the elaboration of waste management strategies at national and international levels" and "enable the management of radioactive waste and materials to benefit from progress of scientific and technical knowledge".

The IGSC is the main technical advisory body to the RWMC regarding methodologies and strategies for characterising and evaluating disposal sites and for repository design as well as for developing and documenting safety assessment and safety cases for geological repositories to accommodate various waste types. In principle, the scope of its activities is the whole range of elements to be addressed in a safety case. In particular, the IGSC:

- Advises the RWMC on major and emerging issues in the strategic areas of the process of repository development and of their related system analyses and technological advances;

- Promotes the exchange of information on such issues;

- Strives to achieve shared approaches and tools, where appropriate.

The IGSC mandate covers not only site characterisation, design development and safety assessment, but also addresses other elements of the safety case, including: 
- Compilation and documentation of safety cases;

- Appropriate statements of confidence in the system and in the safety assessment;

- Providing support to interactions with decision makers and other stakeholders.

Activities of the IGSC have traditionally focused on long-term safety. However, as some national programmes approach licensing, a higher degree of integration is required, not only for all elements related to long-term safety, but also of engineering and operational considerations.

It is recognised that to achieve confidence in (and acceptance of) a repository, it must be shown not only that the system will be safe over the long term, but also that it can be built and operated safely."

\section{Extract from document [NEA/RWM(2005)6]}

$" \ldots$

1. To define, oversee and carry out a work programme of technical activities related to the development, evaluation, and communication of safety cases as a basis for confidence and decision making within the development of repositories for long-lived radioactive waste as well as other specific aspects of repository development as assigned by the RWMC.

2. To inform and advise the RWMC in strategic areas II and VI of its programme of work and, in particular, to promote discussion and recommend relevant initiatives within the RWMC and its subsidiary bodies.

3. To facilitate multilateral communication and information exchange among the IGSC members, and promote a frank interchange in an open dialogue among peers. In particular, the IGSC provides a neutral forum for dialogue amongst representatives of waste management agencies, regulatory authorities and other relevant institutions regarding confidence in the technical results of safety cases with a view to identify emerging issues and trends, review the state of the art, promote further understanding and common views, including the development of tools.

4. To define and address challenges and issues related to developing, evaluating, and communicating confidence in the technical safety case of deep geologic disposal projects in relation to the need for decision making in repository development. Emphasis is on the identification and pursuit of issues and on the development of technical tools for which there is pan-national interest, and on publishing the group's findings where this is found appropriate.

5. To promote discussion, information exchange and joint initiatives with other groups both within the NEA, e.g., the FSC, and outside the NEA, e.g., the IAEA, the EC, and the ICRP, as well as with the scientific community at large." 


\section{FORUM ON STAKEHOLDER CONFIDENCE (FSC)}
Chair:
Ms. Janet Kotra
(United States)
Vice-Chairs:
Ms. Jo-Ann Facella
(Canada)
Mr. Gérald Ouzounian
(France)
Mr. Mariano Molina Martín
(Spain)
Ms. Elizabeth Atherton
(United Kingdom)
Members:
Participation in the work:
Observer:
Date of creation:
Duration:
All NEA Member countries
European Commission Under the NEA Statute
International Atomic Energy Agency (IAEA)
By agreement
August 2000
31st December 2010

Mandate: - Mandate of the RWMC Working Party "Forum on Stakeholder Confidence" [NEA/RWM/FSC(2000)1]

- Forum on Stakeholder Confidence - Mandate: Phase 2 [NEA/RWM/2003)4/REV2]

- FSC Mandate [NEA/RWM(2005)13/REV1]

- Mandate of the RWMC Working Party "Forum on Stakeholder Confidence (FSC)" [NEA/RWM(2005)13/REV2]

\section{Extract from document [NEA/RWM/(2005)13/REV2]}

"...

1. To define, oversee and carry out work programme activities in the strategic area of public perception and stakeholders' confidence as assigned by the RWMC.

2. To advise the RWMC on major and emerging issues in the area of public perception and stakeholders' confidence related to waste management.

3. To act as a forum to share experience in achieving stakeholders' confidence and, in particular, in how to obtain the trust of local communities, and their representatives and intermediaries with the technical decision makers. Public input to decision making, while maintaining a workable decision-making process, needs to be more fully explored, especially in relation to the role of the regulator.

4. To analyse today's processes for embedding waste management programmes into a socio-political decision-making context.

5. To identify opportunities for harmonised views of Member countries, regarding:

- Successful and unsuccessful experiences in interacting with stakeholders (e.g., compiling and reviewing factual information and experiences related both to outreach programmes and to public inquiries, drawing out and examining generic elements that are required to ensure and maintain credibility of waste management organisations);

- Technical concerns of stakeholders;

- Effective means of communicating with technical and non-technical audiences." 


\section{WORKING PARTY ON DECOMMISSIONING AND DISMANTLING (WPDD)}

\begin{tabular}{|c|c|c|}
\hline Chair: & Mr. Ivo Tripputi & (Italy) \\
\hline Vice-Chairs: & $\begin{array}{l}\text { Mr. Doug Metcalfe } \\
\text { Mr. Jean-Guy Nokhamzon } \\
\text { Mr. Luis Valencia } \\
\text { Mr. Juan Luis Santiago } \\
\text { Mr. Rateb Abu-Eid }\end{array}$ & $\begin{array}{l}\text { (Canada) } \\
\text { (France) } \\
\text { (Germany) } \\
\text { (Spain) } \\
\text { (United States) }\end{array}$ \\
\hline Members: & \multicolumn{2}{|l|}{ All NEA Member countries } \\
\hline Participation in the work: & \multicolumn{2}{|c|}{$\begin{array}{l}\text { International Atomic Energy Agency (IAEA) } \\
\text { By agreement }\end{array}$} \\
\hline Observer: & \multicolumn{2}{|l|}{ Russian Federation } \\
\hline Date of creation: & \multicolumn{2}{|l|}{ May 2001} \\
\hline Duration: & 31st October 2010 & \\
\hline
\end{tabular}

Mandate: - Mandate of the RWMC Working Party on Management of Materials from Decommissioning and Dismantling [NEA/RWM/WPDD(2001)2]

- Mandate on the RWMC Working Party on Management of Materials from Decommissioning and Dismantling [NEA/RWM(2003)10]

- Update of the RWMC Working Party on the Management of Materials from Decommissioning and Dismantling (WPDD) Mandate [NEA/RWM(2005)5]

- Summary record of the 38th meeting of the RWMC [NEA/RWM(2005)16, para. 7 e]

- Mandate of the RWMC Working Party on Decommissioning and Dismantling (WPDD) [NEA/RWM(2008)8]

\section{Extract from document [NEA/RWM(2008)8]}

"The remit of the WPDD is as follows:

1. To define, oversee and carry out work programme activities as assigned by the RWMC, in order to increase the outreach and efficiency of both the RWMC and NEA in the field of Decommissioning as described in the NEA Strategic Plan 20052009.

2. To identify and analyse main issues regarding policies and strategies for the Decommissioning of phased-out nuclear facilities, including funding related issues, and the attending issues of recycling, reuse and/or disposal of materials and the release of buildings and sites.

3. To observe, on a world-wide level, the development of the state of the art of management and technique of decommissioning projects, and make it better available to other NEA bodies engaged in this crosscutting field, in particular building on the experience from the technical information exchange performed within the CPD. 
4. To facilitate multilateral communication and information exchange among the WPDD members, and to promote an open dialogue among peers, in particular the regulatory authorities, $R \& D$ institutions and the decommissioning industry both private and public,

5. To keep the WPDD members and the RWMC aware of progress and activities in other international fora and their implications, and help the RWMC participate in international initiatives. Co-ordination with EC and IAEA initiatives is important.

6. In close co-operation with the FSC examine and further develop the link between decommissioning, decision-making and public confidence and acceptance, keeping in mind the long time scales for planning and carrying out decommissioning projects.

7. To set up, manage, and make broadly available a database of information on decommissioning in NEA Member countries.

8. To be of service to the other NEA committees with the goal to strengthen overall visibility of decommissioning as a NEA crosscutting activity." 


\section{COMMITTEE ON RADIATION PROTECTION AND PUBLIC HEALTH (CRPPH)}

Chair:

Vice-Chairs:

Members:

Participation in the work:

Observers:

Date of creation:

Duration:
Mr. Jacques Lochard

Ms. Karla Petrova

Mr. Wolfgang Weiss

Mr. Sigurdur Magnusson

Ms. Ann McGarry

Mr. Yasuhiro Yamaguchi

All NEA Member countries

European Commission

Under the NEA Statute

International Atomic Energy Agency (IAEA)

By agreement

Russian Federation
Slovenia

International Commission on Radiological Protection (ICRP) International Radiation Protection Association (IRPA)

UN Scientific Committee on the Effects of Atomic Radiation

(UNSCEAR)

World Health Organization (WHO)

3rd July 1957

31st December 2010

Mandate : $\quad$ - Minutes of the 322nd Meeting of the Council on 18th April 1973 [C/M(73)10(Final), Item 108]

- Report by the Steering Committee on the Programme and Priorities of the Agency [C(73)55]

- Proposed Strategy and Programme of Work in the Field of Radiation Protection and Public Health [NE(82)5]

- Review of the Mandate of the Committee on Radiation Protection and Public Health (CRPPH) [NEA/NE(93)13/CORR1]

- Review of the NEA Committee Structure [NEA/NE(2000)11/REV1]

- Review of Mandates of the NEA Standing Technical Committees [NEA/NE(2005)2]

- Summary of decisions taken at the 117th session of the Steering Committee for Nuclear Energy [NEA/SUM/DEC(2008)2]

\section{Extract from document [NEA/SUM/DEC(2008)2]}

"The Steering Committee:

ii) extended all standing technical committee mandates [...] until 31 December 2010, as presented in Appendix 1 of document NEA/NE(2008)6." 


\section{Extract from document [NEA/NE(2005)2]}

"The general objective of the NEA in the field of radiation protection is to contribute to the adoption and the maintenance of high standards of protection for workers, members of the public, and the environment in all practices involving the use of ionising radiation, and particularly in the field of nuclear energy.

In this context, the mandate of the Committee on Radiation Protection and Public Health (CRPPH) shall be:

- to provide a forum for the exchange of information and the transfer of experience between national radiation protection and public health authorities on radiation protection policies, regulatory issues and approaches, and their implementation in the various practices and situations involving radiation exposures;

- to seek international understanding and guidance, in support of national authorities, on questions of common concern regarding the interpretation and implementation of the ICRP recommendations and other international standards in various fields of application of radiation protection, and to contribute to the development of harmonised positions in this field;

- to keep under review and contribute to the advancement of the state of the art in the field of radiation protection at the scientific and technical levels and promote the preparation of authoritative advice and reference documents, for use by national authorities and policy makers, on emerging policy, regulatory and operational issues, and in those areas where international consensus on radiation protection concepts, regulatory issues and practices is required;

- to advance concepts and policies which make the system of radiation protection more simple, transparent and adaptable to the broader social dimensions of decision making in complex radiological situations;

- to promote and initiate international co-operative activities on specific radiation protection and radiation-related public health topics of interest to NEA Member countries in the framework of the NEA Strategic Plan.

In the fulfilment of its mandate, the CRPPH will work in close co-operation with other

NEA committees as appropriate, particularly the CNRA and the RWMC, as well as with the competent bodies within relevant OECD directorates and other international organisations active in the field." 


\title{
WORKING PARTY ON NUCLEAR EMERGENCY MATTERS (WPNEM)
}

\author{
Chair: \\ Mr. Vince McClelland \\ (United States) \\ Vice-Chair: \\ Mr. Finn Ugletveit \\ (Norway) \\ Members: \\ All NEA Member countries \\ Participation in the work: \\ European Commission \\ Under the NEA Statute \\ International Atomic Energy Agency (IAEA) \\ By agreement \\ Observer: \\ Russian Federation \\ UN Food and Agricultural Organization (FAO) \\ World Health Organization (WHO) \\ Date of creation: \\ September 1993 \\ Duration: \\ March 2009
}
Mandate : - CRPPH - Report on the First International Nuclear Emergency Exercise (INEX 1) [NEA/SEN/SAN(93)2]
- Summary Record of the 51st Meeting of the CRPPH [NEA/SEN/SAN(93)8]
- Summary Record of the 58th meeting of the Committee on Radiation Protection and Public Health [NEA/CRPPH(2000)12]
- Summary record of 62 nd meeting of the Committee on Radiation Protection and Public Health [NEA/CRPPH(2004)8]
- Summary Record of the 64th Meeting of the Committee on Radiation Protection and Public Health (CRPPH) [NEA/CRPPH(2006)3]

\section{Extract from document [NEA/CRPPH(2006)3]}

"The mission of the CRPPH Working Party on Nuclear Emergency Matters (WPNEM) is to improve nuclear emergency management systems within member states, and to share its knowledge and experience widely. In this context, emergency matters refer to all aspects of planning, preparedness and response for the "early" and "intermediate" phases of a nuclear/radiological event, with a view towards preparation of recovery actions.

Within this framework, the WPNEM develops its programme of work by identifying and analysing areas for improvement in emergency management systems. The programme of work is developed in coordination with member states and other relevant organisations.

Participants are emergency management experts from OECD NEA countries with recognised knowledge, skills and abilities in the nuclear field. The Working Party employs a flexible approach to address issues across the entire spectrum of nuclear and radiological emergency and recovery management. Participants share information, data, knowledge, and experience to test all aspects of emergency management systems and theories, identify gaps and provide recommended strategies to improve nuclear emergency management worldwide.

The Working Party on Nuclear Emergency Matters successfully fulfilled the tasks laid down in its Terms of Reference, NEA/CRPPH/INEX(2003)3, which were approved by the CRPPH at its 62nd meeting in March 2004. The Terms of Reference were valid for a period ending in 2006. 
The proposed new Terms of Reference of the Working Party on Nuclear Emergency Matters for 2006-March 2009 are as follows:

- Continue development of INEX series exercises to address best practices and identify areas for improvement in nuclear/radiological emergency management systems.

- Continue INEX series post-exercise evaluations, conduct international evaluation workshops, and publish reports to enable improvements to nuclear/radiological emergency management systems.

- Provide a framework for validation of relevant products coordinated in advance with the working party. Such products may include those developed under the IAEA International Action Plan, the EURANOS project or other coordinated activities.

- Identify and investigate as appropriate further advancements in all aspects of emergency planning, preparedness and response for nuclear accidents and radiological emergencies, for example:

-- Withdrawal of early countermeasures;

-- International harmonisation;

-- Sustainable approaches;

-- Knowledge of best practices;

-- $\quad$ Approaches to stakeholder involvement;

-- Strategies for implementation of lessons identified;

-- $\quad$ Third party liability issues;

-- Public information.

- $\quad$ As needed, review and update WPNEM documents and reports.

- Upon request, provide input as appropriate for the development of international standards and recommendations on emergency management. Such request may include ICRP and IAEA documents;

- Develop, co-ordinate and evaluate WPNEM objectives for inclusion in international exercises such as those organised under the auspices of the Inter-Agency Committee on the Response to Nuclear Accidents (IACRNA);

- Periodically report programme progress to the CRPPH.

These Terms of Reference, approved for the period 2006-2009, will be used as the basis for the yearly programme of work." 


\section{NUCLEAR SCIENCE COMMITTEE (NSC)}

Chair:

Vice-Chairs:

Members:

Participation in the work:

Observers:

Date of creation:

Duration:

Mr. John Herczeg

Mr. Pierre Joseph D'Hondt

Mr. Alain Zaetta

Mr. Takamasa Mori

Mr. Rakesh Chawla
(United States)

(Belgium)

(France)

(Japan)

(Switzerland)

All NEA Member countries

European Commission

Under the NEA Statute

International Atomic Energy Agency (IAEA)

By agreement

Russian Federation

Slovenia

1st October 1991

31st December 2010

Mandate: - Terms of Reference for the Committee and an Executive Group [NEA/SEN/NSC(91)1]

- Review of the NEA Committee Structure [NEA/NE(2000)11/REV1]

- Review of Mandates of the NEA Standing Technical Committees [NEA/NE(2005)2]

- Summary of decisions taken at the 117th session of the Steering Committee for Nuclear Energy [NEA/SUM/DEC(2008)2]

\section{Extract from document [NEA/SUM/DEC(2008)2]}

"The Steering Committee:

ii) extended all standing technical committee mandates [...] until 31 December 2010, as presented in Appendix 1 of document NEA/NE(2008)6."

\section{Extract from document [NEA/NE(2005)2]}

\section{"SCIENCE}

1. The general objective of the NEA in the field of nuclear science is to help Member countries identify, collate, develop and disseminate basic scientific and technical knowledge required to ensure safe, reliable and economic operation of current nuclear systems and to develop next-generation technologies.

2. In this context, the mandate of the Committee is to:

- help advance the existing scientific knowledge needed to enhance the performance and safety of current nuclear systems;

- contribute to building a solid scientific and technical basis for the development of future-generation nuclear systems and spin-off technologies; 
- $\quad$ support the preservation of essential knowledge in the field of nuclear science;

especially, but not exclusively, in the following areas:

- nuclear physics; nuclear data measurements and evaluations;

- computational science and mathematical modelling methods;

- reactor physics, neutronics and coupling with thermal-hydraulics; fuel behaviour;

- criticality safety issues related to the front- and back-end of the fuel cycle;

- fuel cycle physics and chemistry;

- partitioning and transmutation of nuclear waste;

- $\quad$ radiation shielding and dosimetry;

- accelerator development for future technologies;

- preservation and renewal of expertise in nuclear science.

3. In the fulfilment of its mandate, the Committee will interact with other standing technical committees of the Agency in matters of common interest and with other bodies within the Organisation, as well as with other international organisations, as appropriate.

\section{COMMITTEE OFFICERS}

The Committee shall designate a bureau with one Chair and four Vice-chairs for a oneyear term. One of the Vice-chairs will act as chair of the Executive Group. The bureau undertakes tasks delegated to it by the Committee, and participates in the preparation of Committee meetings and in the follow-up of Committee decisions, in close co-operation with the Secretariat." 


\title{
WORKING PARTY ON INTERNATIONAL NUCLEAR DATA EVALUATION CO-OPERATION
} (WPEC)

\author{
Chair: \\ Mr. Jun-ichi Katakura \\ (Japan) \\ Members: \\ Representatives of the co-operating nuclear data projects \\ Participation in the work: European Commission \\ Under the NEA Statute \\ International Atomic Energy Agency (IAEA) \\ By agreement \\ Observer: \\ Russian Federation \\ Date of creation: \\ June 1999
}

Duration:

October 2009
Mandate: - Status of the NEA Nuclear Science Committee Projects and their Evolution in 2007 [NEA/SEN/NSC(2006)2]
- Summary Record of the 17th meeting of the Nuclear Science Committee (NSC) [NEA/SEN/NSC(2006)3]

\section{Extract from document [NEA/SEN/NSC(2006)2]}

"Mission

The goal of the Working Party is to improve the quality and completeness of evaluated nuclear data available for use in science and technology and to promote the efficient use of available resources through international collaboration.

\section{Scope}

The nuclear data evaluation co-operation activities described within this document will involve the evaluation projects in the following regions: Japan (JENDL), United States (ENDF), Western Europe (JEFF), and non-OECD countries (BROND, CENDL, and FENDL). The participation of the evaluation projects in non-OECD Member countries will be channelled through the Nuclear Data Section of the International Atomic Energy Agency (IAEA).

\section{Objectives}

The Working Party is established under the auspices of the NEA Nuclear Science Committee (NSC) to promote the exchange of information on nuclear data evaluations, measurements, nuclear model calculations, validation, and related topics, and to provide a framework for co-operative activities between the participating projects. The Working Party will assess needs for nuclear data improvements and address those needs by initiating joint evaluation and/or measurement efforts. The Working Party will meet and report to the NSC on an annual basis.

Participation

The Working Party will consist of four representatives of each participating region, nominated by the respective projects. The representative from the IAEA Nuclear Data Section will nominate participants from non-OECD countries. At least one member of each regional group will 
be a representative of the nuclear data measurement community. Former Working Party chairmen are permanent members of the Working Party.

The Working Party may identify specific activities to be co-ordinated directly by the Working Party. The individuals assigned to co-ordinate these activities will be ex-officio members of the Working Party.

In order to promote close co-operation with other relevant activities, the Chairman and Secretariat may invite appropriate experts to participate in Working Party meetings, following approval by the designated heads of the participating projects.

A limited number of observers may be invited to specific Working Party meetings, following official nomination by a designated head of a participating project with the concurrence of the Chairman and the Secretariat.

Chairman

A Working Party chairman shall be elected for a two-year period, with possible yearly extensions; the guiding principal being an alternating chairmanship between the ENDF, JEFF and JENDL projects. Eligible candidates are representatives of the OECD evaluation projects.

Methods of Work

At its annual meeting the Working Party will review its mandate, discuss the status of the participating projects, review ongoing subgroup activities, and review proposals for new cooperative activities. In addition, the Working Party may organise workshops and specialists' meetings.

Status reports from each of the projects and each of the ongoing co-operative activities will be submitted to the Secretariat for distribution to the participants.

Only proposals for new co-operative activities submitted on the standard proposal form (template available from the NEA secretariat) and having support from at least two evaluation projects will be considered.

The Working Party will set up a Subgroup to perform the agreed technical co-operative activities. The number of active Subgroups at one time shall be limited, depending on the available resources within the participating projects, and at the discretion of the Working Party chairman in consultation with the project leaders.

All above-mentioned documents and reports must be submitted to the Secretariat at least six weeks before the Working Party meeting.

\section{Subgroups}

Subgroups will be established with an initial mandate of two years. The mandate can be extended by the Working Party. Subgroups will consist of members, who have special expertise in the subject area and are willing and able to participate in the work on a voluntary basis. Subgroups will be responsible for their own working methods. The Subgroup Co-ordinator will be designated by the Working Party.

The Subgroup Co-ordinator will prepare an annual progress report for presentation at the Working Party meeting. The Co-ordinator will also be responsible for producing the final report of the Subgroup and for having it reviewed by Subgroup members before it is submitted to the Working Party for publication approval. Final reports should be submitted at least two months before a Working Party meeting. 
A member of the Working Party (Monitor) will be assigned to each Subgroup to actively follow the progress. The Monitor will advise the Working Party on the status of the subgroup and will recommend specific measures to promote progress towards the agreed time-schedules and goals.

Each Subgroup will be dissolved when its task is completed. The Working Party can decide to dissolve a Subgroup due to lack of progress.

\section{Secretariat}

The NEA will assure the Secretariat of the Working Party and will be responsible for maintaining the official records of the Working Party and for organising its meetings in consultation with the Chairman. In particular, the Secretariat will consult with the Subgroup Monitors and Coordinators on the Subgroup presentations at Working Party meetings and will send out necessary reminders at least two months before these meetings. The Secretariat will maintain a list of the cooperative activities in progress, the official Working Party Web site and will be responsible for the publication of the final Subgroup reports.

Availability of Information

The data files and the results of all co-operative activities will be available without restrictions to all participants. Information developed within the co-operation will be distributed to the Secretariat, the chairmen of the projects, and the IAEA Nuclear Data Section. Distribution of information about the co-operation, to parties outside the co-operation, will be made via the Secretariat." 


\section{WORKING PARTY ON SCIENTIFIC ISSUES OF REACTOR SYSTEMS (WPRS)}

\begin{tabular}{|c|c|c|}
\hline Chair: & Mr. Kevin Hesketh & (United Kingdom) \\
\hline Vice-Chair: & Mr. Pierre Joseph D'Hondt & (Belgium) \\
\hline Members: & \multicolumn{2}{|l|}{ All NEA Member countries } \\
\hline Participation in the work: & \multicolumn{2}{|l|}{$\begin{array}{l}\text { European Commission } \\
\text { Under the NEA Statute }\end{array}$} \\
\hline & \multicolumn{2}{|c|}{$\begin{array}{l}\text { International Atomic Energy Agency (IAEA) } \\
\text { By agreement }\end{array}$} \\
\hline Observer: & \multicolumn{2}{|l|}{ Russian Federation } \\
\hline Date of creation: & \multicolumn{2}{|l|}{2004} \\
\hline Duration: & June 2010 & \\
\hline
\end{tabular}
Mandate: - Summary Record of the 15th meeting of the Nuclear Science Committee [NEA/SEN/NSC(2004)3]
- Summary Record of the 18th meeting of the Nuclear Science Committee [NEA/SEN/NSC(2007)3]

\section{Extract from document [NEA/SEN/NSC(2007)3]}

"Scope

Under the guidance of the Nuclear Science Committee the Working Party will deal with reactor physics, fuel cycle, radiation transport and dosimetry, fuel behaviour, thermal hydraulics and dynamics/safety and uncertainty analysis of present and future nuclear power systems.

Objectives

To provide the member countries with up-to-date information to preserve knowledge on and develop consensus regarding:

- Reactor physics, fuel behaviour, thermal hydraulics and dynamics/safety issues associated with innovative fuels in present and future nuclear power systems.

- Reactor physics aspects considered include:

-- Reactivity characteristics,

-- Core power/flux distributions,

-- Core kinetics and reactivity control,

-- Reactivity coefficients,

-- Safety / system dynamics,

-- Vessel dosimetry,

-- Uncertainty analysis in modeling.

- Fuel cycle aspects considered will focus on fuel loading and discharge requirements, fission product and minor actinide inventories and radiotoxicity profiles versus time.

- Fuel behaviour, thermal hydraulics and kinetics/safety, coupled core-plant analysis will be considered insofar as they impinge on the reactor performance. 
- Radiation transport and dosimetry will cover aspects relevant for reactor vessels and internal, and irradiation facilities.

Reactor types considered include, but are not limited to the following:

- Present generation LWRs with advanced and innovative fuels, evolutionary and innovative LWRs and HWRs.

- $\quad$ Novel reactor systems (GNEP, Gen IV Systems).

- Accelerator driven (sub-critical) and critical systems for waste transmutation.

To liaise closely with other relevant NEA working groups, especially those operating under the guidance of the NDC and CSNI, to ensure the respective work programmes are complementary and to provide advice and support where required and undertake common work where appropriate. Particularly close working relationships will be maintained with the Working Party on the scientific issues in Fuel Cycle (WPFC).

To provide advice to the nuclear community on the developments needed to meet the requirements (data and methods, validation experiments, scenario studies) for different reactor systems." 
WORKING PARTY ON NUCLEAR CRITICALITY SAFETY (WPNCS)

\author{
Chair: \\ Ms. Véronique Rouyer \\ (France) \\ Members: \\ All NEA Member countries \\ Participation in the work: \\ European Commission \\ Under the NEA Statute \\ International Atomic Energy Agency (IAEA) \\ By agreement \\ Observer: \\ Russian Federation \\ Date of creation: \\ June 1996
}

Duration:

June 2010

Mandate: $\quad$ - Agreed at the 7th Meeting of the Nuclear Science Committee [NEA/SEN/NSC(96)3]

- Summary Record of the 15th meeting of the Nuclear Science Committee [NEA/SEN/NSC(2004)3]

- Summary Record of the 18th meeting of the Nuclear Science Committee [NEA/SEN/NSC(2007)3]

\title{
Extract from document [NEA/SEN/NSC(2007)3]
}

"Scope

Under the guidance of the Nuclear Science Committee, the Working Party will deal with technical and scientific issues relevant to criticality safety. Specific areas in interest include, but are not limited to investigations concerning static and transient configurations encountered in the nuclear fuel cycle such as fuel fabrication, transport and storage. Areas of activities include:

- Evaluation of available experimental data;

- Assessment of experimental needs;

- Code and data inter-comparison;

- Development of codes and models;

- Development of criticality methodologies and data;

- Establishment of technical bases for the application of burnup credit.

Objectives

- Exchange of information on national programs in the area of criticality safety.

- Guide, promote and co-ordinate high priority activities of common interest to the international criticality safety community, establish co-operations.

- Monitor the progress of all activities and report to the NSC.

- Publish databases, handbooks, and reports.

- Facilitate communications within the international criticality safety community through relevant Internet sites.

- Co-ordinate the ongoing series of International Conferences on Nuclear Criticality Safety (ICNC), to be held every four years.

- Co-ordinate WPNCS activities with other working groups within the NEA and in other international frameworks to avoid duplication of activities.

- Provide a technical basis for other international activities (e.g. ISO, IAEA)." 


\title{
WORKING PARTY ON SCIENTIFIC ISSUES OF THE FUEL CYCLE (WPFC)
}

\author{
Chair: \\ Ms. Kathryn A. McCarthy \\ (United States) \\ Members: \\ All NEA Member countries \\ Participation in the work: \\ European Commission \\ Under the NEA Statute \\ International Atomic Energy Agency (IAEA) \\ By agreement \\ Observer: \\ Russian Federation \\ Date of creation: \\ June 2004 \\ Duration: \\ June 2010
}

Mandate: - Summary Record of the 15th meeting of the Nuclear Science Committee (NSC) [NEA/SEN/NSC(2004)3]

- Summary Record of the 18th meeting of the Nuclear Science Committee (NSC) [NEA/SEN/NSC(2007)3]

\section{Extract from document [NEA/SEN/NSC(2004)3]}

"Scope

Under the guidance of the Nuclear Science Committee, the Working Party will deal with scientific issues in various existing and advanced nuclear fuel cycles, including fuel cycle physics, associated chemistry and flowsheets, development and performance of fuels and materials, and accelerators and spallation targets.

Objectives

To provide the member countries with up-to-date information on and develop consensus regarding:

Separations science;

-- Develop a scientific basis for optimisation of the use of future nuclear waste repositories.

-- Establish a methodology for evaluating impacts of various existing and advanced fuel cycle scenarios on potential storage and repositories.

-- Provide a means for the development and evaluation of advanced processing concepts, including design bases for future reprocessing plants.

Fuel cycle scenarios;

-- Assemble and organise scientific information critical to the understanding of the issues involved in transitioning from current fuel cycles to future fuel cycles.

-- Provide scientific bases for fuel cycle deployment strategies.

Chemical partitioning;

-- Keep updated information on separation technologies, including advanced aqueous and pyrochemical processing issues.

-- Perform a detailed scientific study of separations processes for different fuel cycle scenarios.

Fuels and materials; 
-- Undertake studies needed for development of fuels and materials for implementing advanced nuclear fuel cycles.

-- Deal with performance and behaviour of advanced fuels.

-- Update the handbook on lead and lead-bismuth eutectic (LBE) technoloby as new information becomes available.

-- Thermal-hydraulic studies of lead-alloy coolants.

Accelerators and targets;

-- Deal with accelerator reliability issues.

-- Target performance, including spallation products.

-- Window performance, including thermal stress and radiation damage, windowless targets.

To liaise closely with other relevant NSC Working Parties and NEA Standing Technical Committees, especially the Committee for Technical and Economic Studies on Nuclear Energy Development and the Fuel Cycle (NDC) and the Radioactive Waste Management Committee (RWMC), to ensure the respective work programmes are complementary and to provide advice and support where required and undertake common work where appropriate. Particularly close working relationships will be maintained with the Working Party on scientific issues of Reactor Systems (WPRS).

To provide advice to the nuclear community on the developments needed to meet the requirements for implementing advanced long-term sustainable nuclear fuel cycles, including partitioning and transmutation." 


\section{WORKING PARTY ON MULTI-SCALE MODELLING OF FUELS AND STRUCTURAL MATERIALS FOR NUCLEAR SYSTEMS (WPMM)}

Chair:

Members:

Participation in the work:

Observer:

Date of creation:

Duration:

Mandate:

Summary Record of the 18th meeting of the Nuclear Science Committee [NEA/SEN/NSC(2007)3]

\section{Extract from document [NEA/SEN/NSC(2007)3]}

"Scope

Under the guidance of the Nuclear Science Committee, the Working Party will deal with materials science aspects of fuels and structural materials, aiming at establishing their multi-scale modelling and simulation as a validated predictive tool for the design of nuclear systems.

Objectives

To form the basis for international cooperation between member countries for issues such as:

- Ab-initio modelling and simulation of fuels for advanced nuclear systems, specifically including aspects related to first principles description of the actinide bearing phases;

- Atomistically informed modelling and simulation of nuclear fuels and structural materials at progressively longer time and length scales, paying attention to radiation damage effects and to the methodologies needed to achieve inter-scale integration;

- Validation of simulations and model predictions by benchmarking exercises and identification of experimental data that would be most urgent or important for this validation;

- Identification of fundamental problems encountered in the development of fuels and structural materials and amenable to analysis by both modelling/simulation and experiment to reduce the time and resources needed to develop new fuels and structural materials;

- Harmonisation of experimental and testing practices; establishment of reference experimental and simulation datasets and databases, aiming at improving the joint utilisation of modelling/simulation and experimental techniques; 
- Development of new applied mathematics and software tools, particularly those of common interest for fuels and structural materials;

- Integration of results from multi-scale modelling and simulation into performance codes and materials qualification processes, as well as into multi-physics environments, such as the coupling of materials and neutronics.

Methods of work

To carry out its objectives, the Working Party will provide a framework for joint undertakings to further develop issues under its scope, such as:

- Contribute to the exchange of information between the fuel and structural materials communities on progress and key issues in the multi-scale modelling and simulation approach;

- Report progress at the annual meetings of the NEA Nuclear Science Committee;

- Publish state-of-the-art reports and others stemming from the Working Party activities;

- Sponsor or co-sponsor information exchange meetings and other outreach activities." 


\section{EXECUTIVE GROUP OF THE NSC (DATA BANK MANAGEMENT COMMITTEE) (DB)}

Chair:

Members:

Participation in the work:

Date of creation:

Duration:
Mr. Pierre Joseph D'Hondt

Austria

Belgium

Czech Republic

Denmark

Finland

France

Germany

Greece

Hungary

Italy

Japan
(Belgium)

Korea

Mexico

Netherlands

Norway

Portugal

Slovak Republic

Spain

Sweden

Switzerland

Turkey

United Kingdom

\footnotetext{
Mandate : - Terms of Reference for the Committee and an Executive Group [NEA/SEN/NSC(91)1]

- Review of the NEA Committee Structure [NEA/NE(2000)11/REV1]

- Review of Mandates of the NEA Standing Technical Committees [NEA/NE(2005)2]

- Summary of decisions taken at the 117th session of the Steering Committee for Nuclear Energy [NEA/SUM/DEC(2008)2]
}

\section{Extract from document [NEA/SUM/DEC(2008)2]}

"The Steering Committee:

ii) extended all standing technical committee mandates, including the mandate of the Executive Group of the Nuclear Science Committee which acts as the management committee of the Data Bank, until 31 December 2010, as presented in Appendix 1 of document NEA/NE(2008)6."

\section{Extract from document [NEA/NE(2005)2]}

"Data Bank

The Committee shall also supervise the work of the Data Bank, which acts as an international centre of reference for its Member countries with respect to basic nuclear tools, such as computer codes and nuclear data, used for the analysis and prediction of phenomena in the nuclear field, and which provides a direct service to its users by developing, improving and validating these tools and making them available as requested.

To this end, the Committee shall establish an Executive Group with the task of establishing proposals for the work programme and budget for the Data Bank services, to be 
considered by the Committee with a view to making recommendations to the Steering Committee. The Executive Group shall consist of members of the Committee from each Participating country of the Data Bank: Representatives from non-participating countries may participate as appropriate.

In particular, the Data Bank will:

i) assume responsibility for the development, compilation, validation and dissemination within its Participating countries of bibliographic and numerical nuclear and chemical thermodynamic data (including experimental, evaluated and integral data) and computer programs for nuclear technology;

ii) collaborate in the above work with other data and software centres outside the group of Participating countries, notably in the United States and the International Atomic Energy Agency;

iii) maintain the necessary expertise in computing and scientific information;

iv) carry out work in other fields of science as determined by the NSC, either to the benefit of the Participating countries or to that of the Agency's full membership." 


\section{THE SCIENTIFIC CO-ORDINATION GROUP OF THE JOINT EVALUATED FISSION AND FUSION (JEFF) DATA PROJECT}

Chair:

Members:

Date of creation:

Duration:
Mr. Arjan Koning

(Netherlands)

Austria

Belgium

Czech Republic

Denmark

Finland

France

Germany

Greece

Hungary

Italy

Japan
Korea

Mexico

Netherlands

Norway

Portugal

Slovak Republic

Spain

Sweden

Switzerland

Turkey

United Kingdom

Mandate: - Established at the meeting of the NEA Steering Committee in October 1981

- Prolonged at the 15th meeting of the Executive Group on the Nuclear Science

Committee [NEA/SEN/NSC/EG(2006)4]

- Progress Report for 2005, Work in Hand in 2006 and Programme of Work for 2007 [NEA/SEN/NSC/EG(2006)2]

\section{Extract from document [NEA/SEN/NSC/EG(2006)2]}

"Scope and Objectives

The objective of the Joint Evaluated Fission and Fusion (JEFF) file Project is to develop and promote the use of high quality evaluated nuclear data sets in standard formats for a wide range of scientific and technical applications.

The Project assesses the needs for nuclear data improvements and addresses those needs by initiating the necessary measurements, evaluation and benchmarking efforts.

Participation

The JEFF Project is a collaborative effort between NEA Data Bank Member countries, mainly the European countries and in particular Austria, Belgium, Finland, France, Germany, Italy, the Netherlands, and the United Kingdom.

The Project provides a framework for co-operative activities between participating countries while seeking to make the most rational and efficient use of the available resources.

As with other NEA activities, the participation is on a voluntary basis, where each participating organisation is responsible for covering the cost of its own contributions.

The Project will maintain close links with other similar international efforts or projects aimed at producing evaluated nuclear data, for example through active participation in the NEA Working Party on International Nuclear Data Evaluation Co-operation (WPEC). 
The Project will also maintain close links with the International Nuclear Data Committee (INDC) of the IAEA and with nuclear data activities carried out by the Joint Research Centre (JRC) of the European Commission. Specific tasks, mainly on nuclear data for fusion, are monitored by the European Fusion Development Agreement (EFDA).

\section{Organisation}

The Project is established under the auspices of the Executive Group of the Nuclear Science Committee (NSC).

The Project management is assured by a Scientific Co-ordination Group (SCG) composed of up to two representatives for each participating country. The NSC Executive Group nominates the representatives.

The JEFF Project Chairman is elected by the SCG for a three-year renewable term. Eligible candidates are members of the SCG.

The Chairman and the Secretariat may invite a limited number of specialists to participate in SCG meetings.

The SCG elects its representatives to the NEA Working Party on International Nuclear Data Evaluation Co-operation (WPEC).

The Secretariat of the Project is the Nuclear Energy Agency (NEA) Data Bank. The Secretariat is responsible for maintaining the official records of the Project and for organising its meetings in consultation with the Chairman. The Secretariat is also responsible for the publication and distribution of the JEFF documents, as well as for the updating and maintenance of the JEFF files.

\section{Method of Work}

The SCG forms appropriate subgroups to perform technical activities. Subgroup leaders are nominated by the SCG and report to the SCG. Subgroup leaders are systematically invited to SCG meetings.

The technical activities cover the following themes: experiments, model codes, data evaluations, assessment of uncertainties, verification \& compilation of the data under strict quality assurance procedures, file processing and benchmarking.

The SCG is responsible for reviewing its mandate and the progress of the different subgroups, providing directions for further developments or new initiatives, and scheduling the official release of the JEFF files.

The JEFF meeting is generally held twice per year. The sub-groups and Scientific Coordination Group meet at least once a year. Official summary records of each SCG meeting are produced.

Deliverables

JEFF libraries are distributed by the Secretariat in the form of computer files. All past $J E F(F)$ libraries are considered frozen. The Project will provide assistance and recommendations to users of the JEFF library and of subsequent official releases of the JEFF files according to the attached policy.

A specific development plan is produced for each mandate period of the Project (see Annex 2). The data files and the results of the Project activities are available without restrictions to authorised users in participating countries. Information developed within the Project is distributed via the Secretariat. 
Officially released versions of the file are uniquely identified by a two or three-digit indexing system. Each part of the file contains a reference to the release number. Any change, correction or complement can be considered only for the next official release of the file.

User Support

One of the goals of the project is to do its best efforts to satisfy users requests. Distinct procedures are defined for allowing users to:

- request information,

- report bugs/problems with or provide comments on a particular version of the file,

- request changes/corrections/improvements or complements to the file.

This is done via the Project on-line web services administered by the Secretariat.

Each request is analysed by the Project, which decides upon the proper course of action. If the request is found to be valid, and if the needed resources are available, it is included in the list of JEFF actions. The Project initiates the appropriate response in terms of benchmarking, evaluation or measurement.

The project regularly reviews this list of actions and the assigned priorities.

The JEFF list of planned actions, together with the identity of the requester, the particular JEFF working group who is in charge of the response, the target date for completion and the future JEFF file version that will include the response are made available to all Project participants via the web server." 


\section{COMMITTEE FOR TECHNICAL AND ECONOMIC STUDIES ON NUCLEAR ENERGY DEVELOPMENT AND THE FUEL CYCLE (NDC)}

$\begin{array}{lll}\begin{array}{ll}\text { Chair: } \\ \text { Vice-Chairs: }\end{array} & \begin{array}{l}\text { Mr. Kazuaki Matsui } \\ \text { Mr. Théofiel van Rentergem } \\ \text { Ms. Sylvana Guindon } \\ \text { Mr. Sándor Élö } \\ \text { Mr. Pierre Multone }\end{array} & \begin{array}{l}\text { (Belgium) } \\ \text { (Canada) } \\ \text { (Hungary) } \\ \text { (Switzerland) }\end{array} \\ \text { Members: } & \text { All NEA Member countries } \\ \text { Participation in the work: } & \begin{array}{l}\text { European Commission } \\ \text { Under the NEA Statute }\end{array} & \\ & \begin{array}{l}\text { International Atomic Energy Agency (IAEA) } \\ \text { By agreement }\end{array} \\ \text { Observers: } & \text { Russian Federation } \\ \text { Slovenia } & \\ \text { Date of creation: } & \text { 26th October } 1977 \\ \text { Duration: } & \text { 31st December } 2010\end{array}$

Mandate: - Minutes of the 55th Session of the Steering Committee for Nuclear Energy [NE/M(77)2]

- Proposed Strategy and Programme Objectives in the Field of Development of Nuclear Energy and the Fuel Cycle [NE(81)19]

- Review of the NEA Committee Structure [NEA/NE(2000)11/REV1]

- Review of Mandates of the NEA Standing Technical Committees [NEA/NE(2005)2]

- Summary of decisions taken at the 117th session of the Steering Committee for Nuclear Energy [NEA/SUM/DEC(2008)2]

\section{Extract from document [NEA/SUM/DEC(2008)2]}

"The Steering Committee:

ii) extended all standing technical committee mandates [...] until 31 December 2010, as presented in Appendix 1 of document NEA/NE(2008)6."

\section{Extract from document [NEA/NE(2005)2]}

"Under the authority of the Steering Committee for Nuclear Energy, to conduct technical, resource, economic, strategic and policy-support studies and publish documented, authoritative reports on nuclear energy development, its fuel cycle and related issues in support of Member countries' national energy or nuclear energy policies. Specifically, the following topics should be included in the programme of activities:

- Economics of the nuclear option, including fuel cycle, waste management and disposal and decommissioning costs, covering new issues raised by energy market liberalisation. 
- Innovation in the nuclear sector and advanced reactor and fuel cycle technologies.

- Infrastructure required for the nuclear option.

- Production, supply and demand of nuclear materials, including radioisotopes, and other aspects of their management.

- Future role of nuclear energy in a sustainable development perspective.

- Support national and international organisations, upon request, in the fields covered by the NDC programme of work according to the Strategic Plan of the NEA.

Furthermore the Committee should address the preceding topics by:

- Contributing to the dissemination of information in the areas listed above.

- Establishing a liaison with other NEA committees and other parts of the OECD, as appropriate, to analyse and comment on aspects within its competence contained in any report relating to the mission of the NEA or specifically submitted to the Steering Committee.

- Reviewing related work in national and other international governmental organisations, especially the International Atomic Energy Agency and advising the Steering Committee on the co ordination of the NDC work with that of others.

- Maintaining an understanding of the role and work of all organisations relevant to the area of interest of the Committee, such as industry, trade organisations, regulators, interest groups or professional associations.

- Reporting every year to the Steering Committee, reviewing NEA activities in this field and making proposals for the future programme of work." 


\section{JOINT NEA/IAEA GROUP ON URANIUM (UG)}

Chair:

Vice-Chairs:

Members:

Participation in the work:

Date of creation:

Duration:
Mr. Georges Capus

Mr. Alberto Castillo

Mr. Ian Lambert

Mr. Alexander V. Boitsov

Mr. Scott Sitzer
(France)

(Argentina)

(Australia)

(Russian Federation)

(United States)

All NEA Member countries

Open also to all IAEA Member countries

European Commission

Under the NEA Statute

International Atomic Energy Agency (IAEA)

By agreement

April 1996

31st December 2011

Mandate : - Proposed reconstitution of the Joint NEA/IAEA Uranium Group [NEA/NE(96)6]

- Minutes of the 92nd Session of the Steering Committee for Nuclear Energy [NEA/NE/M(96)1/REV1]

- Summary Record of the 48th NDC Session [NEA/NDC(2003)25/REV1]

- Summary record of the 55th NDC Session [NEA/NDC(2008)34]

\section{Extract from document [NEA/NE(96)6, Annex 1]}

\section{"General Objectives}

To co-ordinate the preparation of the periodic assessments of the world's supply of natural uranium; to examine the relationship of these supply capabilities to projection of natural uranium demand; to foster the exchange of technical information in the fields of uranium resources, exploration and production technology in co-operation with members, and with other international organisations as appropriate; and to recommend to the NEA and IAEA actions that might be taken to assure an adequate long-term supply of uranium for nuclear power development.

Mandate

1. To plan, direct and co-ordinate the preparation of periodic assessments of the world's uranium supply capabilities (i.e. levels of uranium exploration activity, estimates of resources and production capability) in co-operation with members, and with other international organisations as appropriate;

2. To examine the world's uranium supply capabilities in relationship to projections of natural uranium demand, and to recommend to the NEA and IAEA actions that might be taken to assure an adequate long-term supply of uranium for nuclear power development;

3. To foster the exchange of technical information in the fields of uranium geology, resources, exploration, mining and ore processing technology, in co-operation with members, and with other international organisations as appropriate, with a view to 
promoting collaborative R\&D efforts in areas that may be identified through these exchanges;

4. To promote the expansion of the geological coverage of information on uranium activities throughout the world, with particular emphasis on developing countries."

\section{Extract from document [NEA/NE/M(96)1/REV1]}

"The Steering Committee:

a) considered the proposal to reconstitute a joint NEA/IAEA Group to prepare studies on uranium resources, with a mandate as specified in the terms of reference presented in Annex 1 of document NEA/NE(96)6; and

b) agreed to reconstitute the joint NEA/IAEA Uranium Group as proposed, with the understanding that its mandate would be interpreted to include exchanges of information on environmental effects and environmental protection technologies associated with mining and ore processing."

\section{Extract from document [NEA/NDC(2003)25/REV1, item 15]}

"NDC Members reaffirmed their support for the joint NEA/IAEA Uranium Group and approved its mandate for a further five years following the expiration of the previous mandate on 12 October 2003." 


\section{WORKING PARTY ON NUCLEAR ENERGY ECONOMICS (WPNE)}

\section{Co-Chairs:}

Member:

Observers:

Participation in the work:

Date of creation:

Duration:
Mr. Matthew Crozat

Dr. Alfred Voss

All NEA member countries

Russian Federation

Slovenia

European Commission

Under the NEA Statute

12th November 2007

30th November 2010
(United States)

(Germany)

Mandate: - Summary Records of the 53rd and the 54th meetings of the Committee for Technical and Economic Studies on Nuclear Energy [NEA/NDC(2007)12, Item 5, para. 20 and NEA/NDC(2008)1] and document [NEA/NDC(2007)4/REV1]

\section{Extract from [NEA/NDC(2007)4/REV1]}

"Mandate

1. To provide a forum for exchange of information between experts on all economic aspects of nuclear energy systems.

2. To carry out, on a periodic basis, studies on the total costs - including investment, operation and maintenance and fuel cycle - of generating nuclear electricity and non-electricity products.

3. In co-operation with appropriate others (e.g. IAEA, IEA) examine the competitiveness of nuclear energy systems as compared with alternatives for electricity generation and non-electricity products, e.g. hydrogen and desalinated water.

4. To examine, on an ad hoc basis, specific economic issues, such as capital costs of nuclear facilities and their financing, management and financing of liabilities (e.g. decommissioning, waste disposal), identification and valuation of externalities.

5. To develop methods, models and computer tools for assessing the costs of nuclear energy systems including innovative reactors and fuel cycles.

6. The NDC will identify activities to be conducted by the WPNE but will also expect the WPNE to provide its own suggestions.

7. The NDC will select the activities to be undertaken by the WPNE in the process of establishing its biennial programme of work.

8. All reports, publications and products of the WPNE will be reviewed and approved by the NDC before being released.

9. The WPNE will report to the NDC on its progress and activities as requested, and at least on an annual basis." 


\section{NUCLEAR LAW COMMITTEE (NLC)}

Chair:

Vice-Chairs:

Members:

Participation in the work:

Observers:

Ad hoc Observers:

Date of creation:

Duration:
Mr. Roland Dussart-Desart

Mr. Yrjö Sahrakorpi

Ms. Florence Touitou-Durand

Ms. Vanda Lamm

Mr. Ki-Gab Park

Mr. Ben McRae

All NEA Member countries

European Commission

Under the NEA Statute

International Atomic Energy Agency (IAEA)

By agreement

Russian Federation

Slovenia

Bulgaria

Hong Kong, China

Lithuania

Romania

Ukraine

24th January 1957

31st December 2010
(Belgium)

(Finland)

(France)

(Hungary)

(Korea)

(United States)

Mandate : - Review of the Mandates of the Agency's Committees and Working Groups [NE(74)4]

- Review of the NEA Committee Structure [NEA/NE(2000)11/REV1]

- Review of Mandates of the NEA Standing Technical Committees [NEA/NE(2005)2]

- Summary of decisions taken at the 117th session of the Steering Committee for Nuclear Energy [NEA/SUM/DEC(2008)2]

\section{Extract from document [NEA/SUM/DEC(2008)2]}

"The Steering Committee:

ii) extended all standing technical committee mandates [...] until 31 December 2010, as presented in Appendix 1 of document NEA/NE(2008)6."

\section{Extract from document [NEA/NE(2005)2]}

"The Nuclear Law Committee will work to encourage provisions for equitable compensation of damage in the event of a nuclear incident. In particular, the Committee is mandated to deal with issues relating to civil liability for damage caused by a nuclear incident and to financial security mechanisms designed to ensure that funds will be available to compensate such damage. It addresses these issues in the context of Member countries' nuclear legislation and of international nuclear liability instruments, including 1) the 1960 Paris Convention on Third Party 
Liability in the Field of Nuclear Energy and the 1963 Brussels Convention Supplementary to the Paris Convention, as amended, 2) the 1963 Vienna Convention on Civil Liability for Nuclear Damage and the 1997 Protocol to Amend the Vienna Convention, 3) the 1988 Joint Protocol Relating to the Application of the Vienna Convention and the Paris Convention, and 4) the 1997 Convention on Supplementary Compensation for Nuclear Damage. The Nuclear Law Committee will also strive to eliminate or minimise any legal impediments to the safe use of nuclear energy.

More specifically, the Committee has a mandate to:

i) examine issues relating to the interpretation and application of international nuclear liability instruments, especially with respect to their harmonious application under Member countries' national laws, and encourage broader adherence to those instruments with a view to fostering further progress towards a global regime of liability and compensation for nuclear damage;

ii) promote the harmonisation of national policies and legislation in the nuclear liability and compensation field amongst its Member countries;

iii) encourage the development of national legislation governing the peaceful uses of nuclear energy based upon internationally accepted principles, particularly in the area of liability and compensation;

iv) develop recommendations concerning the Paris Convention and the Brussels Supplementary Convention, as amended, for submission, if appropriate, to the Steering Committee for Nuclear Energy;

v) promote the exchange of information and the sharing of experience between Member countries on these issues;

vi) advise the Secretariat on collecting, analysing and disseminating information on major developments in the nuclear law field at both national and international levels.

The Nuclear Law Committee is also mandated to undertake all other work involving legal issues that may be entrusted to it by the NEA Steering Committee.

The Nuclear Law Committee will co-operate with other NEA standing technical committees. It may set up subsidiary bodies to better facilitate the achievement of its goals, invite experts in other fields to attend its meetings, and sponsor meetings of specialists. It may also establish contacts with its counterparts in the European Community, the International Atomic Energy Agency, and other international organisations on matters of common interest." 
JOINT SUBSIDIARY BODIES TO THE CO-ORDINATED ORGANISATIONS 



\section{CO-ORDINATING COMMITTEE ON REMUNERATION (CCR)}

Chair:

Vice-Chair:

Members:

Date of creation:

Duration:
Mr. Hans-Stefan Kruse

(Germany)

Mr. Juan Francisco Carmona

Choussat

All the Member countries of the Co-ordinated Organisations:

Council of Europe

European Centre for Medium Range Weather Forecasts (ECMWF)

European Space Agency

North Atlantic Treaty Organisation (NATO)

Western European Union (WEU)

OECD

1st July 1991

Unspecified

Mandate: - Regulation concerning the Co-ordination System

- Appendix to the OECD Council Decision adopted at its 690th session [C(88)117/FINAL]

- Revised by the OECD Council Decision [C(2004)6 and CORR1] adopted at its 1081st session, on 30 March 2004 [C/M(2004)7, Item 107]

\section{Decision of the Council [C(2004)6 and CORR1]}

"THE COUNCIL

a) noted documents $\mathrm{C}(2004) 6$ \& CORR1, and the 154th Report on the Co-ordinating Committee on Remuneration [CCR/R(2004)2];

b) reaffirmed the final authority of Member States of the Co-ordinating Committee on Remuneration to issue recommendations on remuneration issues, including those on the remuneration adjustment method;

c) requested that the CCR examines, as a matter of urgency, alternatives to the current remuneration adjustment method, in order to more closely reflect the real trends in salaries in the national civil services of the reference countries;

d) adopted the revised Regulations concerning the co-ordination system set out in Annex 1 of the 154th Report. These Regulations shall come into force when adopted in identical terms by the Councils of the six Co-ordinated Organisations;

e) subjected its adoption of these Regulations to the reservation that the mandate of the concertation group established pursuant to Article 7, paragraph a) shall cease to be in effect on 31 December 2007 unless the Council agrees to its continuation in force;

f) invited the Secretary-General to communicate this decision to the other Co-ordinated Organisations, as well as to the Committees of the system of co-ordination, with the understanding that the Revised Regulations would have only provisional effect pending acceptance of the reservation set out in paragraph e) by the other Co-ordinated Organisations, either expressly or tacitly within twelve months from notification, and 
that, in the event any other co-ordinated Organisation objected to the reservation within that period, the Regulations dated 1 July 1991 would once again be in effect."

\section{Extract from document [C(2004)6]}

\section{ANNEX I}

\section{REGULATIONS CONCERNING THE CO-ORDINATION SYSTEM}

"The following Regulations update those which came into effect on 1 July 1991.

For several decades, a co-ordinated system of remuneration has been maintained by a group of international organisations [North Atlantic Treaty Organisation (NATO), European Space Agency (ESA), Organisation for Economic Co-operation and Development (OECD), Council of Europe, Western European Union (WEU) and the European Centre for Medium Range Weather Forecasts (ECMWF)]. These Co-ordinated Organisations at present have more than 50 member States, 11000 staff members, and 4000 pensioners. The Co-ordinating Committee on Remuneration (CCR) was established with a role of making recommendations on remuneration, allowances and pensions to the Councils of the Co-ordinated Organisations. The CCR works in conjunction with the Committee of Representatives of the Secretaries/Directors-General (CRSG) and the Committee of Staff Representatives (CRP). The legal and organisational basis for co-ordination is set out in the Regulations below.

\section{Article 1}

\section{Scope of Co-ordination}

(a) The object of the co-ordination system is to provide recommendations to the Governing bodies of the Co-ordinated Organisations, in accordance with the provisions of these Regulations, concerning:

(i) Basic salary scales, and the method of their adjustment, for all categories of staff and for all countries where there are active staff or recipients of a pension;

(ii) Pension Scheme Rules;

(iii) The object, the amount and the method of adjustment of:

- expatriation allowance

- household allowance

- installation allowance

- dependent person's allowance

- daily subsistence allowance

- kilometric allowance

- expatriated child's allowance

- education allowance

- handicapped child's allowance.

(b) According to the procedure referred to in Article 6, recommendations to the Governing bodies are made by the Co-ordinating Committee on Remuneration (CCR), to the extent possible in conjunction with the Committee of Representatives of Secretaries/Directors-General (CRSG) and after consultation with the Committee of Staff Representatives (CRP). Where divergent conditions exist in different Coordinated Organisations, recommendations on allowances may take the form of frameworks applicable to all the Organisations, within which each Organisation shall have the flexibility to adopt implementing provisions to meet its specific needs. The CCR shall be kept informed of these provisions.

(c) According to the procedure referred to in Article 6, the CCR shall give its advisory opinion on any question falling within its mandate asked by the Governing body of any Co-ordinated Organisation. 


\section{Co-ordinating Committee on Remuneration (CCR)}

(a) Each member State of one of the Co-ordinated Organisations may nominate one representative to the CCR who may be assisted by alternate delegates and advisers.

(b) The CCR shall elect its Chairperson by consensus for a three year mandate extendible on a yearly basis, after consultation with the CRSG and after being informed of the views of the CRP.

(c) The Chairperson of the CCR shall act as the impartial Chairperson of the whole co-ordination process and shall look after its harmonious, rapid and efficient functioning.

(d) The Chairperson shall be assisted by one Vice-Chairperson elected annually by the CCR.

(e) The CCR may designate one of its members to act as its spokesperson.

\section{Article 3}

\section{Committee of Representatives of the Secretaries/Directors-General (CRSG)}

(a) The Secretary/Director-General of each Co-ordinated Organisation shall appoint one representative to the CRSG who may be assisted by alternate delegates and advisers.

(b) The Chairperson and Vice-Chairperson of the CRSG shall be designated according to the procedures established by the CRSG.

(c) The Chairperson of the CRSG shall act as its spokesperson.

(d) The Secretaries/Directors-General may meet as the Committee of Secretaries/Directors-General (CSG).

(e) The CRP shall be given the prior possibility to outline to the CRSG any subjects related to remuneration policy which they consider should be raised at the sessions of the CSG.

Article 4

The Committee of Staff Representatives (CRP)

(a) The representative statutory body of the staff of each Co-ordinated Organisation and the Association of Pensioned Staff of the Co-ordinated Organisations and of their Dependants (AAPOCAD) may appoint one delegate to the CRP as well as the alternate delegates and advisers who may accompany him/her.

(b) The Chairperson of the CRP shall act as its spokesperson. He/she may be assisted by a ViceChairperson.

\section{Article 5}

Proposals and work programme

(a) The CCR shall adopt a detailed work programme, the draft of which is drawn up by its Chairperson in consultation with the CRSG and the CRP, of all items to be discussed in the next calendar year. This approved work programme shall include the timetable for considering all items mentioned therein. The Secretaries/Directors-General shall submit, each with his/her own comments if appropriate, the CCR work programme to the Governing body of each Co-ordinated Organisation for information and possible suggestions. 
(b) The CRSG, after consultation with the CRP, may make proposals relating to matters which fall within the competence of the CCR as defined in Article 1 above, and present them to the CCR accompanied by any comments and views of the CRP.

(c) Any member of the CCR may make proposals to the CCR. After appropriate consultations, the Chairperson of the CCR shall decide which proposals have broad support amongst member States and therefore shall be brought forward for discussion in the joint meetings.

\section{Article 6}

\section{Recommendations and advisory opinions}

(a) Recommendations, in the form of reports, shall be made by the CCR by consensus and, to the extent possible, in conjunction with the CRSG. The CRP shall be consulted on the draft reports with a view to considering its position.

(b) If no agreement can be reached between the CCR and the CRSG after two meetings following the submission of the proposal, the CCR will issue a report which will reflect the reasons for disagreement and set out dissenting opinions of the CRSG and comments of the CRP. However, discussions concerning the remuneration adjustment method may take longer and could require three meetings.

(c) If no agreement can be reached among the CCR delegates after two meetings following the submission of the proposal, the Chairperson of the CCR shall draft a report in which he/she shall set out the positions that have the largest support of the CCR. Dissenting opinions of CCR delegates as well as the opinion of the CRSG and comments of the CRP shall be set out in the body of the report.

(d) Proposals by the CRSG which are considered non-controversial by the Chairperson of the CCR may be submitted to the CCR through a written procedure. In this case, recommendations shall be considered as accepted by the CCR if no objection has been brought to the attention of the Chairperson of the CCR. Normally any such objection should be brought to his/her attention within three weeks of the notification of the recommendations to the members of the CCR, or before such other deadline as may be set by the Chairperson of the CCR which should be not less than five working days.

(e) Advisory opinions of the CCR shall be made by consensus after consultation of the CRSG and the CRP representatives from the Organisation(s) concerned. In case the subject in question is specifically related to one or more Organisations, the CCR delegations whose country is not a member of the Organisation(s) concerned will exercise due restraint in discussions on the adoption of the opinion. If no agreement can be reached among the CCR delegations after two meetings following submission of the request for an opinion, the Chairperson of the CCR shall draft a report in which he/she shall set out the advisory opinion which has the largest support in the CCR. Dissenting opinions provided in writing shall be annexed to the report.

\section{Article 7}

\section{Concertation group and formal and informal sessions}

(a) The CCR, CRSG and CRP shall establish a concertation group which will be held as needed, in a flexible manner, either as a preparatory step to open discussion, or as a final attempt to achieve a meeting of minds among the Committees. The concertation group shall be limited to two representatives of each Committee. It shall be chaired by the Chairperson of the CCR. The representatives of the Committees will be expected to take into due account the positions of all their members during discussions in the concertation group.

(b) The CCR, the CRSG and the CRP may meet together, separately or any two together in formal or informal sessions. The Chairperson of the CCR shall act as Chairperson whenever the CCR meets with the CRSG or with the CRP. 


\section{Article 8}

Notification and implementation

(a) The Chairperson of the CCR shall notify the Secretaries/Directors-General of all reports, recommendations and advisory opinions. The Secretaries/Directors-General shall transmit these reports, recommendations or advisory opinions, to the Governing body of their Organisations, as soon as possible.

(b) The Governing body of each Co-ordinated Organisation shall decide on the reports, recommendations and advisory opinions made to it by the CCR.

(c) The Secretary/Director-General of each Organisation shall be responsible for the implementation of the decisions.

\section{Article 9}

\section{Members and Observers}

(a) The Governing bodies of the Co-ordinated Organisations may, after having sought the advice of the CCR, accept unanimously that other international organisations participate in the system of coordination as members or observers.

(b) An international organisation may only become a member of the co-ordination system upon approval by its Governing body of the decisions concerning co-ordination then in force.

(c) When an international organisation has been admitted to participate in the system of co-ordination as an observer, the agenda, minutes and documents of the CCR, CRSG and CRP shall be provided respectively to its member countries, Secretary or Director-General and representative statutory body of its staff. Their representatives shall attend as observers the meetings of the CCR, CRSG and CRP.

(d) The Governing body of any Co-ordinated Organisation may decide to terminate the application of these Regulations to that Organisation by giving one calendar year's notice to that effect. It will transmit such a decision to the other Co-ordinated Organisations. In such instance, these Regulations will remain applicable as far as the other Co-ordinated Organisations are concerned.

Article 10

Entry into force

These Regulations shall enter into force when approved by the Governing bodies of the six Co-ordinated Organisations. On such date, the Regulations concerning the co-ordination system dated 1 July 1991 shall be replaced by the present Regulations. After three years of operation of the system, these Regulations may be reviewed by the Governing bodies of the Co-ordinated Organisations." 
OECD PUBLISHING, 2, rue André-Pascal, 75775 PARIS CEDEX 16 PRINTED IN FRANCE

(01 2009081 P) ISBN 978-92-64-05270-3 - No. 566932009 


\section{Directory of Bodies of the OECD}

The original Member countries of the OECD since 1961 are:

Austria

Luxembourg

Belgium

Netherlands

Canada

Norway

Denmark

Portugal

France

Spain

Germany

Sweden

Greece

Switzerland

Iceland

Turkey

Ireland

United Kingdom

Italy

United States

The following countries became Members through accession at the dates indicated hereafter:

Japan

Finland

Australia

New Zealand

Mexico

Czech Republic

Hungary

Poland

Korea

Slovak Republic
28 April 1964

28 January 1969

7 June 1971

29 May 1973

18 May 1994

21 December 1995

7 May 1996

22 November 1996

12 December 1996

14 December 2000

The online database is available for reference at this link:

www.oecd.org/oecdgroups

OECDpublishing

www.oecd.org/publishing www.oecd.org

ISBN 978-92-64-05270-3

$012009081 \mathrm{P}$ 